ORP-44236

Revision 0

\title{
Melt Rate Enhancement for High Aluminum HLW Glass Formulation \\ Final Report 08R1360-1
}

Prepared for the U.S. Department of Energy

Assistant Secretary for Environmental Management

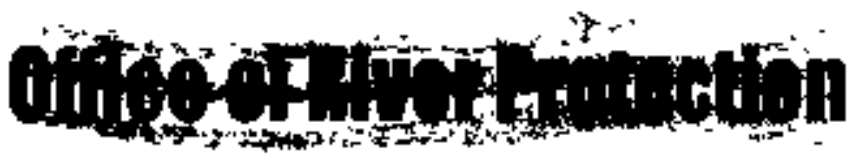

P.O. Box 450

RIchland, Washington 99352 
ORP-44236

Revision 0

\section{Melt Rate Enhancement for High Aluminum HLW Glass Formulation}

\section{Final Report 08R1360-1}

K. S. Matlack

Vireous Stale Laboratory, The Catholic University of America

I. Joseph

Energys Solutions Federal EPC, Inc.
A. A. Kruger
Department of Energy - Office of River Protection

T. Bardakci

M. Chaudhuri

H. Gan

W. Gong

W. Kot

I. L. Pegg

Vitreous State Laboratory. The Cathoifc University of America

Date Publkshed

December 2009

Prepared for the U.S. Department of Energy Assistant Secretary for Environmental Management

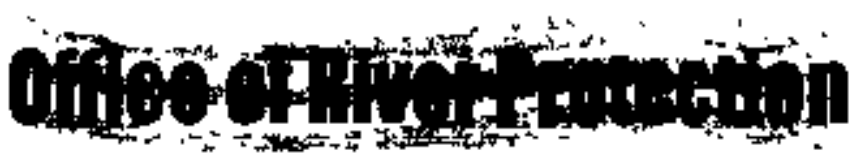

P.O. Box 450

Rlchland, Washington 99352

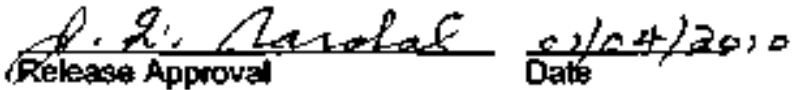




\section{LEGAL DISCLAMER}

This report was prepered as an accolunt of work tponsored by an agency of the United States Gevemmeni, Neither the United slates Govemment nor any apency thereof, nor any of their employees, nor any of their contuactors, subcontractors or the ir employes, makes any warranty, express or impled, or assumes any legal liability or nesponsibility for the ecculracy. completeness, or any third party's use or the result's of such iste of any infomation, apparatus, product, or process disckesed, or repressants thal its use would not Iniringe privately owned rights. Rerlerence herein to arm gpectific commerclal product, procoss, or service by bade name, trademark, manutaclurer. of olherwise, does not necessarily const'bute or imply its endorsement, recommendation, or fauraing by the United States Goveriment or any agency thereof or its contractors or subcontraclors. The views and opinions of aulhors expressed harein do not nectessarly state of reflect thase of the Unllod Stales Government or any agenny thereot.

This report has bean reproduced from lha best available copy.

Pnnted in the Unwed Stoteg ol Amencs 
Final Report

Melt Rate Enhancement for High Aluminum HLW Glass Formulations

\author{
prepored by
}

Keith S. Matlack, Hao Gan, Malabika Chaudhuri, Wing Kot, Weiliang Gong, Tevfïk Bardakci, and Ian L. Pegg

Vitreous State Laboratory

The Catholic University of America

Washington, DC 20064

and

Innocent Joseph

EnergySolutions Federal EPC, Inc.

Laurel, MD

$$
\text { for }
$$

Department of Energy

Office of River Protection

November 5, 2008

Rev. $0 ; 12 / 19 / 08$ 
ORP-44236, Rev. 0

The Catholic Universthy of America Vit eous State Laboratory
Mell Rate Enhoncement for High Aluminglm HLW Glass Fosmulations

Final Repost LSL-08RI360-I, Rev 0

Document Title: Melt Rate Enhancement for High Aluminum HLW Glass Formulations

Document Number

and Revision:

VSL-08R1360-1, Rev 0

Issue Date:

$12 / 19 / 08$

Performing Organfzation: Vitreous State Laboratory, The Catholic University of America

Test PJan:

High Level Waste Glass Development Testing,

VSL-07I1360-1, Rev. 0

This report describes the results of testing specified by the above Iest Plan The work was performed in compliance with the quality assurance requizements specified in the Iest Plan Resuits required by the Iest Plan are reported The test results and this report have been reviewed for correctness, technical adequacy, completeness, and accur acy.

I.L. Pegg: Q $\quad$ Date: $12 / 19 / 08$

VSL Program Dir ector/Principal(Ijvestigator

I. Joseph: Ammoccot toseb $\quad$ Date: $12 / 19 / 08$ 
The Catholic University of America Vitreons State Laboratory

\section{TABLE OF CONTENTS}

LIST OF TABLES

LIST OF FIGURES

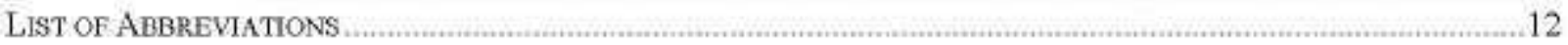

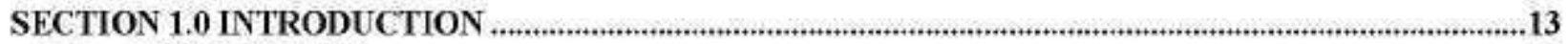

1.1 TEST OBJECTIVES

1.2 QUALTTY ASSURANCE $\quad 16$

1.3 DMIOOMELTER SYSTEM $\ldots \ldots \ldots$

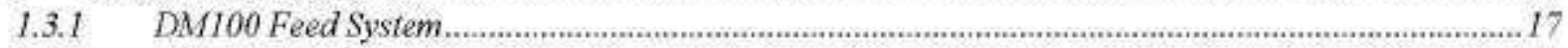

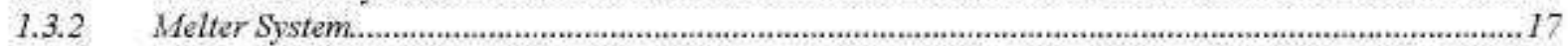

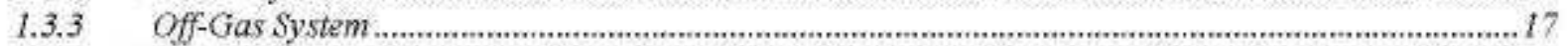

14 DM1200 18

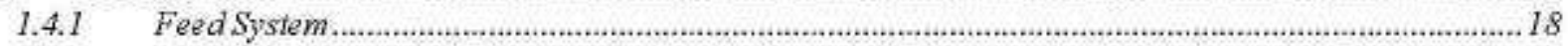

1.4.2 Melter System..................................................................................................................... 18

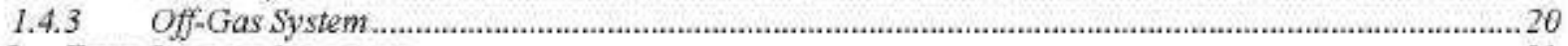

15 FEED SAMPLE ANALYSIS _._. 21

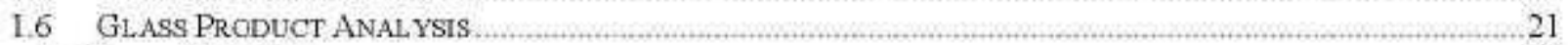

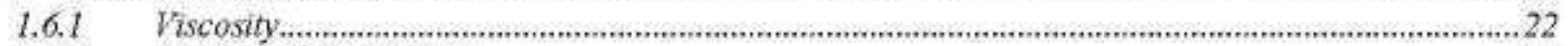

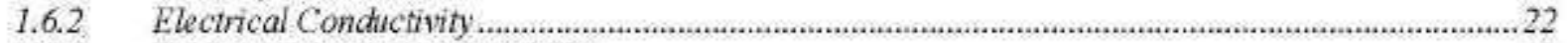

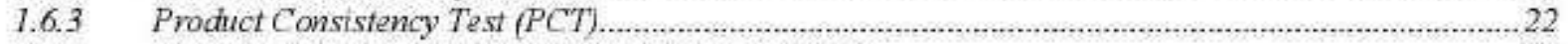

1.6.4 Toxicity Characteristic Leaching Procedure (TCLP) .................................................................23

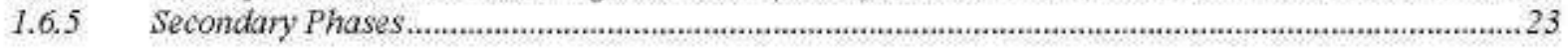

SECTION 2.0 WASTE SIMULANT AND BASE GLASS COMPOSTTION ...............................................24

2.1 WASTE SIMUL.ANTS .

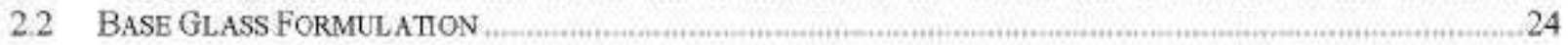

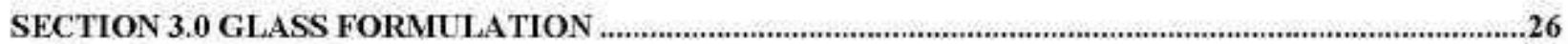

3.1 INTRODUCTION

3.2 EXPERIMENTAL METHODS $\quad 27$

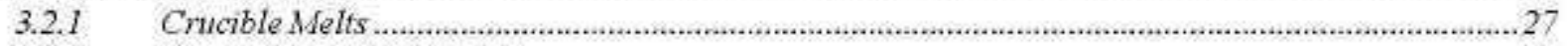

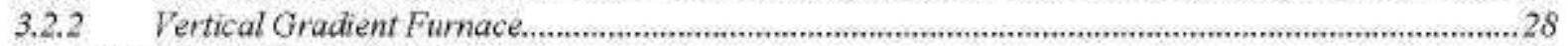

3.3 RESULTS AND DISCUSSION

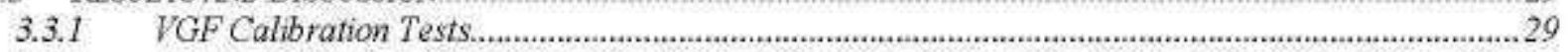

3.3.2 Component Effects on the HLW-E-Al-27 Formulation ..............................................................30

3.3.3 Group I Glass and Feed Formulations .................................................................................31

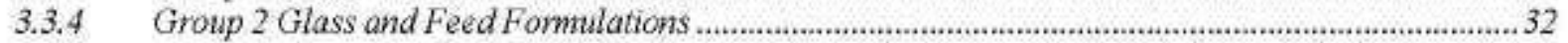

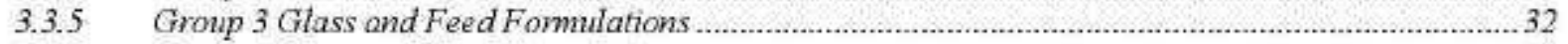

3.3.6 Group 4 Glass and Feed Formulations …..................................................................................3

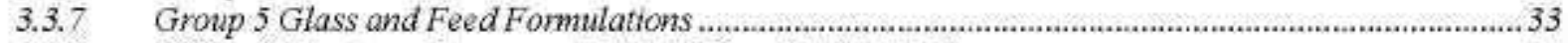

3.3.8 Effect of Aluminum Source on HWI-AL-16 and HWI-Al-19 …....................................................34

3.3.9 Confimation of VGF Melt Rate Predictions....................................................................................34

3.4 DMIOFEED CONSUMPTION (DFC) MELT RATE TESTS

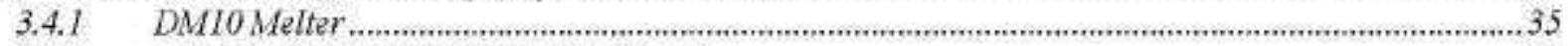

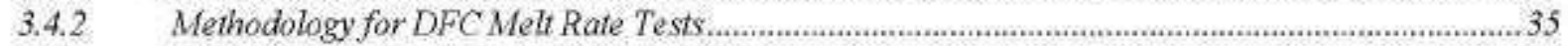

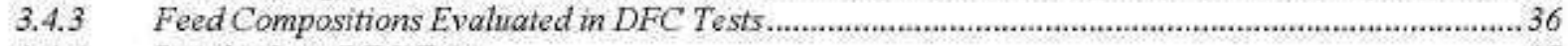

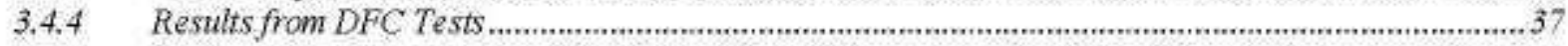

3.5 SUMMARY AND FORMULATIONS FOR MELTER TESTING

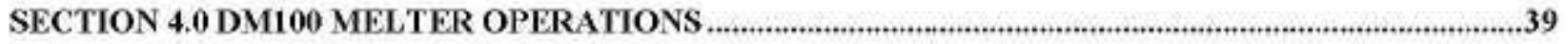


SECTION 5.0 DM1200 OPERATIONS

5.1 MELTER OPERATIONS 43

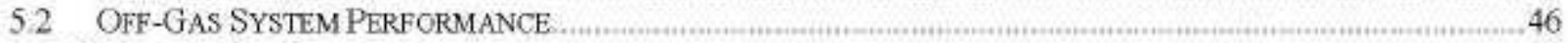

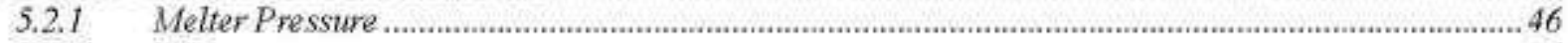

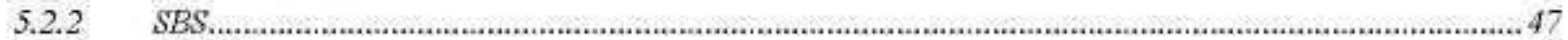

5.2.3 WESP

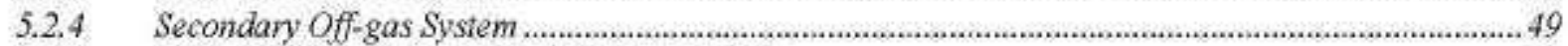

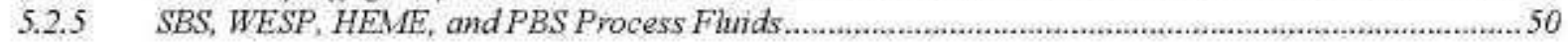

SECTION 6.0 FEED SAMPLE AND GLASS PRODUCT ANALYSIS..........................................................52

61 ANALYSIS OF FEED SAMPLES

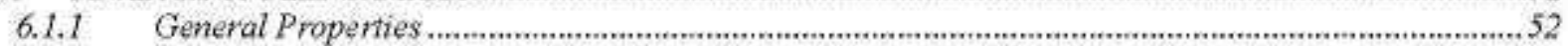

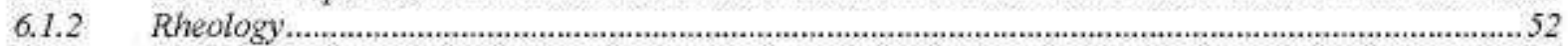

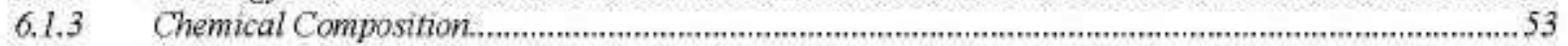

6.2 ANAL YSIS OF GLASS SAMPLES. 54

6.2.1 Compositional Analysis of Discharge Glasses ................................................................................54

6.2 .2 Chemical Durability of Discharge Glasses .............................................................................55

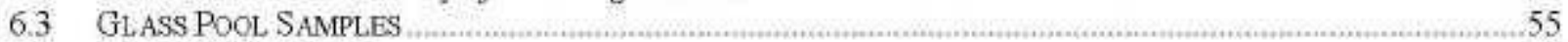

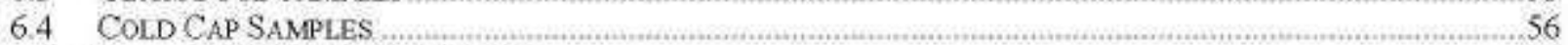

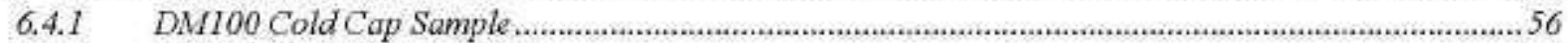

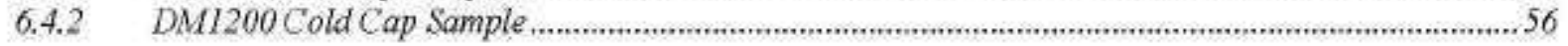

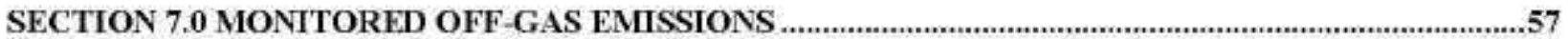

7.1 PARTICULATE SAMPLING

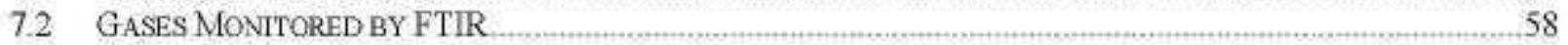

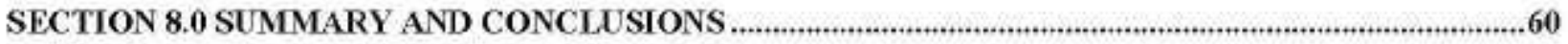

8.1 RECOMMENDATIONS FOR FUTURE WORK

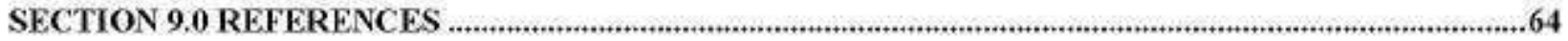




\section{List of Tables}

Table 2.1 Oxide Compositions of Limiting Waste Streams (wt\%)

$\underline{\text { Page \# }}$

Table 2.2

Compositions of the Al-Limited Waste (Oxide Basis) and the $\mathrm{HLW}$

T-1

Waste Simulant to Produce $100 \mathrm{~kg}$ of Waste Oxides $120 \mathrm{Fr} \%$ suspended solids) LIsing $\mathrm{Al}_{3} \mathrm{O}_{3}$ as the Aluminum Source.

$\mathrm{T}-2$

Table 2.3 Compositions of the Al-Limited Waste (Oxide Basis) and the HLW Waste Simulant to Produce $100 \mathrm{~kg}$ of Waste Oxides $(20 \mathrm{Ft} \%$ suspencled solikls) LIsing $\mathrm{Al}(\mathrm{OH})_{3}$ as the Aluminum Source.

Table 2.4 Composition and Properties of Aluminum Limited Waste and Glass Folmulation at 45\% Waste Loading LIsed in Previous Melter Tests.

Table 2.5 Compositions of Melter Feed to Produce $100 \mathrm{~kg}$ of Target Glass HL W-E-Al-27 (Glass Yield $=500 \mathrm{~g} / \mathrm{L}$ Feed) fiom the Al-Limited Waste Simulant Using Al( $\mathrm{OH}_{\mathrm{s}}$ as the Aluminum Source.

Table 3,1 Summary of Glass Fotmulations and the Associated Feed Tests by VGF and Waste Glass Melters (DM100 or DM1200).

T-5

Tatger and XRF Analysis of HWI Glasses Tesied 9w1\%).

Table 3.2

Table 3.3 Characterization of HWI Glasses.

$T-7$

$\mathrm{T}-12$

Table 3.4a

XRF Analysis ( $\% 1 \%$ ) of Four Melter Feeds Fused at $1150^{\circ} \mathrm{C}$ and After VGF Experiments.

T-16

Table 3.4b XRF Analysis (wt\%) of Group 1 Folmulation Feeds Fused at $1150^{\circ} \mathrm{C}$ and After VGF Experiments.

Table 3.4c XRF Analysis ( and After VGF Experiments.

Table 3.4d XRF Analysis ( $\% 1 \%$ ) of Group 4 Folmulation Feeds Fused at $1150^{\circ} \mathrm{C}$ and After VGF Experiments.

Table 3.4e XRF Analysis (wr\%) of Group 5 Folmulation Feeds Fused at $1150^{\circ} \mathrm{C}$ and After VGF Experiments.

T-17

T-18

$\mathrm{T}-19$

$\mathrm{T}-20$

Talble 3.4f

XRF Analysis (wt\%) of Existing High Fe Melter Feeds and Variations of Baseline Feed for HLW-E-A]-27.

$\mathrm{T}-22$

Table 3.5

Ranking Definition for Feed Conversion after 30 Minures in VGF.

$\mathrm{T}-24$

Table 3.6. Compositions of the Al-Limited Waste (Oxide Basis) and the HLW Wiaste Simulant to Produce $100 \mathrm{~kg}$ of Waste Oxides $(20 \mathrm{Ft} \%$ suspended solicls) (from VSL teport [2]).

$\mathrm{T}-25$

Table 3.7

TCLP Results (ppm) for Selected HW] Glasses.

$\mathrm{T}-26$

Talble 3.8 Melt Rate Ranking of Feed Samples by VGF vs. Glass Production Rate by DM100 at $1150^{\circ} \mathrm{C}$.

$\mathrm{T}-26$

Table 3.9 Crystalline Phases in the Partially Reacted Feed (VGF) Identified by SEMEDS and XRD.

Table 3.10 Target Glass Compositions for Base Feeds Llsed During DMI 0 Melter Rate Tests (w1\%).

Table 3.11 Targer Compositions for Vittified Melter Feed with Various Additives During DMI 0 Melter Rate Tests (w\%).

Table 3.12 Composition and Properties of Aluminum Limited Waste and Glass Fotmulation HWI-Al-16 with $43,65 \%$ Waste Loading (wt $\%$ ).

Table 3.13 Composition and Properties of Aluminum Litmíted Waste and Glass Folmulation HWI-A]-19 with $45 \%$ Waste Loading (w1\%). 
Table 3.14 Composition of Melter Feed to Produce $100 \mathrm{~kg}$ of Target Glass HWI-Al-16 (Target Glass Yield $=500 \mathrm{~g} / \mathrm{L}$ Feed) from the Al-Limited Waste Simulant Using $\mathrm{Al}(\mathrm{OH})_{3}$ as the Aluminum Source.

Table 3.15 Composition of Melter Feed to Produce $100 \mathrm{~kg}$ of Target Glass HWI-Al-16 (Target Glass Yield $=500 \mathrm{~g} / \mathrm{L}$ Feed) from the Al-Limited Waste Simulant Using $\mathrm{Al}_{2} \mathrm{O}_{3}$ as the Aluminum Source.

Table 3.16 Composition of Melter Feed to Produce $100 \mathrm{~kg}$ of Target Glass HWI-Al-19 (Target Glass Yield $=500 \mathrm{~g} / \mathrm{L}$ Feed) from the Al-Limited Waste Simulant Using $\mathrm{Al}(\mathrm{OH})_{3}$ as the Aluminum Source.

Table 4.1

Table 4.2 Summary of Results from DM100 Tests.

$T-35$

Steady-State Production Rates Achieved with HLW Compositions on the DM100 at Melt Pool Bubbling of $9 \mathrm{lpm}$ and Solids content near $500 \mathrm{~g}$ glass/liter.

Table 4.3

Summary of Measured DM100 Parameters.

$\mathrm{T}-43$

Summary of DM1200 Test Conditions and Results.

Table 5.1

Table 5.2 Summary of Operational Events.

$\mathrm{T}-46$

Operator Observations of Cold Cap (CC).

$\mathrm{T}-47$

Table 5.3

Table 5.4

DM1 200 Tests Performed with Final HL W Bubbler Configuration and Glass Temperature of $1150^{\circ} \mathrm{C}$.

$\mathrm{T}-50$

Table 5.5

Table 5.6

Measured DM1200 Melter System Parameters (8/6/2008 - 8/16/2008).

Table 5.7

Mcasured DM1200 Off-Gas System Parameters.

T-67

Off-Gas Solution Volumes.

$\mathrm{T}-68$

$\mathrm{T}-70$

Analytical Results for Solutions from the DM1200 Off-gas System

Sampled at End of Testing $(\mathrm{mg} / \mathrm{L})$.

$\mathrm{T}-71$

Table 5.8

Table 6.1

Characteristics of Melter Feed Samples.

$\mathrm{T}-72$

Rheological Properties of Melter Feed Samples.

T-74

Table 6.2

XRF Analyzed Compositions of Vitrified Melter Feed Samples (wt\%).

Table 6.3

Table 6.4

Listing of Glass Discharged, Masses, and Analysis Performed During DM100 Tests.

T-76

$\mathrm{T}-77$

Table 6.5 List of Glass Discharged, Masses, and Analysis Performed during DM1200 Tests.

T-80

Table 6.6 XRF Analyzed Composition for Glass Discharged During DM100 Melter Test (wt\%).

Table 6.7 XRF Analyzed Composition for Glass Discharged During DM1200

T-87 Melter Test (wt \%).

Table 6.8 XRF and DCP Analyzed Compositions of Selected Glass Samples Discharged during DM100 and DM1200 Melter Tests (wt \%).

T-98

Table 6.9

PCT Results for Melter Glasses

$\mathrm{T}-101$

TCLP Results for Melter Glasses (mg/L).

$\mathrm{T}-102$

Glass Pool Samples and Secondary Phase Observations. T-103

Table 6.11

Table 7.1

Table 7.2

Table 7.3

Results from DM100 Off-Gas Emission Samples.

$\mathrm{T}-104$

Results from DM1200 Off-Gas Emission Samples.

T-108

Concentrations (ppmv) of Selected Species in DM100 Exhaust

Measured by FTIR Spectroscopy.

$\mathrm{T}-110$

Table 7.4 Concentrations [ppmv] of Selected Species in DM1200 Test 1

Exhaust Measured by FTIR Spectroscopy.

$\mathrm{T}-112$

Table 7.5 Concentrations [ppmv] of Selected Species in DM1200 Test 2

Exhaust Measured by FTIR Spectroscopy.

$\mathrm{T}-113$

Table 7.6 Concentrations [ppmv] of Selected Species in DM1200 Test 3

Exhaust Measured by FTIR Spectroscopy.

$\mathrm{T}-114$ 


\section{List of Figures}

Figure 1.1

Figure 1.2.a

Figure 1.2.b

Figure $1.2 \propto$

Figure 1.3

Figure 1.4

Figure 1.5

Figure 1.6

Figure 1.7

Figure 3.1

Figure 3.2

Figure 3.3

Figuse 3,4

Figure 3.6

Figure 3.7

Fìgure 3.8

Figure 3.9

Figure 3.10

Figure 3.11

Figure 3.12

Figure 3.13

Figure 3.14

Figure 3.15

Figure 3.16

Figure 3.17
Schematic diagram of DuraMelter 100 vitrification system.

Schemaric diagram showìng cross-section through

the DM100-BL-melter.

Schematic diagram showing eross-section through the

DMllo0-BL melter.

Schematic diagram showing cross-section through the

DM100-BL melter.

Cross-section of the DM1200 melter through the discharge chamber.

Cross-section through the DM1200 melter showing electrodes.

Specifications of Double Outlet " J" Bubbler.

Placement of double outlet bubblers.

Schematic diagram of DMl 200 off-gas system.

Schematic drawing of vertical gradient fumace (VGF) for

feed conversion test.

Temperature Gradient (inside the loaded ceramic crucible) of

the Vertical Gradient Fumace (VGF).

Top views and cross sections of six existing melter feeds after

VGF tests ( 30 minutes)

Preliminary evaluation of melt cate ranking by VGF as compased

to the glass production rate delecmined by DMlo0 melter test using

the same melter feed.

F-14

Time evolution of the baseline Al-limited melter feed ( $\mathrm{HL} W-\mathrm{E}-\mathrm{Al}-27)$

after VGF tests

F-15

Impacts of boron and aluminum sources on melt rate in VGF

experiments ( 45 minules).

F-16

Top views and cross sections of Group 1 formulations afler 30

minute test in VGF.

F-17

Top viewis and cross sections of Group 3 formulations afler 30 minute test in VGF.

F-18

F-19

minute test in VGF.

F-20

minute test in VGF.

F-21

test in VGF.

$\mathrm{F}-22$

F-25

rate determined by DM100 melter test.

F-26

feet consumption tests.

Correlation of DFC melt rate screening test data

and DMlon production rales for a wide variety of feed compositions.

F-27

Compatison of Base Feeds from DFC melt tate sireening tests.

Compatison of additives combined with $\mathrm{HL}$ W-E-AL-27 $\left(\mathrm{Al}_{2} \mathrm{O}_{1}\right)$

from DM10 small-scale melt rate screening tests.
F-28

F-29 
Figure 3.18 Compatison of adiitives combined with $\mathrm{HL}$ W-E-AL-27 ( $\left.\mathrm{Al}(\mathrm{OH})_{3}\right)$ from DFC melt rate screening tests.

F-30

Figure 3.19 Comparison of additives combined with HL W-E-AL-27

( $\mathrm{Al}_{2} \mathrm{O}_{3}+$ botic acid'sodn ash replacing borax) from $\mathrm{DFC}$

melt rate screening tests.

F-31

Figure 3.20

Comparison of additives combined with HL W-E-AL-27

( $\mathrm{Al}_{2} \mathrm{O}_{3}$ +boric acid/potassium carbonate replacing borax) from

DFC melt rate screening tesis.

F-32

Figure 3.21

Compatison of additives and amounts combined with

$\mathrm{HL}$ W-E-AL-27 $\left(\mathrm{Al}_{2} \mathrm{O}_{3}\right)$ from DFC melt rate screening tests.

F-33

Figure 3.22 Compatison of additives and amounts combined with $\mathrm{HL}$ W-E-AL-27 ( $\mathrm{Al}_{2} \mathrm{O}_{3}+$ botic acid'potassium carbonate replacing borax) from $\mathrm{DFC}$ melt rate sireening tests.

F-34

Figure 3.23 Compatison of additives and amounts combined with HL W-E-AL-27 $\left(\mathrm{AlOH}_{3}\right.$ ) from DFC melt titte sereening tests.

Figure 4.1.a Glass production rates (hourly moving averages) for DM100

Tests 1 and 2.

$\mathrm{F}-36$

Figure 4.1.b Glass production rates (hourly moving averages) for DM100

Tests 3 and 4.

$\mathrm{F}-37$

Figure 4.1.e Glass production rates (hourly moving averages) for DM100 Tests 5 and 6.

F-38

Figure 4.1. Glass production rates (hourly moving averages) for DM100 Tests 7 and 8 .

F-39

Figure 4.2 Steady-state glass production rates during DMI00 tests at constant bubbling rate, glass temperature $\left(1150^{\circ} \mathrm{C}\right)$, and feed solids content $500( \pm 50) \mathrm{g}$ glass per liter feed.

Figure 4,3,a Glass temperatures (houty averages) during DM100 Tests 1 and 2.

$\mathrm{F}-41$ Glass temperatures (hourly averages) during DM100 Tests 3 and $4, \quad$ F-42

Figure 4.3.c Glass temperatures (hourty averages) during DMloo Tests 5 and 6.

$\mathrm{F}-43$ Glass temperatures (houty averages) during DM100 Tests 7 and $8 . \quad$ F-44

Figure 4.3.x

Figure 4.4.a

Figure 4,4.b Plenum temperatures (hourly averages) duing DM100 Tests 1 and 2.

$\mathrm{F}-45$

Plenum temperatures (hourly averages) duing DM100 Tests 3 and $4 . \quad$ F-46

Figure 4.4.c

Figure 4.4.d Plenum temperatures (hourly averages) duing DM100 Tests 5 and 6.

$\mathrm{F}-47$

Plenum temperatures (hourly averages) duing DM100 Tests 7 and $8 . \quad$ F-48

Figure 4.5.a

Electrode temperatures and power (hourty averages) during DM100 Tests 1 and 2.

F-49

Figure 4.5.b Electrode temperatures and power (hourly averages) during DMloo Tests 3 and 4.

F-50

Figure 4.5.c Electrode temperatures and power (hourty averages) during DM100 Tests 5 and 6 .

F-51

Figure 4.5.d Electrode temperatures and power (houty averages) during DM100 Tests 7 and 8 .

F-52

Figure 4.6.a Melt pool resistance and total electrode power during DMI00

Tests 1 and 2.

F-53

Figure 4.6.b Melt pool resistance and total electrode power during DM100

Tests 3 and 4.

F-54

Figure 4.6.c Melt pool resistance and total electrode power during DM100

Tests 5 and 6.

F-55 
Figure 4.6.1 Melt pool resistance and total electrode power cluring DMlo0

Tests 7 and 8 . F-56

Figure 5.1 Picture of cold cap through north view port showing the thickness of the cold cap. $\quad$ F-57

Figure 5.2.a Production rates for DM1200 Test 1.

Figure 5.2.b Production rates for DM1200 Tests 2 and 3. Plenum temperatures and electrode power (houty averages) for

F-61 DM1 200 Test 1.

F-62

Figure 5.4.b Plenum temperatures and electrode power (houtly averages) for DM1 200 Tests 2 and 3.

Figure 5.5.a Electrode temperatures and power (houty averages) for DM1 200 Test 1 .

Figure 5.5.b Electrode temperatures and power (houtly averages) for DM1200 Tests 2 and 3.

Figure 5.6.a Electrode power and glass resistance for DM1200 Test 1.

Figure 5.6.b Electrode power and glass resistance for DM1200 Tests 2 and 3 .

Figure 5.7.a Glass density and level for DM1200 Test 1.

Figure 5.7.b Glass density and level for DM1200 Tests 2 and 3.

Figure 5.8.a Glass pool bubbling for DM1200 Test 1 .

Figure 5.8.b Glass pool bubbling for DMl200 Tests 2 and 3.

Average gas temperatures along the DM1200 off-gas train during Test 1 .

F-64

F-65

F-66

F- 67

$\mathrm{F}-68$

F-69

F-70

F-71

Figure 5.9.b Average gas temperntures along the DM1 200 off-gas train during Test 2.

F-72

Figure 5.9.c Average gas temperntures along the DM1 200 off-gas train during Test 3 .

Figure 5.10.a Melter pressure at instrument port and control air flow rate during Test 1.

Figure 5.10.b Melter pressure at instrument port and control air flow rate during Tests 2 and 3 .

Figure 5.11a Differential pressure across the transition line and film cooler during DM1200 Test 1.

Figure 5.11.b Differential pressure across the transition line and film cooler during DM1200 Tests 2 and 3.

Figure 5,12,a

Figure 5.12.b

Figure 5.13.a

Figure 5,13.b

Figure 5,14.a

Figure 5.14.b

Figure 5.15.a

Figure 5.15.b
SBS inlet and outlet gas temperatures during Test 1 .

SBS inlet and outlet gas temperatures during Tests 2 and 3.

SBS inlet, outle1, and differential pressures (hourly average values) during Test 1 .

SBS inlet outle1, and differential pressures (hourly average values) during Tests 2 and 3 .

SBS downcomer annulus pressure (houty average values) duting Test 1 .

SBS downcomer annulus pressure (hourly average values) during Tests 2 and 3.

Off-gas temperatures in the SBS downcomer and sump water temperatures (houty average values) during Tes1 1.

Off-gas temperatures in the SBS downcomer and sump water temperatures (houtly average values) during Tesis 2 and 3 .
F-73

F-74

F-75

F-76

F-77

F-78

F-79

F-80

F-81

F-82

F-83

F-84

F-85

F-86 
Figure 5.16.a SBS cooling coil ìnlet, cooling coil oulet/jacket inlet and jacket outlet water temperatures (houty average values) duing Test 1 .

Figure 5.16.b SBS cooling coil inlet, cooling coil oullet/jacket inlet and jacket outlet water temperatures (houty average values) duing Tests 2 and 3 .

Figure 5.17.a SBS cooling coil jacket water flow rate (hourty average values) luring Test 1.

F-87

F-88

F-89

Figure 5.17.b SBS cooling coil/jacket water flow rate (houly average values) during Tests 2 and 3 .

F-90

Figure 5.18,a Calculated heat loads on the inner coil and jacket (hourly average values) during Test 1 .

Figure 5.18.b Calculated heat loads on the inner coil and jacket (hourly average values) during Tests 2 and 3 .

Figure 5.19.a Accumulated SBS blowdown volume and accumblated feed witer luring Test 1.

Figure 5.19.b Accumulated SBS blowdown volume and accumulated feed water during Tests 2 and 3 .

Figure 5.20.a WESP inlet and outlet gas temperatures during Test 1 .

Figure 5.20.b WESP inlet and outlet gas temperatures during Tests 2 and 3 . WESP differential pressure and outlet gas flow rate (hourly average values) during Test 1 .

Figure 5.21.b WESP differential pressure and outlet gas flow rate (hourly average values) durìng Tests 2 and 3 .

Figure 5.22.a Accumulated WESP blowdown volume, accumulated fiesh spray water, and water removed from off-gas during Test 1 .

Figure 5.22.b Accumulated WESP blowdown volume, accumulated fresh spray water, and water removed from off-gas during Tesis 2 and 3 .

Figure 5,23,a

Figure 5.23.b

Figure 5.24.a

Figure $5.24, \mathrm{~b}$ Voltage and current actoss the WESP during Test 1.

Voltage and current actoss the WESP during Tests 2 and 3.

Outle1 gas temperature and differential pressure for HEME \#1 during Test 1.

F-9l

F-92

F-93

F-94

F-95

F-96

F-97

F-98

F-99

$\mathrm{F}-100$

F-101

F-102

F-103

F-104 during Tests 2 and 3 .

Figure 5.25.a Outle1 temperature and differential pressure for HEPA \#1 (hourly average values) during Test 1 .

F-105

Figure 5,25.b Outle1 temperature and differential pressure for HEPA \#1 (hourly average values) during Tests 2 and 3.

F-106

$\mathrm{F}-107$ average values) during Test 1 .

Figure 5.26.b Inlet gas temperature and differential pressure for PBS (hourty average values) during Tests 2 and 3 .

F-108

Figure 5.27.a Sump temperature and $\mathrm{pH}$ for PBS (hourly average values) during Test 1.

F-109

Figure 5.27.b Sump Temperature and $\mathrm{pH}$ for $\mathrm{PBS}$ (hourty average values) during Tests 2 and 3.

F-110

Figure 6.1.a Figure 6.1.b Figure 6.1.c Figure 6.2.a
DM100 product and target glass compositions determined by XRF. DM1 00 product and target glass compositions determined by XRF. DM1 00 product and target glass compositions determined by XRF. DM1 200 product and target glass compositions determined by XRF,
F-111

$\mathrm{F}-112$

F-113

F-114 
Figure 6.2.b Figure 6.2.c Figure 6.3.a Figuse 6.3.b Figure 6.4 Figure 7.1 Figure 7.2 Figure 7.3 Figure 7.4 Figure 7.5 Figure 7.6 Figure 7.7 Figure 7.8
DM1200 product and target glass compositions detemined by XRF. DM1 200 product and target glass compositions determined by XRF. SEM image of cold cap sample fiom DM100 Test 8. SEM image of cold cap sample from DM100 Test 8. SEM image of cold cap sample from DM1200 Test 1. FTIR monitored $\mathrm{NO}$ and HF emissions during DM100 Tests 1 and 2. FIIR montored NO and HF emissions during DMl ho Tests 3 and 4. FTIR monitored NO and HF emissions during DM100 Tests 5 and 6. FTIR monitored $\mathrm{NO}$ and HF emissions during DM100 Tests 7 and 8. FTIR Monitored NO emissions during DM1200 Test 1. FTIR monitored HF emissions duing DM1200 Test 1 . FTIR monitored NO emissions during DM1 200 Tests 2 and 3 . FTIR monitored HF emissions duing DM1200 Tests 2 and 3.
F-115

F-116

F-117

F-118

F-119

F-120

F-121

F-122

F-123

F-124

F-125

F-126

$F-127$ 


\section{List of Abbreviations}

\begin{tabular}{|c|c|}
\hline$A A$ & Atomic Absorpton Spectroseopy \\
\hline $\mathrm{ADS}$ & Alr Displacement Sluny \\
\hline ANL-LRM & Asgonne National Laboratory - Low Actrvity hiaste Reference Matenal \\
\hline $\mathrm{AOD}$ & Alr Operated Diaphragm \\
\hline$\infty$ & Canister Center Line Coolng \\
\hline DCP-AES & Durect Current Plasma Atornic Emission Spectroscopy \\
\hline $\mathrm{DF}$ & Decontamınatıon Factor \\
\hline $\mathrm{DFC}$ & DMlO Feed Consumpition (test) \\
\hline DM & Duraketter(i) \\
\hline DOE & Department of Energy \\
\hline DRE & Destruction \& Removal Efticiency \\
\hline DHPF & Defense Waste Processing Facility \\
\hline EA & Environmental Assessment \\
\hline EPA & Environmental Protection Agency \\
\hline EDS & Energy D1spersite X-Ray Spectroscopy \\
\hline FTIR & Fourier Transform Infrared Spectroscopy \\
\hline $\mathrm{GC}$ & Gas Chromatography \\
\hline HEPA & Hıgh-Efficlency Particulate Alr Filter \\
\hline HEME & High-Efficleficy Mist Elıminator \\
\hline HLw & High Level Waste \\
\hline IHLW & Inumobilized Hugh Level Waste \\
\hline LAW & Low Activity Waste \\
\hline $\mathrm{M}$ & Molerity \\
\hline $\mathrm{N}$ & Normalıty \\
\hline NIST & National Inststute of Standards and Technology \\
\hline ORP & Office of River Protection \\
\hline PBS & Packed Bed Scrubber \\
\hline PCT & Froduct Consistency Test \\
\hline$Q A$ & Qualıty Assurance \\
\hline QAPJP & Quality Assurance Project Plan for Testung Progranıs Generatung Enyıronmental Regulatory Data \\
\hline QAPP & Qualıty Assurance Project Plan \\
\hline RPP & Ruver Protection Project \\
\hline SBS & Submerged Bed Scrubber \\
\hline SEM & Scanting Electron Microscopy \\
\hline SIPP & Sem1 Integrated Pllot Plant \\
\hline SOP & Stantard Operating Frocedure \\
\hline SRM & Standard Reference Material \\
\hline SRS & Sayannah River Site \\
\hline TCLP & Toxicty Characteristic Leachung Procedure \\
\hline $\mathrm{T} \subset \mathrm{O}$ & Thermal Catalytic Oxidation \\
\hline VGF & Vertıcal Gradıent Fumace \\
\hline VSL & V'treous State Laboralory \\
\hline$W C$ & Wiater Column \\
\hline WESP & Wet Electrostatic Precipltator \\
\hline WTP & Hanford Tank Waste Treatnent and Immobilization Plant \\
\hline WYDP & West Valley Demonstration Froject \\
\hline $\mathrm{XRD}$ & X-ray Diffraction \\
\hline $\mathrm{XRF}$ & X.Ray Fluorescence Spectroscopy \\
\hline
\end{tabular}




\section{SECTION 1.0 INTRODUCTION}

This report describes the development and testing of new glass fonuulations for high aluminum waste streans that achieve high waste loadings while maintaining high processing rates. The testing was based on the compositions of Hanford High Level Waste (HLW) with limiting concentrations of aluminum specified by the Office of River Protection (ORP). The testing identified glass formulations that optimize waste loading and waste processing rate while meeting all processing and product quality requirements. The work included preparation and characterization of crucible melts and small scale melt rate screening tests. The results were used to select compositions for subsequent lesting in a DuraMelter 100 (DM100) system. These tests were used to determine processing rates for the selected formulations as well as to examine the effects of increased glass processing temperature, and the form of aluminum in the waste sinulant. Finally, one of the formulations was selected for large-scale confirmatory testing on the HLW Pilot Melter (DM1200), whish is a one third scale prototype of the Hanford Tank Waste Treatment and Immobilization Plant (WTP) HLW melter and off-gas treatment system. This work builds on previous work performed at the Vitreous State Laboratory (VSL) for Department of Energy (DOE) to increase waste loading and processing rates for high-iron HLW waste streanus [1] as well as previous tesis conducted for $O R P$ on the same high-aluminum waste composition used in the present work and other Hanford HLW compositions [2]. The scope of this study was outlined in a Test Plan [3] that was prepared in response to an ORP-supplied statement of work [4].

It is currently estimated that the number of HLW canisters to be produced in the WTP is about 13,500 (equivalent to $40,500 \mathrm{MT}$ glass) [4]. This estimate is based upon the inventory of the tank wastes, the anticipated performance of the sludge treatment processes, and current understanding of the capability of the borosilicate glass waste fom. The WTP HLW melter design, unlike earlier DOE nelter designs, incorporates an active glass bubbler system. The bubblers create active glass pool convection and thereby improve heat transfer and glass melting rate. The WTP HLW melter has a glass surface area of $3.75 \mathrm{~m}^{2}$ and depth of $\sim 1.1 \mathrm{~m}$. The two melters in the HLW facility together are designed to produce up to $7.5 \mathrm{MT}$ of glass per day at $100 \%$ availability. Further increases in HLW waste processing rates can potentially be achieved by increasing the melter operating temperature above $1150^{\circ} \mathrm{C}$ and by increasing the waste loading in the glass product. Increasing the waste loading also has the added benefit of decreasing the number of eanisters for storage.

The curtent estimates and glass formulation efforts have been conservative in tems of achievable waste loadings. These formulations have been specified to ensure that the glasses are homogenous, contain essentially no crystalline phases, are processable in joule-heated, ceramic-lined melters and meet WTP Contract terms. The WTP's overall mission will require the immobilization of tank waste compositions that are dominated by mixtures of aluminum (Al), chromium ( $\mathrm{Cr})$, bismuth $(\mathrm{Bi})$, iron $(\mathrm{Fe})$, phosphorous $(\mathrm{P})$, zirconitun $(\mathrm{Zr})$. and sulfur $(\mathrm{S})$ compounds as waste-limiting components. Glass compositions for these wasle mixtures have been developed based upon previous experience and current glass property models. Recently, 
DOE has initiated a testing program to develop and characterize HLW glasses with higher waste loadings [4,5]. Results of this work have demonstrated the feasibility of increases in wasteloading from about $25 \mathrm{wt} \%$ to $33-50 \mathrm{wt} \%$ (based on oxide loading) in the glass depending on the waste strean. It is expected that these higher waste loading glasses will reduce the HLW canister production requirement by about $25 \%$ or nore [2].

DOE HLW treatment programs have featured joule heated ceramic melter technology for the vitrification of high level tank waste. The melter technology used at the West Valley Demonstration Project (WVDP) in New York and at the Defense Waste Processing Facility (DWPF) at the Savannah River Site (SRS) process(ed) HLW in ceramic melters at an operating temperature of $1150^{\circ} \mathrm{C}$. Historically, HLW melters are operated at temperatures of $1150^{\circ} \mathrm{C}$ to allow for sufficient temperature control for normal as well as upset conditions in an operating melter, while still protecting the electrodes from potential damage due to unanticipated high temperature swings. Since the HLW melters deployed in the United States at West Valley and DWPF do not actively mix the glass pool, temperature variations within the glass pool can be relatively large $\left(\sim \pm 75^{\circ} \mathrm{C}\right.$ ) with respect to the nominal operating temperature since natural convection within the glass pool is limited in the viscous molten glass. In advancing the teclunology, Energy Solutions/VSL have demonstrated on very large scale melters (Energy Solttions M-Area facility, RPP-WTP HLW Pilot Melter, and the RPP-WTP LAW Pilot Melter) that active mixing of the glass pool using our patented bubbler teclnnology significantly rednces the temperature gradjent within the glass pool and allows the melter to be controlled in a tighter operating band. As a result, the operating temperature of the melter wat be modestly increased to about $1175^{\circ} \mathrm{C}$ with the current materials of construction, (and up to $1225^{\circ} \mathrm{C}$ with changes of electrode and bubbler materials) while maintaining the operating integrity of the melter at the higher temperature. Tests conducted with various HLW waste streams on the DM100 and DM1200 melters have demonstrated increases in glass production rates from 0 to 225 percent while increasing the processing temperature from $1150^{\circ} \mathrm{C}$ to $1175^{\circ} \mathrm{C}[2,6]$. Further increases in operating temperature to higher temperatures $\left(1200^{\circ} \mathrm{C}\right)$ have the potential to further increase processing rate as well as increased waste loading. both of which translate into significant cosi savings.

Under a separate contrant to support the WTP, the VSL is developing and testing glass formulations for WTP HLW waste compositions to provide data to meet the WTP contract requirements and to support system design activities [7-13]. That work is based upon small-scale batch inelts ("crucible melts") using waste simulants. Selected formulations have also been tested in small-scale, continuous]y fed, joule-heated melters (DM100) [14-17] and, ultimately, in the HLW DM1200 Pilot Melter [6, 16-23]. More recently, a series of tests were conducted on the DM100 to deterunine the effect of systemtatic variations in various glass properties (viscosity and conductivity) and oxide concentrations on glass production rates with HLW feed streans [24. 25]. Such melter tests provide information on key process factors such as feed processing belavior, dynamic effects during processing. secondary phase formation, processing rates, off-gas anounts and compositions, foaming control. etc., that cannot be reliably obtained from crucible melts. This sequential scale-up approach in the vitrification testing program ensures that maximum benefit is oltained from the more costly larger-scale melter tests and that the most effective use is made of those test resources. 
The glass formulation and melter testing work described in this report led to the identification of glass compositions that achieve high processing rates while maintaining high waste loadings of a high-aluminum HLW stream; that HLW composition was one of the four waste streams previously specified by ORP [5]. The previous tests with these waste streams demonstrated substantial increases in waste loading, however, production rates with the aluminum limited waste stream and with a waste stream limited by aluminum in combination with sodium were only a third to a half of the rates obtained for chromium, and iron limited wastes. The goal of the current work was, therefore, to retain high waste loadings and acceptable glass properties for the aluminum limited waste while increasing the glass production rate through the manipulation of the glass formulations and glass forming additives. An extensive literature review was performed during the first phase of this work, the results of which were included in the final report [2]. In the present work, the literature was further reviewed with particular emphasis on factors affecting melt rates. Although directly relevant literature on increasing the processing rates of high aluminum waste vitrification feeds is very limited, the more general literature on melt rates and feed to glass conversion processes (see for example [26 - 43]) provided a useful starting point for the present work.

The results from this test program will provide ORP with a basis for projection of the amount of Immobilized High Level Waste (IHLW) to be produced at Hanford and the potential waste processing rate, and evaluation of the likely potential for future enhancements of the WTP over and above the present well-developed baseline. It should be noted that the compositions of the four ORP-specified waste streams differ significantly from those of the feed tanks (AZ-101, AZ-102, C-16/AY-102, and C-104/AY-101) that have been the focus of the extensive technology development and design work performed for the WTP baseline. In this regard, the work detailed in this report is complementary to and necessarily of a more exploratory nature than the work in support of the current WTP baseline. It should be noted, therefore, that considerable further work would be required to bring the level of confidence in the new glass composition regions to a similar level of maturity to that of the current WTP baseline. Additional testing at the crucible and melter seales will be needed to determine the robustness of the new compositions with respect to variations in the feed compositions that may results from process variations as well as for the collection of data to support engineering and permitting requirements using a WTP prototypic off-gas system. In addition, since the high waste loading glass compositions are in a new composition space as compared to the current WTP compositions, additional effort will be required to develop and extend the current qualified glass composition region and supporting models to include these new compositions.

\section{$1.1 \quad$ Test Objectives}

The principal objective of the work reported here was to develop and identify HLW glass compositions that maximize waste processing rates for the aluminum limted waste composition specified by ORP while maintaining high waste loadings and acceptable glass properties. This was accomplished through a combination of crucible-scale tests, confirmation tests on the DM100 melter system, and demonstration at pilot scale (DM1200). The DM100-BL unit was selected for these tests since it was used previously with the HLW waste streams evaluated in this study [2], was used for tests on HLW glass compositions [14-17] to support subsequent tests 
on the HLW Pilot Melter $[6,16-23]$, conduct tests to determine the effect of various glass properties (viscosity and conductivity) and oxide concentrations on glass production rates with HLW feed streams $[24,25]$, and to assess the volatility of cesium and technetium during the vitrification of an HLW AZ-102 composition [44]. The same melter was selected for the present tests in order to maintain comparisons between the previously collected data. These tests provide information on melter processing characteristics and off-gas data, including formation of secondary phases and partitioning. Once DM100 tests were completed, one of the compositions was selected for further testing on the DM1200; the DM1200 system has been used for processing a variety of simulated Hanford waste streams $[6,16-23]$. Tests on the larger melter provide processing data at one third of the scale of the actual WTP HLW melter and, therefore, provide a more accurate and reliable assessment of production rates and potential processing issues.

The work focused on maximizing waste processing rates for high aluminum HLW compositions. In view of the diversity of forms of aluminum in the Hanford tanks, tests were also conducted on the DM100 to determine the effect of changes in the form of aluminum on feed properties and production rate. In addition, the work evaluated the effect on production rate of modest increases in melter operating temperature.

Glass composition development was based on one of the HLW waste compositions specified by ORP that has a high concentration of aluminum. Small-scale tests were used to provide an initial screening of various glass formulations with respect to melt rates; more definitive screening was provided by the subsequent DM100 tests. Glass properties evaluated included: viscosity, electrical conductivity, crystallinity, gross glass phase separation and the 7day Product Consistency Test (ASTM-1285). Glass property limits were based upon the reference properties for the WTP HLW melter. However, the WTP crystallinity limit ( $<1$ vol\% at $950^{\circ} \mathrm{C}$ ) was relaxed slightly as a waste loading constraint for the crucible melts.

\subsection{Quality Assurance}

This work was conducted under a quality assurance program that is based on NQA-1 (1989) and NQA-2a (1990) Part 2.7 that is in place at the VSL. Recently, the quality assurance program was updated to be compliant with applicable criteria of 10 CFR 830.120 ; Office of Civilian Waste Management DOE/RW-0333P, Quality Assurance Requirements and Description (QARD) Revision 18; the American Society of Mechanical Engineers (ASME) NQA-1, 2000; and DOE Order $414.1 \mathrm{C}$, Quality Assurance. This program is supplemented by a Quality Assurance Project Plan for RPP-WTP work [45] that is conducted at VSL. Test and procedure requirements by which the testing activities are planned and controlled are also defined in this plan. The program is supported by VSL standard operating procedures that were used for this work [46]. In addition, the requirements of DOE/RW-0333P were applicable to the following specific aspects of this work:

- Crucible melt preparation

- Analysis of crucible melt glasses

- $\mathrm{PCT}$ 


\subsection{DM100 Melter System}

\subsubsection{DM100 Feed Systen}

A schenatic diagram of the DM 100 vitrification system is shown in Figure 1.1. The melter feed is introduced in batches into a feed container that is mounted on a load cell for weight monitoring. The feed is stirted with a variable speed mixer and constantly recirculated except for periodic, momentary interruptions during which the weight is recorded. Feed is nomally introdued into the melter via a system designed to mimic the operation of an Air Displacenent Slumy (ADS) punt, which is the present WTP baseline; however, a peristaltic pump was used in these tests in order to provide a uniform delivery of feed to the melt surface. In this systen. a recirculation loop extends to the top of the melter where feed is diverted from the recirculation loop to the peristaltic pump and subsequently into the melter through a Teflon-lined feed line and water-cooled, vertical feed tube.

\subsubsection{Melter System}

Cross-sectional diagrams of the DM 100-BL melter are shown in Figures 1.2.a-c. The DM100-BL unt is a seramic refractory-lined melter fitted with five electrodes: two pairs of opposing Inconel 690 plate electrodes and a bottom electrode. Power can be supplied in either three-phase or single-phase configurations. All of the tests in the present work were performed with the upper and lower electrodes on each side conuected together and powered by a single-phase supply; the bottom electrode was not powered. Melt pool agitation is achieved by either a renovable lance entering from the top of the nelter or a permanent bubbler installed through the bottom electrode. In these tests the lance bubbler was used. The glass product is removed from the nelter by means of an airlift discharge systent. The melter has a melt surface area of $0.108 \mathrm{~m}^{2}$ and a variable glass inventory of between $110 \mathrm{~kg}$. when only the bottom pais of electrodes is used, and about $170 \mathrm{~kg}$ when both pairs of electrodes are used, which was the case in the present tests.

\section{3 .3 Off-Gas System}

For operational simplicity, the DM100-BL is equjpped with a dry off-gas treatment system involving gas filtration operations only. Exhaust gases leave the melter plenum through a film cooler device that minimizes the formation of solid deposits. The film-cooler air has constant flow rate and its temperature is themostatically controlled. Consecjuently, under steady-state operating conditions, the exhaust gases passing through the transition line (betwen the metter and the first filtration device) cau be sampled at constant temperature and airflow rale. The geometry of the transition line conforms to the requirements of the 40-CFR-60 air sampling technicues. Inumediately downstream of the transition line are cyclonic filters followed by conventional pre-filters and HEPA filters. The temperature of the cyclonic filters is maintained above $150^{\circ} \mathrm{C}$ while the temperatures in the HEPAs are kept sufficiently high to prevent moisture condensation. The entire train of gas filtration operations is duplicated and each train is used alternately. An induced draft fan completes the system. 


\subsection{DM1200}

\subsubsection{Feed System}

The feed material for these tests was prepared and controlled according to VSL specificalions by a chemical supplier, as detailed in Section 2. Each batch of feed slurry was shipped to VSL in lined 55-gallon drums, which were staged for unloading into the mix tank. Both the mix tank and the feed tank are 750 -gallon polyethylene tanks with conjeal bottons that are fitted with mechanical agitators: the feed tank is also fitted with baffles to improve mixing. Any required feed additive can be added to the mix tank. Five calibrated load cells directly nounted on the legs of the feed tank are used to measure additions to, and renoval from, the feed tank and are electronically monitored to determine the feed rate to the melter. The requisite amount of feed is pumped to the feed tank from the nix tank; measured amounts of water are combined by weight with the feed at this point to adjust the concentration of the melter feed. The material in the feed tank is constantly recirculated from the feed tank discharge outlet. at the tank botion, to the tank inlet a1 the top. which provides additional mixing.

The feed is introduced into the melter using an ADS pump, which is the present WTP baseline. The feed transfer line extends from the outlet of the ADS pump in the feed tank to the top of the melter. Feed is introduced into the melter through an un-cooled feed nozzle that is located above the center of the glass pool. Only one feed tube is used to represent the planned number of feed tubes per unit melt surtace area in the full-scale WTP HLW melter. The operation of the ADS pump is controlled from the melter computer control system. The ADS pump works by opening the puntp reservoit to the feed tank using a double-acting air cylinder and mechanical link to actuate the poppet. The reservoir is filled with slury by gravity. After sufficient time is allowed to fill the reservoir (a few seconds), the poppet is toggled to close the reservoir to the tank and open the transfer line. After a desired delay time (dependent on the desired feed rate) the reservoir is pressurized with air to transfer the slutry (about 1.6 liter shot) to the melter. This cycle is repeated at the rate required to provide the desired feed rate.

When necessary, a backup system is used to introduce feed into the melter with an air operated diaphragm (AOD) pump system that simulates the pulsed feading action of an ADS pump. The recirculation loop extends to the top of the melter where feed is diverted from the recirculation loop into the melter through a Teflon-lined feed line and waler-cooled feed tube. Two computer-operated pincl valves, one on the feed line and one on the recirculation loop, are activated in a timed sequence to introdnoe feed into the melter at the desired rate. The feed rate is regulated by adjusting the length of each pulse, the time between each pulse, and the pressure applied to the recirculation loop.

\subsubsection{Melter System}

The DuraMelter 1200 (DM1200), which is the HLW Pilot Melter, was used for these tests. Cross-sectional diagrams of the melter illustrating the discharge chamber and electrode configuration are provided in Figures 1.3 and 1.4 . The DM1200 is a Joule-heated meller with Inconel 690 electrodes and thus has an upper operating temperature of about $1200^{\circ} \mathrm{C}$. The melter 
shell is waler-sooled and incorporates a jack-bolt thermal expansion system. The footprint of the melter is approximately $8 \mathrm{ft}$. by $6.5 \mathrm{ft}$. with a $4 \mathrm{ft}$. by $2.3 \mathrm{ft}$. air-lift discharge chamber appended to one end; the melter shell is almost $8 \mathrm{ft}$. tall. The melt surface area and the melt pool height are approxintalely 32 percent and 57 percent, respestively, of the corresponding values for the fullscale HLW melter. The discharge riser and trough are full-scale to verify pouring perfonmance. Other aspects of the discharge system are also prototypical such as the chamber ventilation scheme. The glass contact refractory is Monofrax $\mathrm{K}-3$ while the plenum area walls are constructed of Monofrax ${ }^{*} \mathrm{H}$ refraclory. The surface of the glass pool is $34^{\prime \prime}$ by $54^{\prime \prime}$ with a nominal glass depth of $25^{n}$. The resultant melt volume is approximately 45,000 cultic inches (735 liters), which represents a glass tank capacity of more than 1.7 metric tons of glass. However, since the typical operating glass level is closer to 29 inches, the effective glass volume during testing is actually about 849 liters, giving an inventory of about 2.0 metric tons. The DuraMelter TM 1200 is fitted with one pair of electrodes placed high on opposite walls of the melter as well as one bottom electrode. The side electrodes are 11 " by 34 " giving an electrode area for the pait of about $750 \mathrm{sq}$. in. Depending on the glass level, the plenum space extends about $33^{\mu}$ to $36^{\prime \prime}$ above the melt surface resulting in a plenum volume ranging from about 43 to $46 \mathrm{ft}^{3}$.

The single-phase power supply to the melter electrodes ( $250 \mathrm{~kW}$ design power) is derived from the DuraMelter 1000 transformers by wiring them in parallel and using a single large silicon controlled rectifier. Current can be passed either from the side electrodes to the botton electrode or between the two side electrodes only, by rearranging jumpers; only side-to-side operation was used for 1he present tests. Programmable process controllers are installed and can be used to control temperature or power. The melt temperature is controlled by configuring the process controller to maintain constant power and adjusting the power set-point as needed to maintain the desired operating temperature. Alarms can be set to detect out-of-range temperatures or power in the nelter. Backup process controllers are installed to be used in case of failure of the main controllers. The entire system is supported by a back-up generator that is tripped on in the event of a power outage.

The DuraMelter 1200 has several other features. The lid refractory is prototypic and also includes a two-piece construction, which sinulates the seant needed for the LAW lid that was planned to be fabricated in three pieces. Nozzles are provided for the off-gas film cooler, a standby off-gas port. discharge airlift. along with 11 ports available for top-entering bubblers, start-up heaters and other components as needed. In addition, a bubbler anangement is installed in the bottom electrode with the objective of developing permanent bubblers for possible use on future melters. For the present tests the optimum bubbler configuration estalolished during previous tests with HLW simulants [6] consisting of two double-outlet, top-entering bubblers was used, located in positions to mimic conditions in the WTP HLW melter. Figure 1.5 shows a schematic of the prototypical double-outlet bubbler design that was based on the conbination of the results from these DM1200 tests [6] and room-temperature tests that were performed in a transparent fluid simulating the properties of the glass melt [47]. These bubblers bave outlets 8 inches apart and were placed on the melter floor. The orientation of the bubblers in the melter, as shown in Figure 1.6, results in one of the bubbling outlets being 11.3 inches from the feed tube. 


\subsubsection{Off-Gas System}

The melter and entire off-gas treatment system are maintained under negative pressure by two Paxton extemal induced draft blowers. This negative pressure is necessary to diret the gases from the melier to the prototypical off-gas system. The off-gas treatment system, shown schematically in Figure 1.7, consists of a submerged bed scrubber (SBS); a wet electrostatic precipitator (WESP); a high-efficiency mist eliminator (HEME), a high-efficiency particulate air (HEPA) filter; a thermal calalytic oxidation unit (TCO); a $\mathrm{NO}$ removal system (SCR); a caustic packed-bed scrubler (PBS); and a second HEME. Note that the PBS and the second HEME are not part of the WTP off-gas train, which effectively ends at the SCR. The HEME is used to limit entrained particle carryover into the balance of the VSL ventilation system. The system can be functionally divided into four subsystems:

Particulate Removal: Components from the SBS to the HEPA serve to remove essentially all of the particulate from the gas strean with an estimated removal efficiency of greater than $99.9999 \%$ for parlicles greater than $0.3 \mu \mathrm{m}$ in size. In the WTP facility, this provision serves to segregate the radioactive from the nonradioactive components in the system for maintenance and handling purposes.

VOC Control/Acid Gas: The TCO unit is designed to oxidize any hazardous organics that are present in the off-gas stream. This is followed by a SCR to remove $N O_{x}$ gases and a $P B S$ to remove remaituing acid gases.

Stack System: $\quad$ The emergencylbypass exhaust system, which includes a second HEPA, and the primary off-gas system both feed into the building stack system for exhausting to the atmosphere.

Liquid Processing: Components including the water spray lines, liquid sampling and water storage tanks, as well as the effluent evaporator, function to sample and process the system licuids for recyele or discharge.

With minor exceptions, the DM1200 off-gas system processing sequence follows the design for the full-scale WTP HLW melter system. except for cooling of the off-gas stream discharged fron the SCR unit (which is present in the WTP off-gas train, but absent in the DM1200 system). Per WTP direction, the SBS unit that was used for previous DM 1200 testing was modified in early 2004. Installation of the new system was completed in March 2004 and that unit was used for the present tests. The changes were implemented to reflect modifications to the WTP SBS design that have taken place since the original DM1200 unit was insialled. These modifications included clanges to the diffuser plate design, down-comer jacket and combection to the diffuser plate, bed diameter, bed packing materials, cooling coils, and liquid overflow level.

Initial quenching of the melter exhaust gas stream is effected by the film cooler. Immediately upstream of the film cooler is the injection point for control air, which is used to 
regulate melter pressure. The gas entering the balance of the off-gas system is at a tentperature of about 250 to $350^{\circ} \mathrm{C}$ and a flow rate of about $100-250 \mathrm{scfm}$, of which about $10-80 \mathrm{sctm}$ is water vapor. The off-gas is then rapidly quenched by direct liquid water contact in the SBS. which also effects removal of most of the larger particulates. The piping between the film cooler and SBS has a high superficial gas velocity to minimize particulate deposition. The gas siream leaving the SBS is at a low temperature (typically between $40^{\prime}-50^{\prime \prime} \mathrm{C}$ ). Further mist and particulate removal is effected in the WESP. HEME and HEPA. The TCO and SCR follow the particle removal components and serve to destroy organic compounds and nitrogen oxides. These two units were off-line during the present tests due to the low concentrations of these components in the exhaust strean. Finally, the PBS provides acid gas removal. Water sprays are located in the WESP. PBS. and facility HEME to wash down deposits and dissolved species into their respective collection sumps from which they can be sampled. The system components are fabricated from corrosion resistant malerials, including AL6YN and $316 \mathrm{~L}$ stainless steel, and various plastics in less demanding locations. There are extensive provisions for sampling both the gas and liquid streams throughout the system in order to collect mass balance information and renoval efficiency data for each treatment stage.

The off-gas system maintains the melter plenum under slight negative pressure, typically about -5 in. W.C. The plenum pressure is controlled by means of an air injection system that introduces a controlled air flow into the off-gas jumper just after the film cooler. The air is supplied by a blower through a diverter valve. The setting of the diverter valve, and therefore the air flow rate, is controlled by a process controller that responds to the signal from a melter pressure transducer. When the plenum pressure becomes more positive, the air injection flow rate is decreased, which tends to restore the pressure to the set-point. Conversely, the flow rate is increased when the plenum pressure becontes more negative.

\subsection{Feed Sample Analysis}

Feed saniples were taken directly from the feed recirculation line during each test. Feed samples were poured into a platinum/gold crucible that was placed into a programmed fumace for drying and fission to form a glass. The glass produced from this fusion was ground to less than 200 mesh and sealed in 20 -ml vials for subsequent analysis by $x$-ray fluorescence spectroscopy (XRF). or by acid digestion followed by direct current plasma - atomic emission spectroscopy (DCP-AES) on the resulting solution. The feed samples were also characterized for their rheological properties, density, $\mathrm{pH}$, water content, and glass yield.

\subsection{Glass Product Analysis}

The glass product was discharged from the melter into either 5-gallon steel pails (DM100) or 55-gallon drums (DM1200) periodically using an ait-lift system. The discharged produc1 glass was sampled at the end of each test by removing sufficient glass from the top of the cans for compositional analysis and secondary phase determinations. In addition. the Product Consistency Test (PCT) and Toxicity Characteristic Leaching Procechure (TCLP) were performed on samples of the glass product from the DM100 melter tests. Prior to those tests, the PCT and 
TCLP were also performed on the crucible melt compositions that were selected for the melter tests to ensure their compliance with the present WTP contract requirements. All of these procedures are routinely contucted at VSL and, therefore, standard operating procedures (SOPs) are in place.

Sample preparation for chemical analysis typically involves size reduction and sieving. All samples were subjected to XRF to determine the concentration of all elements except boron and lithium. A series of National Institute of Standards and Technology (NIST) reference materials were used for confirmation of the XRF data. Boron and lithium were determined by total acid dissolution of ground glass samples in $\mathrm{HF}_{2} \mathrm{HNO}_{3}$ and subjecting the resulting solutions to DCP-AES analysis.

\subsubsection{Viscosity}

The melt viscosity, $\eta$, was measured using a Brookfield viscometer. Measurements are performed in the temperature range of $950-1250^{\circ} \mathrm{C}$ and the data are interpolated to standard temperatures using the Vogel-Fulcher equation: $\ln \eta=\left[A /\left(T-T_{0}\right)\right]+B$, where $A, B$, and $T_{0}$ are fitting parameters. The equipment is calibrated at room temperature using standard oils of known viscosity and then checked at $950-1250^{\circ} \mathrm{C}$ using a NIST standard reference glass (SRM 711). Both precision and accuracy of the viscosity measurements are estimated to be within \pm 15 relative\%.

\subsubsection{Electrical Conductivity}

The electrical conductivity, $\sigma$, of each glass melt was determined by neasuring the resistance of the glass melt as a function of frequency using a calibrated platinumirhodium electrode probe attached to a Hew]ett-Packard nodel 4194A impedance analyzer. Measurenents are performed over sinilar temperalure ranges to those employed for the melt viscosity measurements. The results are analyzed and modeled to obtain the $D C$ electrical conductivity. The electrical conductivity data are then interpolated to standard temperatures using the Vogel-Fulcher equation: In $\sigma=\left[A\left(T-T_{0}\right)\right]+B$, where $A, B$ and $T_{0}$ are fitting parameters. Estimated uncertainties in the electrical conductivity measurements are \pm 20 relative $\%$.

\subsubsection{Product Consistency Test (PCT)}

The product consistency test (PCT; ASTM C 1285) is used to evaluate the relative chemical durability of glasses by measuring the concentrations of the chemical species released from 100-200 mesh erushed glass $(75-149 \mu \mathrm{m})$ to the test solution (de-ionized water in this case). PCT tests on the HLW glasses are performed at $90^{\circ} \mathrm{C}$, in accordance with the current WTP contract requirement. The ratio of the glass surface area to the solution volume for this test is about $2000^{-l}$ (typically, $10 \mathrm{~g}$ of 100 -200 mesh glass is immersed in $100 \mathrm{ml}$ deionized water). All tests are conducted in triplicate, in $304 \mathrm{~L}$ stainless steel vessels, and in parallel with a standard glass included in each test set. The internal standard is the Argonne National Laboratory - Low 
Activity Waste Reference Material (ANL-LRM) referenes glass [48] andior the Defense Waste Processing Facility (DWPF)-Environmental Assessnient (EA) glass, both of which have undergone round-robin testing. The leachates are sampled at predetermined times, the first of which is seven days. One milliliter of sampled leachate is mixed with $20 \mathrm{mll}$ of $1 \mathrm{M} \mathrm{HNO}_{3}$ and the resulting solution is analyzed by DCP-AES; another $3 \mathrm{ml}$ of sanpled leachate is used for $\mathrm{pH}$ measurement.

\subsubsection{Toxicity C.1haracteristic Leaching Procedure (TCLP)}

The TCLP was performed at VSL using SW-846 Method 131 1, which employs leaching of crushed glass $\left(c 3 / 8^{\circ}\right)$ in a sodium acetate buffer solution for 18 hours at $22^{\circ} \mathrm{C}$ with constant end-over-end agitation. A mass of about 100 grams of glass is leached in 2 liters of TCLP extract, according to the extraction method for non-wolatiles. The surface area to volume ratio for this test is alout $20 \mathrm{~m}^{-1}$. which is about two orders of magnitude lower than that in the PCT. The leachates are analyzed by DCP-AES according to VSL standard operating procedures.

\subsubsection{Secondary Phases}

Secondary phases in the glass samples were detemined by optical nucroscopy and scanning electron nicroscopy coupled with energy dispersive $x$-ray spectroscopy (SEM-EDS). Secondary phases due to crystallization and phase separation can be identified using these methods. Quantitative determitation of the amount of crystals in glass samples were made by $S E M$ in conjunction with image analysis. 


\section{SECTION 2.0 \\ WASTE SIMULANT AND BASE GLASS COMPOSITION}

\subsection{Waste Simulants}

The waste stream compositions previously provided by DOE are given in Table 2.1 on an oxide basis [5]. The work described in this report focused exclusively on the alnminum limited waste stream in response to the comparatively low glass production rates aclieved with this waste stream in the earlier tests [2]. Actual Hanford HLW tank wastes are aqueons solutions with suspended solids and dissolved salts including hydroxides, nitrates, nitrites, halides, and sarbonates. For the purpose of the previous [2] and present work, the concentrations of the volatile components (i.e., carbonate, nitrite, nitrate, and organic carbon) are assumed to be similar to those found for the $A Z 102 \mathrm{HLW}$ waste [21]. With the waste composition defined, formulation of the HLW waste simulant proceeds in a straightforward fashion. In general, oxides and hydroxides are used as the starting materials, with slusry of iron (III) hydroxide (13\% by weight) as one of the major constituents. Volatile inorganic components are added as the sodium salts, whereas organic carbon is added as oxalic acid. Finally, water content was adjusted to target a glass yield of $500 \mathrm{~g}$ of glass per liter of feed. Two waste simulants were employed, with the only difference being the replacement of aluminum oxide by aluminum hydroxide in order to investigate the effects of variations in the fom of aluminum in the Hanford HLW streans on feed properties and processing rates. The compositions of the waste simulants with aluminum oxide and alumionm bydroxide, fommlated to prodnce $100 \mathrm{~kg}$ of waste oxides, are given in Tables 2.2 and 2.3 , respectively.

\subsection{Base Glass Formulation}

Several glass compositions spanuing a range of waste loading were previously evaluated for suitability for the high alumitum simulated waste [2]. Based on those resulls, a glass with 45 wt \% waste loading. HLW-E-Al-27, which employed moderate additions of alkali and alkaline earth oxides $\left(\mathrm{Na}_{2} \mathrm{O}, \mathrm{Li}_{2} \mathrm{O}\right.$. and $\left.\mathrm{CaO}\right), \mathrm{B}_{2} \mathrm{O}_{3}$, and $\mathrm{SiO}_{2}$, was selected as providing the best conbination of higl waste loading and glass and melt properties [2]. Table 2.4 presents the composition of this glass and the measured properties of the crucible glass, which meet all of the processing and product quality requirements. The glass contains $23.97 \mathrm{wt} \% \mathrm{Al}_{2} \mathrm{O}_{3}$, which is more than two times the WTP contract minimum for $\mathrm{Al}_{2} \mathrm{O}_{3}(\mathrm{ll}$ wt \%). All of the measured processing parameters are within acceptable ranges. The PCT leach rates are over an order of nagnitude lower than those of the DWPF-EA glass and the TCLP leachate concentrations are all below the WTP delisting limits. Sodium aluminosilicate formation (e.g., nepleline) on heat treatonent (especially canister centerline cooling (CCC) beat treatnent) is a known concem with high-aluminum formulations and was the waste-loading-limiting factor in the formulation of HLW-E-Al-27. The selested glass produced very little crystallization (-1.9 vol\%) after CCC heat treatment and the PCT response of the heat treated glass also meets the PCT requirentents by wide margins. 
Based on the results from the previous work [2], the HLW-E-Al-27 glass fomulation was used as the starting point for the present work Although the HLW-E-Al-27 glass formulation achieved high waste loadings, the results of DM 100 melter tests showed that the glass production rates were lower than desired [2]. Therefore, the HLW-E-Al-27 glass formulation was used as the starting point for the glass fonnulation work in the present study with the objective of achieving increased glass production rates while maintaining the high waste loading. That work is described in Section 3. In addition, this glass fomulation was used in DM100 melter tests to assess the effects of variations in the form of aluminum in the waste simulant by replacing aluninum oxide, which was used in the previous work [2]. by aluminum hydroxide. The melter feed formulation for that ease is presented in Table 2.5. The results of that and other DM100 melter tests are presented in Section 4. 


\section{SECTION 3.0 GLASS FORMULATION}

\subsection{Introduction}

The priocipal objective of the glass formulation and snuall scale melt rate testing work was identifying glass compositions that maximize processing rates for the Al-linited HLW waste stream specified by ORP. The previous tests [2] with the Al-limited waste steam demonstrated substantial increases in waste loading: however, the DM100 production rates were significantly lower than the rates obtained for typical iron limited wastes and, at the nominal bubbling rate and temperature, were also below the WTP target rate of $800 \mathrm{~kg} / \mathrm{m}^{2} / \mathrm{d}$ (corresponding to $3 \mathrm{MT}$ of HLW glass per day per HLW melter). The goal of the current work was therefore to retain high waste loadings and acceptable glass properties for the aluminum limited wasie while increasing the glass production rate through the manipulation of the glass formulations and glass forming additives.

In view of the above objectives, melt rate detemination was a critical paraneter in the glass formulation effort. Melt rates are affected by many factors and are the net result of a combination of many somplex processes that cecur in the feed-to-glass conversion process. The cold cap that forms when liquid slutry feed is introdiced onto the melt surface is highly stratified in both temperature (from $\sim 100^{\circ} \mathrm{C}$ on the top to $\sim 150^{\circ} \mathrm{C}$ at the bottom) and composition. In this region, water and other volatiles are evaporated, salts ate decomposed and melted, various transient phases are formed and consumed, and finally, new glass is formed. In addition, these reactions are goverued by the subsiantial flows of heat and mass through this region. In view of this complexity, continuous melter tests provide the most reliable means of capturing these phenomena and, therefore, for reliably determining melt rates; furthermore, such tests become increasingly nore reliable as the melter scale and test duration are increased. However, because of the cost and schedule implications, such tests are not well suited for integration into a glass formulation development program in which a large number of formulation variations need to be assessed. For this reason, in the present work we have employed two types of melt rate screening tests that permitted rapid evaluation of relative melt rates. The results from these tests were used to refine the glass formulations and down-select a subset of glasses for DM100 melter testing. The results of the DM100 tests were then used to select one formulation for pilot scale testing on the DM 1200 melter system.

The two melt rate screening tests used in this work were designed to capture many of the essential features of the feed-to-glass conversion process, albeit in a necessarily simplified fashion. In the Vertical Gradient Fumace (VGF) tests, dried feed is placed on top of pre-melted glass in a crucible and subjected to a vertical temperature gradient for predetermine times (see Section 3.2.2). The crucible is then quenched, sectioned, and examined to determine the mature and extent of the feed conversion process. In the DMlo Feed Consumption (DFC) tests, an aliquot ( $\sim \mathrm{kg}$ ) of slury feed is introduced onto the surface of the DM 10 nielter and the time to consume the feed is detemined by a combination of visual observation and the change in 
plenum temperature (sece Sestion 3.4). Both tests ate well suited to quickly and efficiently screening relatively large numbers of composition variations. The tests successfully identified formulations with significantly improved melting rates and the results were subsequently contirmed in continuous melter tests at the DM100 and DM1200 pilot melier scale.

This section presents descriptions of the glass formulation approach, the test methods employed, and the results and conclusions from the melt rate screening tests and glass formulation development work.

\subsection{Experimental Methods}

The results from the earlier work on the aluminum limited waste [2], and specifically the glass fomulation selected in that work (HLW-E-AJ-27), provided the starting point for the present glass formulation effort. An iterative approach was employed in which composition modifications were designed that were intended to improve melt rates, crucible melts of those formulations were prepared, and characterization data were collected. The results were then analyzed and used to design additional formulations for testing. To improve efficiency, glass characterization was conducted in stages such that glasses that failed any processabilty or produc1 quality requirement were not subjected to further 1esting. All glasses were tested for phase behavior, both as-melted and after heat treatment, since that was expected to be one of the most limiting constraints. Acceptable glasses were then sulojected to testing with respect to PCT. melt viscosity, melt electrical conductivity, and TCLP. Glasses that met these requirements were then subjected to melt rate screening tests. In parallel, a series of DFC melt rate screening tests were performed on base glass formulations in which simple one or two component variations were made in order to collect information on component effects on melt rate (see Section 3.4), These results were also factored into the glass formulation design effort. The experimental methods that were enployed in this program are described in the following sections.

\subsubsection{Crncible Melts}

Crucible melts of each glass were fabricaled at VSL using reagent grade chemicals, mostly oxides and carbonates. Glass preparation began with a batching sheet that provided information on the required starting materials. The information included the chemicals needed. identification of the chemicals according to the vendors and catalog numbers, the associated purity, together with the amount required to produce a given anount of glass. Chemicals were weighed and batched according to the batching sheets. After the starting materials were weighed and batched, a blender was used to $\mathrm{mis}$ and homogenize the starting materials before they were loaded into platimum/gold crucibles that were engraved with individual identification numbers. The loaded platinum/gold crucible was placed inside a Deltech DT-28 (or DT-29) furnace, the heating of which was controlled by a Eurotherm 2404 temperature controller. The melting temperature was $1200^{\circ} \mathrm{C}$, at which the melt was kept for 2 hours. Mixing of the melt was accomplished mechanically using a platinum stirrer, beginning 20 minutes afler the furnace 
temperature reached $1200^{\circ} \mathrm{C}$ and continuing for the next 90 minutes. The molten glass was poured at the end of 120 minutes onto a graphite plate to cool before recovery.

All of the as-melted glasses were inspected for signs of phase separation and conpleteness of melting: secondary phases were analyzed by SEM-EDS and optical microscopy, as described in Section 1.6.5. The composition was checked XRF and DCP analysis, as described in Section 1.6.

Selected glasses were subjected to heat treatment for 70 hours at $950^{\circ} \mathrm{C}$ and below $(900$. 850 and $800^{\circ} \mathrm{C}$ ). Glass samples (about 5 grams each) were heat-treated in platinum, platioumgold. or platinum-rhodium crucibles $\left(5 \mathrm{ml}\right.$ ) at a pre-melt temperature of $1200^{\circ} \mathrm{C}$ for 1 hour. followed by heat treatment at the prescribed temperatures. At the end of the heat-treatment period. the glass samples were quencled by contacting the crucible with cold water. This quenching freezes in the phase assemblage in equilibrium with the melt at the heat-treatment temperature. The types and amounts (wol\%) of erystalline phases were detemined by SEM-EDS.

Selected glasses were subjected to canister centerline cooling (CCC) beat treatment according to the WTP HLW CCC temperature profile [13]. As in the case of isothermal heattreatment, the glass samples in platinum crucibles were maintained at a pre-melt temperature of $1200^{\circ} \mathrm{C}$ for 1 hour before initiation of the $\mathrm{C} C \mathrm{C}$ treatment. The samples recovered after $\mathrm{CCC}$ heat treatment were subjected to SEM-EDS examination.

Selected glasses were also characterized with respect to their melt viscosity and electrical conductivity, and PCT and TCLP leach testing, as described in Sections 1.6.1 - 1.6.4. respectively. The PCT was perfomed on both quenched samples and glass samples that had been subjected to $\mathrm{CCC}$ heat treatment.

Tables $3.1-3.3$ provide the identifications, compositions and properties of the glass formulations and crucible melts that were tested in this work.

\subsubsection{Vertical Gradient Furnace}

As described above, the cold cap in a continuously fed melter is subject to a large temperature gradient in the vertical direction. This gradient can drive heat and mass flows and leads to variations of reaction rates at different heights in the cold cap; the gradient is therefore a potentially significant factor in determining the melt rate. The design of the Vertical Gradient Furnace (VGF) melt rate screening tesi emphasizes the large temperature gradient in the vertical direction across the cold cap.

Figure 3.1 is a schematic diagram the VGF setup. The temperature gradient inside the VGF is maintained by two separate sets of heating elements, both of which are arranged in cylindrical form and aligned along their axis. The inner heater is set at $1150^{\circ} \mathrm{C}$, which is the nominal temperature of the glass pool, and the ambient beater is set at $600^{\circ} \mathrm{C}$, which is similar to the melter plenum temperature. A ceramic cnicible ( 4 inches tall) is used to contain the reacting melter feed. The temperature gradient in the loaded furnace is shown in Figure 3.2. For a typical 
feed conversion test, a sample of dried melter feed equivalent to 20 grans of glass is introduced into the ceramic crucible, which already contained about 10 grams of pre-melted glass of the same composition that had been preheated in the inner heater. Feed reactions under the controlled tenperature gradient are allowed to continue for the designated test duration and then stopped by rapid cooling in room temperature air. The top sufface, and the cross section (by sectioning the crucible) of the reacted feed are then inspected and photographed. Samples of the partially reacted feed are taken for further characterization by SEM-EDS, X-ray diffraction (XRD), and XRF. The composition of the feed was confirmed by XRF analysis of samples that were fused at $1150^{\circ} \mathrm{C}$.

All of the melter feed samples were prepared using the same HLW simulant and preparation methods that were used for the melter tests, as described in Section 2. The only difference was that samples used for VGF tests were dried, crushed, and sieved, before use.

The VGF results were used to evaluate the melt rate on a relative scale using the degree of the melting that had occurred, the structure of the feed materials that were undergoing reaction and transformation, and the conversion progression with time. A numerical ranking of relative melt rate was assigned based on calibration tests using feeds whose melt rates had been determined previously in DMl00 melter tests.

\subsection{Results and Discussion}

The identifications, compositions and properties of the glasses designed and tested in the present work are listed in Tables $3.1-3.3$. The feeds that were subjected to VGF testing are listed in Tables 3.1 and 3.4. These include the feeds corresponding to new glass formulations. several feeds from previons work that were used for calibration, and several feeds that are based on the earlier HLW-E-A1-27 formulation [2]. The resulss of the glass fomulation, characterization, and nelt rate tests are presented together below in groups according to the changes made in key glass formers with respect to the earlier HLW-E-Al-27 glass [2].

\subsubsection{VGF Calibration Tests}

As part of the system calibration and method development work, six melter feeds of known glass production rate (as determined in DM100 tests at $1150^{\circ} \mathrm{C}$ with nominal bubbling) were tested in the VGF. The DMI00 glass production rates, glass compositions, and the feed recipes were reported previously $[2,24$, and 25$]$. The same feed samples as those tested in the DM100 melter were used for the VGF tests. Two of the feeds were based on iron-linited glasses $[24,25]$ and the remaining four were based on $\mathrm{Cr}-, \mathrm{Bj}-, \mathrm{Al}-$, or $\mathrm{Al}+\mathrm{Na}-$ limited HLW streams [2].

Figure 3.3 shows the 1op views and the cross sections of the six feed samples after VGF tests. It is apparent that the six melter feeds exhibit a wide range of feed conversion progress, from virtually completely melted (HLW-E-CrM) to development of a complete cold cap "dome" that has lost contact with the underlying glass and shows little sign of reaction on the suface 
(HLW-E-Al-27). Feed of HLW-E-Bi-6 slows greater melting progress than HLW-E_Al-27, but exhibits a partial dome structure. Similar to HLW-E-CrM, the two iron-limited feeds (Matrix 1$\mathrm{Bl}$ and Matrix 2-9) and the $A \mathrm{~L} / \mathrm{Na}$-limited feed (HLW-E-ANa-22) display only traces of the once-present dome, with remnats of rims folded on the side wall and undergoing melting. On a relative scale, using the slowest (HLW-E-A1-27) at one end and the fastest (HLW-E-CrM) at the other end the degree of conversion of the dried melter feed materials after 30 minute VGF experiments can be divided into several intemediate stages based on the top views and cross sections. Table 3.5 lists the key observations for each stage and their assigned ranking on a relative scale. It should be emphasized that these assignments are simply rankings: a melt rate ranking of 2 should not be interpreted to mean two tintes faster than a melt rate ranking of 4 .

The results for the six feed samples in tems of their ranking values are plotted against the glass produclion rates of the same melter feeds as by determined in DM 100 tests in Figure 3.4. A nore or less linear trend is defined by the two extreme feed samples and tluee intemediate samples. It is not clear why the resul1 for HLW-E-ANa-22 feed falls off this trend. However, the DM100 rate of $400 \mathrm{~kg} / \mathrm{m}^{2} / \mathrm{d}$ is unusually low and. in fact, is the lowest rate ever measured under these test conditions. Furthemore, the increase in the DM100 rate result when the temperature was increased from $1150^{\circ} \mathrm{C}$ to $1175^{\circ} \mathrm{C}$ was unusually large $(125 \%$ vs. the more typical $\sim 25 \%)$ [2]; based on the measured rate at $1175^{\circ} \mathrm{C}$ and the nore typical change with temperature. a rate of about $720 \mathrm{~kg} / \mathrm{m}^{2} / \mathrm{d}$ at $1150^{\circ} \mathrm{C}$ would have been expected, which would be much more consistent with the VGF trend. It is possible that other atypical effects were involved in the unusually low rates in the $1150^{\circ} \mathrm{C}$ DM100 test. Further tests would be useful to clarify this issue. Nevertheless, the general trend proved to be adequate to render the VGF test a useful screening tool for the development of glass and feed fomulations with improved melt rates. This is particularly so when the VGF is used in conbination with the DFC sereening test results, as was the case in the present work

\subsubsection{Component Effects on the HLW-E-Al-27 Formulation}

The high waste loading glass (HLW-E-Al-27) developed for the aluminum limited waste in the earlier work [2] was used as the starting point for the melt rate improvement work. During DM100 tests [2] the phenomenon of "shelving" or "bridging" in the cold cap region was observed. The slurry feed had a tendency to develop a shelf-like structure of hardened feed materials that could attach to the side walls of the DM 100 melter. Without intervention, the shelf could extend and form a bridge above the glass line. The separation between the melter feed and the hot glass melt san cause the melt rate to decrease. It is interesting to note that a similar phenomenon was also observed in the partially reacted melter feed of HLW-E-A1-27 in VGF tests. As shown in Figure 3.5, a closed dome-like structure developed after 30 nimutes in the VGF. The partially molten inner lining of the done apparently provides a sufficient seal to allow the gas from the feed materials closer to hot glass surface to cause the cold cap to balloon upwards and loose contact with the underlying glass melt. As the dome expands, the temperature drops because of the vertical temperature gradient and the dome hardens. Feed materials on the top of the dome are relatively insulated from the hot glass surface by the dome and intervening gas. As slown in the top view, the granular feed materials do not exhibit much sign of 
reaction itransformation after 30 minutes in the VGF. Eventually, sufficient heat is delivered to melt away part of the dome and a vent enterged after 45 minutes in the VGF. As the reaction/melting continues, the dome structure softens and collapses to the side wall of the ceramic cricible. The sinilarity of the evolution of the done-like structure observed in a series of VGF experiments and the cold cap behavior in the DM100 tests suggesis that the VGF lests indeed capture some of the key features of the melt rate determining processes.

The chemicals used in Al-limited HLW sinulant in the previous melter test are listed in Table 3.6. The typical glass former additives are lithium and sodium cartonates, borax or boric acid. and simple oxides such $\mathrm{SiO}_{2}$ and $\mathrm{ZnO}$. The development of a dome-like structure in VGF tests suggests a need for more lower-melting or more reactive components in the HLW-E-Al-27 glassifeed formulation. The original feed formulation used aluminun oxide and borax [2]. The selection of alunimum oxide was based a conservative (io terms of melt rate) interpretation of the form of aluminum in the waste; more likely forms are the hydroxide (gibbsite), oxy-hydroxide (boehmite), and various silicates. Therefore lests were performed with the feed of HLW-E-Al-27 reformulated using aluminum hydroxide andior boric acid (sodium carbonate was used to compensate the sodium difference). Three slurry feeds of the same target glass composition HLW-E-AJ-27 were prepared with different combinations of $\mathrm{Al}(\mathrm{OH})_{3}$ and borax, $\mathrm{Al}_{2} \mathrm{O}_{3}$ and boric acid. and $\mathrm{Al}(\mathrm{OH})_{3}$ and boric acid (Table 3.1). The feed materials were tested in the VGF under the same experimental conditions for 45 ninutes (Figure 3.6). The results suggest that both substitution (aluminum hydroxide for aluminum oxide or boric acid for borax) improve the melt rate. The best result was olotained for the feed that includes both aluninum bydroxide and boric acid. The VGF feed conversion results strongly suggest that boric acid should be used instead of borax as the primary boron source.

In summary, boric acid appears to be preferred as the primary boron source. Also, in view of the variability and nocertainty with respect to the form of aluminun in the waste, it is reasonable to include both aluminum oxide and aluminum hydroxide versions in the nelt rate evaluation to provide reasonable bounds. In the subsequent VGF tests, all of the melter feeds for the new glass formulations were prepared using botic acid and $\mathrm{Al}_{2} \mathrm{O}_{3}$. The two formulations that were later selected for DMlo0 melter tests were also tested using the corresponding $\mathrm{Al}(\mathrm{OH})_{3}$ versions.

\subsubsection{Group 1 Glass and Feed Formulations}

The glass formulation and feed test results are presented in groups according to changes made in key glass formers with respect to the baseline glass HLW-E-AJ-27.

After reviewing the chenistry of $\mathrm{HLW}-\mathrm{E}-\mathrm{Al}-27,5 \mathrm{wt} \% \mathrm{CaO}$ added as a glass former was suspected as a likely a contributor to the overall slow melt rate observed in the DM100 melter tests. The calciun addition was found to be effective in suppressing spinel fomation, which allowed higher waste loadings 10 be achieved. Therefore, many of the new glass formulations in this work investigated the phase behavior of high- $\mathrm{Al}$ glasses at different levels of $\mathrm{CaO}$ (zero is not possible because the Al-limited waste contains snall amounts of $\mathrm{CaO}$ ) and their melt rate as 
deternined by VGF. In the first variation, HWI-Al-1 has the same 45 wt\% waste loading as the baseline glass but with the $\mathrm{CaO}$ additive replaced by $\mathrm{B}_{2} \mathrm{O}_{3}$ and $\mathrm{Li}_{2} \mathrm{O}$; this glass ontained minor amounts of crystalline phase (spinel) in the quenched glass (Tables 3.2 and 3.3). More spinel erystallized after heat treatment at temperatures from 950 to $800^{\circ} \mathrm{C}$ (Table 3.3). Although the substitution of $\mathrm{B}_{2} \mathrm{O}_{3}$ and $\mathrm{Li}_{2} \mathrm{O}$ for $\mathrm{CaO}$ increased crystallization near the glass melting temperature, it improved the melt rate, as shown in Figure 3.7 and Table 3.3.

At a reduced waste loading of 40 wt $\%$ glass HWI-A1-9 was homogeneous as-melted and developed little crystallization after heat treatment at temperatures from 950 to $800^{\circ} \mathrm{C}$ and under CCC conditions (Tables 3.2 and 3.3). In this case, the rednced waste loading coupled with higher sodium contributed to the suppression of spinel crystallization. The results from VGF testing indicate similar melt rates for feeds of HWI-Al-9 and HWI-Al-1. HWI-Al-10 was formulated in a manter similar to $\mathrm{HWI}-\mathrm{Al}-9$ but with minor adjustments in $\mathrm{B}_{2} \mathrm{O}_{3}$ and $\mathrm{Li}_{2} \mathrm{O}$ concentrations. Since very similat heat treatment result were obtained (Tables 3.2 and 3.3), no further tests were performed on this glass.

The results for the three glasses investigated in this group highlight one of the challenges involved in modification of the baseline glass formulation. Although the melt rate for HWI-A1-9 by $\mathrm{VGF}$ is considerably faster than for the baseline feed. the reduction in waste loading needed to suppress crystallization is undesirable. In the four groups of fomulations presented below, other glass forming additives are investigated for their roles in achieving the overall goal of improving the melt rate while suppressing crystallization of spinels, without reducing the waste loading.

\subsubsection{Group 2 Glass and Feed Formulations}

Two glasses, HW]-Al-2 and HWI-Al-3, were formulated with an additional one percent of $\mathrm{P}_{2} \mathrm{O}_{5}$ and at similar levels of $\mathrm{Na}_{2} \mathrm{O}$ and $\mathrm{B}_{2} \mathrm{O}_{3}$ to HWI-Al-9. Both glasses showed signs of pluase separation in the quenched samples (Tables 3.2 and 3.3 ) and therefore no further testing was performed.

\subsubsection{Group 3 Glass and Feed Formulations}

In this group. $\mathrm{CaO}$ as an additive in $\mathrm{HLW}-\mathrm{E}-\mathrm{Al}-27$ was partially or completely replaced by $\mathrm{MgO}$ to produce glasses HWI-Al-5 and HWI-Al-7, respectively (Tables 3.2 and 3.3). Spinel crystallization near the glass melting temperature that was observed in many low $\mathrm{Ca} O$ glasses in this work was not present in either of the $\mathrm{MgO}$-added glasses (Table 3.3). However, more crystalline plases developed after heat treatment at temperatures from 950 to $800^{\circ} \mathrm{C}$ and under CCC conditions (Table 3.3). Similar to the baseline feed, the melt rates of the both formulations in VGF tests were rather slow (Figure 3.8 and Table 3.3). Although a well developed dome structure was not present, the $\mathrm{MgO}$-added feeds appeared to soften but were resistive to further melting. In view of the increased crystallization and linited indication of improved melting. substitution of $\mathrm{MgO}$ for $\mathrm{CaO}$ was not further pursued. 


\subsubsection{Group 4 Glass and Feed Formulations}

The effect of $\mathrm{K}_{2} \mathrm{O}$ was investigated in this group. One of the motivations for introducing $\mathrm{K}_{2} \mathrm{O}$ into the glass formulations is to suppress the formation of iron-chromium spinel near the glass melting temperature, which was employed in previous work with high-iron HLW [1]. In addition, the results from DFC melt rate screening tests (Section 3.4) suggested some improvement in melt rates with additions of $\mathrm{K}_{2} \mathrm{O}$.

Three glasses, HW[-Al-4, HWI-A]-6 and HWI-Al-8, were formulated with different levels of $\mathrm{K}_{2} \mathrm{O}(4,6$, and 8 wt\% respectively; Table 3.2) largely in place of CaO. However; all three glasses showed clear signs of secondary phases in the quenched samples (Table 3.3). Additional $\mathrm{Li}_{2} \mathrm{O}$ and $\mathrm{B}_{2} \mathrm{O}_{3}$ in HWI-Al-20 failed to suppress the formation of secondary phases. atthough the VGF melt rate was significantly inmproved compared to the baseline formulation (Tables 3.2 and Table 3.3; Figure 3.9).

At a similar level of $\mathrm{CaO}$ as in the baselune glass but with additional $\mathrm{K}_{2} \mathrm{O}$ in place of $\mathrm{Na}_{2} \mathrm{O}$ (HWI-Al-13, HWI-A]-14) or $\mathrm{B}_{2} \mathrm{O}_{3}$ (HWI-Al-15), crystallization of spinel in the quenched glasses was reduced considerably for HW]-Al-13 and HWI-Al-14 and little changed for HWI-Al-15 (Taloles 3.2 and 3.3). HWI-Al-13 displayed increased crystallization of spinel and apatite after heat treatment at temperalures from 950 to $800^{\circ} \mathrm{C}$ (Table 3.3). Reducing the waste loading in HWI-Al-17 (to $43.6 \mathrm{wt} \%$ ) did not significantly reduce spinel crystallization (Tables 3.2 and 3.3). VGF tests on $\mathrm{HWI}-\mathrm{Al}-13$ and $\mathrm{HWI}-\mathrm{Al}-17$ showed only minor improvement from the baseline feed and presence of extensive foam layer (Figure 3.9).

In summary, addition of $\mathrm{K}_{2} \mathrm{O}$ was not effective in suppressing spinel crystallization in formulations without $\mathrm{CaO}$ as an additive and did not improve melt rates at higher $\mathrm{CaO}$ concentrations.

\subsubsection{Group 5 Glass and Feed Formulations}

From the results of the above tests, it is apparent that a certain level of $\mathrm{CaO}$ as glass forming additive is needed in order to suppress spinel crystallization near the glass melting temperature if high waste loadings are to be maintained. Five glasses in Group 5 were formulated to investigate the effect of increased boron content in glasses at two levels of $\mathrm{CaO}$. The beneficial effects of higher boron content on melt rate is suggested by both VGF and DFC (see Section 3.4) melt rate screening test results.

Two glasses, HWI-AL-11 and HWL-Al-12, were formulated with increased $\mathrm{B}_{2} \mathrm{O}_{3}$ at moderate amounts of $\mathrm{CaO}$ ( 2 and $3 \mathrm{wt} \%$, respectively; Table 3.2). Phase separation was observed in the quenched glass samples (Table 3.3) and therefore no further characterization was performed.

Two glasses. HWI-Al-16 and HWI-Al-19, were formulated at similar CaO concentrations as in the baseline HLW-E-A]-27 glass (Table 3.2). HWL-Al-16 results from a renonmalized 
mixture of the baselioe glass and $3 \mathrm{wt} \% \mathrm{BrO}_{3}$ at a rednced waste loading of $43,6 \mathrm{wt} \%$. HWI-Al-19 results from replacement of $3.5 \mathrm{wt}^{\%} \% \mathrm{SiO}_{2}$ and $0.5 \mathrm{wt} \% \mathrm{CaO}$ by $4 \mathrm{wt}^{\circ} \mathrm{B}_{1} \mathrm{O}_{3}$ at the same waste loading as the baseline glass (45 wt\%; Tables 3.2 and 3.3). Both HWI-A1-16 and HWI-Al-19 showed little evidence of phase separation in the quenched samples. The glass samples afler heat treatment at temperatures of 950 to $800^{\circ} \mathrm{C}$ and under $\mathrm{CCC}$ conditions showed limited crystallization, mostly of spinel with minor amounts of apatite (Table 3.3). The VGF melt rates were considerably faster than most of the formulations investigated in this work (Talo]e 3.3, Figure 3.10). HWI-Al- 18 was formulated with an additional $3 \ldots t \% \mathrm{~B}_{2} \mathrm{O}_{3}$ based on $\mathrm{HWI}-\mathrm{Al}$ 16 , but at a further reduced waste loading of 42.4 wt $\%$ (Table 3.2). However, HWI-Al-I8 displayed similar levels of crystallization and melt rate to those of HWI-AI-16 and HWI-Al- 19 (Figure 3.10. Table 3.3).

The combination of higher boron while retaining modest additions of calcium was successful in inproving the VGF melting rate while controlling spinel crystallization near the glass meltiog temperature. All three feeds fomulated using $\mathrm{Al}_{2} \mathrm{O}_{3}$ as the alumimun souroe underwent transition/melting considerably faster than the baseline feed. These melt rate improvements were also supported by the results from DFC tests (Section 3.4). Since the HWI-Al-16 and HWI-A1-19 achieve only slightly lower and the same waste loadings as the baseline formulation. respectively, these were selected in consultation with ORP for DM100 melter testing. Characterization results for glasses HWI-Al-16 and HWI-Al-19 are summarized in Table 3.3. TCLP leachate concentrations are lisled in Table 3.7.

\subsubsection{Effect of Aluminum Source on HWI-Al-16 and HWI-Al-19}

As discussed earlier, the choice of $\mathrm{Al}_{2} \mathrm{O}_{3}$ as the source of aluminum for the HLW-E-A127 melter tests [2] represents a conservative scenario with respect to feed processing tate. The actual forms of aluminum in the waste are likely to be much less refractory. Therefore the feeds of target glasses HWI-Al-16 and HWI-Al-19 were reformulated using $\mathrm{Al}(\mathrm{OH})_{3}$ and subjected to VGF tests. The top and cross section views of the partially reacted feed samples after 30 minute VGF tests are shown in Figure 3.11 in comparison to their $\mathrm{Al}_{2} \mathrm{O}_{3}$ counterparts. Overall, the results indicate that the $\mathrm{Al}(\mathrm{OH})_{3}$ feeds tend to react and convert somewhat faster in VGF tests. The VGF rankings of the melt rates are listed in Table 3.8. Feed samples after 30 minute VGF tests were examined by SEM-EDS and XRD. Figure 3.12 shows SEM images of the crystalline phases observed on the surface of the partially reacted feed samples. Table 3.9 lists the major phases jdentified from analysis of the crystalline phases by SEM and XRD.

\subsubsection{Confirmation of VGF Melt Rate Predictions}

Based on the glass formulation work and melt rate screening using the VGF and DFC tests DM100 tests were performed on HWI-Al-16 $\left(\mathrm{Al}_{2} \mathrm{O}_{3}\right.$ and $\left.\mathrm{Al}(\mathrm{OH})_{3}\right)$ and $\mathrm{HWI}-\mathrm{Al}-\mathrm{I9}$ $\left(\mathrm{Al}(\mathrm{OH})_{3}\right)$; in addition the HLW-E-A.1-27 formulation was tested with $\mathrm{Al}(\mathrm{OH})_{3}$ to further assess the effect of aluminum source. The tests are discussed in Section 4. The results from those DM100 tests are used here to evaluale the relative melt rate predictions made based on the VGF 
test results. The four additional data points were added to the original calibration plot shown in Figure 3.4 to produce Figure 3.13. As is evident from the plot, the new data are consistent with the expectations based on the original trend line, with the sane single outlier. The results suggest that the VGF test provides a valuable screening tool in glass and feed formulation, which should improve as more data become available.

\subsection{DM10 Feed Consumption (DFC) Melt Rate Tests}

In view of the sonplexity of the feed-to-glass conversion process, a combination of small-scale tests was used to screen feed and glass composition variations with respect to projected melt rates in order to down-select the preferted conpositions for subsequent melter testing. In addition to the VGF tesis described above, a second test utilizes the DMIO nielter to deternine the relative rate at which feed is consumed into the glass melt. This test is referred to as the DM10 Feed Consumption (DFC) test. This procedure permits the evaluation of many feed compositions and additive blends in a relatively short amount of time. Da1a from these tests was used both to provide guidance and confimation of the glass fomulation process.

\subsubsection{DM10 Melter}

The DM10 unit is a ceranic refractory-lined melter fitted with two Inconel 690 plate electrodes that are used for joule-heating of the glass pool and a bubbler for stirting the melt. The glass product is removed from the melter by neans of an air-lift discharge systent. The DMI0 uni1 has a melt surface area of $0.02 \mathrm{I} \mathrm{m}^{2}$ and a glass inventory of about $8 \mathrm{~kg}$. In these tests, feed is introduced rapidly as a single charge using a peristaltic pump. For operational simplicity, the DM10 is equipped with a dry off-gas treatment system involving gas filtration operation ouly. Exhaust gases leave the melter plenum through a film cooler device that minimizes the formation of solid deposits. The film-cooler input air has constant flow rate and its temperature is themostatically controlled. Consequently, under steady-state operating conditions, the exhausi gases passing through the transition line (between the melter and the first filtration device) can be sampled at constant temperature and air flow rate. The geometry of the transition line conforms to the requirements of the $40-\mathrm{CFR}-60$ air sampling tecluiques. Inmediately downstream of the transition line are coarse particulate filters followed by conventional pre-filters and HEPA filters. The temperature of the filters is kept sufficiently high to prevent moisture condensation. An induced draft fan completes the system.

\subsubsection{Methodology for DFC Melt Rate Tests}

The DM10 is rapidly charged with a standardized amount of feed while maintaining standard operating conditions in the melter. The mass of feed used in these tests was $1 \mathrm{~kg}$. Once introduction of the feed clarge is complete, bubbling is increased from near zero to 1.7 lpm. This rate comssponds to the $9 \mathrm{lpm}$ used for standardized melt rate testing on the DM100 (see Section 4). Visual observations of the cold cap and monitored plenum temperatures are used as indicators 
of the rate of feed consumption. An example of changes in plenum temperature over a series of DFC tests is provided in Figure 3.14. The abrupt drops in plenum temperature correspond to the additions of feed and the time required for the system to re-equilibrate is an indication of time recuired to consume each feed charge. The plenum temperature measurements are analyzed and conpared to visual observations of the cold cap to generale a melt rate index. The melt rate index reported here is the time in minutes needed to fully consume $1 \mathrm{~kg}$ of feed in the DM10 melter at a bubbling rate of $1.7 \mathrm{lpm}$ and a nominal melt pool temperature of $1150^{\circ} \mathrm{C}$. The time needed to fully consume the feed is determined through observation of the cold-cap and analysis of the changes in the plenum temperature. Results from new feed formulations are compared to results obtained from feed samples with known DM100 processing rates to provide a projected melt rate. The relationship between production rates obtained from DMl00 tests and melt rate index from this method is illustrated in Figure 3.15. As is evident from the figure, the technique is especially effective at distingujshing melt rate differenoes at the lower melter rates that are most important in the present work.

\subsubsection{Feed Compositions Evaluatel in DFC Tests}

Six different base feed compositions were evaluated using the DFC method:

- HLW-E-Al-27 glass composition: $\mathrm{Al}_{2} \mathrm{O}_{3}$ as the alumitum source (see Table 2.2); 45 wt\% oxide waste loading.

- HLW-E-Al-27 glass composition; $\mathrm{Al}(\mathrm{OH})$ ) as the aluminum source (see Table 2.3); 45 w1\% oxide waste loading.

- HLW-E-Al-27 glass conposition: $\mathrm{Al}_{2} \mathrm{O}_{3}$ as the aluminum source (see Table 2.2); boric acid + soda asll replacing borax; 45 wt\% oxide waste loading.

- HLW-E-Al-27 glass conposition: $\mathrm{Al}_{2} \mathrm{O}_{3}$ as the alumionm source (see Table 2.2); boric acid $+\mathrm{K}_{2} \mathrm{CO}_{3}$ replacing borax: 45 wt\% oxide waste loading.

- HWI-Al-9 glass composition: $\mathrm{Al}_{2} \mathrm{O}_{3}$ as the aluminum source (see Table 2.2); 40 wt\% oxide waste loading.

- HWI-Al-9KSM glass composition; $\mathrm{Al}_{2} \mathrm{O}_{3}$ as the aluminum source (see Table 2.2); 45 wt\% oxide waste loading.

Glass compositions for each of these base feeds are provided in Table 3.10. These base feeds were tested as $1 \mathrm{~kg}$ batches for comparison to previously tested feeds and to each other. They were also processed at reduced masses with a variety of additives to bring the mass to $1 \mathrm{~kg}$ in order to evaluate the effect of these additives on nett rates. Additives evaluated on the base feeds were:

* Nitric acid and sugar

- Boric acid

- Borax

- Sodium carbonale

- Potassium carbonate 
- Calcium carbonate

- Lithium carbonate

- Silica

The combinations of base feeds and additives evaluated with the resulting glass compositions are provided in Table 3.11. It is important to note that, escept for nitric acid and sugar, all of the additives result in slightly reduced waste loadings. The intent of these tests was to investigate which additives have the potential to improve melt rates and should therefore be given preference as additives in improved feed formulations. It is also worth noting that the glass compositions given in Tables 3.10 and 3.11 represent the feed compositions, not the glass pool composition. Therefore the DFC tests primarily evaluate reactions laking place in the cold cap and at the melt interface rather than effects extending throughout the nelt pool.

\subsubsection{Results from DFC Tests}

The rate of feed consumption for the six base feeds is shown in Figure 3. 16. Variations based on the original HLW-E-AJ-27 feed formulation showed melt rate index variations from about 60 to 100 ; the base feed with both forms of alumiunn gave indices of about 80 . Increasing the boron concentration in HWI-Al-9 and HWI-AJ-9KSM reduced the melt rate index below the values for the original HLW-E-Al-27 composition. whereas simply changing the boron source increased it. The reason for the longer melt time when only the boron source was changed is unclear, particularly since HWI-AI-9 and HWI-Al-9KSM, which showed much faster melt rates. also used boric acid as the boron source. Also, previous DMl00 tests evaluating the effect of boron (and sodium) source on production showed no effect on production rate [24]. However. these test results clearly indicate that feed fornulations with higher boron concentrations have the potential for higher melt rates.

The effect of adding a variety of additives to four of the base feeds is illustrated in Figures $3.17-3.20$. In these tests, $50 \mathrm{~g}$ of each additive was combined with $950 \mathrm{~g}$ of the base feed to generate $1 \mathrm{~kg}$ of feed that was subsequently introduced into the melter. The results indicate that some of additives lave the potential to reduce melting times, some slow anbiguous results, and others appear to have no effect or increase melting times. The addition of nitric acid and sugar, silica, and calcium carbonate appear to have little or no benefit with respect to reducing melt times, particularly considering the decrease in waste loading when adding silica or calcium carbonate. Lithium and sodium catbonate dranatically increase melt times in some tests, have little effect in some, and significan1ly decrease melt time in others. This anbiguity may be attributable to foaming on the melt pool surface generated by carbonates, which complicated cold cap observations and isolates the plenum from the hot glass pool, which slows the temperature rise. Previous tests varying elemental concentrations with a single feed composition have shown that increasing concentrations of alkali metals increase production rates [25] supporting the notion that another mechanism other than the alkali increase is responsible for the slow melt times. Potassiun carbonate in all four compositions and with both forms of boron for nost compositions resulted in siguificant decreases in melt times; hence its selection for evaluation in the glass formulation work (Section 3.3.6). Both these observation are in keeping 
with previous tests that show prodection rate increases with increasing concentrations of alkali metals and boron [25].

Additional tests were conducted with laree of the base formulations to determine if progressively increasing the concentration of borax, boric acid, and potassium carbonate provides continued melt rate improvements. The results of these tests are illustrated in Figures $3.2 \mathrm{l}-3.23$. The addition of more boron in the form of borax or boric acid either maintains the initial reduction in feed consumption time from the nominal feed composition or continues to reduce the time with increasing proportion of the additives. Conversely, the feed consumption times increase with increasing proportions of potassium carbonate in the feed. The decreased effectiveness of potassium carbonate with increasing feed concentration may be due to foaming from the carbonate obscuring the results of the tests. However, potassium additions were not found to be effective in the VGF melt rate screening tesis (Section 3.3.6).

The DFC tests results suggest that melt rate improvements are possible for high aluninum waste by appropriate feed and glass formulation changes. Based on the DFC test results, boric acid, borax, and potassium carbonate were identified as additives that have the greatest potential for increasing HLW feed processing rates whereas silica, calcium carbonale, and nitric acid plus sugar either have little effect or decrease melt rate.

\subsection{Summary and Formulations for Melter Testing}

An integrated approach has been developed to identify feed and glass fomulations with improved nelt rates. The approach employs two melt rate screening test that have been developed (VGF and DFC) and confirmatory testing in continuous melters. The VGF and DFC tests methods are sufficiently rapid and cost effective to provide for effective integration into the overall glass formulation development, testing, and optimization program.

The test results identified several additives with the potential for improving meli rates but other factors. such as increased crystallization and reduced waste loadings, also need to be considered. The HWI-Al-16 and HWI-Al-19 formulations were identified as the preferred candidates for confimatory DM100 melter testing. Both of these formulations emphasize increased boron concentrations to improve melt rates and compensating changes to maintain other glass properties in acceptable ranges. Of these two formulations. HWI-A1-19 has the additional advantage of higher waste loading; it achieves the same 45 wt $\%$ waste loading as the baseline glass fornulation but is expected to exlibit a substantial improvement in glass production rate over the baseline formulation.

The conposition and properties of the HWL-Al-16 and HWI-Al-19 formulations are listed in Tables 3,12 and 3,13. The melter feed compositions for the HWI-Al-16 formulation with $\mathrm{Al}(\mathrm{OH})_{3}$ or $\mathrm{Al}_{2} \mathrm{O}_{3}$ as the aluninum source are shown in Tables 3.14 and 3.15, respectively, The melter feed composition for the HWI-Al-19 formulation with $\mathrm{Al}(\mathrm{OH})_{3}$ as the aluminum source is shown in Table 3.16. 


\section{SECTION 4.0 \\ DMIOO MELTER OPERATIONS}

Melter tests were conducted on the DM100-BL between 2/408 and 6/27/08. These tests produced almost two metric tons of glass from over $3600 \mathrm{~kg}$ of feed. Prior to each change of feed composition, the glass inventory was reduced from about $170 \mathrm{~kg}$ to about $100 \mathrm{~kg}$ in order to decrease the feeding time required to change over the composition of the melt pool. The series of eight nominally 50 -hour tests were divided as follows:

- HLW-E-AJ-27 with altminum bydroxide $-490 \mathrm{~kg}$ of glass produced

$-1200 \circ \mathrm{C}$ glass temperature, $9 \mathrm{lpm}$ bubbling. $500 \mathrm{~g}$ glass per liter feed.

$\because \quad 1150^{\circ} \mathrm{C}$ glass temperature, $9 \mathrm{lpm}$ bubbling, $500 \mathrm{~g}$ glass per liter feed.

- HWI-Al-16 with aluminum hydroxide - $506 \mathrm{~kg}$ of glass produced

- $1200 \circ \mathrm{C}$ glass temperature, 9 lpm bubbling. $500 \mathrm{~g}$ glass per liter feed.

$\Rightarrow \quad 1150^{\circ} \mathrm{C}$ glass temperature, $9 \mathrm{lpm}$ bubbling, $500 \mathrm{~g}$ glass per liter feed.

- HLW-Al-16 with aluminum oxide - $468 \mathrm{~kg}$ of glass produced

$\because \quad 1200^{\circ} \mathrm{C}$ glass temperature, $9 \mathrm{lpm}$ bubbling, $500 \mathrm{~g}$ glass per liter feed.

$-1150^{\circ} \mathrm{C}$ glass temperature, $9 \mathrm{lpm}$ bubbling. $500 \mathrm{~g}$ glass per liter feed.

- HLW-Al-19 with aluminum hydroxide - $484 \mathrm{~kg}$ of glass produced

$\because \quad 1200^{\circ} \mathrm{C}$ glass temperature, $9 \mathrm{lpm}$ bubbling, $500 \mathrm{~g}$ glass per liter feed.

- $1150^{\circ} \mathrm{C}$ glass temperature, 9 lpu bubbling, $500 \mathrm{~g}$ glass per liter feed.

Summaries of the tests are provided in Table 4.1. Attempts were made to replicate the melter configuration and operating conditions used for previous tests with HLW simulants [2, 14-17, 23-25, 44]. These conditions include a near-complete cold cap, which is between $80-95 \%$ melt surface coverage for the DM 100 since a $100 \%$ cold cap tends to lead to "bridging" in smaller melters. The bubbling rate was fixed at $9 \mathrm{lpm}$ and the feed rate was adjusted to maintain a complete cold cap. This use of bubbling is in contrast to some previous tests where the production rate was fixed between 1000 and $1050 \mathrm{~kg} \mathrm{~m}^{2} / \mathrm{day}$ and the bubbling rate was adjusted to maintain the complete cold cap [14-17,44]. The approach used in the present tests, in which the bubbling rate is held constant, provides a more direct evaluation of the effects of waste aluminum form (hydroxide ws, oxide), glass temperature, and glass composition on production rate. The changes in glass composition that were tested were based on the results from the glass formulation development studies (see Section 3,0) and were intended to demonstrate faster waste processing rates in comparison to previous DM100 tests with the sane high-aluminum waste.

Figures 4.1.a - 4.1.d illusirate the glass production rates as moving hourly averages throughout the tests. Steady-state protuction rates for current and previous tests $[2,14,15,23-$ 25. 44] conducted at the same constant bubbling rate at similar feed solids content are tabulated in Table 4.2; Figure 4.2 displays the results for tests conducted at a melt pool temperature of 
$1150^{\circ} \mathrm{C}$. Taken together, the past and present test results show large differences in production rate with different waste/feed compositions and glass temperature. In previous tests [2], the effect of waste composition was greater than that of any other tested variable and this is further confirmed by the data from the current tests; in particular, the iron and chromium wastes were found to process at about twice the rate of aluninum linited wasles [2]. The higher processing rates are not only attributable to the differences in waste composition but also the lower waste loadings (24-28 vs. $45-47$ wt. \% oxide) used in many of the previous tests $[14,23]$. Further, the current tests clearly demonstrate that feeds of the same composition but with the aluminum in the form of aluminum hydroxide instead of aluminum oxide process at faster rates. Comparison of tests conducted with both forms of aluminum using two different glass compositions (HLW-E$\mathrm{Al}-27$ and $\mathrm{HWl}-\mathrm{Al}-16$ ) show an approximate thirty percent production rate increase when alomioum oxide is replaced by alnminum hydroxide.

Inportantly, the test results also showed that significant rate enhancentents were achieved as a result of manipulation of the glass forming additive blends and glass compositions:

* For both forms of aluminum, produclion tates increased by $-30 \%$ by changing from the original HLW-E-Al-27 glass formulation to the new HWI-Al-16 glass formulation.

- A similar $\sim 30 \%$ rate increase was also observed with the new HWI-Al-19 glass formulation for the aluminum hydroxide based waste simulant (the only one tested with that glass fomulation). This formulation bas a higher waste loading than the HWI-Al-16 formulation.

- The highest production rates (950 and $1500 \mathrm{kgm}^{2}$ day a1 1150 and $1200^{\circ} \mathrm{C}$. respectively) were obtained for the HWI-AJ-19 glass formulation, which also had the bighest waste loadiug tested ( $45 \mathrm{w1} \%$ ).

These rexults corroborate the results from the glass formulation development studjes. which indicated that higher ntelt tates could be achieved by manipulation of the blend of additives that are combined with waste. These rate enlancements are also consistent with previous DM 100 tests. which showed a positive effect of increasing the boron concentration in the additives on the production rate $[25]$.

As expected, glass production rates increased with increased glass pool temperature. Increases in response to the $50^{\circ} \mathrm{C}$ increase in melt pool temperature ranged from 47 to 86 percent in the curtent tests. The percentage melt rate inctease per unit temperature increase of $-1 \%$ is comparable to that oltained in previous work with WTP LAW feeds but, with the exception of the sodiun and alumioum waste [2], somewhat larger than that obtained in previous DM100 tests with the Al-, Cr- and Bi-limited HLW simulants [2] (although it should be noled that a smaller temperature change $\left(25^{\circ} \mathrm{C}\right)$ was used in those tests).

Overall there were no significant difficulies in processing these feed and glass compositions during these tests. Cold cap conditions were similar to the range of conditions observed in previous tests with HLW feeds [14-17, 23-25, 44], parlicularly those feeds high in aluminum [2]. The feeds had a tendency to adhere to melter walls to form "shelves" and "bridges," sonte of which recuired manual dislodging from the walls. The feed used in Tests 7 
and 8 formed a more fluid cold cap and formed softer deposits on the walls than the feeds used in the other tests. Inieruptions during feeding totaled no more than about an hour for each test. These short interruptions were required in order to energize the top pair of electrodes, transfer feed to the feed tank, adjust the feed line in the peristaltic pump as a resull of weat fron the punp rollers, clear the feed tube, and during Tests 1 and 6 , to allow deposits in the plenum space to assimilate into the glass. There was no clear trend between feed composition (including aluminum source) and the need to clear the feed tube or dislodge deposits in the plenum. Spikes in feed rate often occurred immediately after feed transfers due to adjustments in tank mixer speeds and pump settings. During steady-state feeding periods, production rates typically varied by about ten percent from the mean rate. No foany glass was observed in the glass discharge and no foam was observed on the melt pool surface or cold cap.

The results of various operational measurements that were made during these tests are given in Table 4.3. Glass temperatures are shown in Figures 4.3.a-4.3.d, plenum temperatures in Figures 4.4.a - 4.4.d, electrode tenperatures in Figures 4.5.a - 4.5.d, and glass resistanoe in Figures 4.6.a-4.6.d; electrode power is included in the figures with electrode temperatures and glass resistance. The target bubbling rale of $9 \mathrm{lpni}$ was maintained throughout the tests. Bulk glass temperatures (measured at 5 and 10 inches from the bottom of the melt pool) were largely within $10^{\circ} \mathrm{C}$ of the target glass temperatures of $1200^{\circ} \mathrm{C}$ and $1150^{\circ} \mathrm{C}$ throughout the vast majority of the tests. The test-segment-average bulk glass temperatures were $1190-1203^{\circ} \mathrm{C}$ and 1135 $1157^{\prime \prime} \mathrm{C}$ for tests targeting glass temperatures of $1200^{\circ} \mathrm{C}$ and $1150^{\prime \prime} \mathrm{C}$, respectively. Glass temperatures closer to the top of the melt pool (measured at 16 and 27 inches from the bottom) are not reliable indicators of bulk glass temperatures as a result of their sensitivity to variations in the level of glass in the melter and gradients near the melt surface. As a result of the intentionally lower glass level, glass temperatures measured at these locations were even lower at the beginning of each test with a new feed composition, prior to the glass level in the melter being increased to above the upper pair of electrodes. Plenunt temperatures typically ranged from 300 to $500^{\circ} \mathrm{C}$, which is lower than the 550 to $650^{\circ} \mathrm{C}$ target. The lower temperature ranges were the consequence of maintaining a more complete cold cap. Similar plenum temperatures were measured in previous tests with alumioum limited wasles that also featured sinilar cold cap conditions [2].

The lower pair of electrodes was hotter than the upper pair of electrodes at the beginning of each test with a new feed composition due to the lower starting glass level. Once the melter was filled with glass above the top electrodes, the two electrode pairs are 0 to $150^{\circ} \mathrm{C}$ colder than the glass pool, depending on the measured points in the glass pool and electrodes. The bottom electrode, which was not powered, was 350 to $400^{\circ} \mathrm{C}$ colder than the powered side electrodes. Power supplied to the electrodes avernged between 18 and $26 \mathrm{~kW}$ for tests conducted at melt pool temperatures of $1150^{\circ} \mathrm{C}$ and $1200^{\circ} \mathrm{C}$. respectively. The higher power requirement for the higher melt pool temperature also corresponds to higher production rates. The opposite trend is observed when power usage is normalized to glass production due to the amount of energy required to maintain the glass pool at the target melt temperature (i.e., the essentially constant idling power). The ealculated glass pool resistance decreased dramatically as the melter was filled with glass, as would be expected. The nelt pool resistance increased by about 0.015 to 0.02 ohnus as the glass pool temperature was decreased from $1200^{\circ} \mathrm{C}$ to $1150^{\circ} \mathrm{C}$. 
The gas temperature at the film cooler averaged between $275-287^{\circ} \mathrm{C}$ and depended on the plenum temperature, the amount of added film cooler ait, and the temperature of the added film cooler air. Drops of less than seventeen degrees in gas temperature were observed across the (insulated) transition line: the bigh tenuperature is maintained in order to prevent condensation in the downstrean filtration units.

Based on the results of the DM100 tests, the HWI-Al-19 glass formulation was selected for larger scale testing in the DM $1200 \mathrm{HLW}$ pilot melter. This formulation showed the highest productions rates, showed no processing issues in the DM100 test, meets all of the processing and prodnct quality requirements, and has the highest waste loadiog. 


\section{SECTION 5.0 DM1200 OPERATIONS}

Three tests with the high aluminum HLW simulant and the HWI-Al-19 glass composition were conducted between $8 / 6 / 08$ and $8 / 16 / 08$, producing almost 9 metric tons of glass. The total testing duration, including the time for water feeding and cold-cap burn-off, was 157 hours, during which over 24 metric tons of feed was processed. A summary of the test conditions and results is provided in Table 5.1. The tests were conducted to determine glass production rates for a high aluminum waste and optimized glass composition at two glass temperatures and bubbling rates. The HWI-Al-19 glass selected for the DM1200 tests had the highest processing rate of those evaluated on the DM100 (950 and $1500 \mathrm{~kg} / \mathrm{m}^{2} /$ day at 1150 and $1200^{\circ} \mathrm{C}$, respectively) at the highest waste loading (45\%). Each DM1200 test was nominally two days in duration, employed double-outlet prototypical bubblers, and processed feed with a solids content of $500 \mathrm{~g}$ glass per liter. The tests are summarized below in the order they were conducted:

- Test 1: Melt pool bubbling rate and glass temperature were optimized to yield the maximum production rate.

- Test 2: Glass temperature held constant at $1150^{\circ} \mathrm{C}$ and melt pool bubbling rate adjusted to maintain a production rate of $1050 \mathrm{~kg} / \mathrm{m}^{2} /$ day.

- Test 3: Glass temperature held constant at $1175^{\circ} \mathrm{C}$ and melt pool bubbling rate adjusted to maintain a production rate of $1050 \mathrm{~kg} / \mathrm{m}^{2} /$ day.

The target glass production rate in Tests 2 and 3 was selected to provide direct comparisons with previous tests $[6,23]$.

\section{$5.1 \quad$ Melter Operations}

The DM1200 melter tests employed a prototypical ADS feed system, a single feed tube in the center of the melter, and a side-to-side electrode firing pattern. Two double ported bubblers (see Figure 1.5) positioned in a manner to mimic the WTP HLW melter (see Figure 1.6) were used throughout testing. In each test, the cold-cap-limited production rate was determined by visual observations of the cold cap and confirmed by the plenum temperature. The ADS feed system performed well in all tests. A summary of operational events is provided as Table 5.2. Operators observed the cold eap through view ports on the side of the melter on average every 20 minutes to guide melter operation, particularly the adjustment of bubbler air flow and feed rate. These observations are listed in Table 5.3.

Feeding was interrupted each day for about five minutes to collect feed samples. It was also paused once for eight minutes to remove a blockage in the film cooler, once for thirteen minutes to change a defective blower, and once for thirteen minutes to remove a blockage from the end of the feed tube. The majority of the film cooler deposits were readily removed by 
running a rod down through the film cooler and deposits on the feed tube were easily removed by tapping extenally with a hamner. These feeding hiatuses did not compronise the objective of determining a steady production rate for any of the test segments. The feed used in these tests formed cold caps that often fomed mounds, ridges, and cones under the feed nozzle. The aqueous feed was often observed boiling on the cold cap surface or running off onto the melt surface through holes in the cold cap generated from bubbling. A picture of one of these holes in the cold cap is provided in Figure 5.1. Ridges or mounds forming in the center of the melt pool often made direct observation of the melt surface opposite the view ports impossible. In these instances, the amount of cold cap was estimated by the amount of light visible as a result of openings in the cold cap. Ridges and monnds typically did not prevent free flow of the aqueous feed slurry across the cold cap surface and were managed by manjpulating bubbler air flow. The configuration of the cold wap was constantly in flux throughout the tests; however, the extent of coverage was typically between 75 and 90 percent. The visual observations of the DM 1200 melt pool is a key operational aspect of current DM1200 testing. In contrast to the operation of the LAW Pilot Melter, use of notn-visual data, such as plenum temperature, have not been developed as reliable indicators of cold-cap conditions while processing HLW feeds [49]. In fact, high plenum temperatures can result from a high nound over a portion of the inelt surface preventing feed from spreading across the melt surface and creating an opening on the glass surface. Without the visual evidence. an operator may conclude that feed rates should be increased. which could exacerbate the problem.

The glass production rates achieved doring testing are provided in Table 5.1 ; these are illustrated in Figures 5.2.a and 5.2.b and are compared to rates achieved with other HLW feeds using the DM1200 with the optimized bubbling configuration in Table 5.4 . The rate of $1500 \mathrm{~kg} / \mathrm{m}^{2} /$ day achieved during Test 1 was the highest production rate achieved with this configuration. This higher rate is due in part to higher feed solids content of $500 \mathrm{~g}$ glass per liter as opposed to 340 to $430 \mathrm{~g}$ glass per liter used in previous tests. Coincidently, the rate of $1500 \mathrm{~kg} / \mathrm{m}^{2} /$ day achieved on the DM1200 with optimized bubbling was the same rate obtained on the DM100 at $1200^{\circ} \mathrm{C}$. Previous DM100 tests with HLW simulants have shown that produclion rates can be doubled while optimizing the bubbling as opposed to using the standard $9 \mathrm{lpm}$ [2]. It is reasonable therefore that optimization of bubbling on the DM100 would have increased the rate of $950 \mathrm{~kg} / \mathrm{m}^{2} /$ day at $9 \mathrm{lpm}$ to about $1500 \mathrm{~kg} / \mathrm{m}^{2} /$ day. The target glass production rate of $1050 \mathrm{~kg} / \mathrm{m}^{2} /$ day was easily achieved at glass processing temperatures of 1150 and $1175^{\circ} \mathrm{C}$. This rate had been previously attained at $1150^{\circ} \mathrm{C}$ with $\mathrm{HLW}$ AZ -101 waste at $400 \mathrm{~g}$ glass per liter [6] with comparab]e bubbling (64 vs. 71 lpm), with HLW C-106/AY-102 waste at $340 \mathrm{~g}$ glass per liter [23] with more bubbling ( $90 \mathrm{vs} .71 \mathrm{lpm}$ ), and could not be obtained with HLW AZ-102 at $340 \mathrm{~g}$ glass per liter [23]. These results demonstrate that both waste composition and feed solids content have a big effect on production rate. Increasing the glass pool temperature by $25^{\circ} \mathrm{C}$ pemitted the reduction of the bubbling rate by about forty eight percent ( 71 to $48 \mathrm{lpm}$ ) while maintaining a glass production rate of $1050 \mathrm{~kg} / \mathrm{nt}^{2} /$ day. A reduction in bubbling of about thirty percent was observed with HLW AZ-10l waste at $400 \mathrm{~g}$ glass per liter with the same increase in glass temperature [6].

A variety of operational measurements recorded during these tests, including temperatures throughout the melter system, are given in Table 5.5. Data are collected and electronically logged every two minutes, and data and observations are also recorded manually 
throughout the tests. The temperature for most of the glass pool was about $1150^{\circ} \mathrm{C}$ for the first two tests and about $30^{\circ} \mathrm{C}$ higher during the last test, as illustrated in Figures 5.3.a - 5.3.b. During the first test, the $1150^{\circ} \mathrm{C}$ melt temperature best suited the DM1200 power constraints while optinizing bubbling 10 achieve the maxinum glass production rate. Conversely. the $1150^{\circ} \mathrm{C}$ glass temperature was targeted and successfully maintained during Test 2 while achieving the target glass production rate of $1050 \mathrm{~kg} / \mathrm{m}^{2} / \mathrm{day}$. The same targeted production rate was also maintained at the higher glass pool temperature of about $1180^{\circ} \mathrm{C}$ during Test 3 . Glass temperatures near the surface of the glass pool (27" from the floor) were lower due to the thermocouples being in or neas the cold cap. Aside from this excursion, bulk glass temperatures were relatively constant throughout the glass pool. Glass temperatures measured on the east side were 2 to $11^{\circ} \mathrm{C}$ higher than those on the west side of the melter. Plenum temperatures, given in Figures 5.4, a and 5.4,b, spanned a larger range during the testing, 300 to $900^{\circ} \mathrm{C}$, than the 450 to $550^{\circ} \mathrm{C}$ target given in the Test Plan. The test segnent and steady state average temperatures ranged from 482 to $714^{\circ} \mathrm{C}$, which is much closer to this target range. Higher plentm temperatures were observed at the beginning of each test as the cold cap was being formed and as the thermowell and exposed thermocouple are exposed to openings in the cold cap. Conversely, lower plenum temperatures were observed when the thermowell or exposed thermocouple was encased in cold cap material. An example of the feed encasing a thermowell occurred during Test 3 at about 70 hours run time. Notice in Figure 5.4.b that the lower plenum temperature in the themowell at $17^{\circ \prime}$ below the melter lid dropped to as low as $200^{\circ} \mathrm{C}$ due to cold cap material covering that portion of the 1hemowell, while locations higher on the thermowell and the exposed thermocouple showed measured temperatures of about $700^{\circ} \mathrm{C}$ due to openings in the cold cap.

The east and west side electrode temperatures were about 10 to $15^{\circ} \mathrm{C}$ below the glass temperatures on the respective side of the melter. These temperatures typically varied by no more than $20^{\circ} \mathrm{C}$ from the mean during each test, as shown in Figures 5.5.a - 5.5.b. The closeness of the side electrode to the glass temperature was a faclor limiting the glass lemperature used during Test 3 . The hotton electrode, which was not powered during these tests, was about $60^{\circ} \mathrm{C}$ lower than the west electrode. The difference between the two side electrode temperatures was less during Test 1 due to the increased bubbling of the melt pool, which created better mixing. The discharge chanber and riser temperatures were largely maintained above $950^{\circ} \mathrm{C}$ tluroughout the tests. (The riser thermocouple is located about 4 inches above the bottom of the riser pipe, which is about 7.5 inches alove the melter floor.) Gas temperatures at the outlet of the filmcooler were $50-250^{\circ} \mathrm{C}$ lower than the measured plenum temperature as a result of film-cooler and control-air dilution and depending on the position of the themocouple in the plenum with respect to the cold cap. The film cooler was rinsed by a water spray every 12 hours during testing. resulting in a short-duration reduction to about $75^{\circ} \mathrm{C}$ in the film cooler outlet temperature.

Conditions in the glass pool are illustrated for electrical properties in Figures 5.6.a 5.6.b. level and density in Figures 5.7.a - 5.7.b, and bubbling in Figures 5.8.a - 5.8.b. Power supplied to the electrodes was highesi during Test 1 , averaging $224 \mathrm{kV}$ in response to higher bubbling and glass production rates. Power averaged $175 \mathrm{~kW}$ in both Tests 2 and 3 due to the glass production rate in both tests being $1050 \mathrm{~kg} / \mathrm{m}^{2} /$ day, even though the glass temperature was higher during Test 3 (1175 vs. $1150^{\circ} \mathrm{C}$ ) and bubbling was higher during Test 2 (71 vs. 48 lpm). 
Supplied power was relatively constant once the cold cap was established, varying by only about $10 \mathrm{~kW}$ from the average steady state value. The glass pool resistance decreased with bubbling over the course of these tests: Test $1-0.099 \mathrm{ohms}$ at $124 \mathrm{lpm}$ bubbling. Test $2-0.093$ ohms at 7l Ipn bubbling. and Test $3-0.083$ obms at 48 lpm bubbling. Conversely. average glass pool density at steady state conditions during testing decreased with bubbling: Test $1-2.22$ gicc at $124 \mathrm{lpm}$ bubbling. Test $2-2.29 \mathrm{~g} / \mathrm{cc}$ at $71 \mathrm{lpm}$ bubbling, and Test $3-2.33 \mathrm{~g} / \mathrm{cc}$ at $48 \mathrm{lpm}$ bubbling. This decrease was observed even though the glass temperature increased, indicating that the effect of bubbling on glass density is greater than glass temperature. The resistance and density may also have been affected as the glass pool composition changed over to the target composition during testing. Glass pool depth varied between 30 and 34 inches in response to the continuous feeding of the melter and the periodic discharging of glass. Lance bubbling rates decreased over the course of testing. from an average higl of $125 \mathrm{lpm}$ while achieving maximum produclion rates duriog Test 1 , to $48 \mathrm{lpm}$ while maintaituing $1050 \mathrm{~kg} / \mathrm{m}^{2} /$ day at an elevated glass pool temperature. Frequent cllanges to the bubbling rate as well as the distribution of bubbler air between the double ported lances were made to create an even cold cap across the nelt pool surface.

\subsection{Off-Gas System Performance}

Tests on the DM1200 system at VSL have been used extensively to evaluate the performance of a pilot scale off-gas system that is prototypical of that designed for the WTP by BNI engineering $[6,16-23,50]$. In the current tes1s, dala objectives primarily related to glass production rate and melter conditions required to achieve these production rates, not the performance of prototypical off gas system components. However, data for each of the off-gas system components and samples of solutions from the off gas system were collected and evaluated and are provided in this final report. Data are collected and electronically logged every two minutes and data and observations are also recorded manually throughout the tests. The average, minimum, and maximum values of the measured off-gas system parameters are given in Table 5.6. Target operaitional conditions for the system components such as sump temperatures, uni1 spray rates, and sump $\mathrm{pH}$ values that were not specified [3] were adapted from previous tests conducted on DM1200. The catalyst unit was bypassed in these tests. Plots of the typical sequence of gas temperatures through 1he DM1200 off-gas system at various locations are given in Figures 5.9.a, 5.9.b and 5.9.c for Test 1. Test 2, and Test 3. respectively. In summary, plenum gas from the melter is cooled by dilution with film cooler air to between 400 and $450^{\circ} \mathrm{C}$, drops another $100^{\circ} \mathrm{C}$ by control air dilution and heat loss along the transition line, is quenched to 30 to $40^{\circ} \mathrm{C}$ in the SBS. and reheated to about $75^{\circ} \mathrm{C}$ to prevent condensation in the HEPA filtration unit. The exhaust is heated by another 5 to $10^{\circ} \mathrm{C}$ by the Paxton blowers, then quenched to 25 to $35^{\circ} \mathrm{C}$ in the PBS.

\subsubsection{Melter Pressure}

A vacuum on the melter of three to three and half inches of water was targeted and maintained throughout the tests. This is achieved by setting blower speeds and using a control air 
system which constantly monitors the vacuum on the melter and injects sufficient air into the transition line immediately downstream of the film cooler to maintain a relatively constant vacuum on the melter. The computer-logged melter pressures measured at the instrument port and calculated control air flow rates for Test 1 and Tests 2 and 3 are plotted in Figures 5.10.a and $5.10 . \mathrm{b}$, respectively. The range of control air flow rates of up to $80 \mathrm{scfim}$ reflect the changes of melter exhaust volume in response to changes in the cold cap and feed rate, including pulsing of the feed (due to the ADS pump) throughout the tests.

The differential pressure across the film cooler and transition line is given in Figures 5.11.a and 5.11.b for Test 1 and Tests 2 and 3, respectively. The film cooler clogged and required manual cleaning once during Test 1 and once during Test 3 . The film cooler was also rinsed every 12 hours with 5 liters of water The typical film cooler and transition line differential pressures ranged between one and two and half inches water column and two and five inches water column, respectively. Measured values outside these ranges resulted from either manual or spray cleaning of the film cooler, blockage of the film cooler, particularly around 10 hours run time during Test 1 , clogged sensor lines, opening of ports in the transition line and melter lid for sampling activities, and small pressure surges resulting from either the pulsed nature of feeding or changing conditions in the cold cap.

\subsubsection{SBS}

The SBS quenches the melter exhaust, condenses much of the water from the melter feed, and removes the majority of the particulate in the exhaust stream. Many parameters of the SBS were recorded during testing, including inlet and outlet gas temperatures, pressures, and flow rates, pressure drops, sump temperature, heat exchanger inlet and outlet water temperatures, and flow rates. The amounts of heat removed by the SBS jacket, and the SBS inner cooling coil were calculated from the measured data, using the hourly averaged cooling water temperature increases (outlet temperature minus supply temperature) across the SBS inner cooling coil and cooling jacket multiplied by the same time-averaged water flow rate through each.

The SBS inlet and outlet gas temperatures are plotted in Figures 5.12.a and Figure 5.12.b for Test 1 and Tests 2 and 3, respectively. The average SBS inlet and outlet gas temperatures were $341^{\circ} \mathrm{C}$ and $46.2^{\circ} \mathrm{C}, 292^{\circ} \mathrm{C}$ and $39.3^{\circ} \mathrm{C}$, and $303^{\circ} \mathrm{C}$ and $39.4^{\circ} \mathrm{C}$ during Test 1 , Test 2 , and Test 3 , respectively. The higher temperatures during Test 1 were in response to the higher concentration of exhaust gases from feed resulting from the higher melter feed rate.

SBS inlet, outlet, and differential pressures are plotted in Figures 5.13.a and 5.13.b. During Test 1 , the inlet gas pressure averaged -8.9 in. W.C., the outlet pressure averaged -41.2 in. W.C. and the pressure drop across the SBS averaged about $32.3 \mathrm{in}$. W.C. During Test 2, the inlet gas pressure averaged $-7.9 \mathrm{in}$. W.C., the outlet pressure averaged $-39.5 \mathrm{in}$. W.C. and the pressure drop across the SBS averaged about 31.6 in. W.C. During Test 3 , the inlet gas pressure averaged $-8.0 \mathrm{in}$. W.C., the outlet pressure averaged $-40.2 \mathrm{in}$. W.C., and the pressure drop across the SBS averaged about 32.2 in. W.C. 
The SBS down-comer annulus pressures are given in Figure 5.14.a and 5.14.b for Test 1 and Tests 2 and 3 respectively. The SBS off-gas temperatures in the down-comer measured at various depths (from 3 to 58 inches) and the SBS sump water temperature are given in Figures $5.15 . \mathrm{a}$ and $5.15 . \mathrm{b}$, respectively. For Test 1 and Tests 2 and 3 , the average SBS sump temperatures were $39.2^{\circ} \mathrm{C}, 33.1^{\circ} \mathrm{C}$, and $33.0^{\circ} \mathrm{C}$, which are $7.0^{\circ} \mathrm{C}, 6.2^{\circ} \mathrm{C}$, and $6.4^{\circ} \mathrm{C}$ less than the SBS outlet gas temperatures, respectively. The measured off-gas temperatures decrease as the depth from the SBS lid increases due to cooling of the gas in the down-comer pipe by the surrounding SBS liquid.

Water temperatures at the SBS inner cooling coil inlet, inner cooling coil outlet/jacket inlet, and jacket outlet are given in Figures 5.16.a and 5.16.b for Test 1 and Tests 2 and 3 , respectively. The average water temperature difference was $15.5^{\circ} \mathrm{C}$ across the SBS inner cooling coil and $3.9^{\circ} \mathrm{C}$ across the jacket during Test 1 . The average water temperature difference was $12.4^{\circ} \mathrm{C}$ across the SBS inner cooling coil and $2.9^{\circ} \mathrm{C}$ across the jacket during Test 2 . The average water temperature difference was $12.0^{\circ} \mathrm{C}$ across the SBS inner cooling coil and $3.2^{\circ} \mathrm{C}$ across the jacket during Test 3 .

The SBS cooling coil/SBS jacket water flow rates are plotted in Figures 5.17.a and $5.17 . \mathrm{b}$ and averaged $28.7 \mathrm{gal} / \mathrm{min}, 27.0 \mathrm{gal} / \mathrm{min}$, and $27.8 \mathrm{gal} / \mathrm{min}$ for Tests 1,2 , and 3 , respectively. The corresponding amounts of heat removed by the SBS inner coil and jacket are shown in Figures 5.18.a and 5.18.b. For Test 1, heat removal averaged $95.9 \mathrm{~kW}$ by the SBS inner cooling coil and $15.5 \mathrm{~kW}$ by the cooling jacket. This corresponds to about $86 \%$ of the heat load to the SBS being removed by the inner cooling coil and about $14 \%$ by the cooling jacket. For Test 2 , heat removal averaged $72.0 \mathrm{~kW}$ by the SBS inner cooling coil and $16.6 \mathrm{~kW}$ by the cooling jacket. This corresponds to about $81 \%$ of the heat load to the SBS being removed by the inner cooling coil and about $19 \%$ by the cooling jacket. For Test 3 , heat removal averaged $71.5 \mathrm{~kW}$ by the SBS inner cooling coil and $19.2 \mathrm{~kW}$ by the cooling jacket. This corresponds to about $82 \%$ of the heat load to the SBS being removed by the inner cooling coil and about $18 \%$ by the cooling jacket.

One of the functions of the SBS is to condense water that originated in the waste feed. Figures 5.19.a and 5.19.b compare the amount of water fed to the total volumetric accumulations in the SBS over the course of each test. The amount of water fed into the melter is proportional to the amount of water in the feed and the slurry feed rate; hence, Tests 2 and 3 which targeted the same feed rate showed constant water feed rate to the melter. The difference between the amounts of SBS water coming from the feed and the amounts blown down from the SBS sump represents the amount of water carried out in the off-gas stream as a result of it being saturated at the SBS sump temperature, as well as a small amount of entrained droplets. This amount is largely determined by the SBS sump water temperature, which was about $6^{\circ} \mathrm{C}$ higher during Test 1 than in Tests 2 and 3. As a result this temperature difference, the total volume of water exiting the SBS was about the same for Test 1 and the combined volume for Tests 2 and 3 , despite the difference in run time. 


\subsubsection{WESP}

The WESP is used primarily to remove fine, often water soluble particles from the exhaust stream that are not efficiently removed by the SBS. The inlet and outlet gas temperatures, differential pressure across the WESP, and the WESP current and voltage were measured and recorded by the computer data acquisition system. The WESP inlet and outlet gas temperatures are plotted in Figures 5.20.a and 5.20.b for Test 1 and Tests 2 and 3, respectively. A one to two degree increase in temperature is observed in the exhaust temperature as gas passes through the WESP. The periodic downward spikes in the WESP outlet temperature are a result of the daily deluge of the WESP to wash collected deposits off the electrodes and into the WESP sump. The WESP differential pressures and outlet gas flow rates are plotted in Figures 5.21. a and 5.21.b for Test 1 , and Tests 2 and 3, respectively. A pressure drop of about two and a half inches across the WESP was observed during testing. The typical wet gas flow rate exiting the WESP was about 230 sefm.

The amount of liquid accumulated in the WESP is plotted as a function of run time in Figure 5.22.a and Figure 5.22.b, where it is compared with the amount of fresh water sprayed into the WESP during Test 1 and Tests 2 and 3, respectively. The inlet spray water was targeted at $2.0 \pm 0.2 \mathrm{gph}$; however, the actual spray water flow rate was $\approx 1.7 \mathrm{gph}$ because of the limitations of the spray nozzle. As evident from both figures, spray water accounts for the majority of the liquid accumulation in the WESP. The difference between accumulated liquid and fresh water sprayed is equal to the amount of liquid removed from the off-gas, which is also plotted in Figure 5.22.a and Figure 5.22.b. The WESP electrodes were deluged daily, as planned, with water at a nominal rate of $12 \mathrm{gpm}$ for 3.33 minutes.

The WESP voltage and current are plotted as functions of run time in Figure 5.23.a and Figure 5.23.b for Test 1 and Tests 2 and 3, respectively. The current was set at $17 \mathrm{~mA}$ with voltage not to exceed $32 \mathrm{kV}$ prior to introducing water into the melter. The current was subsequently adjusted to that target during testing to the extent possible. During Test 1 , the target current was approximated but it could not be reached during Tests 2 and 3 within the $32 \mathrm{kV}$ voltage limit. The power stabilized shortly after the daily deluges.

\subsubsection{Secondary Off-gas System}

A HEME filtration unit (HEME 1) follows the WESP in the off-gas system to remove water droplets that may be present in water-saturated gas exiting the WESP. For Test 1, and Tests 2 and 3, the outlet gas temperature and differential pressure are plotted in Figure 5.24.a and 5.24.b. The typical pressure drop across HEME 1 during testing was about $1.5 \mathrm{in} \mathrm{W.C.}$

The HEME is followed in the off-gas system by a heater, a HEPA filter (HEPA 1), and a Paxton blower (Blower 1). The purpose of the heater is to ensure that water-saturated gas exiting HEME 1 is heated above its dew point before passing through the HEPA filter in order to prevent moisture condensation in the HEPA filter. The outlet gas temperature and the pressure differential across the HEPA filter are the two parameters monitored by the off-gas data acquisition system; for Test 1 and Tests 2 and 3, these are shown in Figure 5.25.a and 5.25.b, 
respectively. The typical pressure drop across the HEPA filter was about half an inch water column throughout testing.

A vacuum is maintained on the melter by a pair of redundant Paxton blowers (Blowers 701 and 702) immediately downstream of the HEPA filtration unit and a blower (Blower 801) downstream of the packed bed scrubber. During Test 2 at 23.1 hours, Blower 701 failed and Blower 702 was placed in service while the head on Blower 701 was replaced. Also, the speed of the redundant blowers was increased and the speed of Blower 801 was increased to reduce the temperatures in the redundant blowers.

Downstream of the HEPA filter and Paxton blowers in the off-gas train is the packed bed caustic scrubber (PBS) to remove iodine and acid gases from the off-gas stream. The PBS sump solution is derived from process water; caustic solution $(25 \% \mathrm{NaOH})$ is added to control the solids content and pH of the scrubber liquid. The PBS inlet gas temperature, pressure drop across, sump temperature, and sump $\mathrm{pH}$ for Test 1 and Tests 2 and 3 are shown in Figures 5.26.a and 5.26.b, respectively. The typical pressure drop across the PBS during testing was two and a half inches water column. The inlet gas at about $80-85^{\circ} \mathrm{C}$ was quenched to about $25-30^{\circ} \mathrm{C}$ in the PBS during testing. The saw tooth appearance of the measured $\mathrm{pH}$ values around 9 and 10 results from the automated additions of $\mathrm{NaOH}$ solution to maintain the relatively constant $\mathrm{pH}$.

\subsubsection{SBS, WESP, HEME, and PBS Process Fluids}

One-liter samples were collected from the SBS, WESP, PBS, and HEME sumps at the end of testing. Samples were subjected to total dissolved solids (TDS) and total suspended solids (TSS) determinations by gravimetric analysis of filtered material and the evaporated filtrate. An additional sample was filtered to generate solids and filtrate for complete chemical analysis, which included $\mathrm{pH}$ determination, direct current plasma atomic emission spectroscopy (DCP-AES) analysis for metals, and ion chromatography for anions; the dried filtered solids underwent microwave-assisted acid dissolution prior to chemical analysis. The terminal SBS, WESP, PBS, and HEME sump samples as well as the total volume of solution removed from each sump are listed in Table 5.7; the first letter in the sample name is "S", "W", "H", and "P" for the SBS, WESP HEME, and PBS samples, respectively. The "A" and "B" suffixes in the name of the WESP samples correspond to samplings immediately before and after the 40 -gallon deluge. The " 1 " or " 2 " after the " $\mathrm{H}$ " in the HEME sample name correspond to the first HEME located downstream of the WESP and the second HEME located downstream of the PBS, respectively. The analyzed chemical compositions for samples taken at or near the end of each test are provided in Table 5.8 .

The amount of solution removed from the first HEME (immediately downstream of the WESP) at the end of each test and corresponding chemical analysis is given in Table 5.8. The HEME was continuously sprayed at $\sim 0.2 \mathrm{gal} / \mathrm{hr}$, resulting in the addition of about $10 \mathrm{gallons}$ of water for each of the three nominally 50 hour tests. The liquid volume accumulated during each of the tests was five to ten gallons greater than the amount sprayed as a result condensation. The PBS was blown down as required to maintain constant volume. 
The $\mathrm{pH}$ of sump solutions is affected by constituents temoved from the exhaust by each component and the amount of process water or sodium hydroxide added. Feed processed in the curtent tests contains relatively bigher ratios of halides, sulfate, nitrate, and boron to alkali metals, reductants, and silica, as compared to other HLW feeds previously processed [16-23]. As a result, the $\mathrm{pH}$ in the primary off-gas system effluents were significantly more acidic than in previous tests on DM1200 with HLW feeds. The $\mathrm{pH}$ values of less than 2 are more similar to values measured while processing some LAW wastes than to those for HLW wastes, which typically result in near-neutral solution $\mathrm{pH}$ values. The $\mathrm{pH}$ of the post deluge WESP solution is closer to neutral due to dilution with the deluge tap water than is the solution sampled fron the WESP prior to the deluge. The $\mathrm{pH}$ of the solution from the HEME that follows the WESP is very similar to that of the WESP solution, whereas the $\mathrm{pH}$ of the solution from the HEME that follows the PBS is very similat to that of the PBS solution. The $\mathrm{pH}$ of the PBS sump is nainiained around 9 during testing by the addition of $25 \%$ sodjum bydroxide solution, which is reflested by measured $\mathrm{pH}$ values near 9 in the PBS solutions.

The chemical composition as well as the distribution between dissolved and suspended solids fractions was measured on sump solutions from the end of testing and is provided in Table 5.8. Most of the chenical species measured in off-gas system solutions were dissolved due to the efficiency of the SBS at removing coarse particles, which are often insoluble, and the acidic conditions in the primary off-gas system components. As expected, the most abundant solids in the SBS solution were soluble species such as halogens, boron, alkali metals, nitrate, and sulfate. These species are readily volatilized from the glass and cold cap in the melter as soluble salts. Similar results were obtained from analysis of SBS solutions in tests with other HLW simulants [6. 16-23]. Dissolved chloriue and fluoriue were observed in significant proportions in all of the tests, even though cllorine was not targeted in the feed, indicating that these halides were present in the feed as a contaminant. In contrast to previous 1ests with HLW simulants [6, 16-23]. alumioum was also abundant in these solutions as a dissolved species due to the relatively high concentration in the feed and the acidic conditions in the sump solution. The WESP solutions contain mainly volatile salts (alkali halides, borates, and sulfates) carried over from the SBS, and contaminants from previous tests. Impurities in the feed and tap water are major constituents in the WESP solutions. The concentration of suspended solids in the WESP post-deluge sample is over an order of magnitude higher than for pre-deluge solutions; this material was presumably material that was dislodged from the electrodes. Conversely, the dissolved solids concentration in the post-deluge sample is about a third of the pre-deluge sample due to dilution by the deluge water. The chemical analysis of solution from the first HEME indicates that the solutions are essentially diluted WESP solutions, which is consistent with the HEME collecting mist carried over from the WESP. Nitrate and nitrite are higher in the HEME solutions than the contemporaneous WESP solutions, suggesting that the HEME is more efficient at removing these constituents fron the exhanst stream. The relatively high concentrations of sodium. halides, nitrogen oxides, and sulfate in the PBS indicate that the PBS is functioning as intended. The chemical analysis of solution from the second HEME indicales that the solutions are essentially diluted PBS solutions, which is consistent with the HEME collecting mist carried over from the PBS. Since many of the components include tap water sprays or are initially charged with tap water, elements common in tap water, such as calciun, are over represented in the solutions as compared to the amounts in the target feed composition. 


\section{SECTION 6.0 \\ FEED SAMPLE AND GLASS PRODUCT ANALYSIS}

\subsection{Analysis of Feed Samples \\ 6.1.1 General Properties}

Feed samples from each lest were analyzed to confirn pliysical properties and chemical composition. Samples were taken doring nelter testing from an iuline sampling port. Sample names, sampling dates, and measured properties are given in Table 6.1. Density and $\mathrm{pH}$ were measured on all samples: at least one sample per unique waste composition from the DM100 tests and all DM1200 samples were analyzed for water content glass conversion ratio, rheological properties, and oxide composition by XRF. The measured glass conversion ratios for all feed samples except one were within ten percent of the target on a weight per weight basis, validating the use of the target conversion ratio for calculating glass production rates. Samples from the DM 100 tests were closer to the target values due in part to more water being used to flush fecd lines during transfers to the DM1200 feed tanks. The water content, density, glass yield, and $\mathrm{pH}$ varied within a narrow range except for the $\mathrm{pH}$ values for DM100 Tests 1 and 2 . The higher $\mathrm{pH}$ in these samples is attributable to the boron source; borax was the source of boron in the first two DM100 1ests whereas boric acid was the boron source in all other tests. Changing of the aluninum source from oxide to bydroxide increased the $\mathrm{pH}$ by only a quarter of a unit.

\subsubsection{Rheology}

Samples of the melter feeds that were used for these tests were also subjected to stheological sharacterization. The results from theological tharacterization of a variety of other melter feeds and waste simulants, as well as the effects of a range of test variables, are described in detail in a separate report [51]. Melter feeds were characterized using a Haake RS75 rheometer, which was equipped with either a Z40DIN or a FL22-SZ40 sensor. A typical set of measurements consists of identifying the flow characteristics of the slurry by measuring the shear stress on the slurry at controlled shear rates and temperatures. In these measmrements, the sltear rate values are preset and are increased stepwise from $0.01 \mathrm{~s}^{-1}$ to $200 \mathrm{~s}^{-1}\left(70 \mathrm{~s}^{-1}\right.$ for FL22-SZ40) with a sufficient delay (typically 15 to 30 seconds) between steps to ensure that the shear stress is allowed to fully relax and therefore is neasured at equilibrium. This approach is somewhat different from the "flow curve" approach in which the shear rate is ramped up to some maxinum value and then ramped back down to produce a hysteresis curve tha1 is dependent on the selected ramp rate. The viscosity of the sample as a function of the shear rate is then calculated as the ratio of the shear stress to the shear rate. The yield stress data for the melter feeds were neasured using a controlled-stress node in which the torque on the rotor was slowly increased while the resulting deformation of the fluid was monitored. The discontinuity in the measured deformation-torque curve was identified as the yield stress. It should be noted that this direct measurement of the yield stress can be quite different from the value that is often reported 
as the yield stress, which is obtained by extrapolation of the shear stress-shear rate curve to zeto slear rate. All of the measurements in this work were made at $25 \% \mathrm{C}$; previous work [51], which examined a range of temperatures, showed a relatively weak effect of temperature.

Measured values for viscosity at selected shear rates and the yield stress are shown in Table 6.2. The data indicate that the change of the form of aluminum in the waste and the changes in the additive b]ends do not have substantial effects on the rheological properties of the feed samples. A small increase in feed viscosity and yield stress may be attribulable to changing the boron source from borax to boric acid. All feeds were processed by the feed system without significant difficulties.

\subsubsection{Chemical Composition}

The methods used for analysis of feed sample chentical compositions are described in Section 1.5. The boron, fluorine, and lithium oxide target values were used for normalizing the YRF data since their concentrations were not delermined by XRF. These results, conspared to the target composition in Table 6.3, generally corroborate the consistency of the feed compositions and show good agreement with the target compositions for the major elements. All oxides with target concentrations greater than one percent deviated by less than $10 \%$ from target for feed samples from DM1200 tests. Similarly, most oxides in feed samples from DM 100 tests also passed this criterion; however, phosphorus and bismuth deviated by as much as sixteen percent from target. However, the absolute deviation for bisnuth and phosphorus oxides was always less than $0.18 \mathrm{wt} \%$. The iron oxide concentration in the feed sample from DMLO0 test 5 was about nineteen percent above the target value; however, glass made from this feed during melter testing had measured iron concentrations within ten percent of the target value. This deviation may be attributab]e to contamination during sampling or crucible melting. The conposition of this feed is further corroborated by comparison 10 the product glasses (see Section 6.2.1), which shows all oxides with concentrations greater than 1 wt\% in the target composition to be willoin about $10 \%$ of the target, except for phosphorus duritig some tesis.

Low concentrations of manganese, neodymium, and strontium is sone feed compositions, were measured, even though they are not included in the target composition. Also, common elements such as magnesium. titanjum, zirconium. potassium. barium, and chromjum, when 1argeted at low concentrations, were typically above these targets. These positive deviations are often observed in melter feeds due to their ubiquity in the raw materials used to make up the simulants and in the glass forming additives. Analysis of the product glass using a method other than XRF (see Section 6.2.1) indicates that cadmium is present at the low target concentrations; however, these concentrations are below the sensitivity of the XRF for these glass matrices. Analyzed sulfur concentrations are below target concentrations dne to volatilization during sample preparation. Lead. which was targeted at low levels in the glass produch (0.40-0.41 wo $\%$ ). was measured at about nitety percent of target in the feed samples. None of these small deviations would affect the detemination of glass processing rates or negatively impact product quality. 


\subsection{Analysis of Glass Samples}

In the DM100 and DM1200 tests, almost two metric tons and nine metric tons of glass were produced, respectively. The glass was discharged from DM100 periodically into 5-gallon carbon steel pails and from DM1200 into 55 gallon drums, using airlift systems in both cases. The discharged product glass was sampled at the end of each test by removing sufficient glass from the top of the cans for total inorganic analysis. Product glass masses, discharge date, and analysis performed are given in Tables 6.4 and 6.5. Glass samples were also obtained by dipping a rod into the glass pool at the beginning and end of each test. These "dip samples" underwent visual examinations to detect the presence of separate sulfate or crystalline phases on the glass surface.

\subsubsection{Compositional Analysis of Discharge Glasses}

All discharge glass samples were crushed and analyzed directly by XRF. The target values for boron and lithium oxides, which are not determined by XRF, were used for normalizing the XRF data to $100 \mathrm{wt} \%$. Fluorine analysis by XRF required a polished monolith as opposed to the standardized ground glass preparation used for the other elements. Approximately, every fifth discharged glass sample was directly analyzed for fluorine; fluorine concentrations of other glasses were interpolated in between the measured values. The XRF analyzed compositions of discharged glass samples are provided in Tables 6.6 and 6.7. The majority of the XRF analysis results compared very favorably to their corresponding target values and feed sample analyses (see Section 6.1.3). Oxides with a target concentration greater than one weight percent showed around, or below, $10 \%$ deviation from the target values. The only exception is phosphorus oxide which had an absolute deviation of no more than $0.15 \mathrm{wt} \%$. Similar to the feed sample analyses, common elements such as magnesium, titanium, zirconium, and potassium targeted at low concentrations were above their respective targets. Several elements were present in the melt pools prior to these tests but were not included in the current target compositions. Most notable was strontium oxide at about four weight percent in the first glass discharged from the DM100 tests; other elements at much lower concentrations were cerium and neodymium in the DM100 melt pool, and lanthanum, neodymium, antimony, and strontium in the DM1200 melt pool. Sulfur and fluorine are below target for almost all glasses due to volatilization from the glass pool and cold cap.

Corroborative analysis using DCP on solutions of acid-dissolved glass was performed on select glasses produced from each test; the results are compared to the XRF analysis in Table 6.8 . Values for all the major oxides compare favorably with the XRF analysis and target composition except for sodium, which often exhibits a low bias using this procedure [19, 52]. Low biases for aluminum and chromium using the DCP method were observed in previous tests with high aluminum concentrations [2]. It is possible that the aluminum concentrations in these glasses may be higher than the sample preparation method can dissolve or keep in solution with the acid mixture currently being used. Consequently, the XRF values are to be preferred. The closeness of the DCP boron and lithium analyses to the target (deviations less than $10 \%$ ) validates the use of the target boron and lithium concentrations for normalizing the XRF data. 
Compositional trends for selected constituents shown in Figures 6.l a-6.1.c for DM100 tests and 6.2.a-6.2.c for DM1200 tests illustrate the closeness to targets at the end of tests with each composition. Exceptions include volatile species such as sulfit and fluorine, which remain significantly below their target concentrations as a result of significant release to the melter exhaust. Fluorine concentrations also decreased during idling periods in between DM100 tests. At the onset of testing. aluminum, calcium, and fluorine increase in concentration at the expense of silicon, iron, zirconium, and zinc as the steady-state composition is approached. Although not depicted in the figures, oxides present in the melt pool at the beginning of testing but not present in the target glass composition decrease in concentration to the point of being non-detectable by the end of testing. The concentrations of most oxides do not change significantly from composition to conposition during DM100 testing since the waste composition is constant the waste loading changes are very small, and significant additive changes occur for only borou and silica. Complete compositional tumover of the DM1200 melt requires the majority of the test duration due to the approximate two metric ton capacity of the melt pool; therefore the neelt pool composition is evolving toward the targe1 composition over nearly the entire DM 1200 testing period.

\subsubsection{Chemical Durability of Discharge Glasses}

Glass discharge samples from the end of each DM100 test were evaluated for chemical durability using the PCT and TCLP methods. The PCT results ate compared to those for the benclumark DWPF-EA glass in Table 6.10 and the TCLP results are compared to the WTP delisting limits $[53,54]$ and Universal Trealnient Standard (UTS) limits in Table 6.11. The chemical durability determined by both of these methods is excellent for the melter glasses. All measured PCT concentrations and nomalized leach rates on discharge glass samples are at least one hundred forty times lower than the corresponding values for the DWPF-EA glass. All regulated TCLP leachate concentrations are less than $1 \mathrm{mg} 1$ and more than a factor of nine less than WTP delisting limits. All measured concentrations are also well below the UTS linits. The chemical durability of these glasses is similar to that for those previously produced from aluminum limited waste and better than that for those produced from aluminum plus sodiun limited waste [2]. These results confirm that glasses can be formulated from a variety of waste loading limiting constituents without compromising the quality of the vitrified product.

\subsection{Glass Pool Samples}

A list of all dip samples including sample names, sampling dates, target glass pool temperature, and visual observations of secondary phases is provided in Table 6.11. These samples were used to detect the presence of any secondary phases on the melt pool surface. There was no visual evidence of secondary phases in any of the samples as either material adbering to the sampling rod indicative of a surface layer or macroscopic features indicative of crystalline phases in the glass. 


\subsection{Cok Cap Samples}

Samples from DM100 Test 8 and DM1200 Test 1 were laken from the cold cap using a "spoon" device that was introduced into the melter from the top. The spoon penetrated the cold cap and was lowered into the melt, then withdrawn in such a way that it captured a piece of the broken cold cap while allowing the glass melt to drain as much as possible. The sample is then withdrawn from the melter, allowed to cool to room temperature, removed from the sampling device and prepared for SEM-EDS analysis. The samples obtained in this manner are typically a composite of desiceated melter feed. glass, and transitional phases in between these two extremes. Examination of the transitional plases can provide insight into the slower melting components of the melter feed.

\subsubsection{DM100 Cold Cap Sample}

The DM 100 cold-cap was collected and split into two samples labeled BLZ-O-35A and BLZ-0-37A. Figure 6.3.a shows the majority of undigested particles, including quartz and calcium silicate. These particles are enbedded in the fine mixture phase that is high in $\mathrm{Al}, \mathrm{Si}$. $\mathrm{Ca}$. and Fe. Regions it dark contrast are a glass that is rich in light elenents such as sodium, boron. lithium, aluminum, and silicon.

Figure 6.3.b shows a region close to the glass phase in the sample. A1 this location, a1 least $85 \%$ of the melter feed was converted to glass. Undigested particles include quartz and hentatile in two forms: tiny needles of hemalite aggregated to $20-100 \mu \mathrm{m}$ in size and individual needles of about $10-30 \mu \mathrm{m}$ in length. These hematite crystals usually contain nickel, chromium, or titanium. Crystals of $\mathrm{Fe}-\mathrm{Cr}-\mathrm{Ni}$ spinel are present as larger 5 to $20 \mu \mathrm{m}$ crystals as well as smaller 1-2 $\mu \mathrm{m}$ crystallites associated with hematite. Onher crystals include zirconia-rich phases, presumably zircon, and chromium oxide.

\subsubsection{DM1200 Cold Cap Sumple}

The DM1200 sample was identified as 0-12J-106A. Figure 6.4 shows undigestad parlicles of $\mathrm{Al}_{2} \mathrm{O}_{3}, \mathrm{ZrO}_{2}, \mathrm{Fe}_{2} \mathrm{O}_{3}$ and $\mathrm{CaSiO}_{3}$. Undigested particles rich in $\mathrm{Al}_{2} \mathrm{O}_{3}$ are the most abundant. These particles are cemented together by a fune mixture phase with snall bright particles rich in iron, chromium, and zirconium. 


\section{SECTION 7.0 \\ MONITORED OFF-GAS EMISSIONS}

\subsection{Particulate Sampling}

The melter exhaust was sampled for metals/particles according to 40-CFR-60 Methods 3 . 5. and 29 at sleady-state operating conditions doring each test segment. The concentrations of off-gas species that are present as particulates and gaseous species that are collected in impinger solutions were derived from laboratory data on solutions extracted from air samples (fillers and varions solutions) together with measurements of the volume of air sampled. Particulate collection required isokinetic sanpling, which entails removing gas from the exhanst at the same velocity that the air is flowing in the duct (40-CFR-60, Methods 1-5). Typically, a sample size of $30 \mathrm{dscf}$ was taken at a rate of between 0.5 and $0.75 \mathrm{dscfm}$. Total particulate loading was deternined by combining gravimetric analysis of the standard particle filter and chemical analysis of probe rinse solutions. An additional impinger containing $2 \mathrm{~N} \mathrm{NaOH}$ was added to the sampling train to ensure complete scrubbing of all acid gases and, particularly, iodine. The collected nuaterials were analyzed using direct current plasma atomic emission spectroscopy for the majority of the constituents and ion chromatography (IC) for anions. Melter emission fluxes are compared to feed fluxes in Talle 7.1 for DM100 tests and Talole 7.2 for DM1200 tests. Notice the distinction that is made between constituents sampled as particles and as "gas". The "gaseous" constituents are operationally defined as those species that are scrubloed in the impinger solntions after the air stream has passed through a $0.3 \mu \mathrm{m}$ heated filter. All samples but one are well within the $90-110 \%$ limits for isokinetic sampling. The particle filter during the last sample occluded shortly after the start of sampling. which limited the duration and resulted in a less than isokinetie sample.

Particulate emissions from both melters constituted 0.04 to 0.29 percent of feed solids. This level of carry-over is less than that measured for previous tests with chromium. bismuth, aluminum, and aluminum plus sodium limited HLW wastes (0.06 - 0.57) [2], HLW AZ-102 (0.57- 1.47 percent) [44], and HLW C-106:AY-102 SIPP (0.61 to 0.81 percent) [15] simulants processed on the same melter. The higher carry-over in many of the previous tests is due to higher proportions of volatile species in the feed such as rhenium, cesium, and halogens. The carry-over is lower but still comparable to previous lests conducted with HLW AZ-10l sinulants while bubbling the melt pool [14]. In all paired DM100 tests with the same feed, particulate emissions were higher at the higher glass temperature of $1200^{\circ} \mathrm{C}$ than at $1150^{\circ} \mathrm{C}$. An increase in particulate emissions was also observed on the DM1200 with a glass pool temperature increase of only $25^{\circ} \mathrm{C}$ and, separately, with an increase in melt pool bubbling. These trends are in contrast to the lack of clear emissions trends as a function of glass temperature and bubbling in the earlier DM100 tests with Al. Al+Na, Bi, and Cr limited HLW streams [2] but in keeping with nunterous studies using HLW streans that show increased particulate carry-over with increased melt pool bubbling [6, 16-21] and previous tests showing increased particulate melter emissions with increasing glass processing temperature [14,55-58]. It is possible that on the DM100 the effect of the smaller $25^{\circ} \mathrm{C}$ increase in temperature in the earlier tests [2] may be within the variability 
of the measurements [1, 58] whereas the $50^{\circ} \mathrm{C}$ intrease in the curtent tests was sufficient to observe increased enissions. No trend of increased particulate emissions with increasing boron concentration was observed despite the somewhat volatile nature of boron; larger increases in feed borou concentration may be recjuired to see this effect. The amount of moisture collected in each sampling train was proportional to the feed rate; therefore, in the DMlo0 paired tesis, the amount of moisture collected in the tests conducted at a $1200^{\circ} \mathrm{C}$ melt temperature was always higher than moisture collected in tests conducted at $1150^{\circ} \mathrm{C}$.

As expected, the feed elements emitted at the lowest melter DF were clearly fluorine and sulfur. Another element exhibiting some volatile behavior was boron. The relative volatility of barium, cadmium, and titanium are difficult to evaluate due to the low target concentrations in the feed. Emissions of chlorine were measured doring all tests even though they were not included in simulant recipes or in the analyzed compositions. Chlorine has frequently been observed in melter enissions when not present in feed recipe or at levels exceeding the anonnt in the feed recipe doe to its ubiquity in raw materials, presenoe in tap water, and high volatility at glass melting temperatures. Boron. sulfur, and the halides were the only elements detected in the impinger solutions collected downstrean of the healed particle filter in the sampling train, which constitutes the "gas" fraction of the melter emissions.

\subsection{Gases Monitored by FTIR}

Melter emissions were monitored in each test for a variety of gaseous components, most notaloly $\mathrm{CO}$ and nitrogen species, by Fourier Transform Infra-Red Spectroscopy (FTIR). The off-gas system temperature is maintained well above $100 \% \mathrm{C}$ beyond the sampling port downstream of the DM100 HEPA filter to prevent analyte loss due to condensation prior to monitoring. The data therefore, represent the relative concentrations of volatile gaseous species in the melter exhaust. During the DM1200 tests, the exhaust stream was sampled at the outlets of several prototypical components (nelter, SBS, WESP, and PBS) to discen the effect these components have on the volatiles in the exhaust strean. It should be noted, however, that the off-gas system component most responsible for the removal of nitrogen oxide and volatile organics, the TCO-SCR catalyst unit, was bypassed in these tests due to the relatively low concentrations of these components in the exhaust stream. Also, a single FTIR unit was used for all of the measurements and. therefore, locations were sampled sequentially and not simultaneously.

A summary of the range and average concentrations of gaseous species monitored during the DM 100 tests is provided in Table 7.3; similar information for the DM1200 tests is provided in Tables 7.4-7.6. The concentrations of two of the monitored species are plotted in Figures 7.1 - 7.8. The analytes listed in Tables $7.3-7.6$ are those that were thought likely to be observed during the tests based on previous work: no other species were detected in the off-gas stream by FTIR. Gentally, emissions from the DM100 were relatively low as a result of the low concentrations of nitrogen organic carbon, amnonia, and halogens in the feed. The most abundant nitrogen species monitored was NO, which is in keeping with previous nelter tests with both HLW and LAW feeds. No nitrogen was detected as other species, except for NO, which was 10 to 20 times lower in concentration than NO. Similar trends were observed in 
melter emissions during the DMI 200 tests with a greater proportion of nitrogen oxides as $\mathrm{NO}_{2}$ (approximately 6:1, NO:NO ) and very low concentrations of $\mathrm{N}_{2} \mathrm{O}$, nitric acid, and nitrous acid in some of the tests. The variability in the NO concentrations shown in Figures $7.1-7.4$ is attributable to the dynamic conditions in the cold cap and is in keeping with previous melter tests. The concentration of water in the melter exhaust increased with increasing feed rate in both the DM100 and DM 1200 tests. Consistent with the gaseous fluorine concentrations observed using the Method 5-type sampling (see Section 7.1). HF was observed throughout the testing by FTIR The variations in emissions over the course of each test segment are due in part to clanges in the melt pool cold cap. Hydrogen fluoride concentrations were lower at the beginning of testing due to the lack of fluorine in the glass pool and the processing time required for the glass to reach steady-state concentration with respect to fluorine. Also consistent with the Method 5 type results. low sulfur dioxide concentrations were nonitored in each test: however. gaseous sulfit enissions can also be present in forms other than sulfur dioxide that are not monitored by the FTIR, such as sulfuric acid Measured concentrations for most constituents throngh the DM1200 exhaust system were very similar. This confims the expectation that the SBS, WESP, HEME, and PBS do not remove significant proportions of nitrogen and carbon oxides. Conversely, moisture and some minor components such as $\mathrm{HF}$ and $\mathrm{SO}_{2}$ are greatly reduced in concentration by removal in the SBS. These trends can be readily discerned by comparing NO concentrations in Figures 7.5 and 7.7 , which do not show significant differences at the various sampling localities, and HF concentrations in Figures 7.6 and 7.8 , which are noticeably higher in the melter exluuast. Another aspect of the NO emissions is the high degree of variation during testing throughout the off-gas system, as can be discerned from the concentration ranges. 


\section{SECTION 8.0 SUMMARY AND CONCLUSIONS}

A series of tests was conducted to develop HLW glass compositions for the aluminum limited waste conposition specifjed by ORP that maximize processing rates while maintaining high waste loadings and aceeptable glass properties. This was accomplished through a combination of cruible-scale tests, confirmalion tests on the DM100 melter system, and demonstration at pilot melter scale (DM1200). New glass fonmulations and additive blends were developed with the objective of itcreasing processing rates while maintaining high waste loadimgs. The formulations used for melter testing were selected based on the test results from Vertical Gradient Furnace tests, DM10 Feed Consumption tests, and a series of crucible melt glasses that were prepared and characterized. Each of the selected formulations meets all of the produc1 quality, processability, and waste loading requirements. The DM100 melter tests evaluated the effects of a $50^{\circ} \mathrm{C}$ increase in glass processing temperature, alıninum waste fom $\left(\mathrm{Al}_{2} \mathrm{O}_{3}\right.$ vs. $\left.\mathrm{A}(\mathrm{OH})_{3}\right)$, and optimized additive blends on glass production rates. This same melter was used in previous tests with aluninum limited and other HLW wastes thus providing comparisons between the previously collected data on melter processing characteristics: partitioning to off-gas, and formation of secondary phases. Once DMl00 tests were completed. one of the compositions was selected for further testing on the DMI 200; the DM1200 system has been used for processing a variety of simulated WTP waste streams. Tests on the larger melter provide processing data at one third of the scale of the actual WTP HLW melter and therefore provide a more accurate and reliable assessment of production rates and potential processing issues.

For each of the four selected feed formulations. DM 100 melter testing was performed in two 50-hour test segments. These test segments employed glass pool temperatures of $1150^{\circ} \mathrm{C}$ and $1200^{\circ} \mathrm{C}$, bubbling rates of 9 lpnt and $500 \mathrm{~g}$ glass per liter feed solids concentration. Over three and a half metric tons of feed was processed to produce almost two metric tons of glass. Analysis was performed on discharge and glass pool samples throughout the tests for total composition. All of the melter tests were successfully completed with no evidence of processing issues. Glass production rates with the aluminum limited waste at a glass pool temperature of $1150^{\circ} \mathrm{C}$ were increased from $550 \mathrm{~kg} / \mathrm{m}^{2} /$ day it the previous test to $950 \mathrm{~kg} / \mathrm{m}^{2} / \mathrm{day}$ as a result of changes to the feed composition while maintaining the same high waste loading ( $45 \mathrm{wt} \%$ ). Glass production rates as high as $1500 \mathrm{~kg} / \mathrm{m}^{2} /$ day were achieved at the glass pool temperature of $1200^{\circ} \mathrm{C}$. Data collected during DM100 tests also demonstrated the effect of the aluminum souree on production rates, wijh significantly higher rates observed with aluminum bydroxide than with aluminum oxide. Tesis with the aluminum linited waste on the DN1200 demonstrated glass production rates of $1500 \mathrm{~kg} / \mathrm{m}^{2} /$ day at $1150^{\circ} \mathrm{C}$ melt pool temperature with optimized bubbling. The target production rate of $1050 \mathrm{~kg} / \mathrm{m}^{2}$ day was easily obtained with a modest anout of bubbling and the nominal glass pool temperatuse of $1150^{\circ} \mathrm{C}$ as well as with an evell lower bubbling rate at a modestly higher glass pool temperature of $1175^{\circ} \mathrm{C}$. No significant processing problems were encoutered on the DM1200 while producing almost 9 metric tons of glass from over 24 metric tons of feed. 
During each test, melter exhaust was sampled for particulate and gaseous species to determine the effect of the variations in feed composition and glass temperature on emissions. Total particulate carry-over from both melters into the off-gas stream was only 0.04 to 0.29 percent, which is below the range measured previously on the DM100 and DM1200 when processing other HLW simulants. Melter DFs were determined for most elements in the feed for all eight test segments performed. The most volatile species were sulfur and fluorine, which is typical. Particulate emissions from the melter increased with increasing glass pool temperature and bubbling rate but no obvious change was observed with feed composition. Gaseous emissions of nitrogen oxides and byproducts of incomplete combustion, such as carbon monoxide and ammonia, were very low due to the lack of nitrates and organic carbon in the feed.

The new glass formulations meet all processing and product quality requirements for each of the developed compositions, with waste loadings ranging from 43.6 to $45 \mathrm{wt}^{\%} \%$ on a waste oxide basis. Glass samples from the crucible and melter tests were subjected to leach testing using the PCT and TCLP methods in order to evaluate product quality. Despite the high waste loadings, the glass products significantly out-performed the DWPF-EA benchmark glass on the PCT leaching procedure by factors of at least 140 and exhibited TCLP leachate concentrations that were well below the WTP delisting limits. Overall, the results from the melter tests and the associated processing and product quality data support the viability of the proposed HLW enhancement approaches. In addition, the results from the DM100 and DM1200 melter tests provided validation of the VGF and DFC melt rate sereening tests that were developed and successfully integrated into the glass formulation methodology.

The characteristics of the HWI-Al-19 formulation developed in this work and tested on both the DM100 melter and the DM1200 pilot melter include:

- $45 \mathrm{wt} \%$ waste loading

- Limited by crystallization on CCC and impact on PCT; also spinel formation

- $\mathrm{Al}_{2} \mathrm{O}_{3}$ content $=23.97 \mathrm{wt} \%$ vs. WTP contract minimum of $11 \mathrm{wt} \%$, giving a $54 \%$ reduction in the volume of glass produced from this waste

- Melt rate significantly exceeds the WTP target of $800 \mathrm{~kg} / \mathrm{m}^{2} / \mathrm{d}$ (corresponding to $3 \mathrm{MT} / \mathrm{d}$ per WTP HLW melter) under nominal conditions

- Melt rate of $1500 \mathrm{~kg} / \mathrm{m}^{2} / \mathrm{d}$ demonstrated with optimized bubbling, representing an $87 \%$ increase over the WTP target rate.

In view of the importance of aluminum limited waste streams at Hanford (and also Savannah River), the ability to achieve high waste loadings without adversely impacting melt rates has the potential for enormous cost savings from reductions in canister count and the potential for schedule acceleration. Consequently, the potential return on the investment made in the development of these enhancements is extremely favorable. 


\subsection{Recommendations for Future Work}

The results of the testing presented herein clearly demonstrate the viability of the enluancement and optimization strategies that have been developed. Furthermore, the results have the potential for enonmous savings in cost and schedule. As a result, it is recommended that testing and evaluation of these strategies be continued in order to provide a solid basis for their broad implementation in order to maximize the cost and schedole benefits while minimizing techuical risk. Some of the elements of such a program are summarized below. While the discussion is centered around Hanford HLW streans, many of these enhancement strategies would also be applicable to other HLW streans, such as those heing treated at the DWPF, with the potential for similarly large benefits.

- Other WTP HLW Waste Types: The present testing was based on a single high aluminum HLW composition from the Hanford tanks. While these results are also relevant to waste from several tanks. the diversity of the Hanford tank wastes means that there are several such waste-loading-limiting constituents (and combinatjons thereof), each of which needs to be addressed in order to maximize the benefit from these enhacements. As a starting point, a similar test program to the one performed in the present work should be performed for each of the principal waste-loading-liniting constituents. Particular attention sltould be paid to waste streans contaituing sulfur dute to the potential of forming secondary phases on the melt pool surface. In addition. prodnction rates and feed rheology are affected by the form of the major constituents in the waste stream. Melter tests conducted on likely forms of major waste constituents would permit more accurate estimates of potential production rates and processing problems.

- Throughput: A key risk area addressed in the present work relates to the strong dependence of glass production rates on waste composition. The extent of this variation across the full spectrum of HLW waste types needs to be quantified in order to accurately project waste treatment rates. The vast majority of the previous testing for the WTP has been performed on iron-limited wastes and those results have formed the basis for vitrification system capacity projections. The results of the present work suggest that this basis may not be appropriate for other waste types. Testing also needs to be performed to develop approaches to mitigate the potential short-fall in glass production rates.

- Formulating Glasses with higher crystat contents: Previous tests with HLW iron-limited wastes showed that allowing a higher crystal content product can allow significantly increased waste loadings. Evaluation of this enhanced "operational liquidus temperature" approach for other waste streans would result in further waste loading increases.

- Scale-Up Testing: As in the present work, testing should be extended to larger-scale melter systems in order to address potential risks associated with scale-up, particularly with respect to processing rates. Testing should be conducted at the DM1200 WTP HLW Pilot Melter scale $\left(1.2 \mathrm{~m}^{2}\right)$. Optimization of bubbling rate is a critical variable and therefore testing with bubblers in the prototypical orientation at larger scale is required to confirm these findings. 
- Integrated System Testing: Testing on the DM1200 WTP HLW Pilot Melter system provides data from a one-third scale system with a prototypical feed delivery system and off-gas treatment train. Such testing is necessary to evaluate potential interactive effects on system operation arising from implementation of the enhancenent strategies and to provide data on the performance of each unit operation, inpot for flow-sheet models and regulatory requirements, and information of recycle streams.

- Longer-Duration Testing: After validated at larger scale, the duration of testing should be extended in order to address and quantify any chronic issues, such as the slow accumulation of crystals in the nelter cavity, any degradation in the ability to discharge glass, and effects on off-gas line plugging.

Finally, it is likely that the maximum production rate for each set of test conditions would have been significantly impacted for most of the tests if the cold cap conditions were not monitored visually. Consequently, it is recommended that the ability to maintain production rates without use of visual information be evaluated, if that is the planned WTP operating mode. 


\section{SECTION 9.0}

REFERENCES

[1] "HLW Enhancement Tests on the DuraMelter ${ }^{7 M} 10$ with Hanford AZ-102 Tank Waste Simulants," K.S. Matlack, W.K. Kot. H. Gan. W. Gong and l.L. Pegg. Final Report. VSL-06R6260-1, Rev. 0, Vitreous State Laboratory. The Catholic University of America, Washington. $\mathrm{DC}, 2 / 28 / 06$.

[2] "High Level Waste Vitrification System Inprovements," K.S. Matlack, H. Gan. W. Gong. I.L. Pegg, C.C. Chapman and I. Joseph, Final Report, VSL-07R1010-1, Rev, 0. Vitreous State Laboratory, The Catholic University of America, Washington, DC, $4 / 16 / 07$.

[3] "High Level Waste Glass Development Testing," K.S. Matlack, W.K. Kot, and I.L. Pegg, Test Plan, VSL-07T1360-1, Rev, 0, Vitreous State Laboratory, The Catholic University of America, Washington. DC, 1/25:08.

[4] "HLW Glass Development Testing," Contract Number DE- RP27-07RV14884, US Department of Energy, Office of River Protection, Richland, WA, 2007.

[5] "Test and Evaluate High Level Waste (HLW) Vitrification System Inprovements." Contract Number DE-AC27-06RV14790. US Department of Energy. Office of River Protection, Richland, WA, April, 2006.

[6] "lntegrated DM1200 Melter Testing of Bubbler Contigurations Using HLW AZ-101 Simulants." K.S. Matlack, W. Gong, T. Bardakci, N. D'Angelo. W. Lutze, R. A. Callow, M. Brandys, W.K. Kot, and I.L. Pegg. Final Report, VSL-04R4800-4, Rev. 0, Vitreous Stale Laboratory, The Catholic University of America, Washington, DC, 10/5i04.

[7] "Glass Formulation and Testing with RPP-WTP HLW Simulants," W.K. Kot and I.L. Pegg. Final Report. VSL-01R2540-2. Rev. 0, Vitreous State Laboratory, The Catholic University of America, Washington, DC, $2 / 16 \%$ l.

[8] "Glass Formulation to Support Melter Runs with HLW Simulants," Final Report. W.K. Kot, K. Klatt. and I.L. Pegg, Final Report, VSL-03R3760-2, Rev, 0. Vitteous State Laboratory. The Catholic University of America, Washington, DC, 8/8/03.

[9] "HLW Glass Formulation to Support C-106/AY-102 Actual Waste Testing." W.K. Kot and I.L. Pegg. Final Report, VSL-04R4770-1, Rev. 0, Vitreous State Laboratory, The Catholic University of America, Washington. DC, 8/12/04.

[10] "Development of Phase 1 IHLW Models for PCT Response and One-Percent Crystal Fraction Temperature (T $1 \%$ )." W.K. Kot. H. Gan, Z. Feng, F. Perez-Cardenas, l.L. Pegg. S.K. Cooley, and G. F. Piepel. Final Report, VSL-05R5780-1, Rev, 0, Vitreous State Laboratory, The Catholic University of America, Washington, DC, 4i12/05. 
[11] "Preparation and Testing ( $\mathrm{T}_{1 \%}$ and PCT) of HLW Matrix Glasses to Support WTP Property-Composition Model Development," W.K. Kot. H. Gan, and I.L. Pegg. Final Report, VSL-05R5780-2. Rev. 0, Vitteous State Laboratory, The Catholic University of America, Washington, DC, 10/12/05.

[12] "Summary and Recommendations on Viscosity and Conductivity Model Forms to Support HLW Vitrification." H. Gan, Z. Feng. and I.L. Pegg. Letter Report. VSL04L4780-1, Rev, 0, Vitreous State Laboratory, The Catholic University of America. Wasbington. DC, $9: 8 / 04$.

[13] "Preparation and Testing of HLW Algorithm Glasses to Support Small Scale Melter Testing." W.K. Kot and I.L. Pegg. Final Report, Final Report. VSL-07R1240-1. Rev. 0, Vitreous State Laboratory: The Catholic University of America, Washington. $D C$. $8: 2407$.

[14] "Melter Tests with AZ-101 HLW Simulant Using a DuraMelter 100 Vilrification Systen." K.S. Matlack, W.K. Kot. and I.L. Pegg, Füal Report. VSL-ol R10Nó-1. Rev. 1, Vitreous State Laboratory. The Catholic University of America. Washington, DC, $2: 25 / 01$.

[15] "DuraMelter $100 \mathrm{HLW}$ Simulant Validation Tests with C-106/AY-102 Feeds," K.S. Matlack, W. Gong and I.L. Pegg. Final Report. VSL-05R5710-1, Rev. 0. Vitreous State Laboratory, The Catholic University of America, Washington, DC, 6/2/05.

[16] "Integrated DM1200 Melter Testing of HLW C-106:AY-102 Composition Using Bubblers:" K.S. Matlack, W. Gong. T. Bardakci. N. D'Angelo, W. Kot and I.L. Pegg. Final Report, VSL-03R3800-1, Rev. 0, Vitreous State Laboratory, The Catholic University of America, Washington, DC, 9/15/03.

[17] "Integrated DM1200 Melter Testing of HLW C-104/AY-101 Compositions Using Bubblers," K.S. Matlack, W. Gong, T. Bardakei, N. D'Angelo. W. Kot and I.L. Pegg. Final Report. VSL-03R3800-3, Rev. 0, Vitreous State Laboratory, The Catholic University of America. Washington, DC. $11 / 24 / 03$.

[18] "DMI 200 Tests with AZ-101 HLW Simulants," K.S. Matlack. W. Gong, T. Bardakci, N. D'Angelo, W.K. Kot, and I.L. Pegg. Final Report. VSL-03R3800-4, Rev, 0, Vitreous State Laboratory. The Catholic University of America, Washington, DC, 2/17/04.

[19] "Start-Up and Commissioning Tests on the DM1200 HLW Pilot Melter System Using AZ-101 Waste Simulants," K.S. Matlack, M. Brandys, and I.L. Pegg, Final Report. VSLOlRo100-2, Rev, 1, vitreous State Laboratory. The Catholie University of America. Waslinglon, $\mathrm{DC}, 10 / 31: 01$. 
[20] "Tests on the DuraMelter $1200 \mathrm{HLW}$ Pilot Melter System Using AZ-101 HLW Simulants," K.S. Matlack, W.K. Kot, T. Bardakci, T.R. Schatz, W. Gong, and L.L. Pegg. Final Report. VSL-02R0100-2, Rev. 0, Vitreous State Laboratory, The Catholic University of America, Washington. DC, $6 i 11 / 02$.

[21] "Integrated DM1200 Melter Testing of HLW AZ-102 Compositions Using Bubblers," K.S. Matlack, W, Gong, T. Bardakci, N. D'Angelo, W, Kot and I.L. Pegg, Final Report. VSL-03R3800-2, Rev, 0, Vitreous State Laboratory, The Catholic University of America, Washington. DC, $9 / 24 / 03$.

[22] "Integrated DM1200 Melier Testing of Redox Effects Using HLW AZ-10] and C-106/AY-102 Simulants," K.S. Matlack, W. Gong, T. Bardaki, N. D'Angelo. W. Lutze, P. M. Bizot, R. A. Callow. M. Brandys, W.K. Kot, and I.L. Pegg, Final Report, VSL-04R4800-1. Rev, 0, Vitreous State Laboratory. The Catholic University of America. Wastinglon, DC, 5i6/04.

[23] "Inlegrated DM1200 Melier Testing Using AZ-102 and C-106/AY-102 HLW Simulan1s: HLW Simulant Verification." K.S. Matlack, W. Gong. T. Bardakci, N. D'Angelo, M. Brandys, W.K. Kot. and I.L. Pegg, Final Report, VSL-05R5800-1, Rev, 0, Vitreous State Laboratory. The Catholic University of America, Washington, DC. $6 / 27 / 05$.

[24] "Small Scale Melter Testing of HLW Algorithm Glasses: Matrix 1 Tests," K.S. Matlack. W.K. Kot. W. Gong and I.L. Pegg, Final Report, VSL-07R1220-1. Rev. 0, Virreous State Laboratory, The Catholic University of America, Washington. DC, 11/12/07.

[25] "Small Scale Melter Testing of HLW Algorithm Glasses: Matrix 2 Tests," K.S. Matlack. W.K. Kot, W. Gong and I.L. Pegg. Final Report, VSL-08R1220-1, Rev. 0. Vitreous State Laboratory, The Catholic Liniversity of America, Wastington, DC, 6/27/08.

[26] "Dissolution in Ceramic Systems: I. Molecular Diffusion, Natural Convection, and Foreed Convection," A.R. Cooper and W.D. Kingery. J. Am. Ceram. Soc.. 47. 37 (1964).

[27] "Dissolution in Ceranic Systems: III. Boundary Layer and Concentration Gradient," $Y$. Oishi, A.R. Cooper and W.D. Kingery, J. Am. Ceram. Soc., 48, 88 (1965).

[28] "Direct and Indirect Dissolution of Sapphire in Calcia-Magnesia-Alumina-Silica Melts: Dissolution Kinetics," K.H. Sandhage and G.J. Yurek, J. Am. Ceram. Soc., 73, 3633 (1990).

[29] A.R. Cooper in "Encyclopedia of Materials Sejence and Engineering," Ed, M.B. Bever; Pergamon Press, Oxford (1986).

[30] "Fundanentals of Inorganic Glasses," A.K. Varshneya, Academic Piess, Inc., San Diego, CA (1994). 
[31] "Melting Rate of Soda-Line Glasses as Influenced by Grain Sizes of Raw Materials and Additions of Cullet," J.C. Potts, G. Brookover, O.G. Burch, Proc. Am. Ceranic Soc. Annual Meeting (1943).

[32] "Effect of Fine Grinding of Glass Batch on the Rate of Melting. Glass and Ceramics," I.D. Tyachinsky and M.B. Romanovsky, Glass and Ceramics, Vol. 13, Number 1, Springer, New York (1956).

[33] "Electric Melting of Glass," L. Penberthey, Chapter 6. The Handbook of Glass Manufacture, F. V. Tooley, Editor, Books for Industry, Inc, New York (1974).

[34] "BOC Convective Glass Melting System," J, Leblans, R. Marshall, G. Punsia, T. Clayton, A. Richardson, and N. Simpson, 62nd Conference on Glass Problens: Ceranic Engineering and Ssience Proceedings, Vol. 23, Issue 1, J. Kieffer, Ed. (2008).

[35] "Advances in Oxy-Fuel Fired Glass Meltung Tecluology" H. Kobayashi, JX International Congress on Glass (ICG), Kyoto (2004).

[36] "Glass Melting Technology: A Tecluical and Economic Assessment," C.P. Ross and G.L. Tincher, Techuical Report. \#DE-FC36-021D14315, M. Rasnussen, Editor، Glass Manufacturing Industry (2004).

[37] "Computation Fluid Dynamies Simulations of a Glass Melting Furnace." A. Egelja and S.A. Lottes, Energy 2000: The Beginning of a New Millenium: Energex 2000, P.J. Catania, N. Balaban, B. Golchert. Proceedings of the 8th International Energy Fonm, Las Vegas (2000).

[38] "CFD Applications in Glass Melting Systems," C.Q. Jian. Energy 2000: The Beginning of a New Millenium: Energex 2000. P.J. Catania, N. Balaban, B. Golchert, Proceedings of the 8th International Energy Forum, Las Vegas (2000).

[39] "Prediction for Waste Glass Melt Rate", L. M. Lee, Waste Management, '87, Vol. 1, p 591. Arizona Board of Regents. Tucson, AZ (1987).

[40] "Control of Radioacive Waste Glass Melters: II, Residence Time and Melt Rate Linitations", D.F. Bickford, P. Hrma and B.W. Bowan, II, J. Am. Ceramic Soc., 73, 2093 (1990).

[41] "Behavior of Simulated Hanford Slurries During Conversion to Glass", J.G. Darab. E.M. Meiers, and P.A. Snith. Mat. Res. Soc. Proc., Vol. 556, 215 (1999).

[42] "Waste Glass Melting Stages," L.D. Anderson, T. Dennis, M.L. Elliott, and P. Hrma. Ceramic Transactions, Vol. 39. p 213 (1993). 
[43] "Melt Rate Improvement for DWPF Macrobatch 3: Summary and Recommendations," D.P. Lambert, T.H. Lorier, D.K. Peeler, and M.E. Stone, WSRC-TR-2001-00l48. Westinghouse Savannal River Company, Aiken, SC (2001).

[44] "Tecluetium/Cesium Volatility in DM 100 Tests Using HLW AZ-102 and LAW SubEnvelope Al Simulants," K.S. Matlack, W.K. Kot, and I.L. Pegg, Final Report VSL04R4710-1, Rev, 0, Vitreous State Laboratory. The Catholic University of America. Washinglon, $\mathrm{DC}, 9 / 28 / 04$.

[45] "Quality Assurance Project Plan for RPP-WTP Support Activities Conducted by VSL," Vitreous State Laboratory, QAPP Rev. 9, Vitreous State Laboratory. The Catholic University of America, Washington, DC, 6i5/07.

[46] "Master List of Controlled VSL Manuals and Standard Operating Procednres in Use," QA-MLCP, Rev. 29, Vitreous State Laboratory, The Catbolic University of America, Washinglon, $\mathrm{DC}, 7 / 15 / 08$.

[47] "High-Level Waste Melter Altemate Bubbler Configuration Testing" R.K Mohr, C.C. Chapman and I.L. Pegg. Final Report. VSL-04R4800-3. Rev, 0, 6/18/04.

[48] "Round Robin Testing of a Reference Glass for Low-Activity Waste Forms," W.L. Ebert and S.F. Wolf: Department of Energy report ANL-99/22, Argonne National Laboratory. Argonue, IL, 1999.

[49] "Sunmary of DM1200 Operation at VSL," K.S. Matlack, G. Diener, T. Bardakej, and I.L. Pegg, Final Report. VSL-06R6710-2, Rev, 0. Vitreous State Lalworatory: The Catholis University of America, Washington, DC, 9:7/06.

[50] "Regulatory Off-Gas Emissions Testing on the DM1200 Melter System Using HLW and L.AW Simulants," K.S. Matlack, W. Gong, T. Bardakci, N. D'Angelo, M. Brandys, W. Kot, and I.L. Pegg, Final Report VSL-05R5830-1, Rev. 0. Vitreous State Laboratory, The Catholic [iniversity of America, Washington, DC, 10/3 ]:05.

[51] "Physical and Rheological Froperties of Waste Simulants and Melter Feeds for RPPWTP HLW Vitrification." Final Report. K. Kot, H. Gam, and LL. Pegg. VSL-00R2520-1, Rev. 0. Vitreous State Laboratory', The Catholic University of America, Washington, DC, 10/31/01.

[52] "Review of Properties of Simulated Feeds Used for Melter Testing." K.S. Matlack. W. Gong. and I.L. Pegg, Final Report, VSL-06R6410-1, Rev. 0, Vitreous State Laboratory. The Catholic University of Anerica. Washington. DC. Washington, D.C., 8/16/06.

[53] "New Delisting Limits for Arsenic and Cltome. ${ }^{\star}$ D. Blunenkranz, e-mail message to J. Westsik, CCN 069211. River Protection Project, Waste Treatment Plant, Rishland, WA. 9:15:03. 
[54] "Data Quality Objectives Process in Support of LDRDelisting at the WTP," J. Cook and D. Blumenkranz, 24590-WTP-RPT-ENV-01-012, Rev. 2, River Protection Project. Waste Treatment Plant, Richland, WA, 3/26/03.

[55] "High-Temperature Melter Tests for Vitrification of BNFL Nuclear Wastes," K.S. Matlack, I.S. Muller, C. Alearn, R.K. Mohr, and I.L Pegg. Final Report to BNFL, plc, Vitreous State Laboratory, The Catholic University of America, Washington, DC, May 1998.

[56] "Vitrification," I.L. Pegg and I. Joseph, Chapter 4.2 in "Hazardous and Radioactive Waste Treatment Technologies Handbook," Ed. C.H. Oh, CRC Press, LLC, 2001.

[57] "Vitrification Testing for Fernald CRU4 Silo Wastes," S.S. Fu, K.S. Matlack, R.K. Mohr, C. Paul, I.L. Pegg, and P.B. Macedo, Final Report, Vitteous State Laboratory, The Catholic University of America, Washington, DC, 9/27/96.

[58] "Small Scale Melter Testing to Assess Inpact of Higher Temperature Melter Operations," K.S. Matlack, W. Gong, and I.L. Pegg. Final Report to Dept. of Energy, Office of River Protection, VSL-04R4980-1, Rev, 0, Vitreous State Laboratory, The Catholic University of America, Washington, DC, 2/13/04. 
Table 2.1. Oxlue Compositions of Limiting Waste Streams (wt \%).

\begin{tabular}{|c|c|c|c|c|}
\hline $\begin{array}{c}\text { Waste } \\
\text { Component }\end{array}$ & Bt Limited & Cr Limited & Al Limited & $\begin{array}{c}\text { Al and Na } \\
\text { Limited }\end{array}$ \\
\hline $\mathrm{Al}_{2} \mathrm{O}_{3}$ & $2245 \%$ & $2553 \%$ & $4921 \%$ & $4330 \%$ \\
\hline $\mathrm{B}_{2} \mathrm{O}_{3}$ & $058 \%$ & $0.53 \%$ & $039 \%$ & $074 \%$ \\
\hline $\mathrm{CaO}$ & ] $61 \%$ & $247 \%$ & $221 \%$ & $1470 \%$ \\
\hline $\mathrm{Fe}_{2} \mathrm{O}_{3}$ & $1340 \%$ & $1313 \%$ & $1211 \%$ & $571 \%$ \\
\hline $\mathrm{L}_{1} \mathrm{O}$ & $031 \%$ & $036 \%$ & $035 \%$ & $015 \%$ \\
\hline $\mathrm{MgO}$ & $08 \%$ & $016 \%$ & $024 \%$ & $044 \%$ \\
\hline $\mathrm{Na}_{2} \mathrm{O}$ & $1297 \%$ & $20(10 \%$ & $735 \%$ & $2579 \%$ \\
\hline $\mathrm{S}_{1} \mathrm{O}_{2}$ & $1204 \%$ & $1056 \%$ & $1005 \%$ & $622 \%$ \\
\hline $\mathrm{T}_{1} \mathrm{O}_{2}$ & $030 \%$ & $001 \%$ & $002 \%$ & $035 \%$ \\
\hline $\mathrm{ZnO}$ & $031 \%$ & 1) $25 \%$ & $(1170$ & $036^{\circ} \%$ \\
\hline $\mathrm{ZrO}_{2}$ & $040 \%$ & $011 \%$ & $081 \%$ & $025 \%$ \\
\hline $3 O_{3}$ & $091 \%$ & $152 \%$ & $041 \%$ & $044 \%$ \\
\hline $\mathrm{B}_{2} \mathrm{O}_{3}$ & $1291 \%$ & $729 \%$ & $235 \%$ & $235 \%$ \\
\hline $\mathrm{ThO}_{2}$ & $0 \simeq 5 \%_{00}$ & 1) $64 \%$ & $637 \%$ & $004 \%$ \\
\hline $\mathrm{Cr}_{2} \mathrm{O}_{3}$ & $100 \%$ & $307 \%$ & $107 \%$ & $144 \%$ \\
\hline $\mathrm{K}_{2} \mathrm{O}$ & $0.89 \%$ & 1) $37 \%$ & $(1990 \%$ & $134 \%$ \\
\hline $\mathrm{U}_{3} \mathrm{O}_{8}$ & $348 \%$ & $759 \%$ & $725 \%$ & $458^{\circ} \%$ \\
\hline $\mathrm{Ban}$ & $002 \%$ & $003 \%$ & $011 \%$ & $006 \%$ \\
\hline $\mathrm{CdO}$ & $000 \%$ & $001 \%$ & $005 \%$ & $002 \%$ \\
\hline $\mathrm{N}_{1} \mathrm{O}$ & $371 \%$ & ] $06 \%$ & $082 \%$ & $020 \%$ \\
\hline$P(x)$ & $048 \%$ & $048 \%$ & $084 \%$ & $018 \%$ \\
\hline $\mathrm{P}_{2} \mathrm{O}_{5}$ & $960 \%$ & $334 \%$ & $216 \%$ & $410 \%$ \\
\hline F. & $158 \%$ & $200 \%$ & $137 \%$ & $046^{\circ} \%$ \\
\hline Total & $10000^{\circ}$ & $10000 \%$ & $10000 \%$ & $10000^{\circ} \%$ \\
\hline
\end{tabular}


Table 2.2. Compositions of the Al-Linited Waste ( $O$ xide Basis) and the HLW Waste Simulant to Produce $100 \mathrm{~kg}$ of $W$ aste Oxides ( $20 \mathrm{wt} \%$ suspended solids) Using $\mathrm{Al}_{2} \mathrm{O}_{3}$ as the Aluninum Source.

\begin{tabular}{|c|c|c|c|}
\hline \multicolumn{2}{|c|}{ Al-Limited Waste Composition } & \multicolumn{2}{|c|}{ Al-Limited HLW Waste Simulant } \\
\hline Waste Oxide & Wt $\%$ & Starting Materials & Target Weight (kg) \\
\hline $\mathrm{Al}_{2} \mathrm{O}_{3}$ & $4921 \%$ & $\mathrm{Al}_{2} \mathrm{O}_{3}$ & 49707 \\
\hline $\mathrm{B}_{2} \mathrm{O}_{1}$ & $039 \%$ & $\mathrm{H}_{3} \mathrm{BO}_{1}$ & $0700^{\circ}$ \\
\hline $\mathrm{CaO}$ & $221 \%$ & $\mathrm{CaO}$ & 2255 \\
\hline $\mathrm{Fe}_{2} \mathrm{O}_{7}$ & $1211 \%$ & $\mathrm{Fe}(\mathrm{OH})_{r}\left(13^{\circ} \%\right)$ Slury $)$ & 99643 \\
\hline $\mathrm{Ll}_{2} \mathrm{O}$ & $035 \%$ & $\mathrm{Ll}_{2} \mathrm{CO}_{3}$ & 0888 \\
\hline $\mathrm{MgO}$ & $024 \%$ & Mog & 0253 \\
\hline $\mathrm{Na}_{2} \mathrm{O}$ & $735 \%$ & $\mathrm{NaOH}$ & 4235 \\
\hline $\mathrm{S}_{1} \mathrm{O}_{2}$ & $1005 \%$ & $\mathrm{~S}_{1} \mathrm{O}_{2}$ & 10152 \\
\hline $\mathrm{TrO}_{2}$ & $002 \%$ & $\mathrm{~T}_{1} \mathrm{O}_{2}$ & 0020 \\
\hline $\mathrm{ZnO}$ & $017 \%$ & $\mathrm{ZnO}$ & 0172 \\
\hline $\mathrm{ZrO}_{2}$ & $081 \%$ & $\mathrm{Zr}(\mathrm{OH})_{4} \cdot x \mathrm{H}_{2} \mathrm{O}$ & 2093 \\
\hline $\mathrm{SO}_{3}$ & $041 \%$ & $\mathrm{Na}_{2} \mathrm{SO}_{4}$ & 0735 \\
\hline $\mathrm{Bi}_{2} \mathrm{O}_{3}$ & $235 \%$ & $\mathrm{Bl}_{2} \mathrm{O}_{3}$ & 2374 \\
\hline $\mathrm{ThO}_{2}$ & $037 \%$ & Th Surrogate & 0 \\
\hline $\mathrm{Cr}_{2} \mathrm{O}_{3}$ & $107 \%$ & $\mathrm{Cr}_{2} \mathrm{O}_{3} \cdot \mathrm{l} 5 \mathrm{H}_{2} \mathrm{O}$ & 1273 \\
\hline $\mathrm{K}_{\underline{\underline{Y}}} \mathrm{O}$ & $029 \%$ & $\mathrm{KNO}_{3}$ & 0632 \\
\hline $\mathrm{U}_{3} \mathrm{O}_{8}$ & $725 \%$ & U Surrogate & 0 \\
\hline $\mathrm{BaO}$ & $011 \%$ & $\mathrm{BaCO}_{\mathrm{g}}$ & 0143 \\
\hline $\mathrm{CdO}$ & $005 \%$ & $\mathrm{CdO}$ & 0051 \\
\hline $\mathrm{NIO}$ & $082 \%$ & $\mathrm{~N}_{1}(\mathrm{OH})_{2}$ & 1055 \\
\hline $\mathrm{PbO}$ & $084 \%$ & $\mathrm{PbO}$ & 0848 \\
\hline $\mathrm{P}_{2} \mathrm{O}_{3}$ & $216 \%$ & $\mathrm{FePO}_{4} * \mathrm{H}_{2} \mathrm{O}$ & 5738 \\
\hline $\mathbf{F}$ & $137 \%$ & $\mathrm{NaF}$ & 3044 \\
\hline Carbonate & $120^{\ddot{m}}$ & $\mathrm{Na}_{2} \mathrm{CO}_{3}$ & 0806 \\
\hline Notnte & 050 & $\mathrm{NaNO}_{2}$ & 0769 \\
\hline Nitrate & 209 & $\mathrm{NaNO}_{3}$ & 2239 \\
\hline Organic Carbun & 005 & $\mathrm{H}_{2} \mathrm{C}_{2} \mathrm{O}_{4}+2 \mathrm{H}_{2} \mathrm{O}$ & 0264 \\
\hline- & - & Wialer & 279400 \\
\hline- & - & - & - \\
\hline TOTAL & $1000 \%$ & TOTAL & 469478 \\
\hline
\end{tabular}

"Taryet wieights adjusted for assay information of starting materials

*Unit for volatile components is g/ $100 \mathrm{~g}$ of waste oxide

- Empty data field 
Table 2.3. Compositions of the Al-Limited Waste (Oxide Basis) and the HLW Waste Simulant to Produce $100 \mathrm{~kg}$ of Waste Oxides (20 wt \% suspended solids) Using $\mathrm{Al}(\mathrm{OH}) \mathrm{g}$ as the Alumum Source.

\begin{tabular}{|c|c|c|c|}
\hline \multicolumn{2}{|c|}{ Al-Limited Waste Composition } & \multicolumn{2}{|c|}{ Al-Limited HLW Waste Simulant } \\
\hline Waste Oxide & Wt $\%$ & Starting Materials & Target Weight (kg) \\
\hline $\mathrm{Al}_{2} \mathrm{O}_{3}$ & $4921 \%$ & $\mathrm{Al}(\mathrm{OH})$ & 76052 \\
\hline $\mathrm{B}_{2} \mathrm{O}_{1}$ & $039 \%$ & $\mathrm{H}_{3} \mathrm{BO}_{3}$ & $0700^{\circ}$ \\
\hline $\mathrm{CaO}$ & $221 \%$ & $\mathrm{CaO}$ & 2255 \\
\hline $\mathrm{Fe}_{2} \mathrm{O}_{3}$ & $1211 \%$ & $\mathrm{Fe}(\mathrm{OH})_{3}(13 \%$ Slurty $)$ & 99643 \\
\hline $\mathrm{Ll}_{2} \mathrm{O}$ & $035 \%$ & $\mathrm{~L}_{2} \mathrm{CO}_{3}$ & 0888 \\
\hline $\mathrm{MgO}$ & $024 \%$ & $\mathrm{MgO}$ & 0253 \\
\hline $\mathrm{Na}_{2} \mathrm{O}$ & $735 \%$ & $\mathrm{NaOH}$ & 4235 \\
\hline $\mathrm{S}_{1} \mathrm{O}_{2}$ & $1005 \%$ & $\mathrm{~S}_{1} \mathrm{O}_{2}$ & 10152 \\
\hline $\mathrm{TrO}_{2}$ & $002 \%$ & $\mathrm{~T}_{1} \mathrm{O}_{2}$ & 0020 \\
\hline $\mathrm{ZnO}$ & $017 \%$ & $\mathrm{ZnO}$ & 0172 \\
\hline $\mathrm{ZrO}_{2}$ & $081 \%$ & $\mathrm{Zr}(\mathrm{OH})_{4} \times \mathrm{H}_{2} \mathrm{O}$ & 2093 \\
\hline $\mathrm{SO}_{3}$ & $041 \%$ & $\mathrm{Na}_{2} \mathrm{SO}_{4}$ & 0735 \\
\hline $\mathrm{Bl}_{2} \mathrm{O}_{3}$ & $235 \%$ & $\mathrm{Bi}_{2} \mathrm{O}_{3}$ & 2374 \\
\hline $\mathrm{ThO}_{3}$ & $037 \%$ & Th Surrogate & 0 \\
\hline $\mathrm{Cr}_{2} \mathrm{O}_{3}$ & $107 \%$ & $\mathrm{Cr}_{2} \mathrm{O}_{3} \cdot 15 \mathrm{H}_{2} \mathrm{O}$ & 1273 \\
\hline $\mathrm{K}_{\mathrm{r}} \mathrm{O}$ & $029 \%$ & $\mathrm{KNO}_{3}$ & 0632 \\
\hline $\mathrm{U}_{3} \mathrm{O}_{8}$ & $725 \%$ & U Surrogate & 0 \\
\hline $\mathrm{BaO}$ & $011 \%$ & $\mathrm{BaCO}_{\mathrm{f}}$ & 0143 \\
\hline $\mathrm{CdO}$ & $005 \%$ & $\mathrm{CdO}$ & 0051 \\
\hline $\mathrm{NiO}$ & $082 \%$ & $\mathrm{Nl}(\mathrm{OH})_{2}$ & 1055 \\
\hline $\mathrm{PbO}$ & $084 \%$ & $\mathrm{PbO}$ & 0848 \\
\hline $\mathrm{P}_{2} \mathrm{O}_{3}$ & $216 \%$ & $\mathrm{FePO}_{4} \times \mathrm{H}_{2} \mathrm{O}$ & 5738 \\
\hline $\mathbf{F}$ & $137 \%$ & $\mathrm{NaF}$ & 3044 \\
\hline Carbonate & $120^{\ddot{7}}$ & $\mathrm{Na}_{2} \mathrm{CO}_{3}$ & 0806 \\
\hline Notnte & 050 & $\mathrm{NaNO}_{2}$ & 0769 \\
\hline Nitrate & 2019 & $\mathrm{NaNO}_{3}$ & $223 !$ \\
\hline Organic Carbon & 005 & $\mathrm{H}_{2} \mathrm{C}_{2} \mathrm{O}_{4} \cdot 2 \mathrm{H}_{2} \mathrm{O}$ & 0264 \\
\hline- & - & Whater & $279400^{4}$ \\
\hline - & - & - & - \\
\hline TOTAL & $1000 \%$ & TOTAL & $495825^{4}$ \\
\hline
\end{tabular}

'Taryet wieights adjusted for assay information of starting materials

*Unit for volatile components is gi $100 \mathrm{~g}$ of waste oxide

- Empty data field 
Table 2.4. Composition and Properties of Alumimum Limited Waste and HLW-E-Al-27 Glass Formulation at $\mathbf{4 5 \%}$ Waste Loxding Used in Previous Melter Tests (wt \%).

\begin{tabular}{|c|c|c|c|c|}
\hline- & $\begin{array}{c}\text { Al-Limited } \\
\text { Wnste* }\end{array}$ & Waste in Glass & $\begin{array}{c}\text { Glass Forming } \\
\text { Additives }\end{array}$ & $\begin{array}{l}\text { Target Glass } \\
\text { HLW-E.AJ-27 }\end{array}$ \\
\hline $\mathrm{Al}_{2} \mathrm{O}_{3}$ & 5327 & 2397 & - & 2397 \\
\hline $\mathrm{B}_{2} \mathrm{O}_{3}$ & 942 & 919 & $15(\omega)$ & 1519 \\
\hline $\mathrm{BaO}$ & 012 & 005 & - & 005 \\
\hline $\mathrm{B}_{\mathbf{z}} \mathrm{O}_{3}$ & 254 & 114 & - & 114 \\
\hline $\mathrm{CaO}$ & 239 & 108 & 500 & 608 \\
\hline $\mathrm{CdO}$ & 005 & 002 & - & 002 \\
\hline $\mathrm{Cr}_{2} \mathrm{O}_{3}$ & 116 & 052 & & 052 \\
\hline $\mathrm{F}$ & 148 & 067 & - & 067 \\
\hline $\mathrm{Fe}_{2} \mathrm{O}_{3}$ & 1311 & 590 & - & 590 \\
\hline $\mathrm{K}_{2} \mathrm{O}$ & 031 & 014 & - & 014 \\
\hline $\mathrm{Ll}_{2} \mathrm{O}$ & 038 & 017 & 340 & 357 \\
\hline $\mathrm{MgO}$ & 026 & 012 & - & 012 \\
\hline $\mathrm{NB}_{2} \mathrm{O}$ & 796 & 358 & 600 & 958 \\
\hline $\mathrm{N} 1 \mathrm{O}$ & 089 & 040 & - & 040 \\
\hline $\mathrm{P}_{2} \mathrm{O}_{5}$ & 234 & 105 & - & 105 \\
\hline $\mathrm{FbO}$ & 091 & 041 & - & 041 \\
\hline $\mathrm{S}_{1} \mathrm{O}_{2}$ & 1088 & 49) & $25(n)$ & 30) 50 \\
\hline $\mathrm{T}_{1} \mathrm{O}_{2}$ & 002 & 001 & - & 001 \\
\hline $\mathrm{SO}_{3}$ & 944 & 920 & - & 020 \\
\hline $\mathrm{ZnO}$ & 018 & 008 & - & 008 \\
\hline $\mathrm{ZrO}$ & 088 & 039 & - & 039 \\
\hline Sum & 10000 & $4500^{\circ}$ & 5500 & 1000 \\
\hline
\end{tabular}

${ }^{*}$ Rencrmalized from Ref [5] after removal of radinactive components

\begin{tabular}{|c|c|c|c|}
\hline \multicolumn{3}{|c|}{ Viscosty $\& 1150^{\circ} \mathrm{C}, \mathrm{P}$} & 46 \\
\hline \multicolumn{3}{|c|}{ Conductivity $(a) 1150 \mathrm{C}$, Sicm } & 026 \\
\hline \multicolumn{3}{|c|}{ Crystal Content, As Melled } & Trace \\
\hline \multicolumn{3}{|c|}{ Crystal Content, $72 \mathrm{hr}$ at $950^{\circ} \mathrm{C}$} & -10 vol\% \\
\hline \multicolumn{3}{|c|}{ Crystal Content, $\mathrm{CCC}$} & -19 vol\% \\
\hline \multicolumn{3}{|c|}{ TCLP } & Pass \\
\hline \multirow{4}{*}{ PCT, g/L } & - & DIVPF-EA & HLW-E-A]-27 \\
\hline & $\bar{B}$ & 167 & 027 \\
\hline & LI & 96 & 044 \\
\hline & $\mathrm{Na}$ & 133 & 030 \\
\hline
\end{tabular}

- Empty clata tield 
Table 2.5. Compositions of Melter Feed to Produce 100 kg of Target Glass HLW-E-Al-27 (Glass Yield = $500 \mathrm{~g} / \mathrm{L}$ Feed) front dhe Al-Limited Waste Sinulant Using $\mathrm{Al}(\mathrm{OH})_{3}$ as the Aluminum Source.

\begin{tabular}{|c|c|c|c|}
\hline \multicolumn{2}{|c|}{ Al-Limited Waste Simulant } & \multicolumn{2}{|c|}{ Glass-Form ing Additives: } \\
\hline Starting Materials & Target Weight (kg) $)^{*}$ & Starting Materials & Target Wetght (kg) ${ }^{*}$ \\
\hline Alí(OH) & 37047 & - & - \\
\hline $\mathrm{H}_{3} \mathrm{BO}_{3}$ & 0341 & $\mathrm{Na}_{2} \mathrm{~B}_{4} \mathrm{O}_{7} \cdot 10 \mathrm{H}_{2} \mathrm{O}$ & 37292 \\
\hline $\mathrm{BaCO}_{y}$ & 0070 & $\mathrm{H}_{3} \mathrm{BO}_{3}$ & 2729 \\
\hline $\mathrm{Bl}_{2} \mathrm{O}_{3}$ & 1156 & - & - \\
\hline $\mathrm{CaO}$ & 1099 & $\mathrm{CaSIO}_{3}$ (Wollastonite) & 10886 \\
\hline $\mathrm{CdO}$ & 0025 & - & - \\
\hline $\mathrm{Cr}_{2} \mathrm{O}_{3}$ & 0532 & - & - \\
\hline $\mathrm{NaF}$ & 1483 & - & - \\
\hline $\mathrm{Fe}(\mathrm{OH})_{5}(13 \%$ Slurry $)$ & 48539 & - & - \\
\hline $\mathrm{KNO}_{3}$ & 0308 & - & - \\
\hline $\mathrm{L}_{2} \mathrm{CO}_{3}$ & 0432 & $\mathrm{~L}_{2} \mathrm{CO}_{3}$ & 8625 \\
\hline $\mathrm{MgO}$ & 0121 & - & - \\
\hline $\mathrm{NaOH}$ & 2190 & - & - \\
\hline $\mathrm{Nu}(\mathrm{OH})$ & 0514 & - & - \\
\hline $\mathrm{FePO}_{4} \div \mathrm{H}_{2} \mathrm{O}$ & 2795 & - & - \\
\hline $\mathrm{PbO}$ & 0413 & - & - \\
\hline $\mathrm{Na}_{2} \mathrm{SO}_{4}$ & 0358 & - & - \\
\hline $\mathrm{S}_{1} \mathrm{O}_{2}$ & 4945 & $\mathrm{~S}_{1} \mathrm{O}_{2}$ & 20251 \\
\hline $\mathrm{TrO}_{2}$ & 0010 & - & - \\
\hline $\mathrm{ZnO}$ & 0084 & - & - \\
\hline $\mathrm{Zr}(\mathrm{OH})_{4} \times \mathrm{H}_{2} \mathrm{O}$ & 1029 & - & - \\
\hline $\mathrm{H}_{\underline{z}} \mathrm{O}$ & 105479 & - & - \\
\hline $\mathrm{Na}_{2} \mathrm{CO}_{3}$ & 0314 & - & - \\
\hline $\mathrm{NaNO}_{2}$ & 0346 & - & - \\
\hline $\mathrm{NaNO}_{3}$ & 0984 & - & - \\
\hline $\mathrm{H}_{2} \mathrm{C}_{2} \mathrm{O}_{4} 2 \mathrm{H}_{2} \mathrm{O}$ & 0119 & - & - \\
\hline - & - & - & - \\
\hline Simulant Total & 210724 & Additives Total & 79783 \\
\hline- & - & FEED TOTAL & 290507 \\
\hline
\end{tabular}

'Target wenghts adjusted for assay unformation of starting materials

- Empty data field 
Table 3.1. Summary of Glass Formulation and the Assoclated Feed Tests by VGF and Waste Glass Melters (DM100 or DM1200).

\begin{tabular}{|c|c|c|c|c|c|c|}
\hline Glass Name & Feed Name & $\begin{array}{l}\text { Aluminum } \\
\text { Sxurce in } \\
\text { feed }\end{array}$ & $\begin{array}{c}\text { Boron source } \\
\text { un feed }\end{array}$ & VGF Test & DM100 Test & DM1200 Test \\
\hline HLW-E.Al-?7 & BLL-F-135A [2] & $\hat{\mathrm{A}} \mathrm{I}_{2} \mathrm{O}_{3}$ & Borax & Yes & Yes & No \\
\hline $\mathrm{HLW} \cdot \mathrm{E} \cdot \mathrm{A} \mathrm{A} \cdot \mathrm{g} 7$ & BLX-F-50 & $\mathrm{Al}(\mathrm{OH})_{3}$ & Borax & Yes & Yes & No \\
\hline HLW-E.Al-?7 & F-AI-VAR-1 & $\mathrm{Al}_{2} \mathrm{O}_{3}$ & Boric acrd & Yes & $\mathrm{No}$ & No \\
\hline HLW-E.Al-?7 & F-Al-VAR-4 & $\mathrm{Al}(\mathrm{OH})_{3}$ & Borax & Yes & No & No \\
\hline HWL-E.Al-?7 & F-AI-VAR-2 & $\mathrm{Al}(\mathrm{OH})_{3}$ & Bonc acid & Yes: & $\mathrm{No}_{0}$ & $\mathrm{~N}_{0}$ \\
\hline HLLW-E-ANa- 22 & BLN-F-21A [2] & $\mathrm{Al}_{2} \mathrm{O}_{3}$ & Boric Acid & Yes & Yes & No \\
\hline HLW-E-B1-6 & BLK-F-84A[2] & $\mathrm{Al}_{2} \mathrm{O}_{3}$ & Berax & Yes & Yes & No \\
\hline HLW-E-CrM & BLL-F-65A[2] & $\mathrm{Al}_{2} \mathrm{O}_{3}$ & Bone acid & Yes & Yes & $\mathrm{N}_{0}$ \\
\hline Matrlx l-Bl & BLS-F-7A [24] & $\mathrm{Al}_{2} \mathrm{O}_{3}$ & Borax & Yes & Yes & No \\
\hline Mattıx 39 & BLV.F-132B [25] & $\mathrm{Al}_{2} \mathrm{O}_{3}$ & Borax & Yes & Yes & No \\
\hline HWI-Al.l & F-HWI-A1-1B & $\mathrm{Al}_{2} \mathrm{O}_{3}$ & Bonc Acid & Yes & $\mathrm{N}_{0}$ & $\mathrm{~N}_{0}$ \\
\hline HWI-AI.? & . & - & - & - & - & - \\
\hline HWI-AI.3 & $\cdot$ & - & - & - & - & - \\
\hline HLVI-Al.4 & . & $=$ & $\cdot$ & - & - & - \\
\hline HLVI-AI.5 & F.HLVI-AI-5 & $\mathrm{Al}_{2} \mathrm{O}_{3}$ & Bone Acid & Yes & No & No \\
\hline HWVI-Al.6 & . & $\mathrm{Al}_{2} \mathrm{O}_{2}$ & Boric Ackl & - & - & - \\
\hline HW-A1-7 & F-HWI-A1-7 & $\mathrm{Al}_{2} \mathrm{O}_{9}$ & Boric Acid & Y로 & No & $\mathrm{N}_{0}$ \\
\hline HW-A1-8 & $\cdot$ & $=$ & $\cdot$ & - & - & - \\
\hline HW-A1-9 & F-HWI-A1-9 & $\mathrm{Al}_{2} \mathrm{O}_{3}$ & Beric Acid & Yes & No & $N_{0}$ \\
\hline HWI-AI-10 & - & $=$ & - & - & - & - \\
\hline H结-Al-1l & - & - & - & - & - & $\cdot$ \\
\hline HßI-Àl-12 & - & - & - & - & - & - \\
\hline HWi]-A.l-13 & F-HßiI-AI-13 & $\mathrm{Al}_{2} \mathrm{O}_{9}$ & Boric Acld & Yes: & $\mathrm{No}$ & $N_{0}$ \\
\hline HWI-AI-14 & - & - & - & - & $\cdot$ & $\cdot$ \\
\hline HWI-AI-15 & - & - & - & - & - & - \\
\hline HW']-Al-16 & F-HЙ-Al-16 & $\mathrm{Alg}_{3}$ & Boric Acld & Yes & Yes & No \\
\hline Hभil-Al-l6 & F-HWI-AL-16B & $\mathrm{Al}(\mathrm{OH})_{h}$ & Boric Acld & Yes & Yes & No \\
\hline HW]-Al-17 & F-HWI-Al-17 & $\mathrm{Aln}_{\mathrm{n}}$ & Boric Ac1d & Yes & No & No \\
\hline HW]-Ál-18 & F-HИT-Âl-18 & $\mathrm{Aln}_{2}$ & Boric Acid & Yes & No & No \\
\hline Hभi]-Al-19 & F-HWI-AI-19F & $\mathrm{Al}_{2} \mathrm{O}_{3}$ & Boric Acid & Yes & No & No \\
\hline HW]-Al-19 & F-HWT-Al-19B & All $(\mathrm{OH} h$ & Boric Acid & Yes & Yes & Yes \\
\hline HW']-Al-20! & F-HUI-Al-9KSM & $\mathrm{Al}_{2} \mathrm{O}_{3}$ & Borlc Acid & Yes & No & No \\
\hline
\end{tabular}


Table 3.2. Target and XRF Analysis of HWI Glasses Tested (wt\%),

\begin{tabular}{|c|c|c|c|c|c|c|c|c|}
\hline Glass Name & A1-Linı Ited Waste [2] & $\begin{array}{c}\text { HLWi-E-Al-27 } \\
{[2]}\end{array}$ & \multicolumn{2}{|c|}{ HWI-AI-1 } & \multicolumn{2}{|c|}{ HWI-Al-2 } & \multicolumn{2}{|c|}{ HพII-A]-3 } \\
\hline Waste linading \% & 109 & 45 & \multicolumn{2}{|c|}{45} & \multicolumn{2}{|c|}{$4 i$} & \multicolumn{2}{|c|}{425} \\
\hline- & Targel & Target & Taryet & $\mathrm{XRF}$ & Target & XRF & Target & $\mathrm{XRF}$ \\
\hline $\mathrm{Al}_{2} \mathrm{O}_{3}$ & 5327 & 2397 & 2397 & 2216 & 2397 & 2214 & 2264 & 2088 \\
\hline $\mathrm{B}_{2} \mathrm{O}_{3}$ & i) 42 & 1519 & 1819 & 1819 & 1769 & 1769 & 1818 & 1818 \\
\hline $\mathrm{BaO}$ & 012 & 005 & 005 & 006 & 005 & 005 & 005 & 005 \\
\hline $\mathrm{Bi}_{2} \mathrm{O}_{3}$ & 254 & 114 & 114 & 129 & 114 & 121 & 108 & 117 \\
\hline $\mathrm{CaO}$ & 239 & 608 & 108 & 121 & 108 & 113 & $1(12$ & $1(1)$ \\
\hline CdO & 005 & 002 & 002 & - & 002 & - & 002 & - \\
\hline $\mathrm{CH}_{2} \mathrm{O}_{3}$ & 116 & d) $\leqslant 2$ & 052 & 068 & 0.52 & 064 & 49 & 62 \\
\hline $\mathrm{F}$ & 148 & 1) 67 & 067 & NA & 067 & $\mathrm{NA}$ & 63 & NA \\
\hline $\mathrm{Fe}_{2} \mathrm{O}_{3}$ & 1311 & 590 & 590 & 626 & 590 & 585 & 557 & 565 \\
\hline $\mathrm{F}_{2} \mathrm{O}$ & 1) 31 & d) 14 & 014 & a 14 & 014 & 014 & !) 13 & 12 \\
\hline $\mathrm{L}_{12} \mathrm{O}$ & 1) 38 & 357 & 457 & 457 & 217 & 217 & 316 & 316 \\
\hline $\mathrm{MgO}$ & 026 & 012 & 012 & 009 & 012 & 007 & 011 & 007 \\
\hline $\mathrm{Na}_{2} \mathrm{O}$ & 796 & 958 & 958 & 980 & 1258 & 1386 & 1338 & 1419 \\
\hline $\mathrm{N} 1 \mathrm{O}$ & 1) 89 & 1) 40 & 040 & a 42 & 940 & 0.37 & 038 & 1. 39 \\
\hline $\mathrm{P}_{2} \mathrm{O}_{3}$ & 234 & 105 & 105 & 124 & 205 & 234 & 199 & 230 \\
\hline $\mathrm{PbO}$ & 091 & 041 & 041 & 041 & 041 & 037 & 039 & 038 \\
\hline $\mathrm{S}_{1} \mathrm{O}_{2}$ & 1088 & 3050 & 3150 & 3266 & 3040 & 3122 & 3012 & 3099 \\
\hline $\mathrm{TlO}_{2}$ & 002 & 001 & 001 & 003 & 001 & 002 & 001 & 002 \\
\hline $\mathrm{SO}_{3}$ & 0 44 & 020 & 020 & 023 & 020 & 022 & o 19 & 023 \\
\hline $\mathrm{ZnO}$ & 018 & 008 & 008 & 012 & 008 & 010 & 008 & 010 \\
\hline $\mathrm{ZrO}_{2}$ & 088 & 039 & 039 & 038 & 039 & 0.35 & 037 & 036 \\
\hline Sum & 10000 & 10000 & 10000 & 9992 & 10000 & 9994 & 10000 & 9994 \\
\hline
\end{tabular}

- Empty dinta Geld 
Table 3.2. Target and XRF Analysis of HWl Glasses Tested (wt\%) (continued).

\begin{tabular}{|c|c|c|c|c|c|c|c|c|c|c|c|}
\hline Glass Name & \multicolumn{2}{|c|}{ HWI-Al-4 } & \multicolumn{2}{|c|}{ HWi-Al-5 } & \multicolumn{2}{|c|}{ HWI-Al- 6} & \multicolumn{3}{|c|}{ HWI-Al-T } & \multicolumn{2}{|c|}{ HWI-AI-8 } \\
\hline Waste londing $\%$ & 4 & & & & 4 & & & 45 & & 4 & \\
\hline- & Target & $\mathrm{XRF}$ & Target & $\mathrm{XRF}$ & Target & $\mathrm{XRF}$ & Target & $\mathrm{XRF}$ & $\mathrm{DCP}$ & Target & $\mathrm{XRF}$ \\
\hline $\mathrm{Al}_{2} \mathrm{O}_{3}$ & 2397 & 2356 & 2397 & 2333 & 2397 & 2351 & 2397 & 2364 & 2207 & 2397 & 2351 \\
\hline $\mathrm{B}_{2} \mathrm{O}_{3}$ & 1769 & 1769 & 1519 & 1519 & 1519 & 1519 & 1519 & 1519 & 1651 & 1519 & 1519 \\
\hline $\mathrm{BaO}$ & 005 & 005 & 005 & 006 & 005 & ants & 005 & 005 & 006 & 005 & 005 \\
\hline $\mathrm{B}_{2} \mathrm{O}_{3}$ & 114 & 122 & 114 & 122 & 114 & 122 & 114 & 118 & NA & 114 & 115 \\
\hline $\mathrm{CaO}$ & 108 & 111 & 108 & 118 & 108 & 112 & 308 & 324 & 305 & 108 & 111 \\
\hline $\mathrm{CdO}$ & 002 & - & 002 & - & 002 & - & 002 & - & NA & 002 & - \\
\hline $\mathrm{Cr}_{2} \mathrm{O}_{3}$ & 052 & 063 & 052 & 063 & 052 & 064 & 052 & 063 & 046 & 052 & 062 \\
\hline $\mathrm{F}$ & 067 & NA & 067 & $N A$ & 067 & $\mathrm{NA}$ & 067 & NA & NA & 067 & $\mathrm{NA}$ \\
\hline $\mathrm{Fe}_{2} \mathrm{O}_{3}$ & 590 & 585 & 590 & 586 & $\$ 90$ & 584 & 590 & 575 & 582 & $\$ 90$ & 571 \\
\hline $\mathrm{K}_{2} \mathrm{O}$ & 414 & 382 & 014 & 014 & 614 & 594 & 014 & 013 & 017 & 814 & 803 \\
\hline $\mathrm{L}_{12} \mathrm{O}$ & 217 & 217 & 357 & 357 & 257 & 257 & 357 & 357 & 408 & 217 & 217 \\
\hline $\mathrm{MgO}$ & 012 & - & 512 & 463 & 012 & 001 & 312 & 288 & 307 & 012 & 009 \\
\hline $\mathrm{Na}_{2} \mathrm{O}$ & 958 & 995 & 958 & 1042 & 958 & 991 & 958 & 978 & 891 & 908 & 944 \\
\hline $\mathrm{N}_{10} \mathrm{O}$ & 040 & 0.37 & (1) 4(1) & 039 & 040 & 038 & 040 & 0.37 & 038 & 040 & 0.36 \\
\hline $\mathrm{P}_{2} \mathrm{O}_{5}$ & 105 & 123 & 105 & 119 & 105 & 121 & 105 & 119 & 110 & 105 & 124 \\
\hline $\mathrm{PbO}$ & 041 & 037 & $04]$ & 039 & 041 & 038 & 041 & 038 & NA & 041 & 037 \\
\hline $\mathrm{S}_{1} \mathrm{O}_{2}$ & 3040 & 3121 & 3050 & 3097 & 3050 & 3117 & 3050 & 3127 & 3372 & 2940 & 3020 \\
\hline $\mathrm{T}_{1} \mathrm{O}_{2}$ & 001 & 002 & 001 & 002 & 001 & 002 & 001 & 002 & 003 & 001 & 000 \\
\hline $\mathrm{SO}_{3}$ & 020 & 021 & 020 & 026 & 020 & 023 & 020 & 024 & $N A$ & 020 & 023 \\
\hline $\mathrm{ZnO}$ & 008 & 010 & 000 & 010 & 008 & 010 & 008 & 010 & NA & 008 & 010 \\
\hline $\mathrm{ZrO}_{2}$ & 039 & 036 & 039 & 038 & 039 & 037 & 039 & 036 & 049 & 039 & 035 \\
\hline Sum & 10000 & 9992 & 10000 & 9994 & 10000 & 9987 & on & 9997 & 9992 & 10000 & 9994 \\
\hline
\end{tabular}

NA - Not analyzed

- Enpty dita field 
Table 3.2. Target and XRF Analysis of HWI Glasses Tested (wt\%) (continued).

\begin{tabular}{|c|c|c|c|c|c|c|c|c|c|c|c|c|}
\hline Glass Namc & \multicolumn{3}{|c|}{ HWW]-Al-9 } & \multicolumn{3}{|c|}{ H以M-Al-10 } & \multicolumn{2}{|c|}{ HWI-AJ-1 I } & \multicolumn{2}{|c|}{ HW'I-AJ-I2 } & \multicolumn{2}{|c|}{ HW'[-A]-13 } \\
\hline Waste Loadurg \% & \multicolumn{3}{|c|}{40} & \multicolumn{3}{|c|}{40} & \multicolumn{2}{|c|}{$4 \bar{z}$} & \multicolumn{2}{|c|}{45} & \multicolumn{2}{|c|}{45} \\
\hline$=$ & Targal & XRF & DCP & Target & XRF & DC'P & Target & $\mathrm{KRF}$ & Target & XRF & Targel & XRF \\
\hline $\mathrm{Al} \div \mathrm{O}_{3}$ & 2131 & 2076 & 1946 & 2131 & 2062 & 1942 & 2397 & 2330 & 2397 & 2340 & 2397 & 2341 \\
\hline $\mathbf{B}_{2} \mathrm{O}_{3}$ & 1817 & 1817 & 1942 & 1867 & 1867 & 1998 & 1819 & 1819 & 1819 & 1819 & 1519 & 1519 \\
\hline $\mathrm{BaO}$ & 005 & 000 & 005 & 005 & 006 & 005 & 005 & 005 & 005 & 005 & 005 & 000 \\
\hline $\mathrm{Bl}_{2} \mathrm{O}_{3}$ & 102 & 107 & $\mathrm{NA}$ & 102 & 112 & $N_{A}$ & 114 & I 18 & 114 & TI & I 14 & 121 \\
\hline $\mathrm{CaO}$ & $090^{\circ}$ & 100 & 12 | & $0.90^{\circ}$ & 104 & 120 & 308 & 320 & 208 & 214 & 608 & 624 \\
\hline $\mathrm{CdO}$ & 002 & - & $N A$ & 002 & - & NA & 002 & - & 002 & - & 002 & - \\
\hline $\mathrm{Cr}_{2} \mathrm{O}_{3}$ & 046 & $0 \leq 9$ & $0 \leqslant 0$ & 046 & 000 & $0 \leq 0$ & 052 & 063 & 052 & 062 & 052 & 063 \\
\hline $\mathbf{F}$ & 059 & NA & $\mathrm{NA}$ & $0 \leq 9$ & NA & $\mathrm{NA}$ & 0.7 & NA & $00 i$ & $\mathrm{NA}$ & 007 & $\mathrm{NA}$ \\
\hline $\mathrm{Fe}_{2} \mathrm{O}_{3}$ & 524 & 520 & $52 \bar{z}$ & 524 & 539 & $\$ 32$ & 500 & 582 & 590 & 5 il & 590 & 577 \\
\hline $\mathrm{K}_{2} \mathrm{O}^{\mathrm{j}}$ & 013 & 012 & 017 & 013 & 012 & 018 & 014 & 013 & 014 & 014 & 414 & 407 \\
\hline $\mathrm{Ll}_{2} \mathrm{O}$ & 315 & 315 & 355 & 365 & 365 & d 05 & 357 & 35 & 357 & 357 & 357 & 357 \\
\hline $\mathrm{MgO}$ & 010 & 007 & 013 & 010 & 008 & 012 & 012 & 007 & 012 & $0 \mathrm{II}$ & 012 & 010 \\
\hline $\mathrm{Na}_{\mathrm{n}} \mathrm{O}$ & 1318 & 1389 & 1207 & 1318 & 1331 & 1212 & 58 & 988 & 58 & 1018 & 608 & 605 \\
\hline $\mathrm{N}_{1} \mathrm{O}$ & $030^{\circ}$ & 035 & 038 & $030^{\circ}$ & 037 & 038 & 0.10 & 037 & 040 & 036 & 040 & 038 \\
\hline $\mathrm{P}_{2} \mathrm{O}_{\mathrm{z}}$ & $0 \$ 4$ & 106 & 103 & $0 \$ 4$ & 100 & 102 & 105 & 124 & 105 & 122 & 105 & 119 \\
\hline $\mathrm{Pto}$ & 036 & 034 & $\mathrm{NA}$ & 036 & 030 & $\mathrm{NA}$ & 041 & 037 & 041 & 037 & 041 & 038 \\
\hline $\mathrm{S}_{1} \mathrm{O}_{2}$ & 3335 & 3348 & 3631 & 3235 & 3282 & 3539 & 3050 & 319 & 3] 50 & 3201 & 3000 & 3039 \\
\hline $\mathrm{T}_{10} \mathrm{O}_{2}$ & 001 & 002 & 002 & 001 & 002 & 003 & 001 & 002 & 001 & 002 & 001 & 002 \\
\hline $\mathrm{SOO}_{3}$ & 018 & 022 & $N A$ & 018 & 023 & $N A$ & 020 & 024 & 020 & 023 & 020 & 025 \\
\hline 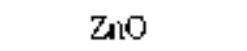 & 007 & 009 & $\mathrm{NA}$ & 007 & 010 & $N_{A}$ & 008 & 010 & 008 & 008 & 008 & 000 \\
\hline $\mathrm{ZvO}_{2}$ & 035 & 034 & 042 & 035 & 035 & 044 & 039 & 035 & 039 & 034 & 034 & 037 \\
\hline Sur & 10000 & 9996 & 9990 & 10000 & 9996 & 10020 & 10000 & 9996 & 10000 & 9993 & 10000 & 9097 \\
\hline
\end{tabular}

NA - Not analyzed

- Enpry dita Eield 
Table 3.2. Target and XRF Analysis of HWI Glasses Tested (wt\%) (continued).

\begin{tabular}{|c|c|c|c|c|c|c|c|c|c|c|c|}
\hline $\begin{array}{l}\text { Glass } \\
\text { Name }\end{array}$ & \multicolumn{2}{|c|}{ HRII-AL-14 } & \multicolumn{2}{|c|}{ HWII-AL-15 } & \multicolumn{2}{|c|}{ HWI-A1-I 6} & \multicolumn{2}{|c|}{ HRI-AII-17 } & \multicolumn{2}{|c|}{ HWI-Al-18 } & HभT-AI-18G \\
\hline $\begin{array}{l}\text { WVaste } \\
\text { Loading }\end{array}$ & \multicolumn{2}{|c|}{45} & \multicolumn{2}{|c|}{45} & \multicolumn{2}{|c|}{436} & \multicolumn{2}{|c|}{436} & \multicolumn{3}{|c|}{424} \\
\hline. & Target & $\mathrm{XRF}$ & Target & XRF & Target & $\mathrm{XRF}$ & Tarret & XRF & Target & XRF & $\mathrm{XRF}$ \\
\hline $\mathrm{Al}_{1} \mathrm{O}_{3}$ & 2397 & 2360 & 2397 & 2349 & 2325 & 2271 & 2325 & 2250 & 2257 & 2189 & 2173 \\
\hline $\mathrm{B}_{2} \mathrm{O}_{3}$ & 1519 & 1519 & 1319 & 1319 & 1773 & 1773 & 1473 & 1473 & 2013 & 2013 & 2013 \\
\hline $\mathrm{BaO}$ & 005 & 007 & 005 & 007 & 005 & 006 & 005 & 005 & 005 & 004 & 006 \\
\hline $\mathrm{Bl}_{2} \mathrm{O}_{3}$ & 114 & 119 & 114 & 117 & 111 & 116 & 111 & 121 & 108 & 113 & 095 \\
\hline $\mathrm{CaO}$ & 508 & 521 & 508 & 516 & 589 & 605 & 589 & 606 & 572 & 594 & 576 \\
\hline $\mathrm{CdO}$ & 002 & - & 002 & - & 002 & - & 002 & - & 002 & - & NA \\
\hline $\mathrm{Cr}_{1} \mathrm{O}_{3}$ & 052 & 964 & 652 & 064 & 051 & 062 & 051 & 064 & 049 & i) 61 & 0.54 \\
\hline $\mathbf{F}$ & 067 & NA & 067 & NA & 065 & NA & 065 & NA & 063 & $\mathrm{NA}$ & NA \\
\hline $\mathrm{Fe}_{2} \mathrm{O}_{3}$ & 590 & 572 & 590 & 572 & 572 & 559 & 572 & 580 & 556 & 558 & 569 \\
\hline $\mathrm{K}_{1} \mathrm{O}$ & 514 & 496 & 514 & $5 i k$ & 014 & 013 & 314 & 307 & 013 & 1) 16 & 016 \\
\hline $\mathrm{L}_{2}, \mathrm{O}$ & 357 & 357 & 317 & 317 & 346 & 346 & 346 & 346 & 336 & 336 & 336 \\
\hline $\mathrm{MgO}$ & 012 & 910 & 012 & - & 011 & 010 & 011 & 007 & 011 & 1) 08 & 0.31 \\
\hline $\mathrm{N}{ }_{2} \mathrm{O}$ & 608 & 614 & 858 & 897 & 929 & 968 & 929 & 1005 & 902 & 960 & 928 \\
\hline $\mathrm{NiO}$ & 040 & 038 & 040 & 037 & 039 & 037 & 039 & 039 & 038 & 037 & 036 \\
\hline $\mathrm{P}_{2} \mathrm{O}_{5}$ & 105 & 124 & 105 & 120 & 102 & 116 & 102 & 113 & 099 & 111 & 111 \\
\hline $\mathrm{PbO}$ & 041 & 037 & 0.41 & 037 & 040 & 0.36 & 040 & 039 & 930 & i) 35 & 035 \\
\hline $\mathrm{S}_{1} \mathrm{O}_{2}$ & 3000 & 3086 & 2990 & 3058 & 2958 & 3009 & 2958 & 2967 & 2872 & 2891 & 2933 \\
\hline $\mathrm{T}_{1} \mathrm{O}_{2}$ & 001 & 0.14 & 001 & 012 & 001 & 002 & 001 & 002 & 001 & 1) 12 & 004 \\
\hline $\mathrm{SO}_{3}$ & 020 & 022 & 029 & 025 & 019 & 023 & 019 & 023 & 019 & 1) 23 & $021 !$ \\
\hline $\mathrm{ZnO}$ & 008 & 010 & 008 & 010 & 008 & 010 & 008 & 010 & 008 & 011 & 008 \\
\hline $\mathrm{ZrO}_{1}$ & 039 & 036 & 039 & 038 & 038 & 035 & 038 & 038 & 037 & 033 & 048 \\
\hline Sum & 10000 & 9996 & 10000 & 9991 & 10000 & 9997 & 10000 & 9996 & $\log 00$ & 9994 & 9991 \\
\hline
\end{tabular}

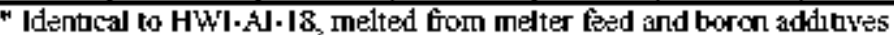

NA - Not analyzed

- Empty data Gield 
Table 3.2. Target and XRF Analysis of HWl Glasses Tested (wt\%) (continued).

\begin{tabular}{|c|c|c|c|c|c|}
\hline Glass Name & \multicolumn{2}{|c|}{ HWI-AI-19 } & \multicolumn{3}{|c|}{$\mathrm{HWI}-\mathrm{Al}-20$} \\
\hline Waste Load17y \% & & & & 45 & \\
\hline- & Target & $\mathrm{XRF}$ & Target & $\mathrm{XRF}$ & DCP \\
\hline $\mathrm{Al}_{2} \mathrm{O}_{3}$ & 2397 & 2294 & 2397 & 2330 & 2200 \\
\hline $\mathrm{B}_{2} \mathrm{O}_{3}$ & 1919 & 1919 & 1819 & 1819 & 1885 \\
\hline $\mathrm{BaO}$ & 005 & 006 & 005 & 007 & 007 \\
\hline $\mathrm{B}_{1} \mathrm{O}_{3}$ & 114 & 134 & 114 & 120 & 130 \\
\hline $\mathrm{CaO}$ & 558 & 606 & 108 & 116 & 128 \\
\hline $\mathrm{do}$ & 90 & - & 002 & - & $\mathrm{NA}_{\mathrm{A}}$ \\
\hline $\mathrm{Cr}_{2} \mathrm{O}_{3}$ & 052 & 069 & 052 & 064 & 050 \\
\hline F & 067 & NA & 067 & NA & $\mathrm{NA}$ \\
\hline $\mathrm{Fe}_{\mathrm{e}_{2} \mathrm{O}_{7}}$ & 590 & 6.32 & 590 & 582 & $\$ 79$ \\
\hline $\mathrm{K}_{2} \mathrm{O}$ & 014 & 016 & 514 & 526 & 461 \\
\hline $\mathrm{L}_{2} \mathrm{O}$ & 357 & 357 & 317 & 317 & 338 \\
\hline $\mathrm{MgO}$ & 012 & $\theta(n)$ & 012 & - & 044 \\
\hline $\mathrm{Na}_{2} \mathrm{O}$ & 958 & 954 & 858 & 948 & 821 \\
\hline $\mathrm{N}_{1} \mathrm{O}$ & a dig & 642 & $04 i$ & 038 & 039 \\
\hline $\mathrm{P}_{2} \mathrm{O}_{5}$ & 105 & 122 & 105 & 121 & 109 \\
\hline PbO & 041 & 043 & 041 & 039 & NA \\
\hline $\mathrm{S}_{1} \mathrm{O}_{2}$ & 2700 & 2710 & 2890 & 2894 & 3116 \\
\hline $\mathrm{T}_{1} \mathrm{O}_{2}$ & 001 & 003 & 001 & 001 & 005 \\
\hline $\mathrm{SO}_{3}$ & 020 & 023 & 020 & 022 & $\mathrm{NA}$ \\
\hline $\mathrm{ZnO}$ & 008 & 012 & 008 & 010 & 008 \\
\hline $\mathrm{ZrO}_{2}$ & 039 & 042 & 039 & 038 & 053 \\
\hline Sum & 10000 & 9992 & 10000 & 9991 & 9993 \\
\hline
\end{tabular}

- Emply dita Geld 


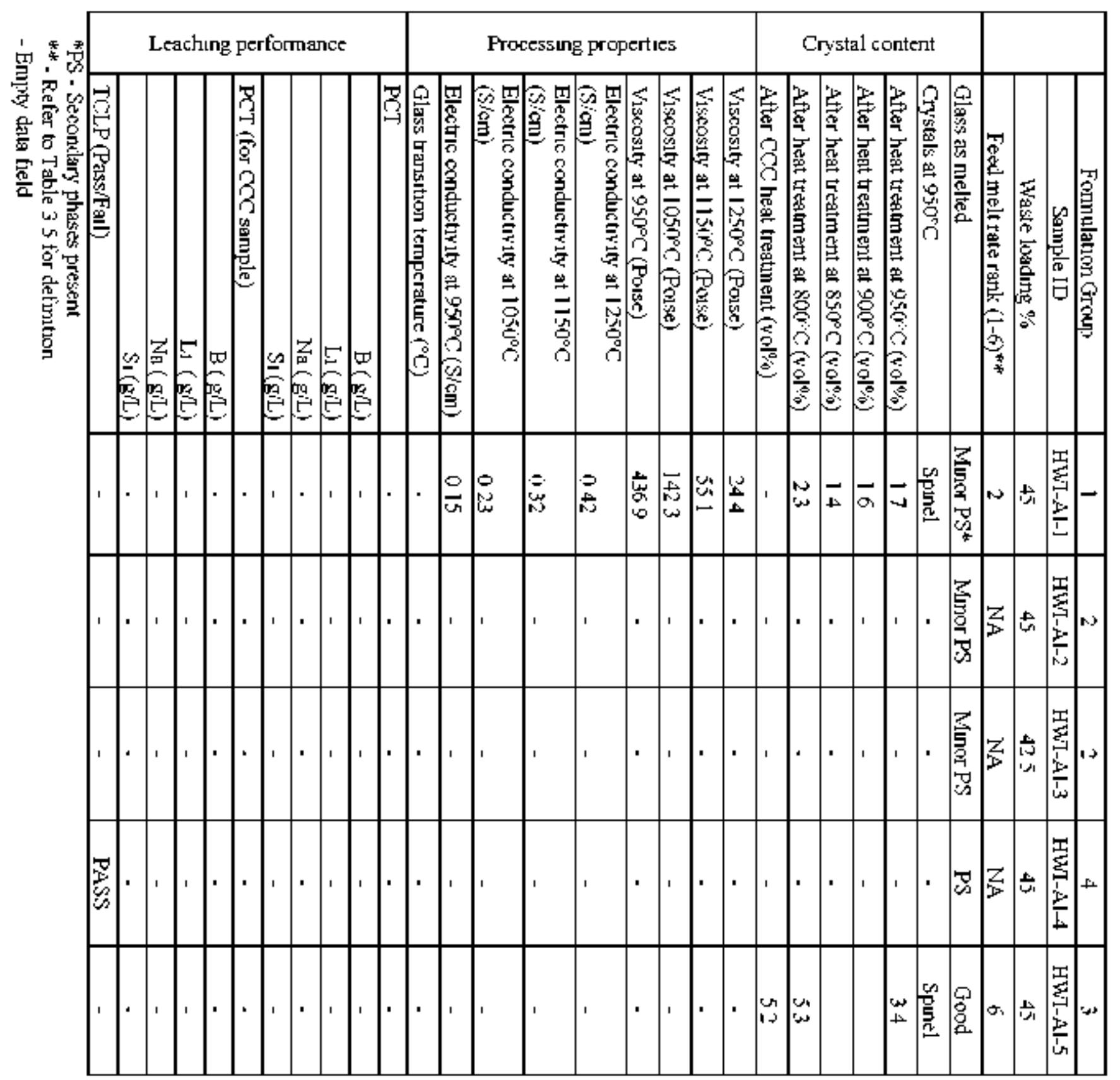


Table 3.3. Characterization of HWI Glasses (continued).

\begin{tabular}{|c|c|c|c|c|c|c|c|}
\hline & Formulation Group & 4 & 3 & 4 & 1 & 1 & 5 \\
\hline & Sample ID & HIVI-Al-6 & HWVI-Al-7 & HนT-A1-8 & HWI-Al-9 & HWI-AI-10 & HWI-A1-II \\
\hline & Wiaste londing $\%$ & 45 & 45 & 45 & 40 & 40 & 45 \\
\hline & Feed melt rate rank $(1-6)^{* * *}$ & NA & 5 & NA & $\underline{2}$ & NA & NA \\
\hline \multirow{7}{*}{ 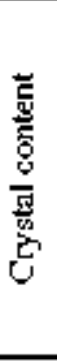 } & Glass as meltad & Munur PS & Good & PS & Good & Good & PS \\
\hline & Crystals at $950^{\circ} \mathrm{C}$ & - & Spunel & . & Spinel & Spinel & - \\
\hline & After heat treatment at $950^{\circ} \mathrm{C}($ vol $\%)$ & - & 27 & - & 07 & 04 & - \\
\hline & After heat treatment at $900^{\circ} \mathrm{C}($ vol $\%)$ & - & 28 & - & 08 & 08 & - \\
\hline & After heat treatment at $850^{\circ} \mathrm{C}\left(\mathrm{vol}^{\circ} \%\right)$ & - & 32 & . & 09 & 09 & - \\
\hline & After heat treatment at $800^{\circ} \mathrm{C}\left(\right.$ vol $\left.^{\circ} \%\right)$ & - & 39 & - & 11 & 08 & - \\
\hline & After CCC heat treatment $(\psi \mathrm{O} / \%)$ & - & 37 & - & 07 & 13 & - \\
\hline \multirow{9}{*}{ 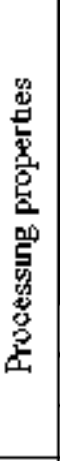 } & Y'Iscosity at 125 irde(Polse) & - & 229 & . & 297 & - & 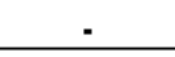 \\
\hline & $V_{\text {Iscosity at }} 1150^{\circ} \mathrm{C}$ (Poise) & - & 606 & - & 632 & - & - \\
\hline & Viscosity at 105 ive (Poise) & - & 1925 & - & 1630 & - & - \\
\hline & Yiscosity at $950^{\circ} \mathrm{C}$ (PoIse) & - & 7775 & . & 5559 & - & - \\
\hline & Electric conductarty at $1250^{\circ} \mathrm{C}$ (Sicm) & - & 035 & . & 044 & - & - \\
\hline & Electric conducturty al 11 sioc $(\mathrm{S} / \mathrm{cm}$ ) & - & 025 & - & 033 & - & - \\
\hline & Electric conduct 1 ty at $11950^{\circ} \mathrm{C}(5 \mathrm{~cm})$ & - & 017 & - & $0 \unlhd 3$ & - & 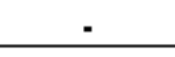 \\
\hline & Electric conduchvity at $950^{\circ} \mathrm{C}(5 \mathrm{~cm})$ & - & 011 & - & 014 & - & - \\
\hline & Glass tratisition temperature $\left.{ }^{\circ} \mathrm{C}\right)(\mathrm{S} / \mathrm{cm})$ & $\cdot$ & $\cdot$ & - & - & - & - \\
\hline \multirow{11}{*}{ 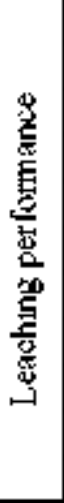 } & PCT & - & - & - & - & - & - \\
\hline & $\mathrm{B}(\mathrm{g} / \mathrm{L})$ & - & 0267 & - & 1435 & - & - \\
\hline & $\mathrm{L}_{1}(\mathrm{~g} / \mathrm{L})$ & $\dot{-}$ & 0467 & - & 1150 & - & - \\
\hline & $\operatorname{Na}(\mathrm{g} / \mathrm{L})$ & - & $(1305$ & - & 0777 & - & - \\
\hline & $\mathrm{S}(\mathrm{g} / \mathrm{L})$ & - & 0201 & - & 0311 & - & - \\
\hline & PCT (for (CCC semple) & - & - & - & & $\dot{-}$ & $\dot{-}$ \\
\hline & $\mathrm{B}(\mathrm{g} \mathrm{L})$ & - & - & - & 3501 & - & - \\
\hline & $L_{1}(g / L)$ & - & - & - & 2552 & - & - \\
\hline & $\mathrm{Na}(\mathrm{g} / \mathrm{L})$ & - & - & - & 1383 & - & - \\
\hline & $S(\mathrm{~g} / \mathrm{L})$ & - & - & - & 0216 & - & 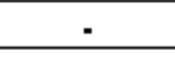 \\
\hline & TCLP,Pass/Fall) & - & PASS & - & - & - & - \\
\hline
\end{tabular}

"PS - Secondary phases present

*** - Refer to Table 35 for definition

- Empty lata field 
Table 3.3. Characterization of HWI Glasses (continued).

\begin{tabular}{|c|c|c|c|c|c|c|}
\hline & Formulation Group & 5 & 4 & 4 & 4 & 5 \\
\hline & Sample ID & HWI-Al-12 & HLVI-Al-13 & HWI-AL-14 & HWI-AL-15 & HWI-AI-16 \\
\hline & Wiaste loading $\%$ & 45 & 45 & 45 & 45 & 436 \\
\hline & Feed melt rate rank $(1-6)^{* *+1}$ & NA & 4 & NA & $\mathrm{NA}$ & 3 \\
\hline \multirow{7}{*}{ 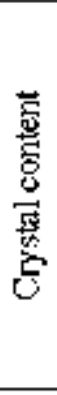 } & Glass as melted & $\mathrm{PS}$ & Munor PS & Munor PS & PS & Good \\
\hline & Crystals at $950^{\circ} \mathrm{C}$ & - & $\begin{array}{l}\text { Spunel + minor } \\
\text { Apatitite }\end{array}$ & - & - & Spunel+Angute \\
\hline & After heat treatment at 950$)^{\circ} \mathrm{C}(y 0 l \%)$ & - & 25 & - & - & 16 \\
\hline & After heat treatruent at $900^{\circ} \mathrm{C}\left(\left.4 \mathrm{O}\right|^{\circ} \%\right)$ & - & 3 & - & - & 22 \\
\hline & After heat treatment at $850^{\circ} \mathrm{C}\left(4 \mathrm{ol}^{\circ} \%\right)$ & - & 34 & - & - & 28 \\
\hline & After heat treatment at $8(\mathrm{~m}))^{\circ} \mathrm{C}(4 \mathrm{ol} \%)$ & - & 44 & . & - & 34 \\
\hline & After $\mathrm{COC}$. heat treatment ( $\mathrm{rol} \%$ ) & - & 26 & - & - & 19 \\
\hline \multirow{9}{*}{ 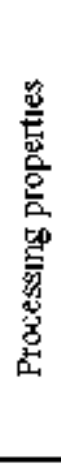 } & Viscosty at $1250^{\circ} \mathrm{C}$ (Po1se) & - & - & - & - & 189 \\
\hline & $V_{15} \cos 1$ ty at $1150 \mathrm{C}$ (P01se) & - & - & - & - & 431 \\
\hline & Viscosity at $105 \pi^{\circ} \mathrm{C}$ (Polse) & - & - & - & - & 1191 \\
\hline & $V_{1 s c o s i t y}$ at $950^{\circ} \mathrm{C}$ (Poise) & - & - & - & - & 4322 \\
\hline & Electric conductirity at $1250^{\circ} \mathrm{C}(\mathrm{S} / \mathrm{cm})$ & - & - & - & - & 035 \\
\hline & Electnc conducturity at I $150^{\circ} \mathrm{C}(\mathrm{S} / \mathrm{cm})$ & - & - & - & - & 024 \\
\hline & Electnc conductivity at $1050^{\circ} \mathrm{C}(\mathrm{S} / \mathrm{cm})$ & $\cdot$ & - & - & - & 016 \\
\hline & Electric conductivity at $950^{\circ} \mathrm{C}$ (Sicm) & - & - & - & - & 009 \\
\hline & Glass transition temuerature $\left({ }^{\circ} \mathrm{C}\right)$ & - & - & - & - & 475 \\
\hline \multirow{11}{*}{ 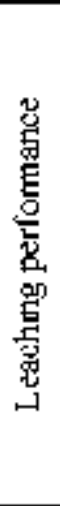 } & PCT & - & - & - & - & - \\
\hline & $\mathrm{B}(\mathrm{g} / \mathrm{L})$ & - & - & - & - & 0314 \\
\hline & $L_{1}(g / L)$ & - & - & - & - & 1) 394 \\
\hline & $\mathrm{Na}(\mathrm{g} / \mathrm{L})$ & - & - & - & - & 1) 285 \\
\hline & $S_{1}(0 / L)$ & - & - & - & - & 0134 \\
\hline & PCT (for CCC sample) & - & - & $\cdot$ & - & . \\
\hline & $\mathrm{B}(\mathrm{g} / \mathrm{L})$ & - & 0200 & - & - & 0263 \\
\hline & $\mathrm{L}_{1}(\mathrm{~N} / \mathrm{L})$ & - & 0177 & - & - & 0329 \\
\hline & $\mathrm{Na}(\mathrm{g} / \mathrm{L})$ & - & 0215 & $\dot{-}$ & - & 0237 \\
\hline & $\mathrm{S}_{1}(\mathrm{~g} / \mathrm{L})$ & - & 0120 & - & - & 1) 132 \\
\hline & TCLP (Pass:Fa1l) & - & - & - & - & PASS \\
\hline
\end{tabular}

"FS - Secondary thases present

*** - Refer to Table 35 for detimition

- Enupty data field 
Table 3.3. Claracterization of HWI Glasses (continued).

\begin{tabular}{|c|c|c|c|c|c|c|}
\hline & Formulation Group & 4 & 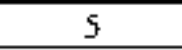 & 5 & 5 & 4 \\
\hline & Sample ID & HLI-AI-17 & HWI-Al-18 & HWI-Al-18G & HWI-Al-19 & HLVI-Al.20 \\
\hline & Waste loading \% & 436 & 424 & 424 & 45 & 45 \\
\hline & Fecd melt rate rank $(1-6)^{* * *}$ & 4 & NA & 2 & 3 & 2 \\
\hline \multirow{7}{*}{ 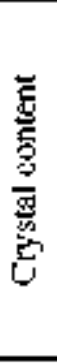 } & Glass as melted & Munor PS & Gow & Gowd & Good & $\mathrm{PS}$ \\
\hline & Crystals at $950^{\circ} \mathrm{C}$ & Sprnel + munor Aplpatıte & - & Spinel & Spunel & Spinel \\
\hline & After heat treatment at $950^{\circ} \mathrm{C}$ ( & 11 & - & $1]$ & 13 & 16 \\
\hline & After heat treatment at $900^{\circ} \mathrm{C}(40 \mathrm{ol} \%)$ & 19 & 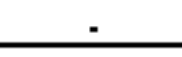 & 24 & 21 & 19 \\
\hline & After heat treatrnent at 85$)^{\circ} \mathrm{C}\left(\mathrm{yol}^{0} ; 0\right)$ & 28 & - & 28 & 3 & 21 \\
\hline & After heat treatment at $800^{\circ} \mathrm{C}$ ( yol $^{\circ} \%$ ) & 33 & - & 36 & 37 & 24 \\
\hline & After $\mathrm{CCC}$ heat treatment (vol $\%$ ) & 13 & - & 18 & 19 & 33 \\
\hline \multirow{9}{*}{ 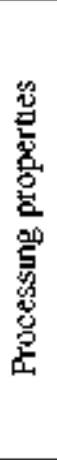 } & Yiscosity at I $250 \mathrm{CO}$ (Polse) & - & - & 194 & 149 & 344 \\
\hline & $V_{1 s c o s i t y}$ at $1150^{\circ} \mathrm{C}$ (Poise) & - & - & 438 & 333 & 783 \\
\hline & Viscosity at $1050 \mathrm{C}$ (Poise) & - & - & 1230 & 908 & 2150 \\
\hline & $Y_{1 s c o s i t y}$ at 95 ive(Polse) & - & - & 4776 & 3271 & 7653 \\
\hline & Electric conductivity at $1250^{\circ} \mathrm{C}(\mathrm{S} / \mathrm{cm})$ & - & - & 029 & 038 & 033 \\
\hline & Electric concluctır ity at $1150^{\circ} \mathrm{C}(\mathrm{Sicm})$ & - & - & 021 & 027 & 023 \\
\hline & Electric comductir ty at $1050^{\circ} \mathrm{C}(\mathrm{Sicm})$ & - & - & 1) 15 & 017 & 015 \\
\hline & Electric conducturity at $950^{\circ} \mathrm{C}(\mathrm{S} / \mathrm{cm})$ & - & - & 009 & 009 & 009 \\
\hline & Glass transition temperature $\left({ }^{\circ} \mathrm{C}\right)$ & - & - & - & 461 & - \\
\hline \multirow{11}{*}{ 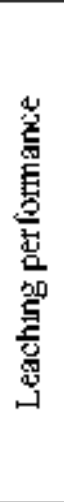 } & PC.T & - & - & - & - & - \\
\hline & $\mathrm{B}(\mathrm{g} / \mathrm{L})$ & - & - & 0377 & 0654 & 2109 \\
\hline & $\mathrm{L} 1(\mathrm{~g} / \mathrm{L})$ & - & - & $041) 0$ & 0794 & 158 \\
\hline & $\operatorname{Na}(g / L)$ & - & - & 0322 & 0624 & $13 \sin 6$ \\
\hline & $S ı(g / L)$ & - & - & 0163 & 0203 & 0.254 \\
\hline & PCT (for COC sample) & - & - & - & - & - \\
\hline & $B(g / L)$ & 0856 & - & 0342 & 0.574 & - \\
\hline & LI $(g / L)$ & 0534 & - & 0402 & 0656 & $\cdot$ \\
\hline & $\mathrm{Na}(\mathrm{a} / \mathrm{L})$ & 0382 & - & 0300 & 0536 & - \\
\hline & $S 1(\mathrm{~g} / \mathrm{L})$ & 1) 664 & - & 0179 & 0232 & - \\
\hline & TCLP (Pass:Fally & & - & PASS & PASS & PASS \\
\hline
\end{tabular}

"PS - Secondary phases present

*** - Refer to Table 35 for definition

- Empty lata field 
Table 3.4a. XRF Analysis (wt $\%$ ) of Four Melter Feeds Fused at $1150^{\circ} \mathrm{C}$ and After VGF Experiments.

\begin{tabular}{|c|c|c|c|c|c|c|c|c|c|c|c|c|}
\hline & \multicolumn{3}{|c|}{ HLW-E-AL-27 } & \multicolumn{3}{|c|}{ HLWW-E-ANQ-22 } & \multicolumn{3}{|c|}{ HLW'-E-B1-6 } & \multicolumn{3}{|c|}{ HLW-E-CrM } \\
\hline & Target & VGFidismmi & Fused il I $\left.50^{\circ} \mathrm{C}\right)$ & Ta1get & Vigf iljmu & Fused (11.50 $\mathrm{C})$ & Target & VGF i4s ming & Fused $\left(1150^{\circ} \mathrm{C}\right)$ & Target & $\mathrm{VGF}\left(s_{\mathrm{m}} \mathrm{mnn}\right)$ & Fused $\left(1150^{\circ} \mathrm{C}\right)$ \\
\hline $\mathrm{Al}_{2} \mathrm{O}_{3}$ & 2397 & 2220 & 2240 & 2134 & 2104 & $20 \div 6$ & 1166 & 1] 04 & 1091 & 808 & 870 & 87 \\
\hline $\mathrm{B}_{2} \mathrm{O}_{3}{ }^{*}$ & 1519 & 1519 & 1519 & 1837 & 1837 & 1837 & 1130 & $1] 30$ & 1130 & 1617 & 1617 & 1617 \\
\hline $\mathrm{BaO}$ & 005 & 036 & 035 & 003 & 004 & 005 & 001 & 002 & 002 & 001 & 002 & 002 \\
\hline $\mathrm{B}_{1} \mathrm{O}_{3}$ & 114 & 116 & 124 & 116 & 122 & 122 & 67 & 645 & 603 & 250 & 263 & 269 \\
\hline $\mathrm{CaO}$ & 0.08 & 583 & 603 & $0 \pi 2$ & 104 & $0 \stackrel{09}{0}$ & 084 & 088 & 088 & 087 & 080 & 088 \\
\hline $\mathrm{C} \mathrm{I}_{2} \mathrm{O}_{3}$ & 052 & 053 & $0 \leq 7$ & 0 וד & 083 & 086 & $0 \leqslant 2$ & 054 & 064 & 108 & 113 & 125 \\
\hline $\mathrm{F}_{\mathrm{C}_{2} \mathrm{O}} \mathrm{O}_{3}$ & 590 & 587 & 627 & 282 & 304 & 300 & 606 & 719 & 741 & 462 & 459 & 475 \\
\hline $\mathrm{K}=0$ & 014 & 034 & 033 & 006 & 009 & 069 & 046 & 0.53 & 053 & 605 & 524 & 568 \\
\hline $\operatorname{Ll} 0^{*}$ & 357 & 357 & 357 & 358 & 3.58 & 358 & 010 & 018 & 010 & 308 & 368 & 308 \\
\hline $\mathrm{MgO}$ & 012 & 030 & 042 & 022 & 025 & 023 & 043 & 052 & 043 & 000 & 021 & 022 \\
\hline $\mathrm{Na}, \mathrm{O}$ & 958 & 996 & 918 & 1271 & 1185 & 1216 & 1574 & 1528 & 1590 & 707 & 724 & 754 \\
\hline $\mathrm{N}_{1} \mathrm{O}$ & 040 & 035 & 039 & 010 & 012 & 012 & 193 & 172 & 187 & 037 & 047 & 039 \\
\hline $\mathrm{P}_{2} \mathrm{O}_{2}$ & 105 & 122 & 118 & 202 & 224 & 212 & 400 & 556 & 530 & 118 & 133 & 138 \\
\hline $\mathrm{PtO}$ & $0 \mathrm{al}$ & 0.35 & 037 & 000 & 010 & 010 & 025 & 029 & 030 & 017 & 015 & 015 \\
\hline $\mathrm{SO}_{3}$ & 020 & $020^{\circ}$ & 020 & 022 & 025 & 022 & 048 & 009 & 052 & 053 & 050 & 044 \\
\hline $\mathrm{S}_{1} \mathrm{O}_{2}$ & 3050 & 3175 & 3165 & 34.66 & 3473 & 3500 & 3626 & 30.04 & 3609 & 4576 & 4000 & 4582 \\
\hline $\mathbf{T}_{1} \mathrm{O}_{2}$ & 0.01 & 004 & 003 & 017 & 018 & 018 & 016 & 019 & 019 & 000 & 003 & 000 \\
\hline $\mathrm{ZnO}$ & 008 & 008 & 009 & 018 & 018 & 017 & 0 ló & 019 & 019 & 009 & 010 & 010 \\
\hline $\mathrm{ZrO}_{2}$ & 030 & 046 & 049 & 012 & 018 & 018 & 021 & 034 & 040 & 004 & 007 & 000 \\
\hline
\end{tabular}

" Target values 
Table 3.4b. XRF Analysis (wt\%) of Group 1 Formulation Feeds Fused at 1150 C and After VGF Experiments.

\begin{tabular}{|c|c|c|c|c|}
\hline Glass Name & \multicolumn{2}{|c|}{ HWI-A]-1 } & \multicolumn{2}{|c|}{ HWIT-Al-9 } \\
\hline Fedil Name & $\begin{array}{c}\text { F.HWVI-AL-1B- } \\
\text { 30M }\end{array}$ & $\begin{array}{c}\text { F-HWL-AL-1B. } \\
\text { DHG }\end{array}$ & $\begin{array}{c}\text { F-HWVI-AL-9. } \\
\text { 30M }\end{array}$ & $\begin{array}{c}\text { F.HWI-AL-9- } \\
\text { DHG }\end{array}$ \\
\hline Semple Condition & VGF (30 munutes) & Fused at $1150^{\circ} \mathrm{C}$ & $\begin{array}{l}\text { VGF (30) } \\
\text { minutes) }\end{array}$ & Fused at $1150^{\circ} \mathrm{C}$ \\
\hline $\mathrm{Al}_{2} \mathrm{O}_{\mathrm{y}}$ & 2268 & 2308 & 2079 & 20,32 \\
\hline $\mathrm{B}_{2} \mathrm{O}_{3}{ }^{*}$ & 1819 & 1819 & 1817 & 1817 \\
\hline $\mathrm{BaO}$ & 007 & d) 05 & 005 & 006 \\
\hline $\mathrm{Bt}_{2} \mathrm{O}_{3}$ & 123 & 105 & 110 & 112 \\
\hline $\mathrm{CaO}$ & 112 & 099 & 110 & 103 \\
\hline $\mathrm{Cr}_{2} \mathrm{O}_{3}$ & 063 & 060 & 058 & 059 \\
\hline $\mathrm{Fe}_{2} \mathrm{O}_{3}$ & 590 & 556 & 525 & 544 \\
\hline $\mathrm{K}_{\mathrm{l}} \mathrm{O}$ & 017 & 015 & 014 & 014 \\
\hline $\mathrm{L}_{\mathrm{I}_{2}} \mathrm{O}^{\mathrm{*}}$ & 457 & 457 & 315 & 315 \\
\hline $\mathrm{MgO}$ & 017 & 1) 34 & 016 & 029 \\
\hline $\mathrm{Na}_{2} \mathrm{O}$ & 958 & 1038 & 1280 & 1358 \\
\hline $\mathrm{NiO}$ & 038 & 036 & 035 & 040 \\
\hline $\mathrm{P}_{2} \mathrm{O}_{5}$ & 116 & 107 & 103 & 101 \\
\hline $\mathrm{PbO}$ & 038 & 029 & 035 & 037 \\
\hline $\mathrm{SO}_{3}$ & 026 & 029 & 024 & 025 \\
\hline $\mathrm{S}_{10} \mathrm{O}_{2}$ & 3287 & 3242 & 3414 & 3344 \\
\hline $\mathrm{T} \mathrm{oO}_{2}$ & 004 & 005 & 005 & 007 \\
\hline $\mathrm{ZnO}$ & $(10$ & 1) 1.6 & 909 & angs \\
\hline $\mathrm{ZrO}_{2}$ & 043 & 042 & 040 & 045 \\
\hline
\end{tabular}

"Target values 
Table 3.4c. XRF Analysis (wt\%) of Group 3 Formulation Feeds Fused at $1150^{\circ} \mathrm{C}$ and After VGF Experiments.

\begin{tabular}{|c|c|c|c|c|}
\hline Glass Name & \multicolumn{2}{|c|}{ HWVI-AI-5 } & \multicolumn{2}{|c|}{ HWI-AI-7 } \\
\hline Fced Name & F-HWI-AL-5-30MI & F-HWI-AL-5-DHG & F-HWI-AL-7-30M & $\begin{array}{c}\text { F-HWII-AL-?- } \\
\text { DHG }\end{array}$ \\
\hline Sample Condition & $\mathrm{VGF}$ (30 minutes) & Fused at $1150^{\circ} \mathrm{C}$ & VGF (30 mustes) & Fused at $1130^{\circ} \mathrm{C}$ \\
\hline $\mathrm{Al}_{2} \mathrm{O}_{3}$ & 2169 & 2313 & 2301 & 2301 \\
\hline $\mathrm{B}_{2} \mathrm{O}_{3}{ }^{\circ}$ & 1519 & 1519 & 1519 & 1519 \\
\hline $\mathrm{BaO}$ & 006 & 005 & ans & 005 \\
\hline $\mathrm{B}_{2} \mathrm{O}_{3}$ & 115 & 125 & 116 & 116 \\
\hline $\mathrm{CAO}$ & 116 & 117 & 316 & 316 \\
\hline $\mathrm{Cr}_{2} \mathrm{O}_{\mathrm{z}}$ & 063 & 064 & 064 & 064 \\
\hline $\mathrm{Fe}_{2}\left(\mathrm{CO}_{3}\right.$ & $\$ 71$ & 602 & 557 & 557 \\
\hline $\mathrm{K}_{2} 0$ & i) 17 & 016 & 017 & 017 \\
\hline $\mathrm{Ll}_{2} \mathrm{O}^{*}$ & 357 & 357 & 357 & 3.57 \\
\hline $\mathrm{MgO}$ & 468 & 463 & 280 & 280 \\
\hline $\mathrm{Na}_{2}(\mathrm{O}$ & 1106 & 959 & 1012 & 1012 \\
\hline $\mathrm{N} 1 \mathrm{O}$ & 039 & 049 & 938 & 0.38 \\
\hline $\mathrm{P}_{2} \mathrm{O}_{5}$ & 116 & 113 & 113 & 113 \\
\hline$P(x)$ & 1) 37 & 033 & 087 & 087 \\
\hline $\mathrm{SO}_{3}$ & 034 & 029 & 034 & 034 \\
\hline $\mathrm{SlO}_{2}$ & 3297 & 3174 & 3115 & 3115 \\
\hline $\mathrm{TlO}_{2}$ & 005 & 005 & 006 & 006 \\
\hline $\mathrm{ZnO}$ & 008 & 908 & 008 & oiv \\
\hline $\mathrm{ZrO}_{2}$ & 049 & 050 & 045 & 045 \\
\hline
\end{tabular}

"Target valuess 
Table 3.4d. XRF Analysis (wt\%) of Group 4 Formulation Feeds Fused at 1150 C and After VGF Experiments.

\begin{tabular}{|c|c|c|c|c|c|c|}
\hline Glass Name & \multicolumn{2}{|c|}{ HWI-A1-13 } & \multicolumn{2}{|c|}{ H1VI-A1-17 } & \multicolumn{2}{|c|}{ H1VI-AI-30 } \\
\hline Fecil Name & F-HWI-AL-I 3-30M & F-HҢҢT-AL-13-DHG & F-HWI-AL-17-30M & F-HWI-AL-I7-DHG & F-HLVI-AL-9KSMA-30M & F-H认iI-AL-gKSM-DHG \\
\hline $\begin{array}{c}\text { Sample } \\
\text { Condition } \\
\end{array}$ & VGF (30 minutes) & Fused at $1150^{\circ} \mathrm{C}$. & VGF (30 minutes) & Fused at $1150^{\circ} \mathrm{C}$. & VGF (30 minutes) & Fused at $1150^{\circ} \mathrm{C}$ \\
\hline $\mathrm{Al}_{2} \mathrm{O}_{3}$ & 2296 & 2290 & 2166 & 2224 & 2311 & 2323 \\
\hline $\mathrm{B}_{2} \mathrm{O}_{3}{ }^{\circ}$ & 1519 & 1519 & 1473 & 1473 & 1819 & 1819 \\
\hline $\mathrm{BaO}$ & 007 & 006 & 007 & 006 & 006 & 006 \\
\hline $\mathrm{Bl}_{2} \mathrm{O}_{3}$ & 119 & 125 & 109 & 124 & 119 & 118 \\
\hline $\mathrm{CaO}$ & 617 & 631 & 589 & 609 & 108 & 107 \\
\hline $\mathrm{Cr}_{2} \mathrm{O}_{3}$ & 065 & 067 & 060 & 063 & 063 & 061 \\
\hline $\mathrm{Fe}_{2} \mathrm{O}_{3}$ & 563 & 6013 & 546 & 593 & $\$ 87$ & 584 \\
\hline $\mathrm{K}, 2 \mathrm{O}$ & 402 & $4 \sin$ & 298 & 312 & 507 & 510 \\
\hline $\mathrm{L}_{12} \mathrm{O}^{\mathrm{*}}$ & 357 & 357 & 346 & 346 & 317 & 317 \\
\hline $\mathrm{MgO}$ & 026 & 028 & 033 & 031 & 029 & 027 \\
\hline $\mathrm{Na}_{2} \mathrm{O}$ & 610 & 624 & 981 & 960 & 883 & 905 \\
\hline $\mathrm{N}_{1} \mathrm{O}$ & 038 & 041 & 037 & 040 & 037 & 037 \\
\hline $\mathrm{P}_{2} \mathrm{O}_{5}$ & 128 & 113 & 118 & 113 & 110 & 108 \\
\hline $\mathrm{PbO}$ & 041 & 045 & 037 & 043 & 033 & 033 \\
\hline $\mathrm{SO}_{2}$ & 033 & 025 & 036 & 018 & 032 & 029 \\
\hline $\mathrm{S}_{1} \mathrm{O}_{2}$ & 3113 & 3048 & 3113 & 2998 & 2986 & 2963 \\
\hline $\mathrm{T}_{1} \mathrm{O}_{2}$ & 006 & 005 & 005 & 005 & 004 & 004 \\
\hline $\mathrm{ZnO}$ & 009 & 010 & 008 & 009 & 008 & 008 \\
\hline $\mathrm{ZrO}_{2}$ & 047 & 030 & 033 & 039 & 037 & 038 \\
\hline
\end{tabular}

"Targit valuiśs 
Table 3.4e. XRF Analysis (wt\%) of Group 5 Fornulation Feeds Fused at $1150 \%$ and After VGF Experiments.

\begin{tabular}{|c|c|c|c|c|c|c|}
\hline Glass Name & \multicolumn{2}{|c|}{ HWI-A1-16 } & \multicolumn{2}{|c|}{ HWT-A1-16 } & \multicolumn{2}{|c|}{ НWП-Al-18 } \\
\hline Fectil Name & $\mathrm{F} \cdot \mathrm{HWT} \cdot \mathrm{AL} \cdot \mathbf{1 6 \cdot 3 0 \mathrm { M }}$ & 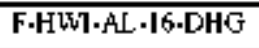 & F.HWI.AL·16B-30M & 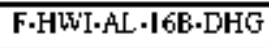 & F.HWI-AL-IS·30MI & F.HWI.AL·I8.DHG \\
\hline $\begin{array}{c}\text { Sample } \\
\text { Condition }\end{array}$ & VGF (30 nimutes) & Fused at $1150^{\circ} \mathrm{C}$ & VGF (30 nimutes) & Fused at $1150^{\circ} \mathrm{C}$ & VGF (30 minutes) & Fused at $1150^{\circ} \mathrm{C}$ \\
\hline $\mathrm{Al}_{2} \mathrm{C}_{3}$ & 2248 & 2240 & 2255 & 2219 & 2175 & 2139 \\
\hline $\mathrm{B}_{2} \mathrm{O}_{3}{ }^{\circ}$ & 1773 & 1773 & 1773 & 1773 & 2013 & 2013 \\
\hline $\mathrm{BaO}$ & 005 & 007 & 005 & 0.46 & 006 & 006 \\
\hline $\mathrm{Bl}_{2} \mathrm{O}_{3}$ & 116 & 122 & 119 & 120 & 094 & 099 \\
\hline $\mathrm{CaO}$ & 583 & 577 & 607 & 6010 & 573 & 586 \\
\hline $\mathrm{Cr}_{2} \mathrm{O}_{3}$ & $06 !$ & 058 & 062 & 062 & 0.54 & 0.58 \\
\hline $\mathrm{Fe}_{2} \mathrm{O}_{3}$ & 543 & 538 & 573 & 582 & 56 & 590 \\
\hline $\mathrm{K}_{2} \mathrm{O}$ & 016 & 914 & 016 & 015 & 017 & 016 \\
\hline $\mathrm{L}_{1} \mathrm{O}^{+}$ & 346 & 346 & 346 & 346 & 336 & 336 \\
\hline $\lg O$ & 021 & 025 & 019 & 031 & 028 & 030 \\
\hline $\mathrm{Na}_{3} \mathrm{O}$ & 987 & 967 & 952 & 900 & 906 & 918 \\
\hline $\mathrm{N} 1 \mathrm{O}$ & 035 & 036 & 037 & 039 & 035 & 039 \\
\hline $\mathrm{P}_{2} \mathrm{O}_{5}$ & 112 & 112 & 111 & 114 & 114 & 113 \\
\hline $\mathrm{PbO}$ & 039 & 064 & 037 & 046 & 035 & 036 \\
\hline $\mathrm{SO}_{3}$ & 929 & 922 & 026 & 924 & 020 & $(114$ \\
\hline $\mathrm{SiO}_{2}$ & 3023 & 3036 & 3005 & 3064 & 2964 & 2937 \\
\hline $\mathrm{T}_{1} \mathrm{O}_{2}$ & 904 & ong & 003 & 004 & 005 & 004 \\
\hline $\mathrm{ZnO}$ & 009 & 008 & 009 & 010 & 008 & 009 \\
\hline $\mathrm{ZrO}_{2}$ & 943 & 43 & 036 & 038 & 046 & $(148$ \\
\hline
\end{tabular}

"Target ralues 
Table 3,4e. XRF Analysis (wt\%) of Group 5 Formulation Feeds Fused at $1150^{\circ} \mathrm{C}$ : and After VGF Experintents (continued).

\begin{tabular}{|c|c|c|c|c|}
\hline Glass Name & \multicolumn{2}{|c|}{ HWII.A1-19 } & \multicolumn{2}{|c|}{ HWI-A1-19 } \\
\hline Fed Name & $\begin{array}{c}\text { F.HWI-AL.19. } \\
\text { 30M }\end{array}$ & $\begin{array}{c}\text { F-HWI-AL-19. } \\
\text { DHG }\end{array}$ & $\begin{array}{c}\text { F-HWFI-AL-19B- } \\
\text { 30M }\end{array}$ & $\begin{array}{c}\text { F-HWT-AL-19B } \\
\text { DHG }\end{array}$ \\
\hline Sample Condition & VGF (30 minutes) & Fused al $1150^{\circ} \mathrm{C}$ & VGF (30 minutes) & Fused at $1150^{\circ} \mathrm{C}$ \\
\hline $\mathrm{Al}_{2} \mathrm{O}_{2}$ & 232.7 & 2291 & 23.68 & 2281 \\
\hline $\mathrm{B}_{2} \mathrm{O}_{3}{ }^{+}$ & 1919 & 1919 & 1919 & 1919 \\
\hline $\mathrm{BaO}$ & 005 & 005 & 005 & 007 \\
\hline $\mathrm{B}_{1}, \mathrm{O}_{3}$ & 119 & 118 & 114 & 118 \\
\hline $\mathrm{CaO}$ & 562 & 5 G & 566 & 571 \\
\hline $\mathrm{Cr}_{2} \mathrm{O}_{2}$ & 063 & 064 & 062 & 062 \\
\hline $\mathrm{Fe}_{2} \mathrm{O}_{2}$ & 580 & ting & $\$ 40$ & 563 \\
\hline $\mathrm{K}_{2} \mathrm{O}$ & 016 & 015 & 016 & 015 \\
\hline $\mathrm{L}_{2} \mathrm{O}^{*}$ & 357 & 357 & 357 & 357 \\
\hline $\operatorname{Mg} O$ & 023 & 033 & 031 & 029 \\
\hline $\mathrm{Na}_{2} \mathrm{O}$ & 1005 & 1000 & 1047 & 1051 \\
\hline $\mathrm{N} 1 \mathrm{O}$ & 038 & 039 & 038 & 038 \\
\hline $\mathrm{P}_{2} \mathrm{O}_{5}$ & 111 & 110 & 109 & 110 \\
\hline $\mathrm{PhO}$ & 979 & 026 & 0,35 & 038 \\
\hline $\mathrm{SO}_{3}$ & 032 & 017 & 036 & 016 \\
\hline $\mathrm{S}_{2}$ & 2763 & 2777 & 2767 & 2769 \\
\hline $\mathrm{T}_{1} \mathrm{O}_{2}$ & 005 & 005 & 004 & 004 \\
\hline $\mathrm{ZnO}$ & 009 & 009 & 007 & 008 \\
\hline $\mathrm{ZrO}_{2}$ & 036 & 038 & 035 & 039 \\
\hline
\end{tabular}

"Target values 
Table 3.4f. XRF Analysis (wt \%) of Existing High Fe Melter Feeds and Variations of Baseline Feed for HLW-E-Al-27.

\begin{tabular}{|c|c|c|c|c|c|c|}
\hline Glass Name & \multicolumn{2}{|c|}{ HLW-E-AI-27 } & \multicolumn{2}{|c|}{ HLW-E-A1-27 } & \multicolumn{2}{|c|}{ HLW-E-A1.27 } \\
\hline Fedil Name & F.AL-VAR1-45H & F.ALEVARI-DHG & F.AL.VAR2.45M & F-AL-VAR2-DHG & F-AL-YARA-45M & F.AL-VARA-DHG \\
\hline $\begin{array}{c}\text { Sample } \\
\text { Condition }\end{array}$ & VGF (45 nimutes) & Fused at $1150^{\circ} \mathrm{C}$ & VGF (45 minules) & Fused at $1150^{\circ} \mathrm{C}$ & VGF (45 mutes) & Fused at $1150^{\circ} \mathrm{C}$ \\
\hline $\mathrm{Al}_{2} \mathrm{O}_{3}$ & 2159 & 2295 & 2333 & 2297 & 2292 & 2339 \\
\hline $\mathrm{B}_{2} \mathrm{O}^{\circ}$ & 1519 & 1519 & 1519 & 1519 & 1519 & 1519 \\
\hline $\mathrm{BnO}$ & 008 & 008 & 005 & 007 & 006 & 007 \\
\hline $\mathrm{Bl}_{2} \mathrm{O}_{3}$ & 116 & 119 & 108 & 121 & 115 & 130 \\
\hline $\mathrm{CaO}$ & 606 & 614 & 593 & 612 & 588 & 593 \\
\hline $\mathrm{Cr}_{2} \mathrm{O}_{3}$ & 064 & 064 & 062 & 064 & 062 & 063 \\
\hline $\mathrm{Fe}_{2} \mathrm{O}_{3}$ & 576 & $\$ 98$ & 554 & 619 & 570 & 590 \\
\hline $\mathrm{K}, \mathrm{O}$ & 016 & 015 & 016 & 015 & 015 & i) 15 \\
\hline $\mathrm{L}_{2} \mathrm{O}^{\mathrm{t}}$ & 357 & 357 & 357 & 357 & 357 & 357 \\
\hline $\mathrm{MgO}$ & 034 & 029 & 033 & 030 & 037 & 1) 36 \\
\hline $\mathrm{M} \operatorname{LnO}$ & 000 & 000 & 000 & 000 & 000 & 000 \\
\hline $\mathrm{Na}_{2} \mathrm{O}$ & 990 & 942 & 991 & 1009 & 975 & 975 \\
\hline $\mathrm{N} 10$ & 038 & 039 & 037 & 041 & 037 & 038 \\
\hline $\mathrm{PrO}_{3}$ & 116 & 104 & 114 & 108 & 113 & 1.6 \\
\hline $\mathrm{PbO}$ & 034 & 036 & 027 & 031 & 028 & 029 \\
\hline $\mathrm{SO}_{2}$ & 039 & 029 & 037 & 924 & 0.35 & i) 27 \\
\hline $\mathrm{SlO}_{2}$ & 3263 & 3163 & 3154 & 3083 & 3184 & 3123 \\
\hline $\mathrm{T}_{1} \mathrm{O}_{2}$ & 004 & 004 & 004 & 004 & 004 & 005 \\
\hline $\mathrm{ZnO}$ & 007 & 008 & 008 & 009 & 008 & 008 \\
\hline $\mathrm{ZrO}_{2}$ & 048 & 050 & 042 & 051 & 046 & 049 \\
\hline
\end{tabular}


Table 3.4f. XRF Analysis (wt \%) of Existing Higl Fe Melter Feeds and Variations of Baseline Feed for HLW-E-Al-27 (continued).

\begin{tabular}{|c|c|c|c|c|c|c|}
\hline Glass Name & \multicolumn{2}{|c|}{ HLW-E-A1.27 } & \multicolumn{2}{|c|}{ Matro l-Bl } & \multicolumn{2}{|c|}{ Matrıx 2-9 } \\
\hline FeediName & BLX.F.50B.60k-I & BLX-F.S0B.DHG & ELS.F-7A & BLS-F-7A & BLV.F.132B & BLY-F.132B \\
\hline $\begin{array}{l}\text { Sample } \\
\text { Condition }\end{array}$ & VGF ( 60 minutes) & Fused at $1150^{\circ} \mathrm{C}$ & $\begin{array}{l}\mathrm{VGF}(15 \\
\text { m lnutes) }\end{array}$ & Fused at $1150^{\circ} \mathrm{C}$ & $\begin{array}{l}\text { VGF (5 } \\
\text { montes) }\end{array}$ & Fused at $1150^{\circ} \mathrm{C}$ \\
\hline $\mathrm{Al}_{2} \mathrm{O}_{3}$ & 2317 & $23+13$ & 604 & $\$ 60$ & 1257 & 1250 \\
\hline $\mathrm{B}_{2} \mathrm{O}_{3}{ }^{+}$ & 1519 & 1519 & 941 & 941 & 1388 & 1388 \\
\hline $\mathrm{BaO}$ & 006 & 007 & 000 & 000 & 000 & 000 \\
\hline $\mathrm{B}_{2} \mathrm{O}_{3}$ & 109 & 124 & 000 & 000 & 000 & 000 \\
\hline $\mathrm{CaO}$ & 585 & 612 & 046 & 046 & 031 & 035 \\
\hline $\mathrm{Cr}_{2} \mathrm{O}_{3}$ & 054 & 061 & 008 & 009 & 008 & 008 \\
\hline $\mathrm{F}_{\mathrm{C}_{2} \mathrm{O}_{3}}$ & 543 & $6.1) 2$ & 1192 & 1239 & $103 \%$ & 1066 \\
\hline $\mathrm{K}_{2} \mathrm{O}$ & 918 & $(18$ & 000 & 000 & 010 & $\theta(\omega)$ \\
\hline $\mathrm{L}_{2} \mathrm{O}^{6}$ & 357 & 357 & 302 & 302 & 243 & 243 \\
\hline $\mathrm{MgO}$ & 1! 23 & 123 & 126 & 122 & 126 & 122 \\
\hline $\mathrm{MnO}$ & 00 & 000 & 3.37 & 381 & 285 & 319 \\
\hline $\mathrm{Na}_{2} \mathrm{O}$ & 1060 & 958 & 1228 & 1078 & 1412 & 1269 \\
\hline $\mathrm{NIO}$ & 0 34 & 038 & 015 & 017 & 013 & 015 \\
\hline $\mathrm{P}_{2} \mathrm{O}_{3}$ & 129 & 121 & 010 & 010 & 011 & 910 \\
\hline $\mathrm{PbO}$ & 0 34 & 037 & 013 & 013 & 011 & 011 \\
\hline$S O_{1}$ & 1125 & $(120$ & 000 & 000 & 0.0 & $(y(N)$ \\
\hline $\mathrm{SlO}_{2}$ & 3138 & 3123 & 4682 & 4805 & 3743 & 3836 \\
\hline $\mathrm{T}_{1} \mathrm{O}_{2}$ & 004 & 004 & 022 & 022 & 033 & 033 \\
\hline $\mathrm{ZnO}$ & 008 & $0(1)$ & 185 & 198 & 155 & 164 \\
\hline $\mathrm{ZsO}_{2}$ & 034 & 040 & 028 & 031 & 025 & 027 \\
\hline
\end{tabular}

Target values 
Table 3.5. Ranking Definition for Feed Conversion after 30 Minutes in VGF.

\begin{tabular}{|c|l|}
\hline 1 & Very Fast, all feed converted \\
\hline 2 & Fast with minor residue on side wall \\
\hline 3 & Moderate with foamy residue on side wall \\
\hline 4 & Slow with thick foam layer \\
\hline 5 & Slow with partially collapsed dome \\
\hline 6 & Very slow with fully developed dome \\
\hline
\end{tabular}


Table 3.6. Compositions of the Al-Limited Waste (Oxide Basis) and the HLW Waste Simulant to Produce $100 \mathrm{~kg}$ of Waste Oxides ( $20 \mathrm{wt} \%$ suspended solids) (from [2]).

\begin{tabular}{|c|c|c|c|}
\hline \multicolumn{2}{|c|}{ Al-Limited Waste Composition } & \multicolumn{2}{|c|}{ Al-Linnited HLW Waste Simulant } \\
\hline Waste Oxide & W1\% & Starting Materials & Target Weiglot (kg)" \\
\hline $\mathrm{Al}_{2} \mathrm{O}_{3}$ & $49 \geq 1 \%$ & $\mathrm{Al}_{2} \mathrm{O}_{3}$ & 49707 \\
\hline $\mathrm{E}_{2} \mathrm{O}_{3}$ & $039 \%$ & $\mathrm{H}_{3} \mathrm{BO}_{3}$ & 700 \\
\hline $\mathrm{CaO}$ & $221 \%$ & $\mathrm{CaO}$ & 2355 \\
\hline $\mathrm{Fe}_{2} \mathrm{O}_{3}$ & $1211 \%$ & $\mathrm{Fe}(\mathrm{OH})(13 \%$ Slurry $)$ & 99643 \\
\hline $\mathrm{L}_{\mathbf{I}_{2}} \mathrm{O}$ & $035 \%$ & $\mathrm{~L}_{2} \mathrm{CO}_{3}$ & 0888 \\
\hline $\mathrm{MgO}$ & $024 \%$ & $\mathrm{MgO}$ & 9253 \\
\hline $\mathrm{Na}_{2} \mathrm{O}$ & $735 \%$ & $\mathrm{NaOH}$ & 4235 \\
\hline $\mathrm{S}_{1} \mathrm{O}_{2}$ & $1005 \%$ & $\mathrm{~S}_{1} \mathrm{O}_{2}$ & 10152 \\
\hline $\mathrm{TrO}_{2}$ & $009 \%$ & $\mathrm{~T}_{1} \mathrm{O}_{2}$ & 0020 \\
\hline $\mathrm{ZnO}$ & $017 \%$ & $\mathrm{ZnO}$ & 0172 \\
\hline $\mathrm{ZrO}_{2}$ & $081 \%$ & $\mathrm{ZrOH}_{4} \times \mathrm{H}_{2} \mathrm{O}$ & 2003 \\
\hline $\mathrm{SO}_{3}$ & $041 \%$ & $\mathrm{Na}_{2} \mathrm{SO}_{4}$ & 935 \\
\hline $\mathrm{B}_{2} \mathrm{O}_{3}$ & $235 \%$ & $\mathrm{~B}_{2} \mathrm{O}_{3}$ & 2374 \\
\hline $\mathrm{ThO})_{2}$ & $0.37 \%$ & \multicolumn{2}{|c|}{ Onutied } \\
\hline $\mathrm{Cr}_{2} \mathrm{O}_{3}$ & $107 \%$ & $\mathrm{Cr}_{2} \mathrm{O}_{3} \times 5 \mathrm{H}_{2} \mathrm{O}$ & 1273 \\
\hline $\mathrm{K}_{2} \mathrm{O}$ & $029 \%$ & $\mathrm{KNO}_{3}$ & 0632 \\
\hline $\mathrm{U}_{3} \mathrm{O}_{8}$ & $725 \%$ & \multicolumn{2}{|c|}{ Omitted } \\
\hline $\mathrm{BaO}$ & $011 \%$ & $\mathrm{BaCO}_{3}$ & 0143 \\
\hline $\mathrm{CdO}$ & $065 \%$ & $\mathrm{CdO}$ & 0051 \\
\hline $\mathrm{N} 1 \mathrm{O}$ & $082 \%$ & $\mathrm{~N}(\mathrm{OH})_{2}$ & 1055 \\
\hline $\mathrm{PbO}$ & $084 \%$ & $\mathrm{PLO}$ & 0848 \\
\hline $\mathrm{P}_{2} \mathrm{O}$ & $216 \%$ & $\mathrm{FePO}_{4} \times \mathrm{H}_{2} \mathrm{O}$ & 5738 \\
\hline $\mathrm{F}$ & $137 \%$ & $\mathrm{NaF}$ & 3044 \\
\hline Carbunate & $120^{\mathrm{a}}$ & $\mathrm{Na}_{2} \mathrm{CO}_{3}$ & 0806 \\
\hline Nitnte & 050 & $\mathrm{NaNO}_{2}$ & 0769 \\
\hline Nitrate & 200 & $\mathrm{NaNO}_{3}$ & 2 $23 \div !$ \\
\hline Organic Carbon & 005 & $\mathrm{H}_{2} \mathrm{C}_{2} \mathrm{O}_{4} \cdot 2 \mathrm{H}_{2} \mathrm{O}$ & 0264 \\
\hline- & - & Water & 279 4im \\
\hline TOTAL & $1(10) 0 \%$ & TOTAL & 469478 \\
\hline
\end{tabular}

"Target weights adjusted for assay information of starting matenals

"Unit for yolatile comporents is gi']00 g of waste oxule

- Empty data field 
Table 3.7. TCLP Results (ppm) for Selected HWI Glasses.

\begin{tabular}{|c|c|c|c|c|c|c|c|}
\hline Element & $\mathrm{Ba}$ & $\mathrm{B}_{\mathbf{1}}$ & $\mathrm{Cd}$ & $\mathrm{Cr}$ & $\mathrm{N}_{1}$ & $\mathrm{~Pb}$ & Zn \\
\hline UTS Lum ts $^{*}$ & 21 & $\mathrm{~N} / \mathrm{A}$ & 011 & 06 & 11 & 075 & 43 \\
\hline Delısting Limits & 100 & $\mathrm{~N} / \mathrm{A}$ & 048 & 495 & 226 & 5 & 225 \\
\hline HLW-E-A12TRI [2] & 012 & 091 & NA & 021 & 020 & 037 & 013 \\
\hline HWI-Ál-4 & 014 & 055 & $\sin 3$ & 013 & $<004$ & 018 & NA \\
\hline HWI-Al-7 & 017 & NA & $\sin 3$ & 002 & 012 & $(143$ & NA \\
\hline HWiI-Al-16 & 013 & NA & $=0003$ & 017 & 027 & 050 & NA \\
\hline HLVI-AL-18G & 017 & 074 & 004 & $0 \operatorname{lng}$ & 023 & 0.31 & $\mathrm{NA}$ \\
\hline HWiI-Al-19 & 017 & 086 & $<003$ & 023 & 023 & 045 & NA \\
\hline HWVI-AI-20 & 016 & 078 & $<003$ & 013 & $<004$ & 030 & NA \\
\hline
\end{tabular}

\# For comperisoth only. does not apply to WTP glasses

N/A. Not Applicable

NA-Not analyzed

Table 3.8. Melt Rate Ranking of Feed Samples by VGF vs. Glass Production Rate by DM100 at $1150^{\circ} \mathrm{C}$.

\begin{tabular}{|c|c|c|c|c|}
\hline Waste Strenm & Glass Name & Feed Simple & $\begin{array}{c}\text { VGF Melt Rate } \\
\text { Ranking }\end{array}$ & $\begin{array}{l}\text { Gass Production } \\
\left.\text { Rate (ko/ } \mathrm{w}^{2} / \mathrm{day}\right)\end{array}$ \\
\hline Al-linited $\left(\mathrm{ALO}_{3}\right)[2$ & HLW-E-Al-27 & BLL-F-135A & 6 & 550 \\
\hline Al-limited (Al(CH) & HLW-E-Al-27 & BLX-F-50 & 5 & 700 \\
\hline Al/Na-limited [2] & HLW-E-ANa-22 & BLN.F.2IA & $\overline{3}$ & 400 \\
\hline B-limited [2] & HLW-E-Bl-6 & BLK-F-84A & 5 & 830 \\
\hline Cr-limited [2] & HLW-E-CrM & BLL-F-65A & $T$ & 1150 \\
\hline Alsorithm Matrix 1 [24] & Matt1 $1 \times 1-\mathrm{B} 1$ & BLS-F-7A & 3 & $10(4)$ \\
\hline Algorithm Matrix 2 25] & Matr1x 2-9 & BL $\forall-F-132 B$ & 3 & 900 \\
\hline $\mathrm{Al}$-Limited $\left(\mathrm{Al}_{2} \mathrm{O}_{3}\right)$ & HWiI-All-16 & F-HนhI-A口-16 & 3 & 700 \\
\hline Al-limited (Al(OH) & HLI-Al.16 & F-HW]-Al-16B & 2 & 950 \\
\hline Al-limited $\left(\mathrm{A} \mid(\mathrm{OH})_{3}\right)$ & HWI-Al-19 & F-HW]-Al-19B & 2 & 950 \\
\hline
\end{tabular}

* Based on Table 35 
Table 3.9. Crystalline Phases in the Partially Reacted Feed (VGF) Identified by SEM/EDS and XRD.

\begin{tabular}{|c|c|c|c|c|}
\hline$\frac{8}{0} \frac{0}{2}$ & $\begin{array}{l}\text { Feed Sample } \\
\text { (VGF test time) }\end{array}$ & $\begin{array}{l}\text { AlForm } \\
\text { in Feed } \\
\text { Recipe }\end{array}$ & $\begin{array}{c}\text { Phase identified by SEM/EDS } \\
\text { (Surface sample) }\end{array}$ & $\begin{array}{l}\text { Phase identified by } \\
\text { XRD } \\
\text { (Bulk sample) }\end{array}$ \\
\hline \multirow{2}{*}{ 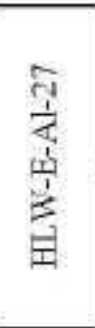 } & $\begin{array}{l}\text { BLL-F-135 } \\
\text { (60 minutes) }\end{array}$ & $\mathrm{Al}_{2} \mathrm{O}_{3}$ & $\begin{array}{l}\text { - Sodalite (wide spread) } \\
\text { - Spinel (NiFe) } \\
\text { - Ca-Phosphate } \\
\text { - NaCaFeAl-Silicate }\end{array}$ & $\begin{array}{l}\text {-Quartz } \\
\text { - Spinel } \\
\text { - Nepheline } \\
\text { - Sodalite }\end{array}$ \\
\hline & $\begin{array}{l}\text { BLX-F-50 } \\
\text { (60 minutes) }\end{array}$ & $\mathrm{Al}(\mathrm{OH})_{3}$ & $\begin{array}{l}\text { - Sodalite } \\
\text { - Zr rich oxide with } \mathrm{Na}, \mathrm{Ca}, \mathrm{A}, \mathrm{ISi} \\
\text { - Fe rich oxide with } \mathrm{Ca}, \mathrm{Al}, \mathrm{Si}\end{array}$ & $\begin{array}{l}\text {-Quartz } \\
\text { - Spinel } \\
\text { - Nepheline } \\
\text { - Sodalite }\end{array}$ \\
\hline \multirow{2}{*}{$\frac{0}{\frac{1}{1}}$} & $\begin{array}{l}\text { F-HWI-Al-16 } \\
\text { (30 minutes) }\end{array}$ & $\mathrm{Al}_{2} \mathrm{O}_{3}$ & $\begin{array}{l}\text { - Spinel (NiCrFe) } \\
\text { - Ca-Phosphate } \\
\text { - NaCaFeAl-Silicate } \\
\text { - CaAl-Silicate with } \mathrm{Zr}\end{array}$ & $\begin{array}{l}\text {-Zircon } \\
\text { - Spinel } \\
\text { - Sodalite }\end{array}$ \\
\hline & $\begin{array}{l}\text { F-HWI-Al-16B } \\
\text { (30 minutes) }\end{array}$ & $\mathrm{Al}(\mathrm{OH})_{3}$ & $\begin{array}{l}\text { - Spinel (NiCrFe) } \\
\text { - Zr oxide with Ca, Al, Si }\end{array}$ & $\begin{array}{l}\text {-Zircon } \\
\text { - Spinel } \\
\text { - Sodalite }\end{array}$ \\
\hline \multirow{2}{*}{ 竞 } & $\begin{array}{l}\text { F-HWI-Al-19F } \\
\text { (30 minutes) }\end{array}$ & $\mathrm{Al}_{2} \mathrm{O}_{3}$ & $\begin{array}{l}\text { - Sodalite (wide spread) } \\
\text { - Spinel (NiCrFe) } \\
\text { - Ca-Phosphate }\end{array}$ & $\begin{array}{l}\text {-Zircon } \\
\text {-Spinel } \\
\text {-Sodalite } \\
\text {-Quartz }\end{array}$ \\
\hline & $\begin{array}{l}\text { F-HWI-Al-19B } \\
\text { (30 minutes) }\end{array}$ & $\mathrm{Al}(\mathrm{OH})_{3}$ & $\begin{array}{l}\text { - NaCaAlFe-Silicate } \\
\text { - Spinel (NiCrFe) } \\
\text { - Zr oxide with } \mathrm{Ca}, \mathrm{Al}, \mathrm{Si}\end{array}$ & $\begin{array}{l}\text {-Zircon } \\
\text {-Spinel } \\
\text { - Sodalite } \\
\text {-Quartz }\end{array}$ \\
\hline
\end{tabular}


Table 3.10. Target Glass Compositions for Base Feeds Used During DM10 Melter Rate Tests (wt\%).

\begin{tabular}{|c|c|c|c|c|c|c|c|c|c|c|c|c|}
\hline Base Feed & \multicolumn{3}{|c|}{$\begin{array}{c}\mathrm{HLW} \text {-E-Al-27 with } \mathrm{Al}_{2} \mathrm{O}_{3} \\
\text { (see Table } 22 \text { ) }\end{array}$} & \multicolumn{3}{|c|}{$\begin{array}{c}\text { HLW-E-Al-27 wrth Al(OH) } \\
\text { (see Table } 23)\end{array}$} & \multicolumn{3}{|c|}{$\begin{array}{c}\text { HLW.E-Al-27 with } \mathrm{Al}_{2} \mathrm{O}_{3} \text { and } \\
\text { Boric Acid/Sodt Ash Replacing } \\
\text { Borax }\end{array}$} & \multicolumn{3}{|c|}{$\begin{array}{c}\text { HLW-E-Al-27 w1th } \mathrm{Al}_{2} \mathrm{O}_{3} \text {, antl } \\
\text { Bonc Acid/ } \mathrm{K}_{2} \mathrm{CO}_{3} \text { Replacong } \\
\text { Brrax }\end{array}$} \\
\hline Test $s$ & $\left|\begin{array}{c}50,51,79 \\
115.153\end{array}\right|$ & \multicolumn{2}{|c|}{64,65} & $\begin{array}{c}66,92 \\
118,149 \\
205\end{array}$ & \multicolumn{2}{|c|}{$86.115,147$} & 67,93 & \multicolumn{2}{|c|}{87,116} & $\begin{array}{c}68.94 \\
119.126 \\
155 \\
\end{array}$ & \multicolumn{2}{|c|}{88.117 .148} \\
\hline Feed (g) & 1000 & \multicolumn{2}{|c|}{950} & 1000 & \multicolumn{2}{|c|}{950} & 1000 & \multicolumn{2}{|c|}{950} & 1000 & \multicolumn{2}{|c|}{990} \\
\hline Type of Adiltit' & None & $\mathrm{HNO}_{3}$ & Sugar & None & $\mathrm{HNO}_{3}$ & Sugar & None & $\mathrm{HNO}_{3}$ & Sugar & None & $\mathrm{HNO}_{3}$ & Sugar \\
\hline Additive & $\lg$ & $50 \mathrm{ml}$ & $17 \mathrm{~g}$ & 0 & $50 \mathrm{ml}$ & $17 \mathrm{~g}$ & $0 \mathrm{~g}$ & $50 \mathrm{ml}$ & $17 \mathrm{~g}$ & $0 \mathrm{~g}$ & $50 \mathrm{ml}$ & $17 g$ \\
\hline $\mathrm{Al}_{2} \mathrm{O}_{3}$ & 2397 & \multicolumn{2}{|c|}{2397} & 2397 & \multicolumn{2}{|c|}{2397} & 2397 & \multicolumn{2}{|c|}{2397} & 2397 & \multicolumn{2}{|c|}{2397} \\
\hline $\mathrm{B} x \mathrm{O}_{\mathrm{y}}$ & 1519 & \multicolumn{2}{|c|}{1519} & 1519 & \multicolumn{2}{|c|}{1519} & 1519 & \multicolumn{2}{|c|}{1519} & 1519 & \multicolumn{2}{|c|}{1519} \\
\hline $\mathrm{BaO}$ & 005 & \multicolumn{2}{|c|}{005} & 005 & \multicolumn{2}{|c|}{005} & 005 & \multicolumn{2}{|c|}{005} & 005 & \multicolumn{2}{|c|}{005} \\
\hline $\mathrm{Br}_{2} \mathrm{O}_{3}$ & 114 & \multicolumn{2}{|c|}{114} & I 14 & \multicolumn{2}{|c|}{114} & 114 & \multicolumn{2}{|c|}{ I 14} & 114 & \multicolumn{2}{|c|}{114} \\
\hline $\mathrm{CaO}$ & 608 & \multicolumn{2}{|c|}{608} & 608 & & & 608 & & & 608 & & \\
\hline $\mathrm{CdO}$ & $00 ?$ & & & 002 & & & 002 & & & 002 & & \\
\hline $\mathrm{Cr}_{2} \mathrm{O}_{3}$ & 052 & & & 052 & & & 052 & & & 052 & & \\
\hline $\mathbf{F}$ & 067 & & & 067 & & & 067 & & & 067 & & \\
\hline $\mathrm{Fe}_{2} \mathrm{O}_{3}$ & 590 & & & 590 & & & 590 & & & 590 & & \\
\hline $\mathrm{KiO}$ & 014 & & & 014 & & & 014 & & & 614 & & \\
\hline $\mathrm{L}_{2} \mathrm{O}$ & 357 & & & 357 & & & 357 & & & 357 & & \\
\hline $\mathrm{MgO}$ & 912 & & & 012 & & & 012 & & & 012 & & \\
\hline $\mathrm{Na}_{2} \mathrm{O}$ & 958 & & & 958 & & & 958 & & & 358 & & \\
\hline $\mathrm{N} / \mathrm{O}$ & 040 & & & 1) 40 & & & 040 & & & 040 & & \\
\hline $\mathrm{P}_{2} \mathrm{O}_{5}$ & 105 & & & 105 & & & 105 & & & 105 & & \\
\hline $\mathrm{PbO}$ & 94 & & & 041 & & & 041 & & & 041 & & \\
\hline $\mathrm{S}_{1} \mathrm{O}_{2}$ & 3050 & & & 3050 & & & 3050 & & & 3050 & & \\
\hline $\mathrm{SO}_{3}$ & 120 & & & 020 & & & 020 & & & 020 & & \\
\hline $\mathrm{T}_{1} \mathrm{O}_{2}$ & 001 & & & 001 & & & 001 & & & 001 & & \\
\hline $\mathrm{ZnO}$ & 008 & & & 008 & & & 008 & & & 008 & & \\
\hline $\mathrm{ZrO}_{2}$ & 039 & & & 039 & & & 039 & & & 039 & & \\
\hline Sum & 10000 & & & 10000 & & & 10000 & & & $100(10)$ & & \\
\hline
\end{tabular}


Table 3.10. Target Glass Compositions for Base Feeds Used During DM10 Melter Rate Tests (wt\%) (continued).

\begin{tabular}{|c|c|c|c|c|c|c|c|c|c|c|}
\hline Feed type & \multicolumn{5}{|c|}{ HW]-A1-9Melt } & \multicolumn{5}{|c|}{ HWI-AJ-9KSM } \\
\hline Test Hs: & $\begin{array}{c}154,166 \\
180\end{array}$ & \multicolumn{2}{|c|}{173,202} & \multicolumn{2}{|c|}{175.204} & $\begin{array}{c}156,179 \\
181\end{array}$ & \multicolumn{2}{|c|}{174,203} & \multicolumn{2}{|c|}{176} \\
\hline Feed (g) & 1000 & \multicolumn{2}{|c|}{950} & \multicolumn{2}{|c|}{975} & 1000 & \multicolumn{2}{|c|}{950} & \multicolumn{2}{|c|}{975} \\
\hline Type of Adilitive & None & $\mathrm{HNO3}$ & Sugar & HNos & Sugar & None & $\mathrm{HNO}$ & Sugar & HNOA & Suygar \\
\hline Additive & $0 g$ & $50 \mathrm{ml}$ & $17 g$ & $25 \mathrm{ml}$ & $85 \mathrm{~g}$ & $0 g$ & $50 \mathrm{ml}$ & $17 g$ & $25 \mathrm{ml}$ & $85 g$ \\
\hline $\mathrm{A}_{2} 1_{2} \mathrm{O}_{3}$ & 2131 & \multicolumn{2}{|c|}{2131} & \multicolumn{2}{|c|}{2131} & 2397 & \multicolumn{2}{|c|}{2397} & \multicolumn{2}{|c|}{2397} \\
\hline $\mathrm{B}_{2} \mathrm{O}_{3}$ & 1817 & \multicolumn{2}{|c|}{1817} & \multicolumn{2}{|c|}{1817} & 1819 & \multicolumn{2}{|c|}{1819} & \multicolumn{2}{|c|}{1819} \\
\hline $\mathrm{BaO}$ & 905 & \multicolumn{2}{|c|}{905} & \multicolumn{2}{|c|}{005} & 005 & \multicolumn{2}{|c|}{005} & \multicolumn{2}{|c|}{005} \\
\hline $\mathrm{Bl}_{2} \mathrm{O}_{1}$ & 102 & \multicolumn{2}{|c|}{102} & \multicolumn{2}{|c|}{102} & 114 & \multicolumn{2}{|c|}{114} & \multicolumn{2}{|c|}{114} \\
\hline $\mathrm{CoO}$ & 996 & \multicolumn{2}{|c|}{96} & \multicolumn{2}{|c|}{096} & 108 & \multicolumn{2}{|c|}{108} & \multicolumn{2}{|c|}{108} \\
\hline $\mathrm{CdO}$ & 002 & & & & & 002 & & & & \\
\hline $\mathrm{Cr}_{2} \mathrm{O}_{3}$ & 046 & & & & & 052 & & & & \\
\hline $\mathbf{F}$ & 059 & & & & & 067 & & & & \\
\hline $\mathrm{Fe}_{2} \mathrm{O}_{3}$ & 524 & & & & & 590 & & & & \\
\hline $\mathrm{K}_{2} \mathrm{O}$ & 013 & & & & & 514 & & & & \\
\hline $\mathrm{L}_{2} \mathrm{O}$ & 315 & & & & & 317 & & & & \\
\hline $\operatorname{Mg}(3)$ & 010 & & & & & 012 & & & & \\
\hline $\mathrm{Na}_{2} \mathrm{O}$ & 1318 & & & & & 858 & & & & \\
\hline $\mathrm{NoO}$ & 036 & & & & & 040 & & & & \\
\hline $\mathrm{P}_{2} \mathrm{O}_{5}$ & 094 & & & & & 105 & & & & \\
\hline $\mathrm{PbO}$ & 036 & & & & & 041 & & & & \\
\hline$\overline{\mathrm{S}_{1} \mathrm{O}_{2}}$ & 3335 & & & & & 2890 & & & & \\
\hline $\mathrm{SO}_{2}$ & 018 & & & & & 020 & & & & \\
\hline $\mathrm{T}_{10} \mathrm{O}_{2}$ & 001 & & & & & 001 & & & & \\
\hline $\mathrm{ZnO}$ & 007 & & & & & 008 & & & & \\
\hline $\mathrm{ZrO}_{2}$ & 035 & & & & & 039 & & & & \\
\hline Sum & 10000 & & & & & 10000 & & & & \\
\hline
\end{tabular}


Table 3.11. Target Compositions for Vitrified Melter Feed with Various Additives During DM10 Melter Rate Tests (wr\%).

\begin{tabular}{|c|c|c|c|c|c|c|c|c|c|c|c|c|}
\hline Base Fed & \multicolumn{12}{|c|}{ HLW-E-Al-27 with $\mathrm{Al}_{2} \mathrm{O}_{3}$} \\
\hline Test \#s & $\begin{array}{c}50,51 \\
64,65,79 \\
105,153\end{array}$ & 58.59 & 32,53 & $\begin{array}{c}75,101 \\
1 \geq 4\end{array}$ & 56.57 & 60.61 & 54,55 & 62.63 & 159,182 & 199 & 162186 & 167,192 \\
\hline Feed (g) & $950-1(1000$ & 950 & 950 & 950 & 950 & 950 & 950 & 950 & 900 & $90 \%$ & 900 & $9(m)$ \\
\hline Type of Additlye & None & Boric Acil & $\mathrm{Na} 2 \mathrm{CO} 3$ & $\mathrm{~K} 3 \mathrm{CO} 3$ & Borax & $\mathrm{Li}_{2} \mathrm{CO}_{3}$ & $\mathrm{CaCO} 3$ & $\mathrm{SiO} 2$ & Bonc Ac1d & $\mathrm{Na}_{2} \mathrm{CO}_{3}$ & $\mathrm{~K} 2 \mathrm{CO} 3$ & Borax \\
\hline Additive (g) & 0 & 50 & 50 & 50 & 50 & 50 & 34 & 50 & 100 & 100 & 160 & $1(w)$ \\
\hline $\mathrm{Al}_{2} \mathrm{O}_{3}$ & 2397 & 2217 & 2212 & 2185 & 2182 & $22+6$ & 2219 & 2098 & 2047 & 2036 & 1989 & 1984 \\
\hline $\mathrm{B}_{2} \mathrm{O}_{3}$ & 1519 & 2155 & 1401 & 1384 & 3004 & 1436 & 1406 & 1329 & 2758 & 1290 & 1260 & 2450 \\
\hline $\mathrm{BaO}$ & 005 & 005 & 005 & 005 & 005 & 005 & 005 & 005 & 005 & 005 & 004 & 004 \\
\hline $\mathrm{B}_{2} \mathrm{O}_{3}$ & 114 & 106 & 106 & 104 & 104 & 108 & 106 & 100 & 098 & 097 & 095 & 095 \\
\hline $\mathrm{CaO}$ & 608 & 562 & 561 & 554 & 553 & 574 & 1306 & 532 & 519 & 516 & 504 & 503 \\
\hline $\mathrm{CdO}$ & 002 & 002 & 002 & 002 & 002 & 002 & 002 & 002 & 002 & 002 & 002 & 002 \\
\hline $\mathrm{Cr}_{2} \mathrm{O}_{3}$ & 052 & 048 & 048 & 047 & 047 & 049 & 048 & 046 & 044 & 044 & 043 & 043 \\
\hline$F$ & 067 & 062 & 062 & 061 & $06 \mathrm{l}$ & 063 & 062 & 0.58 & 057 & 057 & 055 & 055 \\
\hline $\mathrm{Fe}_{2} \mathrm{O}_{3}$ & 590 & 546 & 544 & 538 & 537 & 558 & 546 & 516 & 504 & 501 & 489 & 488 \\
\hline $\mathrm{K}_{2} \mathrm{O}$ & 614 & 013 & 013 & $9(\omega)$ & 013 & 613 & 013 & i) 12 & 012 & 1212 & 1716 & 012 \\
\hline $\mathrm{L}_{1}, \mathrm{C}$ & 357 & 330 & 329 & 325 & 325 & 883 & 330 & 312 & 305 & 3013 & 296 & 296 \\
\hline $\mathrm{M} \cdot \mathrm{g} O$ & 012 & 011 & 011 & 011 & 011 & 911 & 011 & 010 & 010 & !̣ 10 & 010 & 010 \\
\hline $\mathrm{Na}_{2} \mathrm{O}$ & 958 & 886 & 1658 & 873 & 1149 & 906 & 887 & 838 & 818 & 2319 & 795 & 1324 \\
\hline $\left.\mathrm{N}_{10}\right)$ & (14) & 0.37 & 037 & 136 & 036 & 938 & 037 & 0.35 & 034 & 34 & 033 & 033 \\
\hline $\mathrm{P}_{2} \mathrm{O}_{5}$ & 105 & 097 & 097 & 096 & 096 & 099 & 097 & 092 & 090 & 089 & 087 & 087 \\
\hline $\mathrm{PbO}$ & [as] & 038 & 938 & 937 & 0.37 & 39 & 038 & 1) 36 & 035 & 1. 35 & 034 & 034 \\
\hline $\mathrm{S}_{1} \mathrm{O}_{2}$ & 3050 & 2821 & 2813 & 2779 & 2776 & 2883 & 2823 & 3918 & 2604 & 2591 & 2530 & 2524 \\
\hline $\mathrm{SO}_{3}$ & 030 & 018 & 018 & 018 & 018 & 019 & 018 & 017 & 017 & 017 & 017 & 017 \\
\hline $\mathrm{T}_{1} \mathrm{O}_{2}$ & $00]$ & 001 & 001 & 001 & 001 & 001 & 001 & 001 & 001 & 001 & 001 & 001 \\
\hline $\mathrm{ZnO}$ & 008 & 008 & 008 & 008 & 008 & 008 & 008 & 007 & 007 & 007 & 007 & 007 \\
\hline $\mathrm{ZrO}_{2}$ & 039 & 037 & 036 & 036 & 036 & 037 & 037 & 035 & 034 & 034 & 033 & 033 \\
\hline Sum & 10000 & 10000 & 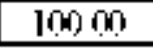 & 10000 & 100 (n) & 10000 & 10000 & 10000 & 10000 & 10000 & 10000 & 100 on \\
\hline
\end{tabular}


Table 3.11. Target Compositions for Vitrified Melter Feed with Various Additives During DM10 Melter Rate Tests (wt\%) (continued).

\begin{tabular}{|c|c|c|c|c|c|c|c|c|c|c|c|}
\hline Base Fectl & \multicolumn{11}{|c|}{$\mathrm{HL} W-\mathrm{E}-\mathrm{Al}-27$ with $\mathrm{Al}_{2} \mathrm{O}_{3}$} \\
\hline Test 荆 & $\begin{array}{c}51.51 .79 \\
105,153\end{array}$ & 160,183 & 200 & $\begin{array}{c}163.188 \\
308\end{array}$ & 168,193 & 161,184 & 164.189 & 194 & 177.185 & 190 & 196 \\
\hline Feed (g) & I0ن் & 850 & 850 & 830 & 850 & 800 & 800 & 800 & 750 & 750 & 750 \\
\hline Type of Additive & None & Bor $\mathbf{c}$ Acid & $\mathrm{Na} 2 \mathrm{CO}_{3}$ & $\mathrm{5} 2 \mathrm{CO}_{3}$ & Borax & Bor ic Acid & $\mathrm{K} 2 \mathrm{CO}_{3}$ & Borax & Boric Aculd & $\mathrm{K} 2 \mathrm{CO}_{3}$ & Borax \\
\hline Additıves (y) & 0 & 150 & 150 & 150 & 150 & 200 & 300 & 200 & 250 & 250 & 250 \\
\hline $\mathrm{Al}_{2} \mathrm{O}_{3}$ & 2397 & 1885 & 1871 & 1807 & 1801 & 1731 & 1639 & 1632 & 1584 & 1483 & 1476 \\
\hline $\mathrm{B}_{2} \mathrm{O}_{3}$ & 1519 & 3331 & 1185 & 1145 & 2861 & 3876 & 1039 & 3242 & 4395 & 940 & 3595 \\
\hline $\mathrm{BaO}$ & 005 & 004 & 004 & 004 & 004 & 004 & 004 & 004 & 004 & 003 & 003 \\
\hline $\mathrm{B}_{12} \mathrm{O}_{\mathrm{y}}$ & 114 & 090 & 989 & पु 86 & 086 & 083 & 978 & 078 & 076 & 071 & i) 70 \\
\hline $\mathrm{CaO}$ & 608 & 478 & 474 & 458 & 457 & 439 & 416 & 414 & 402 & 376 & 374 \\
\hline $\mathrm{CHO}$ & 90 & 012 & $\operatorname{gin}$ & 96 & 002 & 00 & 90 & 002 & 002 & 002 & i) 01 \\
\hline $\mathrm{Cr}_{2} \mathrm{O}_{3}$ & 052 & 041 & 041 & 039 & 039 & 038 & 036 & 035 & 034 & 032 & 032 \\
\hline $\mathbf{F}$ & 067 & 052 & 052 & 050 & 050 & 048 & 046 & 045 & 044 & 041 & 041 \\
\hline $\mathrm{F} \varepsilon_{2} \mathrm{O}_{3}$ & 590 & 464 & 460 & 445 & 443 & 426 & 403 & 402 & 390 & 365 & 363 \\
\hline $\mathrm{K}_{2} \mathrm{O}$ & 0 14 & 011 & 011 & 2470 & 011 & 010 & 3170 & 010 & 009 & 3821 & 009 \\
\hline $\mathrm{Ll}_{2} \mathrm{O}$ & 357 & 281 & 279 & 269 & 268 & 258 & 244 & 243 & 236 & 221 & 720 \\
\hline Mo & 012 & 009 & 009 & 009 & 009 & 008 & 008 & 008 & 008 & 007 & 007 \\
\hline $\mathrm{Na}_{2} \mathrm{O}$ & 958 & 753 & 2943 & 722 & 1485 & 692 & 655 & 1635 & 633 & 593 & 1774 \\
\hline $\mathrm{NIO}$ & 49 & $0 \$ 1$ & 931 & 30 & $0 \mathrm{Bin}$ & 029 & 1927 & 0.7 & 026 & 0.25 & 1) 25 \\
\hline $\mathrm{P}_{2} \mathrm{O}_{3}$ & 105 & 083 & 082 & 079 & 079 & 076 & 072 & 072 & 070 & 065 & 065 \\
\hline $\mathrm{Pb}(\mathrm{b}$ & 41 & 032 & 932 & 1931 & 031 & 030 & 028 & 028 & 027 & 0.25 & 1) 25 \\
\hline $\mathrm{S}_{10} \mathrm{O}_{2}$ & 3050 & 2398 & 2380 & 2299 & 2292 & 2202 & 2086 & 2077 & 2015 & 1887 & 1877 \\
\hline $\mathrm{SO}_{7}$ & 90 & 016 & 916 & 15 & 015 & 014 & 14 & 014 & 013 & 012 & d) 12 \\
\hline $\mathrm{TlO}_{2}$ & प) & 00 & 001 & 19 & 001 & 01 & 19 & 001 & 001 & 001 & i) 01 \\
\hline $\mathrm{ZnO}$ & 108 & 007 & 916 & 16 & 006 & 006 & 016 & 006 & 005 & 005 & 1) 15 \\
\hline$\overline{\mathrm{ZNO}}$ & 93 & 031 & प31 & 30 & 039 & 028 & 127 & 027 & 026 & 024 & 1) 24 \\
\hline Sum & 10000 & 10000 & 10000 & 10000 & 10000 & 10000 & 10000 & 10000 & 10000 & $10000^{\circ}$ & 100000 \\
\hline
\end{tabular}


Table 3.11. Target Compositions for Vitrified Melter Feed with Various Additives During DM10 Melter Rate Tests (wt\%) (continued).

\begin{tabular}{|c|c|c|c|c|c|c|c|c|c|c|}
\hline Base Feetl & \multicolumn{10}{|c|}{ HLW-E-Al-27 with $\mathrm{Al}(\mathrm{OH})_{3}$} \\
\hline Test \#s & $\begin{array}{c}66,86,92,115,118 \\
147,149,215\end{array}$ & $\begin{array}{c}69,95 \\
120\end{array}$ & $72,98,122$ & $\begin{array}{c}76,102 \\
125\end{array}$ & $\begin{array}{c}80,106 \\
145\end{array}$ & 83,109 & 89,112 & 207,209 & 211,213 & 322,226 \\
\hline Feed (g) & $950-1000$ & 950 & 950 & 950 & 950 & 950 & 950 & gin? & 900 & 9000 \\
\hline Type of Additıye & None & Borıc Acid & $\mathrm{Na} 2 \mathrm{CO} 3$ & $\mathrm{~K} 2 \mathrm{CO} 3$ & Borax & $\operatorname{LicO} 3$ & $\mathrm{CaCO} 3$ & Boric Acid & $\mathrm{r} 2 \mathrm{CO} 3$ & Borax \\
\hline Additive (g) & i & 50 & 51 & 51) & 50 & 50 & 5i) & $10 !$ & 10! & 100 \\
\hline $\mathrm{Al}_{2} \mathrm{O}_{3}$ & 2397 & 2217 & 2212 & 2185 & 2182 & 2266 & 2219 & 2047 & 1989 & 1984 \\
\hline $\mathrm{B}_{\mathrm{p}} \mathrm{O}_{\mathrm{y}}$ & 1519 & 2155 & 1401 & 1384 & 2004 & 1436 & $14(6)$ & 2758 & $12(N)$ & 2430 \\
\hline $\mathrm{BaO}$ & 005 & 005 & 005 & 005 & 005 & 005 & 005 & 005 & 004 & 004 \\
\hline $\mathrm{B}_{2} \mathrm{O}_{y}$ & 114 & 11.6 & $1 \omega k$ & 114 & 104 & 108 & 1166 & 098 & 095 & i) 95 \\
\hline $\mathrm{CaO}$ & 608 & 562 & 561 & 554 & 553 & 574 & 1306 & 519 & 504 & 503 \\
\hline $\mathrm{CuO}$ & 102 & 0.2 & 012 & 0.2 & 92 & 002 & d) 2 & 012 & 002 & 1) 12 \\
\hline $\mathrm{Cr}_{2} \mathrm{O}_{3}$ & 052 & 048 & 048 & 047 & 047 & 049 & 048 & 044 & 043 & 043 \\
\hline $\mathbf{F}$ & 067 & 062 & 062 & 061 & 061 & 063 & 1) 62 & 057 & 055 & 055 \\
\hline $\mathrm{Fe}_{2} \mathrm{O}_{3}$ & 590 & 5.46 & 544 & 538 & 537 & 558 & 5.46 & 504 & 489 & 488 \\
\hline $\mathrm{K}_{2} \mathrm{O}$ & 0 14 & 013 & 013 & 900 & 013 & 013 & 013 & 012 & 1716 & 012 \\
\hline $\mathrm{L}_{2} \mathrm{O}$ & 357 & 330 & 329 & 325 & 325 & 883 & 330 & 305 & 296 & 296 \\
\hline $\mathrm{MaO}$ & 012 & 011 & 011 & 011 & 011 & 011 & 011 & 010 & 010 & 010 \\
\hline $\mathrm{Na}_{2} \mathrm{O}$ & 958 & 886 & 1658 & 873 & 1149 & 906 & 887 & 818 & 795 & 1324 \\
\hline $\mathrm{NaO}$ & 40 & 037 & 937 & 036 & 936 & 038 & 1) 37 & 034 & 033 & 1) 33 \\
\hline $\mathrm{P}_{2} \mathrm{O}_{3}$ & 105 & 097 & 097 & 096 & 096 & 099 & 097 & 090 & 087 & 087 \\
\hline $\mathrm{PbO}$ & 41 & 038 & 938 & 0.37 & 037 & 039 & d) 38 & 935 & 0.34 & d) 34 \\
\hline $\mathrm{SIO}_{2}$ & 3050 & 2821 & 2813 & 2779 & 2776 & 2883 & 2823 & 2604 & 2530 & 2524 \\
\hline $\mathrm{SO}_{3}$ & 919 & 018 & 918 & 018 & 018 & 019 & d) 18 & 017 & 017 & d) 17 \\
\hline $\mathrm{T}\left(\mathrm{O}_{2}\right.$ & 01 & 001 & b1 & 001 & by] & 001 & 1) & bo] & 001 & 1) \\
\hline $\mathrm{ZnO}$ & d 18 & 008 & 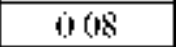 & 008 & ging & 98 & 1) 18 & 907 & 007 & 1) 117 \\
\hline $\mathrm{ZrO}_{2}$ & 039 & 037 & 036 & 036 & 036 & 037 & 037 & 034 & 033 & 033 \\
\hline Sum & 10000 & 10000 & 1000 & 10000 & 10000 & 1000 & 10000 & 10000 & 10000 & 10000 \\
\hline
\end{tabular}


Table 3.11. Target Compositions for Vitrified Melter Feed with Various Additives During DM10 Melter Rate Tests (wt\%), (continued).

\begin{tabular}{|c|c|c|c|c|c|c|c|c|c|c|c|}
\hline Base Fectl & \multicolumn{11}{|c|}{ HLit-E-Al.27 w1th AliOHb } \\
\hline Test \#s & $\begin{array}{c}66,92,118 \\
149,20,5\end{array}$ & 210 & 200 & 212 & 223,227 & 214, 216 & 215,217 & 224,238 & 218,200 & 219,221 & 225 \\
\hline Feed (g) & I0ח? & 850 & 850 & 850 & 850 & 800 & 800 & 800 & 750 & 750 & 750 \\
\hline Type of Additive & None & Bor Acıd & $\mathrm{Ne} 2 \mathrm{CO} 3$ & $\mathrm{K2CO} 3$ & Borax & Borıc Acid & $\mathrm{K} 2 \mathrm{CO} 3$ & Borax & Borıc Acud & $\mathrm{K} 2 \mathrm{CO} 3$ & Borax \\
\hline Additives (g) & 0 & 150 & 150 & 150 & 150 & 200 & 200 & 210 & $25 ! !$ & 250 & 250 \\
\hline $\mathrm{Al}_{2} \mathrm{O}_{3}$ & 2397 & 1885 & 1871 & 1807 & 1801 & 1731 & 1639 & 1632 & 1584 & 1483 & 1476 \\
\hline $\mathrm{B}_{2} \mathrm{O}_{3}$ & 1519 & 3331 & 1185 & 1145 & 2861 & 3876 & 1039 & 3242 & 4395 & 940 & 3595 \\
\hline $\mathrm{BaO}$ & 005 & 004 & 004 & గִ (44 & 004 & 004 & 004 & 004 & 004 & 003 & 003 \\
\hline $\mathrm{Bl}_{2} \mathrm{O}_{3}$ & 114 & 090 & 089 & 086 & 086 & 083 & 078 & 078 & 076 & 071 & 070 \\
\hline $\mathrm{CaO}$ & 608 & 478 & 474 & 458 & 457 & 439 & 416 & 414 & 402 & 376 & 374 \\
\hline $\mathrm{CAO}$ & 002 & 002 & 002 & 002 & 002 & 002 & 002 & 002 & 002 & 002 & 001 \\
\hline $\mathrm{C}_{2} \mathrm{O}_{3}$ & 52 & 041 & 041 & 939 & 039 & 038 & 96 & $0 \$ 35$ & $0 \$ 4$ & 0.32 & 1) 32 \\
\hline$F$ & 067 & 052 & 052 & 950 & 050 & 048 & 046 & 045 & 044 & 041 & 041 \\
\hline $\mathrm{Fe}_{2} \mathrm{O}_{3}$ & 590 & 464 & $4($ (d) & 445 & 443 & 426 & $4(13$ & 402 & 390 & 365 & 363 \\
\hline $\mathrm{K}_{2} \mathrm{O}$ & 914 & 011 & 911 & 2470 & 011 & 010 & 3170 & 010 & 009 & 3821 & 009 \\
\hline $\mathrm{L}_{12} \mathrm{O}$ & 357 & 281 & 279 & 269 & 268 & 258 & 244 & 243 & 236 & 221 & 220 \\
\hline $\mathrm{MgO}$ & 012 & 009 & 009 & 009 & 009 & 008 & 008 & 008 & 008 & 007 & 007 \\
\hline $\mathrm{Na}_{2} \mathrm{C}$ & 958 & 753 & 2943 & 722 & 1485 & 692 & 655 & 1635 & 633 & 593 & 1774 \\
\hline $\mathrm{NIO}$ & 040 & 031 & 031 & 030 & 030 & 029 & 027 & 027 & 026 & 025 & 025 \\
\hline $\mathrm{P}_{2} \mathrm{O}_{5}$ & 165 & 083 & 082 & 079 & 079 & 076 & 072 & 073 & 070 & 065 & 065 \\
\hline $\mathrm{PbO}$ & 041 & 032 & 032 & 031 & 031 & 030 & 028 & 028 & 027 & 025 & 025 \\
\hline $\mathrm{S}_{1} \mathrm{O}_{2}$ & 3050 & 2398 & $2380^{\circ}$ & 2299 & 2292 & 2202 & 2086 & 3077 & 3015 & 1887 & 1877 \\
\hline $\mathrm{SO}_{3}$ & 020 & 016 & 016 & 015 & 015 & 014 & 014 & 014 & 013 & 012 & 012 \\
\hline $\mathrm{T}_{1} \mathrm{O}_{2}$ & 001 & 001 & 001 & 001 & 001 & 001 & 001 & 001 & 001 & 001 & 001 \\
\hline $\mathrm{ZnO}$ & 008 & 007 & 006 & 006 & 006 & 006 & 006 & 006 & 005 & 005 & 005 \\
\hline $\mathrm{ZrO}_{2}$ & 93 & 031 & 931 & 30 & 039 & 028 & 927 & 027 & 026 & 024 & 1) 24 \\
\hline Sull & 100000 & 10000 & 10000 & 100000 & 10000? & 10000 & 10000 & 10000 & 10000 & 10000 & 1000 \\
\hline
\end{tabular}


The Cathold Untwetsty of Amenca Vitreons State Laboratory
ORP-44236, Rev 0

Melt Rate Enhancement for High Alamuntw HLW GLerss Fonmulationts

Final Report, ISL-07RIOIO-1, Rev. 0

Table 3.11. Target Compositions for Vitrified Melter Feed with Various Additives During DM10 Melter Rate Tests (wt\%) (continued).

\begin{tabular}{|c|c|c|c|c|c|c|c|c|c|c|c|c|}
\hline Base Feed & \multicolumn{7}{|c|}{$\mathrm{HLW}$-E-AL-27 with $\mathrm{Al}_{2} \mathrm{O}_{3}$ and Bonc Acid Soda Ash Replacing Borax } & \multicolumn{5}{|c|}{$\begin{array}{l}\mathrm{HLW} \text {-E-Al-27 with } \mathrm{Al}_{2} \mathrm{O}_{3} \text { and Borıs } \mathrm{AcId} \text { ' } \mathrm{K}_{2} \mathrm{CO}_{3} \text { Replacing } \\
\text { Borax }\end{array}$} \\
\hline Test Hs & $\begin{array}{c}67.87 .93 . \\
116\end{array}$ & 70,96 & 73,99 & 77.103 & 81,107 & 84,110 & $\begin{array}{l}90 \\
113\end{array}$ & $\begin{array}{c}68,88,94,117 \\
119,136,148,155\end{array}$ & $71,97,121$ & $\begin{array}{c}74,100 . \\
123\end{array}$ & 78,104 & 82,108 \\
\hline Feed $(\mathrm{g})$ & $950-1000$ & 950 & 950 & 950 & 950 & 950 & 950 & 9501000 & 950 & 950 & 950 & 950 \\
\hline Type of Additiye & None & Bonc Acid & $\mathrm{Na} 2 \mathrm{CO} 3$ & $\mathrm{~K} 2003$ & Borax & $\mathrm{L1} 2 \mathrm{CO} 3$ & $\mathrm{CaCO}$ & None & Boric Acre & $\mathrm{Na} 2 \mathrm{CO} 3$ & $\mathrm{~K} 2 \mathrm{CO} 3$ & Borax \\
\hline Additives (g) & 0 & 50 & 50 & 50 & 50 & 50 & 50 & 0 & 50 & 50 & 50 & 50 \\
\hline $\mathrm{Al}_{2} \mathrm{O}_{3}$ & 2397 & 2217 & 2212 & 2185 & 2181 & 2266 & 2219 & 2397 & 2203 & 2197 & 2167 & 2163 \\
\hline $\mathrm{B}_{2} \mathrm{O}_{3}$ & 1519 & 2155 & 1401 & 1384 & 2008 & 1436 & \begin{tabular}{|l|}
$14 ! 66$ \\
\end{tabular} & 1519 & 2207 & 1392 & 1373 & 20) 47 \\
\hline $\mathrm{BaO}$ & 005 & 005 & 005 & 005 & 005 & 005 & 005 & 005 & 005 & 005 & 005 & 005 \\
\hline$\overline{\mathrm{B}_{2} \mathrm{O}_{3}}$ & 114 & 106 & 166 & 104 & 164 & 198 & 106 & 114 & 105 & 105 & 104 & 103 \\
\hline $\mathrm{CaO}$ & 608 & 562 & 561 & 554 & 553 & 574 & \begin{tabular}{|l|}
1307 \\
\end{tabular} & 608 & 558 & 557 & 549 & 548 \\
\hline $\mathrm{CdO}$ & 612 & 602 & 002 & 602 & $9(12$ & 612 & 002 & 002 & 002 & i) & 002 & 60 \\
\hline $\mathrm{Cr}_{2} \mathrm{O}_{3}$ & 052 & 048 & 048 & 047 & 047 & 049 & 048 & 052 & 048 & 048 & 047 & 047 \\
\hline$F$ & 067 & 062 & 062 & 661 & 61 & 063 & 062 & 067 & 061 & i) 61 & 069 & $0(n)$ \\
\hline$\overline{\mathrm{Fe}_{2} \mathrm{O}_{3}}$ & 590 & 546 & 544 & 538 & 537 & 558 & 546 & 590 & 542 & 541 & 533 & 532 \\
\hline $\mathrm{K}_{2} \mathrm{O}$ & 014 & 013 & 013 & 900 & $\dot{0} 13$ & 013 & 013 & 614 & 564 & 563 & 1514 & 554 \\
\hline $\mathrm{L}_{2} \mathrm{O}$ & 357 & 330 & 329 & 325 & 325 & 883 & 330 & 357 & 328 & 327 & 323 & 322 \\
\hline $\mathrm{MgO}$ & 012 & 011 & u 11 & 011 & $\dot{0} 11$ & 011 & 011 & 012 & 011 & 011 & 011 & 011 \\
\hline $\mathrm{Na}_{2} \mathrm{O}$ & 958 & 886 & 1658 & 873 & 1148 & 906 & 887 & 358 & 329 & 1162 & 324 & 632 \\
\hline No & 040 & 037 & 037 & 036 & 036 & 038 & 037 & 040 & 037 & 037 & 036 & 036 \\
\hline $\mathrm{P}_{2} \mathrm{O}_{3}$ & 105 & 097 & 097 & 096 & 096 & 099 & 097 & 105 & 097 & 096 & 095 & 095 \\
\hline $\mathrm{PbO}$ & 041 & 038 & 038 & 037 & 037 & 039 & 038 & 041 & 038 & 037 & 037 & 037 \\
\hline $\mathrm{S1O}_{2}$ & 3050 & 2821 & 2813 & 2779 & 2774 & 2883 & \begin{tabular}{|l|}
2823 \\
\end{tabular} & 3050 & 2802 & 2795 & 2757 & 2752 \\
\hline$S \mathrm{O}_{3}$ & 920 & 918 & 418 & 018 & 918 & 919 & 018 & 030 & 018 & i) 18 & 018 & 918 \\
\hline $\mathrm{THO}_{2}$ & 001 & 001 & 001 & 001 & 001 & 001 & 001 & 001 & 001 & 001 & 001 & 001 \\
\hline $2 \mathrm{nO}^{\circ}$ & $0 \log 8$ & 008 & 008 & 608 & 908 & $0 \log 8$ & 008 & 008 & 008 & 1) 68 & 007 & 907 \\
\hline $\mathrm{ZrO}_{2}$ & 039 & 036 & 136 & 636 & 936 & 037 & 037 & 039 & 036 & i) 36 & 035 & 036 \\
\hline Sum & 1(1) (10) & 10000 & 10000 & l(M) (N) & ling & 1000 & $10 \mathrm{~g}$ (mi) & 10010 & 100 ing & 10000 & lon ing & 10009 \\
\hline
\end{tabular}


Table 3.11. Target Compositions for Vitrified Melter Feed with Various Additives During DM10 Melter Rate Tests (wt\%) (continued).

\begin{tabular}{|c|c|c|c|c|c|c|c|c|c|c|c|c|c|c|}
\hline Base Feed & \multicolumn{8}{|c|}{ HL hi-E-A]-27 with $\mathrm{Al}_{2} \mathrm{O}_{3}$, and Boric $\mathrm{Aeld} / \mathrm{K}_{2} \mathrm{CO}_{3} \mathrm{Rephang}$ Borax } & \multicolumn{3}{|c|}{ HWI-Al-9Mklt } & \multicolumn{3}{|c|}{ HWi-Al-9K.SH } \\
\hline Test 茾s & $\begin{array}{c}68,94 \\
119.126 . \\
155\end{array}$ & 85,111 & 91,114 & 178 & 165 & 169.178 & 187 & 172 & $\begin{array}{c}154,166,173, \\
175.180,202 . \\
204\end{array}$ & $15 \%$ & 170 & \begin{tabular}{|l|}
156,174 \\
176.179. \\
181,203
\end{tabular} & 157,2016 & 171 \\
\hline Feed (g) & 1000 & 950 & 950 & 900 & 900 & 900 & 850 & 850 & $950-1000$ & 950 & 950 & $950-1000$ & 950 & 950 \\
\hline $\begin{array}{l}\text { Type of } \\
\text { Addilive }\end{array}$ & None & $\overline{\mathrm{L12COA}}$ & GoO3 & Bonc Acld & $\overline{\mathrm{K} 2 \mathrm{CO} 3}$ & Borax & $\mathrm{K} 2 \mathrm{CO}_{3}$ & Borax & None & Boric Acld & Borax & None & $\begin{array}{l}\text { Bonc } \\
\text { Acitl } \\
\end{array}$ & Borax \\
\hline Addilıyes (g) & 0 & 50 & 50 & 100 & 100 & 100 & 150 & 150 & 0 & 50 & 50 & 0 & 50 & 50 \\
\hline $\mathrm{Al}_{2} \mathrm{O}_{3}$ & 2397 & 2255 & $2 \pm 1,4$ & $20 \geq 1$ & 1959 & 1952 & 1768 & 1760 & 2131 & 1970 & 1938 & 2397 & 2217 & 2182 \\
\hline $\mathrm{B}_{2} \mathrm{O}_{3}$ & 1519 & 1429 & 1397 & 2851 & 1241 & 2525 & 1121 & 2960 & 1817 & 2434 & 2278 & 1819 & 2432 & 2277 \\
\hline $\mathrm{BaO}$ & 005 & 005 & 005 & ị & 604 & i! 4 & 0!14 & 604 & 005 & 004 & 004 & 005 & 005 & $0(15$ \\
\hline $\mathrm{Bl}_{2} \mathrm{O}_{3}$ & 114 & 108 & 105 & 096 & 094 & 093 & 084 & 084 & 102 & 094 & 093 & 114 & 106 & 104 \\
\hline $\mathrm{CaO}$ & 608 & 572 & 1364 & 512 & 497 & 495 & 448 & 446 & 096 & 088 & 087 & 108 & 100 & 098 \\
\hline $\mathrm{ClO}$ & 002 & 002 & 002 & $0 \dot{0}$ & 002 & 00 & $0 \dot{0}$ & 002 & 002 & 002 & 002 & 002 & 002 & 00 \\
\hline $\mathrm{Cr}_{2} \mathrm{O}_{3}$ & 052 & 049 & 048 & 044 & 043 & 042 & 038 & 038 & 046 & 043 & 042 & 052 & 048 & 047 \\
\hline$F$ & 067 & 063 & 061 & 056 & 055 & 054 & 049 & 049 & 0.59 & 0.55 & 0.54 & 067 & 062 & 061 \\
\hline $\mathrm{F}_{\bar{z}_{2} \mathrm{O}_{3}}$ & 590 & 555 & 542 & 497 & 482 & 489 & 435 & 433 & 524 & 485 & 477 & 590 & 546 & 537 \\
\hline $\mathrm{K}_{2} \mathrm{O}$ & 614 & 578 & 565 & 518 & 2331 & 500 & 3075 & 451 & 013 & 012 & 011 & 514 & 476 & 468 \\
\hline $\mathrm{L}_{2} 6 \mathrm{G}$ & 357 & 928 & 328 & $3 ! 1$ & 292 & 291 & 263 & 262 & 315 & 291 & 287 & 317 & 293 & 289 \\
\hline $\mathrm{MIgO}$ & 012 & 011 & 011 & 010 & 010 & 010 & 009 & 009 & 010 & 010 & 009 & 012 & 011 & 011 \\
\hline $\mathrm{Na}_{2} \mathrm{O}$ & 358 & 337 & 329 & 302 & 293 & 860 & 264 & 1077 & 1318 & 1219 & 1477 & 858 & 794 & 1057 \\
\hline $\mathrm{N}$ & 040 & 038 & 037 & 034 & 033 & 033 & 029 & 029 & 036 & 033 & 032 & 040 & 037 & 036 \\
\hline $\mathrm{P}_{2} \mathrm{O}_{3}$ & 105 & 099 & 097 & 089 & 086 & 086 & 078 & 077 & 094 & 086 & 085 & 105 & 097 & 096 \\
\hline $\mathrm{PbC}$ & 041 & 038 & 0.38 & 034 & 633 & 033 & 030 & $(130$ & 036 & d) 34 & 033 & 041 & 038 & 037 \\
\hline$\overline{\mathrm{S}_{1} O_{2}}$ & 3030 & 2869 & 2804 & 2571 & 2492 & 2483 & 2250 & 2239 & 3335 & 3084 & 3034 & 2890 & 2673 & 2630 \\
\hline$\$ 03$ & 029 & 019 & 018 & 017 & $(16$ & 016 & 015 & $(115$ & 018 & d) 16 & 016 & 020 & 018 & 018 \\
\hline $\mathrm{TrO}_{2}$ & 001 & 001 & 001 & 001 & 001 & 001 & 001 & 001 & 001 & 001 & 001 & 001 & o0l & 001 \\
\hline $\mathrm{ZnO}$ & 008 & 008 & 008 & 007 & 007 & 007 & 006 & 006 & 007 & 007 & 007 & 008 & 008 & 008 \\
\hline $\mathrm{ZrO}$ & 039 & 037 & 036 & 033 & $(132$ & 032 & 029 & $(129$ & 035 & $0 \sqrt[32]{2}$ & 032 & 039 & 1936 & 036 \\
\hline Sum & 10000 & 10000 & 10000 & 10000 & 10000 & 10000 & 10000 & 10000 & 10000 & 10000 & 10000 & 10000 & 10000 & 10000 \\
\hline
\end{tabular}


Table 3.12. Composition and Properties of Aluminum Limited Waste and Glass Formulation HWI-Al-16 with $\mathbf{4 3 . 6 5 \%}$ Waste Loading (wt $\%$ ).

\begin{tabular}{|c|c|c|c|c|}
\hline- & $\begin{array}{c}\text { Al-Limited } \\
\text { Waste }\end{array}$ & Waste in Glass & $\begin{array}{c}\text { Glass Forming } \\
\text { Additives }\end{array}$ & $\begin{array}{c}\text { Target Glass } \\
\text { HWI-Al-16 }\end{array}$ \\
\hline $\mathrm{Al}_{2} \mathrm{O}_{3}$ & 5327 & 2325 & - & 2325 \\
\hline $\mathrm{B}_{2} \mathrm{O}_{3}$ & 042 & 018 & 1755 & 1773 \\
\hline $\mathrm{B} 80$ & 012 & 005 & - & 005 \\
\hline$\overline{\mathrm{Bt}_{2} \mathrm{O}_{3}}$ & 254 & 111 & - & 111 \\
\hline 69 & 239 & 104 & 485 & 589 \\
\hline $\mathrm{CdO}$ & 005 & 002 & - & 002 \\
\hline $\mathrm{Cr}_{2} \mathrm{O}_{3}$ & 116 & 051 & & 051 \\
\hline$F$ & 148 & 065 & - & 065 \\
\hline $\mathrm{Fe}_{2} \mathrm{O}_{3}$ & 1311 & 572 & - & 572 \\
\hline $\mathrm{K}_{2} \mathrm{O}$ & 031 & 014 & - & 014 \\
\hline $\mathrm{L}_{2} \mathrm{O}$ & 038 & 0.17 & 330 & 346 \\
\hline $\mathrm{MgO}$ & 026 & $(111$ & - & 011 \\
\hline $\mathrm{Na}_{2} \mathrm{O}$ & 796 & 347 & 582 & 929 \\
\hline No & 089 & 039 & - & 039 \\
\hline $\mathrm{P}_{2} \mathrm{O}_{5}$ & 234 & 102 & - & 102 \\
\hline $\mathrm{PbO}$ & 091 & 040 & - & 040 \\
\hline $\mathrm{SO}_{3}$ & 044 & 019 & - & 019 \\
\hline $\mathrm{S}_{1} \mathrm{O}_{2}$ & 1088 & 475 & 2483 & 2958 \\
\hline $\mathrm{T}_{10}$ & 002 & 001 & - & 001 \\
\hline $\mathrm{ZnO}$ & 018 & 008 & - & 008 \\
\hline $\mathrm{ZrO}_{2}$ & 088 & 038 & - & 0.38 \\
\hline Sunı & 1000 & 4365 & 5635 & $1000^{\sharp}$ \\
\hline
\end{tabular}

Renormalized from $\operatorname{Ref}[5]$ after removal of radwactire components

"The sum does not equal to 10000 because of rounding of deciniak

\begin{tabular}{|c|c|c|c|}
\hline \multicolumn{3}{|c|}{ 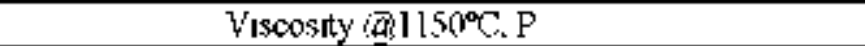 } & 43 \\
\hline \multicolumn{3}{|c|}{ Conductıyity $1150^{\circ} \mathrm{C}, \mathrm{Sicm}$} & 024 \\
\hline \multicolumn{3}{|c|}{ Crystal Content, As Melted } & None \\
\hline \multicolumn{3}{|c|}{ Crystal Content, 72 hr at $95^{\circ} 9^{\circ} \mathrm{C}$} & $16 \%$ \\
\hline \multicolumn{3}{|c|}{ Crystal Content. $C$ CO } & $19 \%$ \\
\hline \multicolumn{3}{|c|}{ TCLP } & Pass \\
\hline \multirow{4}{*}{ PCT, gL } & - & DLVFF-EA & HWI-A1-16 \\
\hline & B & 167 & 0314 \\
\hline & $\mathbf{L}_{\mathbf{I}}$ & 96 & 0394 \\
\hline & Na & 133 & 0283 \\
\hline
\end{tabular}

- Empty data field 
Table 3.13. Composition and Properties of Aluminum Limited Waste and Glass Fonmulation HWI-Al-19 with 45\% Waste Loading (wt\%).

\begin{tabular}{|c|c|c|c|c|}
\hline- & $\begin{array}{c}\text { Al-Limited } \\
\text { Waste }\end{array}$ & Waste in Glass & $\begin{array}{c}\text { Glass Forming } \\
\text { Additives }\end{array}$ & $\begin{array}{c}\text { Targel Glass } \\
\text { HWI-Al-19 }\end{array}$ \\
\hline $\mathrm{Al}_{2} \mathrm{O}_{3}$ & 5327 & 2397 & - & 2397 \\
\hline $\mathrm{B}_{2} \mathrm{O}_{3}$ & 642 & $(19$ & 19 (v) & 1919 \\
\hline $\mathrm{BaO}$ & 012 & 005 & - & 005 \\
\hline $\mathrm{B}_{2} \mathrm{O}_{3}$ & 254 & 114 & - & 114 \\
\hline 690 & 239 & 108 & 450 & 558 \\
\hline $\mathrm{CdO}$ & 005 & 002 & - & 002 \\
\hline $\mathrm{Cr}_{2} \mathrm{O}_{3}$ & 116 & 052 & & 052 \\
\hline $\mathbf{F}$ & 148 & 067 & - & 067 \\
\hline $\mathrm{Fe}_{2} \mathrm{O}_{3}$ & 1311 & 590 & - & 590 \\
\hline $\mathrm{K}_{2} \mathrm{O}$ & 031 & 014 & - & 014 \\
\hline $\mathrm{L}_{1} \mathrm{O}$ & 038 & 017 & 340 & 357 \\
\hline $\mathrm{MgO}$ & 026 & 012 & - & 012 \\
\hline $\mathrm{Na}_{2} \mathrm{O}$ & 796 & 358 & 600 & 958 \\
\hline $\mathrm{NO}$ & 089 & 040 & - & 040 \\
\hline $\mathrm{P}_{2} \mathrm{O}_{5}$ & 234 & 105 & - & 105 \\
\hline $\mathrm{PbO}$ & 091 & 041 & - & 041 \\
\hline $\mathrm{SO}_{\mathrm{y}}$ & 644 & 020 & - & 020 \\
\hline $\mathrm{S}_{1} \mathrm{O}_{2}$ & 1088 & 490 & 2210 & 2700 \\
\hline $\mathrm{T}_{1} \mathrm{O}_{2}$ & 002 & 001 & - & 001 \\
\hline $\mathrm{ZnO}$ & 018 & 008 & - & 008 \\
\hline $\mathrm{ZrO}_{2}$ & 088 & 039 & - & 039 \\
\hline Sum & 1000 & 4500 & 5500 & $1000^{\prime \prime}$ \\
\hline
\end{tabular}

Renormalized from Ref [5] after removal of radicactive components

" The suu does not equal to 10000 because of rounding of decinals

\begin{tabular}{|c|c|c|c|}
\hline \multicolumn{3}{|c|}{ VIscosity $\left(91150^{\circ} \mathrm{C}, \mathrm{P}\right.$} & 33 \\
\hline \multicolumn{3}{|c|}{ Contuctity @1]50 } & 027 \\
\hline \multicolumn{3}{|c|}{ Crystal Content. As Melted } & None \\
\hline \multicolumn{3}{|c|}{ Crystal Content, 72 hr at $95^{\circ} 0^{\circ} \mathrm{C}$} & 13 \\
\hline \multicolumn{3}{|c|}{ Crystal Content, $\mathrm{CCC}$} & 19 \\
\hline \multicolumn{3}{|c|}{ TCLP } & Pass \\
\hline \multirow{4}{*}{ PCT, gL } & - & DWPF-EA & HWI-A1-19 \\
\hline & $\mathrm{B}$ & 167 & 0654 \\
\hline & $\mathrm{L}_{\mathbf{I}}$ & 96 & 0794 \\
\hline & $\mathrm{Na}$ & 133 & 1) 624 \\
\hline
\end{tabular}


The Cathold Untwetsity of Amenca Virreors State Laboratory
ORP-44236, Rev D

Malt Rate Entancement for Hogl Alumintim HLW' Glass Fonmulationts

Final Report, VSL-08R 1360.1, Rev. 0

Table 3.14. Composition of Melter Feed to Produce $100 \mathrm{~kg}$ of Target Glass HWI-Al-16 (Target Glass Yield $=500 \mathrm{~g} / \mathrm{L}$ Feed) from the $\mathrm{Al}$-Limited Waste Simulant Using $\mathrm{Al}(\mathrm{OH})_{3}$ as the Aluminum Source.

\begin{tabular}{|c|c|c|c|}
\hline \multicolumn{2}{|c|}{ Al-Limited Waste Sim ulant } & \multicolumn{2}{|c|}{ Glass-Forming Additives } \\
\hline Starting Materials & Target Weight (kg)" & Starting Materials & Target Weighth (kg)" \\
\hline $\mathrm{Al}(\mathrm{OH})_{y}$ & 35935 & - & - \\
\hline $\mathrm{H}_{3} \mathrm{BO}_{3}$ & 0331 & $\mathrm{H}_{3} \mathrm{BO}_{3}$ & 31487 \\
\hline $\mathrm{BaCO}_{3}$ & 0068 & - & - \\
\hline $\mathrm{Bl}_{2} \mathrm{O}_{3}$ & 1122 & - & - \\
\hline $\mathrm{CaO}$ & 1066 & $\mathrm{CaSIO}_{3}$ (Wollastonite) & 10560 \\
\hline $\mathrm{CdO}$ & 0024 & - & - \\
\hline $\mathrm{Cr}_{2} \mathrm{O}_{3}$ & 0.516 & - & - \\
\hline $\mathrm{NaF}$ & 1438 & - & - \\
\hline $\mathrm{Fe}\left(\mathrm{OH} b_{b}(13 \%\right.$ Slury $)$ & 47083 & - & - \\
\hline $\mathrm{KNO}_{3}$ & $0 \lcm{299}$ & - & - \\
\hline $\mathrm{Ll}_{2} \mathrm{OO}_{3}$ & 0420 & $\mathrm{Ll}_{2} \mathrm{CO}_{3}$ & 8366 \\
\hline $\mathrm{MgO}$ & 0117 & - & - \\
\hline $\mathrm{NaOH}$ & 2124 & $\mathrm{Na}_{2} \mathrm{CO}_{3}$ & 10053 \\
\hline $\mathrm{N}_{1}(\mathrm{OH})_{2}$ & 0498 & - & - \\
\hline $\mathrm{FePO}_{4} x_{2} \mathrm{O}$ & 2711 & - & - \\
\hline $\mathrm{PbO}$ & 0401 & - & - \\
\hline $\mathrm{Na}_{2} \mathrm{SO}_{4}$ & 0.347 & - & - \\
\hline $\mathrm{S}_{1} \mathrm{O}_{2}$ & 4797 & $\mathrm{~S}_{1} \bigcirc_{2}$ & 19643 \\
\hline $\mathrm{T}_{1} \mathrm{O}_{2}$ & 0010 & - & - \\
\hline $\mathrm{ZnO}$ & 0081 & - & - \\
\hline $\mathrm{Zr}(\mathrm{OH})_{4} \cdot \mathrm{H}_{2} \mathrm{O}$ & 0.989 & - & - \\
\hline $\mathrm{H}_{2} \mathrm{O}$ & 95874 & - & - \\
\hline $\mathrm{Na}_{2} \mathrm{CO}_{3}$ & 0304 & - & - \\
\hline $\mathrm{NaNO}_{2}$ & 0336 & - & - \\
\hline $\mathrm{NaNO}_{3}$ & 0,954 & - & - \\
\hline $\mathrm{H}_{2} \mathrm{C}_{2} \mathrm{O}_{4}-2 \mathrm{H}_{2} \mathrm{O}$ & 0115 & - & - \\
\hline- & - & - & - \\
\hline Simulant Tolal & 197950 & Additives Total & 80109 \\
\hline- & - & FEED TOTAL & 278069 \\
\hline
\end{tabular}

" Turget wejghts adyusted for assey information of starting matemals

- Empty data tield 
The Cathold Untwetsity of Amenca Vitreous State Laboratory
ORP-44236, Rev D

Malt Rate Entancement for Hogl Alumintim HLW' Glass Fonmulationts

Final Report, VSL-08R 1360.1, Rev, 0

Table 3.15. Composition of Melter Feed to Produce $100 \mathrm{~kg}$ of Target Glass HWI-Al-16 (Target Glass Yield $=500 \mathrm{~g} / \mathrm{L}$ Feed) from the $\mathrm{Al}$-Linited Waste Simulant Using $\mathrm{Al}_{2} \mathrm{O}_{3}$ as the Aluminum Source.

\begin{tabular}{|c|c|c|c|}
\hline \multicolumn{2}{|c|}{ Al-Limited Waste Simulant } & \multicolumn{2}{|c|}{ Glass-Forming Additives } \\
\hline Starting Materials & Target Weight (kg) ${ }^{*}$ & Starting Materials & Target Weight (kg) ${ }^{*}$ \\
\hline $\mathrm{Al}_{2} \mathrm{O}_{3}$ & 23487 & - & - \\
\hline $\mathrm{H}_{3} \mathrm{BO}_{3}$ & 0.331 & $\mathrm{H}_{\mathfrak{l}} \mathrm{BO}_{\mathfrak{y}}$ & 31487 \\
\hline $\mathrm{BaCO}_{3}$ & 0068 & - & - \\
\hline $\mathrm{Bl}_{2} \mathrm{O}_{3}$ & 1122 & - & - \\
\hline $\mathrm{CaO}$ & 1066 & $\mathrm{CaSiO}_{3}$ (Wollastonte) & 10560 \\
\hline $\mathrm{CdO}$ & 0024 & - & - \\
\hline $\mathrm{C}_{2} \mathrm{O}_{3}$ & 0.516 & - & - \\
\hline $\mathrm{NaF}$ & 1438 & - & - \\
\hline $\mathrm{Fe}(\mathrm{OH})_{3}(13 \%$ Slurry $)$ & 47083 & - & - \\
\hline $\mathrm{KNO}_{3}$ & 0299 & - & - \\
\hline $\mathrm{Ll}_{2} \mathrm{CO}_{3}$ & 0420 & $\mathrm{Ll}_{2} \mathrm{CO}_{3}$ & 8366 \\
\hline $\mathrm{MgO}$ & 0117 & - & - \\
\hline $\mathrm{NaOH}$ & 2124 & $\mathrm{Na}_{2} \mathrm{CO}_{3}$ & 1003 \\
\hline $\mathrm{N}_{1}(\mathrm{OH})_{2}$ & 0498 & - & - \\
\hline $\mathrm{FePO}_{4} \times \mathrm{H}_{2} \mathrm{O}$ & 2711 & - & - \\
\hline $\mathrm{PbO}$ & 0401 & - & - \\
\hline $\mathrm{Na}_{2} \mathrm{SO}_{4}$ & 0.347 & - & - \\
\hline $\mathrm{S}_{1} \mathrm{O}_{2}$ & 4797 & $\mathrm{~S}_{1} \mathrm{O}_{2}$ & 19643 \\
\hline $\mathrm{T}_{10}$ & 0010 & - & - \\
\hline $\mathrm{ZnO}$ & 0081 & - & - \\
\hline $\mathrm{Zr}(\mathrm{OH})_{1} \times \mathrm{H}_{2} \mathrm{O}$ & 0,989 & - & - \\
\hline $\mathrm{H}_{2} \mathrm{O}$ & 105579 & - & - \\
\hline $\mathrm{Na}_{2} \mathrm{CO}_{3}$ & 0.304 & - & - \\
\hline $\mathrm{NaNO}_{2}$ & 0336 & - & - \\
\hline $\mathrm{NaNO}_{3}$ & 0954 & - & - \\
\hline $\mathrm{H}_{2} \mathrm{C}_{2} \mathrm{O}_{4} \cdot 2 \mathrm{H}_{2} \mathrm{O}$ & 0115 & - & - \\
\hline$-^{2}$ & - & - & - \\
\hline Simulant Total & 195217 & Additives Total & 80109 \\
\hline- & - & FEED TOTAL & 275326 \\
\hline
\end{tabular}

* Target wejghts adjusted for assay information of starting matenals

- Eimpty lata ticild 
The Cathold Untwetsity of Amenca Virreors State Laboratory
ORP-44236, Rev D

Malt Rate Entancement for Hogls Alumintim HLW' Glass Fonmulationts

Final Report, VSL-08R 1360.1, Rev. 0

Table 3.16. Composition of Melter Feed to Produce $100 \mathrm{~kg}$ of Target Glass HWI-Al-19 (Target Glass Yield $=500 \mathrm{~g} / \mathrm{L}$ Feed) from the Al-Limited Waste Simulant Using Al(OH), as the Aluminum Source.

\begin{tabular}{|c|c|c|c|}
\hline \multicolumn{2}{|c|}{ Al-Limited Waste Simulant } & \multicolumn{2}{|c|}{ Glass-Forming Additives } \\
\hline Starting Materials & Target Weight (kg) ${ }^{*}$ & Starting Materials & Target Weight (kg) ${ }^{*}$ \\
\hline $\mathrm{Al}(\mathrm{OH})_{5}$ & 37047 & - & - \\
\hline $\mathrm{H}_{3} \mathrm{BO}_{3}$ & 0.341 & $\mathrm{H}_{\mathfrak{l}} \mathrm{BO}_{\mathfrak{y}}$ & 34169 \\
\hline $\mathrm{BaCO}_{3}$ & $007 i$ & - & - \\
\hline $\mathrm{Bl}_{2} \mathrm{O}_{3}$ & 1156 & - & - \\
\hline $\mathrm{CaO}$ & 1099 & $\mathrm{CaSiO}_{3}$ (Wollastonte) & 9798 \\
\hline $\mathrm{CdO}$ & 0025 & - & - \\
\hline $\mathrm{C}_{2} \mathrm{O}_{3}$ & 0.532 & - & - \\
\hline $\mathrm{NaF}$ & 1483 & - & - \\
\hline $\mathrm{Fe}(\mathrm{OH})_{3}(13 \%$ Slurry $)$ & 48539 & - & - \\
\hline $\mathrm{KNO}_{3}$ & 0308 & - & - \\
\hline $\mathrm{Ll}_{2} \mathrm{CO}_{3}$ & 0432 & $\mathrm{Ll}_{2} \mathrm{CO}_{3}$ & 8625 \\
\hline $\mathrm{MgO}$ & 0121 & - & - \\
\hline $\mathrm{NaOH}$ & 2199 & $\mathrm{Na}_{2} \mathrm{CO}_{3}$ & 10364 \\
\hline $\mathrm{N}_{1}(\mathrm{OH})_{2}$ & $0 \$ 14$ & - & - \\
\hline $\mathrm{FePO}_{4} \times \mathrm{H}_{2} \mathrm{O}$ & 2795 & - & - \\
\hline $\mathrm{PbO}$ & 0413 & - & - \\
\hline $\mathrm{Na}_{2} \mathrm{SO}_{4}$ & 0.358 & - & - \\
\hline $\mathrm{S}_{1} \mathrm{O}_{2}$ & 4945 & $\mathrm{~S}_{1} \mathrm{O}_{2}$ & 17276 \\
\hline $\mathrm{T}_{10}$ & 0010 & - & - \\
\hline $\mathrm{ZnO}$ & 0084 & - & - \\
\hline $\mathrm{Zr}(\mathrm{OH})_{1} \times \mathrm{H}_{2} \mathrm{O}$ & 1020 & - & - \\
\hline $\mathrm{H}_{2} \mathrm{O}$ & 91903 & - & - \\
\hline $\mathrm{Na}_{2} \mathrm{CO}_{3}$ & 0.314 & - & - \\
\hline $\mathrm{NaNO}_{2}$ & 0346 & - & - \\
\hline $\mathrm{NaNO}_{3}$ & 0984 & - & - \\
\hline $\mathrm{H}_{2} \mathrm{C}_{2} \mathrm{O}_{4} \cdot 2 \mathrm{H}_{2} \mathrm{O}$ & 0119 & - & - \\
\hline$-^{2}$ & - & - & - \\
\hline Simulant Total & 197148 & Additives Total & 80152 \\
\hline- & - & FEED TOTAL & 277300 \\
\hline
\end{tabular}

* Target wejghts adjusted for assay information of starting matenals

- Eimpty lata ticild 
Table 4.1. Summary of Results from DM100 Tests.

\begin{tabular}{|c|c|c|c|c|c|}
\hline \multicolumn{2}{|r|}{ Test } & 1 & 2 & 3 & 4 \\
\hline \multirow{3}{*}{ 窇 } & Feed Start & $2 / 4 / 08826$ & $2 / 6 / 0812: 15$ & $5 / 5 / 089: 32$ & $5 / 7 / 0814: 32$ \\
\hline & Feed End & $2 / 6 / 0811: 30$ & $2 / 8,0823,00$ & $5 / 7 / 0813-30$ & $5 / 9 / 08 \quad 16: 32$ \\
\hline & Interval & $51.1 \mathrm{hr}$ & $58.75 \mathrm{hr}$ & $52.0 \mathrm{hr}$ & 50.0 \\
\hline \multicolumn{2}{|c|}{ Water Feeding for Cold Cap } & $34 \mathrm{~min}$ & NA & $58 \mathrm{~min}$ & NA \\
\hline \multicolumn{2}{|r|}{ Slurry Fecding } & $50.5 \mathrm{hr}$ & $58.75 \mathrm{hr}$ & $51.0 \mathrm{hr}$ & $50.0 \mathrm{hr}$ \\
\hline \multicolumn{2}{|c|}{ Feeding Interruptions } & $39 \mathrm{~min}$ & $50 \mathrm{~min}$ & $62 \mathrm{~min}$ & $5 \mathrm{~min}$ \\
\hline \multicolumn{2}{|c|}{ Target Glass Temperature } & $1200^{\circ} \mathrm{C}$ & $1150^{\circ} \mathrm{C}$ & $1200^{\circ} \mathrm{C}$ & $1150^{\circ} \mathrm{C}$ \\
\hline \multicolumn{2}{|c|}{ Average Bubbling Rate } & $9.31 \mathrm{pm}$ & $9.2 \mathrm{lpm}$ & $9.1 \mathrm{lpm}$ & $90 \mathrm{lpm}$ \\
\hline \multirow{7}{*}{ 胥 } & Aluminum Source & Hydroxide & Hydroxide & Hydroxide & Hydroxide \\
\hline & Target Glass & HLW-E-Al-27 & HLW-E-Al-27 & HWI-AI-16 & HWI-Al-16 \\
\hline & Waste Loading & $45 \%$ & $45 \%$ & $43.6 \%$ & $43.6 \%$ \\
\hline & Used & $854 \mathrm{~kg}$ & $527 \mathrm{~kg}$ & $879 \mathrm{~kg}$ & $617 \mathrm{~kg}$ \\
\hline & \multirow{2}{*}{ Target Glass yield } & $500 \mathrm{~g} / 1$ & $500 \mathrm{~g} / 1$ & $500 \mathrm{~g} / 1$ & $500 \mathrm{~g} / 1$ \\
\hline & & $0.3596 \mathrm{~kg} / \mathrm{kg}$ & $0,3596 \mathrm{~kg} / \mathrm{kg}$ & $0.358 \mathrm{~kg} / \mathrm{kg}$ & $0.358 \mathrm{~kg} / \mathrm{kg}$ \\
\hline & Average Feed Rate & $16.9 \mathrm{~kg} / \mathrm{hr}$ & $9.0 \mathrm{~kg} / \mathrm{hr}^{\prime}$ & $16.9 \mathrm{~kg} / \mathrm{hr}$ & $123 \mathrm{~kg} / \mathrm{hr}$ \\
\hline \multirow{4}{*}{$\begin{array}{l}\text { उ. } \\
\frac{3}{8} \\
\frac{8}{2} \\
\frac{\pi}{0} \\
\frac{8}{0}\end{array}$} & Poured & $239 \mathrm{~kg}$ & $251 \mathrm{~kg}$ & $225 \mathrm{~kg}$ & $281 \mathrm{~kg}$ \\
\hline & Average Rate ${ }^{*}$ & $1351 \mathrm{~kg} / \mathrm{m}^{2}$ day & $717 \mathrm{~kg} / \mathrm{m}^{2} /$ day & $1371 \mathrm{~kg} / \mathrm{m}^{2} /$ day & $982 \mathrm{~kg} / \mathrm{m}^{2} /$ day \\
\hline & Steady State Rate & $1200 \mathrm{~kg} / \mathrm{m}^{2} / \mathrm{day}$ & $700 \mathrm{~kg} / \mathrm{m}^{2} /$ day & $1400 \mathrm{~kg} / \mathrm{m}^{2} / \mathrm{day}$ & $950 \mathrm{~kg} / \mathrm{m}^{2} /$ day \\
\hline & Average Power Use & $\begin{array}{l}4.1 \mathrm{~kW} \mathrm{hr} / \mathrm{kg} \\
\text { glass }\end{array}$ & $\begin{array}{l}5.4 \mathrm{~kW} \text { hr } \mathrm{kg} \\
\text { glass }\end{array}$ & $\begin{array}{l}4.2 \mathrm{~kW} \mathrm{hr} / \mathrm{kg} \\
\text { glass }\end{array}$ & $\begin{array}{c}4.4 \mathrm{~kW} \mathrm{hr} / \mathrm{kg} \\
\text { glass }\end{array}$ \\
\hline
\end{tabular}

*-Rates calculated from feed data.

Note: Rates do not take into account the time for water feeding and cold cap burn-off. 
Table 4.1. Summary of Results from DM100 Tests (continued).

\begin{tabular}{|c|c|c|c|c|c|}
\hline & Test & 5 & 6 & 7 & 8 \\
\hline \multirow{3}{*}{ 兽 } & Feed Start & 62081252 & $6 / 4 ; 081730$ & $6 / 23 / 08756$ & $6: 25 / 081215$ \\
\hline & Fèd End & $6 / 40815301$ & $6 / 708030$ & $6: 25 \sin 1130$ & 627082330 \\
\hline & Interval & 3itghr & $550 \mathrm{hr}$ & $516 \mathrm{hr}$ & 5925 \\
\hline \multicolumn{2}{|c|}{ Water Feeding for Cold Cap } & $38 \mathrm{mmn}$ & NA & $64 \mathrm{~min}$ & NA \\
\hline \multicolumn{2}{|r|}{ Slurry Feedung } & $500 \mathrm{hr}$ & $550 \mathrm{hr}$ & $505 \mathrm{hr}$ & $5925 \mathrm{hr}$ \\
\hline \multicolumn{2}{|c|}{ Feedung Interruptions } & $13 \mathrm{mmn}$ & $42 \mathrm{mmn}$ & $38 \mathrm{~min}$ & $13 \mathrm{~mm}$ \\
\hline \multicolumn{2}{|c|}{ Target Glass Temperalure } & $1300^{\circ} \mathrm{C}$ & $1150^{\circ} \mathrm{C}$ & $1200^{\circ} \mathrm{C}$ & $1150^{\circ} \mathrm{C}$ \\
\hline \multicolumn{2}{|c|}{ Average Bubbling Rate } & $86 \mathrm{lpm}$ & $88 \mathrm{Ipm}$ & $90 \mathrm{lpm}$ & $901 \mathrm{pm}$ \\
\hline \multirow{7}{*}{ 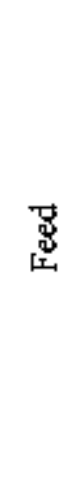 } & Alum trium Source & Oxile & Oxile & Hydroxide & Hydroxide \\
\hline & Target Glass & HWI-Al-16 & HWI.Al- 16 & HLV-All-19 & HWV.Al-19 \\
\hline & Waste Loading & $436 \%$ & $436 \%$ & $45 \%$ & $45 \%$ \\
\hline & Used & $806 \mathrm{~kg}$ & $510 \mathrm{~kg}$ & $902 \mathrm{~kg}$ & $693 \mathrm{~kg}$ \\
\hline & \multirow{2}{*}{ Target Glass yneld } & $500 \mathrm{~g} / 1$ & $500 \mathrm{~g} / 1$ & $500 \mathrm{~g} / \mathrm{l}$ & $500 \mathrm{~g}$ \\
\hline & & $0363 \mathrm{~kg} / \mathrm{kg}$ & $0363 \mathrm{~kg} / \mathrm{kg}$ & $0361 \mathrm{~kg} / \mathrm{kg}$ & $0361 \mathrm{~kg} / \mathrm{kg}$ \\
\hline & Average Feed Rate & $161 \mathrm{~kg} / \mathrm{hr}$ & $93 \mathrm{~kg} / \mathrm{hr}$ & $179 \mathrm{~kg} / \mathrm{hr}$ & $117 \mathrm{~kg} / \mathrm{hr}$ \\
\hline \multirow{4}{*}{ 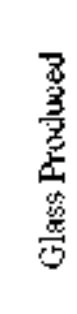 } & Poured & $214 \mathrm{~kg}$ & $254 \mathrm{~kg}$ & $245 \mathrm{~kg}$ & $239 \mathrm{~kg}$ \\
\hline & Average Rale & $1291 \mathrm{~kg} \mathrm{~m}^{2}$ iday & $748 \mathrm{~kg} / \mathrm{m}^{2}$ itlay & $1434 \mathrm{~kg} / \mathrm{m}^{2}$ iday & $938 \mathrm{~kg} \mathrm{~m}^{2} / \mathrm{day}$ \\
\hline & Steady State Rate" & $1300 \mathrm{~kg} / \mathrm{m}^{2} / \mathrm{day}$ & $700 \mathrm{~kg}^{2} \mathrm{ml}^{2} /$ day & $1500 \mathrm{~kg} \mathrm{im}^{2} / \mathrm{day}$ & $950 \mathrm{~kg} \mathrm{~m}^{2} / \mathrm{day}$ \\
\hline & Average Power Use & $\begin{array}{l}4 \mathrm{l} \text { khi hr:kg } \\
\text { glass }\end{array}$ & $\begin{array}{c}48 \mathrm{~kW} \text { hrikg } \\
\text { glass }\end{array}$ & $\begin{array}{l}4 \text { ] kW hr/kg } \\
\text { glass }\end{array}$ & $\begin{array}{c}46 \mathrm{~kW} \text { hrikg } \\
\text { glass }\end{array}$ \\
\hline
\end{tabular}

*. Rates calculated from feed data

Note Rates do not take mto account the tisne for water feeding and cold cap bum-off 
Table 4.2. Stendy-State Production Rates Achieved with HLW Compositions on the DM100 at Melt Pooh Bubbling of $9 \mathrm{lpm}$ and Solids content near 500 g glass/liter.

\begin{tabular}{|c|c|c|c|}
\hline HLW Waste & Glass Yield (g/) & $\begin{array}{l}\text { Glass Temperature } \\
\left({ }^{\circ} \mathrm{C}\right)\end{array}$ & $\begin{array}{c}\text { Production Rate } \\
\mathrm{kg}^{2} \mathrm{~m}^{2} \text { day }\end{array}$ \\
\hline \multirow{2}{*}{$\begin{array}{c}\text { Alumunum Limited } \\
\text { (HLW-E-Al-27, Al hylroxide) }\end{array}$} & 500 & 1200 & 1200 \\
\hline & 500 & 1150 & $7(n)$ \\
\hline \multirow{2}{*}{$\begin{array}{c}\text { Aluminum Limited } \\
\text { (HIVI-Al-16. Al hydroxide) }\end{array}$} & 500 & IIny & 1400 \\
\hline & 500 & 1150 & 950 \\
\hline \multirow{2}{*}{$\begin{array}{l}\text { Alumirum Limited } \\
\text { (HWI-Al-16, AI oxule) }\end{array}$} & 500 & IIing & 1300 \\
\hline & 500 & 1150 & $7(W)$ \\
\hline \multirow{2}{*}{$\begin{array}{c}\text { Aluminum Limited } \\
\text { (HWI-Al-19. Al hydroxide) }\end{array}$} & 500 & 1200 & 1500 \\
\hline & 500 & 1150 & 950 \\
\hline \multirow{2}{*}{$\begin{array}{c}\text { Aluminum Limited } \\
\text { (HLIV.E-Al-27, Al oxide) }\end{array}$} & 500 & 1175 & $550)$ \\
\hline & 500 & 1150 & 550 \\
\hline \multirow{2}{*}{ Ahummum and Sodium Limited [?] } & 500 & 1175 & $g(n)$ \\
\hline & 500 & 1150 & $4(4)$ \\
\hline \multirow{2}{*}{ Bismuth Limited [2] } & 500 & 1175 & 1000 \\
\hline & 500 & 1150 & $831)$ \\
\hline \multirow{2}{*}{ Chrom num Limited [2] } & 500 & 1175 & 1300 \\
\hline & 500 & 1150 & 1150 \\
\hline $\mathrm{A} Z-101[14]$ & 5.30 & 1150 & 1300 \\
\hline AZ-10z Norumal kheology [a3] & 550 & 1150 & 1200 \\
\hline AZ-102. Adjusted Rheology [23] & 550 & 1150 & 1400 \\
\hline C-106/AY-102. SIPP [15] & 470 & 1150 & 1190 \\
\hline HLWio2-24, H1gh V/Scosity [24] & 500 & 1150 & $g(n)$ \\
\hline HLWV-ALG-17, Low Viscosity [24] & 500 & 1150 & 1600 \\
\hline HLW-ALG-16. Hıgh Conductivity [24] & 500 & 1150 & 1209 \\
\hline HLWW02-46, Low Conduet1vity [24] & 500 & 1150 & 900 \\
\hline C.106/AY-102 $[24]$ & 500 & 1150 & $1000^{\circ}$ \\
\hline ClikfAY-102+1.5\%GFCs [24] & 500 & 1150 & 1009 \\
\hline C. $106 \%$ AY $-102-15 \%$ GFCs $[24]$ & 500 & 1150 & 1050 \\
\hline $\begin{array}{l}\text { C-106/AY-102 replacing borax w wh boric ac1d } \\
\text { and soda ash [20] }\end{array}$ & 500 & 1150 & 1050 \\
\hline $\mathrm{C}-106 / \mathrm{AY}-102, \mathrm{SIO}_{2}-33 \%[25]$ & 500 & 1150 & 2000 \\
\hline$C .106 \mathrm{AY}-102, \mathrm{~S}_{1} \mathrm{O}_{2}=531 \%[25]$ & 500 & 1150 & 700 \\
\hline $\mathrm{C}-106 / \mathrm{AY}-102, \mathrm{MnO}=8 \%[25]$ & 500 & 1150 & 750 \\
\hline $\mathrm{C}-106 / \mathrm{AY}=10 \mathrm{C}, \mathrm{Na}_{2} \mathrm{O}-200 \%$ [25] & 500 & 1150 & 2150 \\
\hline $\begin{array}{l}\mathrm{C}-106 / \mathrm{AY}-102, \mathrm{~K}_{2} \mathrm{O}=25 \%, \mathrm{Cr}_{2} \mathrm{O}_{3}=06 \% \\
\mathrm{~L} \mathrm{a}_{2} \mathrm{O}_{3}=12 \%, \mathrm{~T}_{3} \mathrm{O}_{2}=1 \%, \mathrm{ZnO}=4 \%[25]\end{array}$ & 500 & 1150 & 1709 \\
\hline Clink AY-102. $\mathrm{B}_{2} \mathrm{O}_{3}=43 \%[25]$ & 500 & 1150 & g(in) \\
\hline $\mathrm{C}-106 \mathrm{AY}-102 . \mathrm{B}_{2} \mathrm{O}_{2}=15 \%[25]$ & 500 & 1150 & 1550 \\
\hline $\mathrm{C}-106 / \mathrm{AY}-102, \mathrm{Al}_{2} \mathrm{O}_{2}=13 \%[25]$ & 500 & 1150 & 900 \\
\hline $\mathrm{C}-106 \mathrm{AY}-102 . \mathrm{Ln} \mathrm{O}=0 \%[25]$ & 500 & 1150 & $450)$ \\
\hline Algorıthen Genernted. $\mathrm{ZrO}_{2}=1065 \%[25]$ & 500 & 1150 & 850 \\
\hline Algorıthen Generated, $\mathrm{SrO}=927 \%$ [25] & 500 & 1150 & 650 \\
\hline
\end{tabular}


Table 4.3. Summary of Mensured DV100 Parameters.

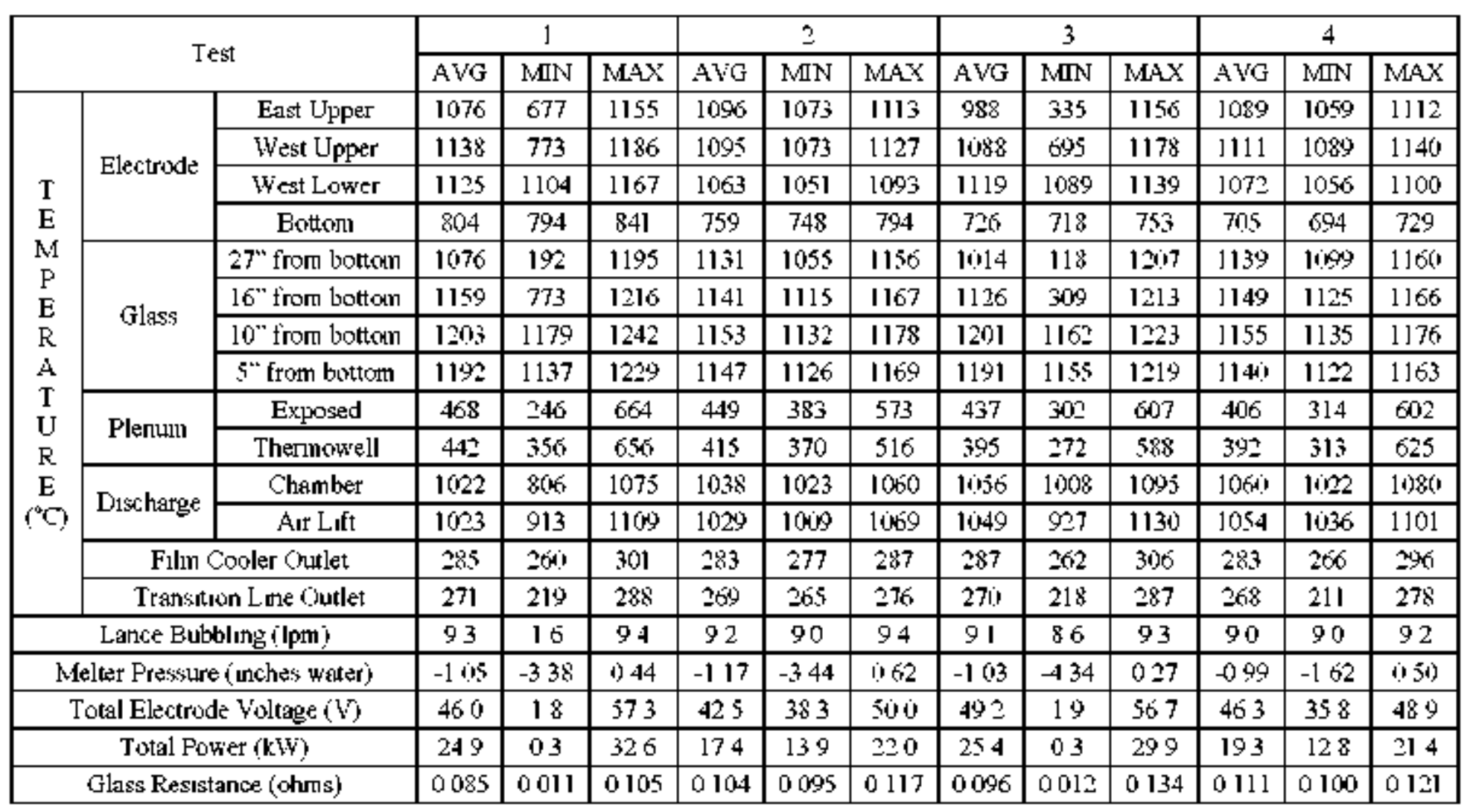


The Catholic Untwersty of Amenca
ORP-44236, Rev 0

Mell Rate Entanticment for Hrgh Altwintim HLW Glass Fomulations

Fonal Report, WSL-0BRI 360-1, Rev 0

Table 4.3. Summary of Measured DMI00 Parameters (continued).

\begin{tabular}{|c|c|c|c|c|c|c|c|c|c|c|c|c|c|c|}
\hline \multirow{2}{*}{\multicolumn{3}{|c|}{ Test }} & \multicolumn{3}{|c|}{5} & \multicolumn{3}{|c|}{6} & \multicolumn{3}{|c|}{7} & \multicolumn{3}{|c|}{8} \\
\hline & & & $A V G$ & $\mathrm{MIN}$ & MAX & $A V G$ & MIN & MLAX & $\mathrm{AVG}$ & $\mathrm{MTN}$ & $\mathrm{MAX}$ & $A V G$ & $\mathrm{MmN}$ & MARX \\
\hline \multirow{14}{*}{$\begin{array}{c}\mathrm{T} \\
\mathbf{E} \\
\mathrm{M} \\
\mathrm{P} \\
\mathrm{E} \\
\mathrm{R} \\
\mathrm{A} \\
\mathrm{T} \\
\mathrm{U} \\
\mathrm{R} \\
\mathrm{E} \\
\left({ }^{\circ} \mathrm{C}\right)\end{array}$} & \multirow{4}{*}{ Electrode } & East Lיןper & 1044 & 719 & 1151 & 1072 & 1010 & 1105 & 1042 & 482 & 1156 & 1087 & 1067 & 1]41 \\
\hline & & West Upper & 1083 & 758 & 1153 & 1073 & 1019 & 1118 & 1107 & 716 & 1170 & 1103 & 1084 & 1169 \\
\hline & & Wiest Lowrer & 1126 & 1108 & 1144 & 1062 & 1035 & 1093 & 1134 & 1114 & 1150 & 1081 & 1068 & $1] 43$ \\
\hline & & Bottor & 716 & 650 & 734 & 699 & 689 & 729 & 714 & 655 & 733 & 7012 & 693 & 733 \\
\hline & \multirow{4}{*}{ Glass } & 27 from bottim & 1129 & 721 & $12(19)$ & 1138 & 1094 & 1160 & 1058 & 323 & 1202 & 1120 & 1075 & 1176 \\
\hline & & 16" from bottom & 1187 & 867 & 1221 & 1149 & 1120 & 1170 & 1118 & 240 & 1304 & 1133 & 1096 & $1] 83$ \\
\hline & & 10 " from bottom & 130 & 1177 & 1227 & 1157 & 1123 & 1185 & 1190 & 1150 & 1214 & 1146 & 1122 & 1200 \\
\hline & & 5" from buttom & 1195 & 1163 & 1217 & 1135 & 1103 & 1168 & 129) 2 & 1173 & 1219 & 1153 & 1132 & 1210 \\
\hline & \multirow{2}{*}{ Plenum } & Exposed & 462 & 316 & 649 & 412 & 157 & 621 & 505 & 417 & 655 & 446 & 345 & 626 \\
\hline & & Thetrmourell & 417 & 286 & 631 & 378 & 156 & 663 & 468 & 397 & 622 & 413 & 343 & 396 \\
\hline & \multirow{2}{*}{ D1scharge } & Chamber & 1063 & 1039 & 1097 & 1058 & 1022 & 1081 & 1061 & 1004 & 1099 & 1060 & 978 & 1084 \\
\hline & & Ait Lift & 1061 & 983 & 1134 & 1048 & $102 A$ & 1120 & 1065 & 967 & 1167 & 1062 & 1007 & 1115 \\
\hline & \multicolumn{2}{|c|}{ Film Cooler Cutlet } & 286 & 256 & 307 & 275 & 241 & 292 & 285 & 281 & 296 & 279 & 268 & 287 \\
\hline & \multicolumn{2}{|c|}{ Transition Lone Outlet } & 272 & 219 & 291 & 263 & 229 & 275 & 273 & 232 & 283 & 268 & 213 & 274 \\
\hline \multicolumn{3}{|c|}{ Lance Bubblıng (Ipm) } & 86 & 11 & 89 & 88 & 86 & 90 & 90 & 15 & 91 & 90 & 89 & 95 \\
\hline \multicolumn{3}{|c|}{ Melter Pressure (unches water) } & -090 & .239 & 031 & .099 & -366 & 031 & -097 & .320 & 080 & .099 & -286 & 038 \\
\hline \multicolumn{3}{|c|}{ Total Electrode Yoltage (V) } & 482 & 12 & 570 & 430 & 391 & 490 & 472 & 12 & 570 & 415 & 289 & 452 \\
\hline \multicolumn{3}{|c|}{ Total Power (kw) } & 239 & 116 & 280 & 163 & 139 & 200 & 263 & 106 & 282 & 188 & 100 & 260 \\
\hline \multicolumn{3}{|c|}{ Glass Ressstance (ohrms) } & 0098 & 0082 & 0132 & 0114 & 0093 & 0151 & 0086 & 0072 & 0136 & 0092 & 0078 & 0101 \\
\hline
\end{tabular}


Table 5.1. Summary of DM1200 Test Conditions and Results.

\begin{tabular}{|c|c|c|c|c|}
\hline & - & 1 & 2 & 3 \\
\hline & Feed Start & $8 / 6018921$ & 8111081445 & $8 / 134181605$ \\
\hline 嘼 & Feed End & $8: 8 / 051021$ & $8: 13: 041600$ & $8 ! 15: 081930$ \\
\hline & Interval & $490 \mathrm{hr}$ & $4925 \mathrm{hr}$ & $\$ 14 \mathrm{hr}$ \\
\hline Wiater & eding tor Cold Cap & $10 \mathrm{hr}$ & $10 \mathrm{hr}$ & NA \\
\hline & ury Feedng & $480 \mathrm{hr}$ & $4825 \mathrm{hr}$ & $514 \mathrm{hr}$ \\
\hline & old cap bum & $32 \mathrm{hr}$ & NA & $40 \mathrm{hr}$ \\
\hline Ave & e Total Bubloilng & 125 Ipn & $65 \mathrm{lpm}$ & 54 lan \\
\hline Ste: & y State Bubbling & $124 \mathrm{IpnI}$ & $7 \mathrm{lpm}$ & $48 \mathrm{Ipm}$ \\
\hline & $\begin{array}{l}\text { verage Glass } \\
\text { nperature, East }\end{array}$ & $11.9 \mathrm{C}^{2} \mathrm{C}$ & $1154^{\circ} \mathrm{C}$ & $1178^{\circ} \mathrm{C}$ \\
\hline & $\begin{array}{l}\text { verage Glass } \\
\text { perature, Wiest }\end{array}$ & $1148^{\circ} \mathrm{C}$ & $1146^{\circ} \mathrm{C}$ & $1170^{\circ} \mathrm{C}$ \\
\hline & $\begin{array}{l}\text { erage Plenum } \\
\text { emperature }\end{array}$ & $653^{\circ} \mathrm{C}$ & $571^{\circ} \mathrm{C}$ & $595^{\circ} \mathrm{C}$ \\
\hline Aver & e Electrode Powert & $225 \mathrm{~kW}$ & $170 \mathrm{~kW}$ & $181 \mathrm{~kW}$ \\
\hline$\Gamma_{0}$ & Used & $9942 \mathrm{~kg}$ & $6932 \mathrm{~kg}$ & $7498 \mathrm{~kg}$ \\
\hline & Average Rate & $2071 \mathrm{~kg} / \mathrm{hr}$ & $1437 \mathrm{kghr}$ & $1459 \mathrm{~kg} / \mathrm{hr}$ \\
\hline 뭉 & Poured & $3737 \mathrm{~kg}$ & $2404 \mathrm{~kg}$ & $2732 \mathrm{~kg}$ \\
\hline 西 & Av' erayge Rates & $15.57 \mathrm{~kg} / \mathrm{m}^{2} / \mathrm{day}$ & $996 \mathrm{~kg}^{2} \mathrm{~m}^{2} / \mathrm{day}$ & $1063 \mathrm{~kg} / \mathrm{m}^{2} / \mathrm{day}$ \\
\hline 出 & Avernuge Ratè & $1495 \mathrm{~kg} / \mathrm{m}^{2} / \mathrm{day}$ & $1038 \mathrm{~kg} \mathrm{~m}^{2} / \mathrm{day}$ & $1053 \mathrm{~kg} / \mathrm{m}^{2} / \mathrm{day}$ \\
\hline 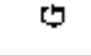 & Steady State Rate & $1500 \mathrm{~kg} / \mathrm{m}^{2} / \mathrm{day}$ & $1050 \mathrm{kgmm}^{2} / \mathrm{day}$ & $1050 \mathrm{~kg} / \mathrm{m}^{2} / \mathrm{day}$ \\
\hline
\end{tabular}

\$- Rates calculated from glass poured

"'- Rates calculated from feed dak

Note Rates do not take unlo account the time for water feeding and cold cap burti-ofr NA Nol applicable 
Table 5.2. Summary of Operational Events.

\begin{tabular}{|c|c|c|}
\hline \multirow[b]{2}{*}{ Test } & \multicolumn{2}{|r|}{ Operational notes } \\
\hline & $\begin{array}{l}\text { Run time } \\
\text { (hours) }\end{array}$ & Run time note \\
\hline \multirow{22}{*}{1} & 0.0 & Start water feeding at $8 / 6 / 20089: 21$ \\
\hline & 1.0 & Started slurry feeding \\
\hline & 5.3 & Paused feeding for 5 minutes to collect feed sample. \\
\hline & 7.5 & During the SBS blowdown, Y-strainer clogged and was cleaned out. \\
\hline & 10.5 & Transferred feed from mixing tank to feed tank. \\
\hline & 109 & Film cooler rinse was performed. \\
\hline & 11.0 & $\begin{array}{l}\text { During film cooler rinse, it was discerned the film cooler was }-90 \% \text { clogged } \\
\text { Paused feeding for } 8 \text { minutes to manually clear film cooler. }\end{array}$ \\
\hline & 20.2 & Transferred feed from mixing tank to feed tank. \\
\hline & 23.4 & Film cooler rinse was performed. \\
\hline & 26.7 & Took picture of cold cap through melter view port (see Figure 5.1) \\
\hline & $27.4-27.5$ & Performed WESP deluge, pre-blowdown and post blow down \\
\hline & 30.4 & Transferred feed from mixing tank to feed tank. \\
\hline & 33.4 & Paused feeding for 4 minutes to collect feed sample. \\
\hline & 35.0 & $\begin{array}{l}\text { Melter tripped into Emergency Off Gas lime because port was opened to } \\
\text { remove exhaust sampling probe. Exhaust immediately returned to main line. }\end{array}$ \\
\hline & 35.6 & $\begin{array}{l}\text { Film cooler rinse was performed. Film cooler blockage was }-40-50 \% \text {. Film } \\
\text { cooler rinse opened up the blockage. Below the film cooler there was still } \\
\text { residual blockage of about } 10 \% \text { after rinsing. }\end{array}$ \\
\hline & 40.7 & Transferred feed from mixing tank to feed tank. \\
\hline & 49.00 & Feed stopped at the end of Test 1. \\
\hline & 49.6 & $\begin{array}{l}\text { Opened port C-1 (see Figure 1.6) to retrieve a cold cap sample. The gasket } \\
\text { ring was replaced. }\end{array}$ \\
\hline & 49.9 & Film cooler rinse was performed. \\
\hline & 51.0 & Feed transferred to mixing tank for Test 2 . \\
\hline & $51.9-60.0$ & Performed WESP deluge, pre-blow down and post blow down. \\
\hline & 52.2 & Off gas shut down is completed. \\
\hline
\end{tabular}


Table 5.2. Summary of Operational Events (continued).

\begin{tabular}{|c|c|c|}
\hline \multirow[b]{2}{*}{ Test } & \multicolumn{2}{|r|}{ Operational notes } \\
\hline & $\begin{array}{c}\text { Run time } \\
\text { (lnours) }\end{array}$ & Run time note \\
\hline \multirow{21}{*}{2} & - & Transferted feed from movng tark to feed tank \\
\hline & 00 & Start water feding at $8 / 11 / 20081445$ \\
\hline & 10 & Slutry feed started \\
\hline & 74 & Paused feedung for 6 munutes to collect feed sample \\
\hline & 106 & Filn cooler rinse was performed \\
\hline & 149 & Transferred feed from muxing tank to feed tank \\
\hline & $18]$ & Transtemed feed to moxing lank \\
\hline & 223 & Paused feeding fort 6 minutes to collect feed semple \\
\hline & 231.233 & Blower 701 falled Paused feeding for 13 minutes to switch to Blower 7i)2 \\
\hline & 235 & $\begin{array}{l}\text { Melter tnpped into Emergency Oft Gas line because port was opened for } \\
\text { remow al of exhaust sempling probe Exhaust unned]ately returned to mam } \\
\text { lune }\end{array}$ \\
\hline & 236.239 & Performed WESP deluge, pre-blow down and post blow down \\
\hline & 238 & Film coolet runse was performed \\
\hline & 253 & $\begin{array}{l}\text { Melter tripped into Emergency Off Gas line due to port opened to remove } \\
\text { exhaust sampling probe Exhaust immedately returned to main line }\end{array}$ \\
\hline & 296 & Transferred feed from mixing tank to feed tank \\
\hline & 349 & F1lm cooler rinse was performed \\
\hline & 412 & $\begin{array}{l}\text { Replaced Blower-701 head for back-up Observed that Blower-702 oullet } \\
\text { temperature is } 90^{\circ} \mathrm{C} \text { This could cause premature fallure Reduced Blower } \\
\text { setting from } 46 \text { to } 45 \mathrm{~Hz} \text { and increased Blower sol setting from } 21 \text { to } 23 \mathrm{~Hz}\end{array}$ \\
\hline & 443 & Transferred feed from musng tark to feed tank \\
\hline & 473 & Film cooler runse was performed \\
\hline & $481-482$ & Perform ing WESP deluge, pre-blow down and post blow dowits \\
\hline & 492 & Film cooler rinse was performed \\
\hline & 493 & Feed stoppet at ent of Test 2 Feet sample was also collected \\
\hline
\end{tabular}


Table 5.2. Summary of Operational Events (continued).

\begin{tabular}{|c|c|c|}
\hline \multirow[b]{2}{*}{ Test } & \multicolumn{2}{|r|}{ Operational notes } \\
\hline & $\begin{array}{l}\text { Run time } \\
\text { (hours) }\end{array}$ & Run time note \\
\hline \multirow{22}{*}{3} & 493 & Changed test conditions at $8 / 13 / 20081605$ \\
\hline & $565-566$ & Fllm cooler differental pessure was up, 95 "WiC film conler was cleared \\
\hline & 583 & Transferred feed from m ixing tank to feed tank: \\
\hline & 639.641 & $\begin{array}{l}\text { Feed tube was partally clogged Tapped with haminer to dislodge the } \\
\text { blockage Feed was penused for } 13 \text { m trut to Feed sample wras collected }\end{array}$ \\
\hline & 646 & $\begin{array}{l}\text { Electric high temperature alann sounded (East Electrode themocouple } \\
\text { reading. TR-21 }=1172^{\circ} \mathrm{C} \text { ) Reduced power from } 150 \text { to } 145 \mathrm{kWW} \text {, bater electric } \\
\text { was shut down Increased lence bubbler } 2 \text { flow rate from } 20 \text { to } 22 \text { lpm }\end{array}$ \\
\hline & 649 & $\begin{array}{l}\text { Electric alann was cleared Sounded East Electrode themocouple reading } \\
\text { was } 1164^{\circ} \mathrm{C}\end{array}$ \\
\hline & 660 & Transfented feed from m kung tank to feed tank \\
\hline & 662 & $\begin{array}{l}\text { Cold cap ridge or cone collapsed, causing pressure surge Energency Off Gas } \\
\text { was actuated Exhaust } 1 \text { mimediately retumel to main line }\end{array}$ \\
\hline & $716-718$ & Perfonmed WESP deluge, pe-blow down and post blow down \\
\hline & $73]$ & Transferred feed from mixing tank to feed tank \\
\hline & 732 & Film cooler runse was performed \\
\hline & 7710 & $\begin{array}{l}\text { High Temperature alarm and power shut off set points attached to the East } \\
\text { Electrode themocouple were inereased to } 1175^{\circ} \mathrm{C} \text { and } 1180^{\circ} \mathrm{C} \text { respectively }\end{array}$ \\
\hline & 848 & Film cooler rinse was performed \\
\hline & 863 & Transferted feed from musug tark to feed tank \\
\hline & 884 & Feed tube was manually flusihed \\
\hline & 925 & Paused feeding for 7 nunutes to collect feed saniple \\
\hline & 967 & Film cooler rinse was performed \\
\hline & $\begin{array}{l}997 \text { and } \\
1007\end{array}$ & $\begin{array}{l}\text { Tapped on the feed tube w clear the stalactute which was growing under the } \\
\text { feed tuhe }\end{array}$ \\
\hline & 1008 & Feed stopped at the end of Test 3 \\
\hline & 1020 & Removed feed from feed tank \\
\hline & 1060.1064 & Performed WESP deluge, pre-blowi down and post blow down \\
\hline & 1076 & Started melter and off-yens shut down \\
\hline
\end{tabular}


Table 5.3. Operator Observations of Cold Cap (CC).

\begin{tabular}{|c|c|c|c|c|}
\hline Test & Date & Tune & $\begin{array}{c}\text { Run } \\
\text { Tinne } \\
\text { (hours) }\end{array}$ & Cold Cap Otseryations \\
\hline \multirow{29}{*}{1} & \multirow{29}{*}{86,2008} & 921 & 00 & Started feedng water at $\$($ wi $\mathrm{mL} / \mathrm{m}$ on \\
\hline & & 1103 & 17 & $\begin{array}{l}C C \sim B \% \% \text { is flat with borlinit on top and feed flowing into openting in } S \text {. } \\
\text { E\&N-W comers }\end{array}$ \\
\hline & & 1115 & 19 & $\begin{array}{l}\text { CC } 75-80 \% \text { with liquid bolling profusely ant flowing into openings in } \\
\text { between feed shots }\end{array}$ \\
\hline & & 1134 & 22 & OC - -75-80\% w ith liquid boilong profusely \\
\hline & & 11 si! & 25 & Copentury on east swle of melter is larger than west \\
\hline & & 1205 & 27 & CC $\sim 80 \%$ with liquid boiling \\
\hline & & 1211 & 28 & CC is $-85 \%$ with liculd flowing to operings in between feed shots \\
\hline & & 1233 & 32 & $\begin{array}{l}\mathrm{CC} \sim 85 \% \text { Flat }-6 \% \text { thick with feed bouling on surface Opening on } \mathrm{S}-\mathrm{E} \text { and } \\
\mathrm{N}-\mathrm{W} \text { corners with feed flowng into the openings }\end{array}$ \\
\hline & & 1305 & 37 & $\begin{array}{l}\mathrm{CC}-85 \% \text { - } 6 " \text { thick with small ndge around openings on S-E } \& \text { N-W } \\
\text { comers Feed bonling on the surface and flowing onto openumss }\end{array}$ \\
\hline & & 1312 & 39 & CC unchanged \\
\hline & & $134 !$ & 43 & $\begin{array}{l}\text { Increase bubblung from } 60 \text { to } 80 \mathrm{lpm}, \mathrm{CC}-85 \% \text { with mare aggresswe liqud } \\
\text { bollung oluserved }\end{array}$ \\
\hline & & 1353 & 45 & CO is still - 84 L $85 \%$ with liquid bolling and flow ung thith openungs \\
\hline & & 1407 & 48 & CC. $-85 \%$ with Inquid nuldly boilung and flowing into openungs \\
\hline & & 1419 & 50 & 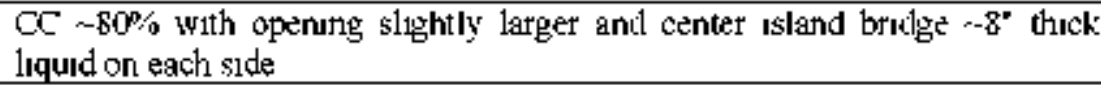 \\
\hline & & 1443 & 54 & CC $-80-85$ and $6-8^{n}$ thick bouling liquid powl and oenter ridge \\
\hline & & 1505 & 57 & C) $-80-\%$ couple of high 1 idges around openings; \\
\hline & & 1535 & 62 & $C C .-80 \%$ and $6-8 "$ thick \\
\hline & & 1556 & 66 & $C C$-gno Can not see east openung due to center ndge \\
\hline & & 1613 & 69 & $\begin{array}{l}\text { CC - }-90 \% \text {, No yisible changes other than larger amount of liquid is flowing } \\
\text { unto melt pool }\end{array}$ \\
\hline & & 1635 & 72 & CC $-85 \%$ Feed is slow to boil but is boiling in between each feed shot \\
\hline & & 1649 & 75 & C, $85 \%$, Nat able $w$ see a ast $\$ 1$ de anymore due to ridge on that s1de \\
\hline & & 1710 & 78 & $\begin{array}{l}\text { CC }-80 \% \text {. large ridge appens to be neas center of melter, can not see east } \\
\text { swle }\end{array}$ \\
\hline & & 1726 & 81 & $C C-75 \%$, large rolge is st1ll present as well as bu1d up on the west wall \\
\hline & & 1738 & 83 & $\begin{array}{l}\text { Co } 75 \% \text {. Ildge seems smaller and vigorously bonlonis feed can be seen on } \\
\text { the east side of the melter }\end{array}$ \\
\hline & & 1753 & 85 & CC $-75 \%$ appears to be the same as last observation \\
\hline & & 1808 & 88 & $\begin{array}{l}\text { Co }-75 \% \text {, appears as before but buld up on the west wall which is just south } \\
\text { of middle view port extencls out past but does not yet touch T/N2 }\end{array}$ \\
\hline & & 1822 & 90 & $C=-75 \%$ \\
\hline & & 1837 & 93 & $\begin{array}{l}\text { CC } \sim 75 \% \text {, buld up has now surrounded Thi } \# 2 \text {, otherwise conditions aplear } \\
\text { unchanged }\end{array}$ \\
\hline & & $184 !$ & 93 & $\begin{array}{l}\text { Increased bubbling on Lance } 1 \text { from } 55 \text { to } 85 \text { Ipm, try to shift the cap around } \\
\text { to lweak the IIdges }\end{array}$ \\
\hline
\end{tabular}


Table 5.3. Operator Observations of Cold Cap (CC) (continued).

\begin{tabular}{|c|c|c|c|c|}
\hline Test & Date & Time & $\begin{array}{l}\text { Run } \\
\text { Tume } \\
\text { (hours) }\end{array}$ & Cold Cap Obsctiations \\
\hline \multirow{26}{*}{1} & \multirow{12}{*}{$8 / 612008$} & 1850 & 95 & $\begin{array}{l}\text { Increased Lance } 2 \text { from } 65 \text { to } 85 \text { lpm and at Lance } 1 \text { reduced bubbling from } \\
85 \text { to } 55 \mathrm{lpm} \text { Trymg to shift capiridges around }\end{array}$ \\
\hline & & 1855 & 96 & $\begin{array}{l}\text { CC } \sim 80 \% \text { The opening on west side has closed up some Feed is bollung over } \\
\text { the ridye Not able to see enst side at this time }\end{array}$ \\
\hline & & 1909 & 98 & 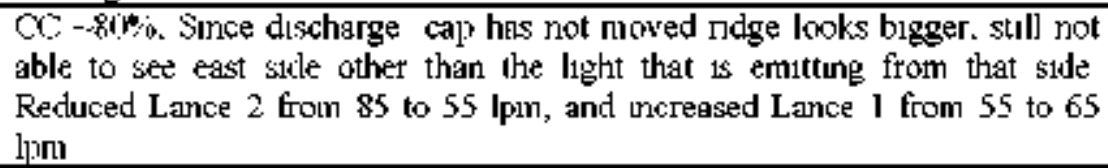 \\
\hline & & 2012 & 109 & $\begin{array}{l}\text { CC }-80 \% \text {, large ridge on the west side is high not allowing to see enst side } \\
\text { Increased bubbling on Lance } 2 \text { tion } 65 \text { to } 901 \text { pm to see if this will break it } \\
\text { down }\end{array}$ \\
\hline & & 2041 & 113 & $\begin{array}{l}\text { CC }-75 \% \text {, Glass level is low Increased bubbling on Lance } 1 \text { to } 85 \text { from } 65 \\
\text { lpm and reduced bubbling on Lance } 2 \text { from } 90 \text { to } 65 \text { lpm }\end{array}$ \\
\hline & & 2108 & 118 & $C,-75 \%$ yery little or no change \\
\hline & & 2213 & 129 & $\begin{array}{l}\text { CC. } \sim 85 \% \text {, ndge st1ll divides east and west East s1de openung can not be seen } \\
\text { Nothung can be seen through middle } \psi_{\text {Iew port }}\end{array}$ \\
\hline & & 2228 & 131 & $C C-85 \%$ as hefore \\
\hline & & 2255 & 136 & $\begin{array}{l}\text { C) - } 80-85 \% \text {, olening y1sible around Lance ? with slight ndge around Light } \\
\text { 1s wisible on east wall }\end{array}$ \\
\hline & & 2310 & 138 & $\mathrm{CO}-80-85 \%$, bastcally unchanged \\
\hline & & 2332 & 142 & $C C-75-80 \%$ \\
\hline & & 2340 & 143 & CC $-80 \%$ Ridge on the west srile seems lower \\
\hline & \multirow{14}{*}{$8 / 7 / 2008$} & 008 & 148 & $\begin{array}{l}\text { C. is at } 85 \% \text {. ndge is much smaller around Lance }{ }_{2} 2 \text {. light is stall yisible on } \\
\text { east }\end{array}$ \\
\hline & & 053 & 155 & C) $-85 \%$, large ridge in center of melter \\
\hline & & 142 & 164 & CC--85\%, ridge has grown laroger near Lafice \#2 \\
\hline & & 223 & 170 & $C C \sim 85 \%$, but ridge m center/ seems to be growing with uncreased bulbbling \\
\hline & & 237 & 173 & CC $-85 \%$, only openung on the west wall partially visible \\
\hline & & 259 & 176 & $\begin{array}{l}\text { From the suruth veew port, "existing wall like" portion of cold cap, positioned } \\
\text { just below the feed tube and stands }<\text { or }=12^{n}\end{array}$ \\
\hline & & 339 & 183 & CC. $-85 \%$, and no v1sible change \\
\hline & & 358 & 186 & $\begin{array}{l}\text { Larges mound growing in nielter seen } \psi 19 \text { south vew port. also large glazed } \\
\text { rudge near Lance } 甘 2\end{array}$ \\
\hline & & 425 & 191 & $\begin{array}{l}\text { Raised and lowered bubbling on both Lance's in an effort to break down large } \\
\text { mound in south view port with no suocess }\end{array}$ \\
\hline & & 451 & 195 & Large mound is still in place around Lance \#2 \\
\hline & & 504 & 197 & Mound is still in place \\
\hline & & 517 & 199 & $\begin{array}{l}\text { Co }-75-80 \% \text {, mound is still in place but starting to see more liquid feed } \\
\text { trickling off of tricge by Lance to and flowing into melt pool }\end{array}$ \\
\hline & & 534 & 202 & $\begin{array}{l}\text { CC - } 80 \% \text {, nound still in place, however, ndge around Lance \#2 has broken } \\
\text { down some }\end{array}$ \\
\hline & & 549 & 205 & CC. $-80-85 \%$ \\
\hline
\end{tabular}


Table 5.3. Operator Observations of Cold Cap (CC) (continued).

\begin{tabular}{|c|c|c|c|c|}
\hline Test & Date & Time & $\begin{array}{c}\text { Run } \\
\text { Tume } \\
\text { (hours) }\end{array}$ & Cold Cap Observations \\
\hline \multirow{27}{*}{1} & \multirow{27}{*}{$8 / 7 / 2008$} & 602 & 207 & $C C-80-85 \%$ \\
\hline & & 705 & 217 & $\begin{array}{l}\text { C) }-85 \% \text {, Latge ridge th center of melter Openings on S-E and N-W } \\
\text { comers Large mound has formed around feed tube }\end{array}$ \\
\hline & & 714 & 219 & $\begin{array}{l}\text { CC-95\%, large ridge and funnel below feed tube Openings on S-E and N-WV } \\
\text { comers }\end{array}$ \\
\hline & & 725 & 221 & $\begin{array}{l}\text { OC } 90-95 \% \text {, with large ridge in center with funnel below feed tube } \\
\text { Openings at S-E and N-W corners }\end{array}$ \\
\hline & & 750 & 225 & $\begin{array}{l}\text { Co - }-90 \% \text {, with high center Lught visible on east side Liciuld wisibly flowing } \\
\text { into L2 bubbler Opening on west side }\end{array}$ \\
\hline & & 810 & 228 & CC conditions are stable $-90-95 \%$ with liculul flowing \\
\hline & & 822 & 230 & CC $-95^{\circ} \%$. liqud flowing into openungs Light visible on east side \\
\hline & & 837 & 233 & No visible change in CC contitions \\
\hline & & 915 & 239 & $C C-95 \%$ with larye ridge in center with optnings wn S-E and N-W comers \\
\hline & & 940 & 243 & 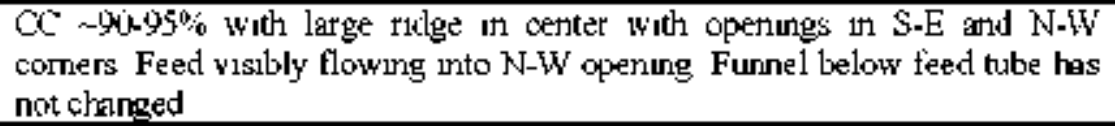 \\
\hline & & 1010 & 248 & $\begin{array}{l}\text { CC -90-95\%, large ndge in center with openings in S-E and N-Wi comers } \\
\text { Feed is flowing untw N-W corner }\end{array}$ \\
\hline & & 1045 & 254 & C) is at $90.95 \%$ with same conditions as before \\
\hline & & 1110 & 258 & OC conditions unchanged (90-95\%) \\
\hline & & 1150 & 26.5 & $\begin{array}{l}\text { CC-90-95\% with large ridge in center with openings on S-E and N-WW } \\
\text { comers Feed tlowing unto } \mathrm{N}-\mathrm{W} \text { comer opening }\end{array}$ \\
\hline & & 1200 & 267 & $\begin{array}{l}\text { Collected picture of the cold cap thru } N \text { ylewport showing part of cep } \\
\text { thickness }\end{array}$ \\
\hline & & 1220 & 270 & $\begin{array}{l}\text { Co -9int\%. Large rilge in center with openings on S-E and N-W corners feed } \\
\text { is flowing into N-W corner }\end{array}$ \\
\hline & & 1241.1 & 273 & Unchanged from prequ kus obterervatikn $(C \mathrm{C}-90-9.5)$ \\
\hline & & 1314 & 279 & $\begin{array}{l}\text { Co }-95 \% \text {, Opening at Lance } 2 \text { hes a "glazed" face Cone helow feed tulie has } \\
\text { growts, it is now almost out of vicw al top }\end{array}$ \\
\hline & & 1320 & 280 & Dislodgug cone below feed tube manually Munor pressure spike \\
\hline & & 1329 & 281 & $C O-95 \%$ \\
\hline & & 1344 & 284 & 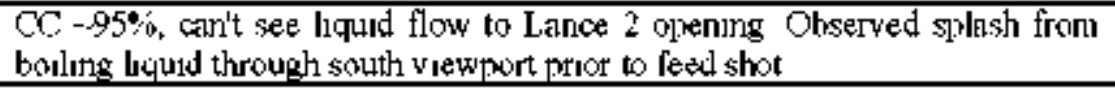 \\
\hline & & 1400 & 287 & CC $-95 \%$ Some lquid now Houring unto Lance 2 onening \\
\hline & & 1417 & 289 & CC $-86 \%$, 11culut bouling in center and flow ing to Lance 2 opentig \\
\hline & & 1434 & 292 & 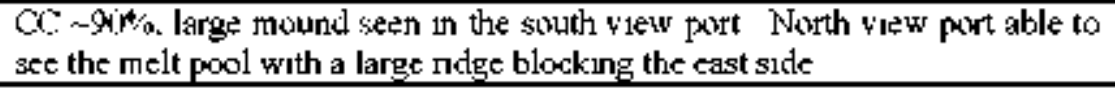 \\
\hline & & 1450 & 295 & $O C$-gno, No risible changes at this tume \\
\hline & & $15 \mathrm{c}$ & 297 & $\begin{array}{l}\text { Increased Latice } 1 \text { from } 60 \text { to } 80 \mathrm{lpm} \text {, trying to collapse the large mound } \\
\text { undemeath feed tube }\end{array}$ \\
\hline & & 1508 & 298 & CC $-90 \%$, starting to see more glow from east side No change on west side \\
\hline
\end{tabular}


Table 5.3. Operator Observations of Cold Cap (CC) (continued).

\begin{tabular}{|c|c|c|c|c|}
\hline Test & Date & Time & $\begin{array}{c}\text { Run } \\
\text { Tume } \\
\text { (hours) }\end{array}$ & Cold Cap Observations \\
\hline \multirow{28}{*}{1} & \multirow{28}{*}{$8 / 7 / 2008$} & 15201 & 300 & $\begin{array}{l}\text { CC -90\% The cap dropped when glass was discharged The mound looks } \\
\text { smaller due to thes }\end{array}$ \\
\hline & & 1539 & 303 & CC $-90^{\circ} \%$, west side capinound is startung to melt down \\
\hline & & 1554 & 306 & $C .-85 \%$. mound on wrast side contumues to melt \\
\hline & & 1609 & 308 & CC $-90 \%$, more liquid is thowing into the wrest opening \\
\hline & & 1616 & 309 & Not much has melted down from the mound on the west stde CC-90\% \\
\hline & & 1639 & 313 & $\begin{array}{l}\text { CC }-90^{\circ} \% \text { Not much light seen emitting from east side through the south } \\
\text { vew port West side mound has bult up some ower the opening }\end{array}$ \\
\hline & & 1648 & 315 & CC. $-90 \%$ \\
\hline & & 1713 & 319 & $C C-90 \%$ \\
\hline & & 1726 & 321 & $\begin{array}{l}C C-90 \% \text {, able to see feed looling hetween shots Mounds and shots have not } \\
\text { grown any }\end{array}$ \\
\hline & & 1742 & 324 & $\begin{array}{l}\text { Co -90\%\% some melting of mound on west side very little changes } \\
\text { elsewhere }\end{array}$ \\
\hline & & 1755 & 326 & $\begin{array}{l}\text { CC -9no\%, The face of the west side mound looks glazed now East side } \\
\text { unchanged }\end{array}$ \\
\hline & & 1811 & 328 & Co-90\% same as before \\
\hline & & 1826 & 331 & $\begin{array}{l}\text { CC }-90^{\circ} \% \text {, lange glazed ridge can be seen in north port, moderate size circular } \\
\text { ridge } v_{1 \text { isible in south port }}\end{array}$ \\
\hline & & 1852 & 335 & $C C-g 0 \%$, no y Isbble changes at this the \\
\hline & & 1910 & 338 & $\begin{array}{l}\text { Co }-90 \% \text { There is large cone shaped mound undermenth the feed tulve It has } \\
\text { gotten larger and taller }\end{array}$ \\
\hline & & 1917 & 339 & Melter pressure spiked almost prositive due to off-gas sampling \\
\hline & & 1937 & 343 & CC $-90 \%$, conditions have not changed \\
\hline & & 1954 & 346 & $\begin{array}{l}C C-90 \%, \text { North side mound is meltung It does not look as glazed from } \\
\text { previous observalion }\end{array}$ \\
\hline & & 2011 & 348 & CC $-95 \%$, Not much light coming from east swile \\
\hline & & 2020 & 350 & $C O-90 \%$ \\
\hline & & 2038 & 353 & $\begin{array}{l}\text { CC- }-90 \text {, Able to see more light on the east side WVest side mound is glazed } \\
\text { over melt pool is smaller with a secondary cap forming }\end{array}$ \\
\hline & & 2055 & 356 & 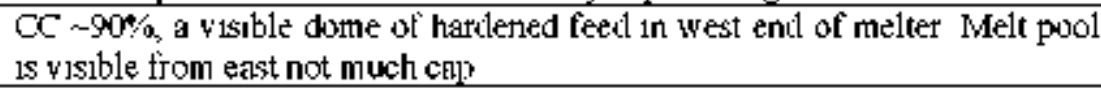 \\
\hline & & 2129 & 361 & $\begin{array}{l}C C \sim 85 \% \text {, a very large glazed wall of glass is visible through north view port } \\
\text { Cylunder like mound which is large can he seen from south port }\end{array}$ \\
\hline & & 2143 & 364 & CC $-85 \%$, conditions are same as previously noted \\
\hline & & 2206 & 368 & CC $-25 \%$, appears unchanged \\
\hline & & 2256 & 376 & $\begin{array}{l}\text { CC - } 80-85 \% \text {, mound is still in place when y iewed from south port and glazed } \\
\text { ridge near Lance } \# 2 \text { although feed is nowr flowing mto openung }\end{array}$ \\
\hline & & 2313 & 379 & $C C-80^{\circ} \%$, large opening stıll present near Lance $\# 2$ Mound unchanged \\
\hline & & 2339 & 383 & CO unchanged sunce prev rous observation \\
\hline
\end{tabular}


Table 5.3. Operator Observations of Cold Cap (CC) (continued).

\begin{tabular}{|c|c|c|c|c|}
\hline Test & Date & Time & $\begin{array}{c}\text { Run } \\
\text { Tume } \\
\text { (hours) }\end{array}$ & Cold Cap Observations \\
\hline \multirow{25}{*}{1} & $8 / 7 / 3008$ & 2358 & 386 & $C C-80-85 \%$ urchanged \\
\hline & \multirow{24}{*}{$8: 82008$} & 033 & 392 & $C C-\$ 0 \%$ unchanged \\
\hline & & 109 & 398 & CC $-80^{\circ} \%$ unchanged \\
\hline & & 127 & 401 & $\begin{array}{l}\text { CC-80-85\% seem like mound has grown taller while ridge has broken down } \\
\text { somewhat }\end{array}$ \\
\hline & & 212 & 409 & Mound still growing, $\mathrm{CC}$ at $85 \%$ \\
\hline & & 255 & 416 & CC - $80-85 \%$, urchanged \\
\hline & & 317 & 419 & $C C-80 \%$ \\
\hline & & 325 & 421 & $\begin{array}{l}\text { Increasing Lance from } 80 \text { to } 120 \text { lpon did not have any eflect on mound } \\
\text { Mound is growing close to melter cellung }\end{array}$ \\
\hline & & 339 & 423 & Mound is large near cellung \\
\hline & & 408 & 428 & $\begin{array}{l}\text { Manually dislodged top of mound allowing feed to flow to melt pool A } \\
\text { bylmonduct of thes seems that glass temps have come hack }\end{array}$ \\
\hline & & 423 & 430 & $\begin{array}{l}\text { Attempted once again to dislodge some of the mound but unable to make } \\
\text { contact with it CC- }-85 \% \text { ralges has broken down sone }\end{array}$ \\
\hline & & 543 & 444 & $\begin{array}{l}\text { CC } \sim 85 \% \text {, ridge near Lance } 2 \text {, has some feed flow ung over it thto melt pool } \\
\text { Majority of mound still eyident yia south riew port }\end{array}$ \\
\hline & & 627 & 451 & No light visible \\
\hline & & 635 & 452 & $\begin{array}{l}\text { CC }-85 \% \text {, frige thear Latice } 2 \text { show's some glazing but liquid flowing into } \\
\text { opening Part of mound still evident via south viewport }\end{array}$ \\
\hline & & 655 & 456 & $\begin{array}{l}\text { Co }-85 \% \text {, some liquid flowing to } \mathrm{L} 2 \text { opening } A \text { small amount of light is } \\
\text { qusible from east side }\end{array}$ \\
\hline & & 710 & 458 & Cold cap unchanged $(95 \%)$ \\
\hline & & 725 & 461 & $\begin{array}{l}\text { CC }-95^{\circ} \% \text { with liquld thowing to L2 opening East side shows some light } \\
\text { reflection on wall }\end{array}$ \\
\hline & & 740 & 463 & Cold cap unchanged \\
\hline & & 751 & 465 & $\begin{array}{l}\text { Observing liquid in center "cone" area is boiling more vigorously pror to } \\
\text { shot the shot with bubbling increased }\end{array}$ \\
\hline & & $8(65$ & 468 & $\begin{array}{l}\text { Opening around L2 shows a more glazed sufface to cap material with tho } \\
\text { liqud flow Center area still bouls vigorously, covered stall }-95 \%\end{array}$ \\
\hline & & 827 & 471 & 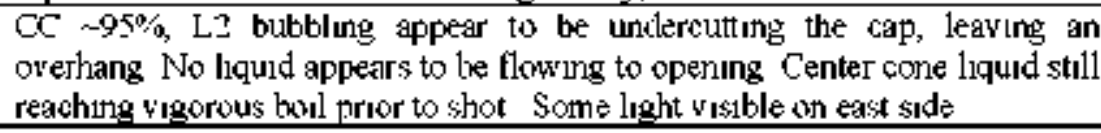 \\
\hline & & 843 & 474 & CC $-90-95 \%$ unchanged visually $10-12$ "thick w1th bollong loquid in center \\
\hline & & 952 & 485 & Some light on east side \\
\hline & & 1006 & 488 & CC unchanged $90-95 \%, 10-12 "$ thick \\
\hline & & 10:21 & 49.0 & End of Test 1 . \\
\hline
\end{tabular}


Table 5.3. Operator Observations of Cold Cap (CC) (continued).

\begin{tabular}{|c|c|c|c|c|}
\hline Test & Date & Time & $\begin{array}{l}\text { Run } \\
\text { Time } \\
\text { (hours) }\end{array}$ & Colil Cap Observatıons \\
\hline \multirow{18}{*}{1} & \multirow{18}{*}{$8: 8: 2008$} & 1055 & 496 & 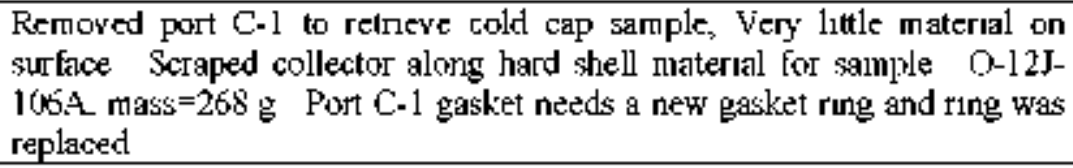 \\
\hline & & 1105 & 497 & Shelf $C C$ still $\sim 80 \%$, and $10-12 "$ thick \\
\hline & & 1118 & 500 & $\begin{array}{l}\text { Shelf begunting to lissolve and expose cavities writhlun Still thick at center } \\
\text { with cone still in place }-12 \text { " at thuckest pounl }\end{array}$ \\
\hline & & 1126 & 501 & $\begin{array}{l}\text { Shelf has dropped from bottom side and ptorided a partial }(-30 \%) \text { cold cap } \\
\text { with } 2-3 " \text { separation to a shelfibridge }\end{array}$ \\
\hline & & 1145 & 504 & Shelf dissolving fon trotton but stall bridged over melt pool \\
\hline & & 1205 & 507 & $\begin{array}{l}\text { Large clumps of cold capibndge pieces in S-WW and N-E comers Openungs } \\
\text { in middle and S-E and N-wi comers Obseryed } 2 \text { mounds on south side of } \\
\text { pool } \sim 8-10^{\circ} \text { thick tw mound or bridge observed through } N \text { viewport } \\
\text { About } 5 \% \text { feed material dessolving on glass surface }\end{array}$ \\
\hline & & 1225 & 511 & $\begin{array}{l}\text { Mount in south area dum mished But still visible through S viewport } \\
\text { Suggestmg } 6-8^{\prime \prime} \text { thick }\end{array}$ \\
\hline & & 1237 & 387 & $\begin{array}{l}\text { Mounds of material have dropped to melt surface Mounds are }-1-1 \text { ?" in } \\
\text { djameter and }-4-46^{\prime \prime} \text { thick }\end{array}$ \\
\hline & & 1105 & 497 & Shelf/CC still $\sim 80^{\circ}$, and $10-12^{\prime \prime}$ thick \\
\hline & & 1118 & 500 & 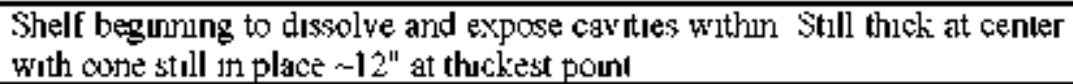 \\
\hline & & 1126 & 501 & $\begin{array}{l}\text { Shelf has dropped from bottom side and priwided a partial }(\cdot-30 \%) \text { cold cap } \\
\text { with } 2-3 \text { " separation to a sheltibridge }\end{array}$ \\
\hline & & 1145 & 5i) 4 & Shelf dissolving from bottom but still bridged werer melt pool \\
\hline & & 1205 & 51) 7 & 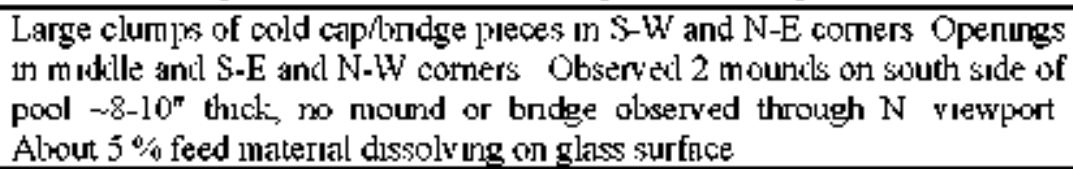 \\
\hline & & 1225 & 511 & $\begin{array}{l}\text { Mound in south area dim inished But still visible through S viewrint } \\
\text { Suggestmg } 6-8^{n} \text { thick }\end{array}$ \\
\hline & & 1237 & 387 & $\begin{array}{l}\text { Mounds of material have dropped to melt surface Mounds are } \sim 1 \cdot 12^{n} \text { in } \\
\text { djameter and }-4-6^{n} \text { thick }\end{array}$ \\
\hline & & 1258 & 516 & Cold cap log of feed materıal floatıng on surface \\
\hline & & 1304 & 387 & $\begin{array}{l}\text { Cold cap material dissolved down to } 3^{\prime \prime} \times 10^{\prime \prime} \text { logs Two chunks of feed } \\
\text { material strll floating on surface One is about the size of a football the } \\
\text { other me is about the size of a softhall }\end{array}$ \\
\hline & & 1317 & 520 & $\begin{array}{l}\text { Only a small area of darker material on melt surface remains No feed } \\
\text { material solids } \psi 1 \text { istele Colclcap } 1 \text { sone }\end{array}$ \\
\hline \multirow{5}{*}{2} & \multirow{5}{*}{$811: 2006$} & 1445 & 00 & Slarted fedinge water for test 2 \\
\hline & & 1555 & 12 & 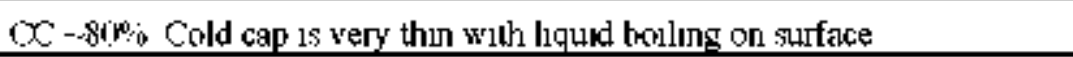 \\
\hline & & 1610 & 14 & $\begin{array}{l}C X-75^{\%} \text {, apenings on thoth sides East side onenung is larger than west } \\
\text { slde's Cokl cap is flat at this time }\end{array}$ \\
\hline & & 1623 & 16 & $O C-80$, Starting to get thicker \\
\hline & & 1637 & 19 & $\mathrm{CC}-80^{\%} \%$, it is a little thicker than last observation \\
\hline
\end{tabular}


Table 5.3. Operator Observations of Cold Cap (CC) (continued).

\begin{tabular}{|c|c|c|c|c|}
\hline Test & Date & Time & $\begin{array}{c}\text { Run } \\
\text { Time } \\
\text { (hours) }\end{array}$ & Colk Cap Observatıons \\
\hline \multirow{27}{*}{2} & \multirow{27}{*}{8112008} & 1645 & 20 & $\mathrm{CC} \sim 80 \%$, cap hot along the walls Heary bouling on the center observed \\
\hline & & 1701 & 23 & $\begin{array}{l}\text { CC } \sim 75 \% \text {. it is starting to stiffen up Laryer amount of feed boiling on the } \\
\text { surface }\end{array}$ \\
\hline & & 1715 & 25 & $\begin{array}{l}\text { CC }-80 \% \text {, Starting to close up some There are small rilges around the } \\
\text { openings but feed is flowing into the melt pools }\end{array}$ \\
\hline & & 1730 & 28 & $\begin{array}{l}\text { CC } \sim 80 \% \text { The ridges are gettong larger The openungs are staying the same } \\
\text { size }\end{array}$ \\
\hline & & 1745 & 30 & C - $-80 \%$. Hot cap around Thermowell $\# 2$ No other cherroses at this time \\
\hline & & 1801 & 33 & $\begin{array}{l}Q C-85^{\circ} \text { Cap has closed up some on east side On west side no } y_{\text {ssible }} \\
\text { changes }\end{array}$ \\
\hline & & 1817 & 35 & 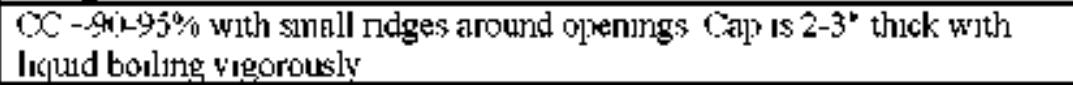 \\
\hline & & 1832 & 38 & $\begin{array}{l}\text { There is more liquid rushung onto the mith pouls at whis time The ridges are } \\
\text { the some as last entry }\end{array}$ \\
\hline & & 1839 & 39 & Cold cop has opened up some on the west side \\
\hline & & 18.3 & 41 & $\begin{array}{l}\text { Cold cap -90\%, Ridge around the openongs have growns some } 3-4 " \text { high } \\
\text { Moderate amount of liquid boilung all the time }\end{array}$ \\
\hline & & 1910 & 44 & $\mathrm{CC} \sim 85 \%$ Cap is floating on the melt pool \\
\hline & & 1927 & 47 & $C C \sim 90 \%$. Not able to see the east sille \\
\hline & & 1942 & 50 & $\begin{array}{l}\text { OC-gno\% More liguld flowing into the wrest side melt prool Only see light } \\
\text { emitting from the east side through the south view port }\end{array}$ \\
\hline & & 2005 & 53 & $\begin{array}{l}\text { CC }-90 \% \text { Able to see a small opening on the east side West side cap } \\
\text { around Thenmowrell H? has darkened up }\end{array}$ \\
\hline & & 2022 & 56 & CC-95\% West side hes closed up more \\
\hline & & 219.36 & 59 & $\begin{array}{l}\text { CC -90\% Not able to see east side Wiest s1le has a ridge that curls back to } \\
\text { the center Feed is bollung over it }\end{array}$ \\
\hline & & $20 \leq 3$ & 61 & CC $\sim 90 \%$ Cond1110ns unchanged \\
\hline & & 2106 & 64 & $\begin{array}{l}\text { C r ano. Conditions are unchanged except that it koks like more feed is } \\
\text { pooling on the west side }\end{array}$ \\
\hline & & 2124 & 67 & $\begin{array}{l}\text { C -90\%. Rudge is larger now on the wrest side but there is no ridge close } \\
\text { to the wiall Feed is towling over Not able to see east side }\end{array}$ \\
\hline & & 2139 & 69 & $O C-90$. There is more lqquid feed flowing into the west melt pool \\
\hline & & 2147 & 70 & CC -90, west side is starting to melt down due to the higher bubbling \\
\hline & & 2217 & 75 & C $\sim 85 \%$. West side opened up some \\
\hline & & 2232 & 78 & $\alpha-90 \%$, Wiest side closed up some \\
\hline & & 2246 & 80 & $C \mathrm{C}$ at $85-90 \%$ farly flat on wrest side, light is y 1 silile on enst side \\
\hline & & 2307 & 84 & CC $-85 \%$, with liculut spillung into opening on west sule \\
\hline & & 2334 & 88 & $(C-85-90 \%$ unchanged \\
\hline & & 2356 & 92 & CC-85\% openung on west sude appears larger \\
\hline
\end{tabular}


Table 5.3. Operator Observations of Cold Cap (CC) (continued).

\begin{tabular}{|c|c|c|c|c|}
\hline Test & Date & Time & $\begin{array}{l}\text { Run } \\
\text { Time } \\
\text { (hours) }\end{array}$ & Cold Cap Observatıons \\
\hline \multirow{26}{*}{2} & \multirow{26}{*}{$812 / 2008$} & 1) 10 & 94 & $\begin{array}{l}\text { CC }-80-85 \% \text { opening on west side is starting to glaze up, not much lipurd } \\
\text { tnckling into opening }\end{array}$ \\
\hline & & 025 & 97 & $\begin{array}{l}O C-80-85 \% \text {, more feed startung to flow into west opening Light is visible } \\
\text { on east side }\end{array}$ \\
\hline & & 040 & 99 & $\begin{array}{l}\text { C }-85^{\circ} \text {. West side opening still has a thick ndge around it But glazing } \\
\text { is reduced Light still on east swle }\end{array}$ \\
\hline & & 055 & 102 & CC $94 \%$ opening on riest sile closed considerably \\
\hline & & 133 & 108 & 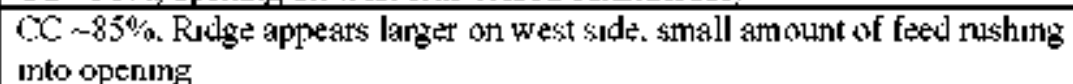 \\
\hline & & $1 \$$ & 111 & $\begin{array}{l}\text { CC -90\%, Opening on wiest s1de is almost closed, but also has about } 5 " \text { or - } \\
6 \text { ridge around it Light still on east }\end{array}$ \\
\hline & & 210 & 1] 4 & CC $-9 \% \%$ unchanged suce preq 1ous obser 4 at ws \\
\hline & & 230 & 118 & C $-85 \%$ same as previous oloseryation \\
\hline & & 250 & 121 & C $-85 \%$ unchatjogd sunce previous \\
\hline & & 305 & 123 & $C C-285 \%$, same as previous \\
\hline & & 348 & 131 & $\begin{array}{l}\text { Not seening any feed flowi ing over ridge currently has a large opening along } \\
\text { west wall CC }-80 \%\end{array}$ \\
\hline & & 406 & 134 & $\begin{array}{l}\text { C } 90-95 \% \text {, finally big nush of feed along wrest wall completely dark on } \\
\text { that sile }\end{array}$ \\
\hline & & 432 & 138 & CC $-90-95 \%$, slight amount of lught visible \\
\hline & & 458 & 142 & 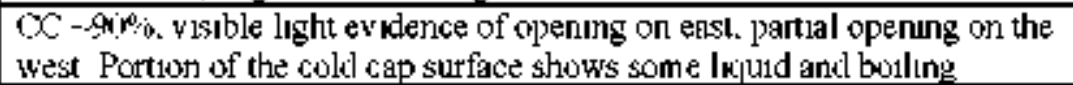 \\
\hline & & 548 & 151 & $O C-80-85 \%$ \\
\hline & & 606 & 154 & $\begin{array}{l}\text { North Port Cold cap portion with liquid boiling alwout lo" towards the } \\
\text { center is a thicker portim limiting further wiew Soluth Port Light from the } \\
\text { east wall, no mounds at the center could be seen }\end{array}$ \\
\hline & & 626 & 157 & $\begin{array}{l}\text { CC - 90\% opening yisible on west side with lower ridge in center Light is } \\
\text { visible on east side }\end{array}$ \\
\hline & & 640 & 159 & $\begin{array}{l}\text { CC - 90\% , large mound in center, blocking view to east side through North } \\
\text { veut port }\end{array}$ \\
\hline & & 711 & 164 & C unchanged in ajpearance. still $90-95 \%$ \\
\hline & & 723 & 166 & 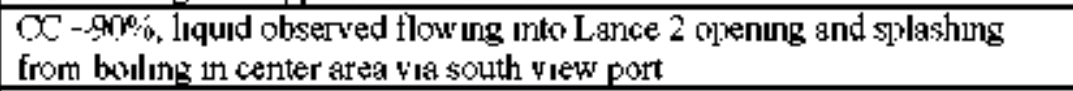 \\
\hline & & 745 & 170 & $\begin{array}{l}\text { Cold cap thichness alpears to be }-12-14 \text { " in center are, currently it } \\
\text { appears most of the feed is flowing to Lance } 2 \text { opening }\end{array}$ \\
\hline & & 814 & 173 & $\begin{array}{l}\text { No chanige un cold cap appearance, still 90-95\% cove erage and lik } 14^{\prime \prime} \text { thick } \\
\text { at the center }\end{array}$ \\
\hline & & 833 & 178 & CC unchanged \\
\hline & & 913 & 185 & $\begin{array}{l}\text { CC unchanged except the surface of opening in Lance } 2 \text { area has a more } \\
\text { "glazed" glass coatung }\end{array}$ \\
\hline & & 937 & 189 & CC appearance unchanged at $90-95 \%, 10-14^{n}$ thick \\
\hline & & 1912 & 195 & OC $-90-95 \%$ with feed flow ung predom wantly into Lance a opening \\
\hline
\end{tabular}


Table 5.3. Operator Observations of Cold Cap (CC) (continued).

\begin{tabular}{|c|c|c|c|c|}
\hline Test & Date & Time & $\begin{array}{c}\text { Run } \\
\text { Time } \\
\text { (hours) }\end{array}$ & Colil Cap Observatıons \\
\hline \multirow{26}{*}{2} & \multirow{26}{*}{$8 / 12 / 20068$} & 1038 & 199 & CC $\sim 90-95 \%$ \\
\hline & & 1113 & 20) 5 & CC $941-95 \%, 10-14^{\prime \prime}$ thick \\
\hline & & 1210 & 2] 4 & CC conditions are unchanged \\
\hline & & 1215 & 215 & CC has softened around thermoutell \#2 \\
\hline & & 1237 & 219 & 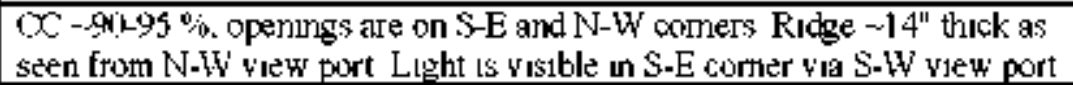 \\
\hline & & 1321 & 226 & $\mathrm{CC}-90 \%$ \\
\hline & & 13.36 & 229 & $O C-80-83 \%$ \\
\hline & & 1344 & 230 & $C D-80$ wrth no feed flowring to Lance 2 area \\
\hline & & 1423 & 236 & $\begin{array}{l}\text { CC } 85 \% \text { Feed is starting w flow unto the west stite of the melt pool Only } \\
\text { see light emitting from the east side }\end{array}$ \\
\hline & & 1439 & 239 & $\begin{array}{l}\text { CC }-90 \% \text {, yery little light on east side, slightly more on west side Nothung } \\
\text { can be seen in center view port Large glazed wrall has surface that looks } \\
\text { crumbly }\end{array}$ \\
\hline & & 1448 & 241 & CC -95\% East side has some loght emittung from the south $\psi$ iew port \\
\hline & & 1504 & 243 & $\begin{array}{l}\text { CC } 95 \% \text { still power lum ited set point is } 155 \mathrm{~kW} \text {, output is } 141 \mathrm{~kW} \text { West } \\
\text { side has large amount of feed flowing toward the west wall }\end{array}$ \\
\hline & & 1517 & 245 & $\begin{array}{l}\text { CC -95\%, there are } 2 \text { pools of feed that can be scen The lower pool along } \\
\text { the wrest wrall A ridge is holding it back unt1 it boils over Not able to see } \\
\text { east side }\end{array}$ \\
\hline & & 1538 & 249 & C $-95 \%$ \\
\hline & & 1552 & 251 & CC -95\%, to v1suble changes since last observation \\
\hline & & 1617 & $25 \xi$ & C $-95 \%$, thot able to see east s1de West 51 de glass is bents splashed up \\
\hline & & 1635 & 238 & $\mathrm{CC} \sim 95 \%$ \\
\hline & & 1710 & 264 & $\begin{array}{l}\text { CX-95\%. there is a hole in the side of the ridge allowing feed to flow } \\
\text { through into the melt pool }\end{array}$ \\
\hline & & 1725 & 267 & 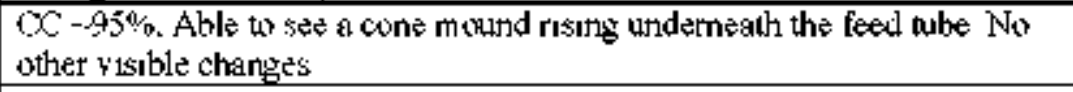 \\
\hline & & 1739 & 269 & CC $-95 \%$. No ehanges from last olservathon \\
\hline & & 1748 & 271 & $\begin{array}{l}\text { O-go\%. cap opened up a little on west s1de Not much light is coming } \\
\text { from east }\end{array}$ \\
\hline & & 1753 & 271 & CC opened up on west skile \\
\hline & & 1816 & 275 & $\begin{array}{l}\text { CC } \sim 85 \% \text {. west side opented up some more There is a hole in the side of } \\
\text { the ridge Foed is flowing into the opening }\end{array}$ \\
\hline & & 1834 & 278 & 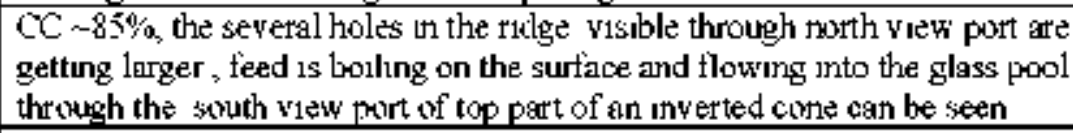 \\
\hline & & 1850 & 381 & $\begin{array}{l}\text { C - } \$ 5 \% \text {. holes in the ndge are getting larger, some areas of the cap near } \\
\text { the middle veur part are floating }\end{array}$ \\
\hline & & 1915 & 285 & CC $-85 \%$, The west stite ridge is melting \\
\hline
\end{tabular}


Table 5.3. Operator Observations of Cold Cap (CC) (continued).

\begin{tabular}{|c|c|c|c|c|}
\hline Test & Date & Time & $\begin{array}{c}\text { Run } \\
\text { Time } \\
\text { (hours) }\end{array}$ & Colk Cap Observatıons \\
\hline \multirow{22}{*}{2} & \multirow{12}{*}{$8 / 122008$} & 1935 & 288 & $\begin{array}{l}\text { CC - } 85 \% \text {, Starting to close up There is large amount of liquid feed on cold } \\
\text { capthat bolls ower into the melt pool nght before each shot }\end{array}$ \\
\hline & & 1951 & 291 & $\begin{array}{l}\alpha C-g 0 \% \text {, the openng on wrest side is closing Around thenmowrell \#2 cold } \\
\text { cap stiffenung up. }\end{array}$ \\
\hline & & 2008 & 294 & $\alpha C-90 \%$, no visible changes \\
\hline & & 2043 & 300 & $\begin{array}{l}\text { CC }-85 \% \text {, ridge on the west side has stopped melting It looks dry Cap is } \\
\text { hot around themotiell } \# 2\end{array}$ \\
\hline & & 2110 & 31) 4 & C -gino. more liquid feed is flow ung onto west melt ponl \\
\hline & & 2124 & 307 & 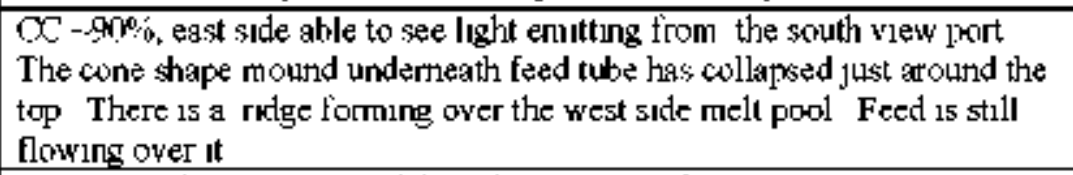 \\
\hline & & 2141 & 309 & $\begin{array}{l}O C-90 \% \text {, the lower part of the ndge is visible from north port is thun and } \\
\text { has lots of holes and looks like there is a thicker section above it A moutwl } \\
\text { is growing in front of middle \% iew port Cone and cast side look mosily the } \\
\text { same }\end{array}$ \\
\hline & & 2157 & 3] 2 & CC $-90 \%$, appears unchanged \\
\hline & & 2242 & 320 & $\begin{array}{l}\text { CC }>8590 \% \text { with feed flowing into opening on west stele of melter mound } \\
\text { is visible via south yew port }\end{array}$ \\
\hline & & 2258 & 322 & $\begin{array}{l}\text { CC }-80-85 \% \text {, there is large opening on the wrest side. mound growing in } \\
\text { the south view port }\end{array}$ \\
\hline & & 2314 & 325 & $O C-80-85 \%$ \\
\hline & & 2334 & 328 & $\begin{array}{l}\text { OC-80-85\% and }-10 \text { mches high ndge on Lance } 2 \text { opening has a hole } \\
\text { revealing heavy liquid accumulation on the cap surface Feed flows to the } \\
\text { melt pool between shots Lance } 2 \text { openung is also visible through the } \\
\text { middle port From the south port obseryahle mound is present Light akng } \\
\text { the mound L1 exists }\end{array}$ \\
\hline & \multirow{10}{*}{$8: 13 / 2008$} & 002 & 333 & $\begin{array}{l}\text { C }-85 \% \text {. otseryed heary liquid flow from the surface through the hole } \\
\text { around Lance } 2 \text { opening }\end{array}$ \\
\hline & & 023 & 336 & $\begin{array}{l}\text { CC }-85 \% \text {. partial Latice } 2 \text { opening visible from the mis-v1ew purt is } \\
\text { slightly reduced Others are the sanie }\end{array}$ \\
\hline & & 040 & 339 & 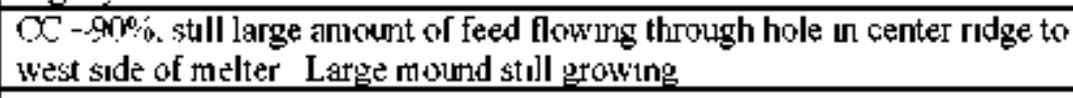 \\
\hline & & $1 \infty$ & 343 & $O C$-givo is same as before \\
\hline & & 112 & 345 & CC $90 \%$, opening on west wall is closing up \\
\hline & & 126 & 347 & $O C$ at $85 \%$, opening on west side appears larger \\
\hline & & 155 & 352 & $\alpha-85 \%$ unchanged \\
\hline & & 215 & 355 & $\begin{array}{l}\text { CC }-85-90 \text {, west openung unchanged, mound growing taller to south wi th a } \\
\text { stalactute Growing near feed tube }\end{array}$ \\
\hline & & $2 \Omega 2$ & 356 & Remoyed top section of mound and stalactite by rodding \\
\hline & & 245 & 360 & $\begin{array}{l}C X-85^{\circ} \% \text {, liquid coning fiom center of cap fomed through-like portion of } \\
\text { cap where it flows freely to melt pool }\end{array}$ \\
\hline
\end{tabular}


Table 5.3. Operator Observations of Cold Cap (CC) (continued).

\begin{tabular}{|c|c|c|c|c|}
\hline Test & Date & Time & $\begin{array}{l}\text { Run } \\
\text { Time } \\
\text { (hours) }\end{array}$ & Colk Cap Observatıons \\
\hline \multirow{23}{*}{2} & \multirow{23}{*}{$8 / 13 / 2006$} & 3.36 & 369 & $\begin{array}{l}\text { CC - } 85-90 \% \text {, opening near west wall appears to have a second small ridge } \\
\text { growing near it Mound is st]ll in place }\end{array}$ \\
\hline & & 405 & 373 & $\mathrm{CC}-85 \%$ \\
\hline & & 426 & 377 & $(\mathrm{C} \sim 85-91) \%$, ndge scems slightly larger \\
\hline & & 447 & 380 & 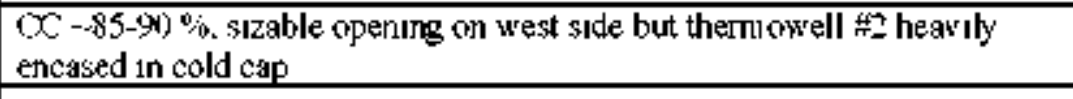 \\
\hline & & 514 & 385 & CC $\sim 85$ unchanged \\
\hline & & 525 & 387 & $\begin{array}{l}\text { Sill large operung on west silde but ridge appears somewhat bigger } \mathrm{CC} \\
-85-90^{\circ}\end{array}$ \\
\hline & & 541 & 389 & 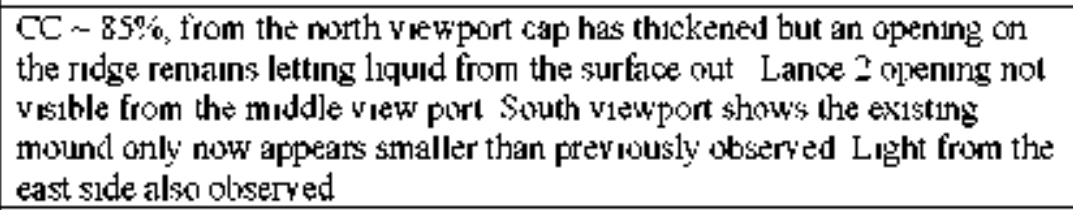 \\
\hline & & 623 & 396 & $\begin{array}{l}C \mathrm{C}-\$ 5-90^{\circ} \% \text {, large ndge in center of melter also large cone shape growth } \\
\mathrm{v}_{\mathrm{kl}} \text { south vew poirt }\end{array}$ \\
\hline & & 650 & 4) 1 & $\begin{array}{l}O C-90^{\circ} \text {. large ndge in center openung on } \mathrm{S}-\mathrm{E} \text { and N-hi comers } \\
\text { Manually remored cone from below feed tube }\end{array}$ \\
\hline & & 721 & 406 & Very thick hard cold cap in Thermowell 2 area $\mathrm{CC}-95 \%$ \\
\hline & & 727 & 4) 7 & Now observing liquid flow into Lance 2 opening: CC-90 \\
\hline & & 742 & 4] 0 & $\mathrm{CC}-90 \% \%$, with liquid flowing to Lance 2 opening \\
\hline & & $8 \infty$ & 4] 3 & $\begin{array}{l}\text { Lance 2 area slightly more open than previously observed, feed st1ll } \\
\text { flowng to opening }\end{array}$ \\
\hline & & 819 & 4] 6 & $\begin{array}{l}\text { CC -90\% wy th liquid still boilmg over into Lance } 2 \text { area in between the } \\
\text { feed shots }\end{array}$ \\
\hline & & 845 & 420 & $\begin{array}{l}\text { CC -9io\% with liquid still bouling orer into Lance area in between the feetl } \\
\text { shots }\end{array}$ \\
\hline & & 853 & 421 & Very little liquikl flowing into Lance 2 atea \\
\hline & & 907 & 424 & $\begin{array}{l}\text { CC-85\%. liquid flowitis to Lance } 2 \text { area better now Some light can be } \\
\text { seen thru center qrew port }\end{array}$ \\
\hline & & 955 & 432 & $\begin{array}{l}\text { CC } \sim 8 \% \text {. feed flowi ing into opening on N-WW comer opening visible on S- } \\
\text { E comer via S-W view port }\end{array}$ \\
\hline & & 1010 & 434 & $\begin{array}{l}\text { C-80-85\%, large ndge in center Feed flowing unto } N-W \text { comer } \\
\text { Opening on S-E and N-W corners }\end{array}$ \\
\hline & & 1035 & 438 & $\begin{array}{l}\text { C } \sim 85 \% \text {. With large uidge in center Feed flowing unto center of ridge and } \\
\text { into melt pool thru openings in tritge Openings in cold cap on S-E and N- } \\
\mathrm{W} \text { comers }\end{array}$ \\
\hline & & 1115 & 445 & $\begin{array}{l}\text { CD-\$5\%, with ridge in center Openings in S-E and Niri comers with leed } \\
\text { flowing into openungs }\end{array}$ \\
\hline & & 1152 & 451 & $\begin{array}{l}\text { CC - } 80-85 \% \text {, more light vislole reflectung on east side Liquid flowing to } \\
\text { Lance 2 area }\end{array}$ \\
\hline & & 1206 & 454 & CC $-80-85 \%$ with feed primar aly flowing to Lance 2 area \\
\hline
\end{tabular}


Table 5.3. Operator Observations of Cold Cap (CC) (continued).

\begin{tabular}{|c|c|c|c|c|}
\hline Test & Date & Tinie & $\begin{array}{l}\text { Run } \\
\text { Time } \\
\text { (hours) }\end{array}$ & Cold Cap Observatıons \\
\hline \multirow{6}{*}{2} & \multirow{6}{*}{$8: 13: 2008$} & 1236 & 459 & $\begin{array}{l}\text { C - Sho\%. with Lance } 2 \text { area is closing up slightly Thermowell } 2 \text { partially } \\
\text { encased in cap tow Cone in center area is taller }\end{array}$ \\
\hline & & 1250 & 461 & $\begin{array}{l}\text { C } \sim 85 \% \text { with large ndge in center cone below feed tube On S-E and N- } \\
\text { Wi comers Fead flow ung into NWW opening }\end{array}$ \\
\hline & & 1432 & 478 & C - Mwo. west side has closed up around thenmowell 2 No other changes \\
\hline & & 1448 & 481 & $\alpha-\operatorname{gn} \%$ \\
\hline & & 1504 & 483 & 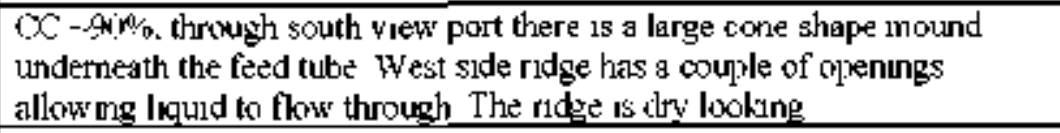 \\
\hline & & 1549 & 491 & $\mathrm{CC}-95 \%$ \\
\hline \multirow{21}{*}{3} & \multirow{21}{*}{$8: 13: 2108$} & 1610 & 494 & 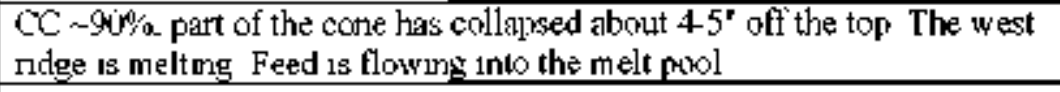 \\
\hline & & 1625 & 497 & CC $\sim 85 \%$ west side has opened up some but only along the west wall \\
\hline & & 16.38 & 499 & $Q C-85 \%$, No y sisile changes at this time \\
\hline & & 1717 & 50) 5 & C - $85 \%$. ridge is meltung on west side The cone has grown some \\
\hline & & 1734 & 508 & CC $-85 \%$, the west side ridge has a tonger hole in $\mathrm{n}$ from mehng \\
\hline & & 1750 & $\$ 11$ & CC\% $\% 5 \%$. unchanged \\
\hline & & 1812 & 515 & $\begin{array}{l}\text { Co }-85 \% \text {, west sde is melting a lot lt looks like the ridge is about to } \\
\text { collapse Large amount of loculd that can be seen through the ndde }\end{array}$ \\
\hline & & 1836 & 519 & $\begin{array}{l}\text { Cold cap - } 83 \% \text {, ridye continues to melt, bollong feed flows into melter } \\
\text { Cone is larger }\end{array}$ \\
\hline & & 1854 & $\$ 22$ & $C C-85 \%$ \\
\hline & & 1912 & 525 & $\mathrm{CO},-80$, r dige is no longer melting doum \\
\hline & & 1931 & 528 & CC $-85 \%$, west slde ridge is not meltung as fast as prew jous \\
\hline & & 1947 & 530 & CC.-85\%, to \%isible chantres \\
\hline & & 2005 & 53.3 & C) $-80 \%$, east slde has opened up \\
\hline & & 2023 & 536 & CC $-85 \%$, west side is closing up \\
\hline & & 2042 & $\$ 40$ & $\begin{array}{l}\text { CC - } 85 \% \% \text {, rille appears slightly larger feed can still be seen boilung and } \\
\text { tlowing intoglass pool }\end{array}$ \\
\hline & & 2059 & 542 & $C C-80 \%$, cap is mostly the same \\
\hline & & 2117 & 545 & $\begin{array}{l}\text { CC }-80 \% \text {, openung on west side a little laryetr, ferd is bolling on surface } \\
\text { and flowwing into glass fool }\end{array}$ \\
\hline & & 2140 & 549 & $\begin{array}{l}\text { CC }-85^{\circ} \% \text {, part of both the ndge and the cone hay collapsed Latge } \\
\text { quantity of feed flotws intoglass mol with each shot }\end{array}$ \\
\hline & & 2157 & 552 & CC, $-80^{\circ} \%$, conditions unchanget \\
\hline & & 2215 & 555 & CC $-85 \%$, unchanged \\
\hline & & 225 & 561 & $\begin{array}{l}\text { CC - 70\%, large opening on wrest side of melter and very bright glow on } \\
\text { west side of melter }\end{array}$ \\
\hline
\end{tabular}


Table 5.3. Operator Observations of Cold Cap (CC) (continued).

\begin{tabular}{|c|c|c|c|c|}
\hline Test & Date & Time & $\begin{array}{l}\text { Run } \\
\text { Tume } \\
\text { (hours) }\end{array}$ & Colk Cap Observatıons \\
\hline \multirow{20}{*}{3} & \multirow{3}{*}{$8: 13 / 2008$} & 2311 & 564 & $\mathrm{CC} \sim 70 \%$, appearance unchanged \\
\hline & & 2323 & 566 & $\mathrm{C}-.75 \%$ \\
\hline & & 2343 & 570 & CC 75\%, basically unchanged \\
\hline & \multirow{17}{*}{$8: 14 / 2008$} & 1) 05 & 573 & $\begin{array}{l}\text { CC }-75 \% \text {, opening on riest stile has closed up somerihat Still lots of light } \\
\text { on east side }\end{array}$ \\
\hline & & 020 & 576 & $\mathrm{CC}-75 \%$ \\
\hline & & 035 & 578 & CC $-75-80 \%$, lots of feed rushing into opeting on west side of melter \\
\hline & & 1) $\$ 5$ & 582 & $\mathrm{OC}-75-80 \%$ basically unchanged \\
\hline & & 1.34 & 588 & $\begin{array}{l}\text { C- }-75-80^{\circ} \text {. large opening on west side of sunface, but feed is constantly } \\
\text { flowing into it Large mound is visble on shuth side but it does not have } \\
\text { pocket at the top to collect liqud. }\end{array}$ \\
\hline & & 158 & 592 & $\begin{array}{l}\text { CC }-80 \% \text {, heary liquel flowing from the surface, mound at the center and } \\
\text { lught from Lance l openung }\end{array}$ \\
\hline & & 235 & 598 & CC $-70-80 \%$, no significant change \\
\hline & & 302 & 603 & $\begin{array}{l}C \mathrm{C}-75-80 \% \text {, stıll have large amount of feed flowing unto openung on west } \\
\text { slde }\end{array}$ \\
\hline & & 312 & 605 & $\alpha C-75-80 \%$ \\
\hline & & 325 & (6) 7 & $\begin{array}{l}\text { CC } 80-85 \% \text {, feed nushing into opeting on west side Mound is still in } \\
\text { phice with lots of light on enst wall }\end{array}$ \\
\hline & & 340 & 609 & $\begin{array}{l}\text { CC- }-80-85 \% \text {, openung on west has feed flowing directly into it, no ndge m } \\
\text { vew Large amount of still on east side }\end{array}$ \\
\hline & & 355 & 612 & $\begin{array}{l}C X-80 \% \text {, large opening on west side cap around it is very ngid Large } \\
\text { mound on the west side with lots of light on east wrall }\end{array}$ \\
\hline & & 415 & 6] 5 & $\begin{array}{l}\text { CC -80\%, west cpening has a glazed ndge around it, visible after } \\
\text { discharge Large mount of feed spillung over ridge and into opening } \\
\text { however East s1le has mound and great deal of light along the wall }\end{array}$ \\
\hline & & 520 & 626 & 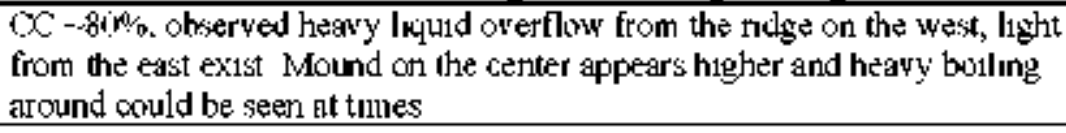 \\
\hline & & 540 & 629 & Mound is stıll in place and reige in center of melter \\
\hline & & 554 & 632 & $\begin{array}{l}\text { CC -80\% observed large unflux of feed into west opening, so feed is still } \\
\text { flowing over ridge }\end{array}$ \\
\hline & & 710 & 644 & $\begin{array}{l}\text { C -9wo west opening is much smaller than prey sous writh liquid still } \\
\text { flowing into opening East area appears larger based on reflected light }\end{array}$ \\
\hline
\end{tabular}


Table 5.3. Operator Observations of Cold Cap (CC) (continued).

\begin{tabular}{|c|c|c|c|c|}
\hline Test & Date & Time & $\begin{array}{c}\text { Rum } \\
\text { Tume } \\
\text { (hours) }\end{array}$ & Cold Cap Observations \\
\hline \multirow{27}{*}{3} & \multirow{27}{*}{$8 / 14 / 2008$} & 720 & 646 & $\begin{array}{l}\text { CC -95\%, west opening reduced to } \sim 6 " \text { diameter with still flowing into } \\
\text { opening East sde Reflected light is reduced from previous observation }\end{array}$ \\
\hline & & 746 & 650 & $\begin{array}{l}\text { CC }-95 \% \text {, with only small holes open on wrest, Lance } 2 \text { side East appears } \\
\text { ahout the same }\end{array}$ \\
\hline & & 805 & 653 & $\mathrm{CC}-95 \%$, condithons of cap has not changed \\
\hline & & 850 & 661 & $\begin{array}{l}\text { Openung is large and not obsering liquid flow East side light is } \\
\text { dimutnished }\end{array}$ \\
\hline & & 859 & 662 & Rudge is collapsed causung pessure surge \\
\hline & & 919 & 666 & $\mathrm{CC}-90 \%$ \\
\hline & & 947 & 670 & CC- $-90-95 \%$ Feat flowing to Lance 2 area freely \\
\hline & & 954 & 672 & A shift on capr coverage on enst is not visible \\
\hline & & 1036 & 679 & $\begin{array}{l}\text { CC-90\%, mamly unchanged in appearance Lnuld bolls over "cone" ndge } \\
\text { between the shots }\end{array}$ \\
\hline & & 1128 & 687 & Cold cap $-85-90 \%$ \\
\hline & & 1145 & 690 & $\begin{array}{l}\text { CC -90\% writh liquid mowing into Lance } 2 \text { area agam Liquid in "cone" } \\
\text { under feet tube bouls \% ugorously ith between the shots }\end{array}$ \\
\hline & & $1 \geq 35$ & 698 & $\mathrm{CC}-90 \%$, observations unchanged from prevous olservation \\
\hline & & 1307 & 704 & $\begin{array}{l}\text { CC }-85 \% \text {, Lance } 2 \text { area slightly opened up with undercut into shelf Liquid } \\
\text { bouling over into opening }\end{array}$ \\
\hline & & 1324 & 707 & $\begin{array}{l}\mathrm{CC}-85 \% \text {, and 12-18" thick Liquid fow is predommantly into Lance } 2 \\
\text { opening }\end{array}$ \\
\hline & & 1341 & 709 & $\begin{array}{l}\text { Light indicates a good opening on east side Due to liquid flow } \\
\text { predominantly to Lance Z area }\end{array}$ \\
\hline & & 1414 & 715 & CC still the same as previous \\
\hline & & 1438 & 719 & $\begin{array}{l}\text { CC-85\% Cone like shape is large West side ridge/dome has feed bolling } \\
\text { over it It looks luke themowell } 2 \text { is encased in feed (dry) }\end{array}$ \\
\hline & & 1450 & 721 & CC $-85 \%$, no \% isible chariges \\
\hline & & 1505 & 723 & $\begin{array}{l}\text { CC - } 850 \% \text {, very little to no change from the east WWest s1de is able to ser } \\
\text { the top of the dome }\end{array}$ \\
\hline & & 1610 & 734 & 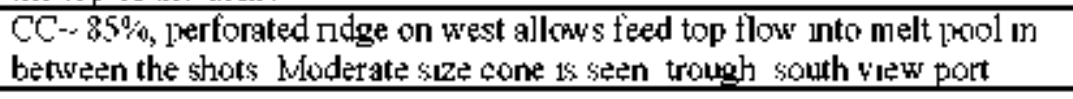 \\
\hline & & 1631 & 738 & Co $-85 \%$, cone appears slightly larger. other conditions are not changed \\
\hline & & 1649 & 741 & CC $-85 \%$, conditions mostly unchanged \\
\hline & & $17(15$ & 743 & $\begin{array}{l}\text { CC - } 85 \% \text {, riche on west skle looks like it is fillongs in feed is still bollung } \\
\text { and flowing unto the melter Cone appears unchanged }\end{array}$ \\
\hline & & 1729 & 747 & $\begin{array}{l}\text { CC }-90 \% \text {, both sides look slightly dasker, also a cellung like growth can be } \\
\text { seen in the upper part of the north \%iew port }\end{array}$ \\
\hline & & 1745 & 750 & CC $-90 \%$, unchanged \\
\hline & & 1813 & 755 & $\begin{array}{l}\text { CC } \sim 85 \% \text {, west side ndge seems smaller, slightly more light can be seen on } \\
\text { the east } \$ 1 \text { de }\end{array}$ \\
\hline & & 1832 & 758 & $\begin{array}{l}\text { CC } \sim 85 \% \text {, west ndge applears to be melting Feed is boilung and flowing } \\
\text { into melt powl, cone looks the same }\end{array}$ \\
\hline
\end{tabular}


Table 5.3. Operator Observations of Cold Cap (CC) (continued).

\begin{tabular}{|c|c|c|c|c|}
\hline Test & Date & Tinie & $\begin{array}{l}\text { Run } \\
\text { Time } \\
\text { (hours) }\end{array}$ & Cold Cap Obserqatıons \\
\hline \multirow{25}{*}{3} & \multirow{15}{*}{$8 / 14 / 2008$} & 1850 & 761 & C.-9not. wrest side has closed up some Large cone undemeath feed tube \\
\hline & & 1918 & 766 & CC $-90 \%$, west side closing up \\
\hline & & 1951 & 771 & $C-90 \%$ \\
\hline & & 2020 & 776 & CC. $-85 \%$ Slughtly darker on east s1de. otherwise unchanged \\
\hline & & 2036 & 779 & CC -9ut\%, both sides sloghtly darker \\
\hline & & 2054 & 782 & $C$ - $-90 \%$. mostly the same \\
\hline & & 2113 & 785 & CC -90\%, slight darker on sides of the melter \\
\hline & & 2127 & 787 & CC -90\%, very little change, mayke a little darker on thoth sides \\
\hline & & 2147 & 790 & C,- $90 \%$, east side looks a little lighter \\
\hline & & 2215 & 795 & CC-90-95\%, west side darker and east stile unchanged \\
\hline & & 2247 & 800 & $\begin{array}{l}\text { CC }-80 \% \text { y dry little light visible on west side Large mound still yisible in } \\
\text { south } 4 \text { lew port }\end{array}$ \\
\hline & & 2312 & 805 & $C C \sim 80$, with a large mound on south enst side of the melter \\
\hline & & 2335 & 808 & Attempt w break shing mound manually \\
\hline & & 2343 & 810 & $\begin{array}{l}\text { CC -9vo\%, loght on the east exsts Previous attempits were able to break } \\
\text { awray part of the volcano releasing liculd accumulation }\end{array}$ \\
\hline & & 3354 & 812 & $\begin{array}{l}\text { West side of the melter is completely dark with no moleten glass visible; } \\
\text { there appears to be a hard dark crusty shell over melt surface That is } \\
\text { bulding quicker that its melting }\end{array}$ \\
\hline & \multirow{10}{*}{$815 / 2008$} & 023 & 816 & $\begin{array}{l}\text { CC }-90-95 \% \text { Some light now visible on west side but with crusty ndge } \\
\text { above it Almost no light visible on east side }\end{array}$ \\
\hline & & 033 & 818 & No light on the eqsit sider \\
\hline & & 054 & 822 & $\begin{array}{l}\text { CC - }-85-90 \% \text {, Wiest sicle has opened up considerably Slight amount of } \\
\text { light on the east side }\end{array}$ \\
\hline & & 117 & 825 & $\begin{array}{l}\text { Large openung on the west side with glazed ridge the thanging it Slight } \\
\text { amount of lught on east side. }\end{array}$ \\
\hline & & 136 & 829 & $\begin{array}{l}\text { CC } \sim 85 \% \text {, large opening on wrest side unchanged, small amount of light on } \\
\text { east side }\end{array}$ \\
\hline & & 156 & 832 & CC $-85 \%$ unchanged \\
\hline & & 206 & 834 & 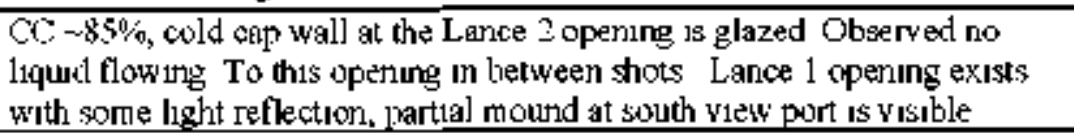 \\
\hline & & 235 & 837 & $\begin{array}{l}\text { CC } \sim 85 \% \text {, openung at Lance } 2 n \text { slightly larger Thun layer of cap floatiog on } \\
\text { the glass, glazed wall with no change }\end{array}$ \\
\hline & & 244 & 840 & 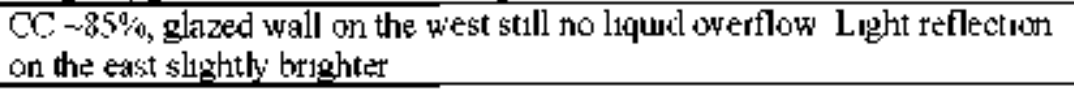 \\
\hline & & 30 & 843 & C) $-85 \%$, west section obsery id skwly dissoly ing \\
\hline
\end{tabular}


Table 5.3. Operator Ohservations of Cold Cap (CC) (continued).

\begin{tabular}{|c|c|c|c|c|}
\hline Test & Date & Tune & $\begin{array}{l}\text { Run } \\
\text { Tume } \\
\text { (hours) }\end{array}$ & Cokl Cap Observations \\
\hline \multirow{22}{*}{3} & \multirow{22}{*}{$8 / 15 / 2008$} & 307 & 844 & Liquid startung to overflowr from the cap to the operung on the west \\
\hline & & 343 & 850 & $\begin{array}{l}C C-85 \% \text {, west has a thin cap on the glass haye now solkified about } 2-3^{\prime \prime} \text {. } \\
\text { glazed wall is stall present }\end{array}$ \\
\hline & & 420 & 856 & CC - $-85 \%$, unchanged \\
\hline & & 525 & 867 & C. $-80.85 \%$. mound startung to buld up again \\
\hline & & 605 & 873 & $C C-80-85 \%$ unchanged \\
\hline & & 708 & 884 & $\begin{array}{l}\text { C }-95 \% \text {, cond is farly high and limiting liquid dispersion Dislodged top } \\
\text { port tor of cone Suspected partial full line clog, But sulisequent shots were } \\
\text { fine Pertormed mamual line flush }\end{array}$ \\
\hline & & 725 & 887 & $\begin{array}{l}\text { CC -90-95\%, liqud flowing to Lance } 2 \text { openuig An area with } \sim 8-10 " \\
\text { diameter is open now }\end{array}$ \\
\hline & & 750 & 891 & $\begin{array}{l}\text { C }-95 \% \text {. east opening appears to be closing, obserye only a small amount } \\
\text { of light }\end{array}$ \\
\hline & & 754 & 892 & $\begin{array}{l}\text { Believed morst if mot all feed is flowing to cast side No liquid flow to } \\
\text { Lance } 2 \text { area is obseryable }\end{array}$ \\
\hline & & 800 & 893 & Observed liculut flowing to Lance 2 area now East side appers unchanged \\
\hline & & 807 & 894 & Observed larse milux of liqurt to Lance 2 area \\
\hline & & 820 & 896 & CC. $-90 \%$ \\
\hline & & 910 & 904 & $\begin{array}{l}\text { CC } 85.90 \% \text {, light is visible from SE corner openung on NWr corther has } \\
\text { been flowing into melt pool }\end{array}$ \\
\hline & & $9 \varsigma 0$ & 911 & $\begin{array}{l}\text { CC }-90 \% \text {, light visible on SE comer Mound in center below feed tube } \\
\text { NW Comer is pen with feed flowng surface }\end{array}$ \\
\hline & & 1010 & 914 & CC unchanged \\
\hline & & 1025 & 917 & $\begin{array}{l}\text { CC - } 90 \% \text {, Light is visible on } S \text { w comer Cone below feed lube is larger } \\
\text { Opening on NW comer has feed flowing through cold capinto melt } \\
\text { surface }\end{array}$ \\
\hline & & 1122 & 926 & $\begin{array}{l}\text { Cold cap } \sim 85 \% \text { Lance } 2 \text { area } 1 \text { s opened up Liquid is flowring unto openting } \\
\text { East side appens unchanged }\end{array}$ \\
\hline & & 1146 & 930 & $\begin{array}{l}\text { CC }-85-90^{\circ} \% \text { with flowing strongly unto Lance } 2 \text { opening Light } \psi \text { isible on } \\
\text { east atpears about the same as prequous }\end{array}$ \\
\hline & & 1220 & 936 & $\begin{array}{l}\text { CC - } 90 \% \text {, light visible on S-E comer Cone is still below leed tube N-WV } \\
\text { opening has been tlowing thru cold cap }\end{array}$ \\
\hline & & 1238 & 939 & CC unchanged \\
\hline & & 1255 & 942 & CC $-90 \%$, little changed since last full descnption \\
\hline & & 1315 & 945 & CC stull very stable \\
\hline
\end{tabular}


Table 5.3. Operator Olsservations of Cold Cap (CC) (continued).

\begin{tabular}{|c|c|c|c|c|}
\hline Test & Date & Tume & $\begin{array}{l}\text { Rum } \\
\text { Time } \\
\text { (hours) }\end{array}$ & Colk Cap Observatıons \\
\hline \multirow{23}{*}{3} & \multirow{21}{*}{$81512(m) 8$} & 1339 & 949 & Dislodged coste during discharge \\
\hline & & 1432 & 958 & 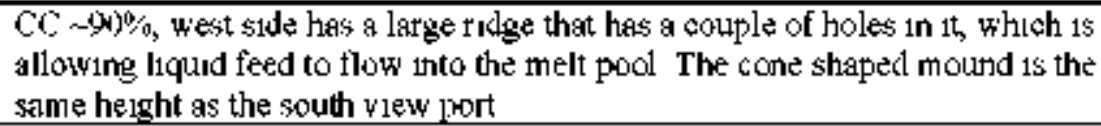 \\
\hline & & 1448 & 961 & CC $\sim 90 \%$, No visible changes \\
\hline & & 1510 & 964 & CC -901\%, west s1de ridge laws dry in spots and glazed in other places: \\
\hline & & 1523 & 966 & $C C-90 \%$, cone shaped mound has grown some No other changes \\
\hline & & 1542 & 970 & $C C-90 \%$, it seems to be stable at thes pount \\
\hline & & 1004 & 913 & $\begin{array}{l}\text { CC } \sim 90 \% \text {, large ridge on the west side Looks more like a double wall than a } \\
\text { cone under feed tule area }\end{array}$ \\
\hline & & 1626 & 977 & $\begin{array}{l}C C-90 \% \text {, most of the wrest side is glazed The cone shape mound looks } \\
\text { hiverer now }\end{array}$ \\
\hline & & 1640 & 979 & $\begin{array}{l}\text { CC }-90 \% \text {, the hole in west ridge is a little larger allowing liquid to flow onto } \\
\text { the melt pool }\end{array}$ \\
\hline & & 1655 & 982 & CC $\sim 90-95 \%$ West side s closing up \\
\hline & & 1715 & 985 & $\begin{array}{l}C C \sim 90 \% \text {, west side opened up some sunce discharge Able to see more light } \\
\text { from the east side Cone shaped mound does not look any bigger }\end{array}$ \\
\hline & & 1736 & 989 & $\begin{array}{l}\text { CC } \sim 90 \% \text { Feed is not flowing into the melt pool on the east side luke it wias } \\
\text { earlier }\end{array}$ \\
\hline & & 1752 & 991 & $\begin{array}{l}\mathrm{CC}-90^{\circ} \% \text { west side ndge is glazed and extends toward the south and can be } \\
\text { seen in the south yiew port Under the feed tulne the mound looks the same }\end{array}$ \\
\hline & & 1811 & 994 & $\begin{array}{l}C C-90 \% \text { a snall hole has opened at the bottom center of the west ridge and } \\
\text { is allowing feed to flow into the wrest side of the melt pool }\end{array}$ \\
\hline & & 1827 & 997 & $\begin{array}{l}\text { CC } \sim 90 \% \text {, hole in ridge is slightly larger, a stalactite has grown under feed } \\
\text { tube causing shots to spray slightly to the south Moderate tappong on feed } \\
\text { tube uncluilug during shot dislodged about half of it The shot is not spraying } \\
\text { now }\end{array}$ \\
\hline & & 1844 & 1000 & CC $-90 \%$, little to to change in conditions \\
\hline & & 1905 & 1003 & 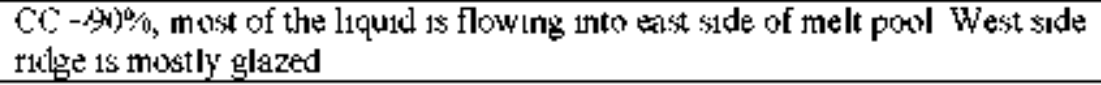 \\
\hline & & $19 \geq 0$ & 1006 & $\begin{array}{l}\text { CC }-90 \% \text {, West stile rilge miltung The stalactite has grown to top of the } \\
\text { cone }\end{array}$ \\
\hline & & $19: 30$ & 100.8 & End of Test 3 . \\
\hline & & 2200 & 1033 & $\begin{array}{l}\text { Most of the cap is gone but the cone shaped mound is still present in the south } \\
\text { view prort which looks luke it is being held up between the themiowrells and } \\
\text { the bubblers }\end{array}$ \\
\hline & & 2323 & 1046 & $\begin{array}{l}\text { Majorty of cold cap 1s gone but still a lot of build up on melter weills Muddle } \\
\text { v1ew port is still entirely blocked }\end{array}$ \\
\hline & \multirow{2}{*}{$8: 16 i_{2008}$} & 037 & 1059 & CC materia] still melting off walls, almost nothing on melter surface \\
\hline & & 120 & 1066 & Cold cap is gone \\
\hline
\end{tabular}


Table 5.4. DM1200 Tests Performed with Final HLW Bubbler Configuration and Glass Temperature of $1150^{\circ} \mathrm{C}$.

\begin{tabular}{|c|c|c|c|c|c|}
\hline Test & Feed & $\begin{array}{l}\text { Glass } \\
\text { Yield }\end{array}$ & Duration & $\begin{array}{l}\text { Bubbling } \\
\text { Rate }\end{array}$ & $\begin{array}{c}\text { Glass Production } \\
\text { Rate }\end{array}$ \\
\hline Test 1 & Al-Limited Waste & $300 \mathrm{~g} i \mathrm{l}$ & $48 \mathrm{hrs}$ & $124 \mathrm{pmm}$ & $1500 \mathrm{~kg}^{2} \mathrm{~m}^{2} \mathrm{id}$ \\
\hline Test 2 & A1-Limited Waste & $500 \mathrm{~g}: 1$ & $48 \mathrm{hrs}$ & $71 \mathrm{lpm}$ & $1050 \mathrm{~kg}^{2} \mathrm{~m}^{2} i \mathrm{~d}$ \\
\hline $\begin{array}{l}\text { Conf guration Test 9A } \\
\text { VSL-44R480i-4 [6] }\end{array}$ & $A Z-101$ & $400 \mathrm{~g} ; 1$ & 145 hrs & 64 וp & $1050 \mathrm{~kg}^{2} \mathrm{~m}^{2} \mathrm{id}$ \\
\hline $\begin{array}{l}\text { Configuration Test } 9 \mathrm{~B} \\
\text { VSL-04R4800-4 [6] }\end{array}$ & AZ- 101 & $400 \mathrm{~g} / 1$ & 72 hrs: & $134 \mathrm{lpm}$ & $1400 \mathrm{~kg} / \mathrm{m}^{2} / \mathrm{d}$ \\
\hline $\begin{array}{c}\text { Test IB } \\
\text { VSL-0SRS800-1 [23] }\end{array}$ & $A Z=102$ & $340 \mathrm{~g} / 1$ & $114 \mathrm{hrs}$ & $65 \mathrm{lpm}$ & $900 \mathrm{~kg}^{2} \mathrm{~m}^{2} / \mathrm{d}$ \\
\hline $\begin{array}{c}\text { Test 2B } \\
\text { VSL-0SR58(n)-1 [23] }\end{array}$ & $\begin{array}{c}\text { C-106:AY-102, HIgh Wiaste } \\
\text { Luading }\end{array}$ & $340 \mathrm{~g}: 1$ & 105 hrs & 90 ו וחי & $1050 \mathrm{~kg}^{2} \mathrm{~m}^{2} \mathrm{id}$ \\
\hline $\begin{array}{c}\text { MACT HLIV } 1 \\
\left(400^{\circ} \mathrm{C} \text { plenum) }\right. \\
\text { YSL-05R583(2) } 1[50]\end{array}$ & C-106/AY-102, spiked & $430 \mathrm{~g} / 1$ & 32 hrs: & $24 \mathrm{lpm}$ & $700 \mathrm{kgim}^{2} / \mathrm{d}$ \\
\hline $\begin{array}{c}\text { MACT HLW 2A } \\
\left(345^{\circ} \mathrm{C} \text { plenum }\right) \\
\text { VSL-05R5830-1 [50] }\end{array}$ & C.106/AY-102. spked & $430 \mathrm{~g} / 1$ & $75 \mathrm{hrs}$ & 9 lpm & $550 \mathrm{kgin}^{2} / \mathrm{d}$ \\
\hline 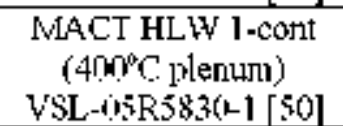 & C-106AY-102, spked & $430 \mathrm{gl}$ & 19 hers & $28 \mathrm{lpm}$ & $742 \mathrm{~kg} / \mathrm{m}^{2} \mathrm{idl}$ \\
\hline $\begin{array}{c}\text { MACT HLW } 2 \mathrm{~B} \\
\text { (ST0\% } \\
\text { WSL-05R5830-1 [50] }\end{array}$ & C.106/AY-102, splked & $430 \mathrm{~g} / 1$ & $54 \mathrm{hrs}$ & $43 \mathrm{lpm}$ & $1072 \mathrm{~kg} / \mathrm{m}^{2} / \mathrm{d}$ \\
\hline
\end{tabular}


Table 5.5. Measured DM1200 Melter \$ystem Paraneters (8/6/2008 - 8/16/2008).

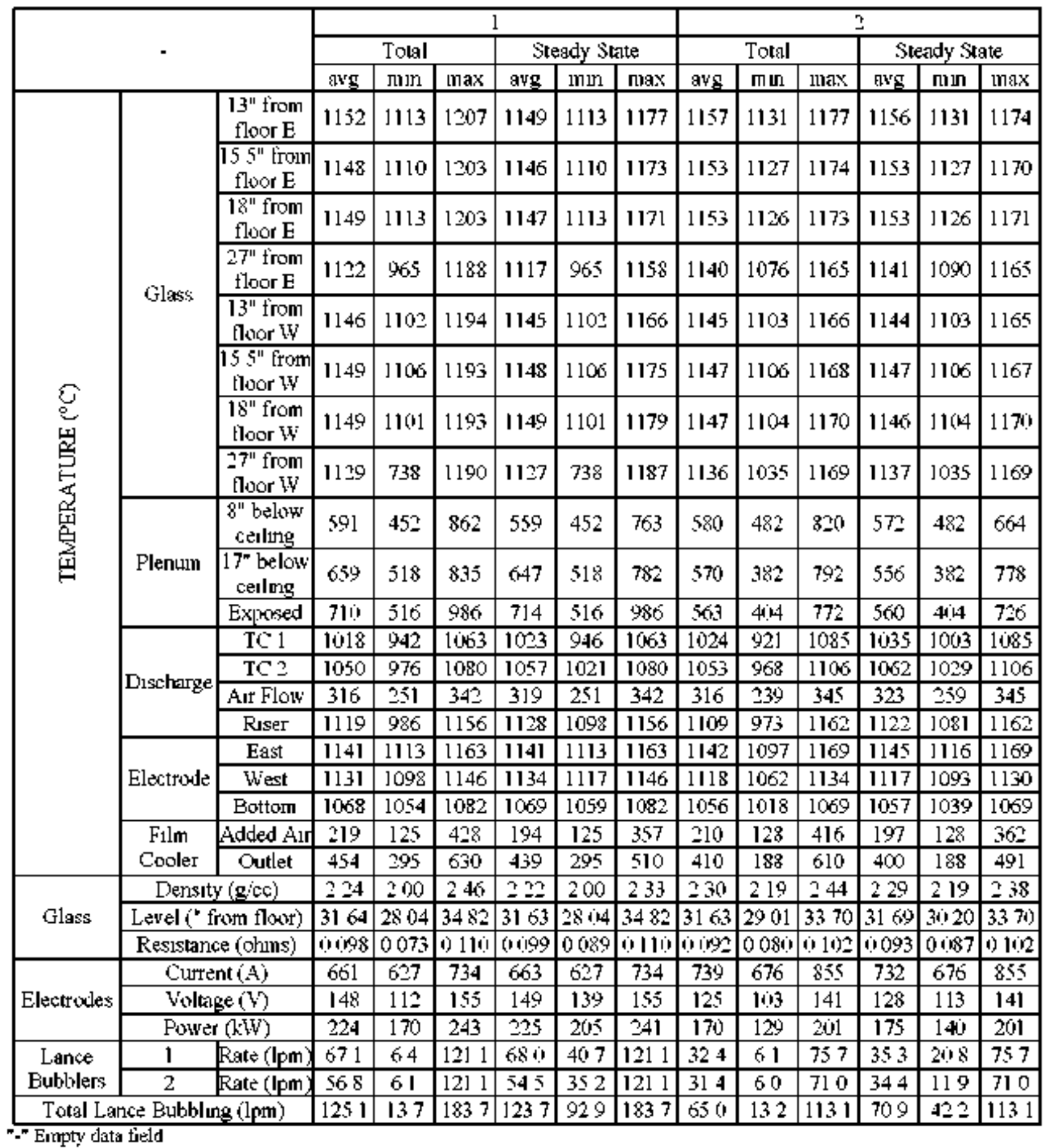


Table 5.5. Measured DM1200 Melter System Parameters (8/6/2008-8/16/2008) (continued).

\begin{tabular}{|c|c|c|c|c|c|c|c|c|}
\hline \multirow{2}{*}{\multicolumn{3}{|c|}{$\cdot$}} & \multicolumn{6}{|c|}{3} \\
\hline & & & \multicolumn{3}{|c|}{ Total } & \multicolumn{3}{|c|}{ Steady State } \\
\hline & & & avg & in in & $\max$ & avg & mun & $\max$ \\
\hline \multirow{20}{*}{ 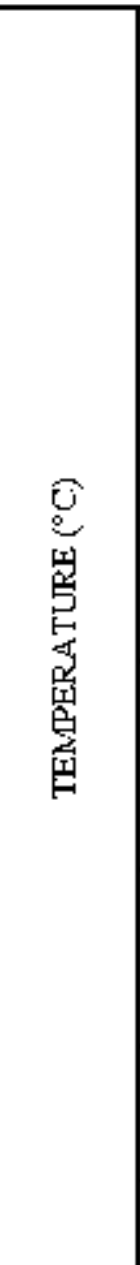 } & \multirow{8}{*}{ Glass } & \begin{tabular}{c|}
$13^{n}$ from \\
flom E
\end{tabular} & 1180 & $11: 0$ & 121.4 & 1180.1 & 1150 & 12014 \\
\hline & & $\begin{array}{c}155^{n} \text { from } \\
\text { flmor } E\end{array}$ & 1177 & 1146 & 1206 & 1177 & 1146 & 1306 \\
\hline & & $\begin{array}{c}18^{n} \text { from } \\
\text { floos } \mathrm{E}\end{array}$ & 1177 & 1143 & 1205 & 1178 & 1143 & 1205 \\
\hline & & \begin{tabular}{c|}
$37^{n}$ from \\
flom E
\end{tabular} & 1165 & 1112 & 1188 & 1166 & 1112 & 1188 \\
\hline & & $\begin{array}{l}13^{n} \text { from } \\
\text { flowr iv }\end{array}$ & 1169 & 1119 & 1191 & 1169 & 1119 & 1191 \\
\hline & & $\begin{array}{c}1.55^{n} \text { from } \\
\text { flower it } \\
\end{array}$ & 1171 & 1115 & 1198 & 1172 & 1115 & 1198 \\
\hline & & $\begin{array}{l}18^{n} \text { from } \\
\text { floor } \mathrm{kW}\end{array}$ & 1171 & 1107 & 1201 & 1172 & 1107 & 1201 \\
\hline & & $\begin{array}{l}27^{n} \text { from } \\
\text { floor } 1 \mathrm{~W}\end{array}$ & 1162 & 1062 & 1201 & 1164 & 1062 & 1201 \\
\hline & \multirow{3}{*}{ Plenum } & \begin{tabular}{|c|}
$8^{\prime \prime}$ helow \\
ceilung
\end{tabular} & 646 & 388 & 821 & 621 & 388 & 821 \\
\hline & & \begin{tabular}{|c|}
17 "below \\
celling
\end{tabular} & 529 & 186 & 777 & 482 & 186 & 734 \\
\hline & & Exposed & 611 & 142 & 914 & 562 & 142 & 898 \\
\hline & \multirow{4}{*}{ Discharge } & $\mathrm{TC} 1$ & 1001 & 833 & 1057 & 999 & 833 & 1055 \\
\hline & & TC 2 & 1031 & 936 & 1074 & 1030 & 936 & 1073 \\
\hline & & A1r Flow & 304 & 209 & 340 & 302 & 309 & 336 \\
\hline & & Ruser & 1143 & 1102 & 1184 & 1143 & 1117 & 1184 \\
\hline & \multirow{3}{*}{ Electrode } & East & 1168 & 1144 & 1183 & 1169 & 1152 & $1] 83$ \\
\hline & & West & 1140 & 1111 & 1156 & 1140 & 1111 & 1156 \\
\hline & & Bottom & 1080 & 1061 & 1092 & 1081 & 1061 & 1092 \\
\hline & Film & Added AII & 197 & 85 & 329 & \begin{tabular}{|l|}
181 \\
\end{tabular} & 85 & 258 \\
\hline & Cooler & Outlet & 413 & 74 & 546 & 46 & 74 & 525 \\
\hline \multirow{3}{*}{ Glass } & \multicolumn{2}{|c|}{ Density (gicc) } & 233 & 222 & 239 & 233 & 224 & 239 \\
\hline & \multirow{2}{*}{\multicolumn{2}{|c|}{$\begin{array}{l}\text { Lelel (" from floor) } \\
\text { Resistance (ohms) }\end{array}$}} & 3179 & 3027 & 3365 & 3179 & 3046 & 3305 \\
\hline & & & 0083 & 000 & 0094 & 0083 & 0000 & $0(n)$ \\
\hline \multirow{3}{*}{ Electrodes: } & \multicolumn{2}{|c|}{ Currentt $(A)$} & 677 & 0 & 1112 & 687 & 0 & 1112 \\
\hline & \multicolumn{2}{|c|}{ Voltage (V) } & 123 & 0 & 142 & 120 & 0 & 142 \\
\hline & \multicolumn{2}{|c|}{ Powier (kWV) } & 181 & 0 & 248 & 174 & 0 & 248 \\
\hline \multirow{2}{*}{$\begin{array}{c}\text { Latuce } \\
\text { Bubblers }\end{array}$} & 1 & Rate (lmo) & 273 & 127 & 610 & 237 & 127 & 460 \\
\hline & 2 & Rate lpm & 256 & 143 & 659 & 230 & 143 & 507 \\
\hline \multicolumn{3}{|c|}{ Total Lance Bubbling (lpm) } & 541 & 334 & 1027 & 478 & 334 & 875 \\
\hline
\end{tabular}


Table 5.6. Measured DM1200 Off-Gas System Parameters.

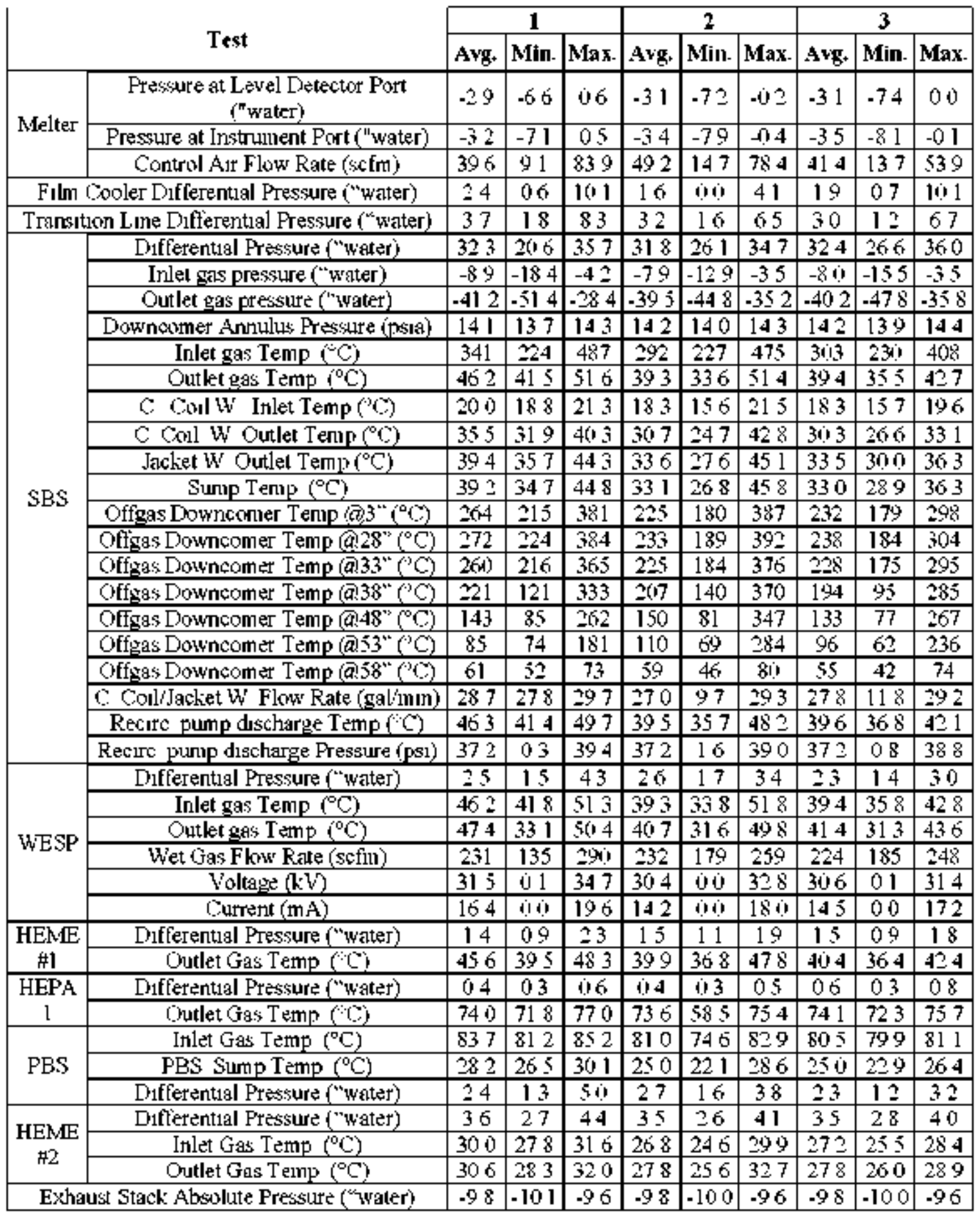


Table 5.7. O1t-Gas Solution Volumes.

\begin{tabular}{|c|c|c|c|c|c|c|}
\hline $\begin{array}{l}\text { Type of } \\
\text { Sample }\end{array}$ & Test & Date & $\begin{array}{c}\text { Sample ID for last } \\
\text { Blow'down }\end{array}$ & $\begin{array}{c}\text { Measured } \\
\text { pH }\end{array}$ & $\begin{array}{c}\text { Number of } \\
\text { Blow-downs } \\
\text { pel- test }\end{array}$ & $\begin{array}{c}\text { Blow-down per- } \\
\text { Test (fal) }\end{array}$ \\
\hline \multirow{3}{*}{ SBS } & 1 & $8 / 8: 2008$ & S-1حJ-106A & 220 & 29 & 117649 \\
\hline & 2 & $8 / 13.2008$ & $\mathrm{~S}-12 \mathrm{~K}-46 \mathrm{~A}$ & 213 & 21 & 85384 \\
\hline & 3 & $8 / 15 / 20108$ & $5-12 \mathrm{~K}-129 \mathrm{~A}$ & 197 & 24 & 95251 \\
\hline \multirow{6}{*}{ WESP } & \multirow{2}{*}{ I } & \multirow{2}{*}{$8: 8 / 2008$} & $\mathrm{~W}-12 \mathrm{~J}-110 \mathrm{~A}$ & 267 & \multirow{2}{*}{4} & \multirow{2}{*}{18651} \\
\hline & & & W-12J-110B & 317 & & \\
\hline & \multirow{2}{*}{2} & \multirow{2}{*}{$9 / 12: 2008$} & $W-12 \mathrm{~K}-46 \mathrm{~A}$ & 286 & \multirow{2}{*}{4} & \multirow{2}{*}{20983} \\
\hline & & & $W-12 \mathrm{~K}-46 \mathrm{~B}$ & 346 & & \\
\hline & \multirow{2}{*}{3} & \multirow{2}{*}{$8: 16 / 20 \mathrm{~m}) \mathrm{s}$} & W-13K-138A & 271 & \multirow{2}{*}{4} & \multirow{2}{*}{21383} \\
\hline & & & $W-12 \mathrm{~K}-138 \mathrm{~B}$ & 4.37 & & \\
\hline \multirow{3}{*}{ PBS } & 1 & $8 / 8: 2008$ & P-12J-110A & 870 & 8 & 26662 \\
\hline & 2 & $8 i 13 i 2008$ & P. $12 \mathrm{~K}-47 \mathrm{~A}$ & 889 & $\xi$ & 15923 \\
\hline & 3 & $8 i 5 i 2008$ & P-12K-138A & 894 & 4 & ]55 08 \\
\hline \multirow{3}{*}{ HEN:E 1} & 1 & $8 / 8,2008$ & $\mathrm{Hl}-12 \mathrm{~J}-108 \mathrm{~A}$ & 263 & 1 & 1616 \\
\hline & 2 & $8 / 13: 2008$ & $\mathrm{HI}-12 \mathrm{~K} .46 \mathrm{~A}$ & 268 & 1 & $20 ! 10$ \\
\hline & 3 & 81608 & $\mathrm{H} 1-12 \mathrm{~K}-138 \mathrm{~A}$ & 268 & 1 & 1463 \\
\hline \multirow{3}{*}{ HEME 2} & $\mathrm{I}$ & $8 / 8 / 20108$ & $\mathrm{H}_{2}^{2}-12 \mathrm{~J}-108 \mathrm{~A}$ & 756 & 2 & 1697 \\
\hline & 2 & $8 / 13 / 2008$ & $\mathrm{H} 2-12 \mathrm{~K}-46 \mathrm{~A}$ & 746 & 1 & 475 \\
\hline & 3 & $8 / 16 /(18)$ & $\mathrm{H} 2-12 \mathrm{~K}-138 \mathrm{~A}$ & 813 & 2 & 3236 \\
\hline
\end{tabular}


Table 5.8. Analytical Results for Solutions from the DM1200 Off-gas System Sampled at End of Testing (mg/L).

\begin{tabular}{|c|c|c|c|c|c|c|c|c|c|}
\hline Sample Type & \multirow{2}{*}{\multicolumn{3}{|c|}{ SBS }} & \multicolumn{6}{|c|}{ WESP } \\
\hline Sample I D & \multicolumn{2}{|c|}{ S-12K-129A } & & \multirow{2}{*}{\multicolumn{3}{|c|}{$\frac{\text { W-12K-138A }}{\text { Before Deluge }}$}} & \multicolumn{3}{|c|}{$W=12 K-138 \mathrm{~B}$} \\
\hline Deluge & \multicolumn{3}{|c|}{ No } & & & & \multicolumn{3}{|c|}{ After Deluges } \\
\hline Fraction & Sus & Dis & Total & Sus & DIS & Total & Sus & Dis & Total \\
\hline Solids & 280 & 3122 & 3402 & 6 & 1491 & 1497 & 96 & 498 & 594 \\
\hline Al & 886 & 19178 & 200.64 & xiol & 170 & 170 & 018 & 034 & 052 \\
\hline $\mathrm{B}$ & 033 & 57146 & 57179 & 001 & 1048 & 10481 & 055 & 1342 & 1397 \\
\hline $\mathrm{Be}$ & $\therefore 001$ & 144 & 144 & $500]$ & 007 & 007 & $<001$ & 004 & 004 \\
\hline $\mathrm{B} 1$ & 769 & 1399 & 2168 & $0(15$ & 244 & 249 & 1792 & a) (1) & 1792 \\
\hline $\mathrm{Ca}$ & 201 & 5372 & 5574 & agit & 4883 & 4883 & 009 & 4405 & 4414 \\
\hline $\mathrm{Cd}$ & $=001$ & 208 & 208 & $.000 \mathrm{~J}$ & 168 & 168 & 046 & 051 & 097 \\
\hline $\mathrm{Cu}$ & 276 & 1125 & 1401 & 003 & 25.35 & 2538 & 1170 & 120 & 1290 \\
\hline $\mathrm{Fe}$ & 4764 & 5808 & 10572 & 003 & 325 & 328 & 567 & x) & 567 \\
\hline $\bar{K}$ & 017 & 1391 & 1408 & 001 & 209 & 2091 & 027 & 728 & 755 \\
\hline LI & 033 & 3445 & 3478 & 001 & 3266 & 3267 & 009 & 857 & 866 \\
\hline Ms & 008 & 783 & 791 & $\infty 00]$ & 1199 & 1199 & 601 & 1225 & 1225 \\
\hline Mn & 033 & 253 & 286 & riol & 008 & 008 & 4001 & \&) (1) & $\therefore 001$ \\
\hline $\mathrm{Na}$ & 025 & 23614 & 23639 & $00 \mathrm{l}$ & 21435 & 21435 & 4001 & 5902 & 5902 \\
\hline $\mathrm{N}_{\mathrm{I}}$ & 226 & 465 & 691 & 001 & 034 & 035 & 046 & 009 & 055 \\
\hline $\mathbf{P}$ & 117 & 882 & 990 & xiol & 124 & 124 & 001 & \&(1) & 9101 \\
\hline $\mathrm{Pb}$ & 150 & 1623 & 1773 & 004 & 467 & 471 & 1243 & 077 & 1320 \\
\hline $\mathrm{S}_{1}$ & 5416 & 8097 & 13513 & 002 & 71 & 710 & 128 & 325 & 453 \\
\hline $5 r$ & 6001 & 194 & 194 & $\infty 00]$ & 043 & 043 & 001 & 032 & 032 \\
\hline $\mathrm{Zn}$ & 050 & 582 & 632 & $x, 01$ & 054 & 0.54 & 046 & 006 & 952 \\
\hline $\mathrm{Zr}$ & 209 & 610 & 819 & $00]$ & 019 & 019 & 4001 & $<001$ & $00]$ \\
\hline Cl & NA & 12849 & $\mathrm{NC}$ & NA & 19488 & $\mathrm{NC}$ & NA & 2539 & $\mathrm{NC}$ \\
\hline $\mathrm{F}$ & NA & 9252 & $\mathrm{NC}$ & NA & 4519 & $\mathrm{NC}$ & $\mathrm{NA}$ & 3405 & $\mathrm{NC}$ \\
\hline Nitrate & $N A$ & 19949 & NC & NA & 7698 & $\mathrm{NC}$ & NA & 1816 & $\mathrm{NC}$ \\
\hline Nitnte & NA & $=001$ & $\mathrm{NC}$ & NA & 017 & $\mathrm{NC}$ & NA & $=01$ & $\mathrm{NC}$ \\
\hline Sulfate & NA & 64795 & $\mathrm{NC}$ & $\mathrm{NA}$ & 31498 & $\mathrm{NC}$ & $\mathrm{NA}$ & 7] 49 & $\mathrm{NC}$ \\
\hline
\end{tabular}


Table 5.8. Analytical Results for Solutions from the DM1200 Off-gas Systenı Sanipled at end of Testing (mg/L) (continued).

\begin{tabular}{|c|c|c|c|c|c|c|}
\hline \multirow{3}{*}{$\begin{array}{l}\text { Sample Typ } \\
\text { Simple I D } \\
\text { Fraction }\end{array}$} & \multirow{2}{*}{\multicolumn{2}{|c|}{$\frac{\text { PBS }}{P \cdot 12 \mathrm{~K}-138 \mathrm{~A}}$}} & \multicolumn{4}{|c|}{ HEME } \\
\hline & & & \multicolumn{2}{|c|}{$\mathrm{Hl}-\mathrm{I} 2 \mathrm{~K}=138 \mathrm{~A}$} & \multicolumn{2}{|c|}{ H2-13K-138A } \\
\hline & Sus & Dis & Sus & DE & Sus & Dis \\
\hline Solıds & 40 & 9859 & $\therefore 1$ & 406 & $\therefore$ & 1252 \\
\hline A] & NA & 264 & NA & 136 & NA & 023 \\
\hline $\mathrm{B}$ & NA & 512 & NA & 1452 & NA & 117 \\
\hline $\mathrm{Ba}$ & NA & 8001 & NA & 006 & NA & 006 \\
\hline $\mathrm{BI}$ & NA & $\sin 25$ & NA & $\sin 25$ & NA & $<0125$ \\
\hline $\mathrm{Ca}$ & NA & 245 & NA & 4687 & NA & 6336 \\
\hline $\mathrm{Cd}$ & NA & 8003 & NA & 014 & NA & $<003$ \\
\hline $\mathrm{Cu}$ & NA & aiol & NA & 065 & $\mathrm{NA}$ & 001 \\
\hline $\mathrm{Fe}$ & NA & 8005 & NA & 218 & NA & 006 \\
\hline $\mathrm{F}$ & NA & 1239 & NA & 421 & NA & 1434 \\
\hline $\mathrm{L}_{1}$ & NA & 008 & NA & 054 & $\mathrm{NA}$ & 064 \\
\hline $\mathrm{Mg}$ & NA & 0.91 & NA & 1185 & NA & 1576 \\
\hline Mn & NA & 8004 & NA & $0(1)$ & NA & 006 \\
\hline $\mathrm{Na}$ & NA & 33058 & NA & 1898 & NA & 22613 \\
\hline N1 & NA & $\sin 04$ & NA & 018 & $\mathrm{NA}$ & $0 \geq 3$ \\
\hline $\mathrm{P}$ & $\mathrm{NA}$ & $<06$ & NA & 096 & NA & 092 \\
\hline $\mathrm{Pb}$ & NA & 801 & NA & 069 & NA & $=01$ \\
\hline$S_{1}$ & NA & 105 & NA & 385 & $\mathrm{NA}$ & 282 \\
\hline SI & NA & 004 & NA & 038 & $\mathrm{NA}$ & 050 \\
\hline $\mathrm{Zn}$ & NA & 019 & NA & 059 & NA & 061 \\
\hline $\mathrm{Zr}$ & NA & 8002 & $\mathrm{NA}$ & (1) 11 & NA & $<6012$ \\
\hline $\mathrm{Cl}$ & NA & 1556 & NA & 3381 & NA & 217 \\
\hline F & NA & 9106 & NA & 3737 & NA & 4458 \\
\hline Nitrate & NA & 8473 & NA & $2(m) 26$ & NA & 50685 \\
\hline Nitrite & NA & 283977 & NA & 191 & NA & 22794 \\
\hline Sullate & NA & 31397 & NA & 13681 & NAA & 10023 \\
\hline
\end{tabular}

NA-Not analyzed 
Table 6.1. Characteristics of Melter Feed Samples.

\begin{tabular}{|c|c|c|c|c|c|c|c|c|c|c|c|c|}
\hline \multirow{2}{*}{ Formulation } & \multirow{2}{*}{$\begin{array}{l}\text { Melter } \\
\text { Type }\end{array}$} & \multirow{2}{*}{ Test } & \multirow{2}{*}{ Al Source } & \multirow{2}{*}{ Date } & \multirow{2}{*}{ Name } & \multirow{2}{*}{$\begin{array}{c}\% \\
\text { Water }\end{array}$} & \multirow{2}{*}{$\begin{array}{c}\text { Density } \\
(\mathrm{g} / \mathrm{ml})\end{array}$} & \multirow{2}{*}{$\mathrm{pH}$} & \multirow{2}{*}{$\begin{array}{c}\text { Glass Yield } \\
\text { (gil) }\end{array}$} & \multicolumn{2}{|c|}{ Glass Yield (kg/kg) } & \multirow{2}{*}{ 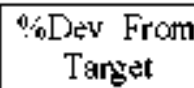 } \\
\hline & & & & & & & & & & Target & Measured & \\
\hline \multirow{6}{*}{$\begin{array}{c}\text { HLW-E-AI- } \\
27\end{array}$} & \multirow{23}{*}{$\begin{array}{l}\text { DM } \\
100\end{array}$} & \multirow{4}{*}{1} & \multirow{6}{*}{$\mathrm{Al}(\mathrm{OH})_{3}$} & $1 / 29 / 08$ & BLX-F-50B & $55 \% 1$ & 141 & 1036 & 507 & 0358 & 0360 & 053 \\
\hline & & & & $2 / 4 / 68$ & BLX-F-62A & $\mathrm{NA}$ & 138 & 1041 & $\mathrm{NAA}$ & 0358 & NA & NC \\
\hline & & & & \multirow{2}{*}{$2: 5: 08$} & BLX-F-71A & NA & ] 37 & 1046 & NA & 0358 & NA & $\mathrm{NC}$ \\
\hline & & & & & BLX-F-79A & NA & 138 & 1017 & NA & 0358 & NA & NO \\
\hline & & \multirow{2}{*}{2} & & \multirow{2}{*}{$26 / 08$} & BLX-F-91A & NA & 138 & 1018 & $\mathrm{NA}$ & 0358 & $\mathrm{NA}$ & NC: \\
\hline & & & & & BLY-F-104A & $\mathrm{NA}$ & 138 & 1020 & $\mathrm{NA}$ & 0338 & $\mathrm{NA}$ & $\mathrm{NC}$ \\
\hline \multirow{12}{*}{ HณI-AI -16 } & & \multirow{4}{*}{3} & \multirow{6}{*}{$\mathrm{Al}(\mathrm{OH})_{j}$} & \multirow{3}{*}{$5 / 5: 08$} & BLX-F-125A & 5843 & 137 & 812 & 487 & 0360 & 0356 & -111 \\
\hline & & & & & BL.Y-F-138A & NA & 137 & 818 & $\mathrm{NAA}$ & 0360 & NA & $\mathrm{NC}$ \\
\hline & & & & & BLX-F.145A & $\mathrm{NA}$ & 139 & 812 & $\mathrm{NA}$ & 0360 & $\mathrm{NA}$ & NC \\
\hline & & & & $5 / 6 / 08$ & BLX-F-153A & $\mathrm{NA}$ & 138 & 813 & NA & 9369 & $\mathrm{NA}$ & $\mathrm{NC}$ \\
\hline & & \multirow{2}{*}{4} & & $5: 7: 08$ & BLY-F-15A & NA & 138 & 828 & $\mathrm{NA}$ & 0360 & NA & $\mathrm{NC}$ \\
\hline & & & & $5 / 8 / 08$ & BLY-F-23A & $\mathrm{NA}$ & 137 & 824 & $\mathrm{NA}$ & 9369 & $\mathrm{NA}$ & NC. \\
\hline & & \multirow{4}{*}{5} & \multirow{6}{*}{$\mathrm{Al}_{2} \mathrm{O}_{\mathfrak{y}}$} & \multirow{2}{*}{62208} & BLY-F-57A & 6000 & 136 & 834 & 487 & 0363 & 0358 & -132 \\
\hline & & & & & BLY-F-59A & $\mathrm{NA}$ & 138 & 833 & $\mathrm{NA}$ & 0363 & NA & $\mathrm{NC}$ \\
\hline & & & & $6 / 3 / 08$ & BLY-F-66A & $\mathrm{NA}$ & 138 & 839 & $\mathrm{NA}$ & 0363 & NA & $\mathrm{NC}$ \\
\hline & & & & \multirow{2}{*}{$6 / 408$} & BLY-F-7AA & $\mathrm{NA}$ & 137 & 842 & $\mathrm{NA}$ & 0363 & $N_{A}$ & $\mathrm{NC}$ \\
\hline & & \multirow{2}{*}{6} & & & BLY-F-84A & $\mathrm{NA}$ & 137 & 861 & NA & 0363 & NA & $\mathrm{NC}$ \\
\hline & & & & $6 / 5: 08$ & BLY-F-99A & $\mathrm{NA}$ & 137 & 844 & $\mathrm{NA}$ & 0363 & NA & $\mathrm{NC}$ \\
\hline \multirow{5}{*}{ HW-A1-19 } & & & & 60300 & BLY-F-132A & 5760 & 138 & 810 & 479 & 0361 & 0347 & .393 \\
\hline & & & & 6.25M, & BLY-F-133A & NA & 137 & 816 & NA & 0361 & NA & $\mathrm{NC}$ \\
\hline & & 7 & $\mathrm{Al}(\mathrm{OH})_{3}$ & & BLY-F-141A & 5644 & 139 & 806 & 491 & 0361 & 0353 & .222 \\
\hline & & & & $6 / 24,08$ & BLY-F-147A & NA & 138 & 815 & NA & 0361 & NA & $\mathrm{NC}$ \\
\hline & & & & $6 / 25: 48$ & BLZ-F-10A & NA & 140 & 821 & NA & 0361 & NA & $\mathrm{NC}$ \\
\hline
\end{tabular}

NA - Not analyzed. NC - Not calculated 
Table 6.1. Characteristics of Melter Feed Samples (continued).

\begin{tabular}{|c|c|c|c|c|c|c|c|c|c|c|c|c|}
\hline \multirow{2}{*}{ Formulation } & \multirow{2}{*}{$\begin{array}{l}\text { Melter } \\
\text { Type }\end{array}$} & \multirow{2}{*}{ Test } & \multirow{2}{*}{ Al Source } & \multirow{2}{*}{ Date } & \multirow{2}{*}{ Nanie } & \multirow{2}{*}{$\begin{array}{c}0 \% \\
\text { Water }\end{array}$} & \multirow{2}{*}{$\begin{array}{c}\text { Density } \\
\text { (g/inl) }\end{array}$} & \multirow{2}{*}{$\mathrm{pH}$} & \multirow{2}{*}{$\begin{array}{c}\text { Glass Y ield } \\
\text { (g/l) }\end{array}$} & \multicolumn{2}{|c|}{ Glass Y ıclil $(\mathrm{kg} / \mathrm{kg})$} & \multirow{2}{*}{$\begin{array}{c}\text { \%0Dev From } \\
\text { Terget }\end{array}$} \\
\hline & & & & & & & & & & Target & Measured & \\
\hline \multirow{10}{*}{ HWI-Al-IQ } & \multirow[b]{2}{*}{ DM100 } & \multirow{2}{*}{8} & \multirow{10}{*}{$\mathrm{Al}(\mathrm{OH})_{3}$} & $6: 26108$ & BLZ-F-18A & NA & 139 & 804 & $\mathrm{NA}$ & 0361 & NA & $\mathrm{NC}$ \\
\hline & & & & $6 / 27,08$ & BLZ-F-28A & NA & 140 & 811 & NA & 9361 & NA & $\mathrm{NC}$ \\
\hline & \multirow{8}{*}{$\begin{array}{l}\text { DM } \\
1200\end{array}$} & \multirow{3}{*}{1} & & $8 / 6 / 08$ & F-1 $2 J-44 A$ & 5540 & 138 & 817 & 497 & 0361 & 0360 & -017 \\
\hline & & & & $8 / 7 / 08$ & $\mathrm{~F}-1 \mathrm{IJ}-79 \mathrm{~A}$ & 5602 & 139 & 810 & $48 !$ & 0361 & 0345 & -432 \\
\hline & & & & $8 / 8 / 08$ & F-12J-106A & 5890 & 136 & 846 & 446 & 0361 & 0328 & -909 \\
\hline & & \multirow{2}{*}{2} & & $8 / 11 / 08$ & F.12J-135A & 5697 & 138 & 842 & 469 & 0361 & 0340 & -.584 \\
\hline & & & & $8: 12,08$ & F-12K-7A & 5650 & 139 & 812 & 477 & 0361 & 0343 & -493 \\
\hline & & \multirow{3}{*}{3} & & $8 / 13 / 08$ & $\mathrm{~F}-12 \mathrm{~K}-47 \mathrm{~A}$ & 5882 & 135 & 812 & 432 & 0361 & 0320 & .1136 \\
\hline & & & & $8 / 14 / 08$ & F-l $2 K^{\circ}-694$ & 5588 & 139 & 817 & 468 & 0361 & 0337 & -665 \\
\hline & & & & $8 / 15 / 08$ & F-12K-113A & 5878 & 137 & 845 & 454 & 0361 & 0331 & .828 \\
\hline
\end{tabular}

NA - Not atralyzed, NC - Not calculeted 
Table 6.2. Rheological Properties of Melter Feed Samples.

\begin{tabular}{|c|c|c|c|c|c|c|c|c|c|c|c|}
\hline \multirow{2}{*}{ Test } & \multirow{2}{*}{ Formulation } & \multirow{2}{*}{ Al Source } & \multirow{2}{*}{ Date } & \multirow{2}{*}{ Name } & \multirow{2}{*}{$\begin{array}{c}\% \\
\text { Water }\end{array}$} & \multirow{2}{*}{$\begin{array}{l}\text { Density } \\
\text { (giml) }\end{array}$} & \multirow{2}{*}{$\mathbf{p H}$} & \multirow{2}{*}{$\begin{array}{c}\text { Yield Stıess } \\
\text { (Pn) }\end{array}$} & \multicolumn{3}{|c|}{ Vtscosity (Potse) } \\
\hline & & & & & & & & & (a) 1 s & (a) $10 / \mathrm{s}$ & a $100 / \mathrm{s}$ \\
\hline$[?]$ & HL说-E-A]-27 & $\mathrm{A}_{2} \mathrm{I}_{3}$ & $10 / 2 / 06$ & BLN-F-9A & 6123 & 137 & 1090 & 01 & 139 & 027 & 006 \\
\hline 3 & Hㄴ. A1 - 16 & $\mathrm{Al}\left(\mathrm{OH}_{3}\right.$ & $5: 5 / 08$ & BLX-F-125A & 5843 & 137 & 512 & 25 & 304 & 058 & 027 \\
\hline 5 & HWI-Al -16 & $\mathrm{Al}_{2} \mathrm{O}_{3}$ & $612 / 40$ & BLY-F-57A & 6000 & 136 & 834 & 19 & 536 & 066 & 016 \\
\hline 7 & HWI-Al-19 & $\mathrm{Al}\left(\mathrm{OH}_{3}\right.$ & $6 / 24: 08$ & BLY-F-141A & 5644 & 139 & 806 & 11 & 272 & 039 & 014 \\
\hline
\end{tabular}


Table 6.3. XRF Analyzed Compositions of Vitrified Melter Feed Samples (wt\%).

\begin{tabular}{|c|c|c|c|c|c|c|c|c|}
\hline Melter Type & \multicolumn{8}{|c|}{ DM100 } \\
\hline Fomlulation & \multicolumn{3}{|c|}{ HLW-E-AI-27 } & \multicolumn{5}{|c|}{ HW]-Al -16 } \\
\hline Al Surres & \multicolumn{3}{|c|}{ Alum inum Hydroxide } & \multirow{4}{*}{ Target } & \multirow{2}{*}{\multicolumn{2}{|c|}{$\frac{\text { Aluminum Hydroxide }}{3}$}} & \multirow{2}{*}{\multicolumn{2}{|c|}{$\frac{\text { Aluminum Oxde }}{5}$}} \\
\hline Test & \multirow{3}{*}{ Target } & \multirow{2}{*}{\multicolumn{2}{|c|}{$\frac{1}{\mathrm{BLX}-\mathrm{F}-50 \mathrm{~B}}$}} & & & & & \\
\hline Sample I D & & & & & \multicolumn{2}{|c|}{ BLX-F-125A } & \multicolumn{2}{|c|}{ BLY-F-57A } \\
\hline Constituent & & $\mathrm{XRF}$ & $\%$ Dev & & $\mathrm{XRF}$ & $\%$ Dev & $\overline{X R F}$ & $\% ;$ ixey \\
\hline $\mathrm{Al}_{2} \mathrm{O}_{3}$ & 2397 & 2301 & -401 & 2325 & 2204 & .522 & 2211 & -491 \\
\hline $\mathrm{B}_{2} \mathrm{O}_{3} *$ & 1519 & 1519 & $\mathrm{NC}$ & 1773 & 1773 & $\mathrm{NC}$ & 1773 & $\mathrm{NC}$ \\
\hline $\mathrm{BaO}$ & 005 & 007 & $\mathrm{NC}$ & 005 & 005 & NC & 005 & NC \\
\hline $\mathrm{Bl}_{2} \mathrm{O}_{3}$ & 114 & 120 & 488 & 111 & 116 & 487 & 126 & 1356 \\
\hline $\mathrm{CaO}$ & 608 & 603 & .071 & 589 & 604 & 253 & 585 & 071 \\
\hline $\mathrm{CdO}$ & 002 & 003 & $\mathrm{NC}$ & 002 & 003 & $\mathrm{NC}$ & 002 & $\mathrm{NC}$ \\
\hline $\mathrm{Cr}_{1} \mathrm{O}_{3}$ & 952 & 060 & $\mathrm{NC}$ & a 51 & 060 & $\mathrm{NC}$ & 059 & NC: \\
\hline $\mathrm{F}^{*}$ & 067 & 067 & $\mathrm{NC}$ & 065 & 065 & $\mathrm{NC}$ & 065 & $\mathrm{NC}$ \\
\hline $\mathrm{Fe}_{2} \mathrm{O}_{3}$ & 59 & $\$ 90$ & $0 \operatorname{los}$ & 572 & 617 & 780 & 683 & 1944 \\
\hline $\mathrm{K}_{2} \mathrm{O}$ & i. 14 & 018 & $\mathrm{NC}$ & ị 14 & 017 & $\mathrm{NC}$ & $(16$ & NC: \\
\hline $\mathrm{Lt}_{2} \mathrm{O}^{*}$ & 357 & 357 & $\mathrm{NC}$ & 346 & 346 & $\mathrm{NC}$ & 346 & $\mathrm{NC}$ \\
\hline $\mathrm{M}(\mathrm{g})$ & a12 & 026 & $\mathrm{NC}$ & a11 & 0.35 & $\mathrm{NC}$ & 026 & NC: \\
\hline $\mathrm{MnO}$ & $\$$ & 002 & $\mathrm{NC}$ & 8 & 004 & $\mathrm{NC}$ & 003 & $\mathrm{NC}$ \\
\hline $\mathrm{Na}_{2} \mathrm{O}$ & 958 & 921 & -388 & 929 & 896 & -359 & 966 & -253 \\
\hline $\mathrm{Ne}_{2} \mathrm{O}_{3}$ & 8 & 8001 & $\mathrm{NC}$ & $\xi$ & $<001$ & $\mathrm{NC}$ & $<001$ & $\mathrm{NC}$ \\
\hline $\mathrm{N} 1 \mathrm{O}$ & 040 & 039 & $\mathrm{NC}$ & 039 & 040 & $\mathrm{NC}$ & 037 & $\overline{N C}$ \\
\hline$\overline{\mathrm{P}_{2} \mathrm{OS}}$ & 105 & 122 & 1601 & 102 & 113 & 1032 & 110 & 752 \\
\hline $\mathrm{PbO}$ & $\dot{0} 41$ & 037 & $\mathrm{NC}$ & 040 & 037 & $\mathrm{NC}$ & 014 & $\mathrm{NC}$ \\
\hline $\mathrm{S}_{1} \mathrm{O}_{2}$ & 3050 & 3128 & 256 & 2958 & 2986 & 895 & 2898 & -2 i 2 \\
\hline $\mathrm{SO}_{2}$ & 020 & 023 & $\mathrm{NC}$ & 019 & 015 & $\mathrm{NC}$ & 016 & $\mathrm{NC}$ \\
\hline Sro & 8 & 005 & $\mathrm{NC}$ & 8 & 002 & $\mathrm{NC}$ & 001 & NC. \\
\hline $\mathrm{T}_{1} \mathrm{O}_{2}$ & 001 & 004 & $\mathrm{NC}$ & 001 & 005 & $\mathrm{NC}$ & 004 & $\mathrm{NC}$ \\
\hline $\mathrm{ZnO}$ & 008 & 008 & $\mathrm{NC}$ & 008 & 009 & $\mathrm{NC}$ & 008 & $\mathrm{NC}$ \\
\hline $\mathrm{ZrO}_{2}$ & 039 & 039 & $\mathrm{NC}$ & 038 & 049 & $\mathrm{NC}$ & 083 & $\mathrm{NC}$ \\
\hline Sum & 10000 & 10000 & $\mathrm{NC}$ & 10000 & 10000 & $\mathrm{NC}$ & 10000 & $\mathrm{NC}$ \\
\hline
\end{tabular}


Table 6.3. XRF A nalyzed Compositions of Vitrifled Melter Feed Samples (wt\%) (continued).

\begin{tabular}{|c|c|c|c|c|c|c|c|c|c|}
\hline Melter Type & \multicolumn{5}{|c|}{ DM100 } & \multicolumn{4}{|c|}{ DM1200 } \\
\hline Fomlukition & \multicolumn{5}{|c|}{ HWT-AI-19 } & \multicolumn{4}{|c|}{ HWT-Al-19 } \\
\hline Al Source & \multicolumn{5}{|c|}{ Aluminum Hydroxide } & \multicolumn{4}{|c|}{ Aluminum Hydroxide } \\
\hline Test & \multirow{3}{*}{ Target } & \multicolumn{4}{|c|}{7} & \multicolumn{3}{|c|}{$\mathbf{1}$} & 2 \\
\hline Sample ID & & \multicolumn{2}{|c|}{ BLY-F-132A } & \multicolumn{2}{|c|}{$\mathrm{BLY}-\mathrm{F}-1 \mathrm{Al} \mathrm{A}$} & $\begin{array}{c}\mathrm{F}-12 \mathrm{~J}- \\
44 \mathrm{~A}\end{array}$ & $\begin{array}{c}\mathrm{F} .12 \mathrm{~J} . \\
79 \mathrm{~A}\end{array}$ & $\begin{array}{l}\mathrm{F}-12 \mathrm{~J}- \\
10.6 \mathrm{~A}\end{array}$ & $\begin{array}{c}\text { F-12J. } \\
135 \mathrm{~A}\end{array}$ \\
\hline Constinuent & & $\mathrm{XRF}$ & $\%$ Dev & $\mathrm{XRF}$ & $\%$ Deq & $\mathrm{KRF}$ & IRF & $\mathrm{XRF}$ & XRF \\
\hline $\mathrm{Al}_{2} \mathrm{O}_{3}$ & 2397 & 2288 & -456 & 2273 & -518 & 2261 & 2274 & 2269 & 2318 \\
\hline $\mathrm{B}_{2} \mathrm{O}_{3}^{*}$ & 1919 & 1919 & $\mathrm{NC}$ & 1919 & $\mathrm{NC}$ & 1919 & 1919 & 1919 & 1919 \\
\hline $\mathrm{BaO}$ & 005 & 006 & $\mathrm{NC}$ & 006 & $\mathrm{NC}$ & 0915 & 1) 4.15 & 006 & 006 \\
\hline $\mathrm{Bi}_{2} \mathrm{O}_{3}$ & 114 & 131 & 1450 & 129 & 1281 & 123 & 119 & 110 & $1 \hat{23}$ \\
\hline $\mathrm{CaO}$ & 558 & $5: 1$ & 417 & 597 & 701 & 561 & 562 & 556 & 580 \\
\hline $\mathrm{CdO}$ & 002 & 002 & $\mathrm{NC}$ & 002 & $\mathrm{NC}$ & 002 & 1) 02 & 002 & 003 \\
\hline $\mathrm{Cr}_{2} \mathrm{O}_{3}$ & 052 & 068 & $\mathrm{NC}$ & 067 & $\mathrm{NC}$ & 063 & 064 & 064 & 067 \\
\hline$F^{*}$ & 067 & 067 & $\mathrm{NC}$ & 067 & $\mathrm{NC}$ & 067 & 1) 67 & 067 & 667 \\
\hline $\mathrm{Fe}_{2} \mathrm{O}_{3}$ & 590 & 641 & 871 & 650 & 1011 & 626 & 622 & 619 & 649 \\
\hline $\mathrm{K}, \mathrm{O}$ & 014 & 019 & $\mathrm{NC}$ & 020 & $\mathrm{NC}$ & 019 & 019 & 020 & 020 \\
\hline $\mathrm{Ll}_{2} \mathrm{O}^{*}$ & 357 & 357 & $\mathrm{NC}$ & 357 & $\mathrm{NC}$ & 357 & 357 & 357 & 357 \\
\hline $\mathrm{MgO}$ & 012 & $\dot{027}$ & $\mathrm{NC}$ & 027 & $\mathrm{NC}$ & 030 & 027 & 029 & 027 \\
\hline $\mathrm{MnO}$ & $\xi$ & 196 & $\mathrm{NC}$ & 002 & $\mathrm{NC}$ & 005 & 002 & 002 & 002 \\
\hline $\mathrm{Na}_{2} \mathrm{O}$ & 958 & 901 & .599 & 920 & -396 & 968 & 964 & 1048 & 931 \\
\hline $\mathrm{NL}_{2} \mathrm{O}_{3}$ & $\$$ & 901 & $\mathrm{NC}$ & 001 & $\mathrm{NC}$ & 6001 & $<001$ & $<0001$ & $<001$ \\
\hline $\mathrm{N}, \mathrm{O}$ & 040 & 044 & $\mathrm{NC}$ & 045 & $\mathrm{NC}$ & 049 & 1) 40 & 039 & 041 \\
\hline $\mathrm{P}_{2} O S$ & 105 & $\dot{090}$ & -1467 & 090 & -1488 & 106 & 111 & 101 & 103 \\
\hline $\mathrm{PbO}$ & 041 & 037 & $\mathrm{NC}$ & 037 & $\mathrm{NC}$ & 935 & i) 34 & 031 & 634 \\
\hline $\mathrm{SlO}_{2}$ & 2700 & 2727 & 103 & 2706 & 026 & 2724 & 2730 & 2684 & 2669 \\
\hline $\mathrm{SO3}$ & 020 & 017 & $\mathrm{NC}$ & 016 & $\mathrm{NC}$ & 022 & i) 19 & 019 & 020 \\
\hline $\mathrm{SrO}$ & $\S$ & 001 & $\mathrm{NC}$ & 001 & $\mathrm{NC}$ & 001 & 5001 & $<001$ & sion \\
\hline $\mathrm{T}_{1} \mathrm{O}_{2}$ & 001 & 004 & $\mathrm{NC}$ & 005 & $\mathrm{NC}$ & 005 & 004 & 004 & 005 \\
\hline $\mathrm{ZnO}$ & 008 & 009 & $\mathrm{NC}$ & 010 & $\mathrm{NC}$ & oidy & 1) 199 & 008 & $0(1)$ \\
\hline $\mathrm{ZrO}_{2}$ & 039 & 060 & $\mathrm{NC}$ & 0.56 & $\mathrm{NC}$ & 053 & 1) 48 & 046 & 052 \\
\hline Sum & 10000 & 10000 & $\mathrm{NC}$ & 10000 & $\mathrm{NC}$ & $1(N)(10$ & 10000 & 10060 & 1 (wigk \\
\hline
\end{tabular}


Table 6.3. XRF Analyzed Compositions of Vitrified Melter Feed Samples (wt\%) (continued).

\begin{tabular}{|c|c|c|c|c|c|c|c|}
\hline Melter Type & \multicolumn{7}{|c|}{ DM1200 } \\
\hline Fomulation & \multicolumn{7}{|c|}{ HWI-Al-19 } \\
\hline Al Source & \multicolumn{7}{|c|}{ Aluminum Hydroxide } \\
\hline Test & \multirow{3}{*}{ Target } & 2 & \multicolumn{3}{|c|}{3} & \multirow{3}{*}{$\begin{array}{l}\text { Arg for } \\
\text { DM1200 }\end{array}$} & \multirow{3}{*}{$\%$ Der } \\
\hline Sample I D & & F.12K-7A & $\mathrm{F} \cdot 12 \mathrm{~K}-47 \mathrm{~A}$ & $\mathrm{~F}-12 \mathrm{~K}-69 \mathrm{~A}$ & F-12K-113A & & \\
\hline Constituent & & $\overline{X R F}$ & $\overline{\mathrm{XRF}}$ & XRF & XRF & & \\
\hline $\mathrm{Al}_{2} \mathrm{O}_{3}$ & 2.397 & 2304 & 2338 & 2406 & 2384 & 2319 & -325 \\
\hline $\mathrm{B}_{2} \mathrm{O}_{3}^{*}$ & 1919 & 1919 & 1919 & 1919 & 1919 & 1919 & NC \\
\hline $\mathrm{BaO}$ & 005 & 007 & 007 & 007 & 006 & 006 & $\mathrm{NC}$ \\
\hline $\mathrm{B}_{2} \mathrm{O}_{3}$ & 114 & 128 & 122 & 118 & 116 & 120 & 446 \\
\hline $\mathrm{CaO}$ & 558 & 582 & 563 & 550 & 548 & 563 & 093 \\
\hline $\mathrm{ClO}$ & 002 & 0.13 & 1) 03 & 5001 & 002 & 002 & $\mathrm{NC}$ \\
\hline $\mathrm{Cr}_{2} \mathrm{O}_{3}$ & 052 & 066 & 069 & 062 & 067 & 066 & $\mathrm{NC}$ \\
\hline $\mathrm{F}^{*}$ & 067 & 667 & i) 67 & 067 & 067 & 067 & NC \\
\hline $\mathrm{Fe}_{2} \mathrm{O}_{3}$ & 590 & 656 & 654 & 620 & 657 & 638 & 812 \\
\hline $\mathrm{K}_{2} \mathrm{O}$ & 014 & 920 & i) 22 & 019 & 020 & 029 & $\mathrm{NC}$ \\
\hline $\mathrm{L}_{2} \mathrm{O}^{*}$ & 357 & 357 & 357 & 357 & 357 & 357 & $\mathrm{NC}$ \\
\hline $\mathrm{MrO}$ & 012 & 025 & 031 & 026 & 029 & 028 & $\mathrm{NC}$ \\
\hline $\mathrm{MnO}$ & $\S$ & 002 & 002 & 002 & 003 & 003 & $\mathrm{NC}$ \\
\hline $\mathrm{Na}_{2} \mathrm{O}$ & 958 & 908 & 935 & 931 & 986 & 959 & 008 \\
\hline $\mathrm{Nd}_{2} \mathrm{O}_{\mathfrak{y}}$ & s & $<001$ & $<001$ & $\varepsilon=001$ & $\because: 00]$ & $<001$ & $\mathrm{NC}$ \\
\hline $\mathrm{NaO}$ & 040 & 043 & 042 & 039 & 042 & 041 & $\mathrm{NC}$ \\
\hline $\mathrm{P}_{2} \bigcirc 5$ & 105 & 110 & 120 & 112 & 113 & 109 & 380 \\
\hline $\mathrm{PbO}$ & 041 & 035 & i) 31 & 033 & 033 & 033 & NC \\
\hline $\mathrm{SIO}_{2}$ & 2700 & 2680 & 2638 & 2651 & 2570 & 2668 & .116 \\
\hline $\mathrm{SO}_{3}$ & 020 & 19 & i) 22 & 021 & 021 & 021 & NC \\
\hline $\mathrm{StO}$ & $\$$ & 8001 & 5001 & $<001$ & 8001 & 8001 & $\mathrm{NC}$ \\
\hline $\mathrm{T}_{1} \mathrm{O}_{2}$ & 001 & 005 & 005 & 004 & 004 & 005 & $\mathrm{NC}$ \\
\hline ZnO & 008 & ging & 1) 18 & 008 & 008 & 008 & $\overline{\mathrm{NC}}$ \\
\hline $\mathrm{ZrO}_{2}$ & 039 & 054 & 047 & 049 & 047 & 049 & $\mathrm{NC}$ \\
\hline Sum & 10000 & $1(\omega)(0)$ & 10000 & 10000 & $100 \infty$ & $100 \mathrm{iw}$ & $\mathrm{NC}$ \\
\hline
\end{tabular}

$\$$ - Not a target constituent

* Target values

$\mathrm{NC}-$ Not calculated 
Table 6.4. Listing of Glass Discharged, Masses, and Analysis Performed During DM100 Tests.

\begin{tabular}{|c|c|c|c|c|c|c|}
\hline Test & $T\left({ }^{\circ} \mathrm{C}\right)$ & Date & Nane & Analysts & Mass (kg) & Cum ulatlve Mass (kg) \\
\hline \multirow{17}{*}{1} & \multirow{17}{*}{1200} & \multirow{2}{*}{$2 / 4 / 08$} & $\mathrm{BLX}-\mathrm{G}-65 \mathrm{~A}$ & - & - & - \\
\hline & & & BLX.G.67A & $X R F, F$ & 2872 & 2872 \\
\hline & & \multirow{10}{*}{$2: 5 / 08$} & BLX-G-67B & $\cdot$ & - & - \\
\hline & & & BLXGG.7]A & $\mathrm{XRF}$ & 3389 & 6252 \\
\hline & & & BLX-G.71B & - & - & - \\
\hline & & & BLX-G-71C & XRF & 3134 & 9386 \\
\hline & & & BLX-G-76A & - & - & - \\
\hline & & & $\mathrm{BLX}-\mathrm{G}-76 \mathrm{~B}$ & $\mathrm{XRF}$ & 2334 & 11720 \\
\hline & & & $\mathrm{BLX}-\mathrm{G}-77 \mathrm{~A}$ & - & - & - \\
\hline & & & BLX-G-79A & $\mathrm{YRF}, \mathrm{F}$ & 2606 & 14326 \\
\hline & & & BLX-G-79B & - & - & - \\
\hline & & & BLX-G.82A & $\mathrm{XRF}$ & 2612 & 16938 \\
\hline & & \multirow{8}{*}{$2 ! 6108$} & $\mathrm{BLX}-\mathrm{G}-82 \mathrm{~B}$ & - & - & - \\
\hline & & & BLX-G.84A & $\mathrm{XRF}$ & 2732 & 19670 \\
\hline & & & $\mathrm{BLX}-\mathrm{G}-84 \mathrm{~B}$ & - & - & - \\
\hline & & & $\mathrm{BLX}-\mathrm{G}-84 \mathrm{C}$ & XRF, PCT, TCLP & 2548 & 23218 \\
\hline & & & BLX-G.89A & - & - & - \\
\hline \multirow{17}{*}{2} & \multirow{17}{*}{1150} & & BLX-G-91A & XRF, F & 3350 & 25568 \\
\hline & & & $\mathrm{BLK}-\mathrm{G}-93 \mathrm{~A}$ & - & - & . \\
\hline & & & BLX-G-96A & XRF & 2140 & 27708 \\
\hline & & \multirow{5}{*}{$2 / 7 \% 18$} & $\mathrm{BLK}-\mathrm{G}-98 \mathrm{~A}$ & - & - & . \\
\hline & & & $\mathrm{BLK}-\mathrm{G}-99 \mathrm{~A}$ & XRF & 2310 & 30018 \\
\hline & & & BLX-G-102A & - & - & - \\
\hline & & & BLX-G.102B & $\mathrm{XRF}$ & 2376 & 32394 \\
\hline & & & BLX-G-104A & - & - & - \\
\hline & & \multirow{7}{*}{$2 / 848$} & BLX-G-108A & XRF, F & 2062 & 34456 \\
\hline & & & BLX-G-10A & - & - & - \\
\hline & & & BLX-G-113A & $\mathrm{YRF}$ & 3196 & 37652 \\
\hline & & & BLY-G-114A & - & - & . \\
\hline & & & BLY-G-114B & $\mathrm{XRF}$ & 2424 & 40076 \\
\hline & & & BLY-G-114C & - & - & . \\
\hline & & & BLX-G-11SA & XRF,PCT, TCLP & 2100 & $4 \geq 176$ \\
\hline & & \multirow{2}{*}{$29: 08$} & BLX-G.119A & XRF & 3578 & 45754 \\
\hline & & & BLY-G-119B & XFF, F & 3256 & 49010 \\
\hline \multirow{10}{*}{3} & \multirow{10}{*}{1200} & $5 / 5008$ & BLX-G-143A & - & - & - \\
\hline & & \multirow{9}{*}{$5 / 6 / 08$} & BLY-G-144A & $\mathrm{XRF}, \mathrm{F}$ & 2016 & 51026 \\
\hline & & & BLY-G-144B & - & - & . \\
\hline & & & BLX-G-145A & XRF & 2426 & 53452 \\
\hline & & & BLX-G-14źB & - & - & - \\
\hline & & & BLX-G-147A & XRF & 2472 & 55924 \\
\hline & & & BLX-G-151A & - & - & - \\
\hline & & & BLX-G-151B & $\mathrm{XRF}$ & 2890 & 58814 \\
\hline & & & BLY-G-152A & - & - & . \\
\hline & & & BLX-G-153A & XRF, F & 2502 & 61316 \\
\hline
\end{tabular}

- Emply data field 
Table 6.4. List of Glass Discharged, Masses, and Analysis Performed During DM100 Tests (continued).

\begin{tabular}{|c|c|c|c|c|c|c|}
\hline Test & $\mathrm{T}\left({ }^{\circ} \mathrm{C}\right)$ & Date & Name & Analysis & Mass (ke) & $\begin{array}{l}\text { Cumulative } \\
\text { Mass (kg) }\end{array}$ \\
\hline \multirow{8}{*}{3} & \multirow{8}{*}{1200} & \multirow{2}{*}{$5: 608$} & BLX-G-154A & - & - & - \\
\hline & & & BLY-G-8A & XRF & 2798 & 63614 \\
\hline & & \multirow{10}{*}{$5: 7108$} & BLY-G-8B & - & - & - \\
\hline & & & BLY-G-10A & $\mathrm{XRF}$ & 2350 & 65964 \\
\hline & & & BLY.G.10B & - & - & - \\
\hline & & & $\mathrm{BLY}-\mathrm{G}-10 \mathrm{C}$ & $\mathrm{XRF}$ & 2350 & 68314 \\
\hline & & & $B L Y-G-14 A$ & - & - & - \\
\hline & & & $\mathrm{BLY}-\mathrm{G}-14 \mathrm{~B}$ & XRF,FCT.TCLPDCP.F & 3188 & 7150 \\
\hline \multirow{23}{*}{4} & \multirow{23}{*}{1150} & & $\mathrm{BL}-\mathrm{Y}-\mathrm{G}-15 \mathrm{~A}$ & - & - & - \\
\hline & & & $\mathrm{BL} Y \bar{Y}-\mathrm{G}-16 \mathrm{~A}$ & $\mathrm{XRF}$ & 2178 & 73680 \\
\hline & & & $\mathrm{BLY} \cdot \mathrm{G} \cdot 16 \mathrm{~B}$ & - & - & - \\
\hline & & & $\mathrm{BLY}=\mathrm{G}-17 \mathrm{~A}$ & $\mathrm{XRF}$ & 1968 & 75648 \\
\hline & & \multirow{10}{*}{$5 / 8108$} & BLY.G.17B & - & - & - \\
\hline & & & $\mathrm{BLY}-\mathrm{G}-22 \mathrm{~A}$ & $\mathrm{XRF}$ & 2120 & 77768 \\
\hline & & & $\mathrm{BLY}-\mathrm{G}-22 \mathrm{~B}$ & - & - & - \\
\hline & & & $\mathrm{BL} Y \bar{Y} \_\mathrm{G}-25 \mathrm{~A}$ & $\mathrm{XRF}, \mathrm{F}$ & 1866 & 79634 \\
\hline & & & $\mathrm{BLY} \cdot \mathrm{G} \cdot 25 \mathrm{~B}$ & - & - & - \\
\hline & & & BLY-G-26A & XRF & 2314 & 81948 \\
\hline & & & $\mathrm{BLY} \cdot \mathrm{G} \cdot 26 \mathrm{~B}$ & - & - & - \\
\hline & & & $\mathrm{BLY}-\mathrm{G} \cdot 36 \mathrm{C}$ & $\mathrm{XRF}$ & 1884 & 83832 \\
\hline & & & $\mathrm{BLY}-\mathbf{i}-28 \mathrm{~A}$ & - & - & - \\
\hline & & & $\mathrm{BL} \bar{Y}-\mathrm{G}-28 \mathrm{~B}$ & $\mathrm{XRF}$ & 1864 & 85696 \\
\hline & & \multirow{9}{*}{5,9108} & $B L Y=G=324$ & - & - & - \\
\hline & & & $\mathrm{BLY}-\mathrm{G}-34 \mathrm{~A}$ & XRF.F & 1864 & 87560 \\
\hline & & & BLY̌G.34B & - & - & - \\
\hline & & & BLY-G-35A & $\mathrm{XRF}$ & 2078 & 89638 \\
\hline & & & $\mathrm{BLY}-\mathrm{G}-36 \mathrm{~A}$ & - & - & - \\
\hline & & & $\mathrm{BL} Y-\mathrm{G}-36 \mathrm{~B}$ & XRF,PCT,TCLP,DCP & 2428 & 92066 \\
\hline & & & BLY-G-40A & $\mathrm{XRF}$ & 2842 & 94908 \\
\hline & & & $\mathrm{BL} Y-\mathrm{G}-\mathbf{4}) \mathrm{B}$ & XRF.F & 2914 & 97822 \\
\hline & & & $B L Y-G-40 C$ & $\mathrm{XRF}$ & 1772 & 99594 \\
\hline \multirow{12}{*}{5} & \multirow{12}{*}{1200} & \multirow{9}{*}{$6 / 3.08$} & BL $Y-G-62 A$ & - & - & - \\
\hline & & & $\mathrm{BLY}-\mathrm{G}-63 \mathrm{~A}$ & XRF.F & 2870 & 102464 \\
\hline & & & BLY-G-66A & $=$ & - & - \\
\hline & & & $\mathrm{BLY}=\mathrm{G} \cdot 66 \mathrm{~B}$ & XRF & 3286 & $105750^{\circ}$ \\
\hline & & & $\mathrm{BLY}-\mathrm{G}-68 \mathrm{~A}$ & - & - & - \\
\hline & & & $\mathrm{BL} Y-\mathrm{G}-69 \mathrm{~A}$ & $\mathrm{SRF}$ & 2666 & 108416 \\
\hline & & & BLY.G.69B & - & - & - \\
\hline & & & $B L \bar{Y}-G-73 A$ & $\mathrm{XRF}$ & 2626 & 111042 \\
\hline & & & BLY-G.7AA & 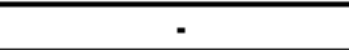 & - & - \\
\hline & & \multirow{3}{*}{61408} & BLY-G.75A & $\mathrm{XRF}, \mathrm{F}$ & 2864 & 113906 \\
\hline & & & $\mathrm{BLY}-\mathrm{G}-79 \mathrm{~A}$ & - & - & - \\
\hline & & & BLY-G-80A & XRF & 2714 & $116620^{\circ}$ \\
\hline
\end{tabular}

- Emply data field 
Table 6.4. List of Glass Discharged, Masses, and Analysis Performed During DM100 Tests (continued).

\begin{tabular}{|c|c|c|c|c|c|c|}
\hline Test & $T\left({ }^{\circ} \mathrm{C}\right)$ & Date & Name & Analysis & Mass (kg) & $\begin{array}{c}\text { Cumulative } \\
\text { Mass (kg) }\end{array}$ \\
\hline \multirow{3}{*}{5} & \multirow{3}{*}{1200} & \multirow{5}{*}{$6 / 408$} & BLY-G-80B & - & - & - \\
\hline & & & BLY-G-80C & XRF,FCT,TCLP,DCF & 2740 & 119360 \\
\hline & & & BLY-G-84A & - & - & - \\
\hline \multirow{20}{*}{6} & \multirow{20}{*}{1150} & & BLY-G-85A & $\mathrm{XRF}$ & 3364 & 122724 \\
\hline & & & BLY-G-87A & - & - & . \\
\hline & & \multirow{9}{*}{$6: 5 / 68$} & BLY-G-\$1A & XRF.F & 2268 & 124992 \\
\hline & & & BL Y-G-92A & - & - & - \\
\hline & & & BLY-G-93A & $\mathrm{XRF}$ & 20) 42 & 127034 \\
\hline & & & BLY-G-93B & - & - & - \\
\hline & & & BLY-G-93C & $\mathrm{XRF}$ & 1578 & 128612 \\
\hline & & & BLY-G-94A & - & - & $\dot{.}$ \\
\hline & & & BLY-G.98A & - & - & . \\
\hline & & & BLY-G-98B & $\mathrm{XRF}$ & 2034 & 130646 \\
\hline & & & BLY-G-GMA & $\cdot$ & $\cdot$ & . \\
\hline & & \multirow{6}{*}{$6 / 608$} & BLY-0-101A & $\mathrm{XRF}$ & 1556 & 132202 \\
\hline & & & BLY-G-106A & - & - & - \\
\hline & & & BLY-G-107A & $\mathrm{XRF}, \mathrm{F}$ & 2862 & 135064 \\
\hline & & & BLY-G.111A & - & - & . \\
\hline & & & BLY-G-11IB & $\mathrm{XRF}$ & 2354 & 137418 \\
\hline & & & BLY $=G=112 \mathrm{~A}$ & - & $\cdot$ & $\cdot$ \\
\hline & & $6 / 7 / 68$ & $B L Y-0-114 A$ & XRF,PCT,TCLP.DCP & 2176 & 139594 \\
\hline & & \multirow{2}{*}{$6: 19108$} & $\mathrm{BLY}-\mathrm{G}-120 \mathrm{~A}$ & $\mathrm{XRF}$ & 2716 & 142310 \\
\hline & & & $\mathrm{BLY}=\mathrm{G}-120 \mathrm{~B}$ & $\mathrm{XRF}$ & 4104 & 146414 \\
\hline \multirow{16}{*}{7} & \multirow{16}{*}{1200} & 623108 & BLY-G-135A & - & - & - \\
\hline & & \multirow{9}{*}{$6 / 24: 08$} & BLY-G=139A & $\mathrm{XRF}, \mathrm{F}$ & 3234 & 149638 \\
\hline & & & BLY-G-141A & - & - & . \\
\hline & & & $B L Y-G-141 B$ & $\mathrm{XRF}$ & 3358 & 152996 \\
\hline & & & $\mathrm{BLY}-\mathrm{G}-144 \mathrm{~A}$ & - & - & - \\
\hline & & & $B L Y-G=144 B$ & $\mathrm{XRF}$ & 3i) 16 & 156012 \\
\hline & & & BLY-0 $-145 A$ & - & - & - \\
\hline & & & BLY-G-145B & XRF & 3138 & 159150 \\
\hline & & & BLY-G=147A & $\cdot$ & $\cdot$ & . \\
\hline & & & BLY-G-15lA & $\mathrm{XRF}, \mathrm{F}$ & 3398 & 162548 \\
\hline & & \multirow{8}{*}{$6 / 25: 00$} & BLY-G-15IB & - & - & $\cdot$ \\
\hline & & & BLY $-G=152 \mathrm{~A}$ & $\mathrm{XRF}$ & 3034 & 165582 \\
\hline & & & BLY-0 $-153 \mathrm{~A}$ & - & - & - \\
\hline & & & BLY-G-15.3B & $\mathrm{XRF}$ & 2616 & 168198 \\
\hline & & & BLZ-G-5A & - & - & . \\
\hline & & & $\mathrm{BLZ}-\mathrm{G}-5 \mathrm{~B}$ & XRF,PCT,TCLP,DCP & 2736 & 170934 \\
\hline \multirow{4}{*}{8} & \multirow{4}{*}{1150} & & BLZ-G-11A & $\cdot$ & - & $\cdot$ \\
\hline & & & BLZ-G-13A & $\mathrm{XRF}, \mathrm{F}$ & 3196 & 174130 \\
\hline & & \multirow{2}{*}{$6 / 2608$} & $\mathrm{BLZ}-\mathrm{G}-1,3 \mathrm{~B}$ & - & - & - \\
\hline & & & BLZ-G-16A & $\mathrm{XRF}$ & 2574 & 176704 \\
\hline
\end{tabular}

- Empty data field 
Table 6.4. List of Glass Discharged, Masses, and Analysis Performed During DM100 Tests (continued).

\begin{tabular}{|c|c|c|c|c|c|c|}
\hline Test & $\mathrm{T}\left({ }^{\circ} \mathrm{C}\right)$ & Dite & Name & Analysis & Mass (kg) & $\begin{array}{l}\text { Cumulative } \\
\text { Mass (kg) }\end{array}$ \\
\hline \multirow{15}{*}{8} & \multirow{15}{*}{1150} & \multirow{6}{*}{$6 / 2608$} & BLZ-Cj-18A & - & - & - \\
\hline & & & BLZ-G-21A & XRF & 2462 & 179166 \\
\hline & & & BLZ-G-21B & - & - & - \\
\hline & & & BLZ-G-23A & XRF & 3432 & 181598 \\
\hline & & & $\mathrm{BLZ}-\mathrm{G}-23 \mathrm{~B}$ & - & - & - \\
\hline & & & BLZ-G-27A & $\mathrm{XRF}, \mathrm{F}$ & 2528 & 184126 \\
\hline & & \multirow{9}{*}{$6: 27 / 08$} & $\mathrm{BLZ}-\mathrm{G}-27 \mathrm{~B}$ & - & - & - \\
\hline & & & $\mathrm{BLZ}-\mathrm{G}-28 \mathrm{~A}$ & $\mathrm{YRF}$ & 2570 & 186696 \\
\hline & & & BLZ-G-29A & - & - & - \\
\hline & & & $\mathrm{BLZ}-\mathrm{G}-29 \mathrm{~B}$ & $\mathrm{MFF}$ & 2260 & 188956 \\
\hline & & & BLZ-G-33A & - & - & - \\
\hline & & & BLZ-G-33B & XRF & 2306 & 191262 \\
\hline & & & BLZ-G-35A & - & - & - \\
\hline & & & BLZ-G-35B & $\mathrm{XRF}, \mathrm{F}$ & 2414 & 193676 \\
\hline & & & BLZ-G-37A & XRF, PCT, TCLP. DCP & 1164 & 194840 \\
\hline
\end{tabular}

- Enipty data field 
Table 6.5. List of Glass Discharged, Masses, and Analysis Performed during DM1200 Test.

\begin{tabular}{|c|c|c|c|c|c|}
\hline Test & Date & Nalle & Auralysis & Mass (kg) & $\begin{array}{l}\text { Cumulative } \\
\text { Mass (kg) }\end{array}$ \\
\hline \multirow{43}{*}{1} & \multirow{12}{*}{$8 / 6 / 08$} & G-1_J_-4]A & - & - & - \\
\hline & & $\mathrm{G}-12 \mathrm{~J}-42 \mathrm{~A}$ & - & - & - \\
\hline & & G-12J-42B & - & - & - \\
\hline & & $\mathrm{G} \cdot 12 \mathrm{~J} \cdot 43 \mathrm{~A}$ & - & $\cdot$ & . \\
\hline & & $\mathrm{G}-12 \mathrm{~J}-43 \mathrm{~B}$ & - & . & - \\
\hline & & G-12J-44A & - & - & - \\
\hline & & $\mathrm{G} \cdot 12 \mathrm{~J} \cdot 45 \mathrm{~A}$ & XRF, DCP, F & 4785 & 4785 \\
\hline & & $G-12 J-45 B$ & - & - & - \\
\hline & & G-12J-46A & - & - & - \\
\hline & & $\mathrm{G} .12 \mathrm{~J} .48 \mathrm{~A}$ & - & - & . \\
\hline & & $G-12 J-48 \mathrm{~B}$ & - & - & - \\
\hline & & $G \cdot 12 \mathrm{~J} \cdot 60 \mathrm{~A}$ & & 5020 & 9805 \\
\hline & \multirow{26}{*}{$8 / 7 / 08$} & G.12J-60B & - & - & - \\
\hline & & $\mathrm{G}-12 \mathrm{~J}-6 \mathrm{G} \mathrm{A}$ & - & - & - \\
\hline & & G-12J-6lB & - & - & - \\
\hline & & $G \cdot 12 \mathrm{~J} \cdot 62 \mathrm{~A}$ & - & - & . \\
\hline & & $G-12 J-62 \mathrm{~B}$ & - & - & - \\
\hline & & G-1 IJ-64A & XRF & 4815 & 14620 \\
\hline & & $\mathrm{G} \cdot 12 \mathrm{~J} \cdot 6 \overline{\mathrm{gA}}$ & - & - & $\dot{.}$ \\
\hline & & $\mathrm{G} .12 \mathrm{~J} .69 \mathrm{~A}$ & - & - & $\dot{.}$ \\
\hline & & $\mathrm{G}-12 \mathrm{~J}-69 \mathrm{~B}$ & - & - & - \\
\hline & & G-1 $2 \mathrm{~J}-70 \mathrm{~A}$ & - & - & - \\
\hline & & $\mathrm{G}-12 \mathrm{~J}-71 \mathrm{~A}$ & - & - & - \\
\hline & & G-12J-7lB & - & - & - \\
\hline & & $\mathrm{G}=12 \mathrm{~J}-7 \mathrm{lC}$ & - & - & - \\
\hline & & $\mathrm{G} \cdot 12 \mathrm{~J} .72 \mathrm{~A}$ & XRF_F & 4990 & 19610 \\
\hline & & $\mathrm{G}-12 \mathrm{~J}-72 \mathrm{~B}$ & - & - & - \\
\hline & & $\mathrm{G} .12 \mathrm{~J} .73 \mathrm{~A}$ & - & - & $\dot{.}$ \\
\hline & & $\mathrm{G}-12 \mathrm{~J}-73 \mathrm{~A}$ & - & - & - \\
\hline & & $\mathrm{G}-12 \mathrm{~J}-75 \mathrm{~B}$ & - & - & - \\
\hline & & G.12J.77A & - & - & . \\
\hline & & $\mathrm{G} .12 \mathrm{~J} .79 \mathrm{~A}$ & - & - & $\dot{.}$ \\
\hline & & G.12J-79B & XRF & 4850 & 34460 \\
\hline & & $\mathrm{G} .12 \mathrm{~J} .88 \mathrm{~A}$ & - & - & $\dot{.}$ \\
\hline & & $\mathrm{G}-12 \mathrm{~J}-89 \mathrm{~A}$ & - & - & - \\
\hline & & G-12J-89B & - & - & - \\
\hline & & G-1 JJ-90A & - & - & - \\
\hline & & $\mathrm{G}-12 \mathrm{~J}-9(\mathrm{~B}$ & - & - & - \\
\hline & \multirow{5}{*}{$8: 808$} & G-12J-100A & XRF & 4465 & 28925 \\
\hline & & G.12J-100B &. & . & . \\
\hline & & $\mathrm{G}=12 \mathrm{~J}-101 \mathrm{~A}$ & - & - & . \\
\hline & & $G-12 J-102 \mathrm{~A}$ & - & - & - \\
\hline & & G-12J-104A & - & - & $\dot{.}$ \\
\hline
\end{tabular}

- Emply data field 
Table 6.5. List of Glass Discharged, Masses, and Analyssis Performed during DM1200 Test (continued).

\begin{tabular}{|c|c|c|c|c|c|}
\hline Test & Date & Name & Analysts & Mass (kg) & $\begin{array}{l}\text { Cumulative } \\
\text { Mass (kg) }\end{array}$ \\
\hline \multirow{5}{*}{$\mathbf{1}$} & \multirow{5}{*}{$8 / 8 / 08$} & G-12J-105A & - & - &. \\
\hline & & $\mathrm{G}-12 \mathrm{~J}-10 \mathrm{sB}$ & $\mathrm{XRF}, \mathrm{DCP}, \mathrm{F}$ & 4805 & 33730 \\
\hline & & G-12J-106A & - & - & - \\
\hline & & $G-12 J-110 \mathrm{~A}$ & - & - & - \\
\hline & & $\mathrm{G}-12 \mathrm{~J}-110 \mathrm{~B}$ & - & - & - \\
\hline \multirow{28}{*}{2} & \multirow{4}{*}{$8 / 11 / 08$} & G-12J-133A & - & - &. \\
\hline & & G-12J-135A & XRF & 4925 & 38655 \\
\hline & & $\mathrm{G}-12 \mathrm{~J}-13 \mathrm{SB}$ & - & - & - \\
\hline & & G-12J-136A & - & - & . \\
\hline & \multirow{18}{*}{$8 / 12 / 08$} & $\mathrm{G}-12 \mathrm{~J}-137 \mathrm{~A}$ & - & - &. \\
\hline & & $\mathrm{G}-1 \geq \mathrm{J}-139 \mathrm{~A}$ & - & - & - \\
\hline & & G-12J-139B & - & - & - \\
\hline & & $\mathrm{G}=12 \mathrm{~J}=148 \mathrm{~A}$ & - & - & . \\
\hline & & $\mathrm{G}-12 \mathrm{~J}-149 \mathrm{~A}$ & - & - & . \\
\hline & & G.12J-149B & XRF, DCP & 4985 & 43640 \\
\hline & & G-12J-153A & - & - &. \\
\hline & & $\mathrm{G}-12 \mathrm{~J}-15 \geq \mathrm{B}$ & - & - & - \\
\hline & & G-12J-154A & - & - & - \\
\hline & & G-12J-155A & - & - & . \\
\hline & & $\mathrm{G}-12 \mathrm{~K}-7 \mathrm{~A}$ & - & - & - \\
\hline & & G-12K-11A & - & - & . \\
\hline & & $\mathrm{G}=12 \mathrm{~K}-11 \mathrm{~B}$ & - & - & - \\
\hline & & $\mathrm{G}-12 \mathrm{~K}-21 \mathrm{~A}$ & $\mathrm{XRF}$ & 4955 & 48595 \\
\hline & & $\mathrm{G}-12 \mathrm{~K}-22 \mathrm{~A}$ & - & - & - \\
\hline & & G-12K-23A & - & - & - \\
\hline & & $G-12 \mathrm{~K}-24 \mathrm{~A}$ & - & - & - \\
\hline & & $\mathrm{G}-12 \mathrm{~K}-24 \mathrm{~B}$ & - & - & - \\
\hline & & G-12K-26A & - & - & . \\
\hline & & $G \cdot 12 \mathrm{~K}-26 \mathrm{~B}$ & - & - & - \\
\hline & & $\mathrm{G}-12 \mathrm{~K}-28 \mathrm{~A}$ & - & - & $\cdot$ \\
\hline & & $\mathrm{G}=12 \mathrm{~K}-28 \mathrm{~B}$ & - & - & - \\
\hline & & $\mathrm{G}-12 \mathrm{~K}-28 \mathrm{C}$ & XRF.F & 4980 & 53575 \\
\hline & & G-12K-37A & - & - & - \\
\hline & & $\mathrm{G}-12 \mathrm{~K}-37 \mathrm{~B}$ & - & - & - \\
\hline & $8 / 13 / 08$ & G-12K-38A & - & - & - \\
\hline & & $\mathrm{G}-12 \mathrm{k}-38 \mathrm{~B}$ & - & - & - \\
\hline & & $G=12 K-42 A$ & - & - & . \\
\hline 3 & & $\mathrm{G}-12 \mathrm{~K}-43 \mathrm{~A}$ & - & - & - \\
\hline & & $\mathrm{G}-12 \mathrm{~K}-43 \mathrm{~B}$ & - & - & - \\
\hline & & $\mathrm{G}-12 \mathrm{~K}-44 \mathrm{~A}$ & $\mathrm{XRF}$ & 4750 & 58325 \\
\hline & & $G-12 \mathrm{~K}-46 \mathrm{~A}$ & - & - & - \\
\hline & & G.1 IK-47A & - & - &. \\
\hline
\end{tabular}

- Emply data ficklid 
Table 6.5. List of Glass Discharged, Masses, and Analysis Performed during DM1200 Test (continued).

\begin{tabular}{|c|c|c|c|c|c|}
\hline Test & Date & Name & Analysts & Mass (ks) & $\begin{array}{l}\text { Cunoulative } \\
\text { Mass (kg) }\end{array}$ \\
\hline \multirow{43}{*}{3} & \multirow{6}{*}{$8 / 13 / 08$} & G.12K-57A & - & - & - \\
\hline & & $\mathrm{G}-12 \mathrm{~K}-58 \mathrm{~A}$ & - & - & . \\
\hline & & $\mathrm{G}=12 \mathrm{~K}-58 \mathrm{~B}$ & - & - & - \\
\hline & & $\mathrm{G}-12 \mathrm{~K}-59 \mathrm{~A}$ & $\mathrm{XPF}$ & 4625 & 62950 \\
\hline & & G-12K-61A & - & - & . \\
\hline & & $G-1 工 K-63 A$ & - & - & - \\
\hline & \multirow{16}{*}{$8: 14: 08$} & $\mathrm{G}-12 \mathrm{~K}-64 \mathrm{~A}$ & - & - & - \\
\hline & & G.1 IK-66A & $\cdot$ & - & - \\
\hline & & G.12K-67A & - & - & - \\
\hline & & $\mathrm{G}-12 \mathrm{~K}-6 \mathrm{AA}$ & - & - & - \\
\hline & & $\mathrm{G}-12 \mathrm{~K}-81 \mathrm{~A}$ & - & - & . \\
\hline & & $\mathrm{G}-12 \mathrm{~K}-81 \mathrm{~B}$ & $\mathrm{XRF}$ & 5130 & 68080 \\
\hline & & $\mathrm{G}-12 \mathrm{~K}-84 \mathrm{~A}$ & - & - & $\cdot$ \\
\hline & & G-12K-85A & - & - & . \\
\hline & & G-1?K-86A & - & - & - \\
\hline & & $\mathrm{G}-12 \mathrm{~K}-87 \mathrm{~A}$ & - & - & - \\
\hline & & $G-12 K-87 \mathrm{~B}$ & - & - & - \\
\hline & & $\mathrm{G}-12 \mathrm{~K}-89 \mathrm{~A}$ & - & - & - \\
\hline & & $\mathrm{G}-13 \mathrm{~K}-91 \mathrm{~A}$ & XFF, F & 5020 & 73100 \\
\hline & & $\mathrm{G}-12 \mathrm{~K}-9 \mathrm{gA}$ & - & . &. \\
\hline & & G-1 $3 \mathbf{K}-92 \mathrm{~B}$ & $\cdot$ & - & - \\
\hline & & $\mathrm{G}-12 \mathrm{~K}-100 \mathrm{~A}$ & - & - & - \\
\hline & \multirow{20}{*}{$8 / 15 / 08$} & (j-12K-104A & - & - & - \\
\hline & & G.12K-105A & - & - & - \\
\hline & & $\mathrm{G}-12 \mathrm{~K}-105 \mathrm{~B}$ & - & - & - \\
\hline & & G-12K-107A & - & - & - \\
\hline & & $\mathrm{G}=12 \mathrm{~K}-10 \mathrm{~B}$ & - & - & - \\
\hline & & $\mathrm{G}-12 \mathrm{~K}-1 \mathrm{kgA}$ & XPF & 4835 & 77935 \\
\hline & & G-12k-109B & - & - & - \\
\hline & & G.12K-111A & - & - & - \\
\hline & & $\mathrm{G}=12 \mathrm{~K}-112 \mathrm{~A}$ & - & - & - \\
\hline & & G-IZK-112B & - & - & - \\
\hline & & G-12K-113A & - & - & - \\
\hline & & (j-12K-114A & - & - & - \\
\hline & & G-1느-1]4B & - & - & - \\
\hline & & $\mathrm{G}=12 \mathrm{~K}-1 \mathrm{~d} \mathrm{AC}$ & - & - & - \\
\hline & & $\mathrm{G}-12 \mathrm{~K}-115 \mathrm{~A}$ & XPF & 4945 & 82880 \\
\hline & & (j-12K-117A & - & - & - \\
\hline & & $\mathrm{G}-12 \mathrm{~K}-117 \mathrm{~B}$ & - & - & - \\
\hline & & $9-12 \mathrm{~K}-127 \mathrm{~A}$ & - & - & - \\
\hline & & G-12K-129A & - & - & - \\
\hline & & G.12K-138A & XRF, DCP, F & 4725 & 87605 \\
\hline & 81608 & G-12K-139A & XRF & 1125 & 88730 \\
\hline
\end{tabular}

- Empty data field 
Table 6.6. XRF Analyzed Composition for Glass Discharged During DM100 Melter Test (wt \%).

\begin{tabular}{|c|c|c|c|c|c|c|c|c|c|c|c|}
\hline Fonmukation & \multicolumn{11}{|c|}{ HLW'E-AI-27 } \\
\hline Al Sources & \multicolumn{11}{|c|}{ Aluminum Hydroxide } \\
\hline Temperature & \multirow{4}{*}{ Target } & \multicolumn{8}{|c|}{$1200^{\circ} \mathrm{C}$} & \multicolumn{2}{|c|}{$1150^{\circ} \mathrm{C}$} \\
\hline Test & & \multicolumn{8}{|c|}{1} & \multicolumn{2}{|c|}{2} \\
\hline Glass (big) & & 2872 & 6252 & 9386 & 11720 & 14326 & 16938 & 19670 & 22218 & 25568 & 27708 \\
\hline Constituent & & $\begin{array}{l}\text { BLX- } \\
\text { G.67A }\end{array}$ & $\begin{array}{l}\text { BLX- } \\
\text { G-JlA }\end{array}$ & $\begin{array}{l}\text { BLX- } \\
\text { G-7IC }\end{array}$ & $\begin{array}{l}\text { BLX- } \\
\text { G.76B }\end{array}$ & $\begin{array}{l}\text { BLY- } \\
\text { G.79A }\end{array}$ & $\begin{array}{l}\text { BLX- } \\
\text { G-82A }\end{array}$ & $\begin{array}{l}\text { BLX- } \\
\text { G-84A }\end{array}$ & $\begin{array}{l}\text { BLX- } \\
\text { G-84C }\end{array}$ & $\begin{array}{l}\text { BLX- } \\
\text { G-9lA }\end{array}$ & $\begin{array}{l}\text { BLX- } \\
\text { G.96A }\end{array}$ \\
\hline $\mathrm{Al}_{2} \mathrm{O}_{3}$ & 2397 & 1236 & 1393 & 1526 & 16.75 & 1749 & 1796 & 1865 & 1933 & 1977 & 2025 \\
\hline $\mathrm{B}_{2} \mathrm{O}_{3}^{*}$ & 1519 & 1398 & 1419 & 1435 & 1445 & 1455 & 1464 & 1471 & \begin{tabular}{|l|}
1478 \\
\end{tabular} & 1485 & 1489 \\
\hline $\mathrm{BaO}$ & 005 & 2001 & cojol & $\therefore 001$ & 0001 & 8001 & 8001 & 001 & aj01 & $<001$ & 801 \\
\hline$\overline{\mathrm{B}_{2} \mathrm{O}_{3}}$ & 114 & 079 & 19. & 095 & 90 & 090 & 1 ing & 110 & 106 & 105 & 112 \\
\hline $\mathrm{CaO}$ & 608 & 267 & 335 & 374 & 389 & 434 & 469 & 486 & 498 & 505 & 525 \\
\hline $\mathrm{CdO}$ & 002 & 004 & 004 & 004 & 003 & 003 & 003 & 003 & 003 & 003 & 003 \\
\hline $\mathrm{Ce}_{2} \mathrm{O}_{3}$ & $\$$ & 004 & 004 & 003 & 002 & 002 & 001 & 002 & 002 & 002 & $00 z$ \\
\hline $\mathrm{Cr}_{2} \mathrm{O}_{3}$ & 0.52 & 052 & 054 & 053 & 050 & 051 & 056 & 056 & 0.55 & 056 & 056 \\
\hline $\mathrm{F}$ & 067 & $022^{7}$ & 026 & 029 & 032 & $035^{\#}$ & 036 & 036 & 037 & $038^{11}$ & 039 \\
\hline $\mathrm{Fe}_{2} \mathrm{O}_{3}$ & 590 & 724 & 718 & 697 & 632 & 652 & 678 & 663 & 638 & 616 & 627 \\
\hline $\mathrm{K}_{2} \mathrm{O}$ & 014 & 029 & 028 & 027 & 024 & 024 & $02 A$ & 024 & 023 & 021 & 021 \\
\hline $\mathrm{La}_{2} \mathrm{O}_{3}$ & $\xi$ & 007 & 6001 & $<001$ & 004 & 004 & 003 & 002 & 002 & $<001$ & $>001$ \\
\hline $\mathrm{Ll}_{2} \mathrm{O}^{*}$ & 357 & 260 & 276 & 289 & 297 & 305 & 312 & 319 & 324 & 329 & 333 \\
\hline $\mathrm{MgO}$ & 012 & 035 & 030 & 031 & 031 & 029 & 026 & 030 & 030 & 027 & 026 \\
\hline $\mathrm{MnO}$ & 000 & 072 & 061 & 053 & 041 & 039 & 036 & 0.32 & 028 & 024 & 022 \\
\hline $\mathrm{Na}_{2} \mathrm{O}$ & 958 & 1107 & 1063 & 1047 & 1128 & 1051 & 975 & 1001 & 1018 & 1053 & 997 \\
\hline $\mathrm{Nd}_{2} \mathrm{O}_{2}$ & $\$$ & 006 & 005 & 004 & 003 & 003 & 003 & 002 & 002 & 002 & 002 \\
\hline $\mathrm{N}_{1} \mathrm{O}$ & 049 & 951 & 951 & 049 & i) 42 & 943 & 945 & 942 & 041 & 037 & 939 \\
\hline $\mathrm{P}_{2} \mathrm{O}_{3}$ & 105 & 074 & 081 & 085 & 1) 91 & 093 & 099 & $1(\boldsymbol{m})$ & 105 & 104 & 106 \\
\hline $\mathrm{PbO}$ & $\overline{041}$ & 027 & 031 & 031 & 030 & 032 & 035 & 035 & 033 & 033 & 036 \\
\hline $\mathrm{S}_{1} \mathrm{O}_{2}$ & 3950 & 3656 & 3540 & 3479 & 3450 & 3395 & 3345 & 3300 & 3297 & 3271 & 3254 \\
\hline $\mathrm{SO}_{3}$ & $020^{\circ}$ & 012 & 012 & 013 & 012 & 013 & 013 & 012 & 011 & 011 & 013 \\
\hline $\mathrm{SrO}$ & $\$$ & 404 & 358 & 396 & 235 & 220 & 208 & 176 & 145 & 125 & 112 \\
\hline $\mathrm{T}_{1} \mathrm{O}_{2}$ & 001 & 005 & 003 & 003 & 004 & 004 & 004 & 004 & 004 & 004 & 004 \\
\hline $\mathrm{ZnO}$ & 008 & $0(1)$ & 052 & 046 & 1) 36 & 934 & 934 & 1. 39 & i) 27 & 023 & 022 \\
\hline $\mathrm{ZrO}_{2}$ & 039 & 409 & 367 & 320 & 251 & 240 & 228 & 198 & 165 & 147 & 137 \\
\hline Sum & 1000 & 10000 & 10000 & 10000 & 10000 & 10000 & 10000 & 10000 & 10000 & 10000 & 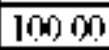 \\
\hline
\end{tabular}

$\$$ - Not a tatyet constipuent

4. for XRF-aralyzed compositions, values for $\mathrm{B}_{2} \mathrm{O}_{3}$ and $\mathrm{L}_{2} \mathrm{O}$ were calculated based on simple well-stitred tank model and target values

\# - Fluorine was measured by XRF on polshed samples. values for other samples calculated by interpolation 
Table 6.6. XRF Analyzed Composition for Glass Discharged During DM100 Melter Test (wt\%) (continued).

\begin{tabular}{|c|c|c|c|c|c|c|c|c|c|c|}
\hline Formulation & \multicolumn{10}{|c|}{ HLW.E-AI-27 } \\
\hline Al Source & \multicolumn{10}{|c|}{ Aluminuı Hydroxide } \\
\hline Temperature & \multirow{4}{*}{ Taryet } & \multicolumn{9}{|c|}{$1150^{\circ} \mathrm{C}$} \\
\hline Test & & \multicolumn{9}{|c|}{2} \\
\hline Glass (kg) & & 30018 & 32394 & 34456 & 37652 & 40076 & 42176 & 45754 & \multicolumn{2}{|c|}{49010} \\
\hline Constinent & & \begin{tabular}{|c|} 
BLX-G- \\
$99 \mathrm{~A}$
\end{tabular} & $\begin{array}{c}\text { BLX-G } \\
10 \mathrm{~B}\end{array}$ & $\begin{array}{c}\text { BLX-G- } \\
108 \mathrm{~A}\end{array}$ & \begin{tabular}{|c|} 
BLX.G. \\
$113 \mathrm{~A}$
\end{tabular} & $\begin{array}{c}\text { BLX-G } \\
114 \mathrm{~B}\end{array}$ & $\begin{array}{c}\text { BLX-G- } \\
115 \mathrm{~A}\end{array}$ & $\begin{array}{r}\text { BLX-G. } \\
119 \mathrm{~A}\end{array}$ & \begin{tabular}{|c|} 
BLX-G- \\
$119 \mathrm{~B}$
\end{tabular} & $\because$ Des \\
\hline $\mathrm{Al}_{2} \mathrm{O}_{3}$ & 2397 & 2070 & 2088 & 2097 & 2138 & 2137 & 2179 & 2140 & 2190 & -864 \\
\hline $\mathrm{B}_{2} \mathrm{O}_{3}{ }^{*}$ & 1519 & 1492 & 1496 & 1498 & 1501 & 1504 & 1505 & 1505 & 1505 & $\mathrm{NC}$ \\
\hline $\mathrm{BaO}$ & 005 & 8001 & 005 & $<001$ & 5001 & 005 & 0,05 & 005 & 004 & $\mathrm{NC}$ \\
\hline $\mathrm{Bl}_{2} \mathrm{O}_{3}$ & 114 & 106 & 111 & 113 & 112 & 117 & 113 & 134 & 110 & .409 \\
\hline $\mathrm{CaO}$ & 608 & 516 & 536 & 544 & 594 & 572 & 557 & 588 & 55 & .866 \\
\hline $\mathrm{ClO}$ & at & 003 & 903 & 043 & 002 & (1) 13 & 003 & 003 & 103 & $\mathrm{NC}$ \\
\hline $\mathrm{Ce}_{2} \mathrm{O}_{3}$ & $\xi$ & 001 & iol & 002 & 902 & 000 & i) $0_{2}$ & 001 & xiol & NC \\
\hline $\mathrm{Cr}_{2} \mathrm{O}_{3}$ & 052 & 053 & 056 & 056 & 056 & 057 & 055 & 059 & $\dot{0} 54$ & NC \\
\hline$F$ & 067 & 040 & (i) 41) & d $41_{\text {म̈ }}$ & 042 & 94 & 043 & 044 & $\left(144^{\#}\right.$ & $\mathrm{NC}$ \\
\hline $\mathrm{Fe}_{2} \mathrm{O}_{3}$ & 590 & 590 & 600 & 608 & 600 & 614 & 599 & 636 & 575 & .253 \\
\hline $\mathrm{K}_{2} \mathrm{O}$ & a 14 & 019 & 20 & 020 & 019 & 19 & 019 & 020 & 19 & $\mathrm{NC}$ \\
\hline $\mathrm{La}_{2} \mathrm{O}_{y}$ & $\xi$ & c001 & - 01 & 001 & 901 & 001 & a)(1) & $=001$ & 1. & $\mathrm{NC}$ \\
\hline $\mathrm{Ll}_{2} \mathrm{O}^{*}$ & 357 & 335 & 338 & 340 & 343 & 345 & 346 & 346 & 346 & $\mathrm{NC}$ \\
\hline $\mathrm{M}(\mathrm{y})$ & 912 & 022 & 025 & 024 & 027 & 923 & 025 & 020 & 1. 26 & $\mathrm{NC}$ \\
\hline $\mathrm{MnO}$ & 000 & 018 & 017 & 016 & 013 & 013 & 012 & 015 & 012 & NC \\
\hline $\mathrm{Na}_{2} \mathrm{O}$ & 9.58 & 1046 & 1040 & 10) 31 & 1038 & 1010 & 1043 & 947 & 10.54 & $\log 3$ \\
\hline $\mathrm{Nd}_{2} \mathrm{O}_{3}$ & 8 & 002 & 001 & $<001$ & 801 & $<001$ & 001 & 001 & 001 & $\mathrm{NC}$ \\
\hline $\mathrm{NoO}$ & a 49 & 035 & a) 36 & 036 & (1) 36 & 037 & i) 35 & 038 & i. 33 & $\mathrm{NC}$ \\
\hline $\mathrm{P}_{2} \mathrm{O}_{5}$ & 105 & 108 & 110 & 111 & 112 & 115 & 111 & 113 & 116 & 1006 \\
\hline $\mathrm{PbO}$ & 041 & 033 & 035 & 036 & 035 & 037 & 036 & 039 & 034 & $\mathrm{NC}$ \\
\hline $\mathrm{S}_{1} \mathrm{O}_{2}$ & 3050 & 3259 & 3205 & 3206 & 3175 & 3161 & 3142 & 3165 & 3159 & 360 \\
\hline $\mathrm{SO}_{3}$ & 020 & 014 & 014 & 015 & 015 & 014 & 016 & 015 & 015 & $\mathrm{NC}$ \\
\hline Sro & 8 & 093 & 086 & 077 & 065 & 062 & 054 & 061 & 049 & $\mathrm{NC}$ \\
\hline $\mathrm{TrO}_{2}$ & 001 & 0163 & 004 & 004 & 004 & 04 & 004 & 004 & 1) & $\mathrm{NC}$ \\
\hline $\mathrm{ZnO}$ & 008 & 019 & 018 & 017 & 016 & 016 & 014 & 017 & 014 & $\mathrm{NC}$ \\
\hline $\mathrm{ZrO}_{2}$ & 0.39 & 121 & 114 & 104 & 092 & 92 & 084 & 094 & 977 & $\mathrm{NC}$ \\
\hline Suㅔㅡ & 1000 & 10000 & 10000 & 10000 & 1000 & 10000 & 10000 & 10000 & 10000 & NC \\
\hline
\end{tabular}

$\$$ - Not a target constituent

* - for XRF-analyzed compositions. values for $\mathrm{B}_{2} \mathrm{O}_{3}$ and $\mathrm{L}_{2} \mathrm{O}$ were calculated based on smple well-stimed tank moilel and target values

\# - Fluonne was measured by XRF on polshed samples, values for other samples calculated by mterpolation NC - Not calculated 
Tahle 6.6. XRF Analyzed Composition for Glass Discharged During DM100BL Melter Test (wt\%) (continued).

\begin{tabular}{|c|c|c|c|c|c|c|c|c|c|c|}
\hline Fomiulation & \multicolumn{10}{|c|}{ HWVI-AI-16 } \\
\hline Al Source & \multicolumn{10}{|c|}{ Aluminum Hydroxide } \\
\hline Temperature & \multirow{5}{*}{ Target } & \multicolumn{9}{|c|}{$1200^{\circ} \mathrm{C}$} \\
\hline Test & & \multicolumn{9}{|c|}{3} \\
\hline Glass (kg) & & 51026 & 5345 & 55924 & 58814 & 61316 & 63614 & 65964 & 68314 & 71502 \\
\hline & & BLX-G. & BLX-G- & BLX-G- & $\mathrm{BLX} \cdot \mathrm{G}-$ & BLX-G- & $\mathrm{BLY}-\mathrm{G}$. & BLY-G- & BLY-G- & BLY-G. \\
\hline Constituent & & $144 \mathrm{~A}$ & $145 \mathrm{~A}$ & $147 \mathrm{~A}$ & $151 \mathrm{~B}$ & $153 \mathrm{~A}$ & $8 \mathrm{~A}$ & $10 \mathrm{~A}$ & $10 \mathrm{C}$ & $14 \mathrm{~B}$ \\
\hline $\mathrm{Al}_{2} \mathrm{O}_{3}$ & 2325 & 2154 & 2185 & $2] 79$ & 2200 & 2189 & 2181 & 2187 & 2203 & 2212 \\
\hline $\mathrm{B}_{2} \mathrm{O}_{3}^{*}$ & 1773 & 1534 & 1564 & 1591 & 1618 & 1638 & 1654 & 1669 & 1682 & 1697 \\
\hline $\mathrm{BaO}$ & 005 & 004 & 004 & 005 & 005 & 006 & 005 & 005 & 004 & 006 \\
\hline $\mathrm{B}_{2} \mathrm{O}_{\mathrm{z}}$ & 111 & 122 & 117 & 114 & 113 & 118 & 132 & 116 & 115 & 113 \\
\hline $\mathrm{CaO}$ & 589 & 597 & 585 & 572 & 574 & 584 & 598 & 591 & 582 & 577 \\
\hline $\mathrm{CdO}$ & 002 & 003 & 003 & 003 & 003 & 1) 018 & 01013 & 003 & 002 & 003 \\
\hline $\mathrm{Ce}_{2} \mathrm{O}_{3}$ & $\S$ & $<001$ & 501 & 001 & 001 & $<001$ & 001 & 001 & 001 & 8001 \\
\hline $\mathrm{O}_{2} \mathrm{O}_{3}$ & 051 & 046 & 946 & 046 & 046 & i) 48 & 650 & 052 & 0.51 & 0.50 \\
\hline F & 065 & $0.36^{*}$ & 037 & 038 & 039 & $040^{\prime \prime}$ & 039 & 038 & 037 & $036^{\circ}$ \\
\hline $\mathrm{F}_{\mathrm{y}_{2}} \mathrm{O}_{3}$ & 572 & 615 & 593 & 580 & 576 & 583 & 649 & 599 & 589 & 575 \\
\hline $\mathrm{K}_{2} \mathrm{O}$ & 014 & $0 \geq 1$ & 018 & 017 & 018 & 1) 17 & 618 & $(18$ & 017 & 016 \\
\hline $\mathrm{La}_{2} \mathrm{O}_{3}$ & \& & 5001 & 002 & $<001$ & 501 & 5001 & 8001 & 0001 & .001 & 001 \\
\hline $\mathrm{L}_{2} \mathrm{O}^{*}$ & 346 & 346 & 346 & 346 & 346 & 346 & 346 & 346 & 346 & 346 \\
\hline $\mathrm{MgO}$ & 011 & 030 & 032 & 029 & 034 & 029 & 027 & 032 & 030 & 030 \\
\hline $\mathrm{MnO}$ & 8 & 920 & 918 & 015 & 014 & d) 13 & $(12$ & $(111$ & 010 & 009 \\
\hline $\mathrm{Na}_{2} \mathrm{O}$ & 929 & 960 & 971 & 10) 17 & 976 & 957 & 953 & 967 & 945 & 948 \\
\hline $\mathrm{NL}_{2} \mathrm{O}_{3}$ & 8 & 001 & (a) 1 & 001 & 001 & 0001 & 001 & 001 & 001 & alil \\
\hline $\mathrm{N} 1 \mathrm{O}$ & 039 & 031 & 032 & 032 & 029 & 031 & 034 & 035 & 034 & 032 \\
\hline$\overline{\mathrm{P}_{2} \mathrm{O}_{5}}$ & 102 & 111 & 112 & 112 & 115 & 111 & 111 & 113 & 112 & 116 \\
\hline $\mathrm{PbO}$ & 040 & 040 & 037 & 037 & 036 & 038 & 039 & 037 & 036 & 036 \\
\hline $\mathrm{S}_{1} \mathrm{O}_{2}$ & 2958 & 3160 & 3145 & 3] 28 & 3131 & 3120 & 3075 & 3071 & 3094 & 3097 \\
\hline $\mathrm{SO}_{3}$ & 019 & 013 & 012 & 011 & 012 & 012 & 011 & 010 & 010 & 011 \\
\hline Sro & $\S$ & 047 & 039 & 032 & 028 & 027 & 024 & 019 & 018 & 015 \\
\hline $\mathrm{T}_{1} \mathrm{O}_{2}$ & 001 & 005 & 005 & 004 & 004 & 004 & 004 & 004 & 005 & 004 \\
\hline $\mathrm{ZnO}$ & 008 & 018 & 016 & 014 & 013 & 013 & 013 & 013 & 012 & 010 \\
\hline $\mathrm{ZrO}_{2}$ & 038 & 086 & 080 & 075 & 069 & 072 & 071 & 063 & 062 & 059 \\
\hline Sum & 1000 & livi) $(00$ & 10000 & 100 (w) & $10010 \%$ & 10000 & I (wiogo & 100 (i) & 10009 & low) (no \\
\hline
\end{tabular}

\$ - Not a target constituent

* - for XRF-analyzed compositions, yalues $\mathrm{for}_{\mathrm{B}} \mathrm{B}_{2} \mathrm{O}_{3}$ and $\mathrm{L}_{2} \mathrm{O}$ were calculated based on simple well-stirted tank mixlel and taryet valuis

\# - Fluorine uias measured by XRF on polshed samples, values for other samples calculated by miterpolation 
Table 6.6. XRF Analyzed Composition for Glass Discharged During DM100 Melier Test (wt\%) (continued).

\begin{tabular}{|c|c|c|c|c|c|c|c|c|c|c|c|}
\hline Formulation & \multicolumn{11}{|c|}{ HWI-Al-16 } \\
\hline Al Source & \multicolumn{11}{|c|}{ Aluminum Hydroxide } \\
\hline Temiperature & \multirow{5}{*}{ Target } & \multicolumn{10}{|c|}{$1150^{\circ} \mathrm{C}$} \\
\hline Test & & \multicolumn{10}{|c|}{4} \\
\hline Glass (kg) & & 73680 & 75648 & 77768 & 79634 & 81948 & 83832 & 85696 & 875 (n) & 89638 & 92066 \\
\hline & & BLY-G. & $\mathrm{BLY}-\mathrm{G}$ & BLY-G & BLY-G & $\overline{B L Y-G}$ & BLY-G. & BLY-G- & BLY.G. & $\overline{\mathrm{LY}=\mathrm{G}}$ & BLY-G- \\
\hline Constituent & & $16 \mathrm{~A}$ & $17 \mathrm{~A}$ & $2 \mathrm{~A}$ & $25 \mathrm{~A}$ & $26 \mathrm{~A}$ & $26 \mathrm{C}$ & $28 \mathrm{~B}$ & $34 \mathrm{~A}$ & $35 A$ & $36 \mathrm{~B}$ \\
\hline$\overline{\mathrm{Al}_{2} \mathrm{O}_{3}}$ & 2325 & 2223 & 2203 & 2196 & 2191 & 2236 & 2201 & 2228 & 2199 & 2304 & 2209 \\
\hline $\mathrm{B}_{2} \mathrm{O}_{3}^{*}$ & 1773 & 1765 & 1712 & 1719 & 1725 & $1730^{\circ}$ & 1735 & 1739 & 1742 & 1745 & 1749 \\
\hline $\mathrm{BaO}$ & 005 & 006 & 005 & 007 & 006 & 006 & 006 & 006 & 006 & 006 & 006 \\
\hline$\overline{\mathrm{B}_{2} \mathrm{O}_{3}}$ & I]1 & ] 08 & 117 & 115 & 121 & 115 & 116 & 112 & 119 & 119 & 122 \\
\hline $\mathrm{CaO}$ & 589 & 564 & 599 & 590 & 607 & 585 & 586 & 576 & 6019 & 598 & 614 \\
\hline $\mathrm{CdO}$ & 002 & 1) 03 & 003 & 003 & 003 & 003 & 003 & 003 & 003 & 003 & 003 \\
\hline $\mathrm{Ce}_{2} \mathrm{O}_{3}$ & $\S$ & 001 & 001 & $<001$ & $<001$ & 001 & 001 & 001 & 001 & 001 & 001 \\
\hline $\mathrm{Cr}_{2} \mathrm{O}_{3}$ & 051 & i) 47 & 059 & 052 & 053 & 052 & 053 & $0 \leqslant 2$ & 055 & 055 & 056 \\
\hline $\mathrm{F}$ & 065 & 037 & 038 & 039 & $040^{*}$ & 040 & 041 & 041 & $04 l^{\prime \prime}$ & 042 & 044 \\
\hline $\mathrm{Fe}_{2} \mathrm{O}_{3}$ & $\$ 72$ & 355 & 584 & 588 & 606 & 583 & 588 & 571 & 604 & 603 & 610 \\
\hline $\mathrm{K}, \mathrm{O}$ & 014 & 1) 16 & 017 & 017 & 017 & 016 & 016 & 016 & 016 & 017 & 017 \\
\hline $\mathrm{Lat}_{3}$ & $\$$ & 002 & $<: 001$ & $<: 001$ & 8001 & 000 & 001 & 001 & 501 & 001 & 8001 \\
\hline $\operatorname{Lix} 0^{*}$ & 346 & 346 & 346 & 346 & 346 & 346 & 346 & 346 & 346 & 346 & 346 \\
\hline $\mathrm{MgO}$ & 011 & 033 & 026 & 032 & 032 & 030 & 032 & 030 & 031 & 033 & 028 \\
\hline $\mathrm{knO} O$ & $\$$ & 1) 08 & 008 & 008 & 008 & 007 & 007 & 006 & 006 & 007 & $000^{\circ}$ \\
\hline $\mathrm{Na}_{2} \mathrm{O}$ & 929 & 988 & 969 & 959 & 907 & 923 & 961 & 977 & 933 & 918 & 871 \\
\hline $\mathrm{Nd}_{2} \mathrm{O}_{3}$ & $\S$ & $\therefore 0(1$ & $\therefore 01$ & 001 & 8001 & 0001 & $\therefore 001$ & $=001$ & 001 & 001 & $<: 001$ \\
\hline $\mathrm{NuO}$ & 039 & 030 & 032 & 033 & 034 & 033 & 032 & 033 & 035 & 034 & 033 \\
\hline $\mathrm{P}_{2} \mathrm{O}_{5}$ & 102 & 113 & 115 & 112 & 116 & 115 & 113 & 114 & 112 & 113 & 116 \\
\hline $\mathrm{PbO}$ & 040 & 035 & 037 & 038 & 040 & 037 & 037 & 035 & 039 & 039 & 039 \\
\hline $\mathrm{S}_{1} O_{2}$ & 2958 & 3085 & 3052 & 3050 & 3054 & 3060 & 3030 & 3027 & 3019 & 3034 & 3039 \\
\hline $\mathrm{SO}_{3}$ & 019 & 010 & 011 & 011 & 011 & 012 & 012 & 013 & 014 & 013 & 013 \\
\hline $\mathrm{SrO}$ & 8 & 013 & 012 & 011 & 011 & 009 & 010 & 008 & 008 & 007 & 007 \\
\hline $\mathrm{T}_{1} \mathrm{O}_{2}$ & 001 & 005 & 004 & 005 & 004 & 004 & 004 & 004 & 004 & 005 & 004 \\
\hline $\mathrm{ZnO}$ & 008 & 011 & 010 & 011 & 010 & 010 & 010 & 009 & 010 & 010 & 010 \\
\hline $\mathrm{ZrO}_{2}$ & 038 & 055 & 0.58 & 058 & 060 & 0.55 & 058 & 053 & 056 & 056 & 0.56 \\
\hline Sum & 10000 & 10001 & liging & 10i! (n) & 1000 & 1000 & $100 \mathrm{~cm}$ & $100(\mathrm{~N})$ & longing & 10i! (N) & 10000 \\
\hline
\end{tabular}

\$ - Not a target constituent

* - for XRF-analyzed compositions, vqlues for $\mathrm{B}_{2} \mathrm{O}_{3}$ and $\mathrm{L}_{2} \mathrm{O}$ were calculated based on sinple well-stimed tank mixlel and taryet valuis

\# - Fluorine uias measured by XRF on polshed samples, values for other samples calculated by miterpolation 
Table 6.6. XRF Analyzed Composition for Glass Dscharged During DM100 Melter Test (wt\%) (contìued).

\begin{tabular}{|c|c|c|c|c|c|c|c|c|c|c|c|}
\hline Formulation & \multicolumn{11}{|c|}{ HWI-Al-16 } \\
\hline Al Source & \multirow{5}{*}{ Target } & \multirow{2}{*}{\multicolumn{4}{|c|}{$\frac{\text { Aluminum Hydroxile }}{1150^{\circ} \mathrm{C}}$}} & \multicolumn{6}{|c|}{ AlumInum Oxldle } \\
\hline Temperature & & & & & & \multicolumn{6}{|c|}{$1200^{\circ} \mathrm{C}$} \\
\hline Test & & \multicolumn{4}{|c|}{4} & \multicolumn{6}{|c|}{5} \\
\hline Glass (kg) & & 949 o8 & 97822 & 995 & 94 & 102464 & 105750 & $\sqrt{108416}$ & 111042 & 113906 & 116620 \\
\hline Constituent & & $\begin{array}{l}\text { BLY- } \\
\text { G-4YA }\end{array}$ & $\begin{array}{l}\text { BLY- } \\
\text { G-4UB }\end{array}$ & \begin{tabular}{|l|}
$\mathrm{BLY}-$ \\
$\mathrm{G}-4 \mathrm{OC}$
\end{tabular} & $\% \operatorname{Der}$ & $\begin{array}{r}\mathrm{BLY}- \\
\mathrm{G}-63 \mathrm{~A}\end{array}$ & $\begin{array}{l}\mathrm{BLF}- \\
\mathrm{g}-66 \mathrm{~B}\end{array}$ & $\begin{array}{l}\text { BLY- } \\
\text { G-69A }\end{array}$ & \begin{tabular}{|l|}
$\mathrm{BLY}-$ \\
$\mathrm{G}-73 \mathrm{~A}$
\end{tabular} & \begin{tabular}{|l|} 
BLY- \\
G-75A
\end{tabular} & $\begin{array}{l}\text { BLY- } \\
\text { G-80A }\end{array}$ \\
\hline $\mathrm{Al}_{2} \mathrm{O}_{3}$ & 2325 & 2207 & 2196 & 2178 & -633 & 2218 & 2218 & 2218 & 2713 & 2213 & 2258 \\
\hline $\mathrm{B}_{2} \mathrm{O}_{3}^{*}$ & 1773 & 1752 & 1752 & 1752 & $\mathrm{NC}$ & 1756 & 1759 & 1761 & 1762 & 1764 & 1765 \\
\hline $\mathrm{BaO}$ & 005 & $9(45$ & 005 & 006 & $\mathrm{NC}$ & 005 & $0(15$ & 005 & 005 & 016 & 006 \\
\hline $\mathrm{B}_{2} \mathrm{O}_{3}$ & 111 & 114 & $1] 7$ & 122 & 970 & 111 & 116 & I 16 & 119 & 119 & 107 \\
\hline $\mathrm{CaO}$ & 589 & 593 & 598 & 619 & 497 & 574 & 588 & 590 & 590 & 599 & 556 \\
\hline $\mathrm{CdO}$ & 002 & 003 & 003 & 003 & $\mathrm{NC}$ & 002 & 002 & 002 & 003 & 003 & 002 \\
\hline $\mathrm{Ce}_{2} \mathrm{O}_{3}$ & $\$$ & sing] & 0001 & 001 & $\mathrm{NC}$ & $=001$ & $0(1$ & 001 & 001 & a) (1) & $=001$ \\
\hline $\mathrm{Cr}_{2} \mathrm{O}_{3}$ & 051 & 053 & 053 & 054 & $\mathrm{NC}$ & 044 & 046 & 049 & 050 & 050 & 046 \\
\hline $\mathrm{F}$ & 065 & a 46 & i) $48^{13}$ & 048 & $\mathrm{NC}$ & $039^{\sharp}$ & 039 & 039 & 039 & $39^{14}$ & 040 \\
\hline$\overline{\mathrm{Fe}_{2} \mathrm{O}_{3}}$ & 572 & 584 & 594 & 616 & 762 & 600 & 625 & 629 & 641 & 654 & 599 \\
\hline $\mathrm{K}_{2} \mathrm{O}$ & 014 & 017 & 017 & 018 & NC & 017 & 017 & 017 & 017 & 017 & 016 \\
\hline $\mathrm{La}_{2} \mathrm{O}_{3}$ & 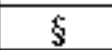 & aiol & 001 & 10 (1) & $\mathrm{NC}$ & $=001$ & xiol & 001 & $=0(1$ & 001 & 901 \\
\hline $\mathrm{L}_{1} \mathrm{O}^{*}$ & 346 & 346 & 346 & 346 & $\mathrm{NC}$ & 346 & 346 & 346 & 346 & 346 & 346 \\
\hline $\mathrm{MgO}$ & 011 & 038 & 035 & 034 & $\mathrm{NC}$ & 029 & 028 & 026 & 025 & 921 & 026 \\
\hline $\mathrm{MnO}$ & $\S$ & 006 & 007 & 008 & NC & 009 & 008 & 007 & 007 & 007 & 006 \\
\hline $\mathrm{Na}_{2} \mathrm{O}$ & 929 & 956 & 937 & 866 & -679 & 989 & 912 & 932 & 940 & 903 & 956 \\
\hline $\mathrm{Nd}_{2} \mathrm{O}_{3}$ & $\S$ & 001 & $\approx 001$ & $\varepsilon=001$ & $\mathrm{NC}$ & $<001$ & $<001$ & $8: 001$ & $\therefore 001$ & $\Leftrightarrow 001$ & $e=001$ \\
\hline $\mathrm{N} 1 \mathrm{O}$ & 039 & 033 & 034 & 034 & $\mathrm{NC}$ & 030 & 030 & 032 & 032 & 032 & 029 \\
\hline $\mathrm{P}_{2} \mathrm{O}_{5}$ & 102 & 113 & 112 & 115 & 1272 & 110 & 113 & 111 & 110 & 113 & 114 \\
\hline $\mathrm{PbO}$ & 040 & 038 & 038 & 041 & $\mathrm{NC}$ & 035 & 035 & 035 & 036 & 035 & 032 \\
\hline $\mathrm{SiO}_{2}$ & 2958 & 3009 & 3019 & 3044 & 292 & 2989 & 3011 & 2982 & 2958 & 2972 & 2996 \\
\hline $\mathrm{SO}_{3}$ & 019 & 913 & 013 & 013 & $\mathrm{NC}$ & 011 & 911 & 011 & 010 & 911 & 011 \\
\hline $\mathrm{S} \mathrm{O}$ & $\S$ & 006 & 007 & 009 & $\mathrm{NC}$ & 007 & 006 & 005 & 005 & 004 & 003 \\
\hline $\mathrm{T}_{10} \mathrm{O}_{2}$ & 001 & $9(44$ & 005 & 005 & $\mathrm{NC}$ & 004 & $9(14$ & 005 & 004 & 005 & 004 \\
\hline $\mathrm{ZnO}$ & 008 & $\dot{0} \phi g$ & 010 & 011 & $N C$ & 010 & 010 & 010 & 010 & 010 & 008 \\
\hline $\mathrm{ZrO}$ & 0.38 & 053 & 055 & 061 & $\mathrm{NC}$ & 065 & 069 & 071 & 076 & 075 & 070 \\
\hline Surt & 10000 & 10000 & 10000 & 10000 & NC & 10000 & 10000 & 10000 & 10000 & 10000 & 10000 \\
\hline
\end{tabular}

\$ - Not a target constituent

* - for XRF-analyzed compositions. values for $\mathrm{B}_{2} \mathrm{O}_{3}$ and $\mathrm{L}_{2} \mathrm{O}$ were calculated based on simple well-stitred tank moitel and target values

\# - Fluonne was measured by . YRF on polshed saniples, values for other samples calculated by mterpolation $\mathrm{NC}-\mathrm{Not}$ calculated 
Table 6.6. XRF Analyzed Composition for Glass Discharged During DM100 Melier Test (wt\%) (continuel).

\begin{tabular}{|c|c|c|c|c|c|c|c|c|c|c|}
\hline Fommulation & \multicolumn{10}{|c|}{ HWI-Al-16 } \\
\hline A1 Source & \multicolumn{10}{|c|}{ Alum inum Oxtde } \\
\hline Temperature & \multirow{5}{*}{ Target } & $1200^{\circ} \mathrm{C}$ & \multicolumn{8}{|c|}{$1150^{\circ} \mathrm{C}$} \\
\hline Test & & 5 & \multicolumn{8}{|c|}{6} \\
\hline Glass (kg) & & 119360 & 122724 & 124992 & 1270,34 & 128612 & 130646 & 132202 & 135064 & 1535410 \\
\hline & & BLY-G. & $\overline{B L Y}-\bar{G}$. & $\overline{B L Y}-G$. & $\mathrm{BLY}-\mathrm{G}$ & $\mathrm{BLY}-\mathrm{G}$ & BLY-G- & BLY.G. & BLY.G- & BLY-G- \\
\hline Constituent & & $80 \mathrm{C}$ & $85 \mathrm{~A}$ & glA & $93 \mathrm{~A}$ & $93 C$ & $9 \mathrm{SB}$ & $101 \mathrm{~A}$ & $107 \mathrm{~A}$ & $111 \mathrm{~B}$ \\
\hline $\mathrm{Al}_{2} \mathrm{O}_{3}$ & 2325 & 2238 & 2225 & 2237 & 2236 & 2253 & 2243 & 22.49 & 2267 & 2223 \\
\hline $\mathrm{B}_{2} \mathrm{O}_{3}{ }^{*}$ & 1773 & 1766 & 1768 & 1768 & 1769 & 1769 & 1770 & 1770 & 1771 & 1771 \\
\hline $\mathrm{BaO}$ & 005 & 005 & 005 & 007 & 006 & 006 & 005 & 005 & 005 & 005 \\
\hline$\overline{\mathrm{B}_{2} \mathrm{O}_{2}}$ & 111 & 116 & 118 & 116 & 113 & 110 & 112 & 111 & 108 & 122 \\
\hline $\mathrm{CaO}$ & 589 & 591 & 583 & 579 & $57 i)$ & 569 & 576 & 573 & 563 & 598 \\
\hline $\mathrm{CdO}$ & 012 & 003 & 003 & 0013 & $\operatorname{cog} 3$ & 003 & 002 & 008 & 9102 & 002 \\
\hline $\mathrm{Ce}_{2} \mathrm{O}_{3}$ & $\S$ & 8001 & 001 & 001 & 5001 & 000 & $<001$ & 001 & -001 & 01 \\
\hline $\mathrm{Cr}_{2} \mathrm{O}_{3}$ & 951 & 050 & 050 & 049 & (95) & 050 & 050 & 948 & i. 49 & 054 \\
\hline $\mathbf{F}$ & 065 & 041 & 043 & $044^{*}$ & 045 & 045 & 046 & 046 & $047^{*}$ & 047 \\
\hline $\mathrm{Fe}_{2} \mathrm{O}_{3}$ & 572 & 644 & 647 & 637 & $631)$ & 622 & 631 & 624 & 612 & 682 \\
\hline $\mathrm{K}_{2} \mathrm{O}$ & 014 & 917 & 017 & 017 & 916 & 017 & 017 & 916 & 917 & 017 \\
\hline $\mathrm{La}_{2} \mathrm{O}_{3}$ & \& & 0001 & $<001$ & $<001$ & 5001 & 501 & $<001$ & $\Leftrightarrow 01$ & 6001 & 001 \\
\hline $\mathrm{L}_{12} \mathrm{O}^{\circ}$ & 346 & 346 & 346 & 346 & 346 & 346 & 346 & 346 & 346 & 346 \\
\hline $\mathrm{MgO}$ & 011 & 023 & 023 & 022 & 026 & 021 & 027 & 020 & 023 & 022 \\
\hline $\mathrm{MnO}$ & 8 & din & 005 & 005 & 005 & 005 & 005 & ond & 904 & 004 \\
\hline $\mathrm{Na}_{2} \mathrm{O}$ & 929 & 893 & 930 & 928 & 958 & 933 & 920 & 926 & 934 & 913 \\
\hline $\mathrm{Nd}_{2} \mathrm{O}_{3}$ & 8 & sing & 8001 & $<001$ & a) 01 & 001 & $<01$ & $<001$ & 8001 & $<01$ \\
\hline $\mathrm{NhO}$ & 039 & 033 & 032 & 030 & 029 & 030 & 030 & 030 & 028 & 034 \\
\hline $\mathrm{P}_{2} \mathrm{O}_{5}$ & 102 & 115 & 120 & 117 & 116 & 118 & 117 & 118 & 118 & 112 \\
\hline $\mathrm{PbO}$ & 040 & 034 & 034 & 035 & 034 & 032 & 032 & 033 & 031 & 036 \\
\hline $\mathrm{S}_{1} \mathrm{O}_{2}$ & 2958 & 2975 & 2947 & 2955 & 2948 & 2969 & 2971 & 2973 & 2978 & 2900 \\
\hline $\mathrm{SO}_{3}$ & 019 & 011 & 010 & 011 & 010 & 011 & 012 & 012 & 013 & 012 \\
\hline Sro & $\S$ & 003 & 003 & 003 & 002 & 002 & 002 & 002 & 002 & 002 \\
\hline $\mathrm{T}_{1} \mathrm{O}_{2}$ & 001 & 005 & 005 & 004 & 004 & 004 & 004 & 004 & 005 & 005 \\
\hline $\mathrm{ZnO}$ & 008 & 009 & 009 & 008 & 008 & 008 & 008 & 008 & 008 & 008 \\
\hline $\mathrm{ZrO}_{2}$ & 038 & 075 & 076 & 077 & 076 & 075 & 075 & 076 & 071 & 083 \\
\hline Sum & 10000 & $1(\omega) \times 0$ & lico ong & 10000 & $\operatorname{lig} 000$ & $100\left(\mathrm{w}^{\circ}\right)$ & loi (n) & 10000 & 10000 & 10 orimi \\
\hline
\end{tabular}

\$- Not a target constibent

* - for XRF-analyzed compositions, values for $\mathrm{B}_{2} \mathrm{O}_{3}$ and $\mathrm{L}_{2} \mathrm{O}$ were calculated based on sumple well-stimed tank mixlel and taryet valuis

\# - Fluorne was measured by XRF on polshed samples, values for other samples calculated by unterpolation 
Table 6.6. XRF Analyzed Composition for Glass Discharged During DM100 Melier Test (wt\%) (continued)

\begin{tabular}{|c|c|c|c|c|c|c|c|c|c|c|}
\hline Fomiulation & \multicolumn{5}{|c|}{ HWT-AF16 } & \multicolumn{5}{|c|}{ HWI-Al-19 } \\
\hline Al Source & \multicolumn{5}{|c|}{ Aluminum Oxide } & \multicolumn{5}{|c|}{ Aluminum Hydroxide } \\
\hline Temperature & \multirow{5}{*}{ Target } & \multirow{2}{*}{\multicolumn{4}{|c|}{$\frac{1150^{\circ} \mathrm{C}}{6}$}} & \multirow{5}{*}{ Target } & \multicolumn{4}{|c|}{$1200^{\circ} \mathrm{C}$} \\
\hline Test & & & & & & & & & \multicolumn{2}{|l|}{7} \\
\hline Glass $(\mathrm{kg})$ & & 139594 & 142310 & \multicolumn{2}{|c|}{146414} & & \multicolumn{2}{|c|}{\begin{tabular}{|l|l|}
149638 & 152996 \\
\end{tabular}} & $15(n) 12$ & 159150 \\
\hline & & BLY-G. & $\overline{B L Y}-\mathrm{G}$. & BLY-G- & & & BLY-G- & BLY-G- & $\mathrm{BLY}-\mathrm{G}$ - & BLY-G- \\
\hline Constituent & & $114 \mathrm{~A}$ & $120 \mathrm{~A}$ & $120 \mathrm{~B}$ & $\%$ Der & & $139 \mathrm{~A}$ & $14] \mathrm{B}$ & $144 \mathrm{~B}$ & l45B \\
\hline $\mathrm{Al}_{2} \mathrm{O}_{3}$ & 2325 & 2236 & 2238 & 2245 & -346 & 2397 & 2231 & 3280 & 2266 & 2267 \\
\hline $\mathrm{B}_{2} \mathrm{O}_{3}^{*}$ & 1773 & 1771 & 1771 & 1771 & $\mathrm{NC}$ & 1919 & 1795 & 1816 & 1832 & 1846 \\
\hline $\mathrm{BaO}$ & 005 & 005 & 005 & 005 & $\mathrm{NC}$ & 005 & 006 & 006 & 006 & 007 \\
\hline $\mathrm{B}_{2} \mathrm{O}_{\mathrm{z}}$ & 111 & 118 & 116 & 115 & 338 & 114 & 139 & 121 & 126 & 129 \\
\hline $\mathrm{CaO}$ & 589 & 584 & 581 & 574 & .263 & 558 & 611 & 585 & 608 & 606 \\
\hline $\mathrm{CdO}$ & 002 & 003 & 002 & 00 & $\mathrm{NC}$ & 1) 2 & 1) 12 & 003 & 002 & 003 \\
\hline $\mathrm{Ce}_{2} \mathrm{O}_{3}$ & $\hat{\xi}$ & $<001$ & -001 & 002 & $\mathrm{NC}$ & $\$$ & 002 & son & 4001 & 001 \\
\hline $\mathrm{O}_{2} \mathrm{O}_{3}$ & 051 & 052 & 051 & 049 & $\mathrm{NC}$ & 1) 52 & i) 59 & 057 & 059 & 059 \\
\hline $\mathbf{F}$ & 065 & 047 & 047 & 047 & $\mathrm{NC}$ & 067 & $035^{\prime \prime}$ & 037 & 0.38 & 0.39 \\
\hline $\mathrm{F}_{\mathrm{y}_{2}} \mathrm{O}_{3}$ & 572 & 655 & 632 & 627 & 958 & 590 & 676 & 633 & 660 & 652 \\
\hline $\mathrm{K}_{2} \mathrm{O}$ & 014 & 017 & 917 & 017 & $\mathrm{NC}$ & 1) 14 & i) 18 & 618 & 019 & 019 \\
\hline $\mathrm{La}_{2} \mathrm{O}_{3}$ & \& & $s 001$ & $\Leftrightarrow 01$ & $<001$ & $\mathrm{NC}$ & $\S$ & $=001$ & $\infty 001$ & $500]$ & 6000 \\
\hline $\mathrm{L}_{2} \mathrm{O}^{*}$ & 346 & 346 & 346 & 346 & $\mathrm{NC}$ & 357 & 348 & 350 & 351 & 352 \\
\hline $\mathrm{MgO}$ & 011 & 021 & 021 & 019 & $\mathrm{NC}$ & 012 & 0229 & 031 & 028 & 028 \\
\hline $\mathrm{MnO}$ & 8 & 004 & 005 & 007 & $\mathrm{NC}$ & $\$$ & (10is & $(104$ & 004 & 004 \\
\hline $\mathrm{Na}_{2} \mathrm{O}$ & 929 & 904 & 953 & 942 & 141 & 958 & 938 & 944 & 889 & 905 \\
\hline $\mathrm{NL}_{2} \mathrm{O}_{3}$ & 8 & $<001$ & a) 01 & $<011$ & $\mathrm{NC}$ & $\S$ & i) (11 & ang1 & 001 & 6001 \\
\hline $\mathrm{N} 1 \mathrm{O}$ & 039 & 031 & 030 & 029 & $\mathrm{NC}$ & 040 & 038 & 034 & 036 & 035 \\
\hline$\overline{\mathrm{P}_{2} \mathrm{O}_{5}}$ & 102 & 115 & 113 & 113 & 1058 & 1 is & 103 & 102 & 101 & 097 \\
\hline $\mathrm{PbO}$ & 040 & 034 & 033 & 033 & $\mathrm{NC}$ & 041 & 038 & 035 & 037 & 039 \\
\hline $\mathrm{S}_{1} \mathrm{O}_{2}$ & 2958 & 2951 & 2936 & 2952 & -021 & $27(00)$ & 2835 & 2852 & 2844 & 2817 \\
\hline $\mathrm{SO}_{3}$ & 019 & 012 & 010 & 011 & $\mathrm{NC}$ & 020 & 010 & 010 & 010 & 010 \\
\hline Sro & $\S$ & 002 & 002 & 003 & $\mathrm{NC}$ & $\xi$ & 002 & 002 & 002 & 002 \\
\hline $\mathrm{T}_{1} \mathrm{O}_{2}$ & 001 & 004 & 004 & 005 & $\mathrm{NC}$ & 001 & 005 & 005 & 005 & 005 \\
\hline $\mathrm{ZnO}$ & 008 & 008 & 008 & 009 & $\mathrm{NC}$ & 008 & 010 & 009 & 009 & 010 \\
\hline $\mathrm{ZrO}_{2}$ & 038 & 080 & 077 & 078 & $\mathrm{NC}$ & 039 & 074 & 069 & 069 & 069 \\
\hline Sum & 10000 & lixiogin & $\operatorname{lig}(000$ & 10060 & $\mathrm{NC}$ & 10000 & I (w)o0 & $1(\omega)(N)$ & 1000 & li(N) 00 \\
\hline
\end{tabular}

\$ - Not a tartget constibent

* - for XRF-analyzed compositions, vqlues for $\mathrm{B}_{2} \mathrm{O}_{3}$ and $\mathrm{L}_{2} \mathrm{O}$ were calculated based on sinple well-stimed tank mislel and tercet valuis

\# - Fluorine was measured by XRF on polshed samples, values for other samples calculated by miterpolation $\mathrm{NC}-$ Not calculated 
Table 6.6. XRF Analyzed Composition for Glass Discharged During DM100 Melier Test (wt \%) (continuel).

\begin{tabular}{|c|c|c|c|c|c|c|c|c|c|c|}
\hline Fomiulation & \multicolumn{10}{|c|}{ HWT-Al-19 } \\
\hline Al Source & \multicolumn{10}{|c|}{ Aluminum Hydroxide } \\
\hline Temperature & \multirow{5}{*}{ Target } & \multirow{2}{*}{\multicolumn{4}{|c|}{$\frac{1200^{\circ} \mathrm{C}}{7}$}} & \multicolumn{5}{|c|}{$1150^{\circ} \mathrm{C}$} \\
\hline Test & & & & & & \multicolumn{5}{|c|}{8} \\
\hline Glass $(\mathrm{kg})$ & & 162548 & 165582 & 168198 & 170934 & 174130 & 176704 & 179166 & 181598 & 184126 \\
\hline & & BLY.G. & $\overline{B L Y}=\mathrm{G}$. & BLY-G- & BLZ.G- & BLZ.G- & BLZ-G- & BLZ-G- & BLZ-G- & BLZ-G- \\
\hline Constituent & & $151 \mathrm{~A}$ & $152 \mathrm{~A}$ & $153 \mathrm{~B}$ & $5 \mathrm{~B}$ & $13 \mathrm{~A}$ & $16 \mathrm{~A}$ & $21 \mathrm{~A}$ & $23 \mathrm{~A}$ & $27 \mathrm{~A}$ \\
\hline $\mathrm{Al}_{2} \mathrm{O}_{3}$ & 2397 & 2253 & 2252 & 2282 & 2273 & 2277 & 2265 & 3272 & 2285 & 2282 \\
\hline $\mathrm{B}_{2} \mathrm{O}_{3}^{*}$ & 1919 & 1859 & 1868 & 1875 & 1881 & 1887 & 1892 & 1895 & 1898 & 1901 \\
\hline $\mathrm{BaO}$ & 005 & 006 & 006 & 005 & 005 & 007 & 007 & 006 & 006 & 006 \\
\hline $\mathrm{B}_{2} \mathrm{O}_{\mathrm{z}}$ & 114 & 128 & 123 & 121 & 125 & 136 & 131 & 127 & 126 & 127 \\
\hline $\mathrm{CaO}$ & 558 & 600 & 593 & 577 & 586 & 588 & 598 & 591 & 585 & 581 \\
\hline $\mathrm{CdO}$ & 002 & 003 & 003 & 00 & 002 & 1) 018 & 1) 113 & 003 & 003 & 003 \\
\hline $\mathrm{Ce}_{2} \mathrm{O}_{3}$ & 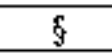 & $<001$ & 5001 & 001 & 001 & 001 & $<001$ & 001 & 001 & 8001 \\
\hline $\mathrm{O}_{2} \mathrm{O}_{3}$ & 052 & 061 & 958 & 057 & 069 & d) 58 & i) 59 & 059 & 058 & 058 \\
\hline F & 067 & $041^{4}$ & $04]$ & 041 & 040 & $040^{\prime \prime}$ & 041 & 042 & 043 & $044^{\circ}$ \\
\hline $\mathrm{F}_{\mathrm{y}_{2}} \mathrm{O}_{3}$ & 590 & 650 & 632 & 597 & 622 & 626 & 638 & 617 & 618 & 607 \\
\hline $\mathrm{K}_{2} \mathrm{O}$ & 014 & 019 & 918 & 018 & 018 & 1) 19 & i) 19 & 619 & 019 & 019 \\
\hline $\mathrm{La}_{2} \mathrm{O}_{3}$ & \& & $s 001$ & $\Leftrightarrow 01$ & $<001$ & $<001$ & 5001 & $=001$ & $\infty 001$ & 5001 & 6000 \\
\hline $\mathrm{L}_{2} \mathrm{O}^{*}$ & 357 & 353 & 353 & 354 & 354 & 355 & 355 & 355 & 356 & 356 \\
\hline $\mathrm{MgO}$ & 012 & 028 & 034 & 035 & 033 & 032 & 028 & 030 & 0.35 & 028 \\
\hline $\mathrm{MnO}$ & 8 & 003 & o. & 003 & 003 & d) 63 & d) 013 & 063 & 003 & 003 \\
\hline $\mathrm{Na}_{2} \mathrm{O}$ & 958 & 940 & 950 & 941 & 978 & 937 & 929 & 943 & 956 & 959 \\
\hline $\mathrm{NL}_{2} \mathrm{O}_{3}$ & 8 & $<001$ & a) 01 & $<(1011$ & $<001$ & 0001 & $<001$ & a) & 0001 & 6001 \\
\hline $\mathrm{N} 1 \mathrm{O}$ & 040 & 037 & 037 & 032 & 035 & 035 & 036 & 034 & 036 & 034 \\
\hline $\mathrm{P}_{2} \mathrm{O}_{5}$ & 105 & 096 & 096 & 102 & 097 & 098 & 099 & 097 & 096 & 097 \\
\hline $\mathrm{PbO}$ & 041 & 037 & 038 & 036 & 038 & 039 & 039 & 039 & 037 & 037 \\
\hline $\mathrm{S}_{1} \mathrm{O}_{2}$ & 2700 & 2796 & 2806 & 2840 & 2765 & 2783 & 2771 & 2780 & 2756 & 2773 \\
\hline $\mathrm{SO}_{3}$ & 020 & 011 & 010 & 011 & 011 & 011 & 013 & 013 & 013 & 013 \\
\hline Sro & $\S$ & 002 & 002 & 001 & 001 & 001 & 001 & 001 & 001 & 001 \\
\hline $\mathrm{T}_{1} \mathrm{O}_{2}$ & 001 & 005 & 005 & 004 & 005 & 005 & 005 & 004 & 005 & 004 \\
\hline $\mathrm{ZnO}$ & 008 & 009 & 009 & 009 & 009 & 009 & 009 & 008 & 009 & 008 \\
\hline $\mathrm{ZrO}_{2}$ & 039 & 064 & 064 & 057 & 0.58 & 061 & 061 & 060 & 0.58 & 059 \\
\hline Sum & $100(\infty)$ & lixogut & $\operatorname{lig} 000$ & 1000 & logy ing & 10000 & 1 (w) 00 & $1(N)(N)$ & 10000 & 10000 \\
\hline
\end{tabular}

\$ - Not a taryet constituent

* - for XRF-analyzed compositions, yalues $\mathrm{for}_{\mathrm{B}} \mathrm{B}_{2} \mathrm{O}_{3}$ and $\mathrm{L}_{2} \mathrm{O}$ were calculated based on simple well-stirted tank mixlel and taryet valuis

\# - Fluorine uias measured by XRF on polshed samples, values for other samples calculated by miterpolation 
Table 6.6. XRF Analyzed Composition for Glass Discharged During DM100 Melter Test (wt\%) (continued).

\begin{tabular}{|c|c|c|c|c|c|c|c|}
\hline Formulation & \multicolumn{7}{|c|}{ HWI-Al-19 } \\
\hline Al Source & \multicolumn{7}{|c|}{ Aluminum Hydroxide } \\
\hline Temperature & \multirow{4}{*}{ Taryet } & \multicolumn{6}{|c|}{$1150^{\circ} \mathrm{C}$} \\
\hline Test & & \multicolumn{6}{|c|}{8} \\
\hline Glass (kg) & & 186696 & 188956 & 191262 & 193676 & \multicolumn{2}{|c|}{194840} \\
\hline Constituent & & $\mathrm{BL} Z-\mathrm{G}-28 \mathrm{~A}$ & $\mathrm{BLZ}-\mathrm{G}-29 \mathrm{~B}$ & $\mathrm{BLZ}-\mathrm{G}-33 \mathrm{~B}$ & $\mathrm{BLZ}-\mathrm{G}-35 \mathrm{~B}$ & $\mathrm{BLZ}-\mathrm{G}-37 \mathrm{~A}$ & $\%$ Des \\
\hline $\mathrm{Al}_{2} \mathrm{O}_{3}$ & 2397 & 2288 & 2311 & 3303 & 3301 & 2994 & -430 \\
\hline $\mathrm{B}_{2} \mathrm{O}_{3}{ }^{*}$ & 1919 & 1903 & 1905 & 1907 & 1908 & 1960 & $\mathrm{NC}$ \\
\hline $\mathrm{BaO}$ & 005 & 006 & 005 & 006 & 006 & $00 \Omega$ & $\mathrm{NC}$ \\
\hline $\mathrm{B}_{12} \mathrm{O}_{3}$ & 114 & 125 & 130 & 128 & 127 & 126 & 996 \\
\hline $\mathrm{CaO}$ & 558 & 587 & 564 & 589 & $58 \%$ & 574 & 289 \\
\hline $\mathrm{CdO}$ & 002 & 002 & 002 & 003 & 003 & 002 & $\mathrm{NC}$ \\
\hline $\mathrm{Ce}_{2} \mathrm{O}_{3}$ & $\bar{f}$ & $\therefore: 001$ & 001 & 5001 & $e: 001$ & $e: 001$ & $\mathrm{NC}$ \\
\hline $\mathrm{Cr}_{2} \mathrm{O}_{3}$ & 052 & 060 & 056 & 059 & 060 & 060 & $\mathrm{NC}$ \\
\hline $\mathrm{F}$ & 067 & 045 & 046 & i) 47 & $048^{\pi}$ & 048 & $\mathrm{NC}$ \\
\hline $\mathrm{Fe}_{2} \mathrm{O}_{3}$ & 590 & 617 & 574 & 618 & 611 & 615 & 421 \\
\hline $\mathrm{K}, \mathrm{O}$ & 014 & 019 & 019 & 019 & 019 & 018 & $\mathrm{NC}$ \\
\hline $\mathrm{La}_{2} \mathrm{O}_{3}$ & f & $<: 00]$ & $<001$ & 4001 & $<001$ & $\therefore: 001$ & $\mathrm{NC}$ \\
\hline $\mathrm{Lu}_{2} \mathrm{O}^{*}$ & 357 & 356 & 356 & 356 & 356 & 356 & $\mathrm{NC}$ \\
\hline $\mathrm{MgO}$ & 012 & 0.31 & 031 & 0.32 & 029 & 0.31 & $\mathrm{NC}$ \\
\hline $\mathrm{MnO}$ & G & 003 & 003 & 1) 03 & 003 & 003 & $\mathrm{NC}$ \\
\hline $\mathrm{Na}_{2} \mathrm{O}$ & 958 & 925 & 988 & 923 & 881 & 9.54 & -1938 \\
\hline $\mathrm{Nd}_{2} \mathrm{O}_{3}$ & 9 & 8001 & 8001 & -j) (1) & 0101 & 8001 & $\mathrm{NC}$ \\
\hline $\mathrm{N}_{1} \mathrm{O}$ & 040 & 036 & 031 & 035 & 034 & 035 & $\overline{N C}$ \\
\hline $\mathrm{P}_{2} \mathrm{O}_{3}$ & 105 & 097 & 099 & 095 & 099 & 094 & -1022 \\
\hline $\mathrm{PbO}$ & 041 & 038 & 035 & 037 & 037 & 036 & $\mathrm{NC}$ \\
\hline $\mathrm{So}_{2}$ & 2700 & 2777 & 2774 & 2765 & 2814 & 2755 & 204 \\
\hline $\mathrm{SO}_{3}$ & 020 & 013 & 013 & 014 & 014 & 014 & $\mathrm{NC}$ \\
\hline $\mathrm{SrO}$ & $\S$ & 001 & 001 & 001 & 001 & 001 & $\mathrm{NC}$ \\
\hline $\mathrm{T}_{1} \mathrm{O}_{2}$ & 001 & 005 & 004 & 004 & 004 & 004 & $\mathrm{NC}$ \\
\hline $\mathrm{ZnO}$ & 008 & 008 & 008 & 008 & 008 & 008 & $\mathrm{NC}$ \\
\hline$\overline{\mathrm{ZrO}_{2}}$ & 039 & 057 & 052 & 056 & 057 & 057 & $\mathrm{NC}$ \\
\hline Sum & 10000 & 10000 & 10000 & 10000 & 10000 & $\operatorname{I0n}(0)$ & $\mathrm{NC}$ \\
\hline
\end{tabular}

$\$$ - Not a tatrot constibuent

* - for XRF-analyzed compositions, yalues for $\mathrm{B}_{2} \mathrm{O}_{3}$ and $\mathrm{L}_{2} \mathrm{O}$ were calculated based on sunple well-stired tank model and target ralues

\# - Fluorine was measured by XRF on polshed samples. values for other samples calculated by miterpolation $\mathrm{NC}$ - Not calculaled 
Table 6.7. XRF Analyzed Composition for Glass Discharget During DM1200 Melter Test $(\mathbf{w t} \%)$.

\begin{tabular}{|c|c|c|c|c|c|c|c|c|c|c|c|}
\hline Test & \multirow{3}{*}{ Triget } & \multicolumn{7}{|c|}{1} & \multicolumn{3}{|c|}{5} \\
\hline Glass (hg) & & 4785 & 9805 & 14620 & 19610 & 24460 & 28925 & 33730 & 38655 & 43640 & 48595 \\
\hline Constituent & & $\begin{array}{c}G=12 \mathrm{~J}- \\
45 \mathrm{~A}\end{array}$ & $\begin{array}{c}\mathrm{G}-12 \mathrm{~J}- \\
60 \mathrm{~A}\end{array}$ & $\begin{array}{c}\text { G-12J- } \\
64 \mathrm{~A}\end{array}$ & $\begin{array}{c}G .12 \mathrm{~J} . \\
72 \mathrm{~A}\end{array}$ & $\begin{array}{c}\mathrm{G}-12 \mathrm{~J}- \\
79 \mathrm{~B}\end{array}$ & $\begin{array}{l}G-12 \mathrm{~J}- \\
\text { loijA }\end{array}$ & $\begin{array}{l}\text { G-12J- } \\
105 \mathrm{~B}\end{array}$ & $\begin{array}{c}\text { G-12J- } \\
135 \mathrm{~A}\end{array}$ & $\begin{array}{c}\mathrm{G} \cdot 1 \mathrm{FJ}- \\
149 \mathrm{~B}\end{array}$ & $\begin{array}{c}G-12 \mathrm{~K}- \\
2 \mathrm{IA}\end{array}$ \\
\hline $\mathrm{Al}_{2} \mathrm{O}_{3}$ & 2397 & 1380 & 1612 & 1729 & 1851 & 1935 & 2023 & 2082 & 2107 & 2171 & 2208 \\
\hline $\mathrm{B}_{2} \mathrm{O}_{3}^{*}$ & 1919 & 1358 & 1581 & 1656 & 1716 & 1761 & 1794 & 1821 & 1843 & 1861 & 1874 \\
\hline $\mathrm{BaO}$ & 005 & 004 & 005 & 004 & 004 & 004 & 004 & 005 & 006 & 005 & 006 \\
\hline$\overline{\mathrm{B}_{2} \mathrm{O}_{3}}$ & 14 & 044 & 061 & 070 & 080 & 094 & 096 & 106 & 109 & 110 & 112 \\
\hline $\mathrm{CaO}$ & 58 & 244 & 318 & 360 & 97 & 444 & 466 & 492 & 516 & 512 & 524 \\
\hline $\mathrm{CdO}$ & 02 & 005 & 005 & 005 & 004 & 004 & 003 & 004 & 004 & 003 & 003 \\
\hline $\mathrm{Cr}_{2} \mathrm{O}_{3}$ & $0 \$ 2$ & 932 & 939 & 041 & 1) 43 & 948 & 948 & !. 51 & 053 & $0 \$ 1$ & 054 \\
\hline $\bar{F}$ & 067 & $014^{*}$ & 019 & 023 & $028^{\pi}$ & 031 & 031 & $030^{7}$ & 032 & 033 & 035 \\
\hline $\mathrm{Fe}_{2} \mathrm{O}_{3}$ & 59 gin & 894 & 821 & 778 & 726 & 724 & 696 & 687 & 693 & 649 & 643 \\
\hline $\mathrm{K}_{2} \mathrm{O}$ & 014 & 024 & 022 & 023 & 21 & 022 & 021 & 020 & 020 & 020 & 019 \\
\hline $\mathrm{La}_{2} \mathrm{O}_{3}$ & $\$$ & 18 & (614 & 013 & 1) 19 & 908 & 607 & 100 & 004 & 903 & 093 \\
\hline $\mathrm{L}_{2} \mathrm{O}^{2 *}$ & 357 & 346 & 290 & 305 & 317 & 326 & 332 & 338 & 342 & 345 & 348 \\
\hline $\mathrm{MgO}$ & 012 & 048 & 040 & 037 & 041 & 038 & 933 & 033 & 0.34 & 036 & 030 \\
\hline $\mathrm{MrO}$ & 00 & 972 & 956 & 047 & 1) 36 & 931 & 925 & 929 & 017 & 914 & 911 \\
\hline $\mathrm{Na}_{2} \mathrm{O}$ & 958 & 1103 & 1018 & 1004 & 1037 & 1000 & 994 & 984 & 948 & 962 & 974 \\
\hline $\mathrm{Nu}_{2} \mathrm{O}_{3}$ & $\$$ & 912 & oing & 007 & 1) 16 & $005^{5}$ & gins & 96 & 003 & 002 & 001 \\
\hline $\mathrm{N} 1 \mathrm{O}$ & 040 & 032 & 033 & 033 & 032 & 032 & 032 & 034 & 035 & 031 & 033 \\
\hline $\mathrm{P}_{2} \mathrm{OS}$ & 105 & 052 & 069 & 075 & 086 & 090 & 094 & 100 & 107 & 107 & 112 \\
\hline Fto & 041 & 016 & 020 & 022 & 025 & 028 & 029 & 032 & 032 & 031 & 033 \\
\hline $\mathrm{Sb}_{2} \mathrm{O}_{3}$ & $\Phi$ & 004 & 0 044 & 002 & 002 & 002 & 001 & $\dot{001}$ & 001 & 001 & 8001 \\
\hline $\mathrm{SiO}_{2}$ & 2700 & 3968 & 3698 & 3531 & 3338 & 3192 & 3109 & 3010 & 3961 & 2936 & 2865 \\
\hline $\mathrm{SO3}$ & 020 & 008 & 010 & 011 & 011 & 012 & 013 & 014 & 012 & 012 & 013 \\
\hline $\mathrm{SrO}$ & $\$$ & 021 & 016 & 014 & 011 & 009 & 007 & 006 & 005 & 004 & 003 \\
\hline $\mathrm{TrO}_{2}$ & 001 & 915 & 012 & 011 & 1) 10 & ong & 008 & 967 & 007 & 007 & 906 \\
\hline $\mathrm{ZnO}$ & 008 & 110 & 086 & 072 & 057 & 049 & 041 & 034 & 030 & 025 & 021 \\
\hline $\mathrm{ZrO}_{2}$ & 039 & 174 & 142 & 127 & 111 & 103 & 989 & 983 & 078 & 070 & 968 \\
\hline Sum & 10000 & 10000 & 10000 & 10000 & 10000 & 10000 & $\mid$ & 10000 & 10000 & 10000 & 10000 \\
\hline
\end{tabular}

$\$$ - Not a target constituent

* - Target vahues calculated by sumple well-sirned tank model using the DCP analyzed values for the first discharge of the wihole test

\# - Fluonne was measured by XRF on polshed samples, values for other samples calculated by unterpolation 
Table 6.7. XRF Analyzed Composition for Glass Discharged During DM1200 Melter Test (wt\%) (continued).

\begin{tabular}{|c|c|c|c|c|c|c|c|c|c|c|c|c|}
\hline \multirow{4}{*}{$\begin{array}{c}\text { Test } \\
\text { Glass (kg) } \\
\text { Const tuent }\end{array}$} & \multirow{4}{*}{ arget } & 2 & \multicolumn{8}{|c|}{$\underline{z}$} & \multirow{2}{*}{\multicolumn{2}{|c|}{$5832-8873$}} \\
\hline & & \multirow{3}{*}{$\begin{array}{c}53575 \\
\mathrm{G}-12 \mathrm{~K} \\
28 \mathrm{C} \\
\end{array}$} & 58325 & 67950 & 68080 & 73100 & 77935 & 82880 & 87605 & 88730 & & \\
\hline & & & $\mathrm{G}-12 \mathrm{~K}-$ & $\mathrm{G}-12 \mathrm{~K}$ & $\mathrm{G}-12 \mathrm{~K}$ & $\mathrm{G}-\mathrm{l} 2 \mathrm{~K}$ & $\mathrm{G}-12 \mathrm{~K}$ & $\mathrm{G}-12 \mathrm{~S}$ & $\mathrm{G}-12 \mathrm{~K}$ & $\mathrm{G}-12 \mathrm{~K}$ & $A$ & ${ }_{0} \mathrm{D}$ \\
\hline & & & $44 \mathrm{~A}$ & $59 \mathrm{~A}$ & $81 \mathrm{~B}$ & $91 \mathrm{~A}$ & $109 \mathrm{~A}$ & $115 \mathrm{~A}$ & $138 \mathrm{~A}$ & $139 \mathrm{~A}$ & $M$ & $6 \mathrm{~L}$ \\
\hline $\mathrm{Al}_{2} \mathrm{O}_{3}$ & 2397 & 2245 & 2280 & $23(\omega)$ & 2299 & 2343 & 2367 & 2383 & 2371 & 2364 & 23.38 & -251 \\
\hline $\mathrm{B}_{2} \mathrm{O}_{3}$ & 1919 & 1884 & 1892 & 1897 & 1903 & 1906 & 1909 & 1911 & 1913 & 1913 & 1906 & NC \\
\hline $\mathrm{BAO}$ & 0195 & 906 & 006 & 1) 97 & g. & 006 & 905 & 007 & 9166 & 097 & 1) 016 & NC \\
\hline $\mathrm{B}_{2} \mathrm{O}_{3}$ & 114 & 112 & 107 & 112 & 119 & 113 & 114 & 117 & 116 & 115 & 14 & $-0 \geq 2$ \\
\hline $\mathrm{CaO}$ & 558 & 531 & 516 & 533 & 555 & 552 & 550 & 547 & 544 & 545 & 543 & -274 \\
\hline $\mathrm{CdO}$ & 002 & 003 & 003 & 003 & 003 & 003 & 002 & 003 & 003 & 003 & 003 & $\mathrm{NC}$ \\
\hline $\mathrm{Cr}_{2} \mathrm{O}_{3}$ & 052 & 053 & 052 & 051 & 055 & 054 & 055 & 054 & 051 & 053 & 053 & $\mathrm{NC}$ \\
\hline $\mathrm{F}$ & 067 & $037^{\sharp}$ & 036 & 035 & 034 & $033^{14}$ & 034 & 036 & $037^{\not 1}$ & 037 & 35 & $\mathrm{NC}$ \\
\hline $\mathrm{Fe}_{2} \mathrm{O}_{3}$ & 590 & 617 & 584 & 592 & 620 & 607 & 608 & 599 & 600 & 607 & 002 & 202 \\
\hline $\mathrm{k}_{2} \mathrm{O}$ & 014 & 019 & 019 & 019 & 020 & 019 & 019 & 018 & 018 & 019 & 019 & $\mathrm{NC}$ \\
\hline $\mathrm{La}_{2} \mathrm{O}_{3}$ & $\S$ & 002 & 002 & 002 & 001 & 001 & a) (1) & 8901 & $=0(01) 1$ & aiol & 001 & $N C$ \\
\hline $\mathrm{L}_{12} \mathrm{O}$ & 357 & 350 & 352 & 353 & 354 & 355 & 355 & 356 & 356 & 356 & 354 & $\mathrm{NC}$ \\
\hline $\mathrm{MgO}$ & 012 & 030 & 031 & 029 & 028 & 033 & 030 & 028 & 033 & 031 & 030 & $\mathrm{NC}$ \\
\hline $\mathrm{MrO}$ & 000 & $0(09$ & 007 & 007 & 006 & 005 & 005 & 004 & 004 & 004 & 005 & $\mathrm{NC}$ \\
\hline $\mathrm{Na}_{2} \mathrm{O}$ & 958 & 976 & 1039 & 991 & 940 & 931 & 954 & 950 & 987 & 984 & 972 & 144 \\
\hline $\mathrm{Nd}_{2} \mathrm{O}_{3}$ & $\xi$ & 001 & $<001$ & 001 & 001 & 4001 & $<001$ & $<001$ & $<001$ & $\$ 001$ & $<001$ & $\mathrm{NC}$ \\
\hline $\mathrm{N}$ & 040 & 031 & 030 & 031 & 034 & 033 & 033 & 031 & 032 & 033 & 032 & $\mathrm{NC}$ \\
\hline $\mathrm{P}_{2} \mathrm{O}_{5}$ & 105 & 111 & 113 & 113 & 114 & 113 & 112 & 114 & 115 & 116 & 114 & 759 \\
\hline $\mathrm{P} 1 \mathrm{O}$ & 041 & 033 & 031 & 032 & 034 & 032 & 031 & 033 & 033 & 034 & 032 & $\mathrm{NC}$ \\
\hline $\mathrm{Sb}_{2} \mathrm{O}_{3}$ & ई & $\Rightarrow 0101$ & $\sin 01$ & $=0101$ & $\Rightarrow$ & 4001 & $\Rightarrow 1$ & 8901 & $\approx 001$ & sign & 4001 & $\mathrm{NC}$ \\
\hline $\mathrm{S}_{1} \mathrm{O}_{2}$ & 2700 & 2848 & 2810 & 2804 & 2785 & 2774 & 2737 & 2728 & 2701 & 2690 & 2755 & 200 \\
\hline$\$ 03$ & 020 & 014 & a 13 & i) 15 & 014 & $(16$ & 014 & a 13 & (1) 13 & 14 & $(14$ & NC: \\
\hline $\mathrm{S} \mathrm{rO}$ & है & on & 019 & 1) & 0101 & 001 & a) (11 & aigl & (1) & ainl & (1)!1 & NC \\
\hline $\mathrm{T}_{1} \mathrm{O}_{2}$ & 0 01 & 006 & 005 & 005 & 005 & 005 & 004 & 005 & 005 & 004 & 005 & $\mathrm{NC}$ \\
\hline $\mathrm{Zmo}$ & 0108 & 018 & 915 & d) 14 & 014 & $(112$ & 011 & 911 & 10 & 911 & 012 & NC \\
\hline $\mathrm{ZrO}_{2}$ & 039 & 062 & $05 \xi$ & 056 & 056 & 053 & 049 & 052 & 050 & 050 & 053 & $N C$ \\
\hline um & 10) & 10000 & $10(1)$ (n) & 6000 & (iv) 00 & (m) 00 & 000 & Wi ding & 10000 & 10) 00 & $1(w) 00$ & NC \\
\hline
\end{tabular}

$\$$ - Not a target constituent

* - Target vahues calculated by sumple well-stirred tank model using the DCP analyzed values for the first dlscharge of the whole test

\# - Fluorine was measured by YRF on polshed saniples. values for other samples calculated by mterpolation NC - Not calculared 
Table 6.8. XRF and DCP Analyzed Compositions of Selected Glass Samples Discharged during DM100 and DM1200 Melter Tests (wt\%).

\begin{tabular}{|c|c|c|c|c|c|c|c|c|c|c|}
\hline Melter Type & \multicolumn{10}{|c|}{ DM100BL } \\
\hline Formulation & \multicolumn{5}{|c|}{ HLW-E-Al.27 } & \multicolumn{5}{|c|}{ HWI-AI-16 } \\
\hline Test & \multirow{3}{*}{ Target } & \multicolumn{2}{|c|}{1} & \multirow{2}{*}{\multicolumn{2}{|c|}{$\frac{\mathbf{2}}{\text { BLX-G-11SA }}$}} & \multirow{3}{*}{ Target } & \multicolumn{2}{|c|}{3} & \multicolumn{2}{|c|}{4} \\
\hline \multirow{2}{*}{ Constituent } & & \multicolumn{2}{|c|}{ BLX-G-S4C } & & & & \multicolumn{2}{|c|}{ BLY-G-14B } & \multicolumn{2}{|c|}{ BLY-G-36B } \\
\hline & & $\mathrm{XRF}$ & $\mathrm{DCP}$ & \multicolumn{2}{|c|}{ 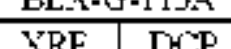 } & & $\mathrm{XRF}$ & DCP & XRF & $\mathrm{DCP}$ \\
\hline $\mathrm{Al}_{2} \mathrm{O}_{3}$ & 2397 & 1933 & 1706 & 2179 & 1876 & 2325 & 2212 & 1965 & 2209 & 1952 \\
\hline $\mathrm{B}_{2} \mathrm{O}_{3}$ & 1519 & $1478^{*}$ & 1370 & $1505 *$ & 1520 & 1773 & $1697^{*}$ & 1716 & $1749^{*}$ & 1766 \\
\hline $\mathrm{BaO}$ & 005 & aiol & $\theta(n$ & 005 & 006 & 005 & 06 & 1) 016 & 006 & 006 \\
\hline $\mathrm{B}_{2} \mathrm{O}_{3}$ & 114 & 106 & 102 & 113 & 111 & 111 & 113 & 111 & 122 & 108 \\
\hline $\mathrm{CaO}$ & 608 & 498 & 450 & 5.57 & 507 & 589 & 577 & 527 & 614 & 535 \\
\hline CdO & 002 & 003 & NA & 003 & NA & 002 & 003 & $\mathrm{NA}$ & 003 & NA \\
\hline $\mathrm{Ce}_{2} \mathrm{O}_{3}$ & $\$$ & 002 & NA & 002 & NA & 8 & $\angle 001$ & $\mathrm{NA}$ & 001 & NA \\
\hline $\mathrm{Cr}_{2} \mathrm{O}_{3}$ & 052 & 055 & 022 & 055 & 022 & 051 & 050 & 021 & 056 & 019 \\
\hline $\mathrm{F}$ & 067 & $037^{5}$ & NA & $043^{3}$ & NA & 065 & $036^{\#}$ & $\mathrm{NA}$ & $044^{3}$ & NA \\
\hline $\mathrm{Fe}_{2} \mathrm{O}_{3}$ & 590 & 638 & 590 & 599 & 538 & 572 & 575 & 533 & 610 & 521 \\
\hline $\mathrm{K}_{2} \mathrm{O}$ & 014 & 023 & 026 & 019 & 023 & 014 & 016 & 020 & 017 & 019 \\
\hline $\mathrm{La}_{2} \mathrm{O}_{3}$ & $\$$ & 002 & $N A$ & $\varepsilon: 001$ & NA & f & 001 & NA & $<001$ & NA \\
\hline $\mathrm{Ll}_{2} \mathrm{O}$ & 357 & $324 *$ & 347 & $346^{*}$ & 352 & 346 & $346^{*}$ & 319 & $340^{*}$ & 319 \\
\hline $\mathrm{MgO}$ & 012 & (130) & 0.34 & 025 & 031 & 011 & 430 & i) 38 & 028 & 0.38 \\
\hline $\mathrm{MnO}$ & $\$$ & $(128$ & $0 \$ 1$ & 012 & 013 & G & 09 & 1) 10 & 006 & 006 \\
\hline $\mathrm{Na}_{2} \mathrm{O}$ & 958 & 1018 & 881 & 1043 & 871 & 929 & 948 & 840 & 871 & 824 \\
\hline $\mathrm{Nd}_{2} \mathrm{O}_{3}$ & $\S$ & 602 & NA & 001 & NA & 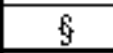 & $=0011$ & $\mathrm{NA}$ & $\therefore 001$ & NA \\
\hline $\mathrm{N}_{10}$ & 040 & 041 & 032 & 035 & 026 & 039 & 032 & 027 & 033 & 024 \\
\hline $\mathrm{P}_{2} \mathrm{OS}$ & 105 & 105 & 092 & 111 & 097 & 102 & 116 & 1) 99 & 116 & 103 \\
\hline $\mathrm{FbO}$ & 041 & 033 & 036 & 036 & 039 & 040 & 036 & 039 & 039 & 038 \\
\hline $\mathrm{S}_{1} \mathrm{O}_{2}$ & 30.50 & 3297 & 3192 & 3142 & 2987 & 2958 & 3097 & 2996 & 3039 & 2932 \\
\hline $\mathrm{SO}_{3}$ & 020 & 011 & NA & 016 & NA & 019 & 011 & $\mathrm{NA}$ & 013 & NA \\
\hline $\mathrm{SrO}$ & $\$$ & 145 & 162 & 054 & 065 & f & 015 & 019 & 007 & 008 \\
\hline $\mathrm{T}_{10}$ & 001 & 004 & 005 & 004 & 005 & 001 & 004 & 005 & 004 & 005 \\
\hline $\mathrm{ZnO}$ & 008 & 027 & 023 & 014 & 013 & 008 & 010 & 010 & 010 & 008 \\
\hline $\mathrm{ZrO}$ & 039 & 165 & 191 & 084 & 099 & 038 & 059 & 071 & 056 & 065 \\
\hline Sum & 10000 & 10000 & 9298 & 10000 & 9210 & 10000 & 10000 & 9372 & 10000 & 9296 \\
\hline
\end{tabular}

$\$$ - Not a taryet constibient.

NA - Not analyzed

* - for XRF-analyzed compositions. yalues for $\mathrm{B}_{2} \mathrm{O}_{3}$ and $\mathrm{L}_{2} \mathrm{O}$ were calculated based on smple well-stined tank moilel with target yalues

\# - Fluonne measured by XRF on polished samples

$\$$ - Fluorine values calculated by interpolation 
Table 6.8. XRF and DCP Analyzed Compositions of Selected Glass Samples Discharged during DM100 and DM1200 Melter Tests (wt\%) (continued).

\begin{tabular}{|c|c|c|c|c|c|c|c|c|c|c|}
\hline Meter Type & \multicolumn{10}{|c|}{ DM100BL } \\
\hline Formulation & \multicolumn{5}{|c|}{ HWI-Al -16 } & \multicolumn{5}{|c|}{ HWI-Al-19 } \\
\hline Test & \multirow{3}{*}{ Target } & \multicolumn{2}{|c|}{5} & \multirow{2}{*}{\multicolumn{2}{|c|}{$\frac{6}{\text { BLY-G-l } 14 A}$}} & \multirow{3}{*}{ Target } & \multicolumn{2}{|c|}{7} & \multicolumn{2}{|c|}{8} \\
\hline \multirow{2}{*}{ Constituent } & & \multicolumn{2}{|c|}{ BLY-G-80C } & & & & \multicolumn{2}{|c|}{ BLZ-G-5B } & \multicolumn{2}{|c|}{ BLZ-G-37A } \\
\hline & & $\mathrm{XRF}$ & $\overline{D C P}$ & \multicolumn{2}{|c|}{\begin{tabular}{|l|l|} 
XRF & DCP
\end{tabular}} & & XRF & $\overline{D C P}$ & XRF & DCP \\
\hline $\mathrm{Al}_{2} \mathrm{O}_{3}$ & 2325 & 2238 & 2017 & 2236 & 1985 & 2397 & 2273 & 3000 & 2294 & 1989 \\
\hline $\mathrm{B}_{2} \mathrm{O}_{3}$ & 1773 & $1766^{*}$ & 1735 & $1771^{*}$ & 1731 & 1919 & $1881^{*}$ & 1913 & $1909^{6}$ & 1917 \\
\hline $\mathrm{BaO}$ & 005 & 005 & 006 & 005 & 005 & 005 & 005 & 006 & 005 & 006 \\
\hline $\mathrm{B}_{\mathbf{5}} \mathrm{O}_{3}$ & 111 & 116 & 110 & 118 & 109 & 114 & 125 & 112 & 126 & 116 \\
\hline $\mathrm{CaO}$ & 589 & 591 & 527 & 584 & 515 & 558 & 586 & 532 & 574 & 510 \\
\hline $\mathrm{CdO}$ & 002 & 003 & NA & 003 & NA & 002 & 162 & 0001 & 0012 & 001 \\
\hline $\mathrm{Ce}_{2} \mathrm{O}_{3}$ & $\$$ & aigl & NA & 0001 & NA & 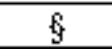 & (101 & NA & $\therefore 001$ & NA \\
\hline $\mathrm{Cr}_{2} \mathrm{O}_{3}$ & 051 & $0 \leq 0$ & 023 & 052 & 022 & 052 & 00 & 034 & 060 & 024 \\
\hline$F$ & 065 & $041^{3}$ & NA & $047^{3}$ & NA & 067 & $040^{3}$ & NA & $048^{3}$ & NA \\
\hline $\mathrm{Fe}_{2} \mathrm{O}_{3}$ & 572 & 644 & 590 & 655 & 572 & 590 & 632 & 550 & 615 & 532 \\
\hline $\mathrm{K}_{2} \mathrm{O}$ & 014 & 017 & $0 ح 0$ & 017 & 020 & 014 & 018 & 023 & 018 & 022 \\
\hline $\mathrm{La}_{2} \mathrm{O}_{3}$ & $\xi$ & 4001 & NA & $<001$ & NA & 8 & 8001 & NA & $=001$ & $\mathrm{NA}$ \\
\hline $\mathrm{Ll}_{2} \mathrm{O}$ & 346 & $346^{*}$ & 357 & $346^{*}$ & 342 & 357 & $354 *$ & 368 & $356^{*}$ & 357 \\
\hline $\mathrm{MgO}$ & 011 & 023 & 029 & 021 & 029 & 012 & 033 & 045 & 031 & 041 \\
\hline $\mathrm{MnO}$ & $\$$ & 006 & 006 & 004 & 005 & E & 008 & 003 & 003 & 003 \\
\hline $\mathrm{Na}_{2} \mathrm{O}$ & 929 & 893 & 819 & 904 & 801 & 958 & 978 & 901 & 954 & 890 \\
\hline $\mathrm{Nd}_{2} \mathrm{O}_{3}$ & $\S$ & $\infty 001$ & NA & $<001$ & NA & f & 6001 & NA & $<001$ & $\mathrm{NA}$ \\
\hline $\mathrm{N} 1 \mathrm{O}$ & 0.39 & 633 & 927 & 031 & 023 & 040 & 935 & i) 26 & 035 & 025 \\
\hline $\mathrm{P}_{2} \bigcirc 5$ & 102 & 115 & 105 & 115 & 093 & 105 & 997 & 1) 81 & 094 & 088 \\
\hline $\mathrm{FbO}$ & 040 & 034 & 035 & 034 & 033 & 041 & 038 & 047 & 036 & 046 \\
\hline $\mathrm{S}_{1} \mathrm{O}_{2}$ & 2958 & 2975 & 2866 & 2951 & 2808 & 2700 & 2765 & 2881 & 2755 & 2811 \\
\hline $\mathrm{SO}_{3}$ & 019 & 011 & NA & 012 & NA & 020 & 0 11 & NA & 014 & NA \\
\hline $\mathrm{SO}$ & $\$$ & 603 & b) & 002 & 002 & 8 & 1010 & d) (11 & 001 & 001 \\
\hline $\mathrm{T}_{1} \mathrm{O}_{2}$ & 001 & 005 & 005 & 004 & 005 & 001 & 005 & 004 & 004 & 004 \\
\hline $\mathrm{ZnO}$ & 008 & 009 & 90 & 008 & 007 & 008 & 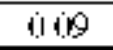 & 1) 46 & 008 & 006 \\
\hline $\mathrm{ZrO}_{2}$ & 038 & 075 & 090 & 080 & 092 & 039 & 058 & 057 & 057 & 057 \\
\hline Sum & 10000 & 10000 & 9379 & 10000 & 9190 & 10000 & 10000 & 9589 & 10000 & 9444 \\
\hline
\end{tabular}

$\$$ - Not a target constibuent.

NA - Not analyzed

* - for XRF-analyzed compositions, yalues for $\mathrm{B}_{2} \mathrm{O}_{3}$ and $\mathrm{L}_{2} \mathrm{O}$ were calculated based on sumple well-stired tank minlel with target values

\# - Fluorine measured by XRF on polished samples

$\$$ - Fluonne values calculated by interpolation 
Table 6.8. XRF and DCP Analyzed Compositions of Selected Glass Samples Discharged during DM100 and DM1200 Melter Tests (wt\%) (continued).

\begin{tabular}{|c|c|c|c|c|c|c|c|c|c|}
\hline Melter Type & \multicolumn{9}{|c|}{ DM1200 } \\
\hline Fomulation & \multicolumn{9}{|c|}{ HWI-A|l-19 } \\
\hline Test & \multirow{3}{*}{ Target } & \multicolumn{4}{|c|}{ I } & \multirow{2}{*}{\multicolumn{2}{|c|}{$\frac{2}{G-12 J-149 B}$}} & \multirow{2}{*}{\multicolumn{2}{|c|}{$\begin{array}{c}3 \\
G-12 K-138 \mathrm{~A}\end{array}$}} \\
\hline \multirow{2}{*}{ Constiquent } & & \multicolumn{2}{|c|}{$\mathrm{G}-12 \mathrm{~J}-45 \mathrm{~A}$} & \multicolumn{2}{|c|}{$\mathrm{G}-12 \mathrm{~J}-105 \mathrm{~B}$} & & & & \\
\hline & & $\mathrm{XRF}$ & $\overline{D C P}$ & $\overline{X R F}$ & DCP & XRF & $\overline{D C P}$ & $\overline{\mathrm{XRF}}$ & $\overline{D C P}$ \\
\hline $\mathrm{Al}_{2} \mathrm{O}_{3}$ & 2397 & 1381 & $1 \geq 46$ & 2083 & 1847 & 2171 & 188 & 2371 & 2144 \\
\hline $\mathrm{E}_{2} \mathrm{O}_{3}$ & 1919 & $1358^{* * *}$ & 1358 & $1821^{\text {水 }}$ & 1775 & $1861 * *$ & 1807 & $1913^{\text {*atk }}$ & 1886 \\
\hline $\mathrm{BaO}$ & 005 & !̣ $(4$ & 006 & 005 & 006 & 005 & 1) 06 & 006 & 006 \\
\hline $\mathrm{B} t_{2} \mathrm{O}_{3}$ & 114 & 044 & 047 & 106 & 099 & 110 & 106 & 116 & 117 \\
\hline $\mathrm{CaO}$ & 558 & 244 & 254 & 492 & 436 & 512 & 460 & 544 & 495 \\
\hline $\mathrm{CdO}$ & 002 & 006 & $<001$ & 004 & $<001$ & 003 & $\mathrm{NA}$ & 003 & 5001 \\
\hline $\mathrm{C}_{\mathrm{e}_{2} \mathrm{O}_{3}}$ & $\$$ & ! 01 & NA & $c 001$ & NA & की & $\mathrm{NA}$ & $\therefore 001$ & NA \\
\hline $\mathrm{Cr}_{2} \mathrm{O}_{3}$ & 052 & 032 & 020 & 051 & 019 & 051 & 020 & 051 & 020 \\
\hline$F$ & 067 & $014^{\#}$ & $\overline{N A}$ & $030^{4}$ & NA & $033^{5}$ & $\mathrm{NA}$ & $037^{\#}$ & $\overline{\mathrm{NA}}$ \\
\hline $\mathrm{F} \varepsilon_{2} \mathrm{O}_{3}$ & 590 & 894 & 897 & 687 & 621 & 649 & 596 & 600 & 56 \\
\hline $\mathrm{K}_{2} \mathrm{O}$ & 014 & 024 & 024 & 020 & 024 & 030 & 034 & 018 & 023 \\
\hline $\mathrm{La}_{2} \mathrm{O}_{3}$ & $\$$ & 018 & NA & 005 & NA & 003 & $\mathrm{NA}$ & $\angle 001$ & NA \\
\hline $\mathrm{L}_{2} \mathrm{O}$ & 357 & $346^{*+1 k}$ & 346 & $338^{2 * *}$ & 369 & $345 * *$ & 373 & $356^{k+4}$ & 385 \\
\hline $\mathrm{MgO}$ & 012 & 048 & 043 & 033 & 0.43 & 036 & 043 & 033 & 043 \\
\hline Mno & $\S$ & 072 & 021 & 020 & 021 & 014 & 016 & 004 & 005 \\
\hline $\mathrm{Na}_{2} \mathrm{O}$ & 958 & 1104 & 995 & 984 & 906 & 962 & 896 & 987 & 864 \\
\hline $\mathrm{Nd}_{2} \mathrm{O}_{y}$ & 5 & 19 12 & NA & 003 & NA & 60 & $\mathrm{NA}$ & $\therefore 001$ & NA \\
\hline $\mathrm{N} 1 \mathrm{O}$ & 040 & 032 & 026 & 034 & 026 & 031 & 025 & 032 & 026 \\
\hline $\mathrm{P}_{2} \bigcirc \mathrm{S}$ & 105 & 1. 52 & 0.00 & 100 & 089 & 107 & 1) 98 & 115 & 101 \\
\hline $\mathrm{PbO}$ & $(141$ & 16 & $0 \geq 4$ & 032 & 040 & 031 & i) $4 \geq$ & 033 & 044 \\
\hline $\mathrm{S}_{1} \mathrm{O}_{2}$ & 2700 & 3969 & 4059 & 3010 & 3124 & 2935 & 3001 & $27 ! 1$ & 2877 \\
\hline $\mathrm{SO}_{3}$ & 030 & 90 & NA & 014 & $\mathrm{NA}$ & 012 & NA & 0) 13 & NA \\
\hline $\mathrm{SrO}$ & $\S$ & $\dot{0} 21$ & 027 & 006 & 007 & 004 & 004 & 001 & 001 \\
\hline $\mathrm{TrO}_{2}$ & 001 & 1915 & 008 & 007 & 008 & 007 & 1) 07 & 005 & 005 \\
\hline $\mathrm{ZnO}$ & 008 & 110 & 114 & 034 & 028 & 025 & 021 & 010 & 008 \\
\hline $\mathrm{ZrO}_{2}$ & 039 & 174 & 206 & 083 & 093 & 070 & 081 & 050 & 058 \\
\hline Sum & 10000 & 10000 & 9811 & 10000 & 9581 & 10000 & 9506 & 10000 & 9667 \\
\hline
\end{tabular}

$\$$ - Not a taryet constituent.

NA. Not analyzed

**t- for XRF-analyzed comprositions, values for $\mathrm{B}_{2} \mathrm{O}_{3}$ and $\mathrm{L}_{2} \mathrm{O}$ wrere calculated hased on siniple well-stıred tank model and DCP analyzed $\psi$ alues for the fitst discharge

\# - Fluorine measured by XRF on polished samples.

$\$$ - Fluonne values calculated by interpolation 
Table 6.9. PCT Results for Melter Glasses (ASTM C1285, 7-days at $90^{\circ} \mathrm{C}$, Stainless Steel Vessel; $\mathrm{S} / \mathrm{V}=2000 \mathrm{~m}^{-1}$ ).

\begin{tabular}{|c|c|c|c|c|c|c|c|c|c|c|}
\hline \multicolumn{2}{|l|}{ Test } & $\mathbf{I}$ & 2 & 3 & 4 & 5 & 6 & 7 & 8 & \multirow[b]{2}{*}{ DWPF-EA } \\
\hline \multicolumn{2}{|c|}{ Glnss Samples } & $\begin{array}{l}\text { BLX- } \\
G-84 C\end{array}$ & $\begin{array}{c}\text { BLß-G- } \\
11 \xi A\end{array}$ & $\mathrm{BLY}=\mathrm{G}-1 \mathrm{AB}$ & $\begin{array}{l}\text { BLY- } \\
G-36 B\end{array}$ & $\begin{array}{c}\mathrm{BLY}-\mathrm{G}- \\
8 \mathrm{M}\end{array}$ & $\begin{array}{c}\text { BLY-G- } \\
114 A\end{array}$ & BLZ-G-5B & $\begin{array}{c}\mathrm{BLZ}-\mathrm{G}- \\
\mathbf{3 7 \mathrm { A }}\end{array}$ & \\
\hline \multirow{4}{*}{$\begin{array}{c}\text { 7-Day PCT } \\
\text { Concentration in } \\
\text { mo/L }\end{array}$} & B & 1015 & 1518 & 1395 & 1296 & 1692 & 1789 & 2958 & 3686 & 16695 \\
\hline & LI & 653 & 679 & 571 & 534 & 732 & 756 & 914 & 1045 & 9565 \\
\hline & $\mathrm{Na}$ & 2189 & 2070 & 1774 & 1656 & 1968 & $20 \simeq 5$ & 3114 & 3597 & 13346 \\
\hline & Sı & 2349 & 2128 & 2433 & 2156 & 2311 & 2431 & 2646 & 2756 & 3920 \\
\hline \multirow{5}{*}{$\begin{array}{c}\text { T-Day PCT } \\
\text { Nonmalized } \\
\text { Concentrations. } \\
\text { g'L }\end{array}$} & B & 022 & 028 & 026 & 024 & 031 & 033 & 051 & 062 & \\
\hline & $\mathrm{L}_{\mathbf{I}}$ & 043 & 042 & 035 & 033 & 046 & 047 & 056 & 063 & \\
\hline & $\mathrm{Na}$ & 029 & 127 & 025 & 026 & 30 & (1) 30) & 043 & $0 \leqslant 1$ & \\
\hline & S. & 015 & 014 & 017 & 015 & 017 & 018 & 020 & 021 & \\
\hline & $\mathrm{pH}$ & 992 & 968 & 941 & 933 & 945 & 942 & $941)$ & 937 & \\
\hline \multirow{4}{*}{$\begin{array}{c}\text { 7-Day PCT } \\
\text { Normalızd Mass } \\
\left.\text { Loss (g/m } \mathrm{gm}^{2}\right)\end{array}$} & B & 011 & 014 & 013 & 012 & 015 & 016 & 025 & 031 & \\
\hline & LI & 022 & 021 & 018 & 017 & 023 & 024 & 028 & 032 & \\
\hline & $\mathrm{Na}$ & 014 & 013 & 013 & 013 & 015 & 015 & 021 & 025 & \\
\hline & Sı & 008 & 007 & 008 & 008 & 008 & 009 & 010 & 011 & \\
\hline \multirow{4}{*}{$\begin{array}{c}\text { 7-Day PCT } \\
\text { Nomalized Loss } \\
\text { Rate, g/dim }\end{array}$} & $\mathrm{B}$ & 002 & 002 & 002 & 002 & 002 & 00 & 004 & 004 & \\
\hline & $\mathrm{L}_{1}$ & 0.13 & 0113 & 003 & 002 & 0103 & 003 & 004 & 005 & \\
\hline & $\mathrm{Na}$ & 002 & 002 & 002 & 002 & 002 & 002 & 003 & 004 & \\
\hline & Sı & 001 & 001 & 001 & 001 & 001 & 001 & 001 & 002 & \\
\hline
\end{tabular}


Table 6.10. TCLP Results for Melter Glasses (mg/L).

\begin{tabular}{|c|c|c|c|c|c|c|c|}
\hline \multirow{2}{*}{ Test } & Sample I D & Ba & Cd & $\mathrm{Cr}$ & $N_{1}$ & Pb & Zn \\
\cline { 2 - 8 } & UTS Lim1ts & 21 & 011 & 060 & 1100 & 075 & 43 \\
\cline { 2 - 8 } & Delistung Lunts & 100 & 048 & 495 & 226 & 500 & 225 \\
\hline 1 & BLX-G.84C & 015 & 004 & 004 & 010 & 011 & 017 \\
\hline 2 & BLX-G-115A & 015 & 004 & 005 & 011 & 021 & 014 \\
\hline 3 & BLY-G-14B & 018 & 005 & 005 & 008 & 021 & 012 \\
\hline 4 & BLY-G-36B & 018 & 005 & 004 & 009 & 027 & 011 \\
\hline 5 & BLY-G.80C & 018 & 004 & 010 & 005 & 027 & 012 \\
\hline 6 & BLY-G-114A & 017 & 004 & 005 & 012 & 011 & 010 \\
\hline 7 & BLZ-G-5B & 026 & 0103 & 007 & 010 & 055 & 011 \\
\hline 8 & BLZ-G-37A & 020 & 003 & 008 & 013 & 039 & 008 \\
\hline
\end{tabular}

\# For comparison only, does not apply to WTP glasses 
Table 6.11. Glass Pool Samples and Secondary Phase Observations.

\begin{tabular}{|c|c|c|c|c|c|}
\hline \multicolumn{2}{|r|}{ Test } & $\mathrm{T}\left({ }^{\circ} \mathrm{C}\right)$ & $\begin{array}{l}\text { Sampling } \\
\text { Date }\end{array}$ & Sanıple I+D. & $\begin{array}{c}\text { Visual Observations Upon } \\
\text { Sanı pling }\end{array}$ \\
\hline \multirow{2}{*}{1} & Before Test & \multirow{2}{*}{1200} & $2 / 4 / 08$ & BLX-D-50B & No Secondary Phase \\
\hline & End of Test & & $2 / 6 / 08$ & BLX-D-88A & No Secondary Phase \\
\hline 2 & Ensl of Test & 1150 & $2 / 9 / 08$ & BLX-D-119A & No Seandary Phase \\
\hline \multirow{2}{*}{3} & Before Test & \multirow{2}{*}{1200} & $5 / 3 / 08$ & BLX-D-125A & No Secondary Phase \\
\hline & End of Test & & $5 / 7 / 08$ & BLY-D-14A & No Secondary Phase \\
\hline 4 & End of Test & 1150 & $5 / 9108$ & BLY-D-36A & No Seandary Phase \\
\hline \multirow{2}{*}{5} & Before Test & \multirow{2}{*}{1200} & 6208 & BLY-D-46A & No Secondlary Phase \\
\hline & End of Test & & $6 / 4 / 08$ & BLY-D-84A & No Secondary Phase \\
\hline 6 & End of Tist & 1150 & $6 / 7 / 08$ & BLY-D-114A & No Seandary Phose \\
\hline 7 & End of Test & 1200 & $6: 25 / 08$ & BLZ-D-5.A & No Secondary Phase \\
\hline 8 & End of Test & 1150 & $6: 28 / 08$ & BLZ-D-40A & No Seoondary Phase \\
\hline
\end{tabular}


The Cathold Untwetsity of Amenca Vitreous State Laboratory
ORP-44236, Rev D

Melt Rate Enthancement for High Altmmnts HLW Glass Fomwlatrons

Final Report VSL-08R1360.1, Rev. 0

Table 7.1. Results from DM100 Off-Gas Emission Samples.

\begin{tabular}{|c|c|c|c|c|c|c|c|c|c|}
\hline & \multicolumn{4}{|c|}{ Test 1} & \multicolumn{4}{|c|}{ Test 2} \\
\hline & & \multicolumn{4}{|c|}{$\begin{array}{c}02061080929-1029 \\
1050 \% \text { Isokmetuc. } 131 \% \text { Molsture }\end{array}$} & \multicolumn{4}{|c|}{$\begin{array}{c}02 / 08081222-1322 \\
1022 \% \text { Isolinelic, } 85 \% \text { Moisture }\end{array}$} \\
\hline & & $\begin{array}{c}\text { Feed } \\
\text { Rete } \\
\text { (migimur) }\end{array}$ & $\begin{array}{c}\text { Enissions } \\
\text { Rate } \\
\text { (mg/min) }\end{array}$ & $\%$ Feed & DF & $\begin{array}{c}\text { Feed } \\
\text { Rate } \\
(m g / m i n)\end{array}$ & $\begin{array}{c}\text { Emissions } \\
\text { Rate } \\
\text { (mig/mıfi) }\end{array}$ & $\%$ Fèd & $\mathrm{DF}$ \\
\hline \multirow{22}{*}{ 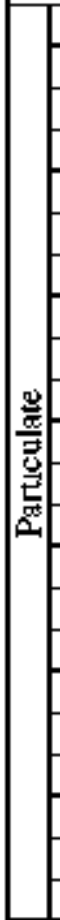 } & Total $^{5}$ & 110500 & 318 & 029 & 348 & 64440 & 647 & $\dot{010}$ & 995 \\
\hline & Al & 11413 & 165 & 014 & 692 & 6657 & 206 & 003 & 3235 \\
\hline & B & 4243 & 176 & 041 & 242 & 2475 & 260 & 011 & 951 \\
\hline & $\mathrm{Ba}$ & 40 & 025 & 063 & 158 & 24 & 027 & 115 & 868 \\
\hline & BI & 460 & 351 & 076 & 131 & 268 & 058 & 021 & 467 \\
\hline & Ca & 3911 & 850 & 022 & 460 & 2282 & 135 & 006 & 1691 \\
\hline & $\mathrm{Cd}$ & 16 & 039 & 239 & 419 & 9 & $<010$ & $\because 106$ & 294 \\
\hline & $\mathrm{Cl}^{*}$ & 0 & 046 & $\mathrm{NC}$ & $\mathrm{NC}$ & 0 & $\therefore 010$ & NC & NC \\
\hline & $\mathrm{Cr}$ & 320 & 325 & 101 & 986 & 187 & 098 & 052 & 191 \\
\hline & $F^{*}$ & 603 & 291 & 482 & 308 & 352 & 687 & 195 & 512 \\
\hline & $\mathrm{Fe}$ & 3713 & 145 & 039 & 256 & 2166 & 223 & 010 & 972 \\
\hline & $\mathrm{k}$ & 105 & 230 & 220 & 454 & $6]$ & 052 & 086 & 117 \\
\hline & $\mathrm{L}_{1}$ & 1493 & 691 & 046 & 216 & 871 & 144 & 017 & 603 \\
\hline & $\mathrm{Mg}$ & 65 & 064 & 099 & 101 & 38 & 011 & 030 & 336 \\
\hline & $\mathrm{Na}$ & 6397 & 385 & 060 & 166 & 3732 & 908 & 024 & 411 \\
\hline & $\mathrm{N}_{1}$ & 283 & 086 & 030 & 330 & 165 & $c 010$ & $\because 006$ & $>1650$ \\
\hline & $\mathrm{P}$ & 413 & 085 & 021 & 487 & 241 & 012 & 005 & 2008 \\
\hline & $\mathrm{Pb}$ & 343 & 238 & 069 & 144 & 200 & 055 & 028 & 361 \\
\hline & $S^{*}$ & 72 & 474 & 658 & 152 & 42 & 236 & 562 & 178 \\
\hline & $\mathrm{S}_{1}$ & 12832 & 193 & 015 & 664 & 7485 & 389 & 005 & 1926 \\
\hline & $Z_{\text {几 }}$ & 58 & 048 & 083 & 121 & 34 & 022 & 066 & 152 \\
\hline & $\mathrm{Zr}$ & 360 & 052 & 020 & 497 & 152 & $<010$ & 0007 & 21516 \\
\hline \multirow{4}{*}{ 参 } & B & 4243 & 539 & 127 & 788 & 2475 & 268 & 108 & 922 \\
\hline & $\mathrm{Cl}$ & 0 & 883 & $\mathrm{NC}$ & $\mathrm{NC}$ & 0 & 376 & NC & $\mathrm{NC}$ \\
\hline & $\mathrm{F}$ & 603 & 151 & 250 & 40 & 353 & 117 & 334 & 30 \\
\hline & $S$ & 72 & 254 & 353 & 28 & 42 & 980 & 233 & 43 \\
\hline
\end{tabular}

5 - From gravimetric analysis of filters and partıculate fitric acid rinses

* - Feed rate calculated from target composition and steady state production rate

* - Calculated from durect aralysis of mitric acid noses.

NA - Not Avallable

$\mathrm{NC}$ - Not Calculated 
The Cathold Untwetsity of Amenca Vitreous State Laboratory
ORP-44236, Rev 0

Melt Rate Enthancement for High Altmmnts HLW Glass Fomwlatrons

Final Report, VSL-08R1360.1, Rev, 0

Table 7.1. Results from DM100 Off-Gas Emission Samples (continued).

\begin{tabular}{|c|c|c|c|c|c|c|c|c|c|}
\hline & \multicolumn{4}{|c|}{ Test 3} & \multicolumn{4}{|c|}{ Test $\mathbf{4}$} \\
\hline & & \multicolumn{4}{|c|}{$\begin{array}{c}05 / 071080940-1040 \\
1058 \% \text { Isokmetic, } 136 \% \text { Molsture }\end{array}$} & \multicolumn{4}{|c|}{$\begin{array}{c}05 / 09.081043-1143 \\
1006 \% \text { Isokinetic, } 103 \% \text { Molsture }\end{array}$} \\
\hline & & $\begin{array}{c}\text { Feed } \\
\text { Rate } \\
\text { (mingimulis) }\end{array}$ & $\begin{array}{l}\text { Emissions } \\
\text { Rate } \\
\text { (mgimin) }\end{array}$ & $\%$ Feed & DF & $\begin{array}{c}\text { Fedd } \\
\text { Rate" } \\
\text { (mo/min) }\end{array}$ & $\begin{array}{c}\text { Emissions } \\
\text { Rate } \\
\text { (mis/miti) }\end{array}$ & $\%$ Feed & $\mathrm{DF}$ \\
\hline \multirow{22}{*}{ - } & Total ${ }^{3}$ & $12\{(N) 0$ & 172 & 014 & 712 & $8321 m !$ & 326 & ign & 2550 \\
\hline & $\mathrm{Al}$ & 13915 & 788 & 006 & 1638 & 8764 & 073 & 001 & 12037 \\
\hline & $\mathrm{B}$ & 5778 & 849 & 015 & 688 & 3920 & 954 & 901 & 7197 \\
\hline & $\mathrm{Ba}$ & 47 & 016 & 0.34 & 296 & 32 & ô11 & 036 & 279 \\
\hline & $\mathrm{B}_{1}$ & 523 & 335 & 064 & 156 & 355 & 035 & 010 & 1005 \\
\hline & $\mathrm{Ca}$ & 4421 & 209 & 005 & 2116 & $3(\omega) 0$ & 031 & og1 & 9773 \\
\hline & Cd & 19 & 0.36 & 190 & 527 & 13 & s: 110 & $\therefore 078$ & $>128$ \\
\hline & $\mathrm{Cl}^{*}$ & 0 & 190 & $\mathrm{NC}$ & $\mathrm{NC}$ & 0 & 125 & $\mathrm{NC}$ & $\mathrm{NC}$ \\
\hline & $\mathrm{Cr}$ & 366 & 311 & 085 & 118 & 249 & 954 & 622 & 462 \\
\hline & $\mathrm{F}^{*}$ & 683 & 186 & 272 & 368 & 463 & 733 & 158 & 632 \\
\hline & $\mathrm{Fe}$ & 4200 & 403 & 010 & 1042 & 2850 & 067 & 00 & 4343 \\
\hline & $\mathrm{K}$ & 122 & 123 & 100 & 996 & 83 & 925 & 931 & 328 \\
\hline & $\mathrm{LI}_{\mathrm{I}}$ & 1684 & 374 & 021 & 431 & 1145 & 069 & ging & 1651 \\
\hline & $\mathrm{Mg}$ & 70 & 024 & 034 & 293 & 47 & $<010$ & $\because 021$ & $>473$ \\
\hline & $\mathrm{Na}$ & 7237 & 217 & 030 & 334 & 4911 & 592 & 910 & 978 \\
\hline & $\mathrm{N}_{1}$ & 322 & 012 & 004 & 2791 & 218 & $\varepsilon 010$ & $\because 005$ & $\approx 2184$ \\
\hline & $\mathrm{P}$ & 468 & 015 & 003 & 3202 & 317 & $\varepsilon 010$ & $\because 003$ & $>3173$ \\
\hline & $\mathrm{Pb}$ & 300 & 215 & 055 & 181 & 265 & 937 & 614 & 712 \\
\hline & $\mathrm{S}^{*}$ & 89 & $6 \geq 3$ & 779 & 128 & 54 & 2(n) & 379 & 27 \\
\hline & $\mathrm{S}_{1}$ & 14519 & 627 & 004 & 2317 & 9852 & 110 & 001 & 8970 \\
\hline & $Z_{n}$ & 67 & 0.31 & 046 & 218 & 46 & 927 & 958 & 171 \\
\hline & $\mathrm{Z} \mathbf{r}$ & 295 & 024 & 008 & 1221 & 200 & $=010$ & $\because 005$ & $\Rightarrow 2 \operatorname{ling}$ \\
\hline \multirow{4}{*}{$\begin{array}{l}\mathscr{0} \\
5\end{array}$} & $\mathrm{~B}$ & $5778^{2}$ & 823 & 142 & 702 & 3920 & 191 & 049 & 205 \\
\hline & \% & 0 & 837 & $\mathrm{NC}$ & $\mathrm{NC}$ & 0 & 626 & $\mathrm{NC}$ & $\mathrm{NC}$ \\
\hline & $\mathrm{F}$ & 683 & 206 & 3012 & 33 & 463 & 884 & 191 & 52 \\
\hline & $\mathrm{S}$ & 80 & 386 & 483 & 21 & 54 & 166 & 306 & 33 \\
\hline
\end{tabular}

- From gravimetric analysis of filters and particulate fitric acid rinses

* - Feed rate calculated from target composition and steady state production rate

* - Calculated from disect analysis of nitnc acid nnses

NC - Not Calculated 
The Cathold Untwetsity of Amenca Vitreous State Laboratory
ORP-44236, Rev D

Melt Rate Enthancement for High Altmmnts HLW Glass Fomwlatrons

Final Report VSL-08R1360.1, Rev. 0

Tahle 7.1. Results from DM100 Off-Gas Enission Samples (continued).

\begin{tabular}{|c|c|c|c|c|c|c|c|c|c|}
\hline & \multicolumn{4}{|c|}{ Test 5} & \multicolumn{4}{|c|}{ Test 6} \\
\hline & & \multicolumn{4}{|c|}{$\begin{array}{c}0604 / 081125-1225 \\
1028 \% \text { Isokmetic, } 143 \% \text { Molsture }\end{array}$} & \multicolumn{4}{|c|}{$\begin{array}{c}0606 i 081250-1350 \\
969 \% \text { Isokinettc, } 86 \% \text { Molsture }\end{array}$} \\
\hline & & $\begin{array}{c}\text { Feed } \\
\text { Rate } \\
\text { (nIg/mm) }\end{array}$ & $\begin{array}{c}\text { Enissions } \\
\text { Rate } \\
\text { (mg/min) }\end{array}$ & $\%$ Feed & $\mathrm{DF}$ & $\begin{array}{c}\text { Feed } \\
\text { Rate } \\
\text { (mg/mun) }\end{array}$ & $\begin{array}{c}\text { Emissions } \\
\text { Rate } \\
\text { (mgimin) }\end{array}$ & $\%$ Ferd & $\mathrm{DF}$ \\
\hline \multirow{22}{*}{ 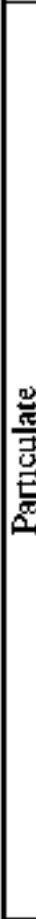 } & Total $1^{5}$ & 108900 & 144 & 013 & 756 & 58700 & 403 & 007 & 1457 \\
\hline & $\mathrm{Al}$ & 11992 & 311 & 003 & 3853 & 6457 & 074 & 001 & 8715 \\
\hline & $\mathrm{B}$ & 5365 & 737 & 014 & 728 & 2889 & 165 & 006 & 1751 \\
\hline & $\mathrm{Ba}$ & 44 & $\therefore 010$ & $<023$ & $\therefore 437$ & 24 & $<010$ & $\because 043$ & $>235$ \\
\hline & $\mathrm{B}_{1}$ & 485 & 237 & 049 & 204 & 261 & 035 & 013 & 742 \\
\hline & $\mathrm{Ca}$ & 4105 & 202 & 005 & 2037 & 2210 & 049 & 002 & 4481 \\
\hline & Cd & 17 & 020 & 112 & 891 & 9 & $<010$ & $\because 106$ & $\therefore 94$ \\
\hline & $\mathrm{Cl}^{*}$ & 0 & 138 & $\mathrm{NC}$ & $\mathrm{NC}$ & 0 & 937 & $\mathrm{NC}$ & $\mathrm{NC}$ \\
\hline & $\mathrm{Cr}$ & 340 & 247 & 073 & 138 & 183 & 068 & 037 & 269 \\
\hline & $\mathrm{Ft}^{4}$ & 634 & 199 & 314 & 319 & 341 & 553 & 162 & 617 \\
\hline & $\mathrm{Fe}$ & 3900 & 447 & 011 & 873 & 2100 & 116 & 006 & 1818 \\
\hline & $\mathrm{k}$ & 113 & 095 & 084 & 119 & $6]$ & 024 & 039 & 258 \\
\hline & $L_{1}$ & 1567 & 357 & 023 & 439 & 844 & 094 & 011 & 899 \\
\hline & $\mathrm{Mg}$ & 65 & 016 & 025 & 398 & 35 & $<010$ & $\because 029$ & $>348$ \\
\hline & $\mathrm{Na}$ & 6730 & 188 & 028 & 357 & 3619 & 545 & 015 & 664 \\
\hline & $\mathrm{N}_{1}$ & 299 & $<010$ & $\angle 003$ & $=2988$ & 161 & $\because 010$ & $\because 006$ & $\therefore 1609$ \\
\hline & $\mathrm{P}$ & 434 & 010 & 002 & 4190 & 234 & $c 010$ & $\because 004$ & $\therefore 2338$ \\
\hline & $\mathrm{Pb}$ & 362 & 148 & 041 & 345 & 195 & 033 & 017 & 591 \\
\hline & $5^{4}$ & 74 & 608 & 822 & 122 & 40 & 184 & 460 & 217 \\
\hline & $\mathrm{S}_{1}$ & 13482 & 407 & 003 & 3316 & 7360 & 101 & 001 & 7173 \\
\hline & $\mathrm{Zn}$ & 63 & 020 & 031 & 320 & 34 & 012 & 036 & 280 \\
\hline & $\mathrm{Zr}$ & 274 & 024 & 009 & 1136 & 148 & $<010$ & $\because 007$ & $\therefore 1477$ \\
\hline \multirow{4}{*}{ 管 } & B & 5363 & 653 & 122 & 821 & 2889 & 197 & 068 & 147 \\
\hline & $\mathrm{Cl}$ & 0 & 794 & $\mathrm{NC}$ & $\mathrm{NC}$ & 0 & 595 & NC & $\mathrm{NC}$ \\
\hline & $F$ & 634 & 206 & 326 & 31 & 341 & 810 & 237 & 42 \\
\hline & $\mathrm{S}$ & 74 & 261 & 352 & 28 & 40 & 140 & 351 & 28 \\
\hline
\end{tabular}

- From gravumetric analysis of filters and particulate nitnc acid nnses

\# - Feed rate colculated from target composition and steady state production rate

* - Calculated from direct analysis of nitric acid noses

NC - Not Calculated 
The Cathold Untwetsity of Amenca Vitreous State Laboratory
ORP-44236, Rev D

Melt Rote Esthancement for High dituminum HLW Glass Fomwlatrons

Final Report VSL-08R1360.1, Rev. 0

Tahle 7.1. Results from DM100 Off-Gas Enission Samples (continued).

\begin{tabular}{|c|c|c|c|c|c|c|c|c|c|}
\hline & \multicolumn{4}{|c|}{ Test ? } & \multicolumn{4}{|c|}{ Test 8} \\
\hline & & \multicolumn{4}{|c|}{$\begin{array}{c}6 / 24 / 081944-2044 \\
985 \% \text { Isokmetic, } 146 \% \text { Molsture }\end{array}$} & \multicolumn{4}{|c|}{$\begin{array}{c}06 / 27 / 08 / 081726-1826 \\
1035 \% \text { Isokınetıc, } 104 \% \text { Molsture }\end{array}$} \\
\hline & & $\begin{array}{c}\text { Feed } \\
\text { Rate" } \\
\text { (mg/nin) }\end{array}$ & $\begin{array}{c}\text { Emissions } \\
\text { Rate } \\
\text { (mg/min) }\end{array}$ & $\%$ Fred & DF & $\begin{array}{c}\text { Feed } \\
\text { Rate } \\
\text { (mig/mon) }\end{array}$ & $\begin{array}{c}\text { Enissions } \\
\text { Rate } \\
\text { (mg/min) }\end{array}$ & $\%$ Feed & $\mathrm{DF}$ \\
\hline \multirow{22}{*}{ 袤 } & Total & 138200 & 171 & 012 & 806 & 87500 & 452 & 005 & 1938 \\
\hline & Al & 14366 & 138 & 010 & 1038 & 9035 & 277 & 003 & 3261 \\
\hline & B & 6700 & 858 & 013 & 781 & 4243 & 199 & 005 & 2127 \\
\hline & $\mathrm{Ba}$ & 50 & $<010$ & $<020$ & $>504$ & 32 & $<010$ & $<031$ & $>319$ \\
\hline & $\mathrm{B}_{\mathbf{I}}$ & 575 & 256 & 044 & 225 & 364 & 050 & 014 & 736 \\
\hline & $\mathrm{Ca}$ & 4487 & 242 & 005 & 1852 & 2843 & 047 & 002 & 6086 \\
\hline & $\mathrm{Cd}$ & 20 & 014 & 071 & 141 & 13 & $<010$ & $<078$ & $\div 128$ \\
\hline & $\mathrm{Cl}^{*}$ & 0 & 021 & $\mathrm{NC}$ & $\mathrm{NC}$ & 0 & 879 & $\mathrm{NC}$ & $\mathrm{NC}$ \\
\hline & $\mathrm{Cr}$ & 400 & 194 & 048 & 207 & 254 & 077 & 030 & 329 \\
\hline & $F^{*}$ & 754 & 193 & 256 & 391 & 477 & 553 & 116 & 863 \\
\hline & $\mathrm{Fe}$ & 4641 & 409 & i) 0 & 1136 & 2939 & 091 & 003 & 3235 \\
\hline & $\mathrm{K}$ & 13] & 119 & 091 & 110 & 83 & 040 & 048 & 208 \\
\hline & L1 & 1866 & 348 & 019 & 537 & 1182 & 111 & 009 & 1065 \\
\hline & $\mathrm{Mg}$ & 81 & 022 & 027 & 369 & 52 & $<010$ & $<019$ & 2516 \\
\hline & $\mathrm{Na}$ & 7996 & 201 & 025 & 399 & 5064 & 738 & 015 & 686 \\
\hline & $\mathrm{N}_{1}$ & 354 & 029 & 008 & 1219 & 224 & $<010$ & $<004$ & $>2240$ \\
\hline & $\mathbf{P}$ & 516 & 041 & 008 & 1258 & 327 & 038 & 012 & 857 \\
\hline & $\mathrm{Pb}$ & 438 & 108 & 025 & 395 & 271 & 039 & 014 & 701 \\
\hline & $s^{*}$ & 90 & 441 & 490 & 204 & 57 & 160 & 281 & 356 \\
\hline & $\mathrm{S}_{1}$ & 14199 & 642 & 005 & 2211 & 8993 & 156 & 002 & 5776 \\
\hline & $\mathrm{Zn}_{1}$ & 72 & 010 & 014 & 700 & 46 & $\therefore 010$ & $=022$ & $=458$ \\
\hline & $\mathrm{Zr}$ & 325 & 015 & 005 & 2209 & 206 & $<010$ & $<005$ & $>2057$ \\
\hline \multirow{4}{*}{ 吠 } & $\mathrm{B}$ & 6700 & 552 & 082 & 121 & 4243 & 241 & 057 & 176 \\
\hline & $\mathrm{Cl}$ & 0 & 148 & $\mathrm{NC}$ & NC & 0 & 876 & NC & $\mathrm{NC}$ \\
\hline & $\mathbf{F}$ & 754 & 175 & 232 & 43 & 477 & 999 & 209 & 48 \\
\hline & $S$ & 90 & 409 & 454 & 23 & 57 & 154 & 270 & 37 \\
\hline
\end{tabular}

3. From gravunetric analysis of filters and particulate nitnc acid nnses

\# - Feed rate calculated from target compositjon and stegdy state production rate

* - Calculated from direct aralysis of nitric acid nonses

NC - Not Calculated 
The Cathold Untwetsity of Amenca Vitreous State Laboratory
ORP-44236, Rev D

Melt Rate Enthancement for High Altmmnts HLW Glass Fomwlatrons

Final Report VSL-08R1360.1, Rev. 0

Table 7.2. Results from DM1200 Off-Gas Emission Samples.

\begin{tabular}{|c|c|c|c|c|c|c|c|c|c|}
\hline & \multicolumn{4}{|c|}{ Test 1} & \multicolumn{4}{|c|}{ Test 3} \\
\hline & & \multicolumn{4}{|c|}{$\begin{array}{c}08: 07 / 081918-2018 \\
1084 \% \text { Isokmetic, 39 } 4 \% \text { Molsture }\end{array}$} & \multicolumn{4}{|c|}{$\begin{array}{c}08 i 121081310-1410 \\
969 \% \text { Isokmetic, } 292 \% \text { Moisture }\end{array}$} \\
\hline & & $\begin{array}{c}\text { Feed } \\
\text { Rate } \\
\text { (nig/mun) }\end{array}$ & $\begin{array}{c}\text { Enissions } \\
\text { Rate } \\
\text { (mg/min) }\end{array}$ & $\%$ Feed & DF & $\begin{array}{c}\text { Feed } \\
\text { Rate } \\
\text { (mg/mu) }\end{array}$ & $\begin{array}{c}\text { Emissions } \\
\text { Rate } \\
\text { (mgimin) }\end{array}$ & $\%$ Fedd & $\mathrm{DF}$ \\
\hline \multirow{22}{*}{ 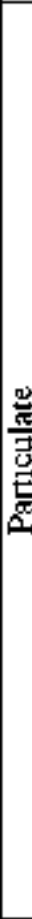 } & Total $^{5}$ & $1 \leq 69000$ & 2453 & 016 & 640 & 1109000 & 1114 & 010 & 995 \\
\hline & $\mathrm{Al}$ & 158508 & 116 & 007 & 1367 & 110955 & 505 & 005 & 2194 \\
\hline & $\mathrm{B}$ & 58927 & 137 & 023 & 430 & 41249 & 599 & 015 & 689 \\
\hline & $\mathrm{Ba}$ & 560 & 265 & 047 & 211 & 392 & 069 & 018 & 564 \\
\hline & $\mathrm{B}_{1}$ & 6391 & 266 & 042 & 240 & 4474 & 131 & 029 & 341 \\
\hline & $\mathrm{Ca}$ & 54324 & 535 & 010 & 1016 & 38027 & 227 & 006 & 1675 \\
\hline & Cd & 224 & 219 & 098 & 102 & 157 & 070 & 044 & 225 \\
\hline & $\mathrm{Cl}^{*}$ & 0 & 141 & $\mathrm{NC}$ & $\mathrm{NC}$ & 0 & 950 & $\mathrm{NC}$ & $\mathrm{NC}$ \\
\hline & $\mathrm{Cr}$ & 4447 & 247 & 055 & 180 & 3113 & $15]$ & 048 & 207 \\
\hline & $\mathrm{F}^{4}$ & 8375 & 332 & 397 & 252 & 5863 & 211 & 360 & 278 \\
\hline & $\mathrm{Fe}$ & 51570 & 111 & 021 & 466 & 36099 & 490 & 014 & 737 \\
\hline & $\mathrm{k}$ & 1453 & 162 & 111 & 897 & 1017 & 847 & 083 & 120 \\
\hline & $L_{1}$ & 20729 & 463 & 022 & 448 & 14511 & 218 & 015 & 667 \\
\hline & $\mathrm{Mg}$ & 904 & 561 & 062 & 161 & 633 & 227 & 036 & 2784 \\
\hline & $\mathrm{Na}$ & 88847 & 310 & 035 & 287 & 62193 & 141 & 023 & 441 \\
\hline & $\mathrm{N}_{1}$ & 3929 & 445 & 011 & 883 & 2750 & 214 & 008 & 1285 \\
\hline & $\mathrm{P}$ & 5731 & 741 & 013 & 773 & 4011 & 327 & 008 & 1326 \\
\hline & $\mathrm{Pb}$ & 4758 & 154 & 032 & 308 & 3330 & 891 & 027 & 374 \\
\hline & $5^{4}$ & 1002 & 795 & 793 & 126 & 701 & 273 & 389 & 257 \\
\hline & $\mathrm{S}_{1}$ & 178321 & 130 & 007 & 1368 & 124755 & 601 & 005 & 3074 \\
\hline & $\mathrm{Zn}$ & 803 & 301 & 037 & 367 & 562 & 115 & 030 & 489 \\
\hline & $\mathrm{Zr}$ & 3609 & 279 & 008 & 1294 & 2526 & 112 & 004 & 2263 \\
\hline \multirow{4}{*}{ 答 } & B & 58927 & 846 & 144 & 697 & 41249 & 4418 & 107 & 934 \\
\hline & $\mathrm{Cl}$ & 0 & 168 & $\mathrm{NC}$ & $\mathrm{NC}$ & 0 & 836 & NC & $\mathrm{NC}$ \\
\hline & $F$ & 8375 & 1914 & 229 & 44 & 5863 & 1091 & 186 & 54 \\
\hline & $\mathrm{S}$ & $10 \mathrm{j} 2$ & 241 & 241 & 42 & 701 & 181 & 258 & 39 \\
\hline
\end{tabular}

3. From gravumetric analysis of filters and particulate nitnc acid nnses

\# - Feed rate calculated from target composition and steady state production rate

* - Calculated from direct analysis of nitric acid noses

NC - Not Calculated 
The Cathold Untwetsity of Amenca Vitreous State Laboratory'
ORP-44236, Rev D

Melt Rate Enthancement for High Altmmnts HLW Glass Fomwlatrons

Final Report VSL-08R1360.1, Rev. 0

Table 7.2. Results from DM1200 Off-Gas Entission Samples (continued).

\begin{tabular}{|c|c|c|c|c|c|}
\hline & \multicolumn{4}{|c|}{$\begin{array}{c}\text { Test } 3 \\
08: 14081318-1350 \\
696 \% \text { [solinetıc, } 269 \% \text { Molsture }\end{array}$} \\
\hline & & $\begin{array}{c}\text { Feed } \\
\text { Rate } \\
\text { (mosimtin) }\end{array}$ & $\begin{array}{l}\text { Emissions } \\
\text { Rate } \\
\text { (mimg/mini) }\end{array}$ & $\%$ Feed & $D F$ \\
\hline \multirow{22}{*}{ 起 } & Total ${ }^{3}$ & $(1120)(4) 0$ & 2351 & 021 & 477 \\
\hline & A1 & 110955 & 126 & 011 & 881 \\
\hline & $\mathrm{B}$ & 41249 & 152 & 037 & 271 \\
\hline & $\mathrm{Ba}$ & 392 & 155 & 040 & 253 \\
\hline & $\mathrm{B}_{1}$ & 4474 & 279 & 062 & 160 \\
\hline & $\mathrm{Ca}$ & 38027 & 597 & 016 & 637 \\
\hline & $\mathrm{cd}$ & 157 & 100 & 069 & $14 d$ \\
\hline & $\mathrm{Cl}^{*}$ & 0 & 523 & $\mathrm{NC}$ & NC \\
\hline & $\mathrm{Cr}$ & 3113 & 192 & 062 & 162 \\
\hline & $\mathrm{F}^{*}$ & 5863 & 351 & 509 & 167 \\
\hline & Fe & 36099 & 109 & 030 & 330 \\
\hline & $\mathrm{K}$ & 1017 & 146 & 143 & 699 \\
\hline & $\overline{\mathrm{L}_{1}}$ & 14511 & 383 & 026 & 379 \\
\hline & $\mathrm{Mg}$ & 633 & 482 & 076 & 131 \\
\hline & $\mathrm{Na}$ & 62193 & 302 & 049 & 306 \\
\hline & $\mathrm{N}_{1}$ & 2750 & 492 & 018 & 539 \\
\hline & $\bar{P}$ & 4011 & 712 & 018 & 5,4 \\
\hline & $\mathrm{Pb}$ & 3330 & 127 & 038 & 263 \\
\hline & $\mathrm{S}^{*}$ & 7i)1 & $\sin 7$ & 724 & 138 \\
\hline & $S_{1}$ & 124755 & 146 & 012 & 852 \\
\hline & Zn & 562 & $220^{\circ}$ & 039 & 255 \\
\hline & $\mathrm{Zr}$ & 2526 & 247 & 010 & 1023 \\
\hline \multirow{4}{*}{5} & $\bar{B}$ & 41249 & 539 & 131 & 765 \\
\hline & $\mathrm{Cl}$ & 0 & 107 & NC & $\mathrm{NC}$ \\
\hline & $\bar{F}$ & 5863 & 1459 & 249 & 40 \\
\hline & $S$ & 701 & 329 & 326 & 31 \\
\hline
\end{tabular}

- From gravimetric analysis of filters and particulate fittric acsel rinses

\# - Feed rate calculated from target composition and steady state production rate

* - Calculated from disect antalysis of nitric acid rinses

NC - Not Calculated 
Table 7.3. Concentrations (ppmv) of Selected Species in DM100 Exhaust Measured by FTIR Spectroscopy.

\begin{tabular}{|c|c|c|c|c|c|c|c|c|}
\hline & \multicolumn{2}{|r|}{1} & \multicolumn{2}{|r|}{2} & \multicolumn{2}{|r|}{3} & \multicolumn{2}{|r|}{4} \\
\hline & $\mathrm{AYB}$ & Range & AYg & Range & Aqg & Rarye & Avg & Range \\
\hline $\mathrm{N}_{2} \mathrm{O}$ & 11 & $<10-15$ & $\therefore 10$ & $\therefore 10-12$ & $\therefore 10$ & $<10-15$ & $<10$ & $\therefore 10-19$ \\
\hline NO & 880 & $10-410$ & 513 & $52-232$ & 840 & $<10-248$ & 599 & $11-250$ \\
\hline $\mathrm{NO}_{2}$ & 50 & $\approx 10.535$ & 41 & $\varepsilon=10.373$ & 63 & $\approx 10.464$ & 89 & $\therefore=10-7] 0$ \\
\hline $\mathrm{NH}_{3}$ & $\therefore 10$ & NA & $\therefore 10$ & NA & $\therefore 10$ & NA & $<10$ & NA \\
\hline $\mathrm{H}_{2} \mathrm{O}[\%]$ & 70 & $08-222$ & 43 & $13-145$ & 74 & $23-191$ & 63 & $99-178$ \\
\hline $\mathrm{CO}_{2}$ & 1337 & $352-4952$ & 1078 & $382-3803$ & 1629 & $92 \cdot 3690$ & 1340 & $56-4179$ \\
\hline $\begin{array}{l}\text { Nitrous } \\
\text { Acid }\end{array}$ & $\because 10$ & NA & $\therefore 10$ & $\mathrm{NA}$ & $\therefore 10$ & NA & $<10$ & NA \\
\hline $\begin{array}{l}\text { Nitric } \\
\text { Acid }\end{array}$ & $\therefore 10$ & NA & $\therefore 10$ & NA & $\therefore 0$ & NA & $<10$ & NA \\
\hline $\mathrm{HCN}$ & $\therefore 10$ & NA & $\therefore 10$ & NA & $\therefore 10$ & NA & $<10$ & NA \\
\hline $\mathrm{SO}_{2}$ & 41 & 410.88 & 19 & $<10.79$ & 34 & $\therefore=10.97$ & 23 & $\therefore 10-61$ \\
\hline $\mathrm{CO}$ & $\therefore 10$ & $<10.29$ & $\therefore 10$ & $<10-701$ & $\because 10$ & $<10.34$ & $<10$ & $\angle 10.28$ \\
\hline $\mathrm{HCl}$ & $\therefore 10$ & $210-21$ & $\therefore 10$ & $\because 10-12$ & 10 & $<10-25$ & $<10$ & $\therefore 10-24$ \\
\hline $\mathrm{HF}$ & 135 & $<10.414$ & 172 & 96.384 & 155 & 13.306 & 221 & $78-373$ \\
\hline
\end{tabular}

NA Not applicable 
Table 7.3. Concentrations (ppmv) of Selected Species in DM100 Exhaust Measured by FTIR Spectroscopy (continued).

\begin{tabular}{|c|c|c|c|c|c|c|c|c|}
\hline & \multicolumn{2}{|r|}{5} & \multicolumn{2}{|r|}{6} & \multicolumn{2}{|r|}{7} & \multicolumn{2}{|r|}{8} \\
\hline & Avg & Range & AVg & Range & Avg & Range & Avg & Ratge \\
\hline $\mathrm{N}_{2} \mathrm{O}$ & $<10$ & $<10-10$ & $<10$ & $\therefore 19-12$ & $<10$ & $<10-28$ & $<10$ & $<10-29$ \\
\hline $\mathrm{NO}$ & 504 & $\therefore 10-270$ & 318 & $<10-254$ & 868 & $367-307$ & 554 & $22-282$ \\
\hline $\mathrm{NO}_{2}$ & 32 & $\therefore=10.549$ & 25 & $\therefore=10.730$ & 69 & $<10.517$ & 54 & $\Leftrightarrow=10.525$ \\
\hline $\mathrm{NH}_{3}$ & $\therefore 10$ & NA & $<10$ & $\therefore 10.92$ & $\angle 10$ & NA & $<10$ & NA \\
\hline $\mathrm{H}_{2} \mathrm{O}[\%]$ & 46 & $20-102$ & $4 !$ & $18-110$ & 75 & $36-160$ & 56 & $15-146$ \\
\hline $\mathrm{CO}_{2}$ & 1073 & $\therefore 10-3402$ & 790 & $\therefore 10-3860$ & 1836 & $922-5169$ & 1336 & $369-5208$ \\
\hline Nitrous Acyd & $\therefore 10$ & $\mathrm{NA}$ & $<10$ & $\mathrm{NA}$ & $<10$ & NA & $<10$ & NA \\
\hline NItIIc AcId & $<10$ & NA & $<10$ & $\therefore 10-39$ & $<10$ & NA & $<10$ & NA \\
\hline $\mathrm{HCN}$ & $\therefore 10$ & $\mathrm{NA}$ & $<10$ & NA & $\therefore 10$ & NA & $<10$ & NA \\
\hline $\mathrm{SO}_{2}$ & 22 & 10.90 & 12 & $\Leftrightarrow 10.302$ & 60 & $11 \cdot 142$ & 36 & $<10.165$ \\
\hline 6 & $<10$ & $r 10-10$ & $<10$ & $\therefore 19-16$ & $<10$ & $<14-32$ & $<10$ & $\therefore 10-31$ \\
\hline $\mathrm{HCl}$ & $<10$ & $\because 10.12$ & $<10$ & $\therefore 10.20$ & 15 & 15.30 & $<10$ & $\therefore 10.14$ \\
\hline$\overline{\mathrm{HF}}$ & 86 & $22-157$ & 119 & $81-254$ & 293 & $95-419$ & 239 & $179-340$ \\
\hline
\end{tabular}

NA Not applicable 
Table 7.4 Concentrations [ppniv| of Selected Species in DM1200 Test 1 Exhaust Measured by FTIR Spectroscopy.

\begin{tabular}{|c|c|c|c|c|c|c|c|c|c|}
\hline & \multicolumn{3}{|c|}{ Melter outlet } & \multicolumn{3}{|c|}{ WESP outlet } & \multicolumn{3}{|c|}{ PBS outlet } \\
\hline & Aver & Mun & Max & $A y^{\prime}$ & Mun & Max & Ay't & Mins & Max \\
\hline $\mathrm{N}_{2} \mathrm{O}$ & 13 & 07 & 20 & 16 & $\therefore 10$ & 109 & 14 & $<10$ & 17 \\
\hline No & 594 & 361 & 751 & 611 & 123 & 1313 3 & 520 & 260 & 636 \\
\hline $\mathrm{NO}_{2}$ & 686 & 441 & 789 & 120 & $\therefore 10$ & 424 & 106 & 548 & 136 \\
\hline $\mathrm{NH}_{3}$ & $\therefore 10$ & $<10$ & $\therefore 10$ & $\therefore 10$ & $\therefore 10$ & 410 & $\therefore 10$ & $<10$ & $<10$ \\
\hline $\mathrm{H}_{2} \mathrm{O} \%$ & 329 & 272 & 352 & 85 & 16 & 161 & 36 & 31 & 38 \\
\hline $\mathrm{CO}_{2} \%$ & 073 & 047 & 078 & 075 & 001 & 189 & 079 & 042 & 095 \\
\hline Netrous Acid & 17 & 12 & 20 & 24 & $=10$ & 72 & $\therefore 10$ & 10 & $<10$ \\
\hline Nitric Ac1d & 14 & 02 & 20 & 15 & $<10$ & 51 & $\therefore 10$ & $\therefore 10$ & $<10$ \\
\hline $\mathrm{HCN}$ & $<10$ & $<10$ & $\because 10$ & $\therefore 10$ & $\therefore 10$ & 32 & $\therefore 0$ & $\div 10$ & $<10$ \\
\hline $\mathrm{SO}_{2}$ & 51 & 33 & 73 & $\therefore 10$ & $\therefore 10$ & 70 & $\therefore 0$ & $<10$ & $<10$ \\
\hline $\mathrm{CO}$ & 25 & 20 & 30 & 29 & $<10$ & 154 & 50 & 10 & 30 \\
\hline $\mathrm{HCl}$ & $<10$ & $<10$ & $\because 10$ & $\therefore 10$ & $\therefore 10$ & $\therefore 10$ & $\therefore 10$ & $\therefore 10$ & $<10$ \\
\hline $\mathrm{HF}$ & 146 & 109 & 163 & 45 & 10 & 78 & 35 & 23 & 28 \\
\hline
\end{tabular}


Table 7.5. Concentrations [ppnv] of Selected Species in DM1200 Test 2 Exhaust Measured by FTIR spectroscopy.

\begin{tabular}{|c|c|c|c|c|c|c|c|c|c|c|c|c|}
\hline & \multicolumn{3}{|c|}{ Melter outlet } & \multicolumn{3}{|c|}{ SBS outlet } & \multicolumn{3}{|c|}{ tWESP outlet } & \multicolumn{3}{|c|}{ PBS outlet } \\
\hline & Ayer & Min & $\operatorname{Mkx}$ & Ayer & $\mathrm{M}$ In & Max & Ayer & Mun & $\operatorname{Max}$ & Ayer & Mun & Max \\
\hline $\mathrm{N}_{2} \mathrm{O}$ & 19 & $<10$ & 18 & 23 & 16 & 55 & 15 & $<10$ & 49 & 20 & $\therefore 10$ & 43 \\
\hline $\mathrm{NO}$ & 459 & 75 & 659 & 561 & 364 & 926 & 397 & 85 & 927 & 399 & 243 & 70)4 \\
\hline $\mathrm{NO}_{2}$ & 736 & 286 & 130 & 107 & 659 & 264 & 927 & 229 & 321 & 902 & 363 & 186 \\
\hline $\mathrm{NH}_{3}$ & $\therefore 10$ & $\leqslant 10$ & 16 & 40 & $\therefore 10$ & $\therefore 0$ & $\therefore 10$ & $\therefore 10$ & $<10$ & $<0$ & $\therefore 10$ & $\therefore 10$ \\
\hline $\mathrm{H}_{2} \mathrm{O} \%$ & 323 & 269 & 535 & 79 & 75 & 83 & 69 & 55 & 110 & 32 & 30 & 46 \\
\hline $\mathrm{CO}_{2} \%$ & 083 & 062 & 115 & 077 & 056 & 127 & 059 & 023 & 123 & 060 & 039 & 106 \\
\hline Nutrous Acrd & $\therefore 10$ & $<10$ & 20 & 13 & 10 & 27 & 14 & $\therefore 10$ & 44 & $<10$ & $\therefore 10$ & $\therefore 10$ \\
\hline Nituıc Acıl & $\therefore 10$ & $\therefore 10$ & 13 & $<10$ & $\therefore 10$ & 18 & $\therefore 10$ & $<10$ & 24 & $<10$ & $\therefore 10$ & 93 \\
\hline HCWN & $\therefore 0$ & $<10$ & $\therefore 10$ & 810 & $<10$ & $<10$ & $\therefore 0$ & $<10$ & $\therefore 10$ & $\therefore 10$ & $\therefore 10$ & $<10$ \\
\hline $\mathrm{SO}_{2}$ & 183 & 106 & 233 & 78 & 44 & 110 & 45 & $<10$ & 95 & 26 & $<10$ & 59 \\
\hline $\mathrm{CO}$ & 59 & 15 & 987 & 58 & 24 & 837 & 33 & $<10$ & 223 & 50 & 10 & 140 \\
\hline $\mathrm{HCl}$ & $\angle 10$ & $<10$ & 52 & $\varepsilon: 10$ & $\angle 10$ & $c: 10$ & $\angle 10$ & $\angle 10$ & 12 & $\therefore: 10$ & $\angle 10$ & 154 \\
\hline $\mathrm{HF}$ & 208 & 97 & 548 & 99 & 93 & 103 & 58 & 28 & 122 & 61 & 45 & 284 \\
\hline
\end{tabular}


Table 7.6. Concentrations [ppntv] of Selected Species in DM1200 Test 3 Exhaust Measured by FTIR spectroscopy.

\begin{tabular}{|c|c|c|c|c|c|c|c|c|c|c|c|c|}
\hline & \multicolumn{3}{|c|}{ Melter outlet } & \multicolumn{3}{|c|}{ SBS outlet } & \multicolumn{3}{|c|}{ WESP outlet } & \multicolumn{3}{|c|}{ PBS outlet } \\
\hline & Aqer & $\mathrm{Mm}$ & Max & Ayer & $\mathrm{M} / \mathrm{m}$ & Max & Aver & $\mathrm{M} m$ & $\operatorname{Max}$ & Ayer & Min & Max \\
\hline $\mathrm{N}_{2} \mathrm{O}$ & 15 & 12 & 17 & 26 & 13 & 42 & 21 & $\therefore 10$ & 119 & 23 & $<10$ & 62 \\
\hline $\mathrm{NO}$ & 423 & 276 & 673 & 559 & 235 & 778 & 415 & 118 & 631 & 375 & $<10$ & $7 \geq 5$ \\
\hline $\mathrm{NO}_{2}$ & 690 & 545 & 776 & 105 & 419 & 206 & 948 & 2า 8 & 178 & 748 & $<10$ & 220 \\
\hline $\mathrm{NH}_{3}$ & -10 & $\therefore 10$ & -10 & -10 & $\therefore 10$ & $\because 10$ & $<0$ & $\therefore 10$ & $<10$ & $\therefore 10$ & $<10$ & 14 \\
\hline $\mathrm{H}_{2} \mathrm{O} \%$ & 299 & 261 & 356 & 81 & 70 & 89 & 72 & 65 & 184 & 31 & 24 & 44 \\
\hline $\mathrm{CO}_{2} \%$ & 067 & 046 & 086 & 075 & 038 & 116 & 058 & $\therefore 10$ & 094 & 050 & $<10$ & 130 \\
\hline Nitrous Acikl & $\because 10$ & $\therefore 10$ & 17 & 12 & $\therefore 10$ & 23 & 14 & $<10$ & 26 & 0 4 & $<10$ & 12 \\
\hline Nitric Acids & $<10$ & $\therefore 10$ & 12 & 08 & $\therefore 10$ & 16 & $<10$ & $<10$ & 18 & $\therefore 10$ & $<10$ & 10 \\
\hline $\mathrm{HCN}$ & $<10$ & $<10$ & $<10$ & 810 & $\therefore 10$ & $<10$ & 810 & $<10$ & $<10$ & $\therefore 10$ & $<10$ & $\therefore 10$ \\
\hline $\mathrm{SO}_{2}$ & 171 & 117 & 228 & 75 & 33 & 118 & 59 & 13 & 116 & 21 & $<10$ & 70 \\
\hline $\mathrm{CO}$ & 36 & 24 & 46 & 38 & 11 & 103 & 40 & $<10$ & 968 & 31 & $<10$ & 327 \\
\hline $\mathrm{HCl}$ & $\varepsilon=10$ & $\approx 10$ & 14 & $c=10$ & $\approx 10$ & 16 & $=: 10$ & $\therefore: 10$ & 49 & $\angle 10$ & $<10$ & 41 \\
\hline $\mathrm{HF}$ & 199 & 116 & 339 & 107 & 93 & 138 & 91 & 11 & 177 & 39 & 21 & 67 \\
\hline
\end{tabular}




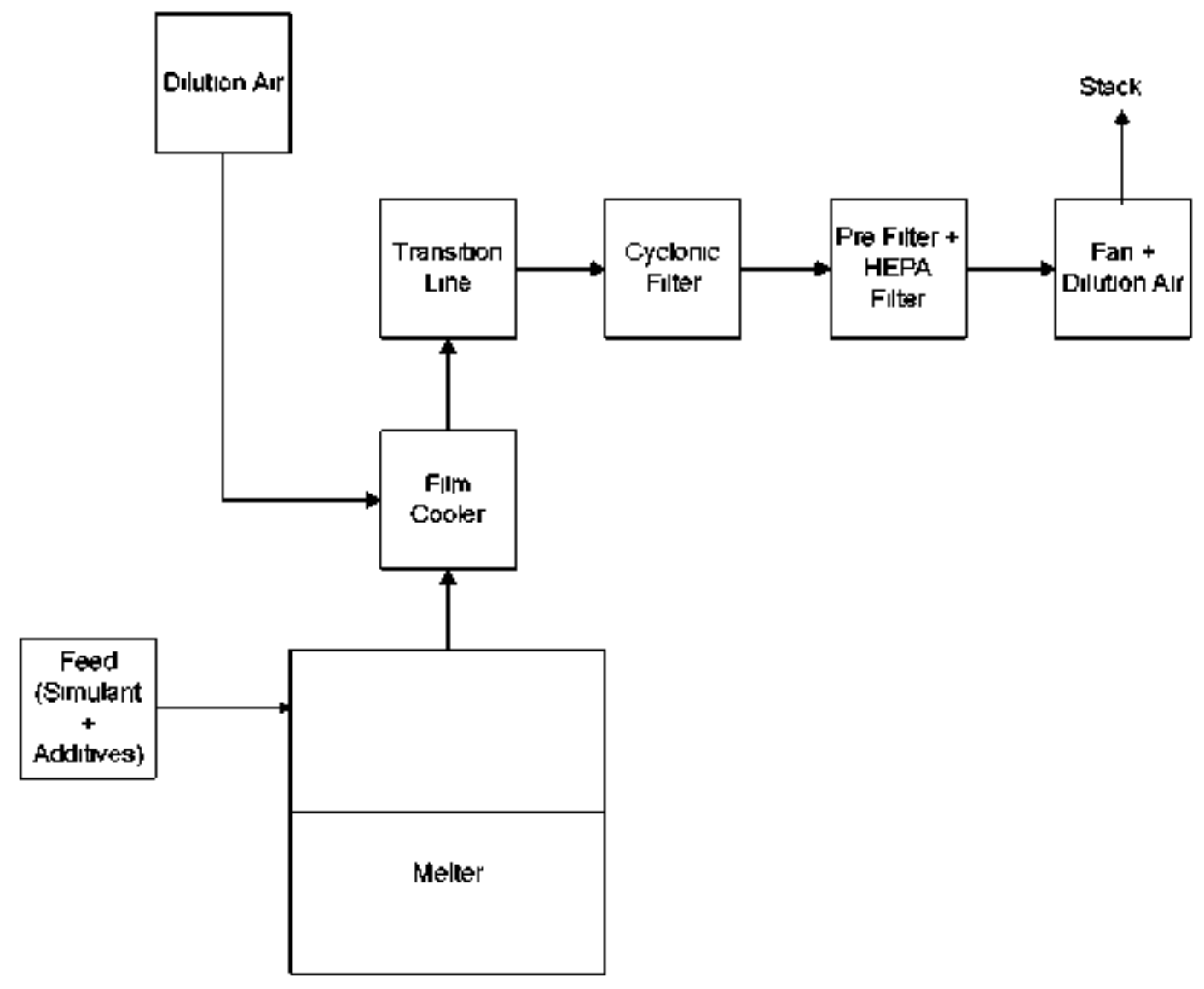

Figure 1.1. Schenutic diagram of DuraMelter 100 vitrification system. 


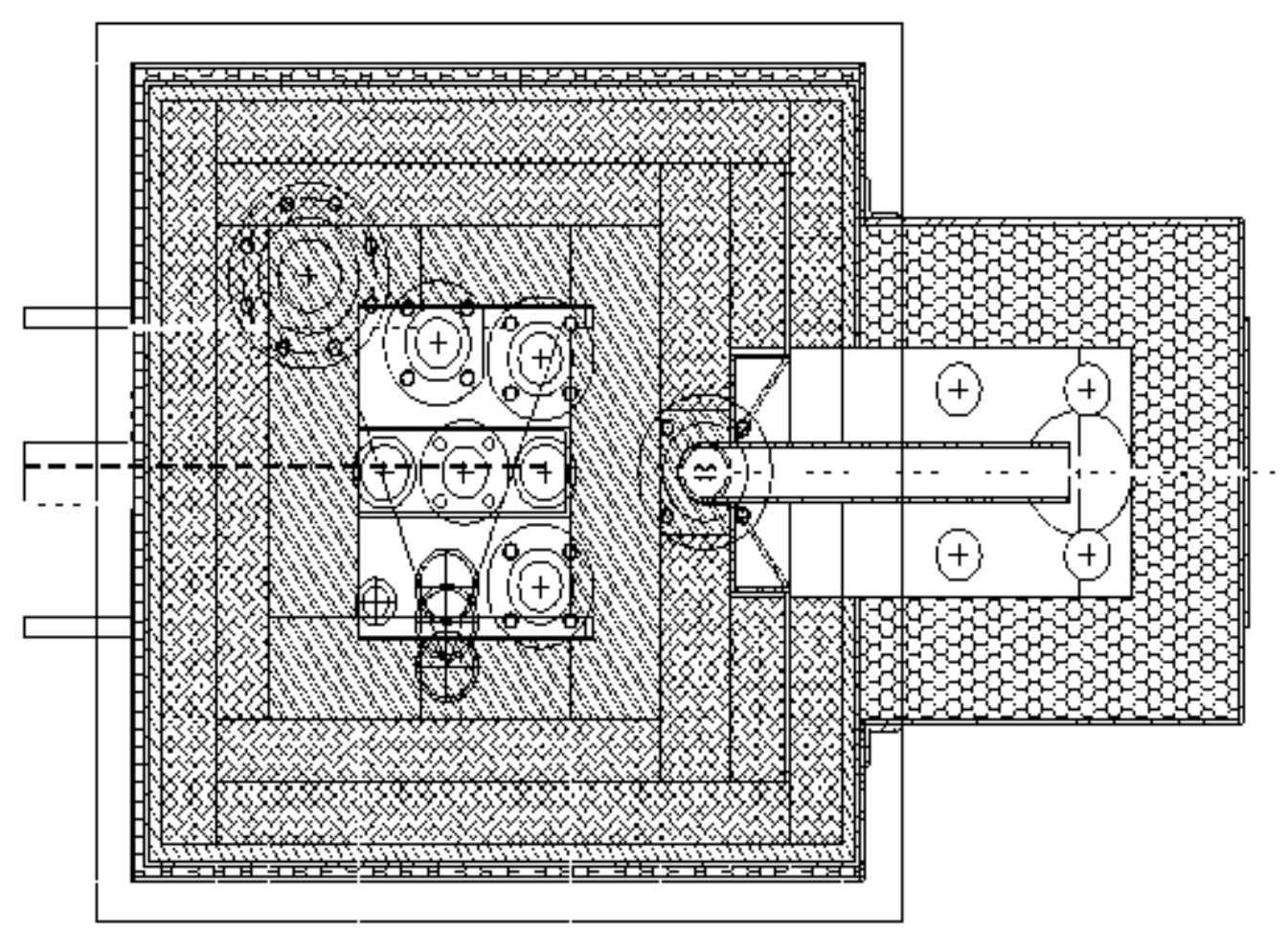

Figure 1.2.a. Schematic diagram showing cross-section through the DM100-BL-melter. Plan view slowing locntions of lid ports. 


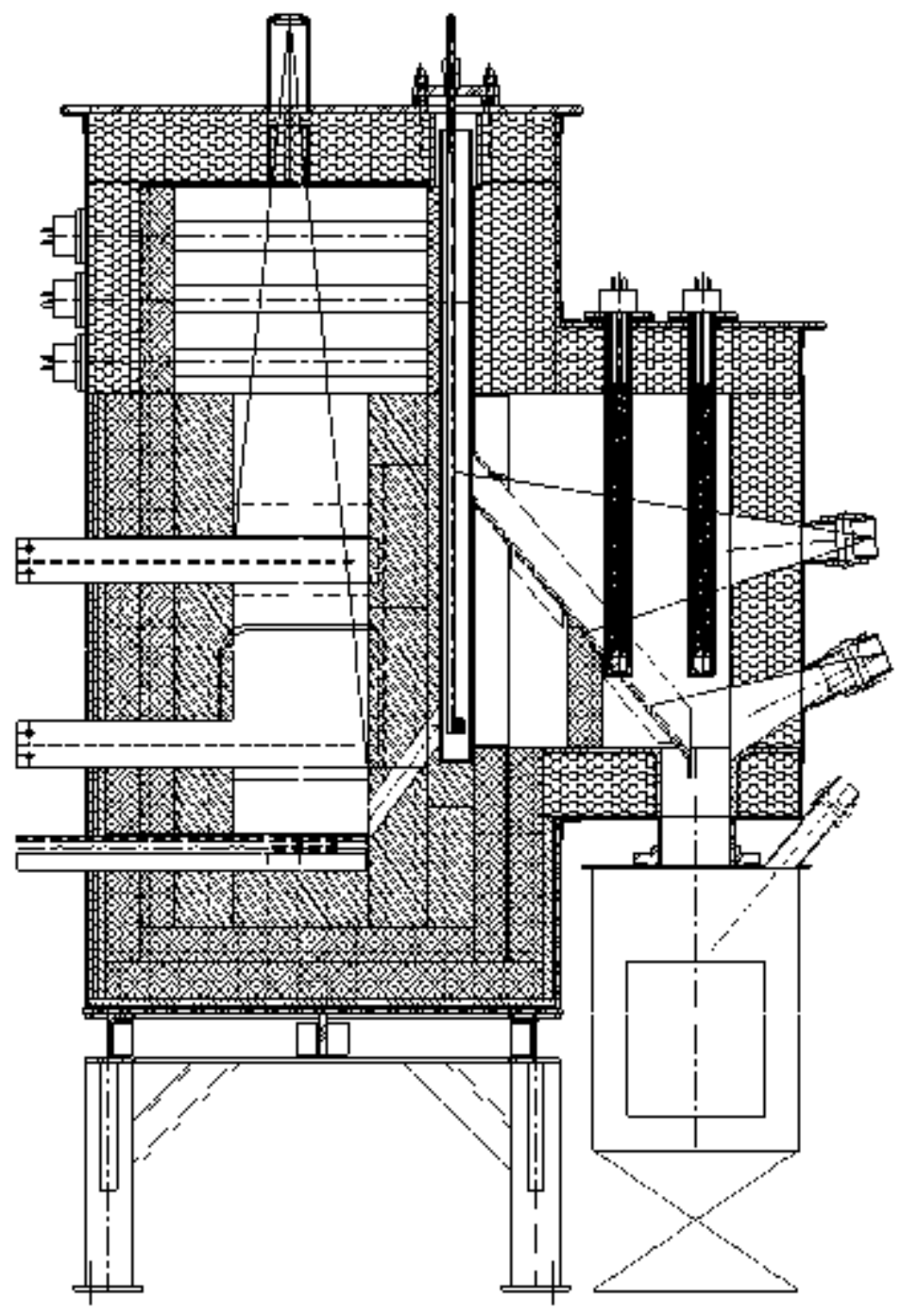

Figure 1.2.b. Schematic dingram showing cross-section through the DM100-BL melter. 
The Cattolic Unnersity of Amenco Intreous State Labaratory
ORP-44236, Rev 0

Melt Rate Enthancement for High alimintsm HLW Glass Fomulatrons Frol Report, I'SL-08R1360-I, Rev. 0

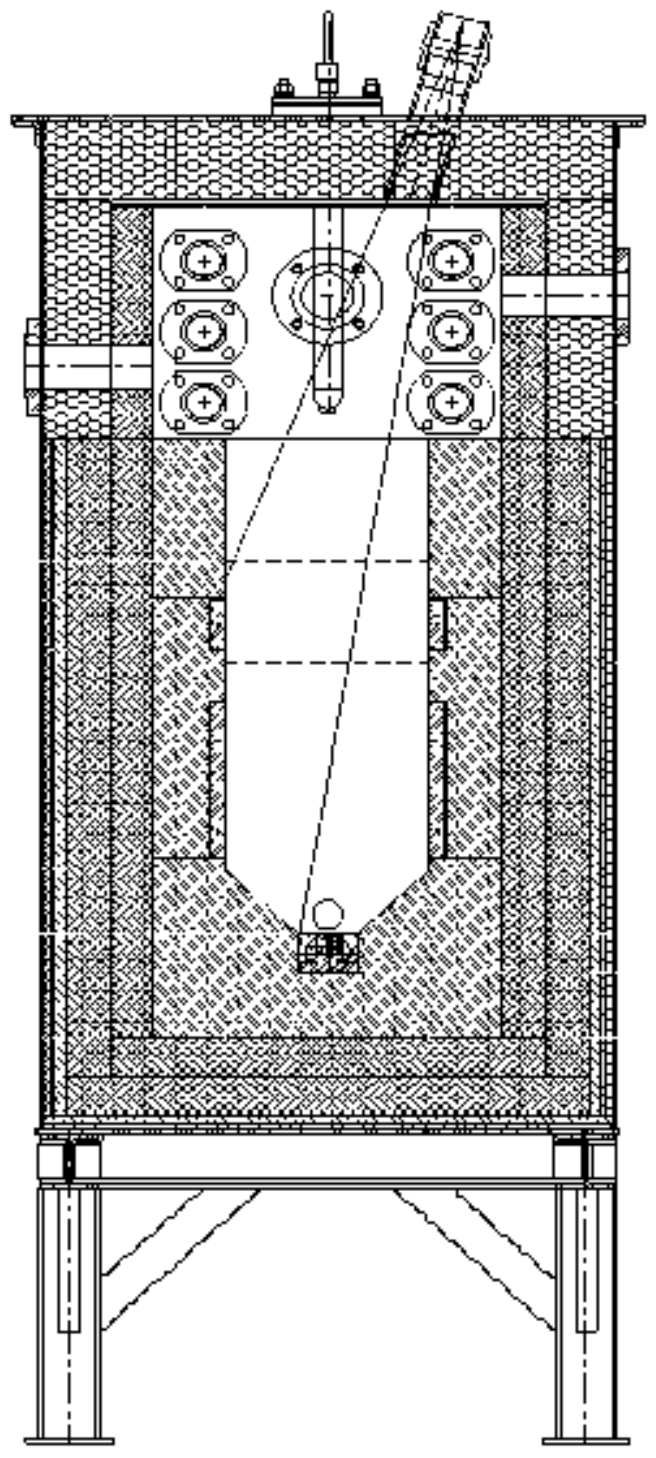

Figure 1.2.c. Schematic diagram showing cross-section through the DMI00-BL melter. 
ORP-44236, Rev 0

The Catholic University of America Vitreous State Laboratory.
Melt Rate Enhancement for High Aluminum HLW Glass Formulations Final Report. VSL-08R1360-1, Rev. 0

Lid Refractory

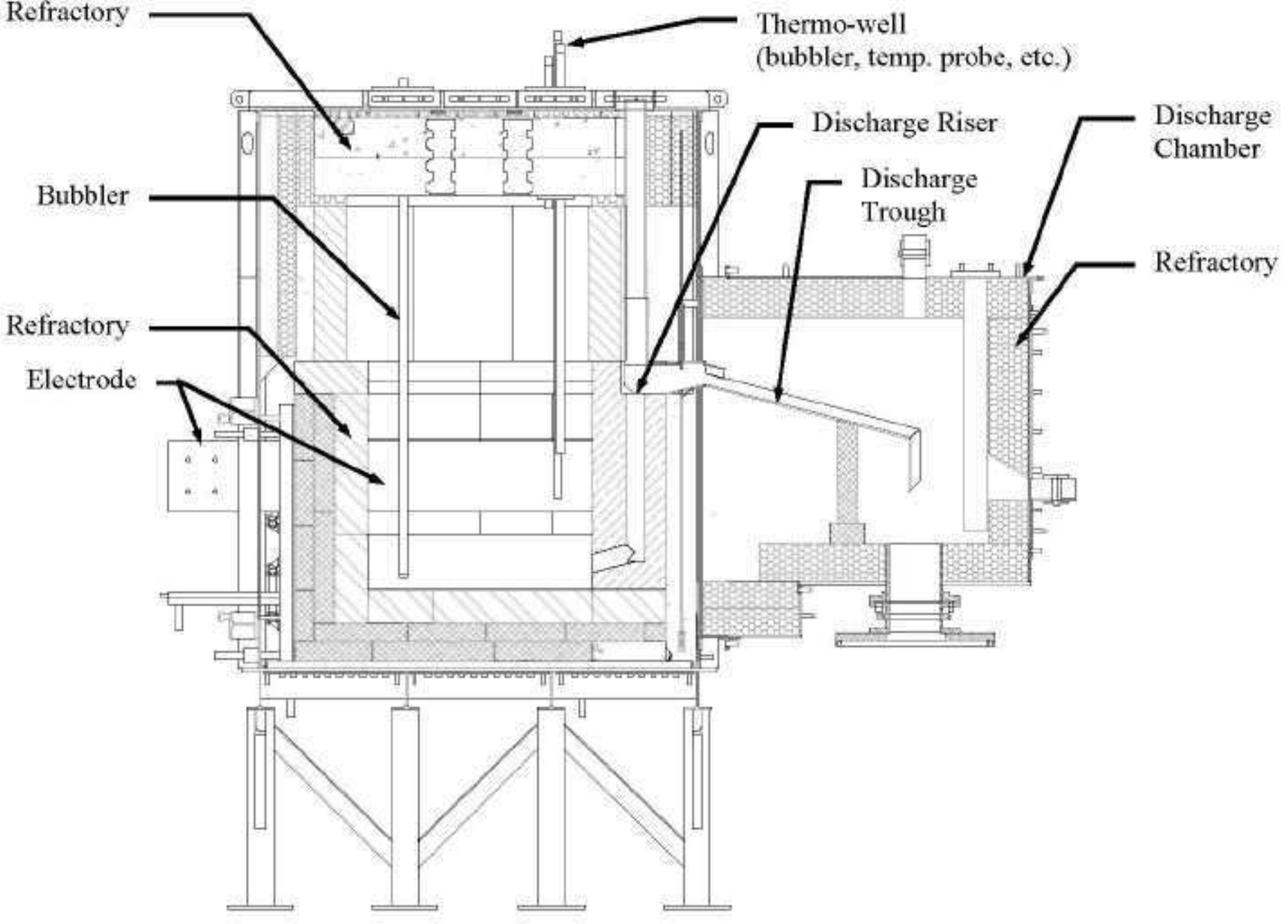

Figure 1.3. Cross-section of the DM1200 melter through the discharge chamber. 
ORP-44236, Rev . 0

The Catholic University of America

Vitreous State Laboratory.

Melt Rate Enhancement for High Aluminum HLW Glass Formulations Final Report, VSL-08R1360-1, Rev. 0

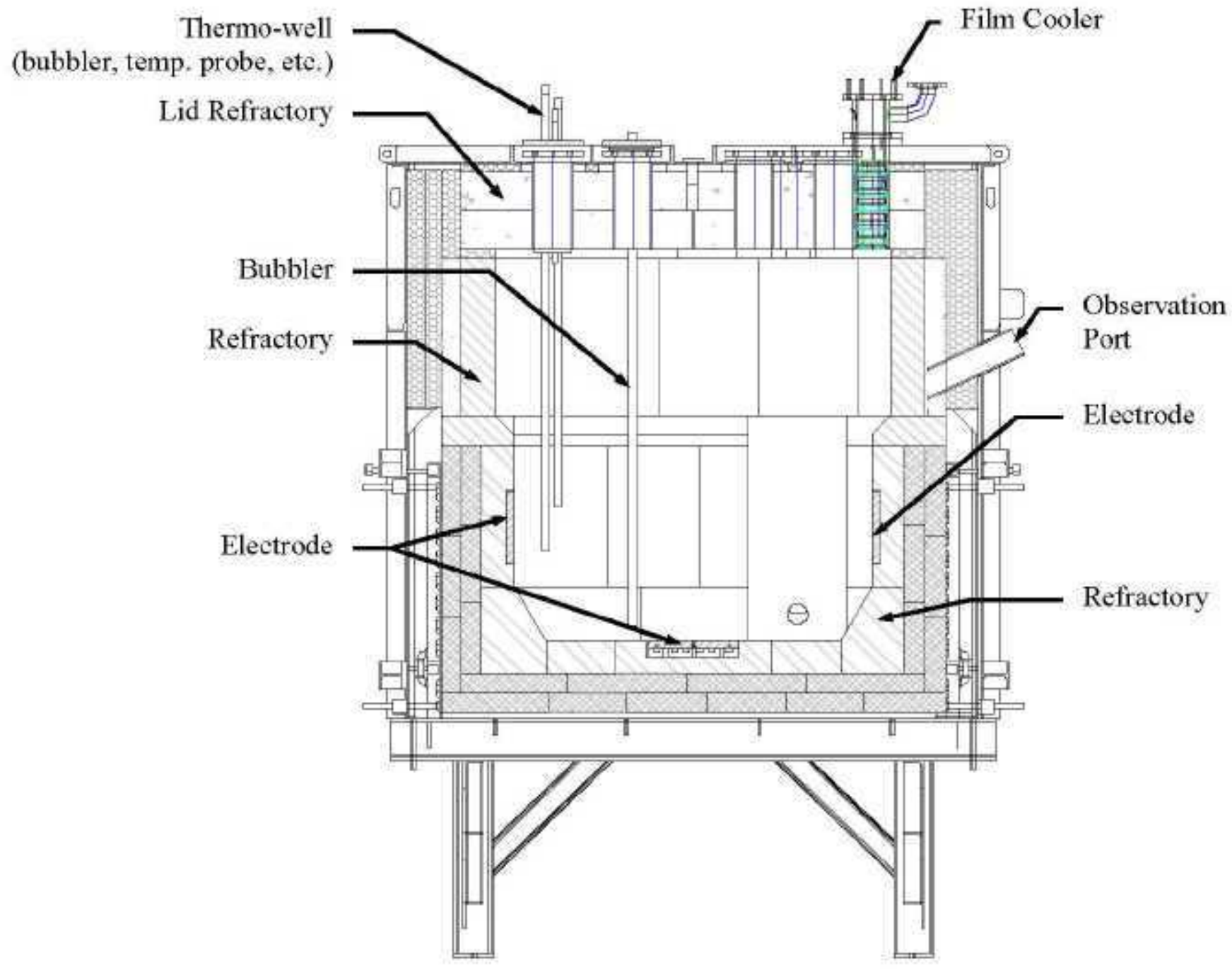

Figure 1.4. Cross-section through the DM1200 melter showing electrodes. 


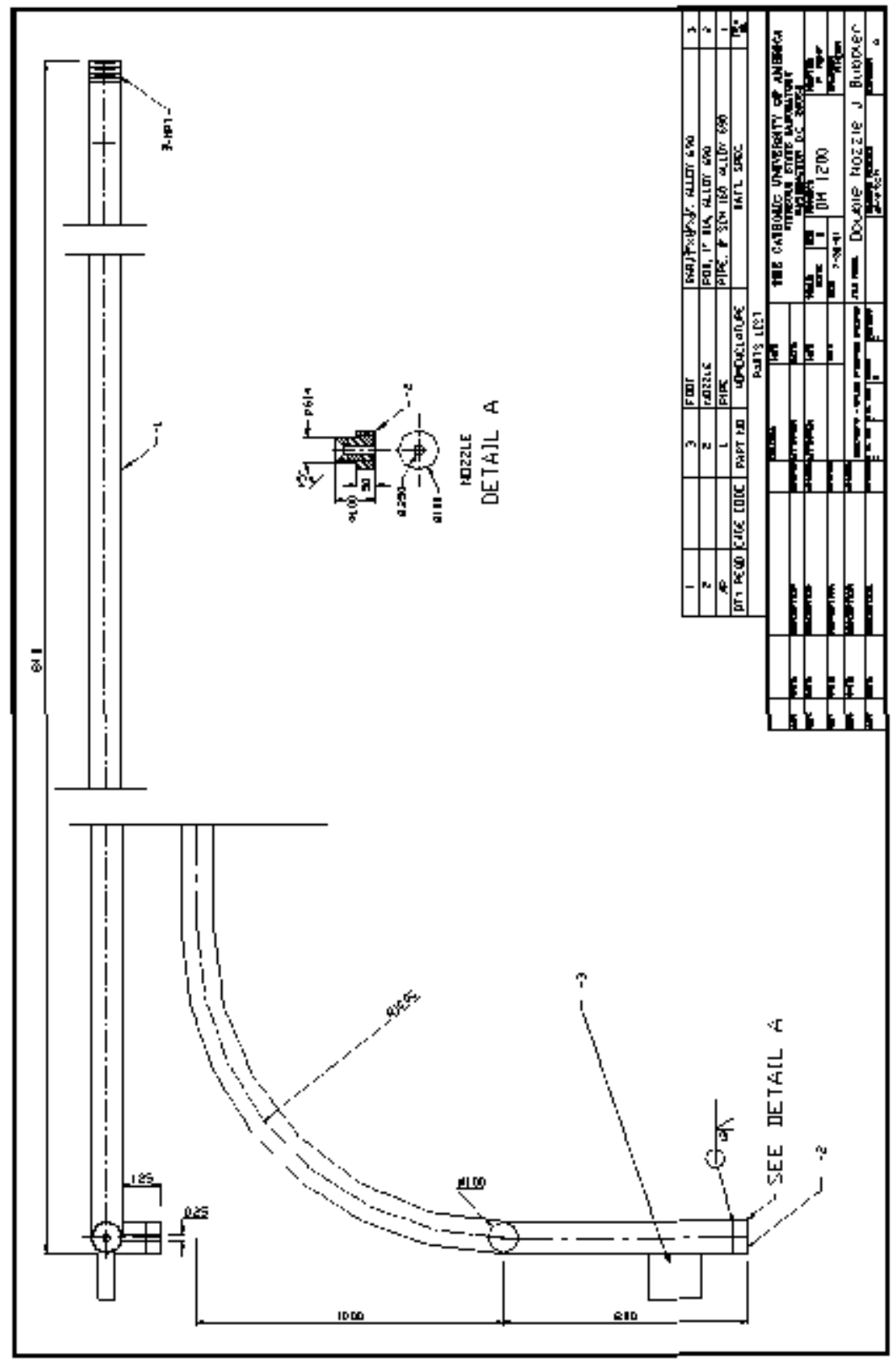

Figure 1.5. Specifications of Double Outlet " $J$ " Bubbler. 


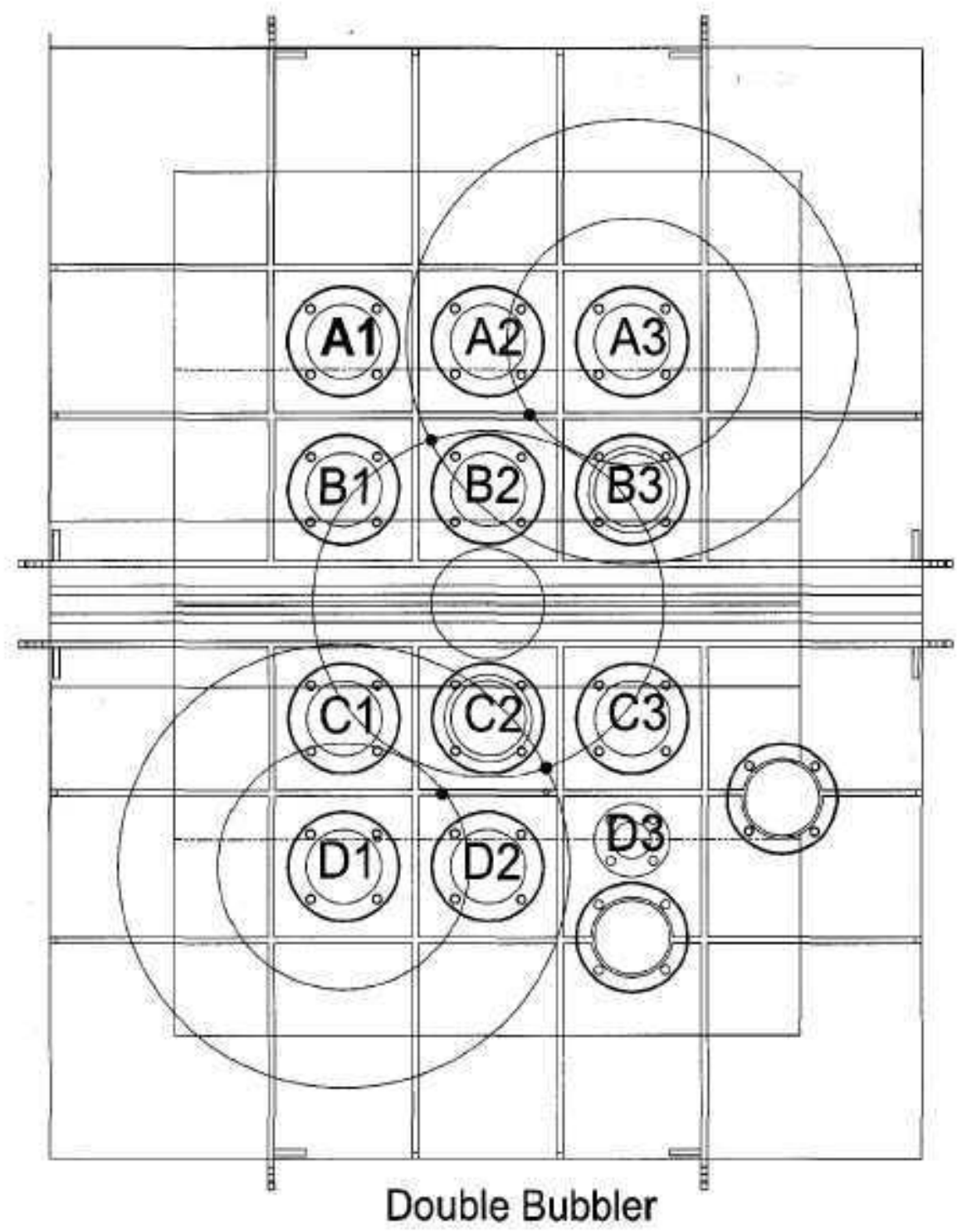

Figure 1.6. Placement of double outlet bubblers. Note: solid circles represent location of bubbler outlet. 


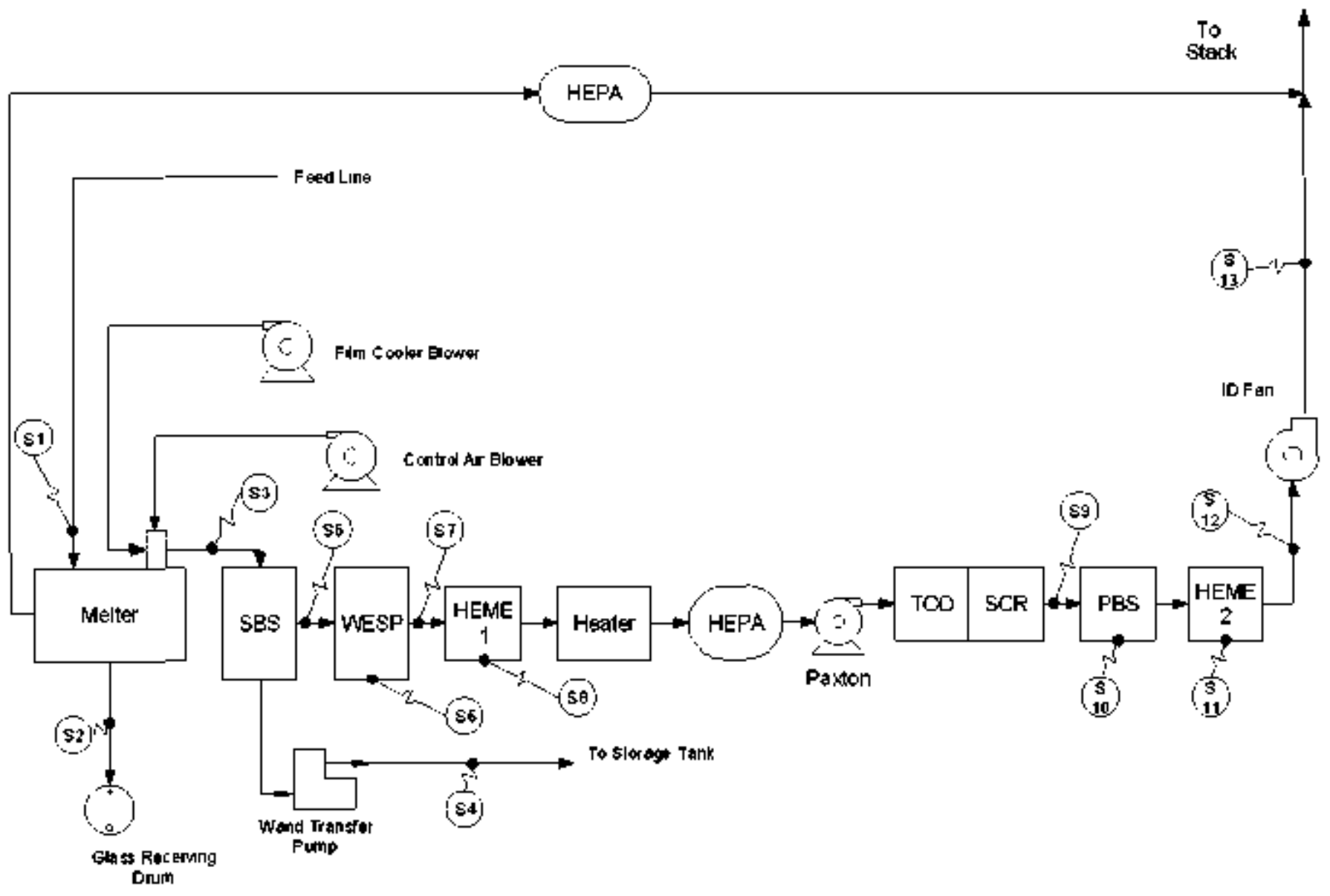

Figure 1.7. Schematic dingram of DM1200 off-gas system. "Sx" indicates sampling point. 


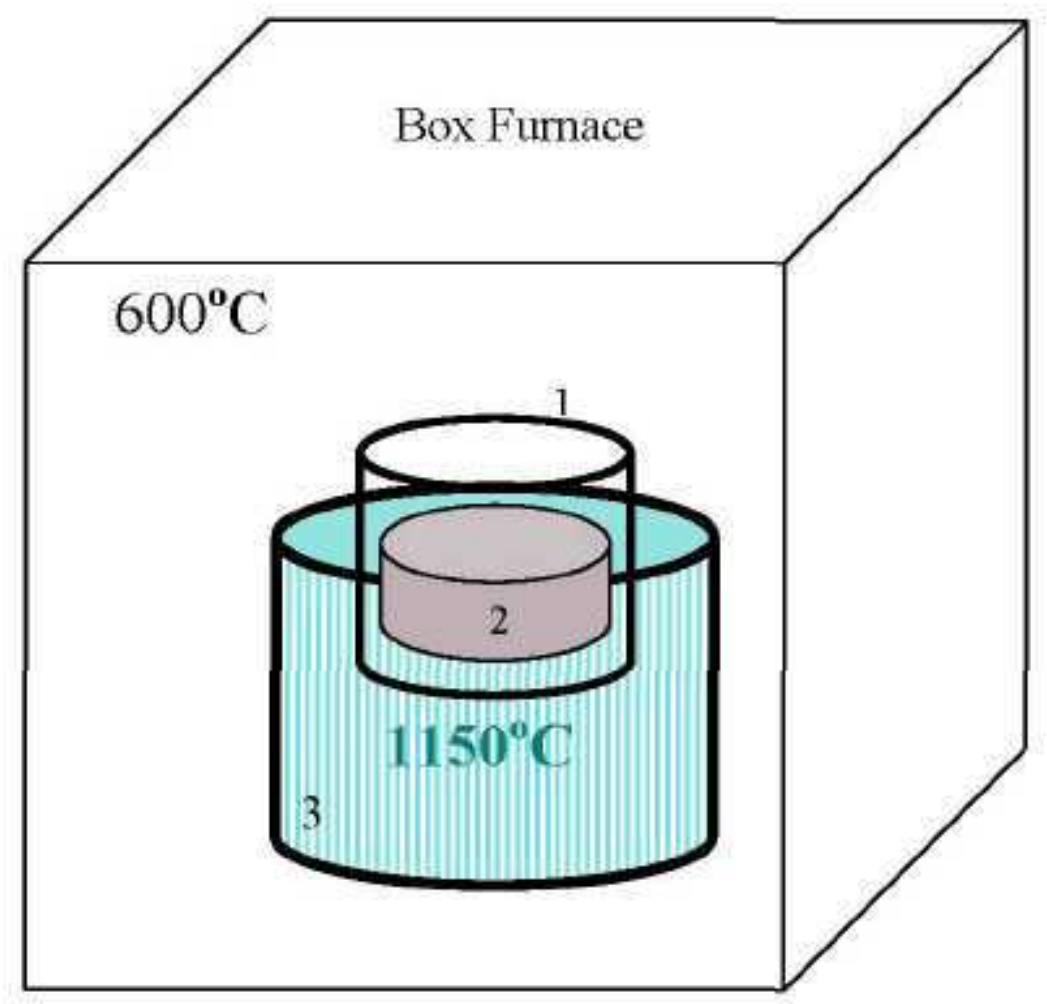

Figure 3.1. Schematic drawing of vertical gradient furnace (VGF) for feed conversion test $(1=$ ceramic crucible half inside the local heater; 2 =feed for $\mathbf{2 0}$ gram glass; $3=$ local heater at $1150^{\circ} \mathrm{C}$ ). 


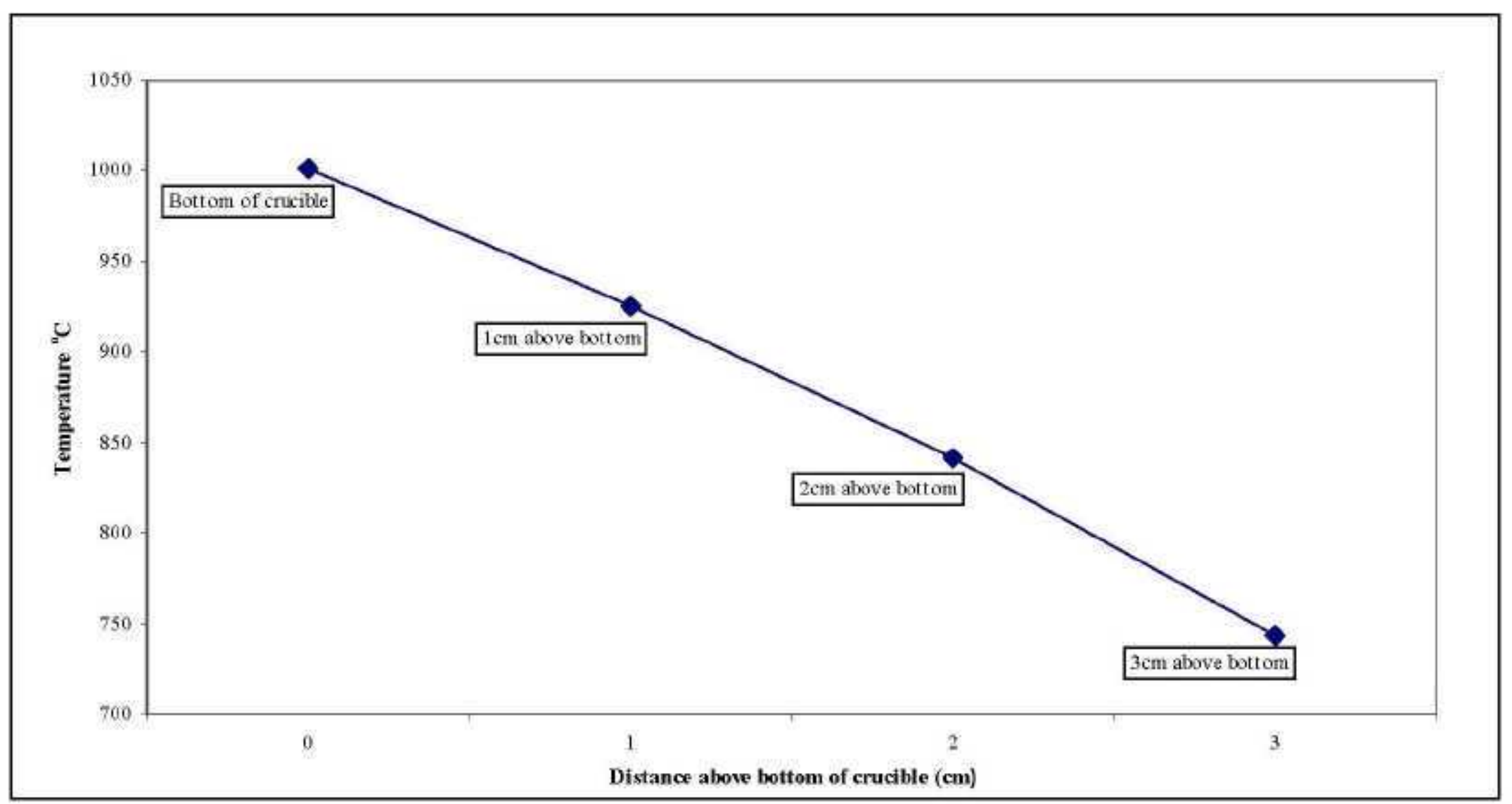

Figure 3.2. Temperature gradient (inside the loaded ceramic crucible) of the Vertical Gradient Furnace (VGF). 
(a)
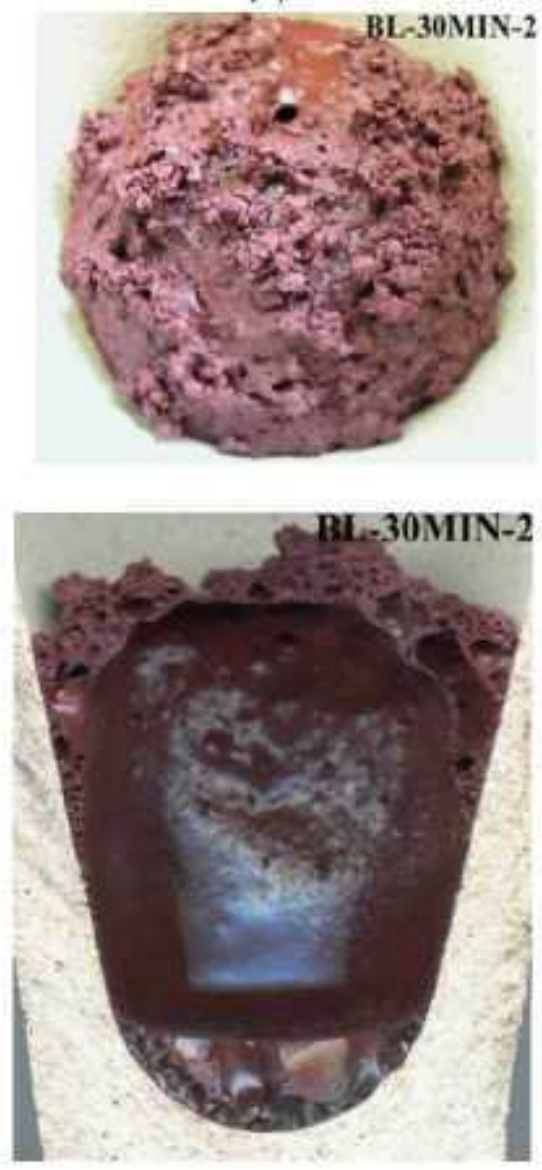

(b)
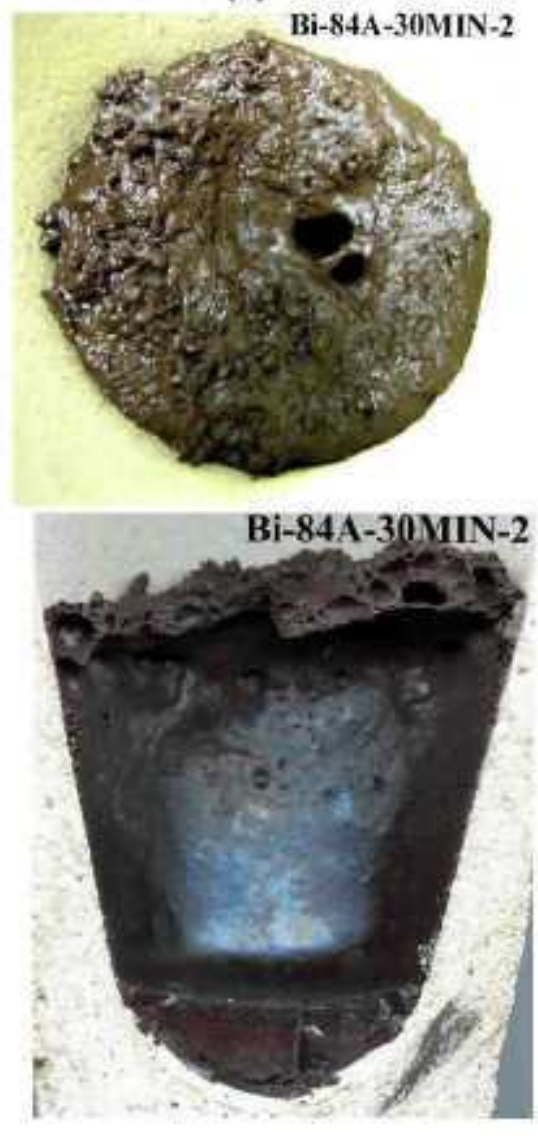

(c)
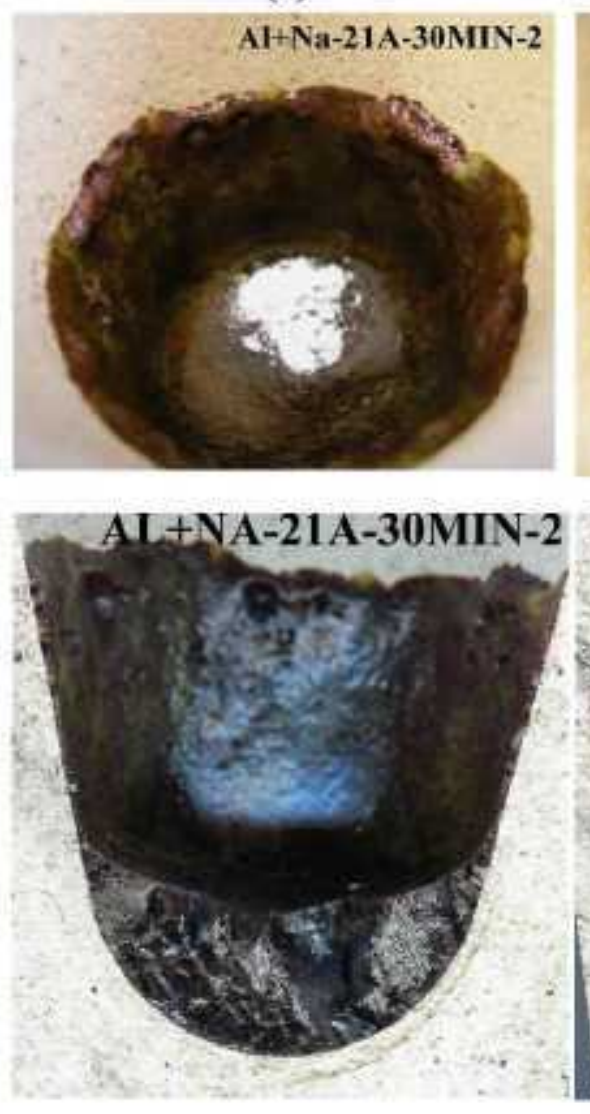

(d)
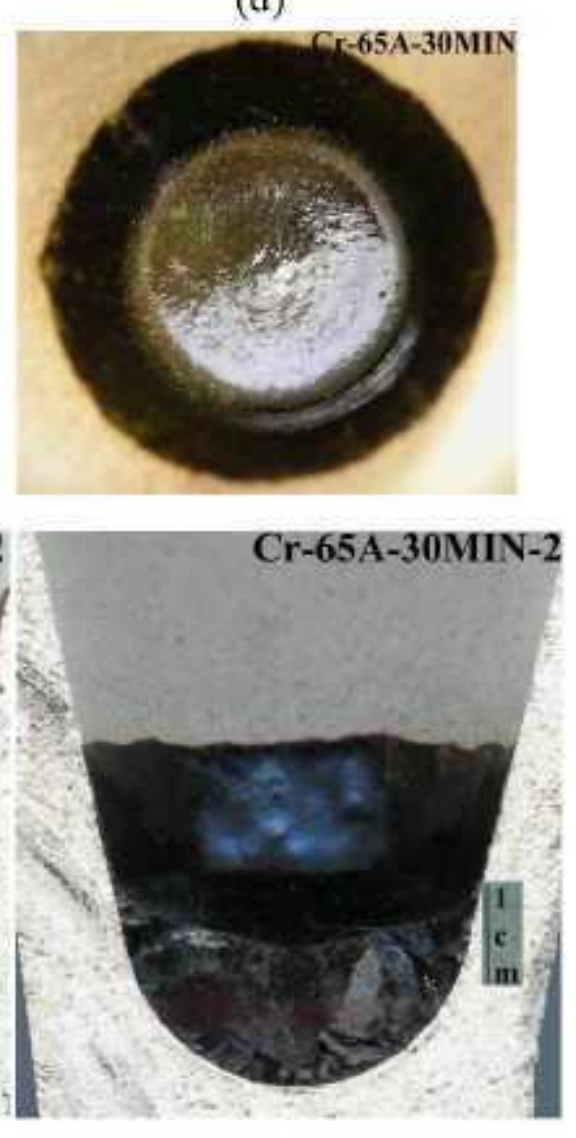

Figure 3.3. Top views and cross sections of six existing melter feeds after VGF tests (30 minutes) (a) HLW-E-Al-27, (b) HLW-E-Bi-6; (c) HLW-E-ANa-22, (d) HLW-E-CrM, (e) Matrix 1-B1, and (f) Matrix 2-9. 
(e)
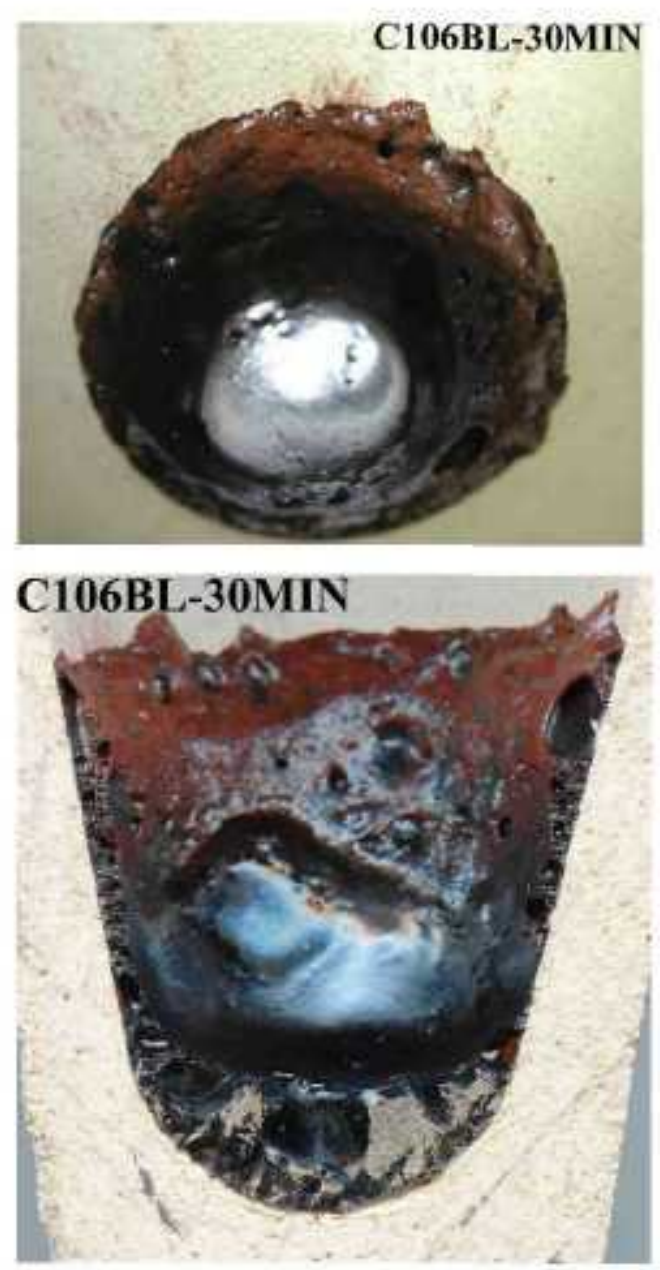

(f)
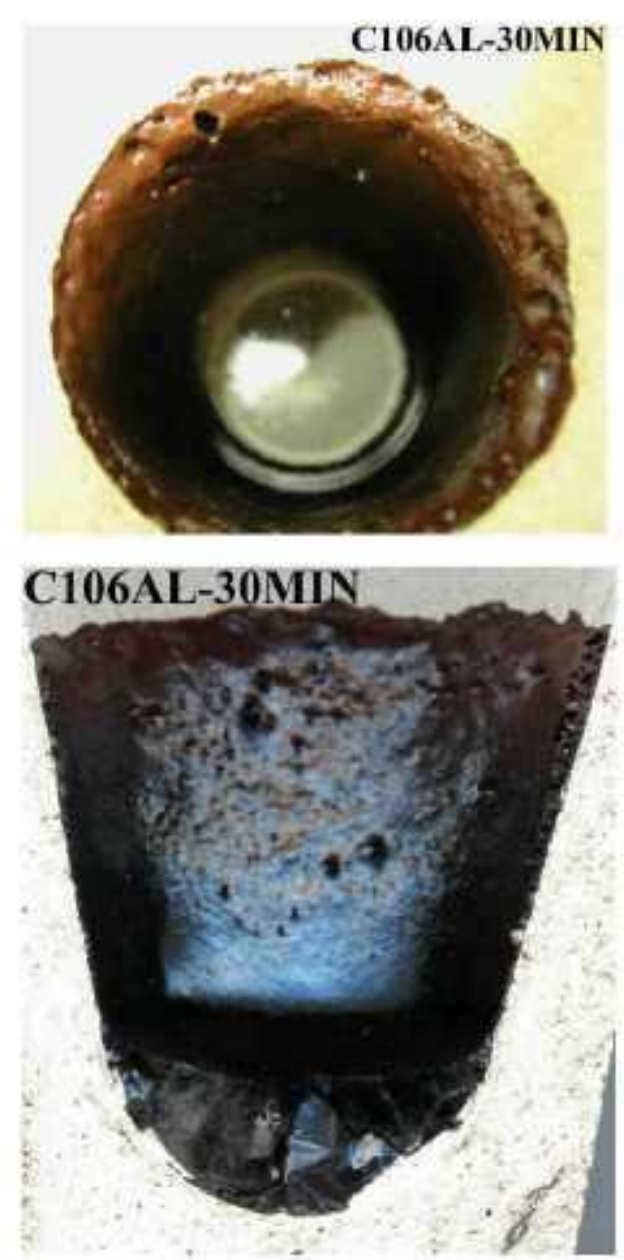

Figure 3.3. Top views and cross sections of six existing melter feeds after VGF tests (30 minutes) (a) HLW-E-AI-27, (b) HLW-E-Bi-6; (c) HLW-E-ANa-22, (d) HLW-E-CrM, (e) Matrix 1-B1, and (f) Matrix 2-9 (continued). 


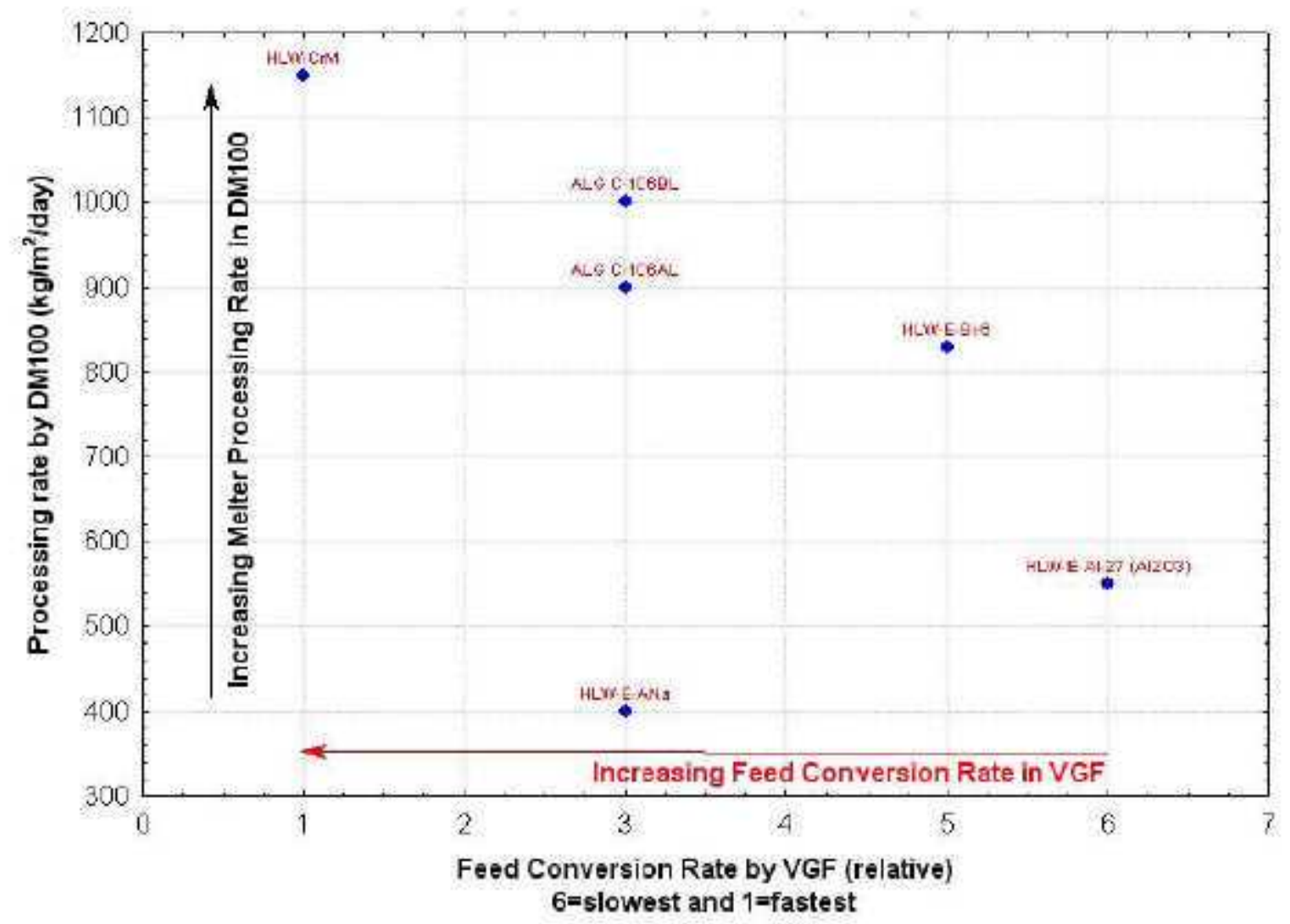

Figure 3.4. Preliminary evaluation of melt rate ranking by VGF as compared to the glass production rate determined by DM100 melter test using the same melter feed. The definition of the VGF melt rate estimation is given in Table 3.5. 
(a)
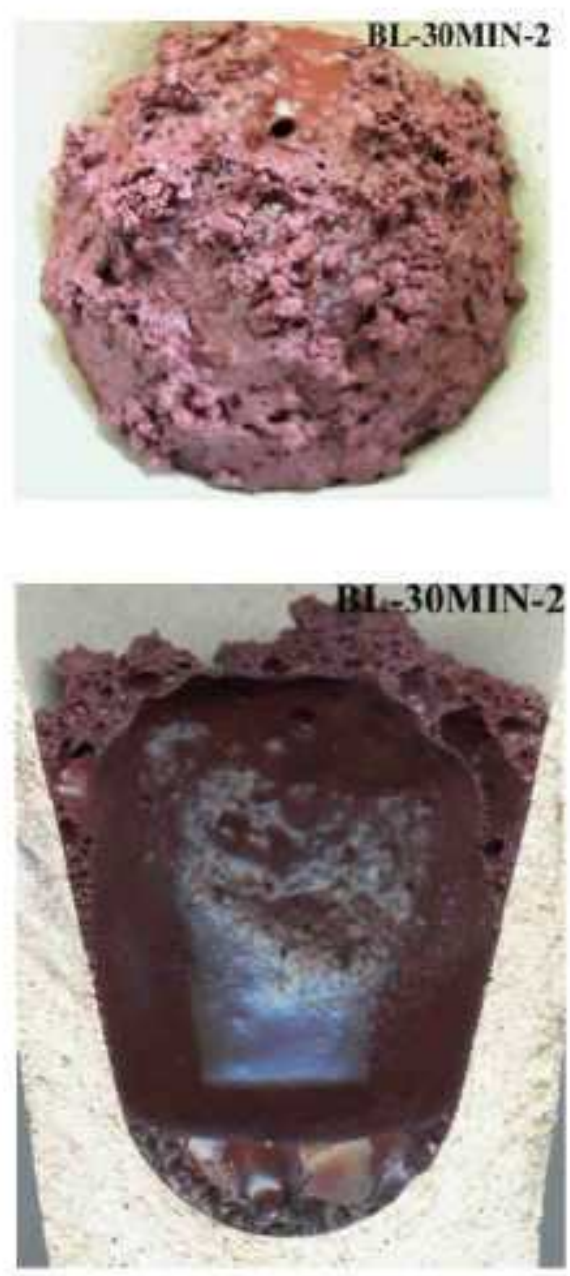

(b)
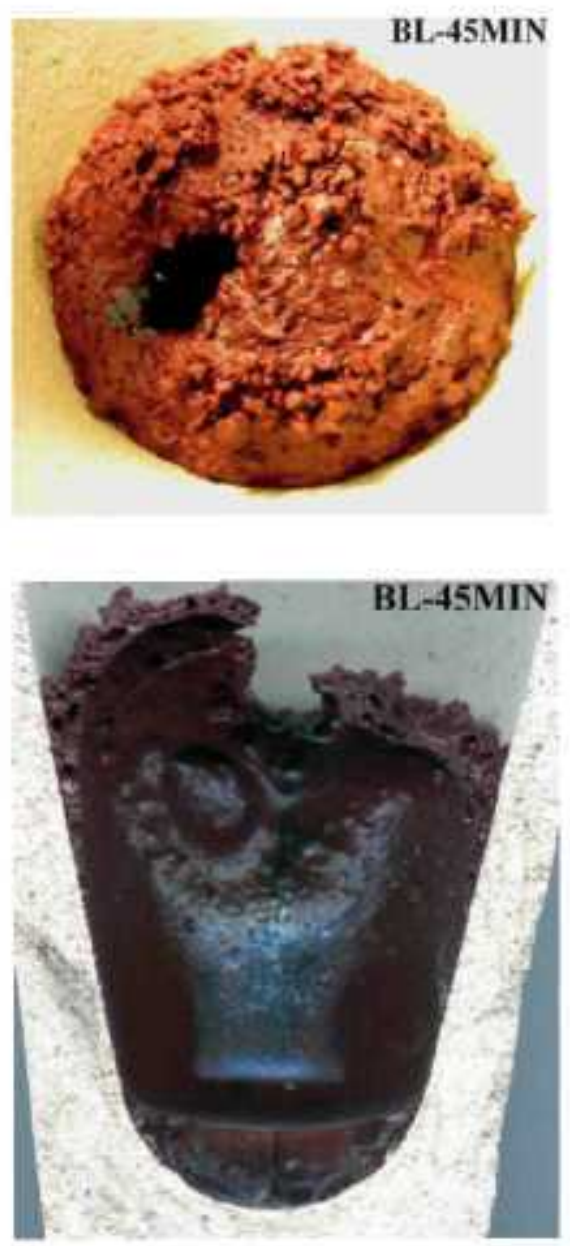

(c)
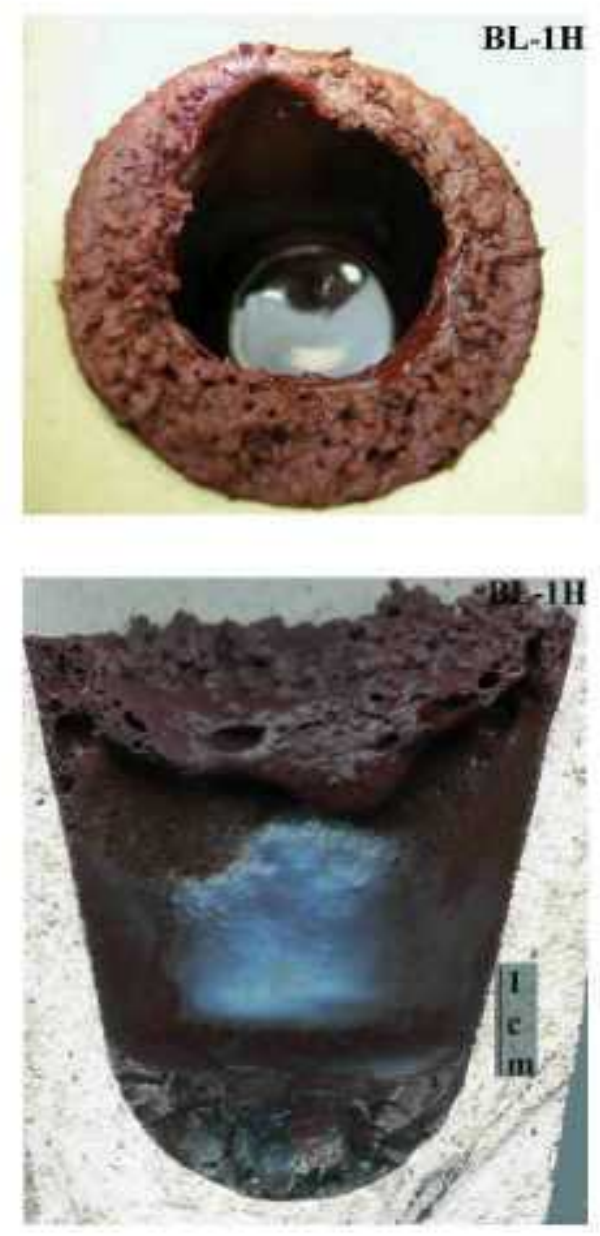

Figure 3.5. Time evolution of the baseline Al-limited melter feed (HLW-E-Al-27) after VGF tests: (a) 30 minutes, (b) 45 minutes and (c) 60 minutes. 
(a)

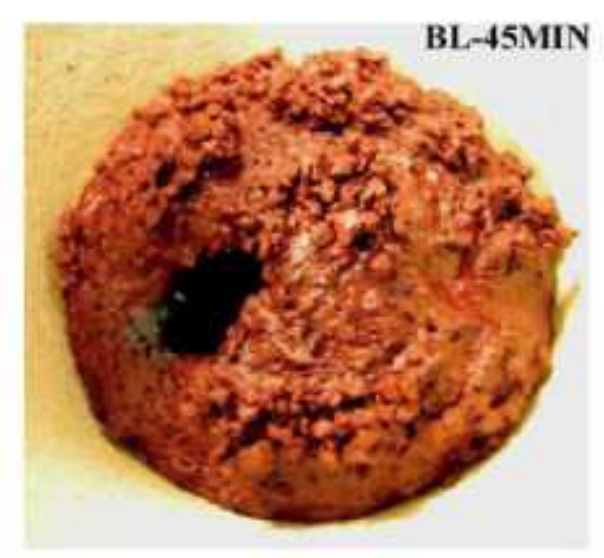

(b)

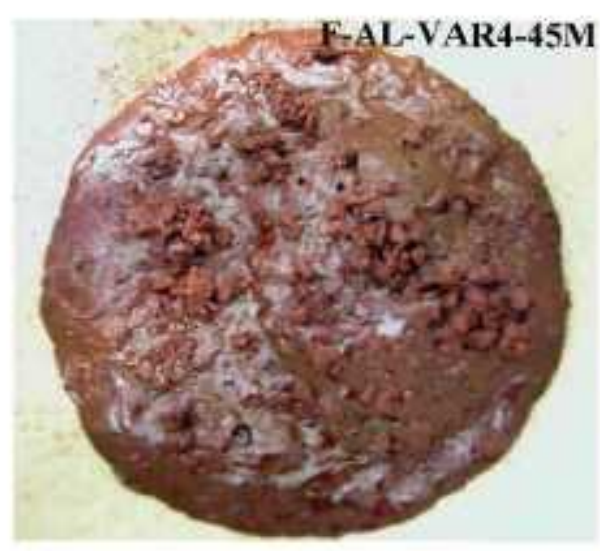

(c)
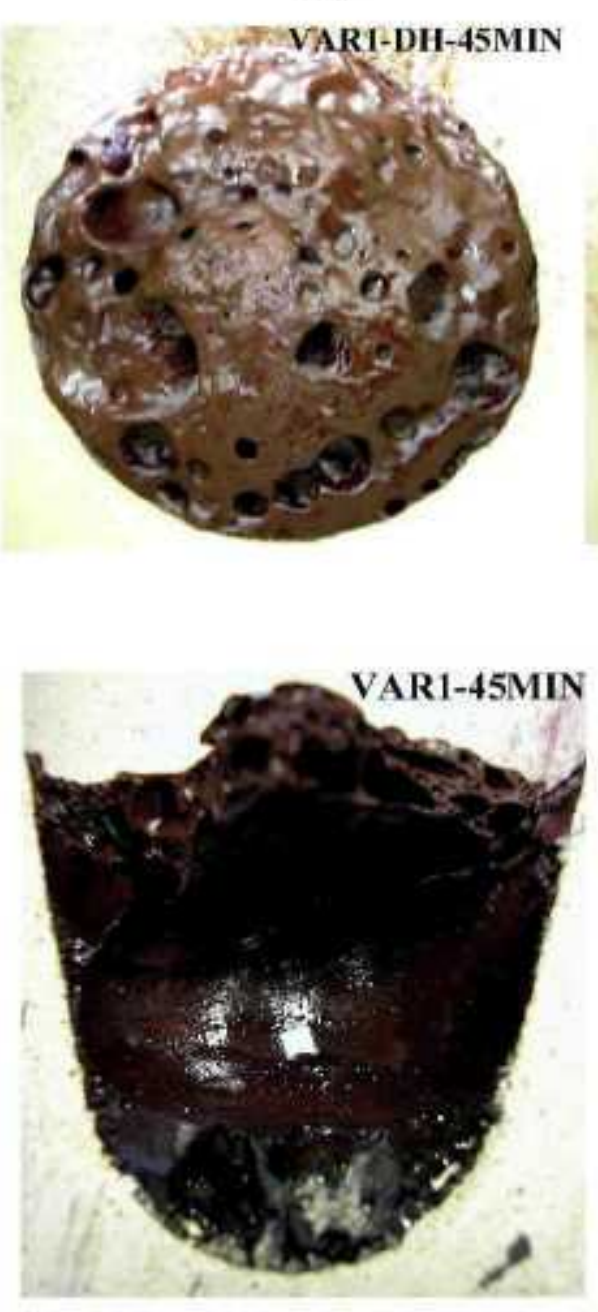

(d)
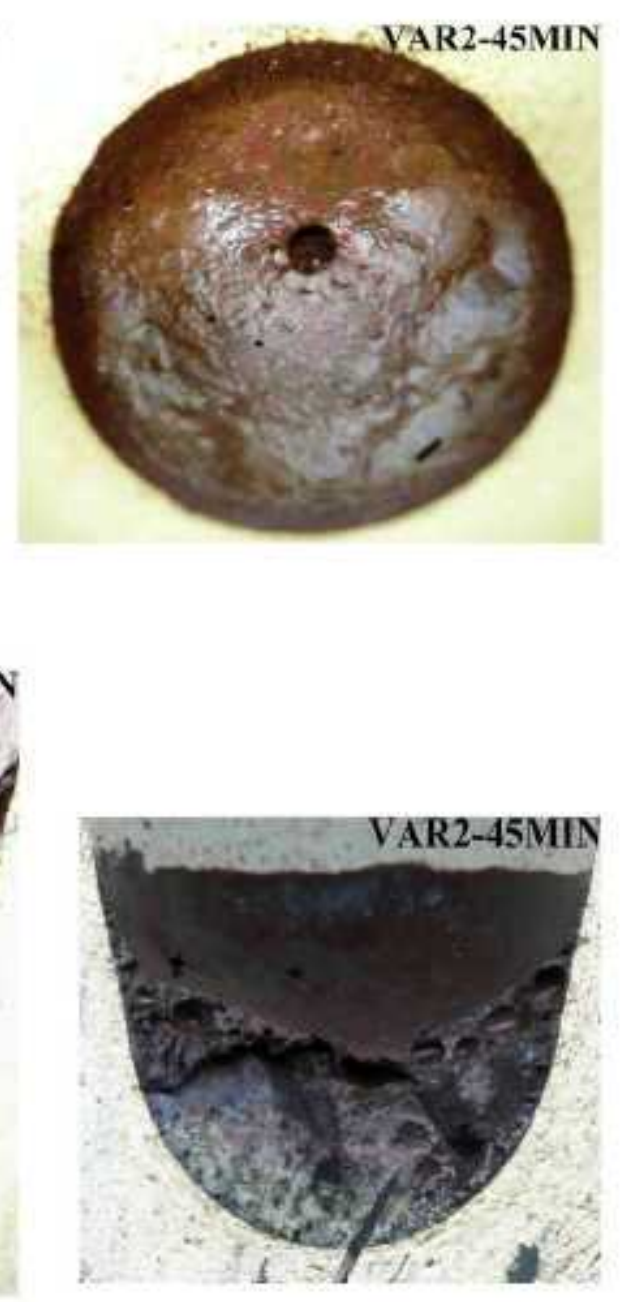
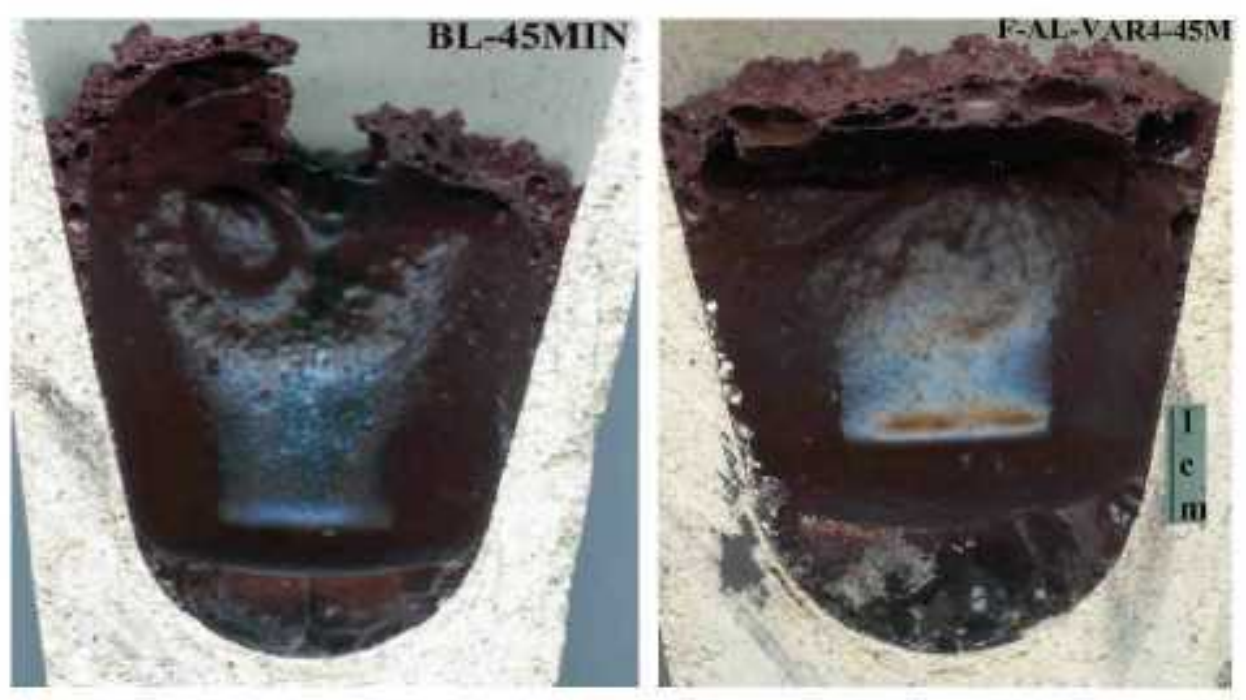

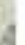

Figure 3.6. Impacts of boron and aluminum sources on melt rate in VGF experiments ( 45 minutes). (a) $\mathrm{Al}_{2} \mathrm{O}_{3}$ and borax, (b) $\mathrm{Al}(\mathrm{OH})_{3}$ and borax, (c) $\mathrm{Al}_{2} \mathrm{O}_{3}$ and boric acid, and (d) $\mathrm{Al}(\mathrm{OH})_{3}$ and boric acid 
(a)
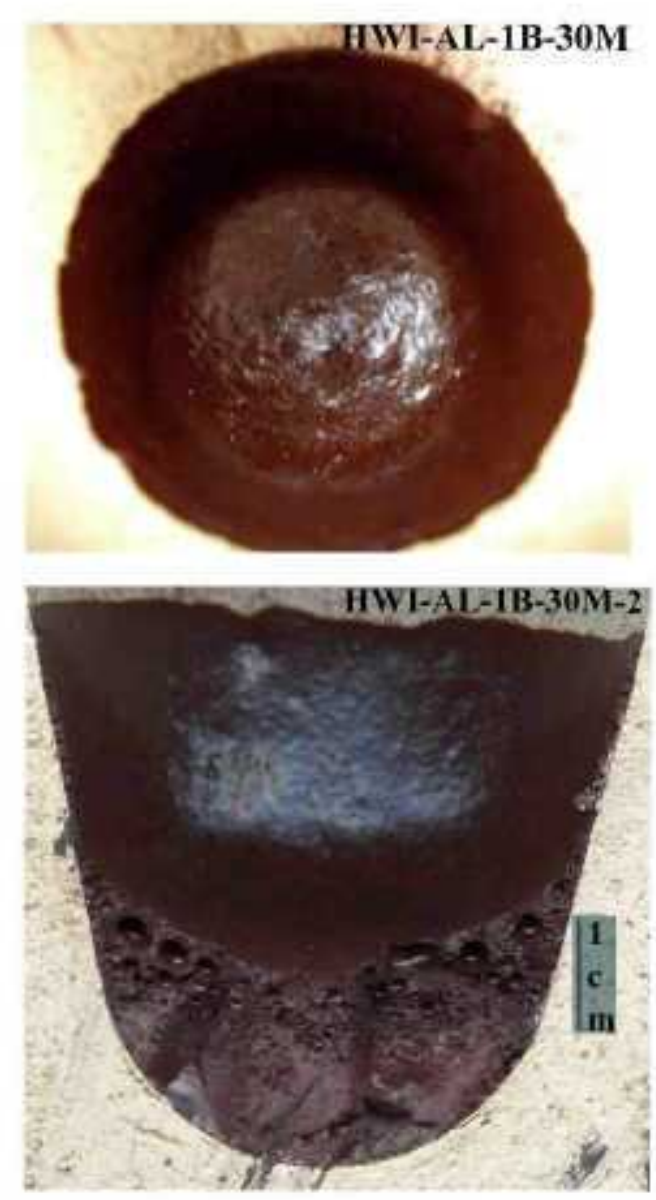

(b)

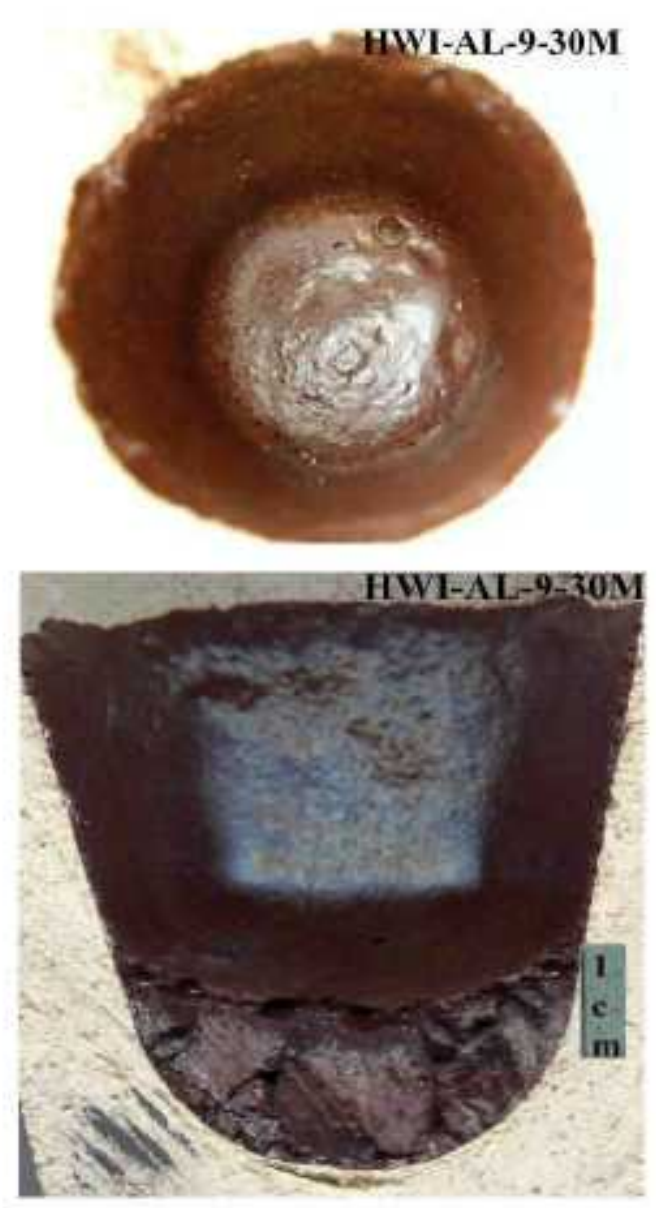

Figure 3.7. Top views and cross sections of Group 1 formulations after 30 minute test in VGF. (a) HWI-Al-1, and (b) HWI-Al-9 
(a)
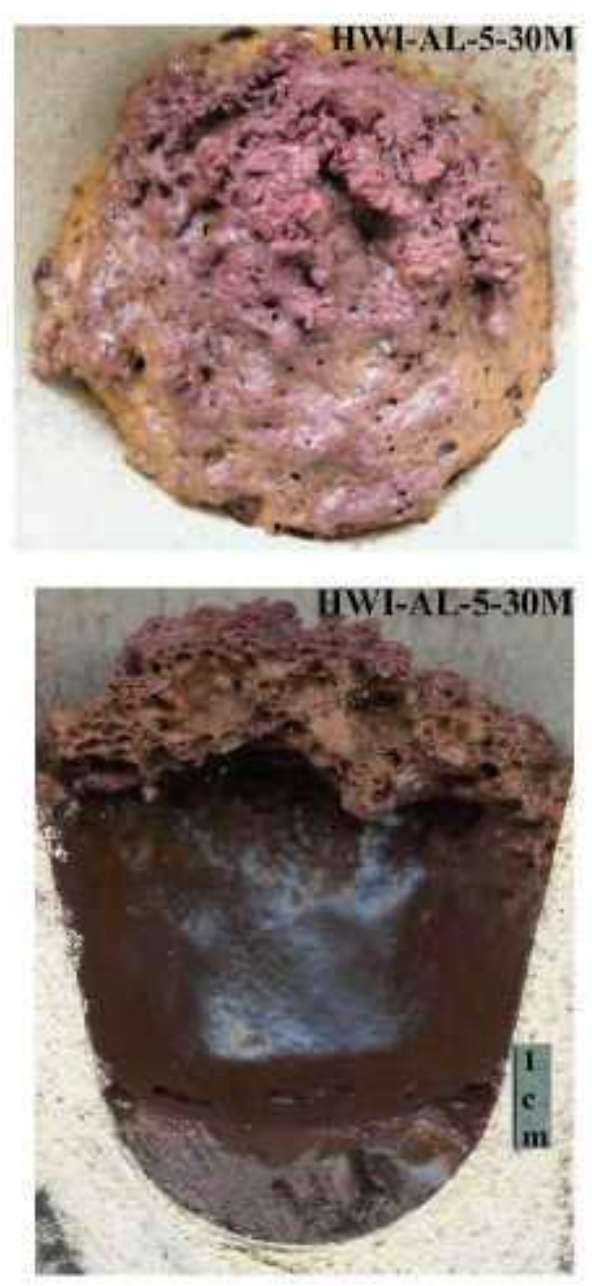

(b)
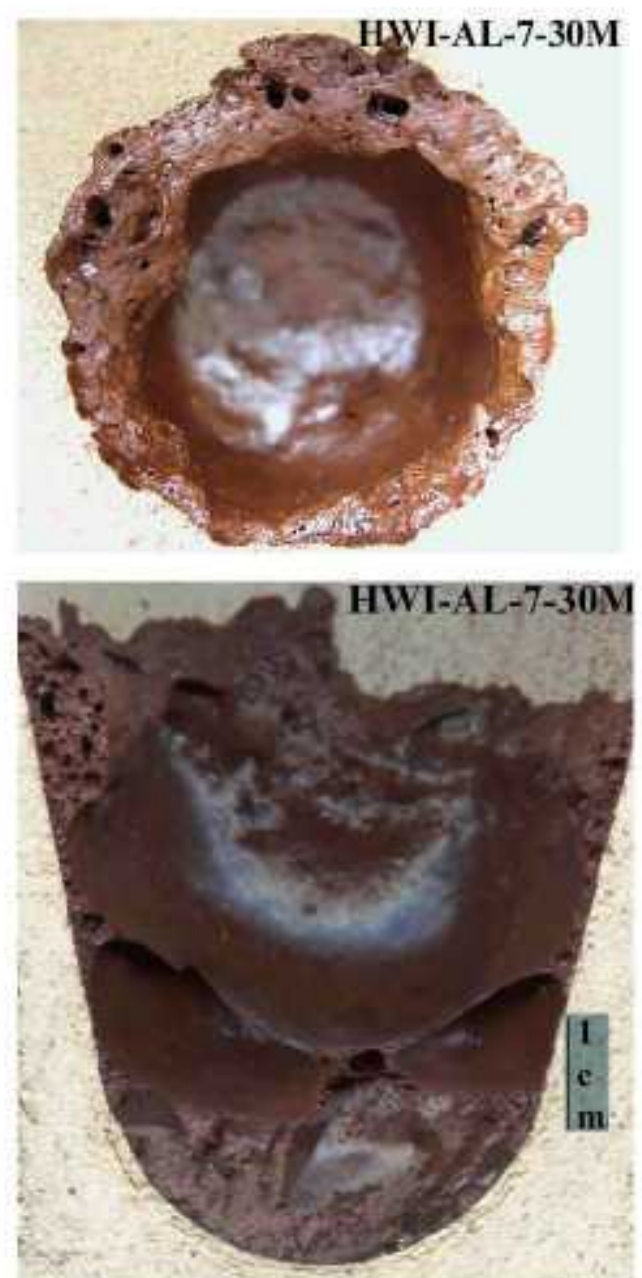

Figure 3.8. Top views and cross sections of Group 3 formulations after 30 minute test in VGF. (a) HWI-Al-5, and (b) HWI-Al-7. 
(a)
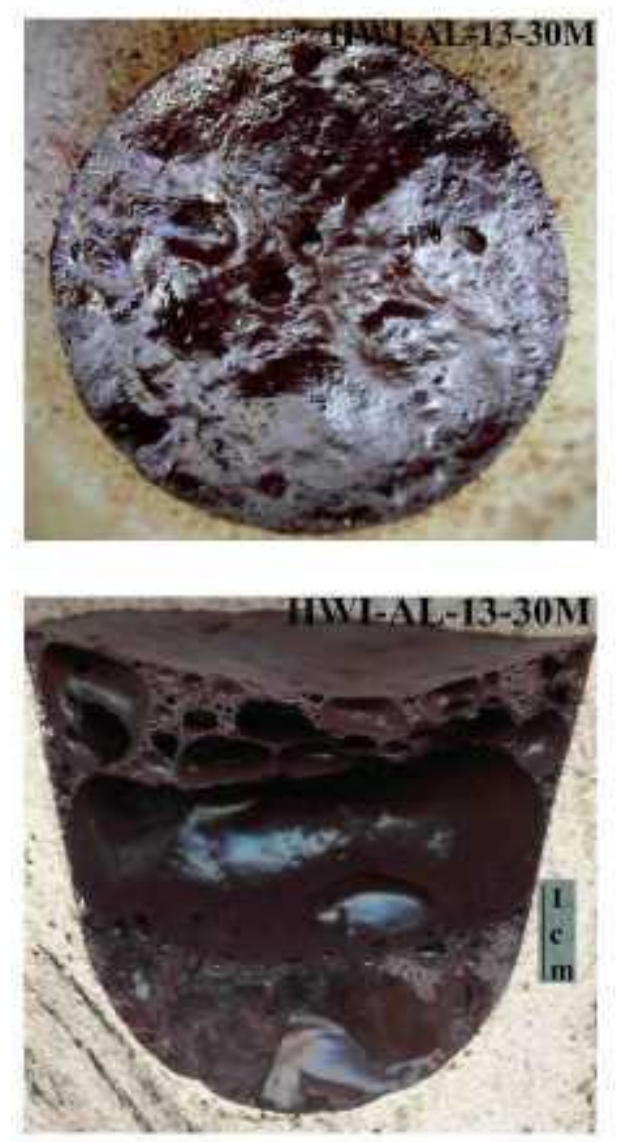

(b)
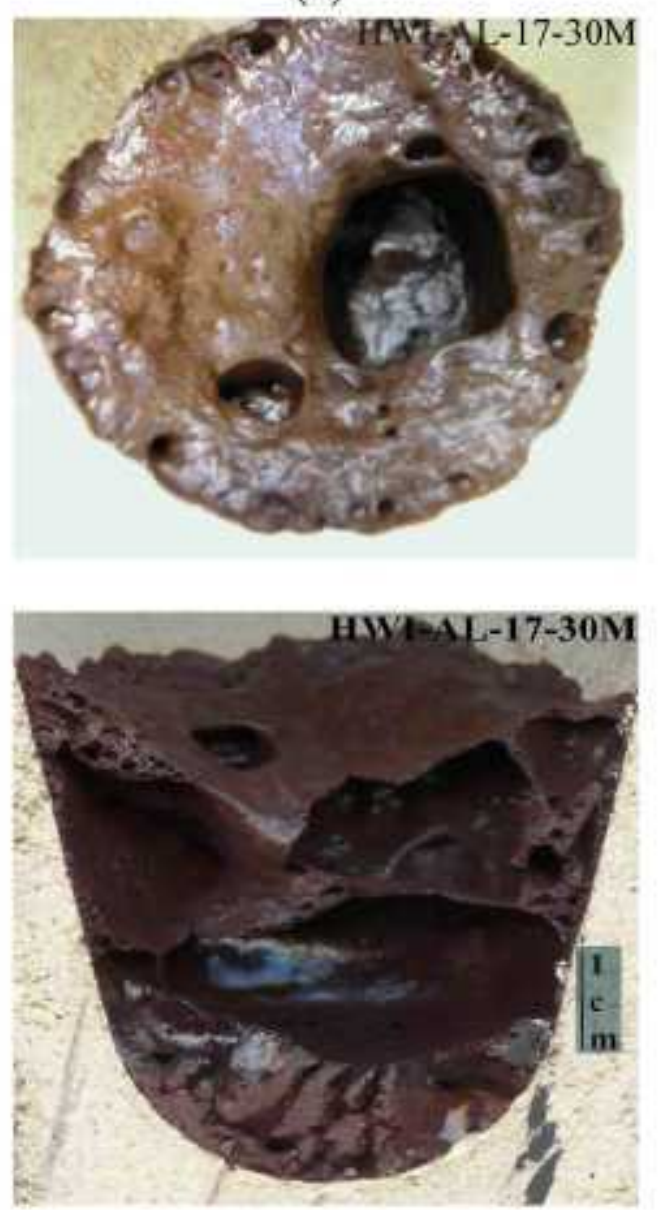

(c)
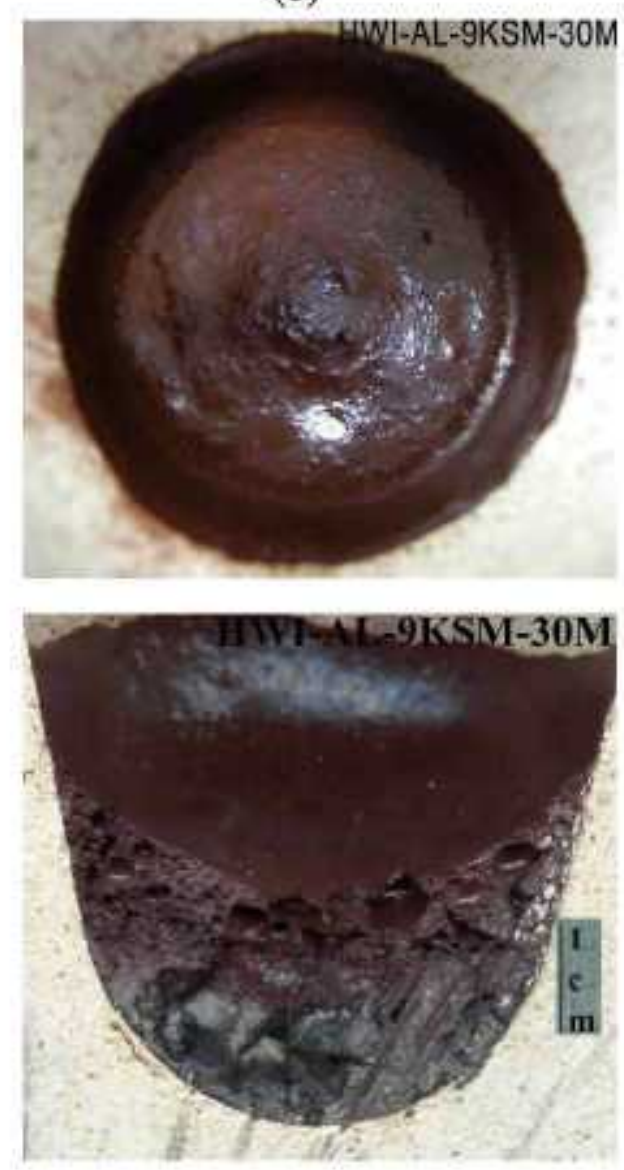

Figure 3.9. Top views and cross sections of Group 4 formulations after 30 minute test in VGF. (a) HWI-AI-13, (b) HWI-Al-17 and (b) HWI-Al-20. 
(a)
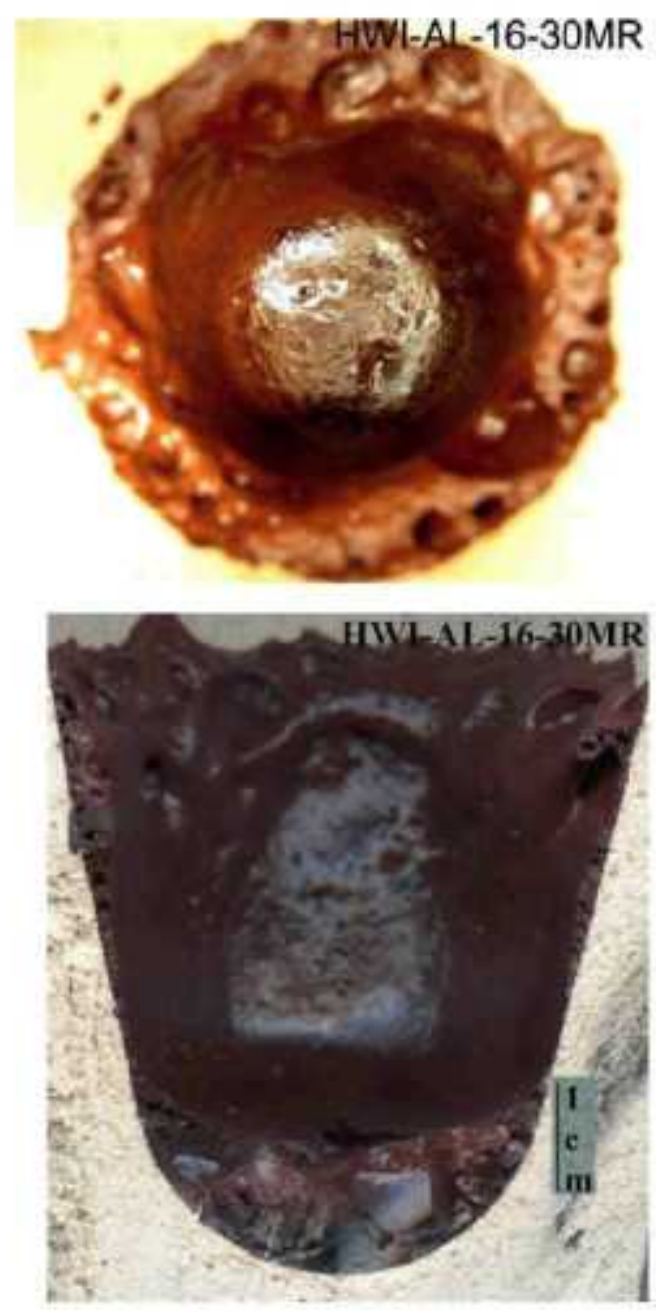

(b)
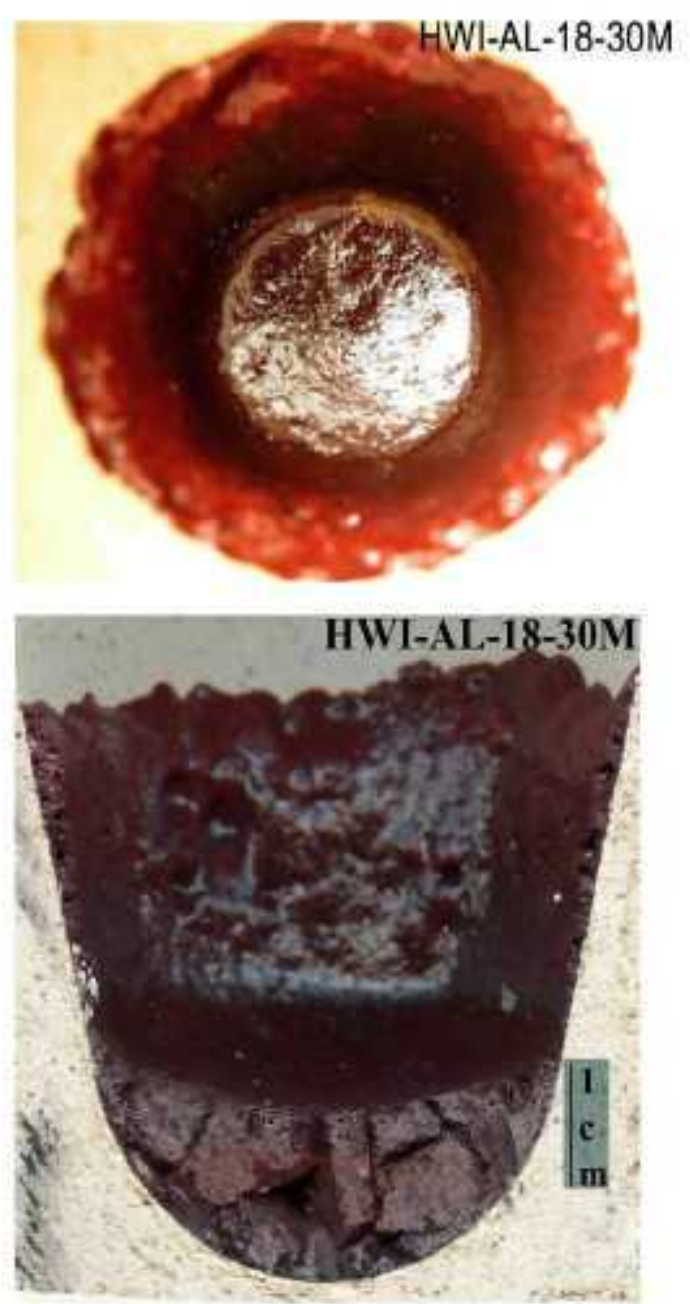

(c)
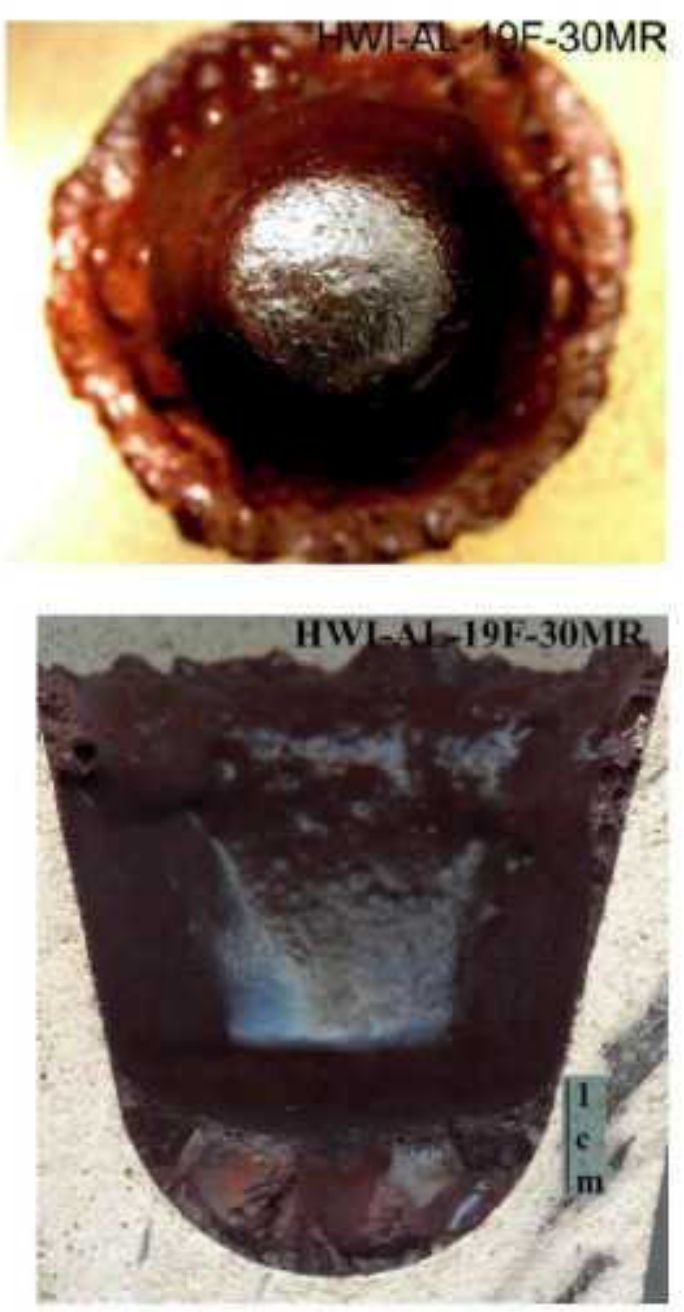

Figure 3.10. Top views and cross sections of Group 5 formulations after 30 minute test in VGF. (a) HWI-Al-16, (b) HWI-Al-18 and (c) HWI-Al-19. 
ORP-44236, Rev. 0

Melt Rate Enhancement for High Aluminum HLW Glass Fomulations Final Report, VSL-08RI360-1, Rev. 0 (a)
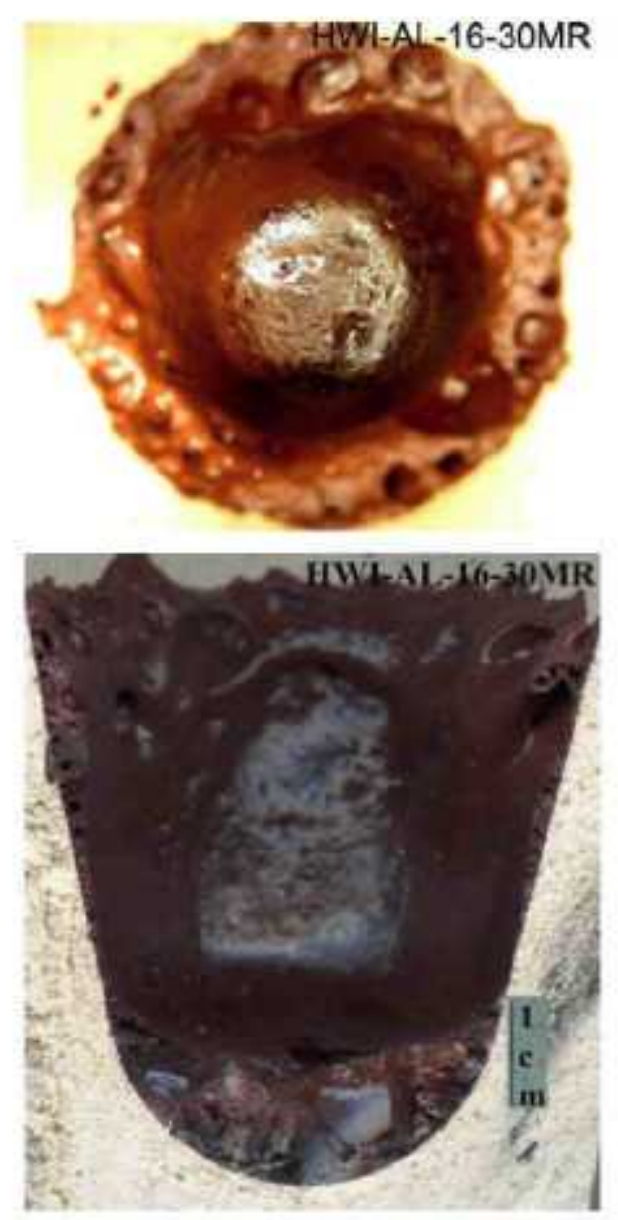

(b)
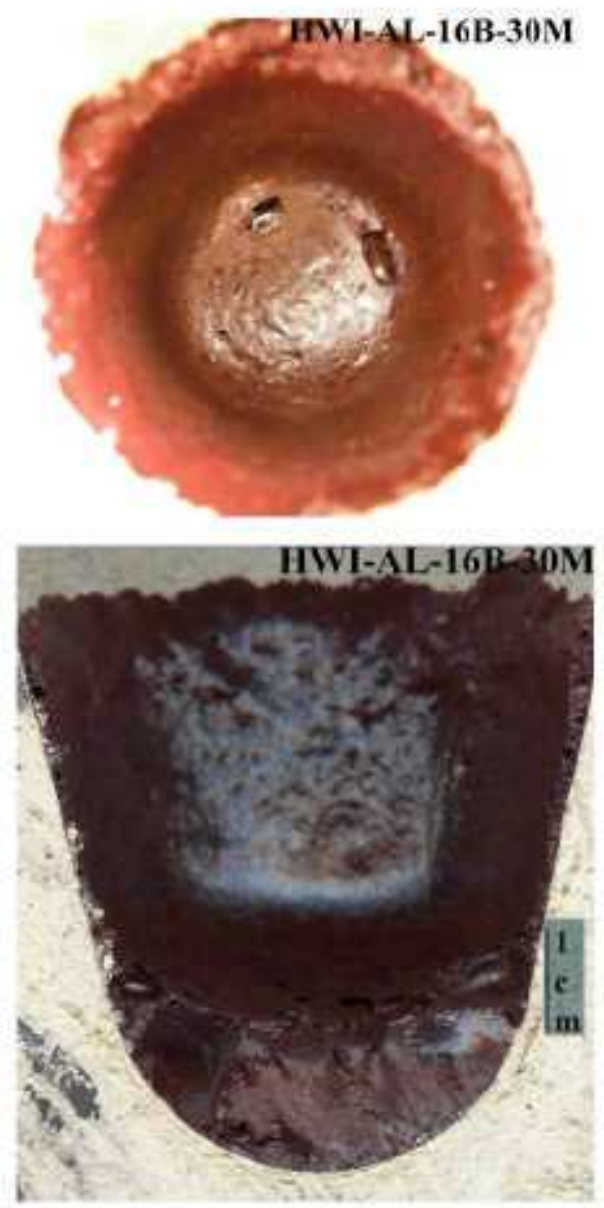

(c)
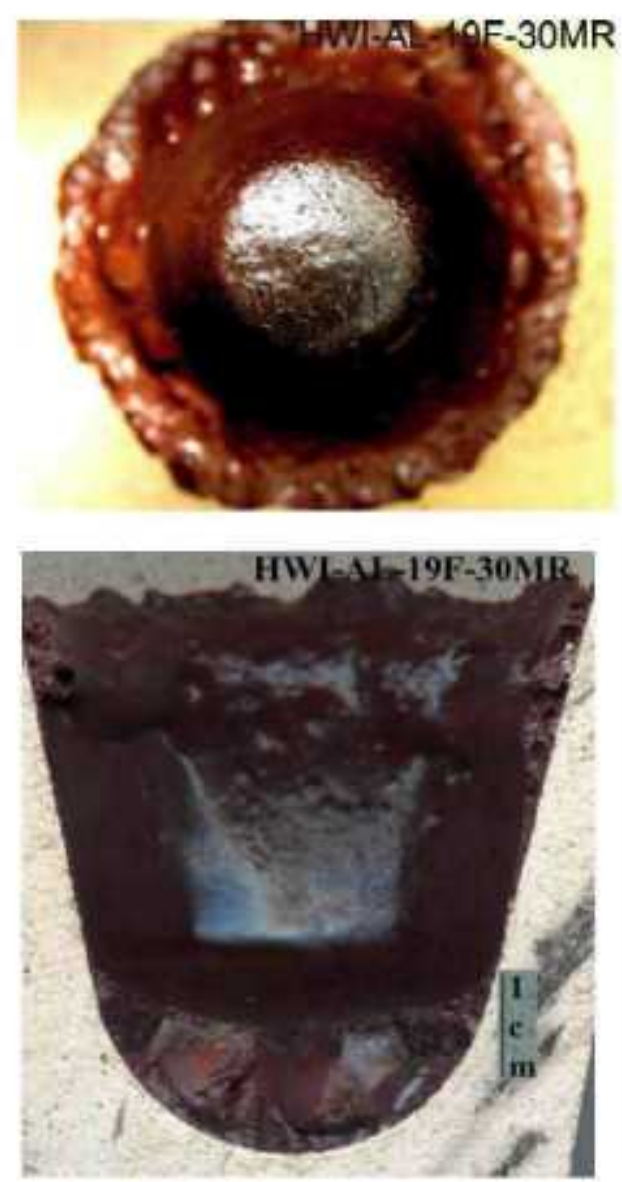

(d)
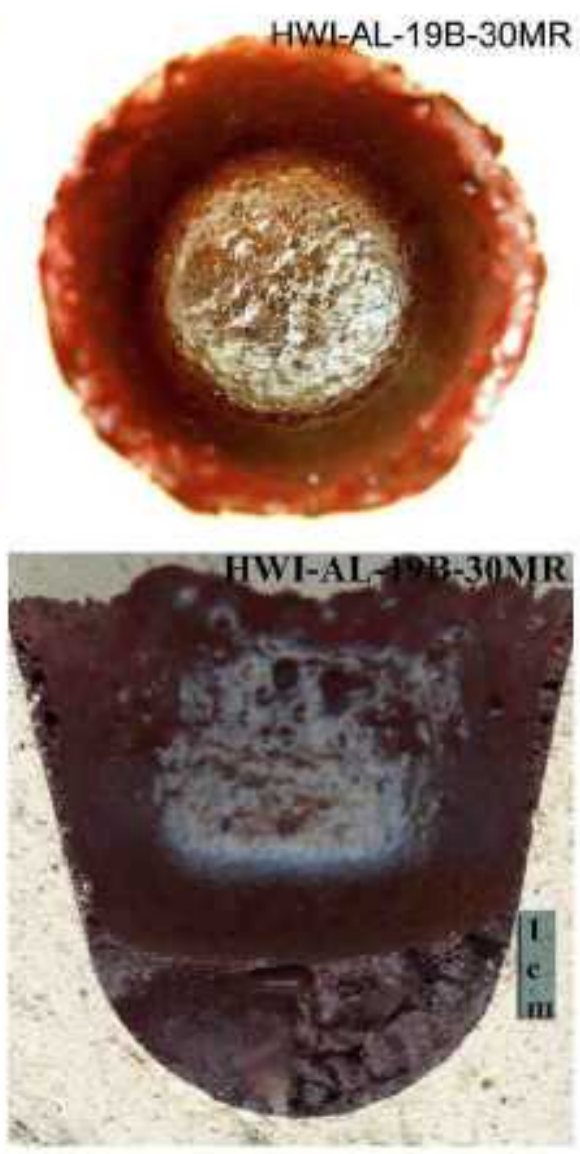

Figure 3.11. Top views and cross sections of feed samples after 30 minute test in VGF. (a) Feed $\mathrm{F}-\mathrm{HWI}-\mathrm{AI}_{\mathrm{I}}-\mathrm{C}_{6}\left(\mathrm{Al} \mathrm{O}_{3}\right.$ ), (b) Feed F-HWI-Al-16B $\left(\mathrm{Al}(\mathrm{OH})_{3}\right)$, (c) Feed F-HWI-Al-19F $\left(\mathrm{Al}_{2} \mathrm{O}_{3}\right)$, and (d) Feed F-HWI-Al-19B $\left(\mathrm{Al}(\mathrm{OH})_{3}\right)$. 


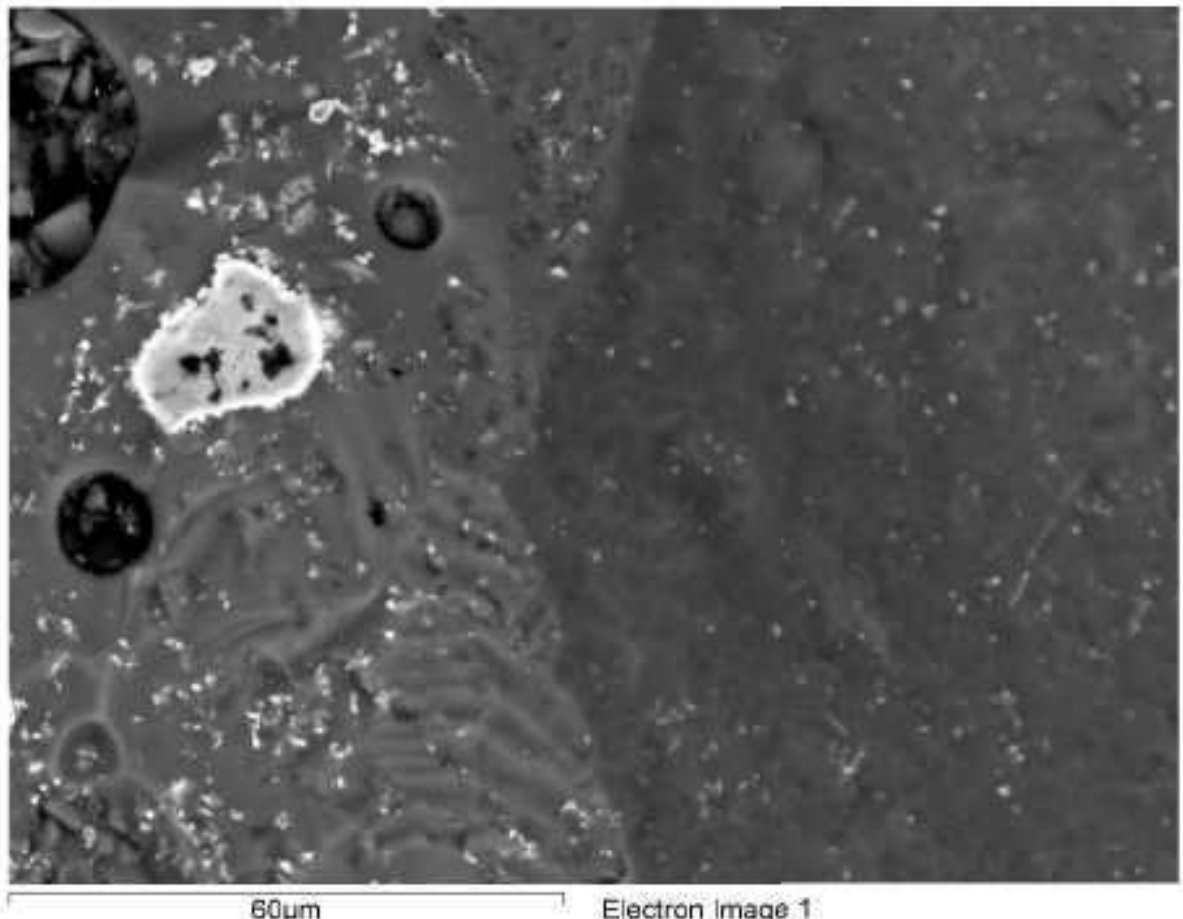

Electron Image 1

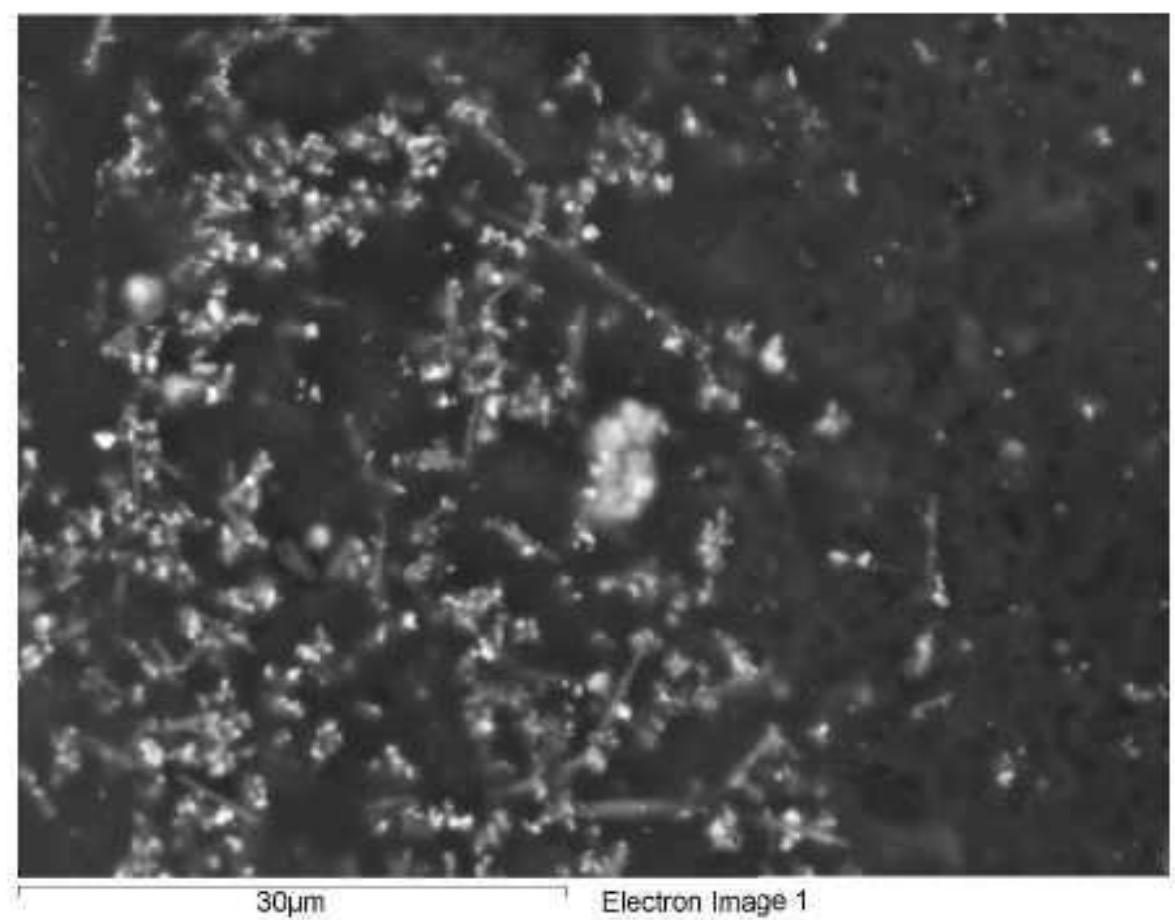

(a) Baseline feed for formulation HLW-E-Al-27 $\left(\mathrm{Al}_{2} \mathrm{O}_{3}\right)$

Figure 3.12. SEM images of partially reacted feed after 30 minute VGF tests. 


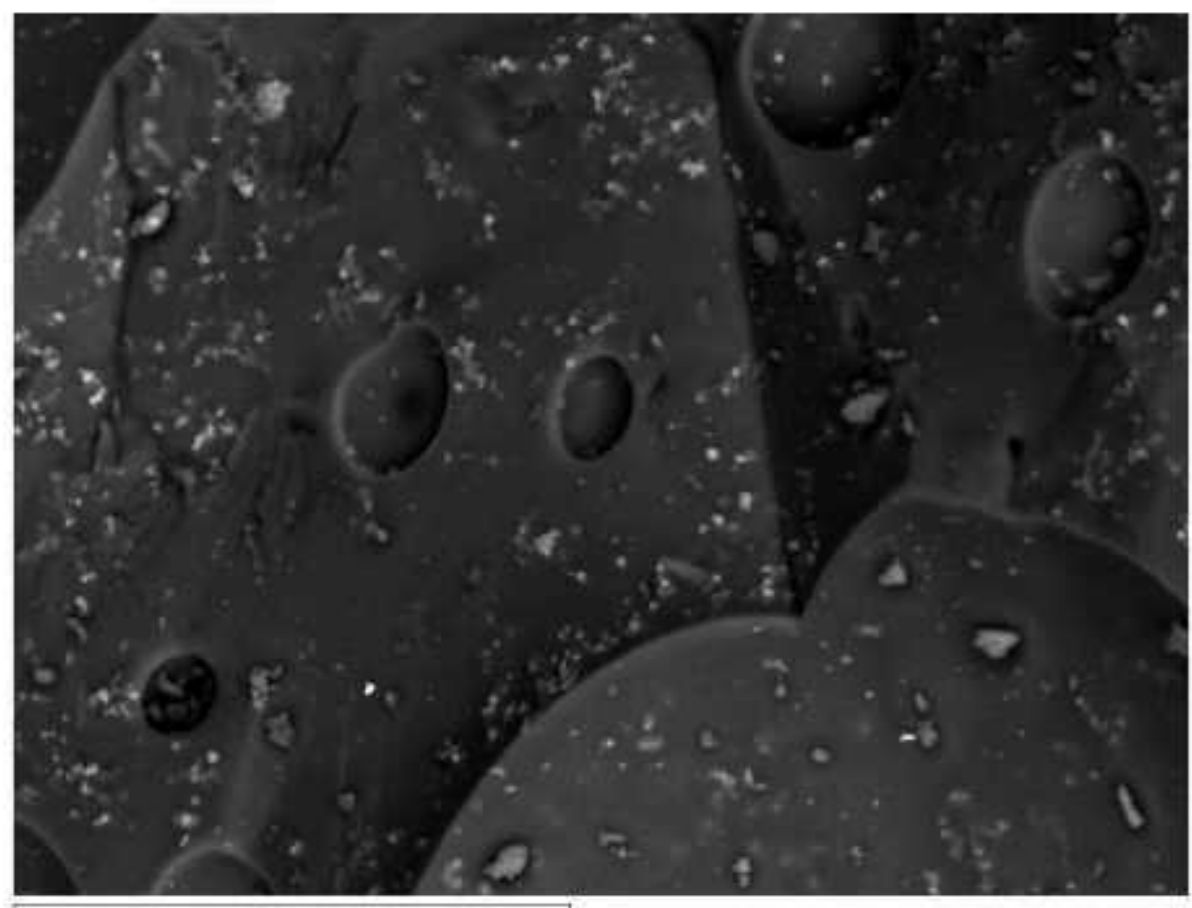

60um

Electron Image 1

(b) Feed for formulation HWI-Al-16 $\left(\mathrm{Al}_{2} \mathrm{O}_{3}\right)$

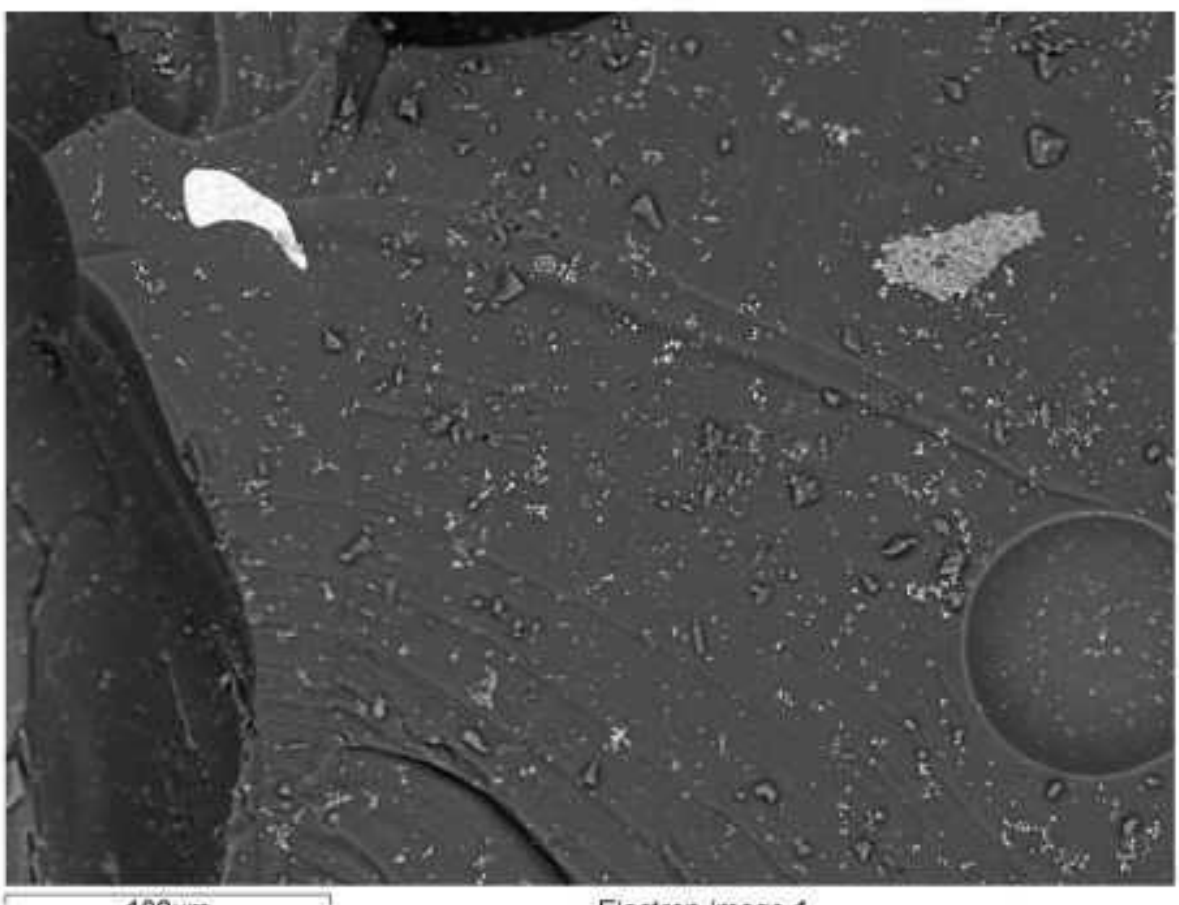

$100 \mu \mathrm{m}$

Electron Image 1

(c) Feed for formulation HWI-Al-16 $\left(\mathrm{Al}(\mathrm{OH})_{3}\right)$

Figure 3.12. SEM images of partially reacted feed after 30 minute VGF tests (continued). 


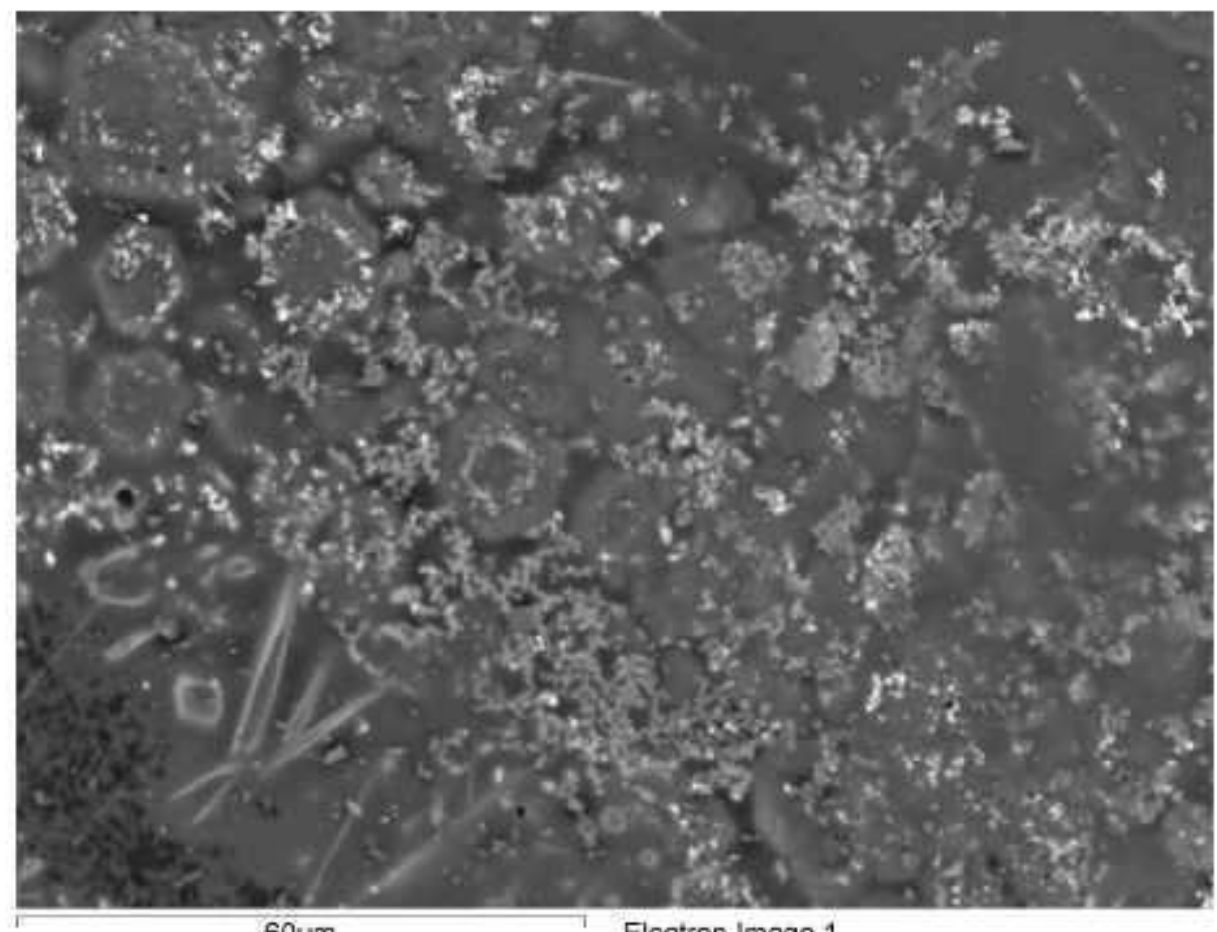

60um

Electron Image 1

(d) Feed for formulation HWI-Al-19 $\left(\mathrm{Al}_{2} \mathrm{O}_{3}\right)$

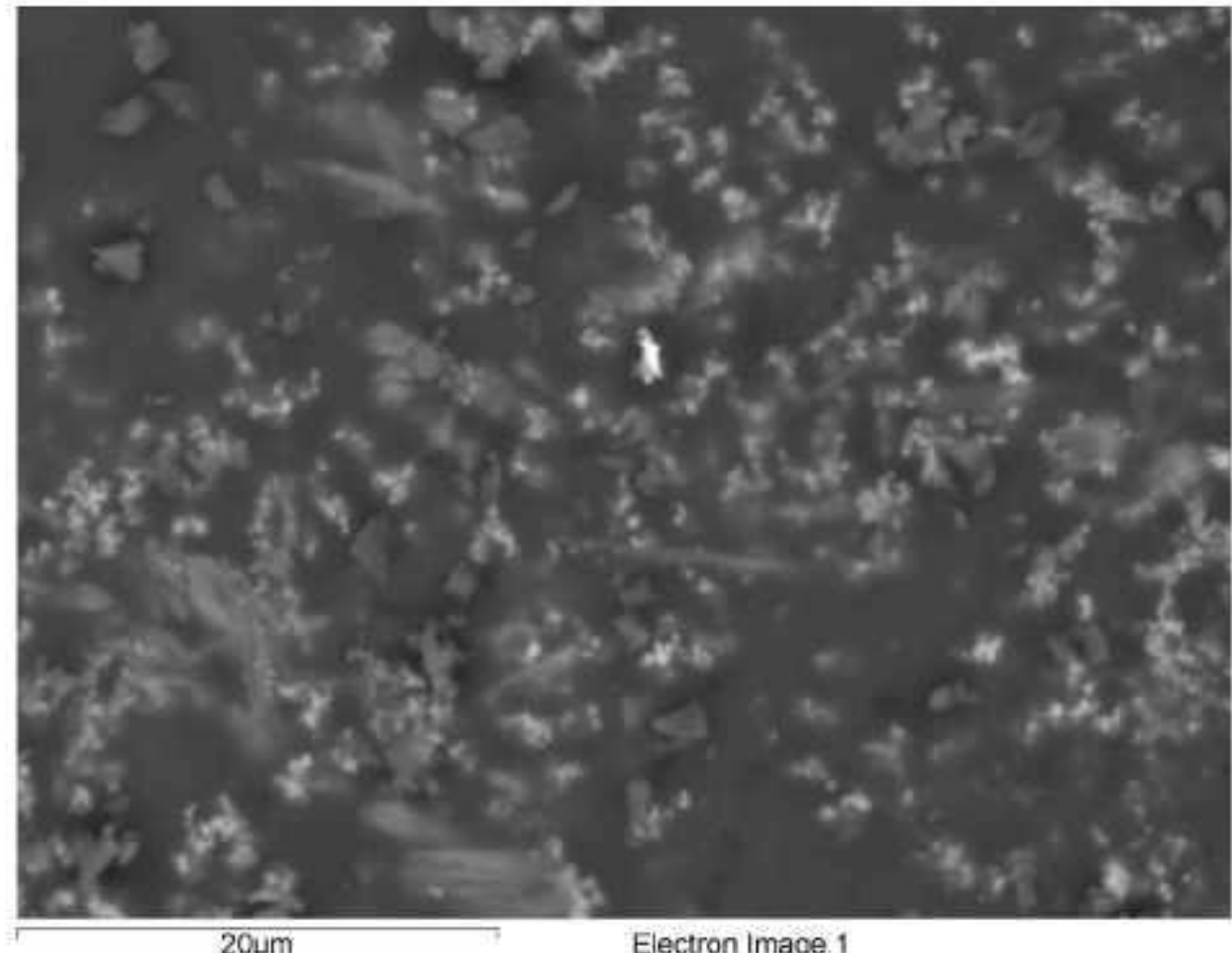

20jm Electron Image 1

(e) Feed for formulation HWI-Al-19 $\left(\mathrm{Al}(\mathrm{OH})_{3}\right)$

Figure 3.12. SEM images of partially reacted feed after 30 minute VGF tests (continued). 


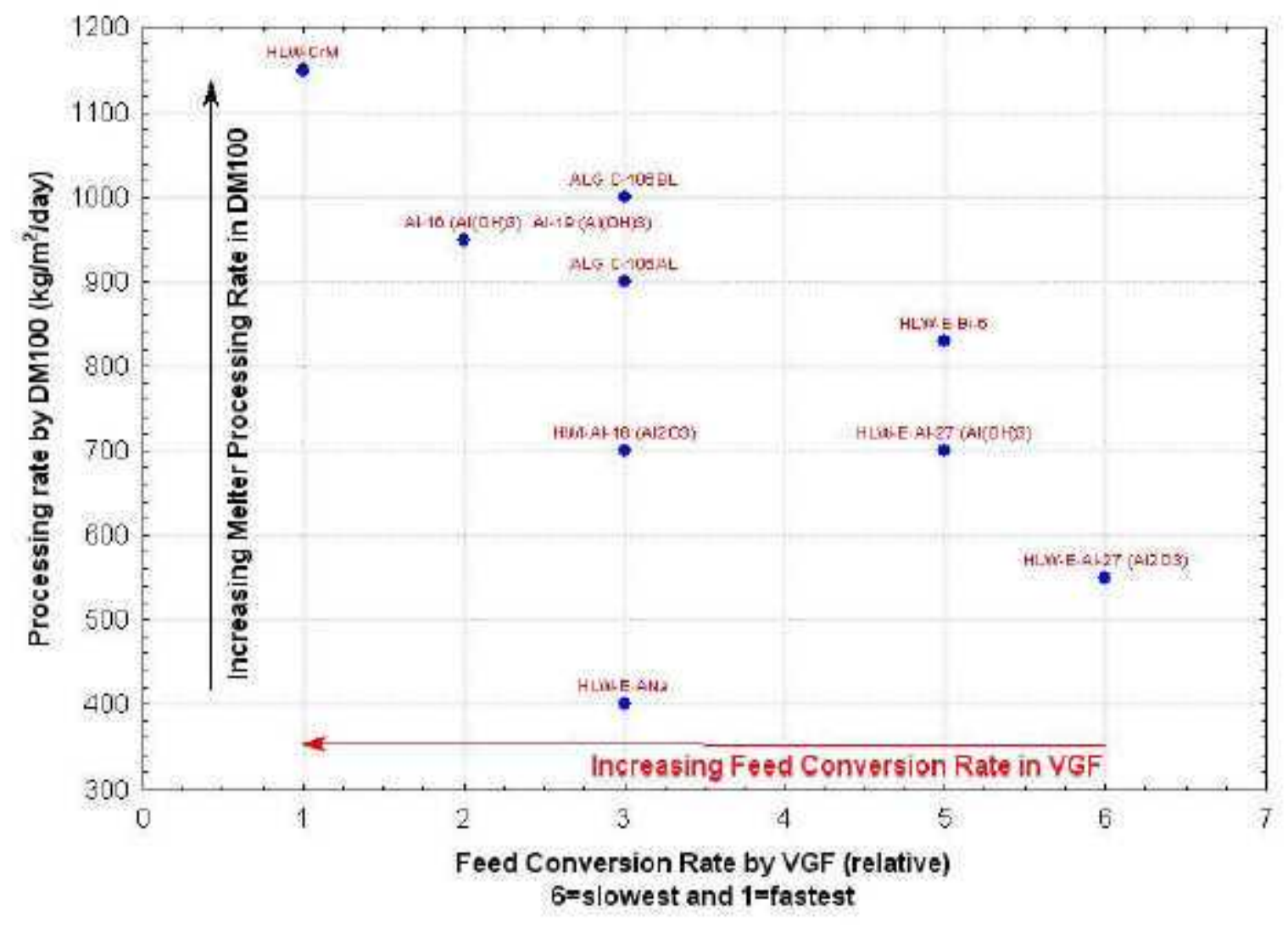

Figure 3.13. Comparison of melt rate ranking by VGF to the glass production rate determined by DM 100 melter test. The definition of the VGF melt rate estimation is given in Table 3.5 . 


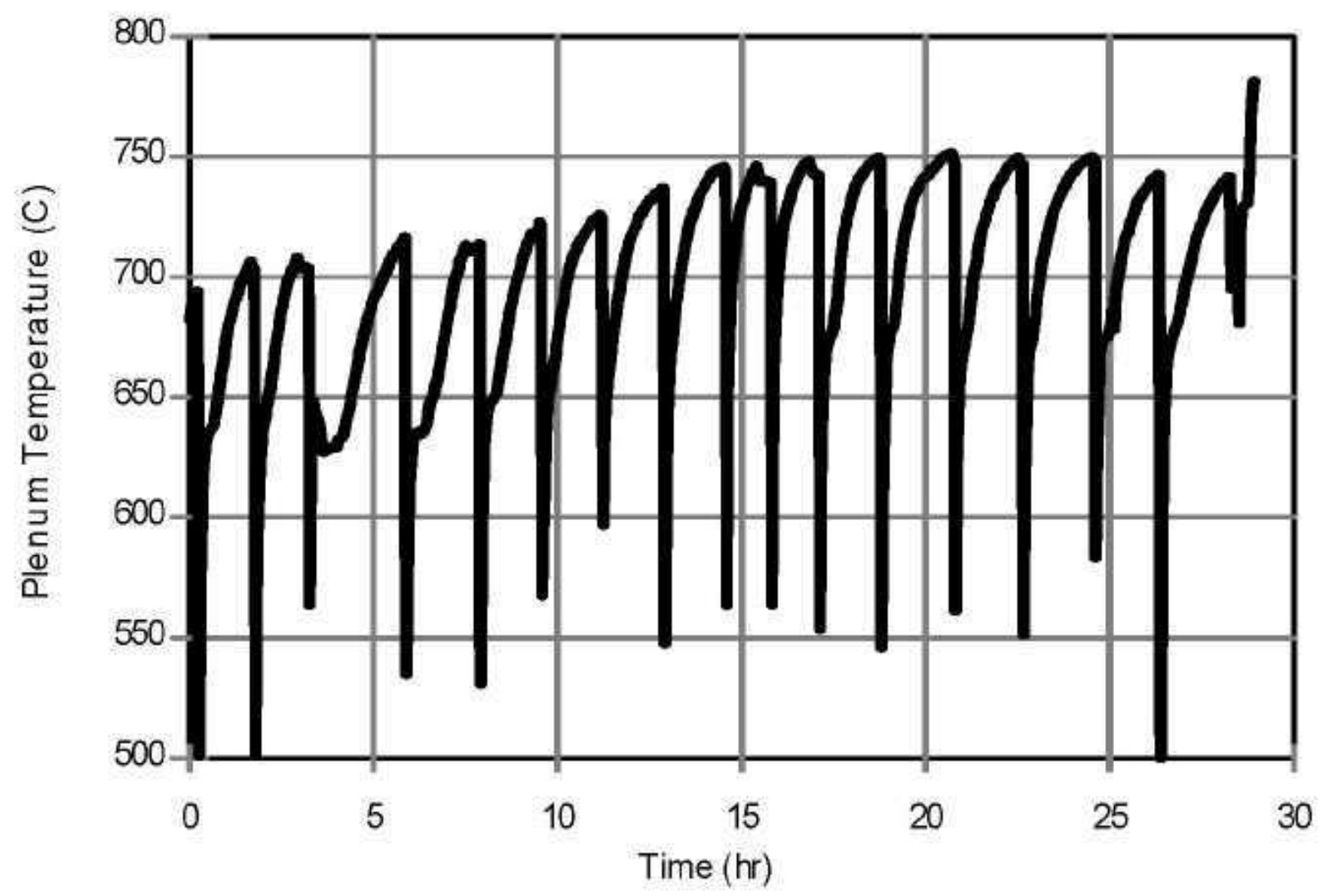

Figure 3.14. Changes in average plenum temperature over a series of DM10 feed consumption tests. 


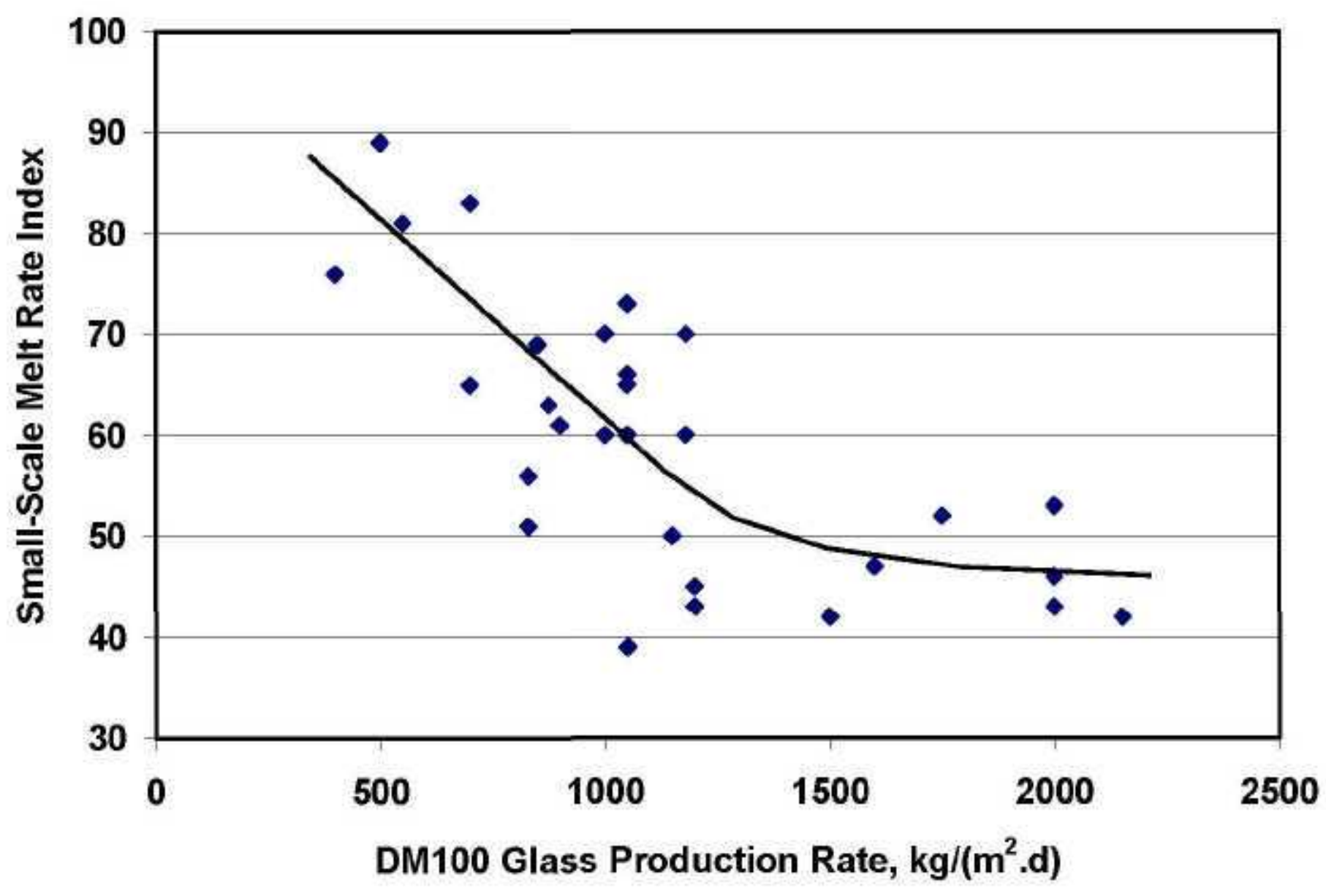

Figure 3.15. Correlation of DFC melt rate screening test data and DM100 production rates for a wide variety of feed compositions. 
HLWE-Al-27 with Al2O3, Boric Acid K2CO3

HWIAI-9KSM

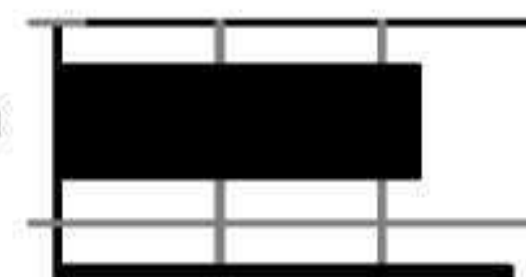

HWI-Al-9
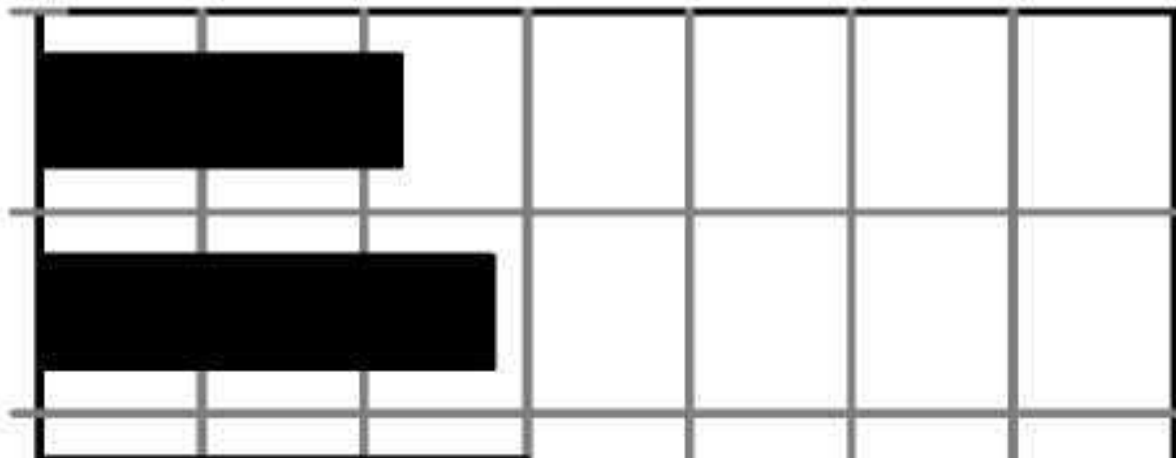

HLW-E Al-27 with Al203, Boric Acid/Soda Ash
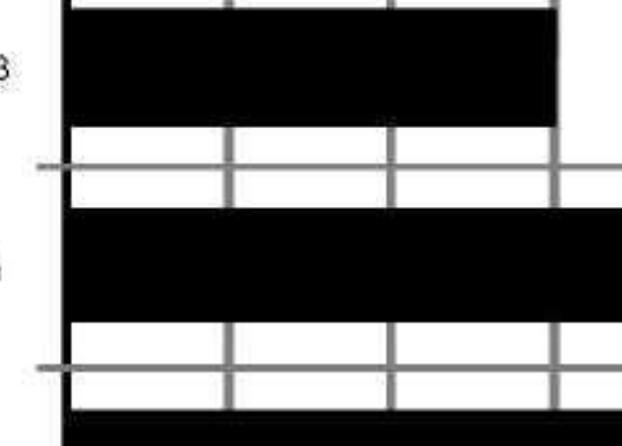

HLW-E-AI-27 with AI $(\mathrm{OH}) 3$

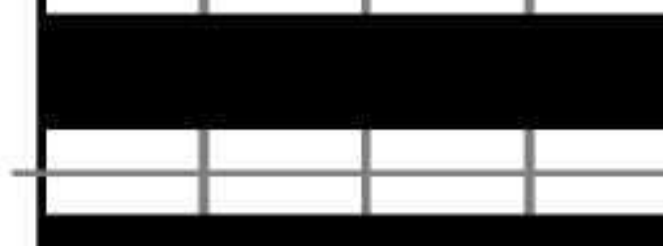

HLW-E-AI-27 with Al203
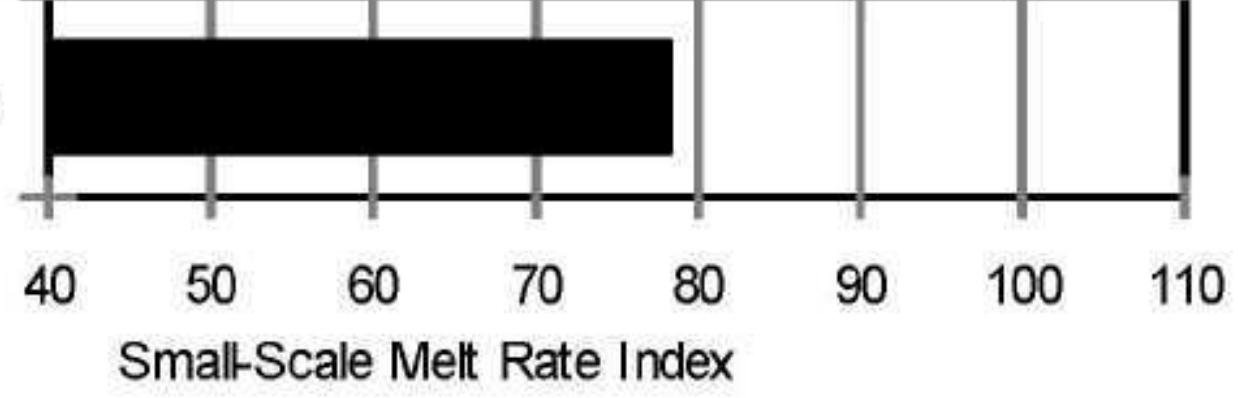

Figure 3.16. Comparison of base feeds from DFCmelt rate screening tests. 


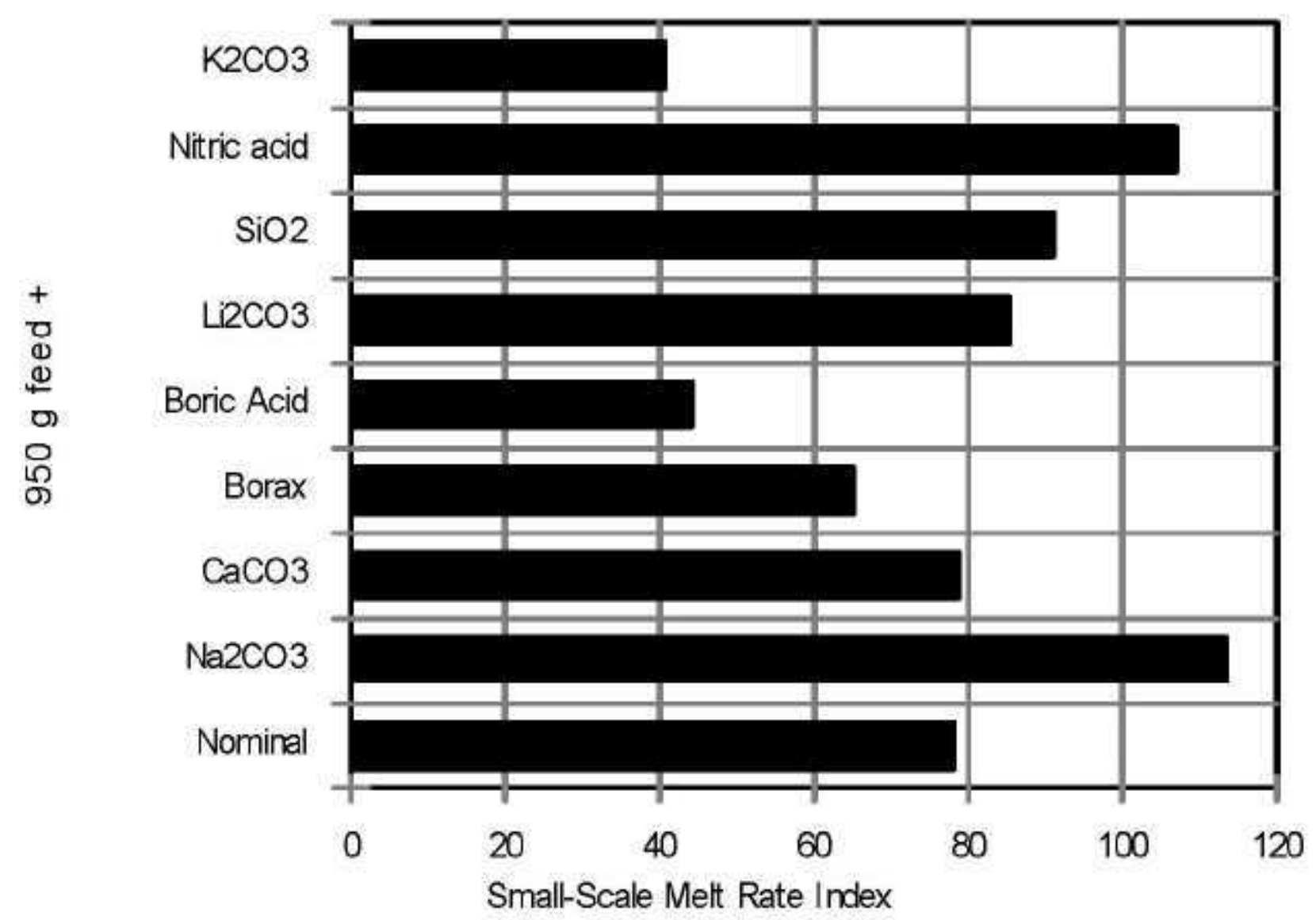

Figure 3.17. Comparison of additives combined with $\mathrm{HLW}-\mathrm{E}-\mathrm{AL}-27\left(\mathrm{Al}_{2} \mathrm{O}_{3}\right)$ from $\mathrm{DFC}$ melt rate screening tests. 


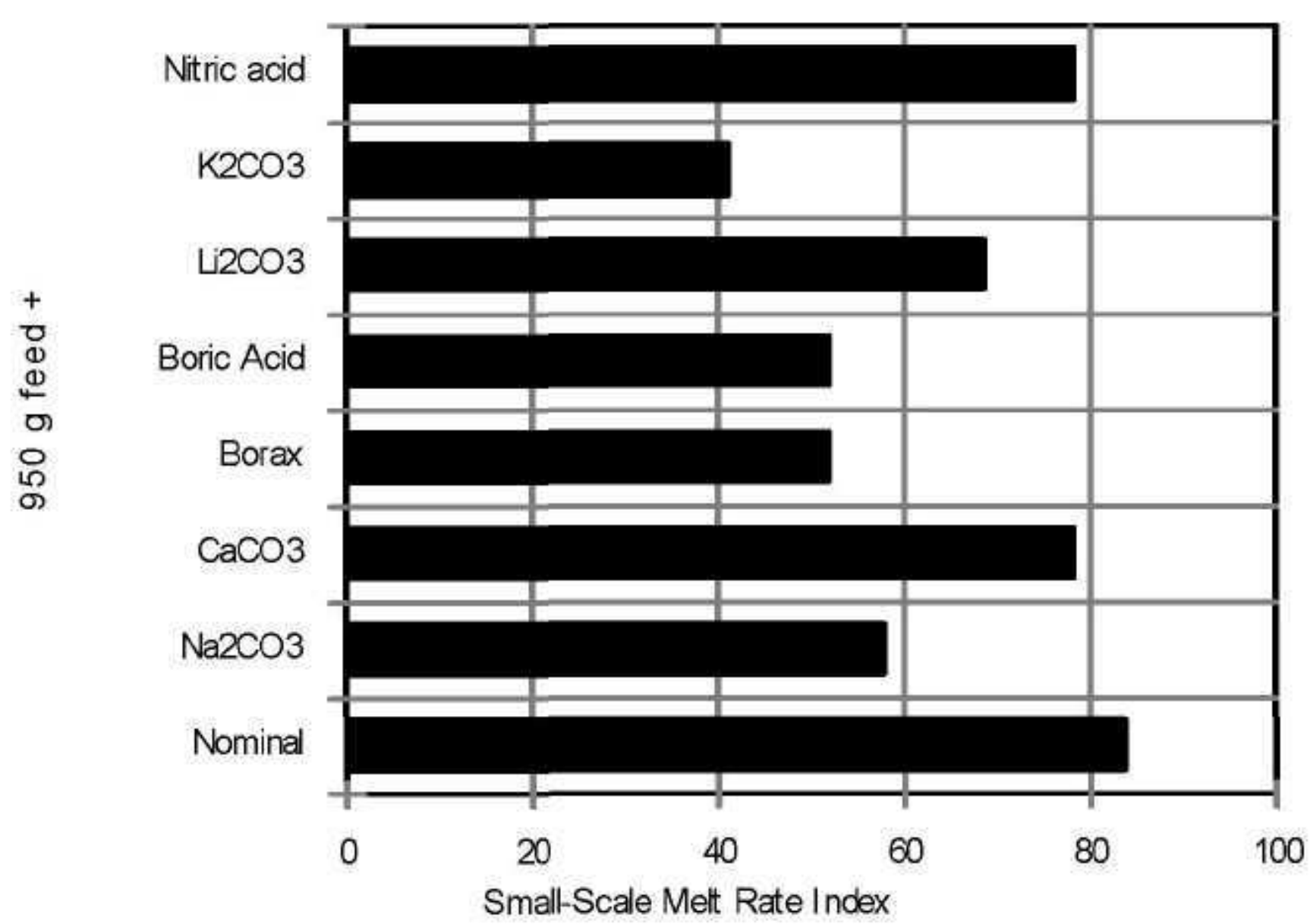

Figure 3.18. Comparison of additives combined with $\mathrm{HLW}-\mathrm{E}-\mathrm{AL}-27\left(\mathrm{Al}(\mathrm{OH})_{3}\right)$ from $\mathrm{DFC}$ melt rate screening tests. 


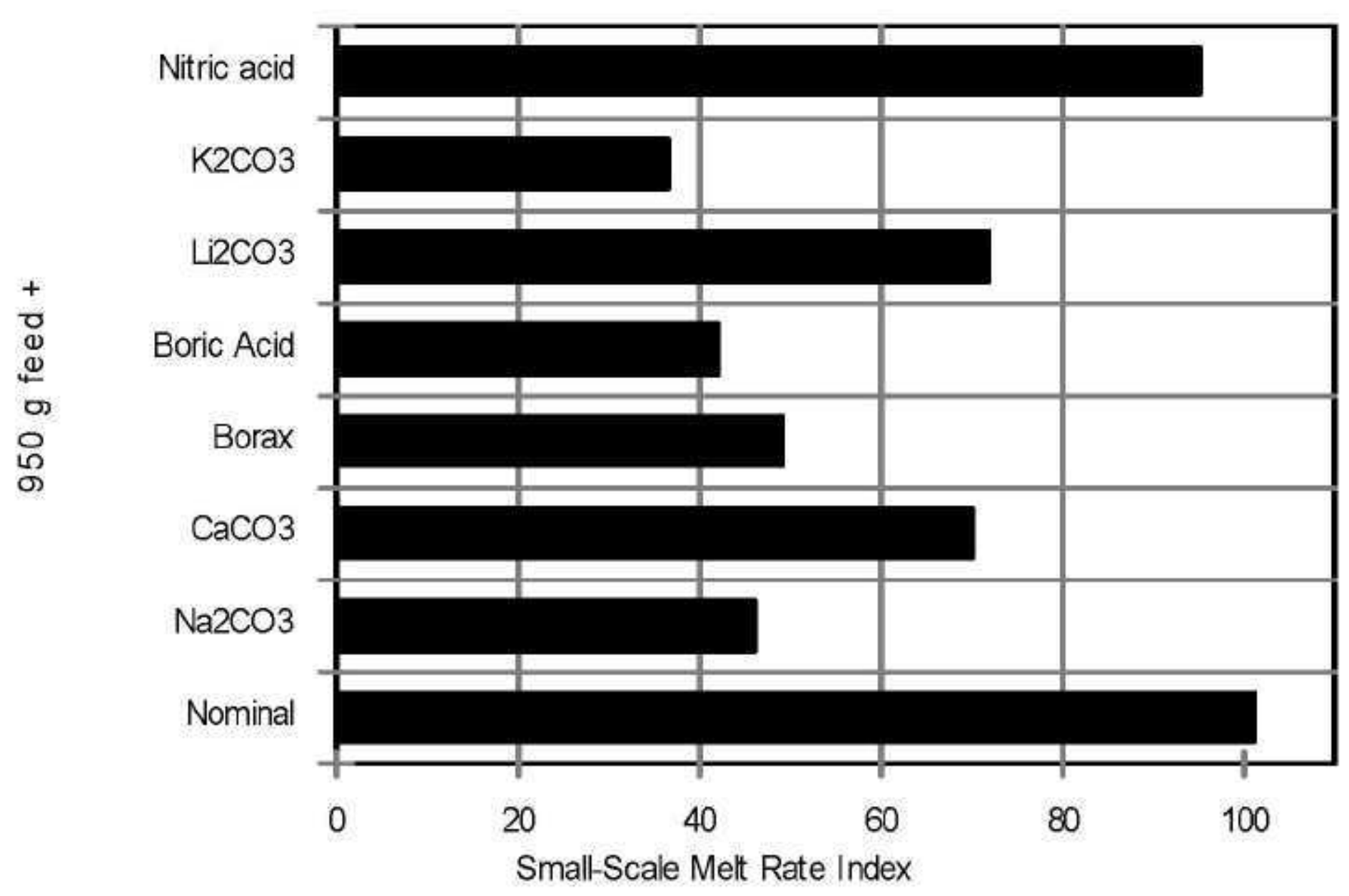

Figure 3.19. Comparison of additives combined with $\mathrm{HLW}-\mathrm{E}-\mathrm{AL}-27\left(\mathrm{Al}_{2} \mathrm{O}_{3}+\right.$ boric acid/soda ash replacing borax) from DFC melt rate screening tests. 


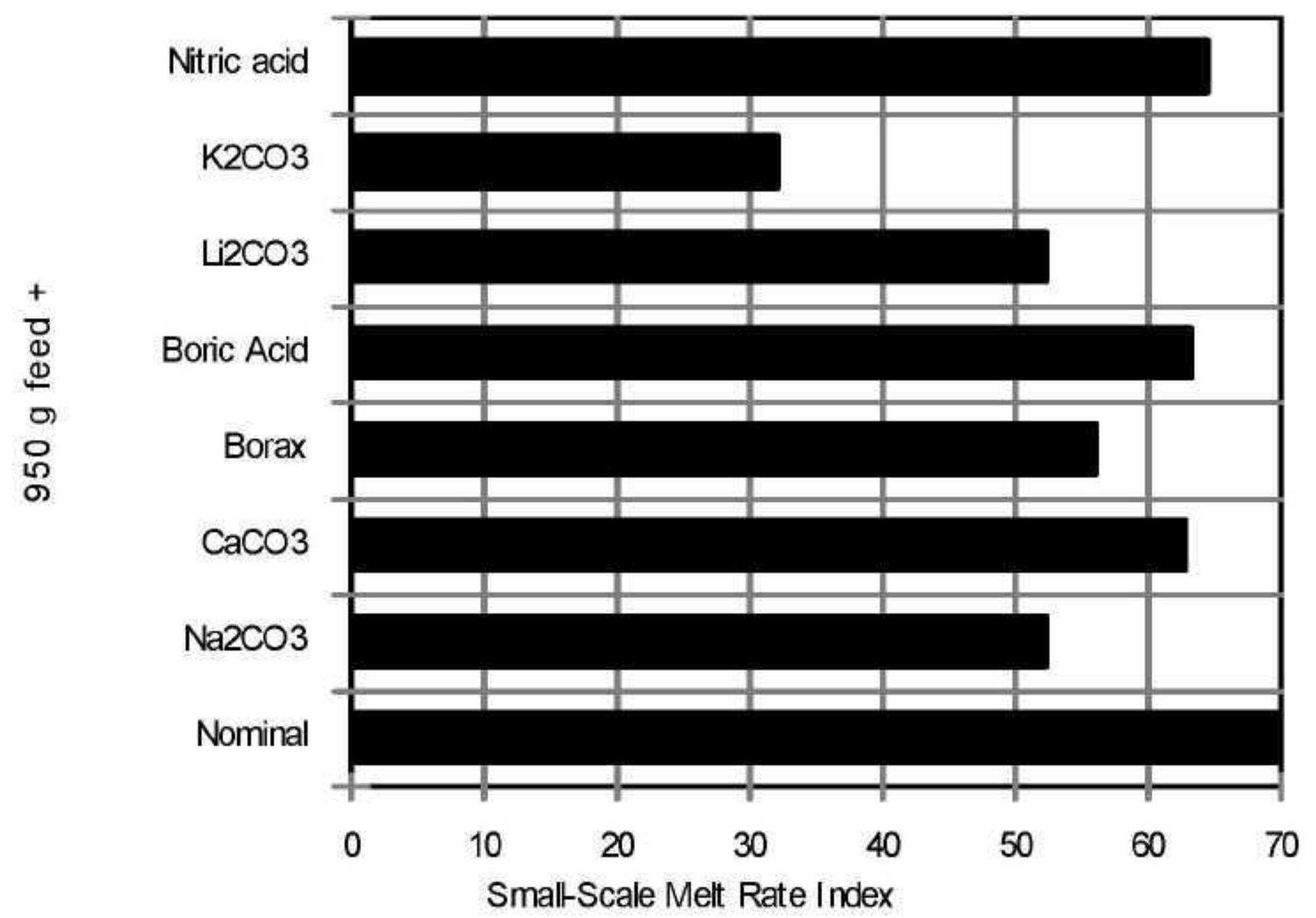

Figure 3.20. Comparison of additives combined with HLW-E-AL-27 $\left(\mathrm{Al}_{2} \mathrm{O}_{3}+\right.$ boric acid/potassium carbonate replacing borax) from DFC melt rate screening tests. 

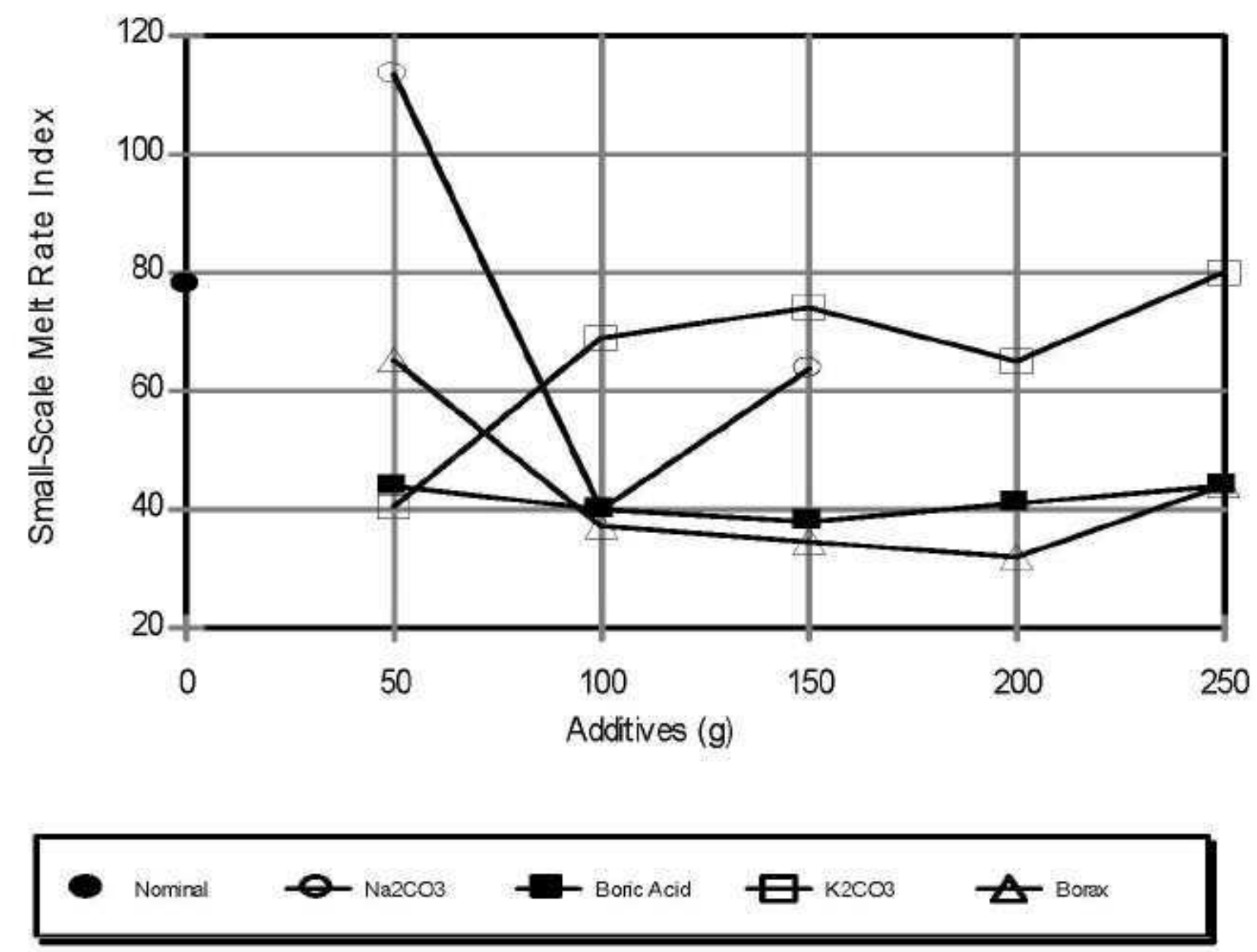

Figure 3.21. Comparison of additives and amounts combined with $\mathrm{HLW}-\mathrm{E}-\mathrm{AL}-27\left(\mathrm{Al}_{2} \mathrm{O}_{3}\right)$ from DFC melt rate screening tests. 


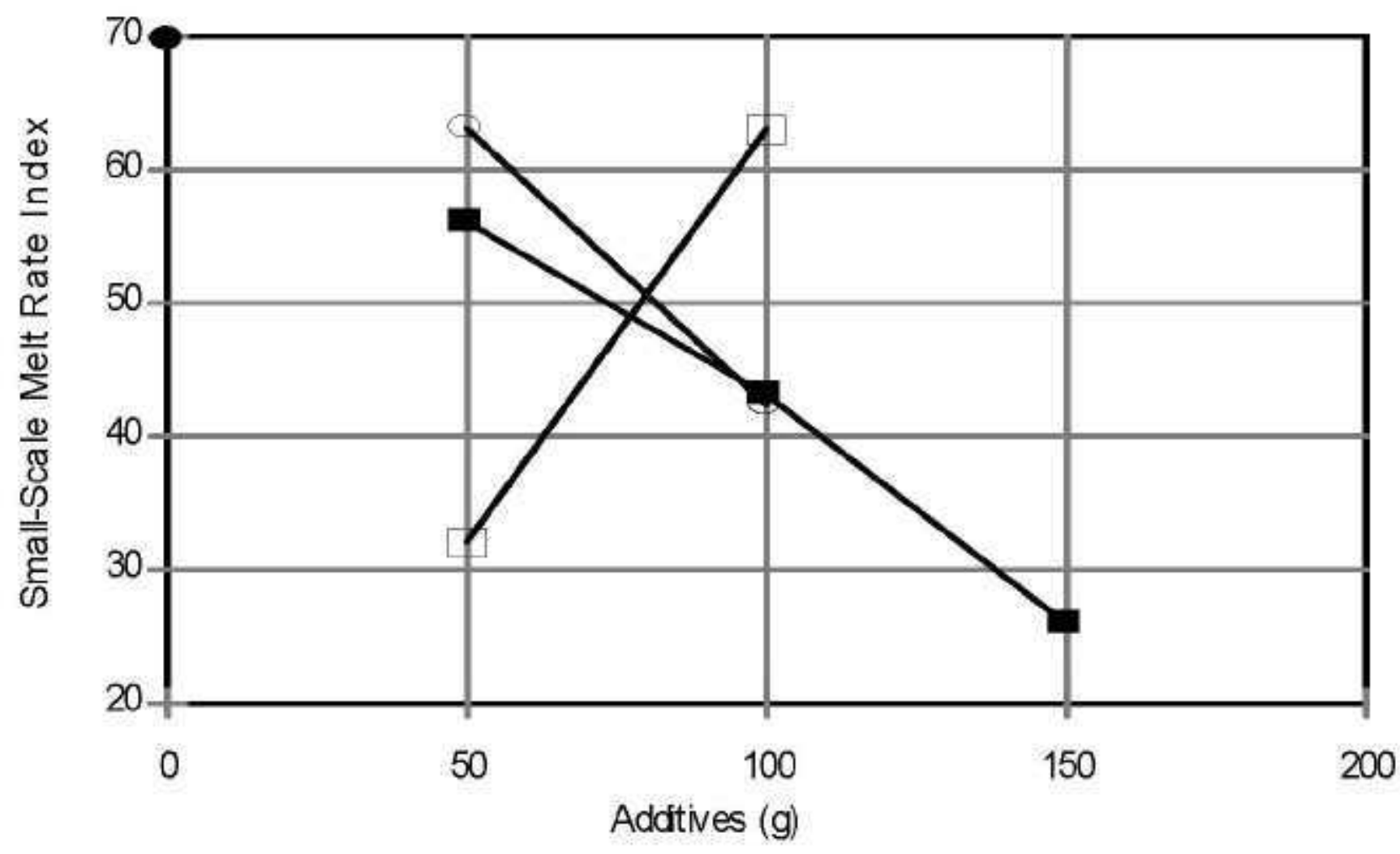

Figure 3.22. Comparison of additives and amounts combined with $\mathrm{HLW}-\mathrm{E}-\mathrm{AL}-27\left(\mathrm{Al}_{2} \mathrm{O}_{3}+\right.$ boric acid/potassium carbonate replacing borax) from DFC melt rate screening tests. 

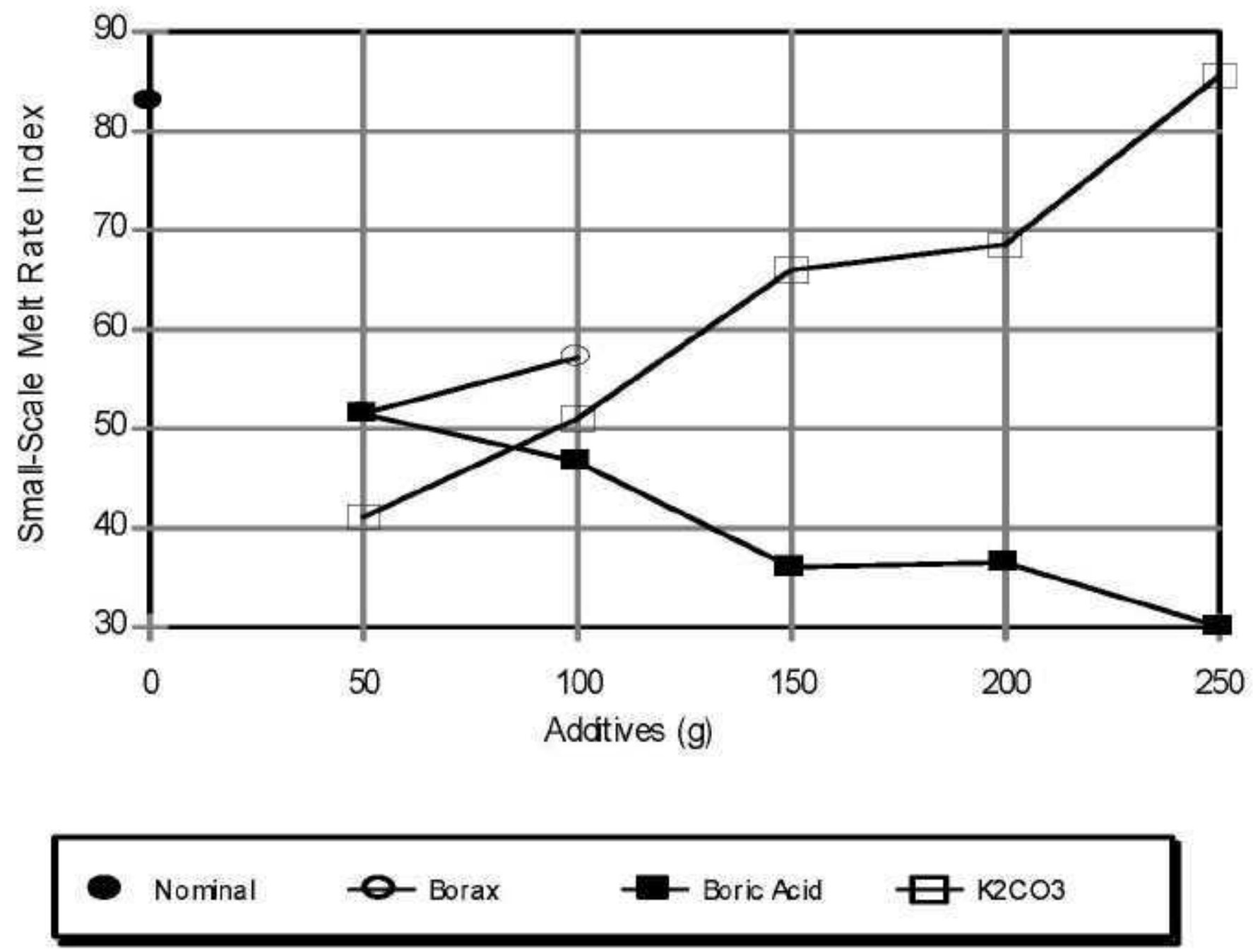

Figure 3.23. Comparison of additives and amounts combined with HLW-E-AL-27 $\left(\mathrm{Al}(\mathrm{OH})_{3}\right)$ from DFC melt rate screening tests. 


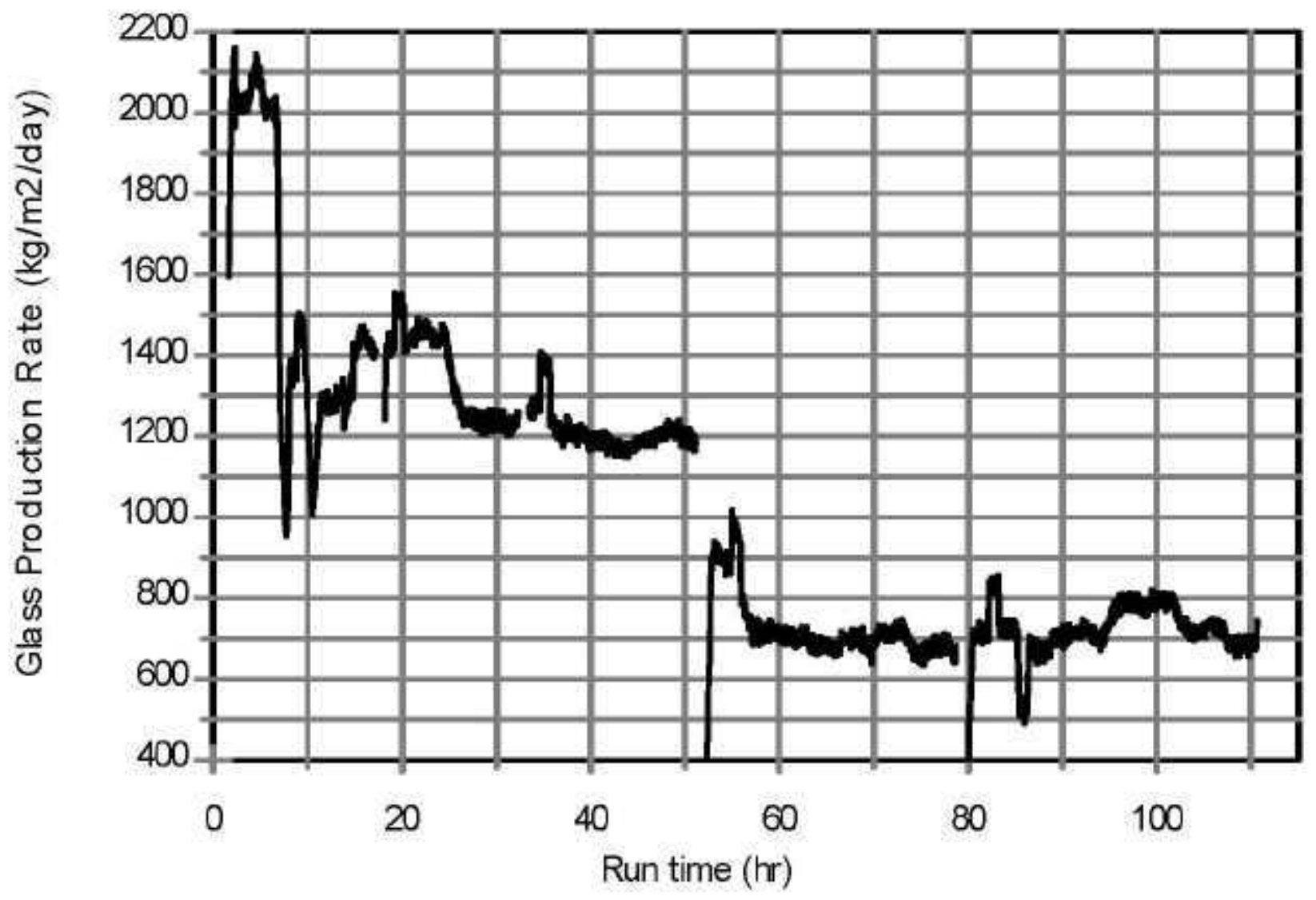

Figure 4.1.a. Glass production rates (hourly moving averages) for DM100 Tests 1 and 2. 


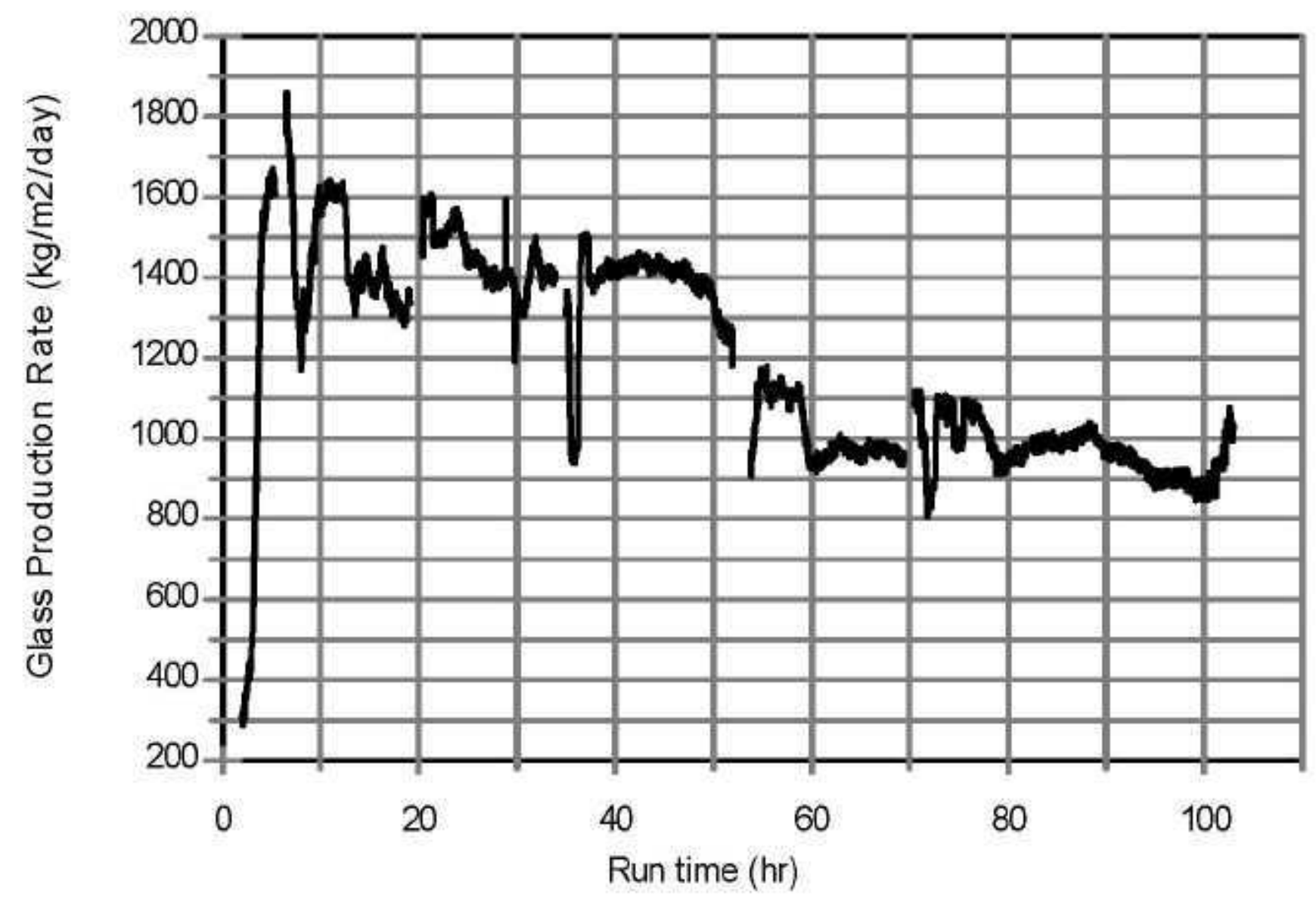

Figure 4.1.b. Glass production rates (hourly moving averages) for DM100 Tests 3 and 4. 


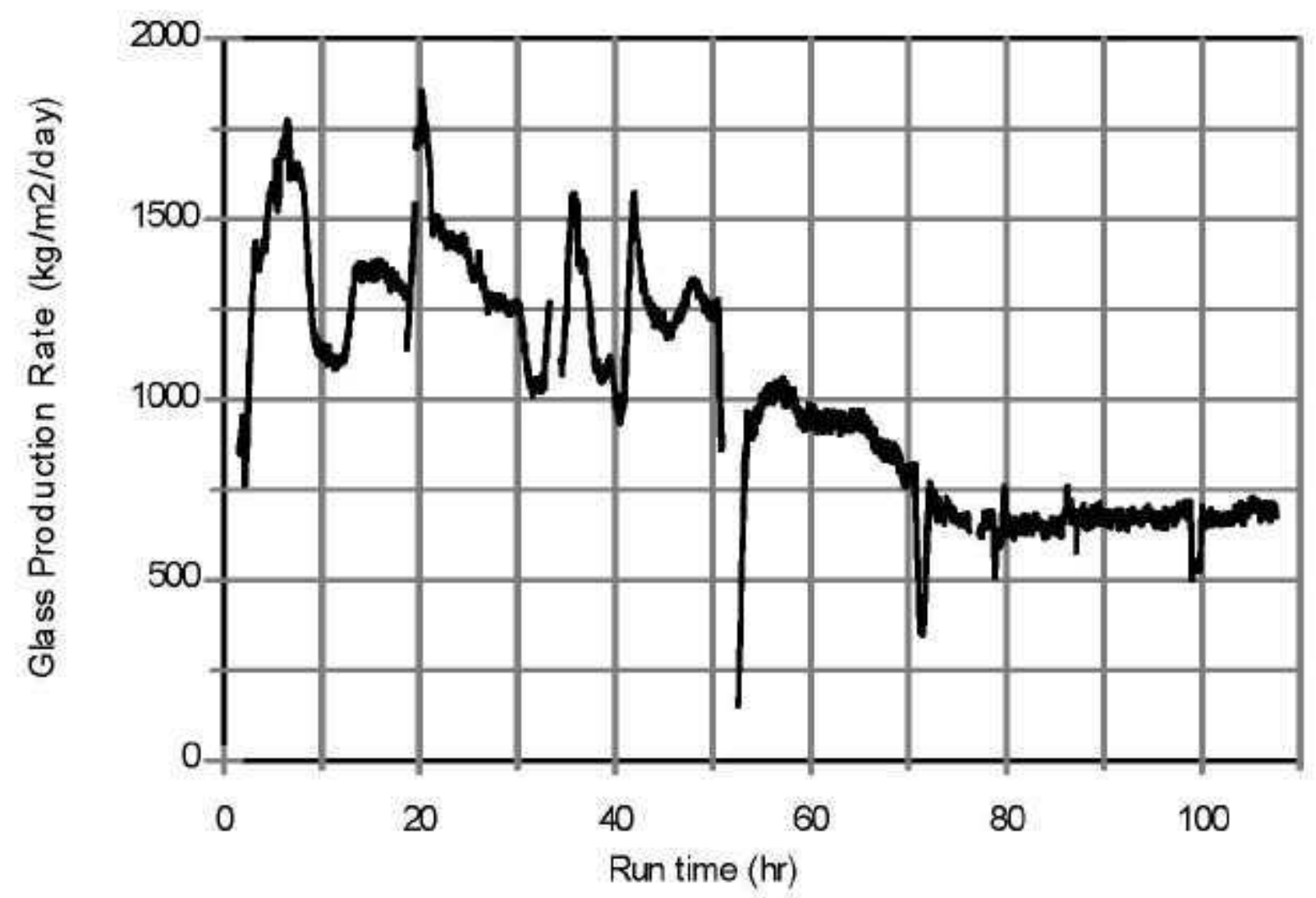

Figure 4.1.c. Glass production rates (hourly moving averages) for DM100 Tests 5 and 6. 


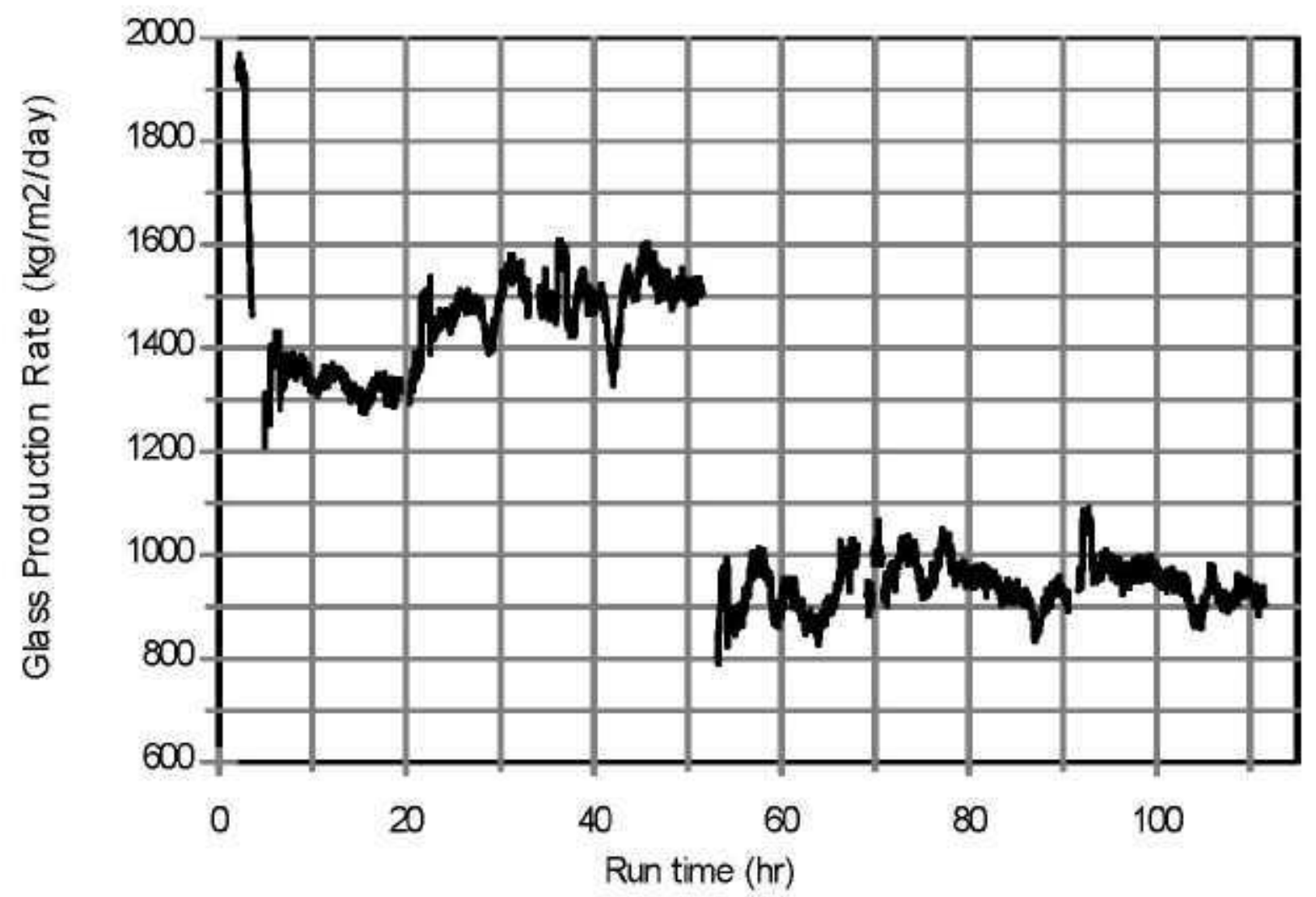

Figure 4.1.d. Glass production rates (hourly moving averages) for DM100 Tests 7 and 8. 


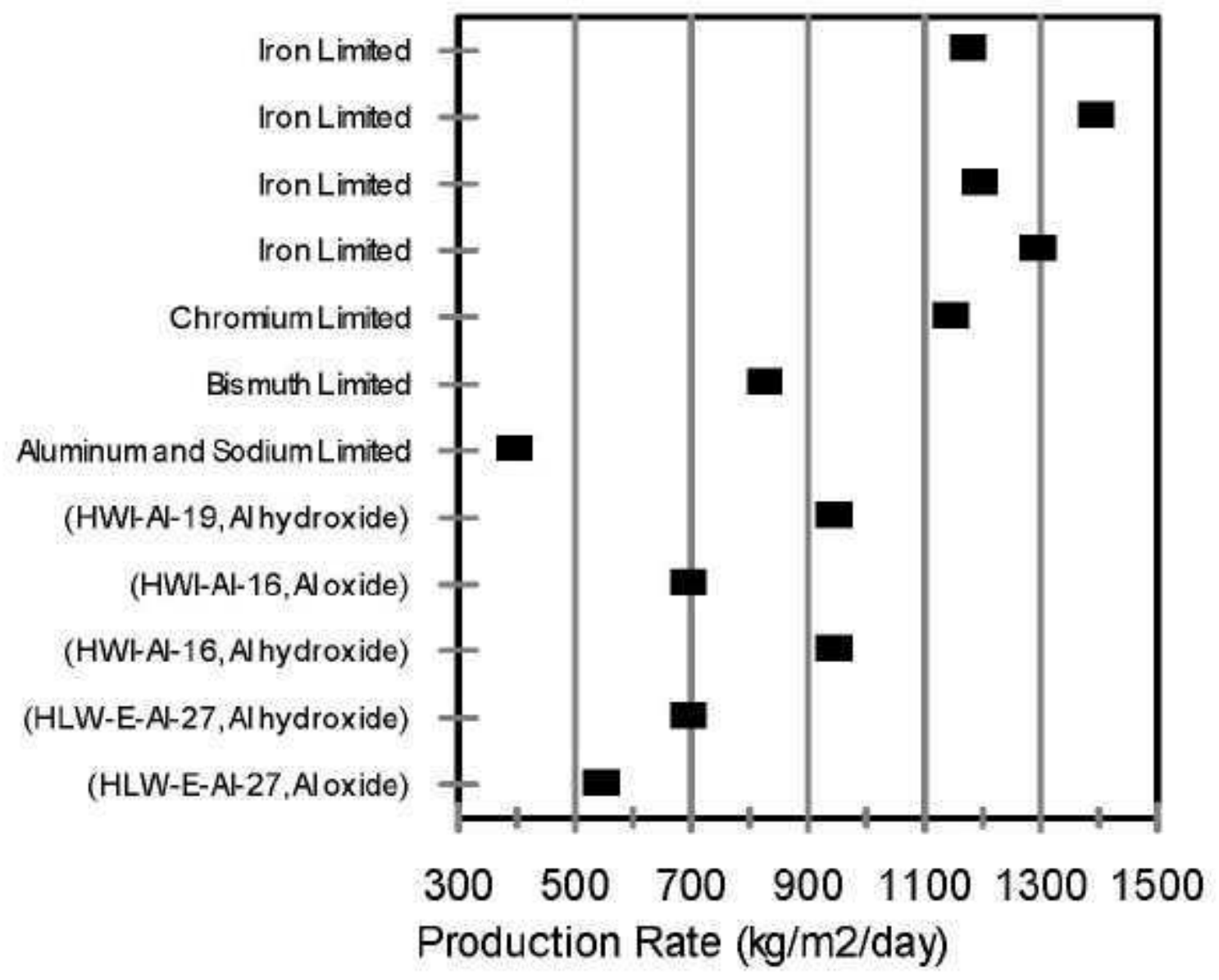

Figure 4.2. Steady-state glass production rates during DM100 tests at constant bubbling rate, glass temperature $\left(1150^{\circ} \mathrm{C}\right)$, and feed solids content $500( \pm 50) \mathrm{g}$ glass per liter feed. 

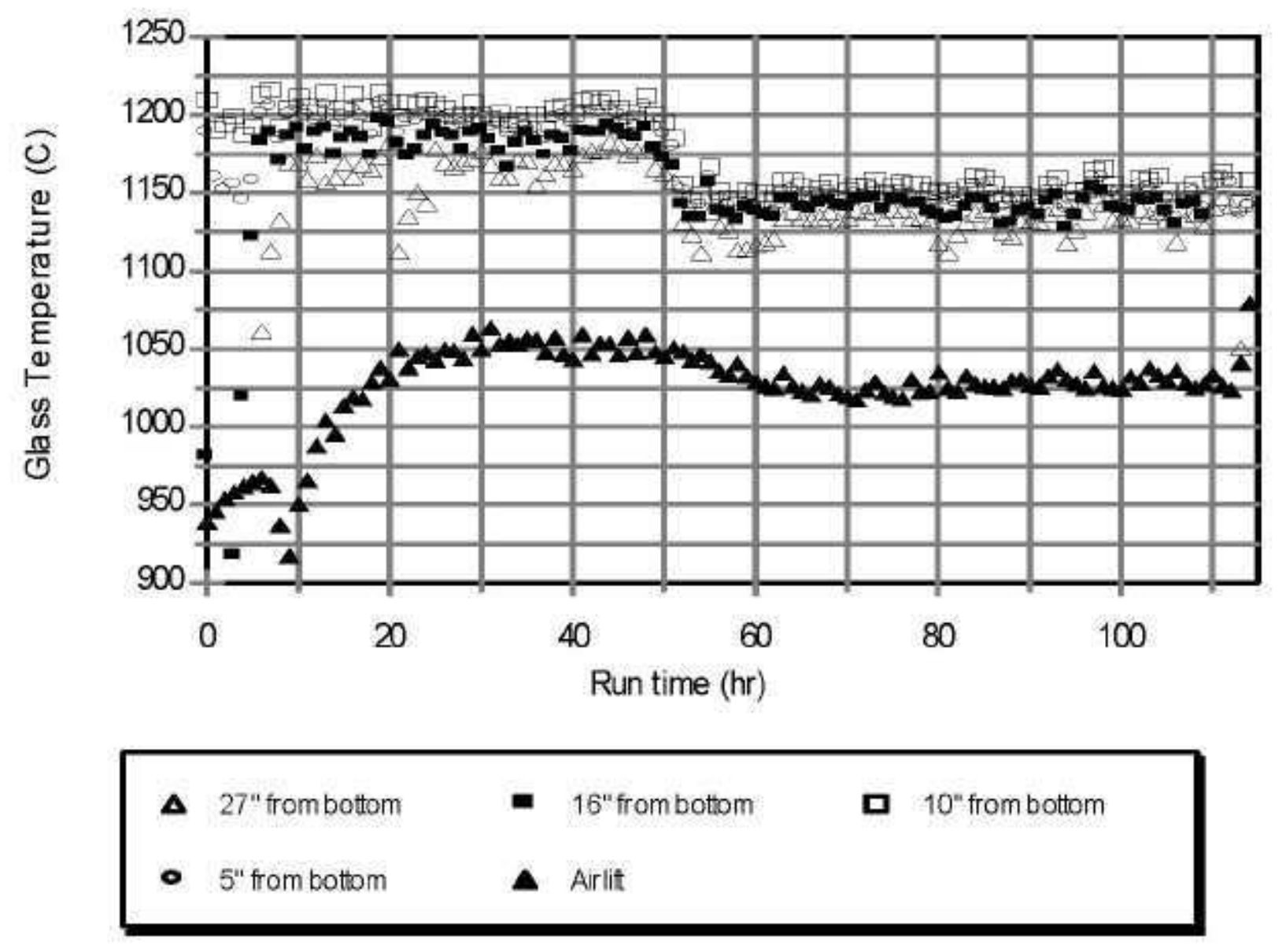

Figure 4.3.a. Glass temperatures (hourly averages) during DM100 Tests 1 and 2. 

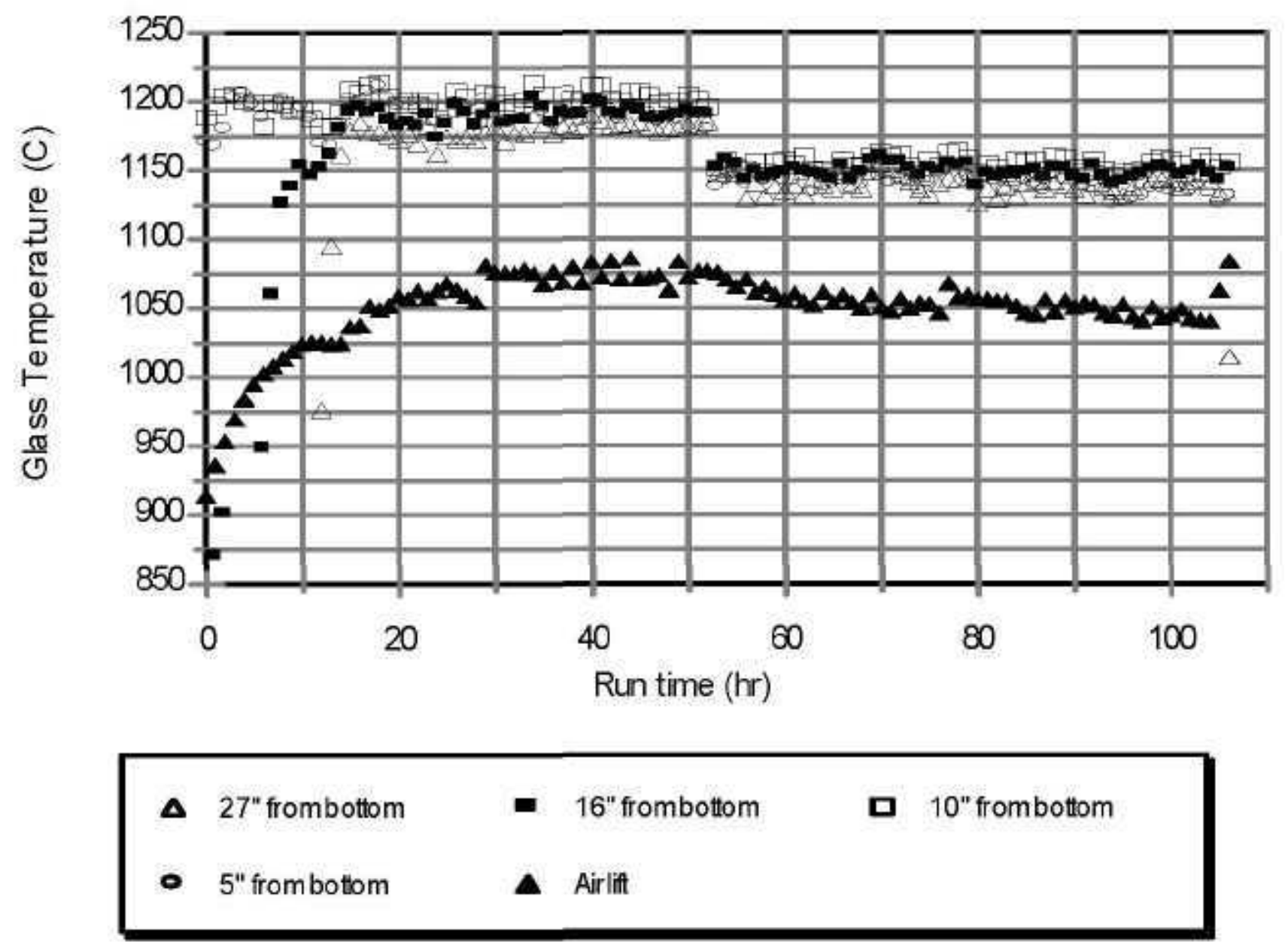

Figure 4.3.h. Glass temperatures (hourly averages) during DM100 Tests 3 and 4. 


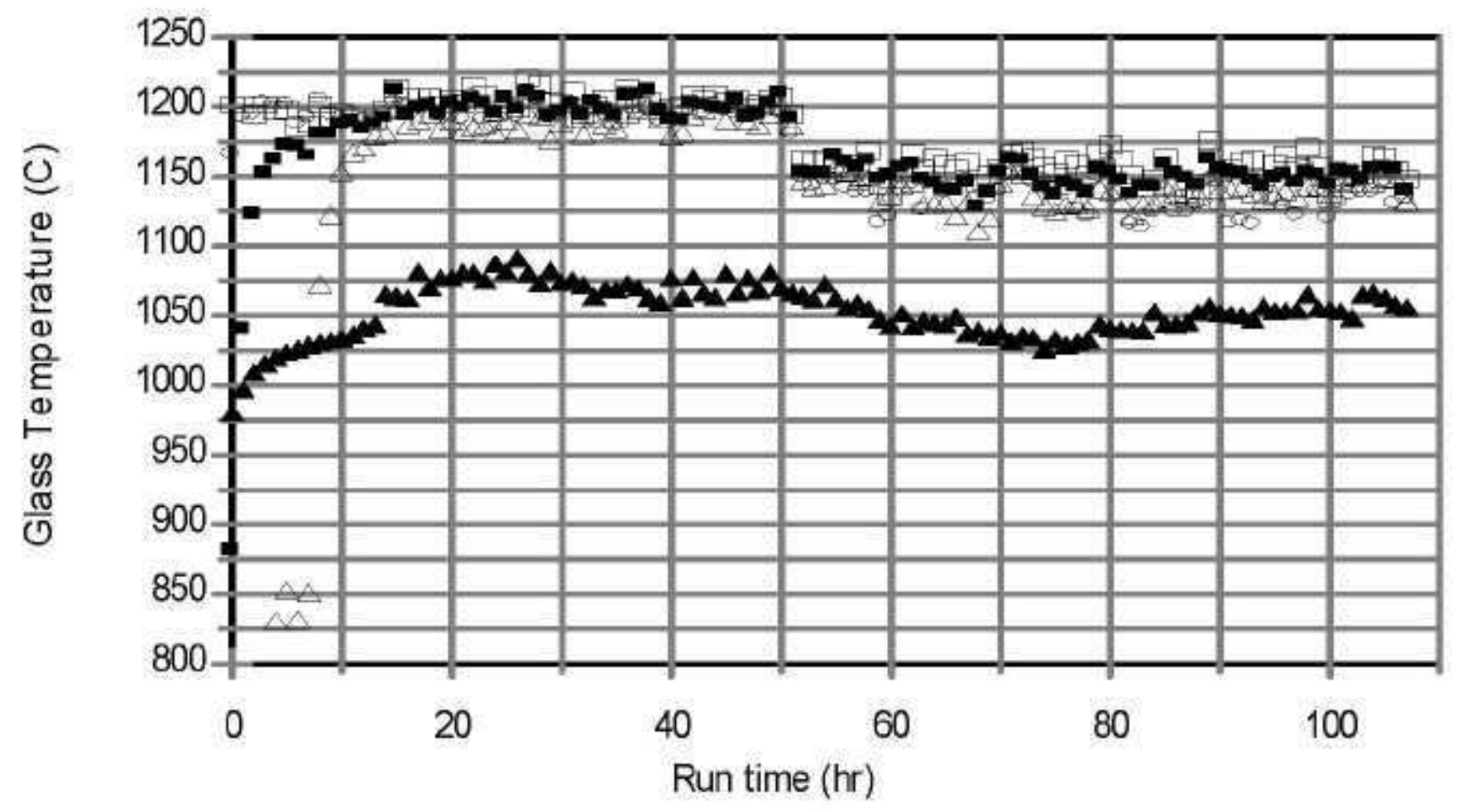
A 27" from bottom
- $16^{\prime \prime}$ frombottom
口 10" from bottom
- 5" from bottom
- Airlift

Figure 4.3.c. Glass temperatures (hourly averages) during DM100 Tests 5 and 6. 


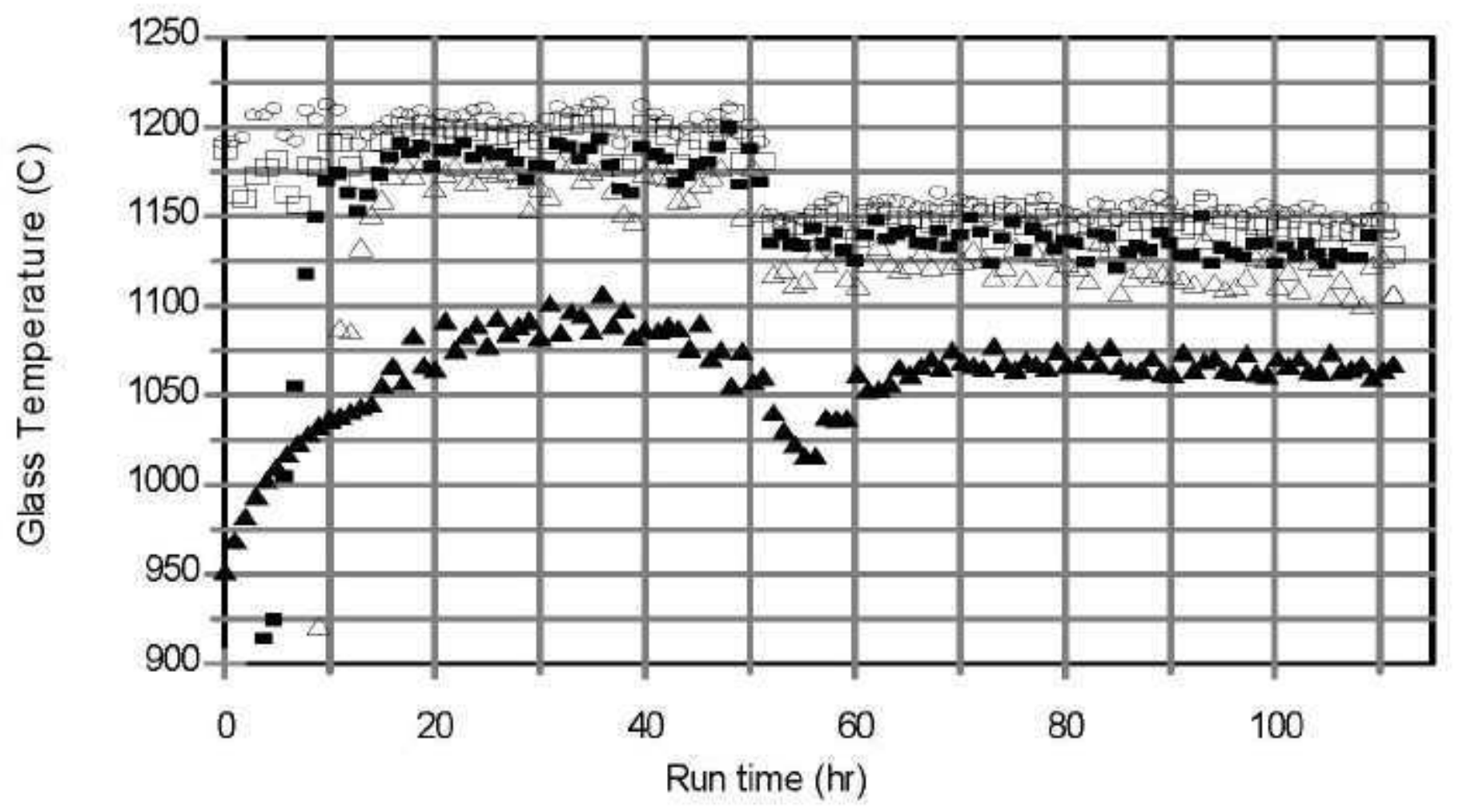
$\Delta \quad 27^{\prime \prime}$ from bottom
- $16^{\text {" from bottom }}$
- 10" frombottom
- $5^{\prime \prime}$ frombottom
$\Delta$ Airlift

Figure 4.3.d. Glass temperatures (hourly averages) during DM100 Tests 7 and 8. 


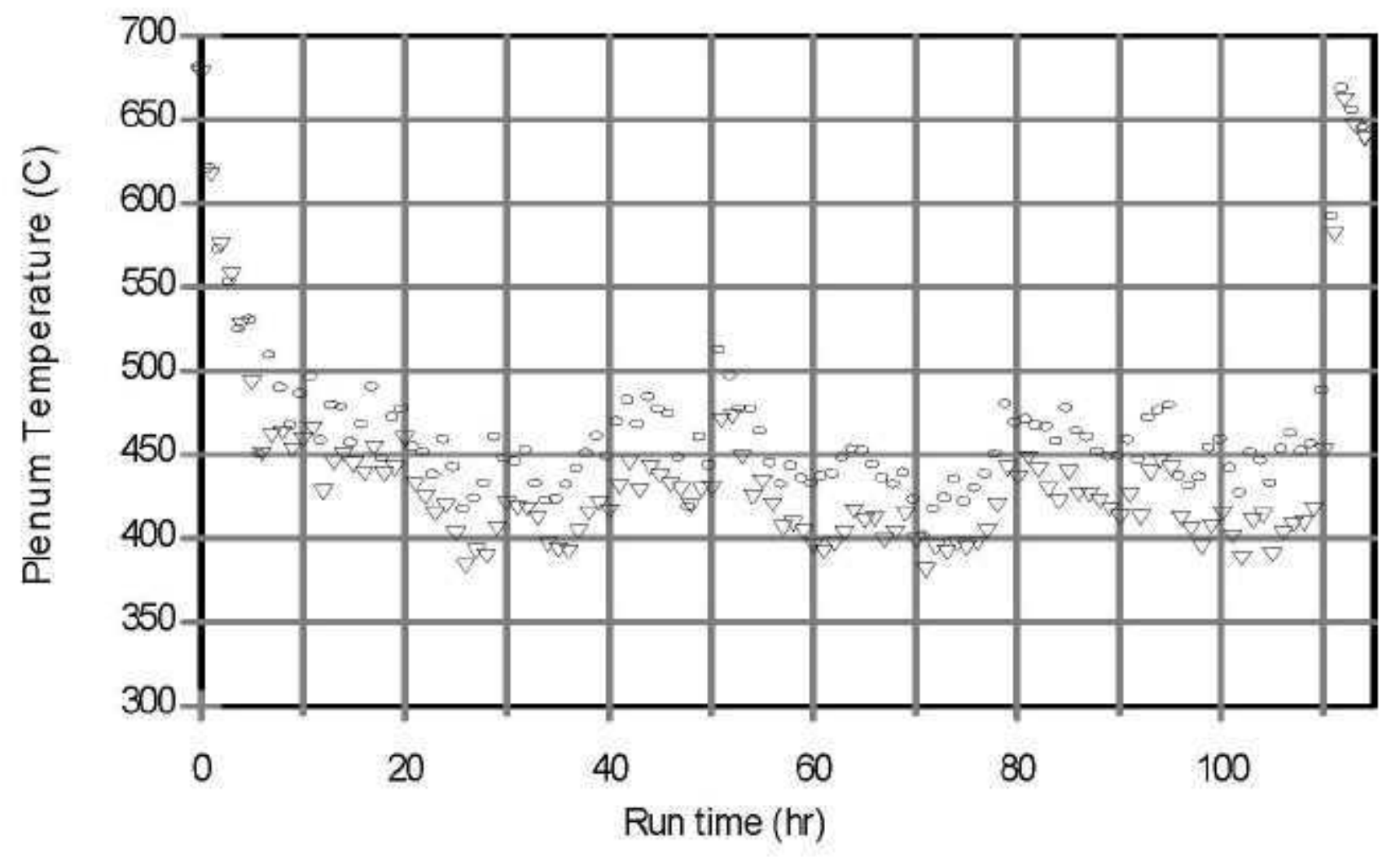

v $17^{\prime}$ from top, Thermowell

- $17^{\prime \prime}$ from top, Exposed

Figure 4.4.a. Plenum temperatures (hourly averages) during DM100 Tests 1 and 2. 


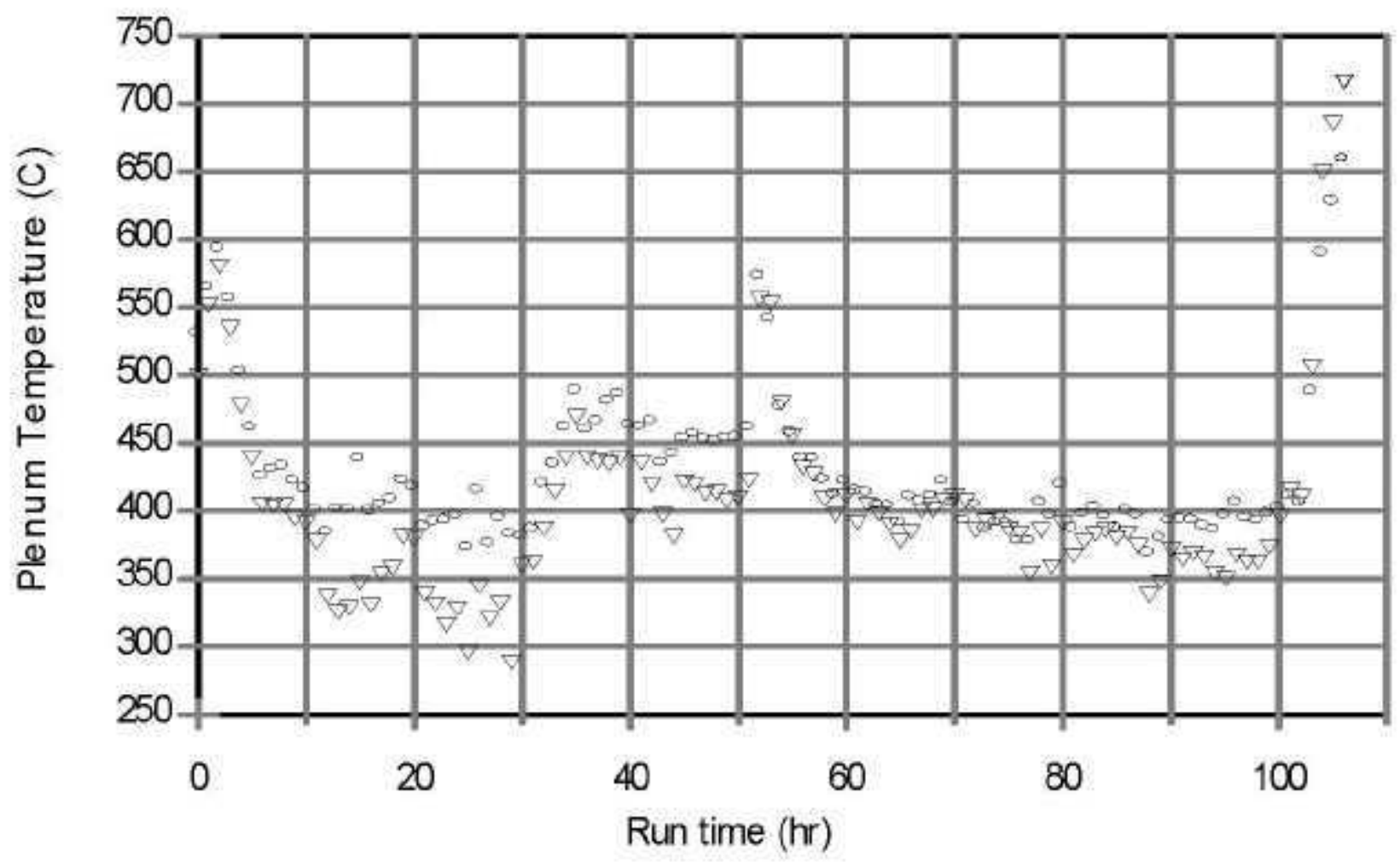

- 17' from top, Thermowell

- $17^{\prime \prime}$ from top, Exposed

Figure 4.4.b. Plenum temperatures (hourly averages) during DM100 Tests 3 and 4. 


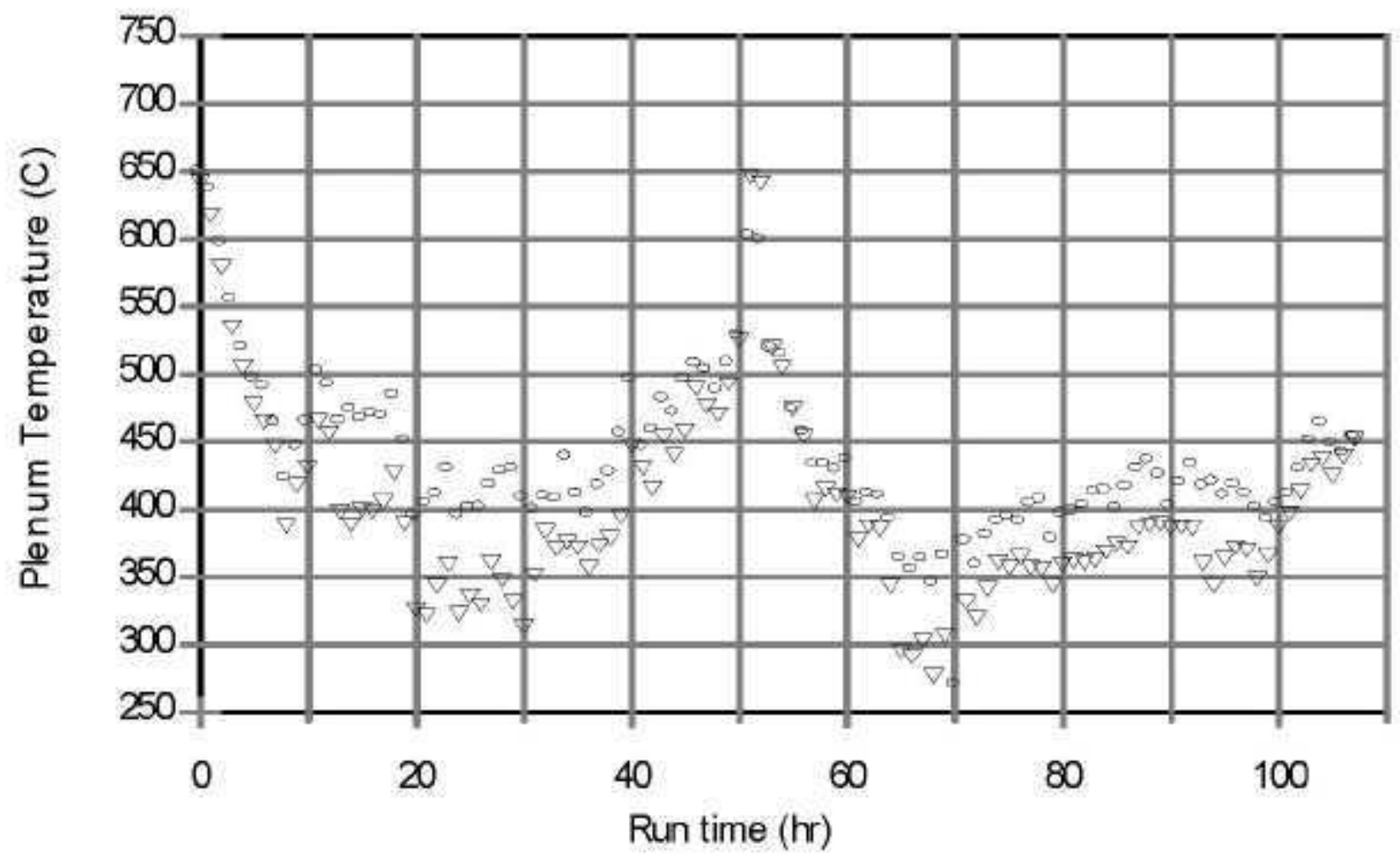

v 17' from top, Thermowell

- $17^{\prime \prime}$ from top, Exposed

Figure 4.4.c. Plenum temperatures (hourly averages) during DM100 Tests 5 and 6. 


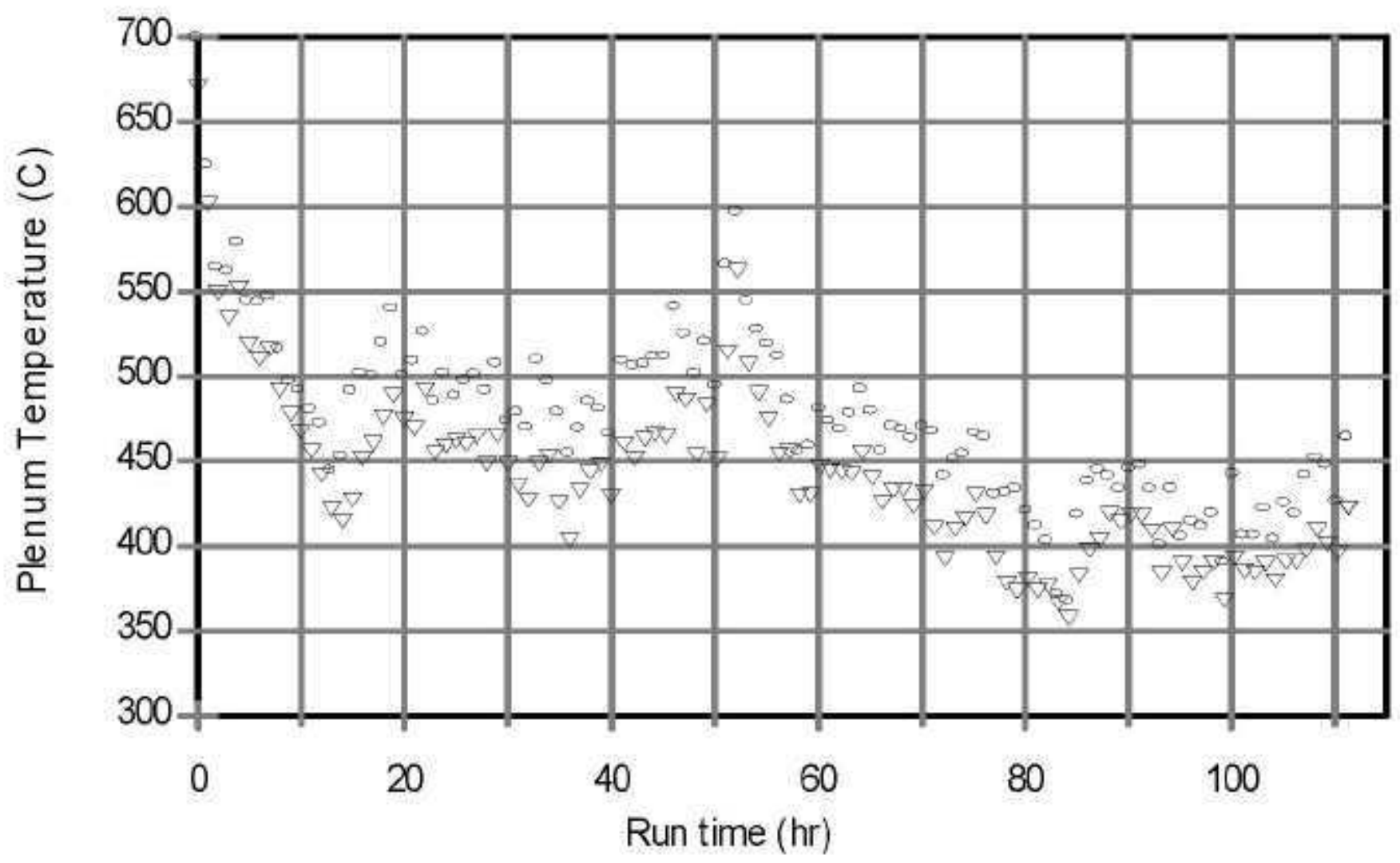

$\nabla 17$ " from top, Thermowell

- $17^{\prime \prime}$ from top, Exposed

Figure 4.4.d. Plenum temperatures (hourly averages) during DM100 Tests 7 and 8. 

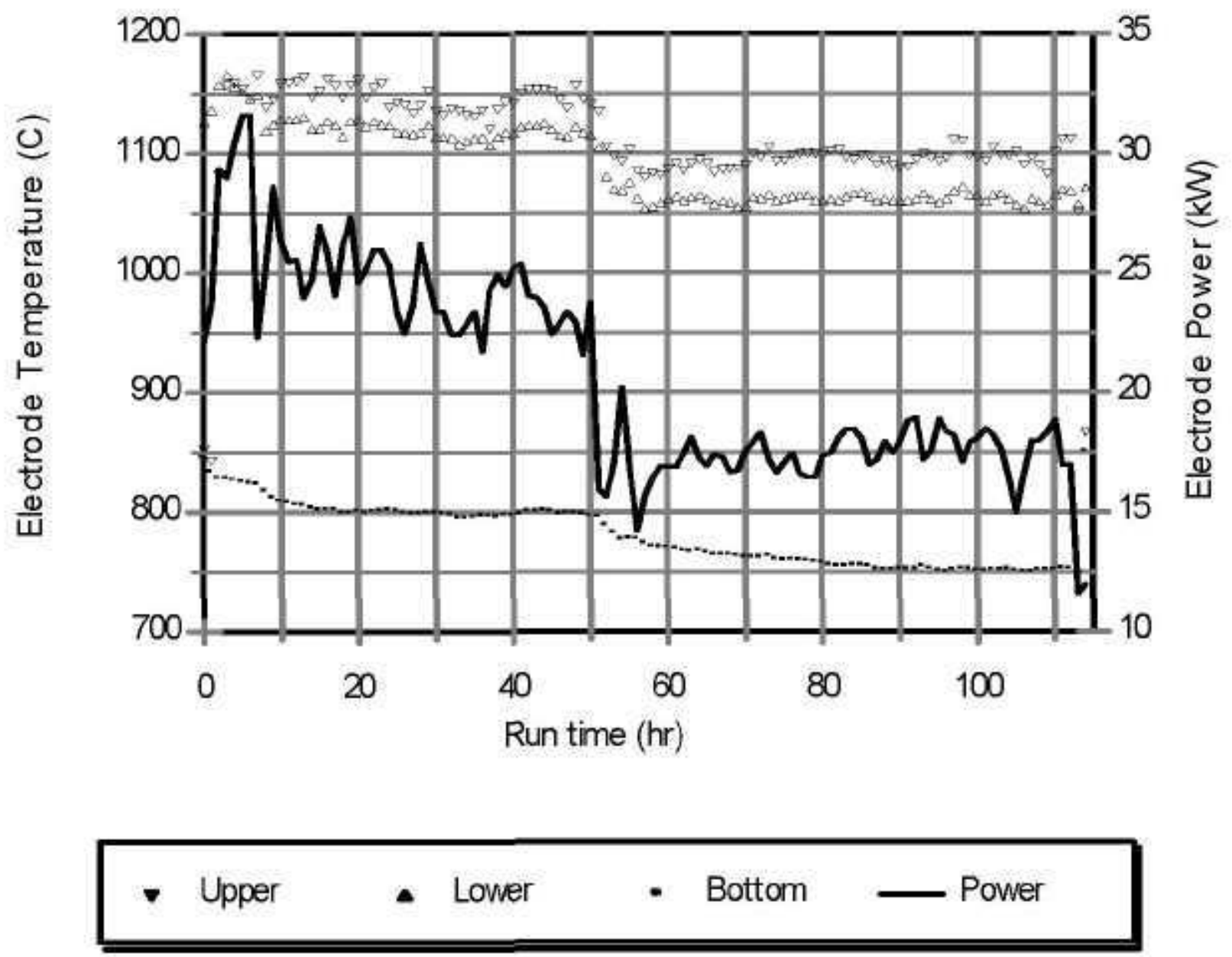

Figure 4.5.a. Electrode temperatures and power (hourly averages) during DM100 Tests 1 and 2. 

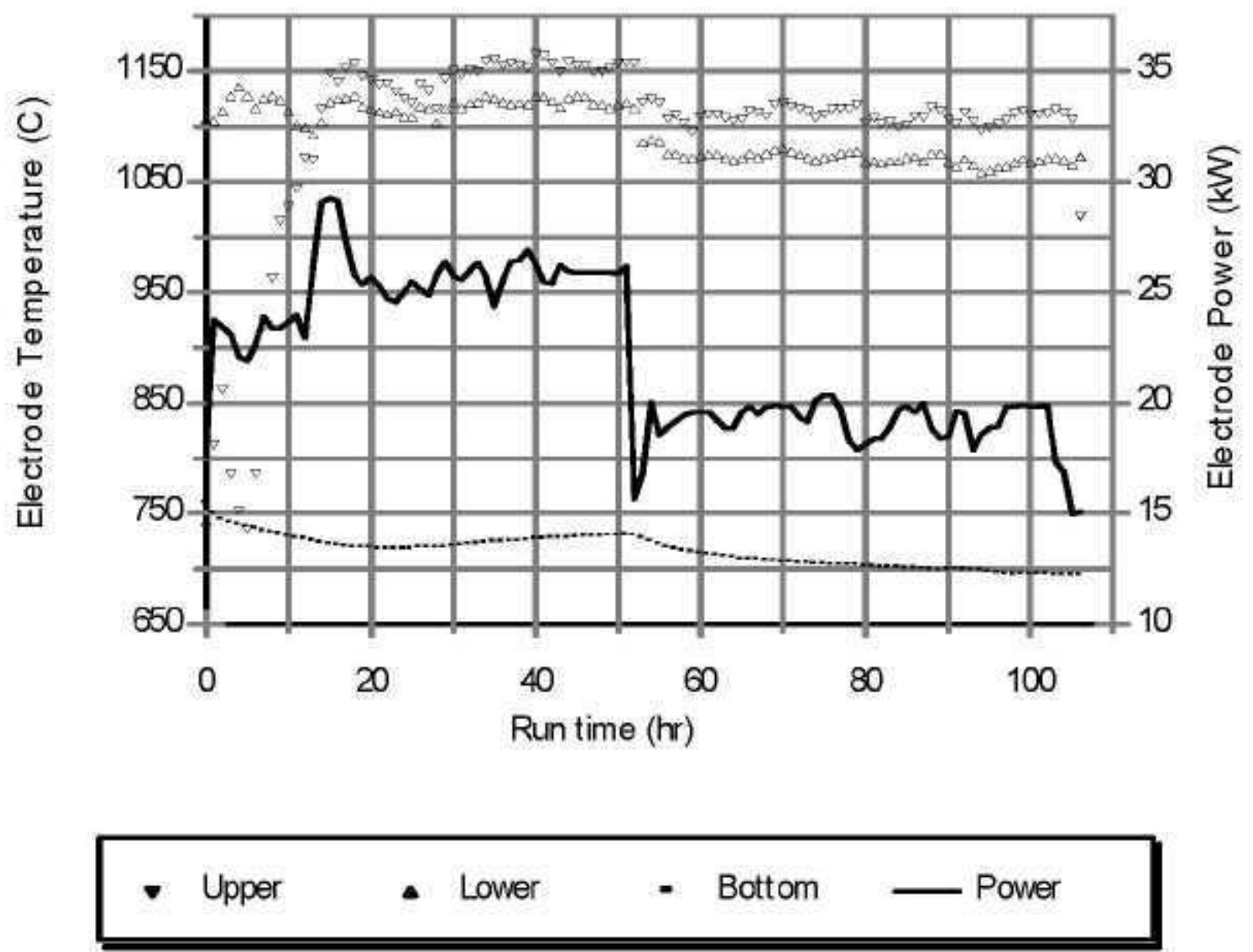

Figure 4.5.b. Electrode temperatures and power (hourly averages) during DM100 Tests 3 and 4. 


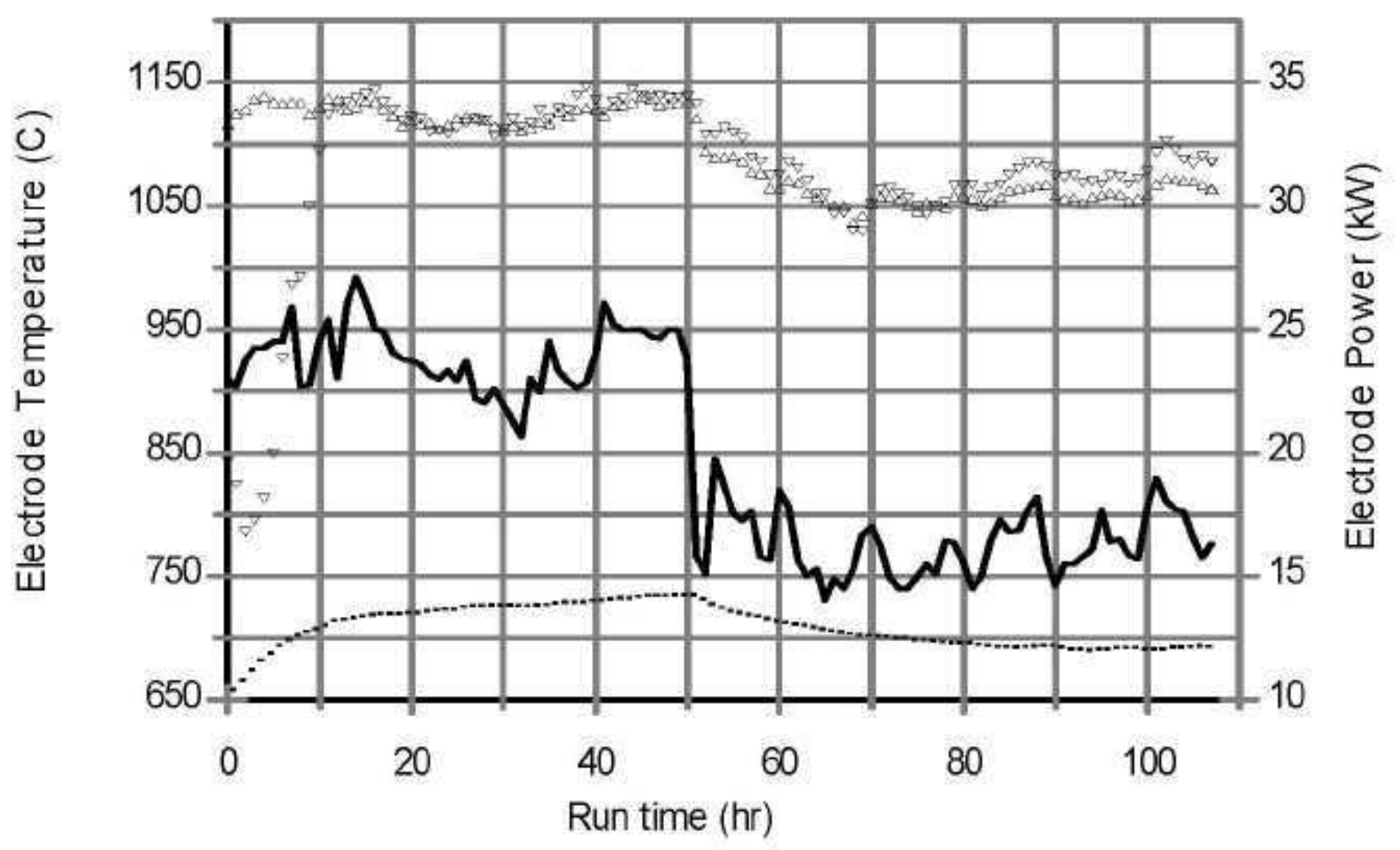

- Upper

- Lower

- Bottom

Power

Figure 4.5.c. Electrode temperatures and power (hourly averages) during DM100 Tests 5 and 6. 


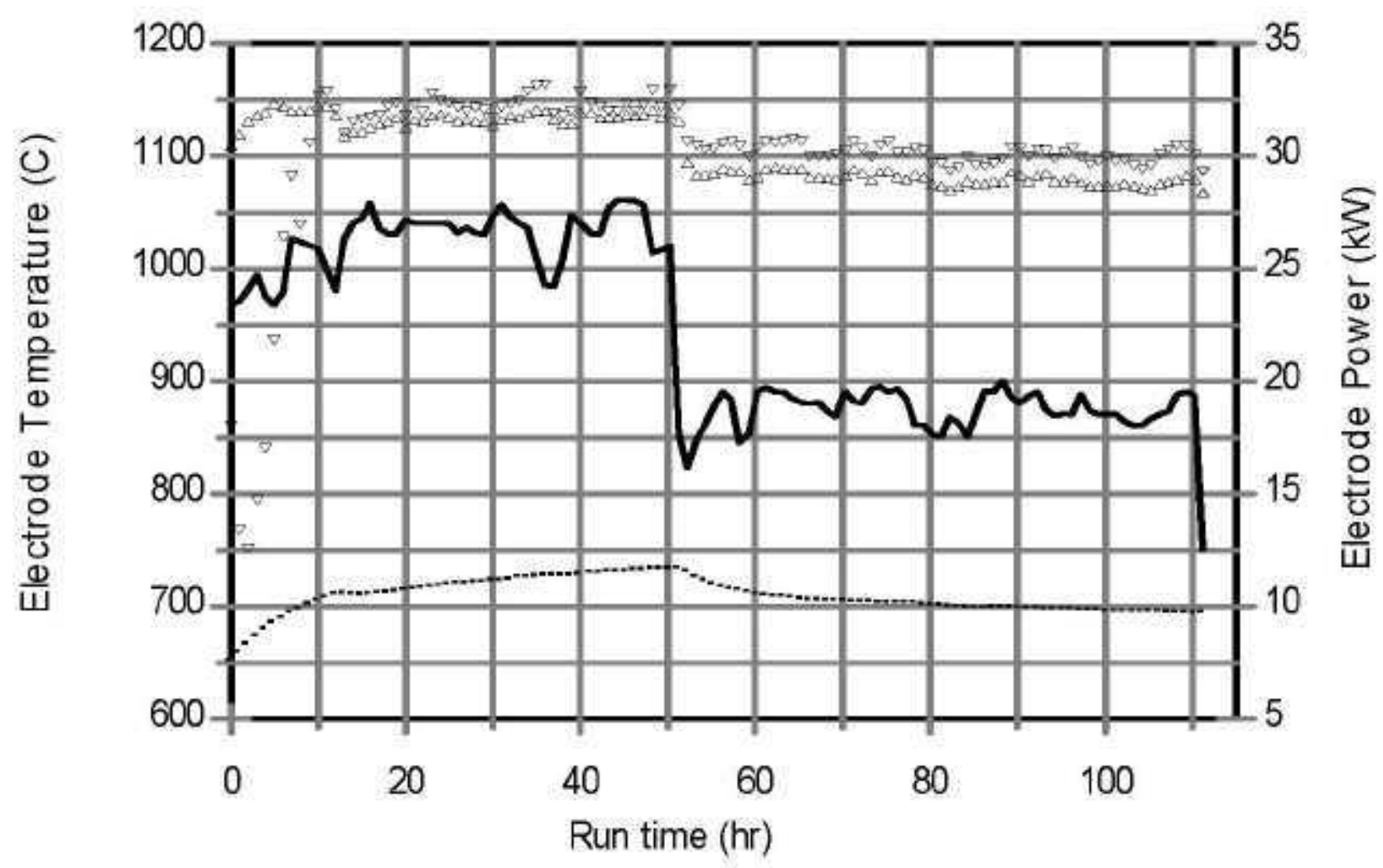

- Upper

- Lower

- Bottom - Power

Figure 4.5.d. Electrode temperatures and power (hourly averages) during DM100 Tests 7 and 8 . 


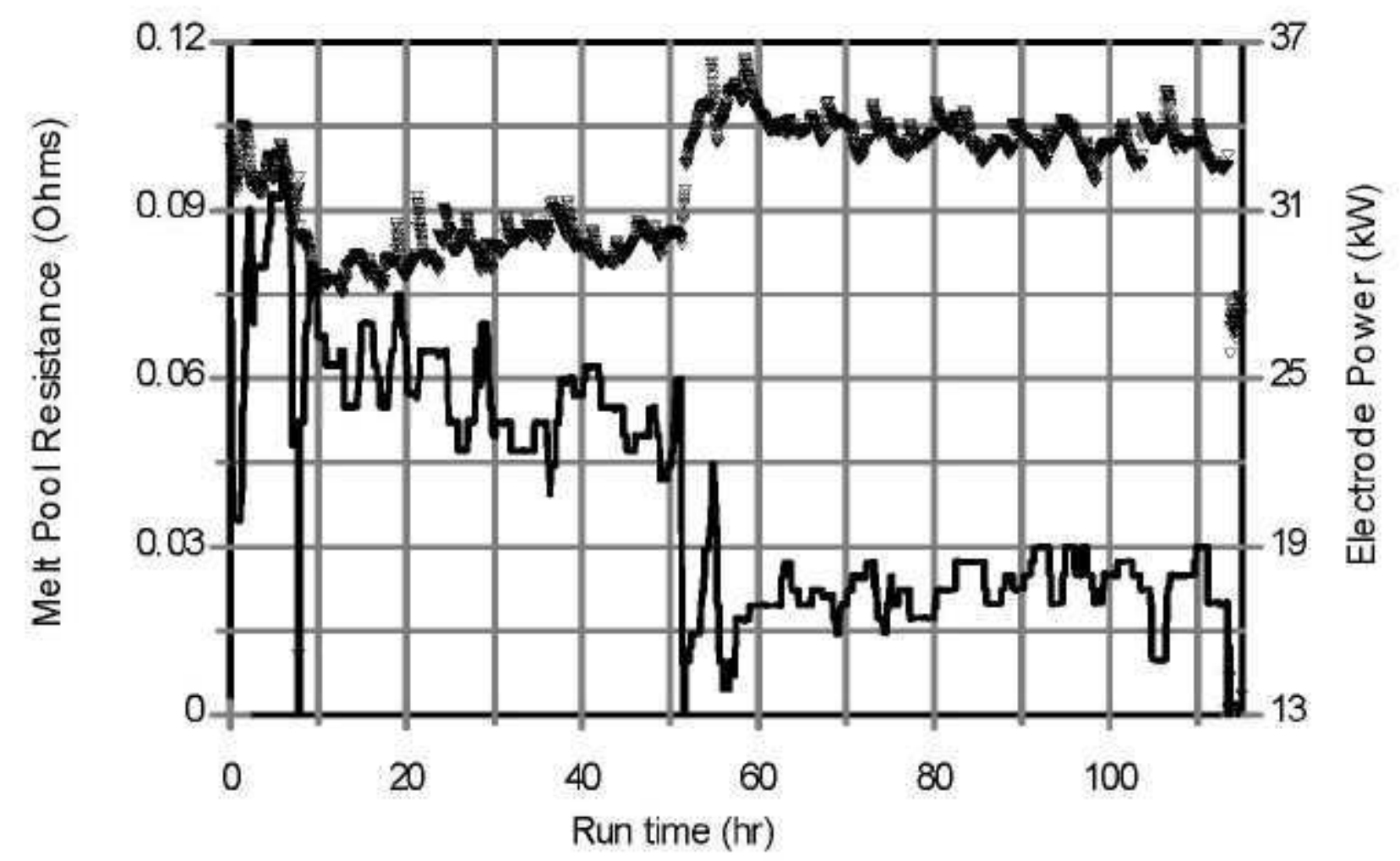

- Resistance Power

Figure 4.6.a. Melt pool resistance and total electrode power during DM100 Tests 1 and 2. 


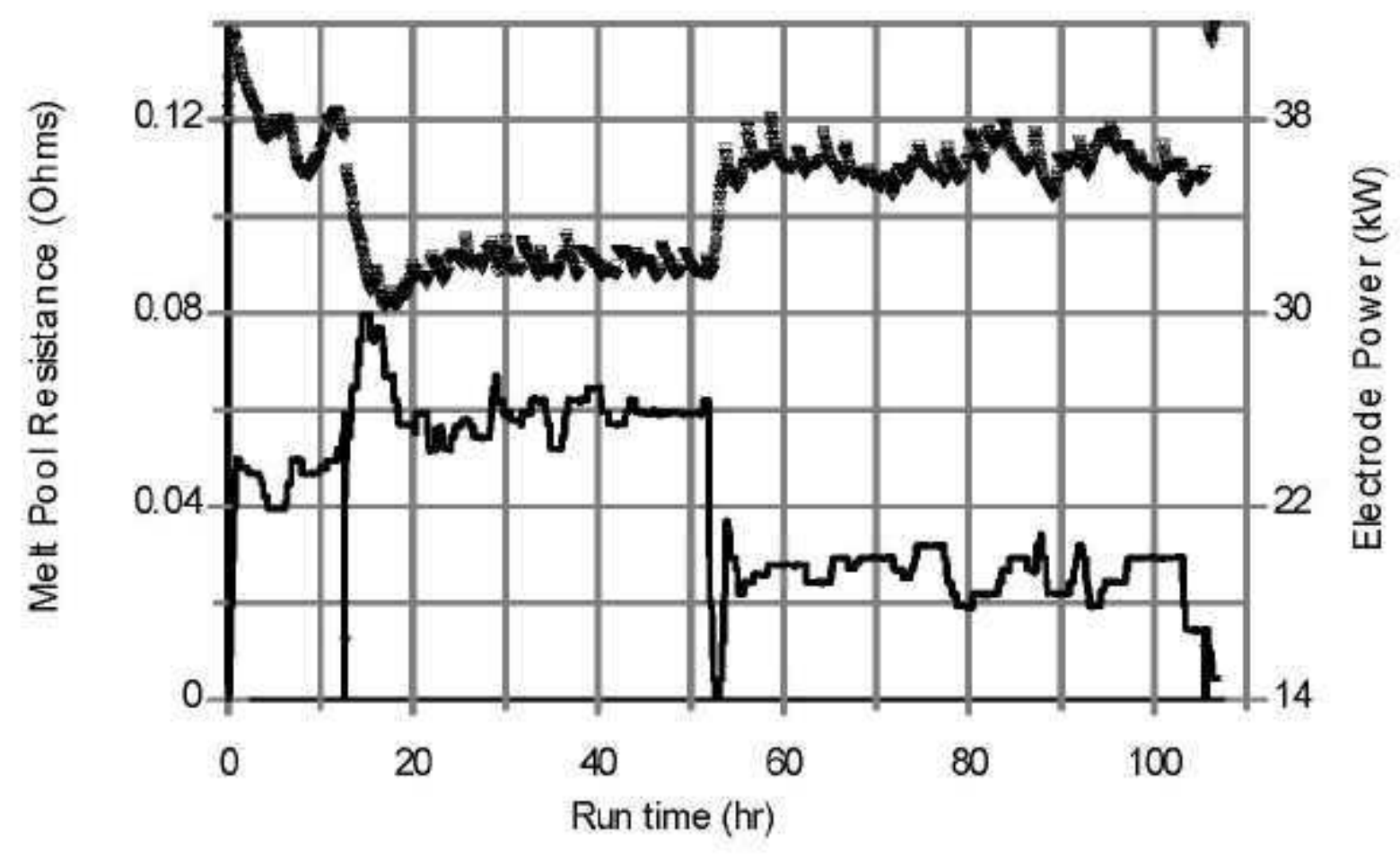

- Resistance - Power

Figure 4.6.b. Melt pool resistance and total electrode power during DM100 Tests 3 and 4. 


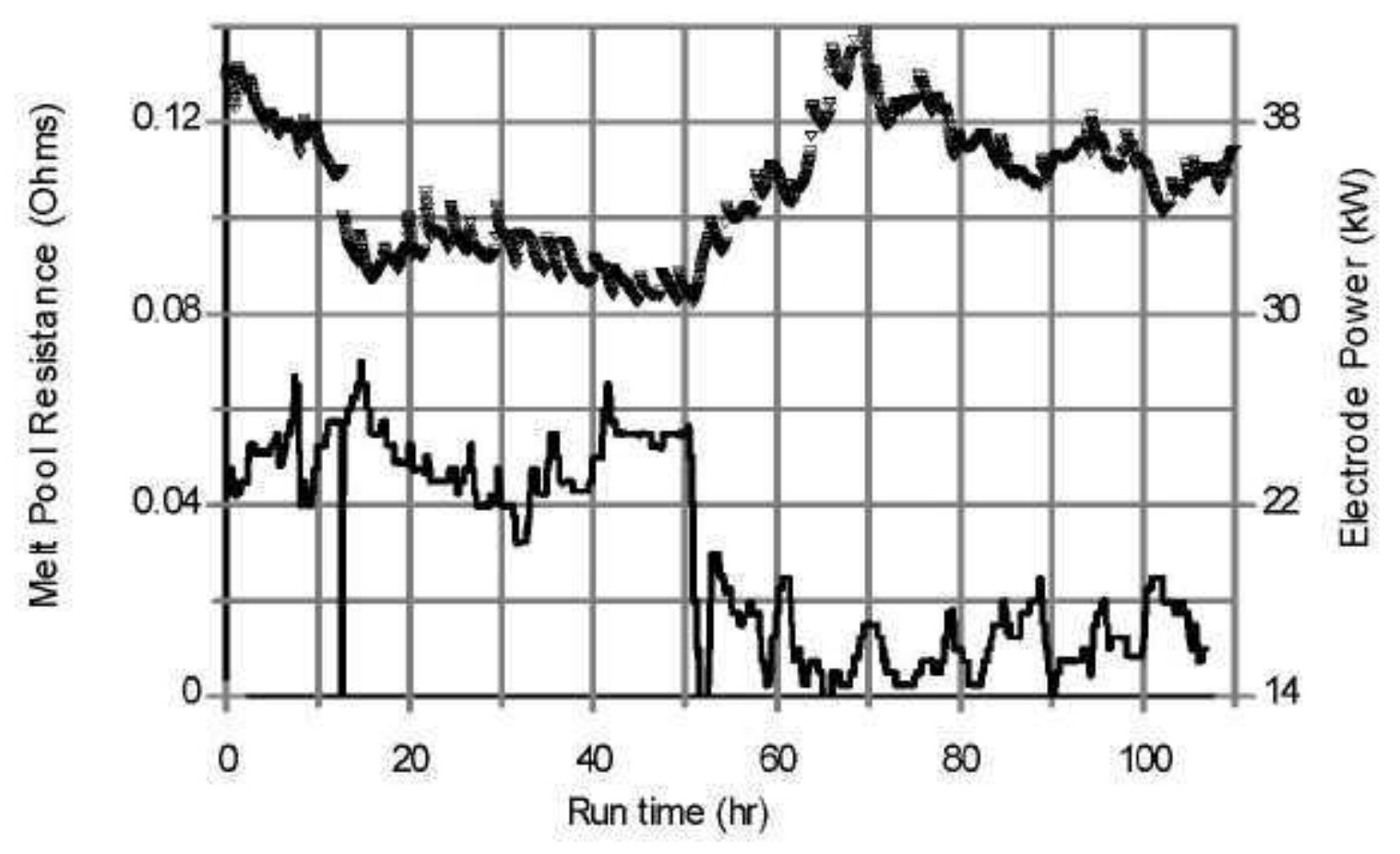

- Resistance Power

Figure 4.6.c. Melt pool resistance and total electrode power during DM100 Tests 5 and 6 . 


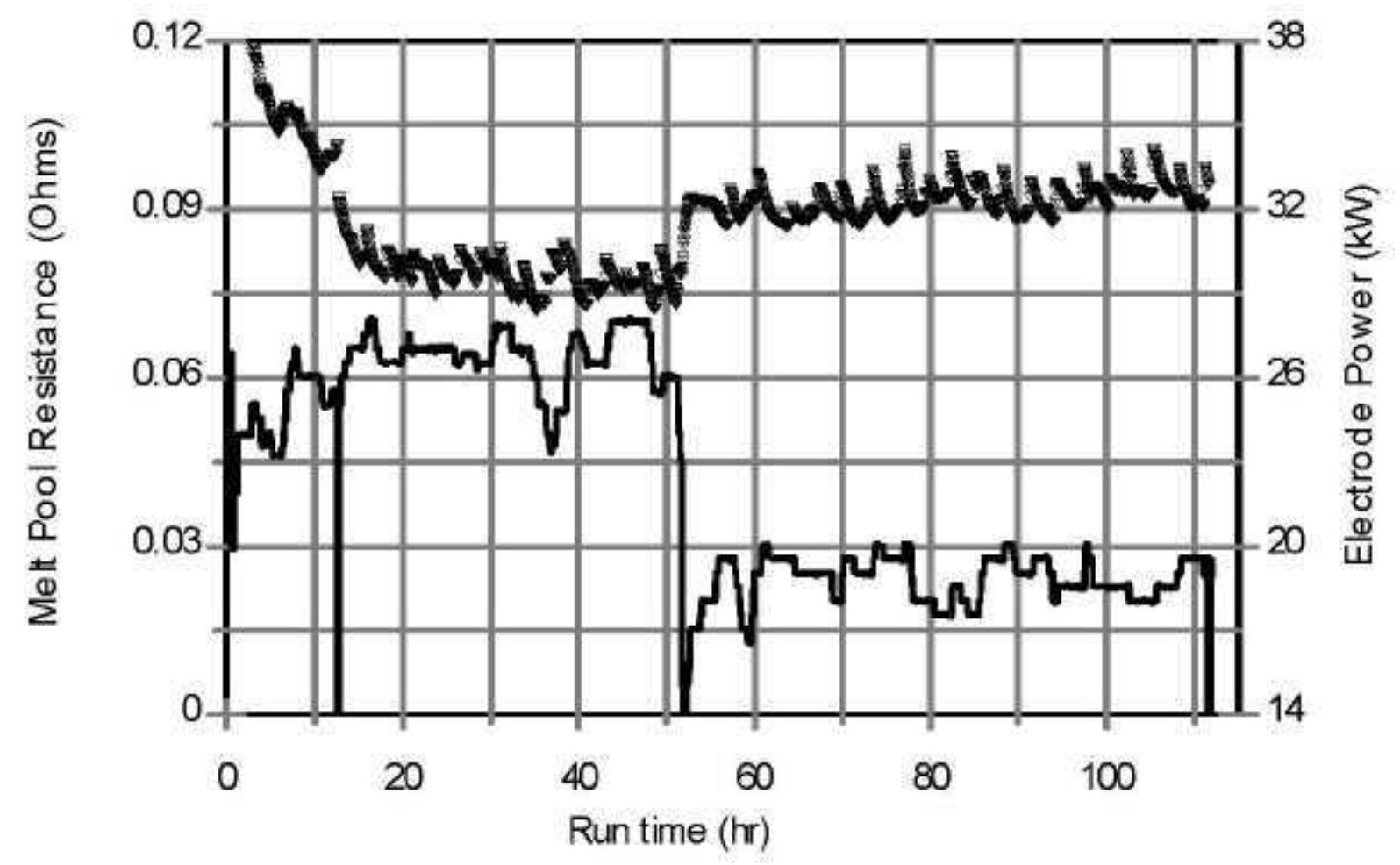

- Resistance Power

Figure 4.6.d. Melt pool resistance and total electrode power during DM100 Tests 7 and 8. 


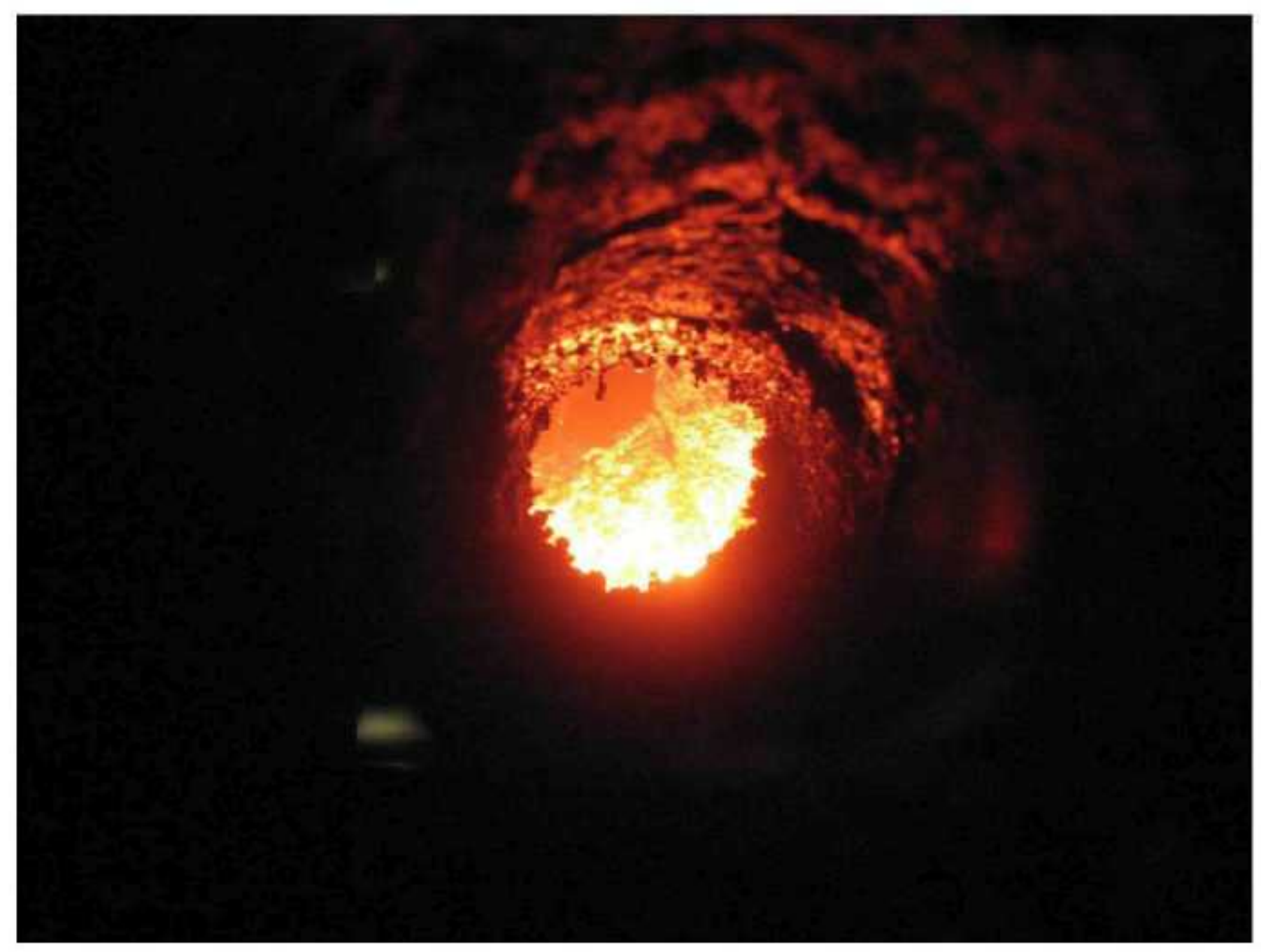

Figure 5.1. Picture of cold cap through north view port showing the thickness of the cold cap. 


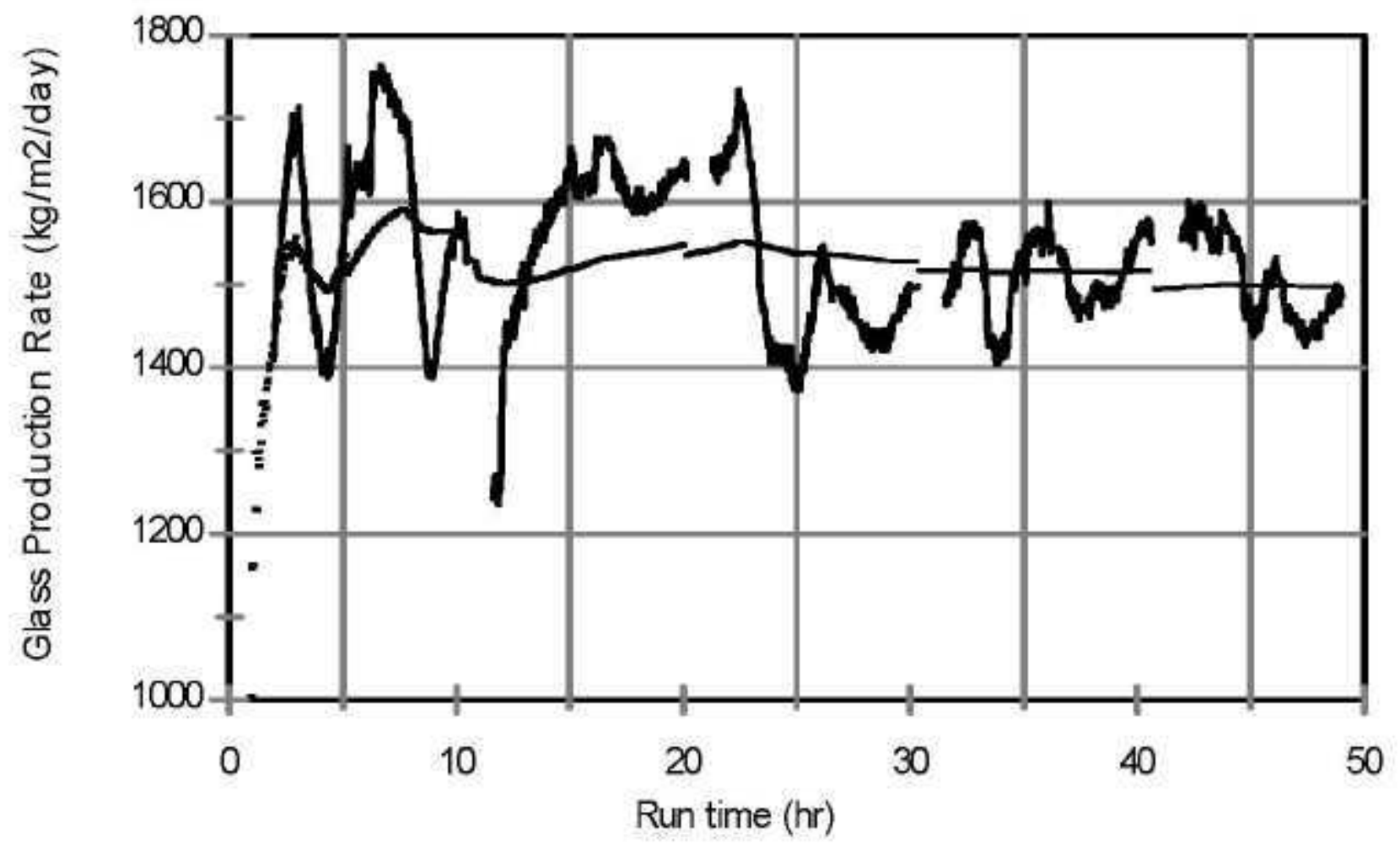

Figure 5.2.a. Production rates for DM1200 Test 1. 


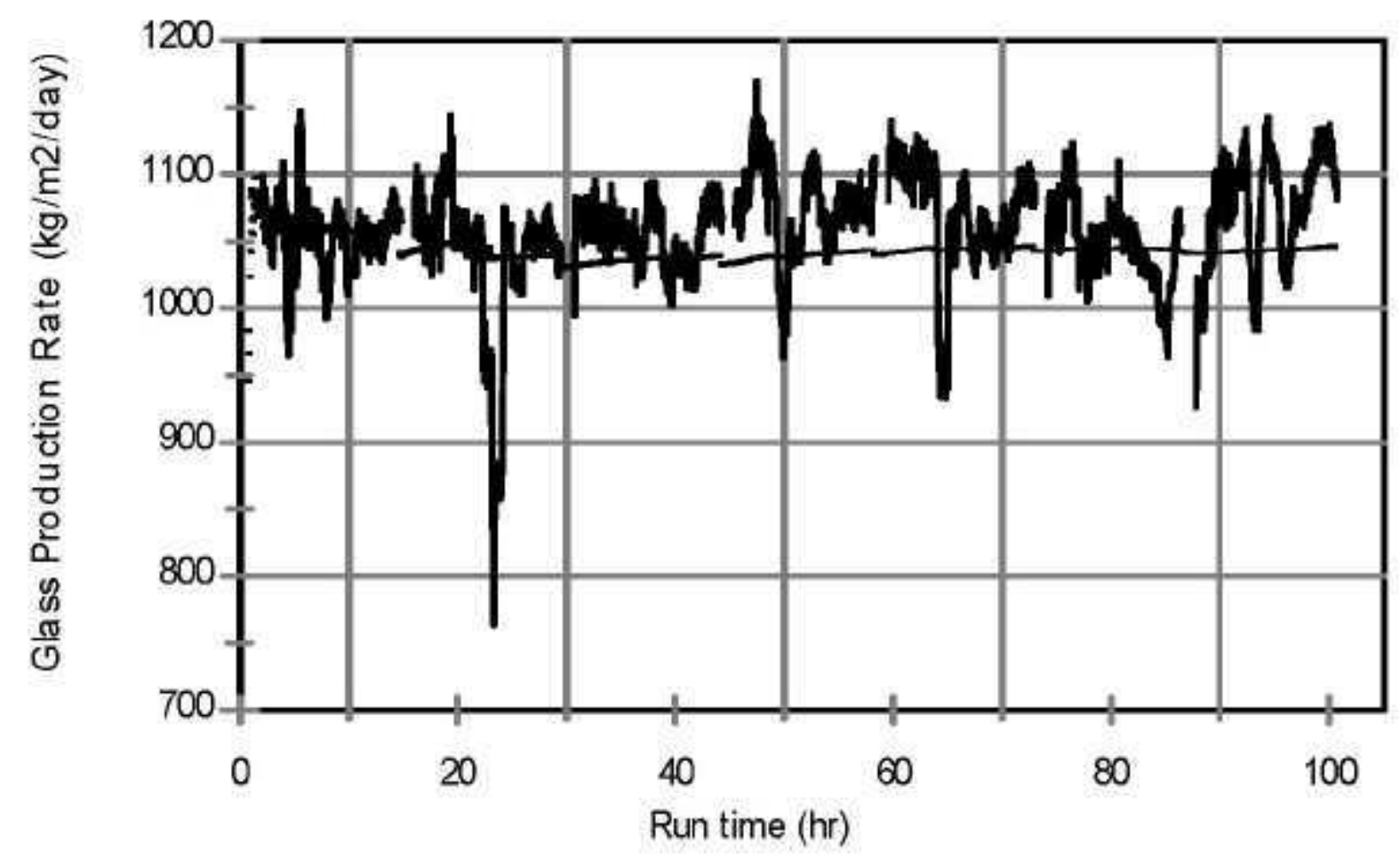

Figure 5.2.b. Production rates for DM1200 Tests 2 and 3. 


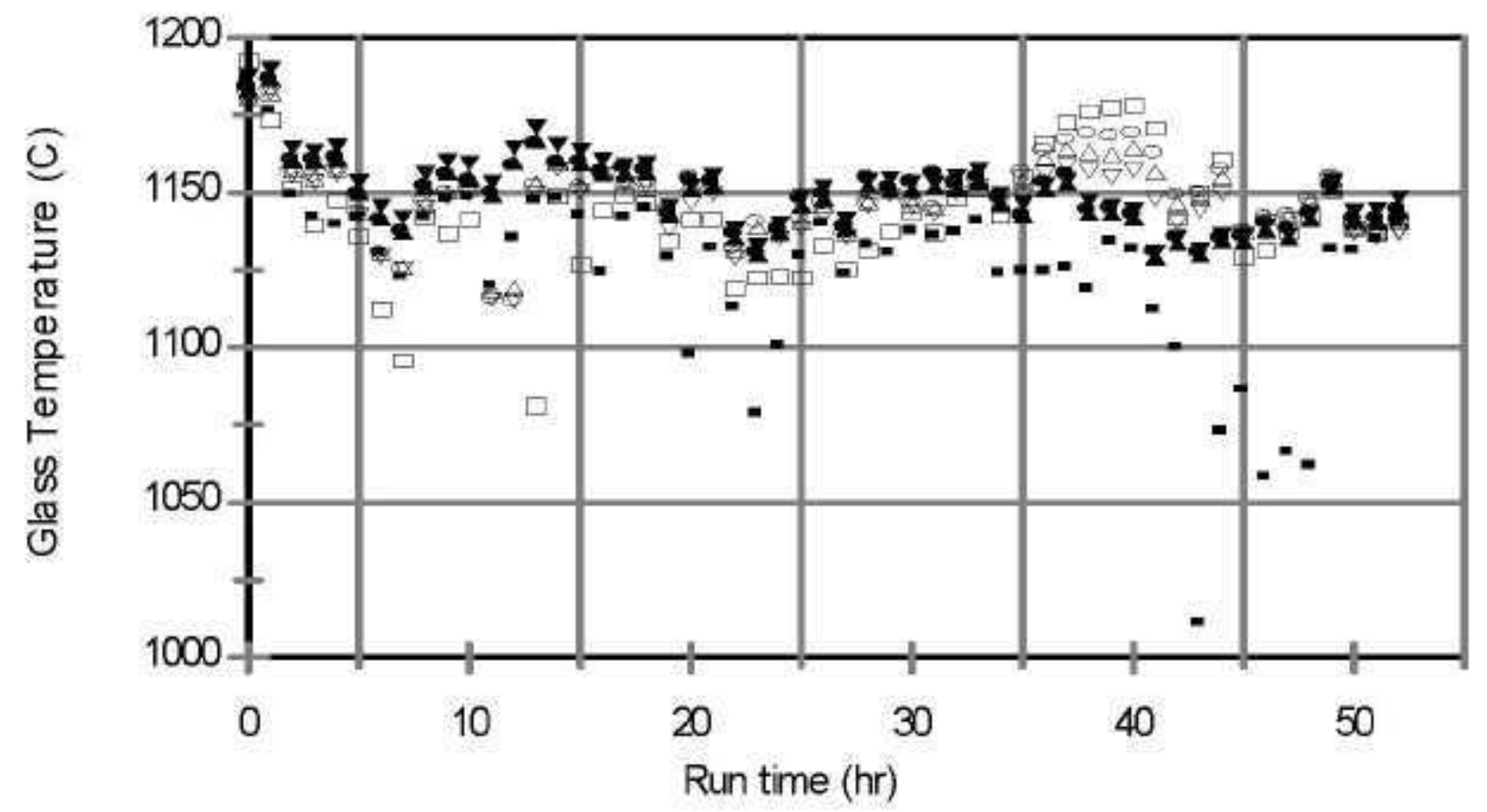

- $13^{\prime \prime}$ from floor

- 13" from floor
- 15.5" from foor

A $15.5^{\prime \prime}$ from foor
- $18^{\text {" from floor }}$

- $18^{\text {" from floor }}$
- $27^{\prime \prime}$ from floor

- 27" from floor

Figure 5.3.a. Glass temperatures (hourly averages) for DM1200 Test 1. 


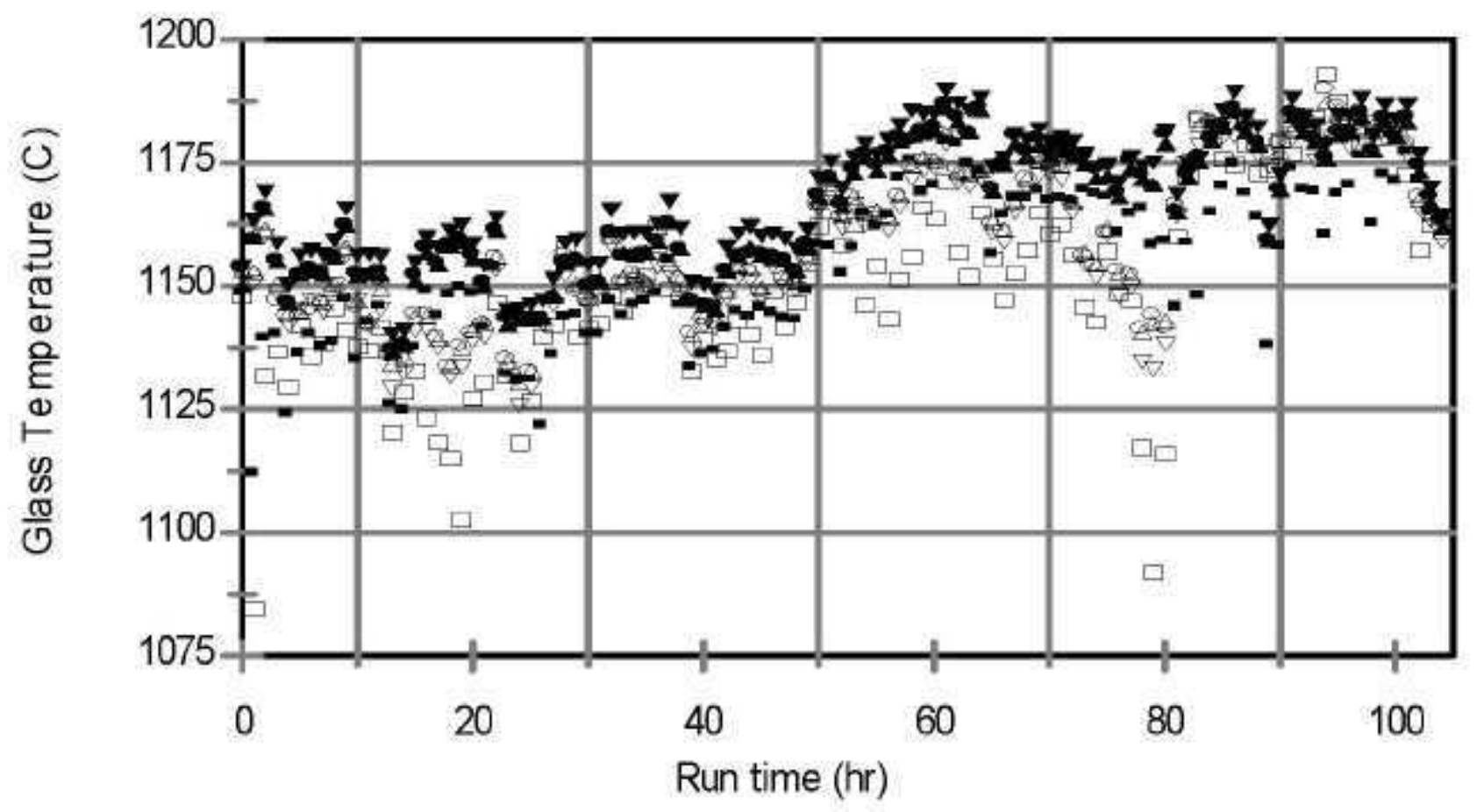

- 13" from floor

- $15.5^{\prime \prime}$ from floor

A $15.5^{\text {" from floor }}$
- $18^{\prime \prime}$ from floor

- $18^{\prime \prime}$ from floor
- 27 "fromfloor

- 27 "fromfloor

Figure 5.3.b. Glass temperatures (hourly averages) for DM1200 Tests 2 and 3. 

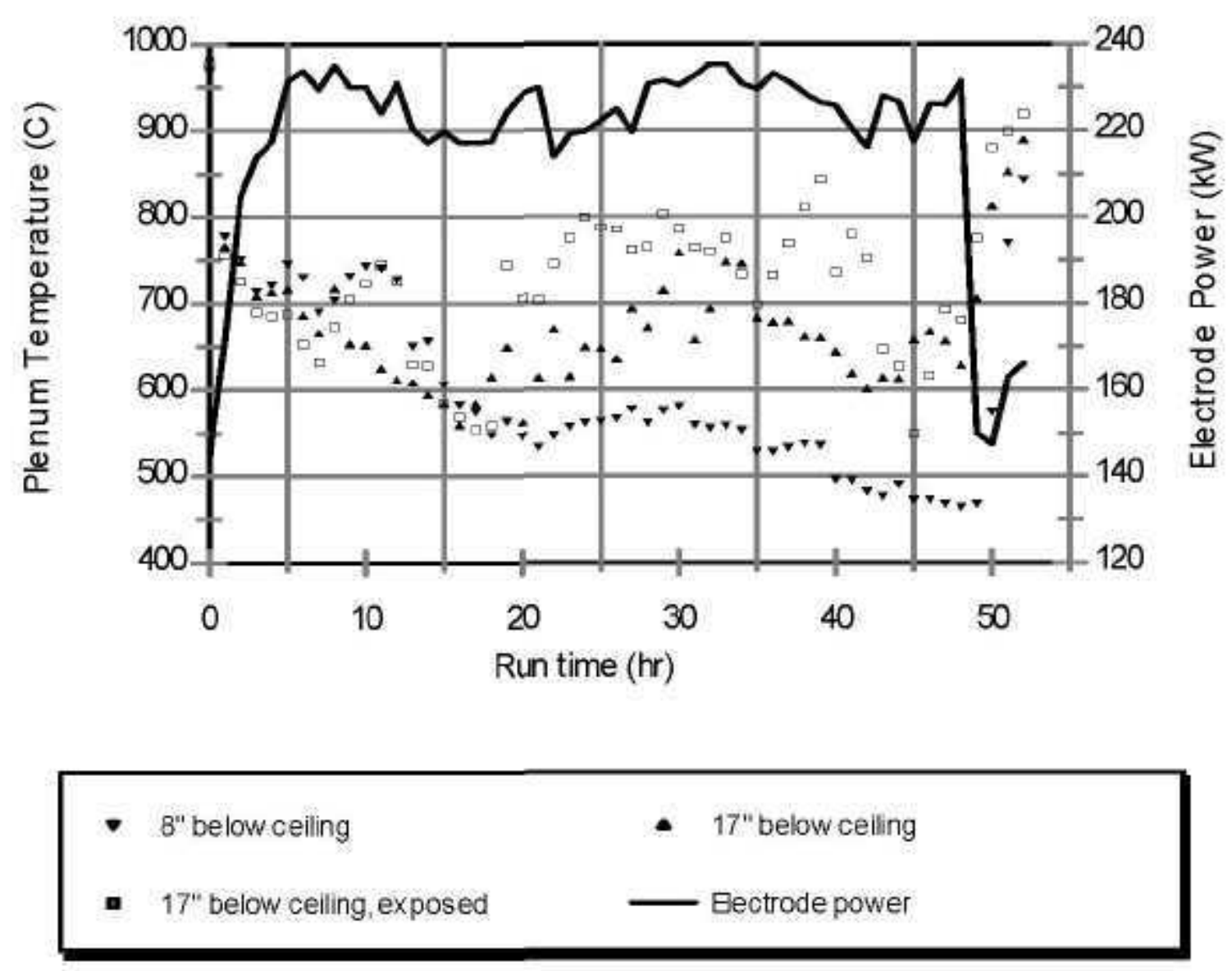

Figure 5.4.a. Plenum temperatures and electrode power (hourly averages) for DM1200 Test 1. 


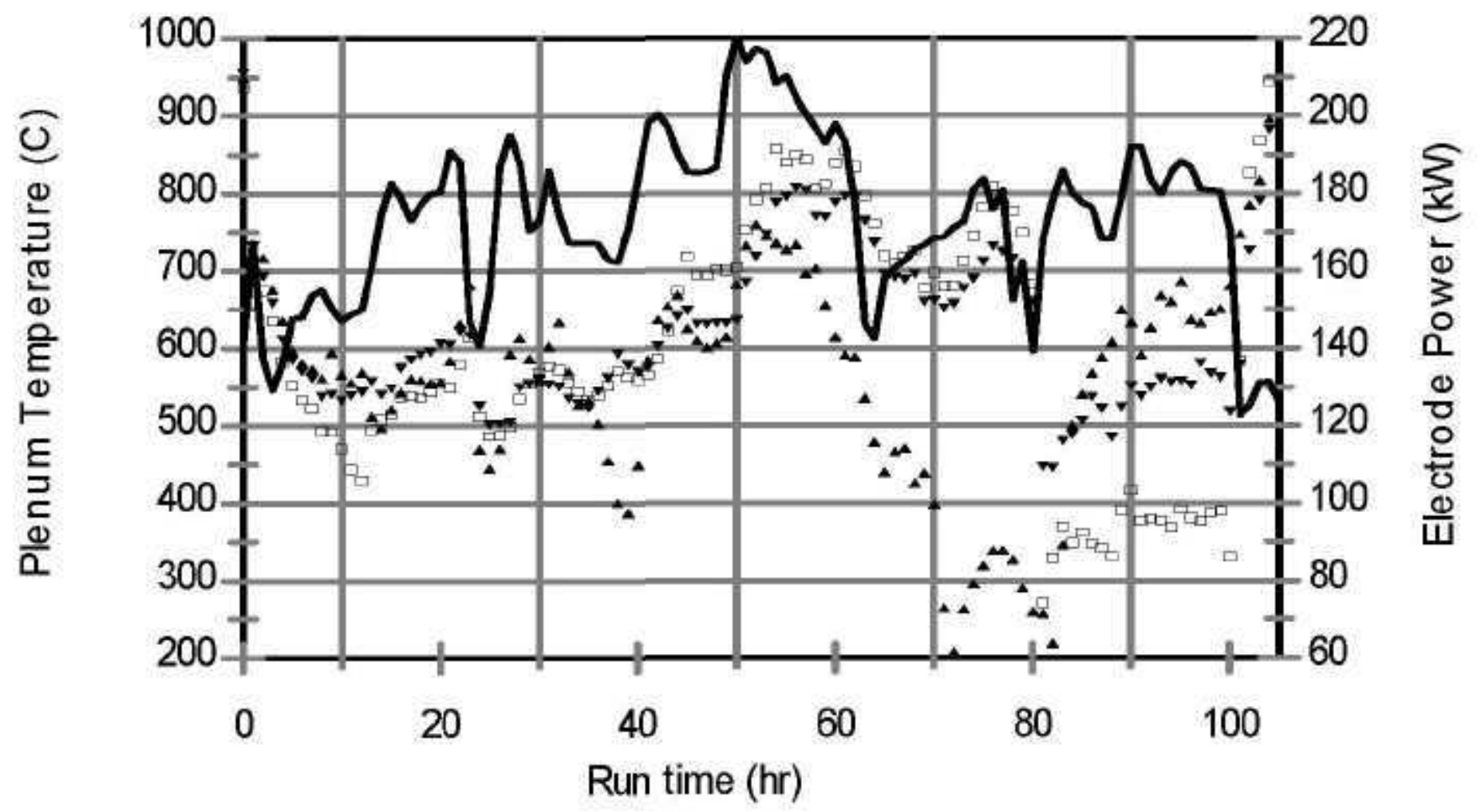

- 8 " below ceiling

- $17^{\prime \prime}$ below ceiling, exposed
- 17 " below ceiling

Electrode power

Figure 5.4.b. Plenum temperatures and electrode power (hourly averages) for DM1200 Tests 2 and 3. 


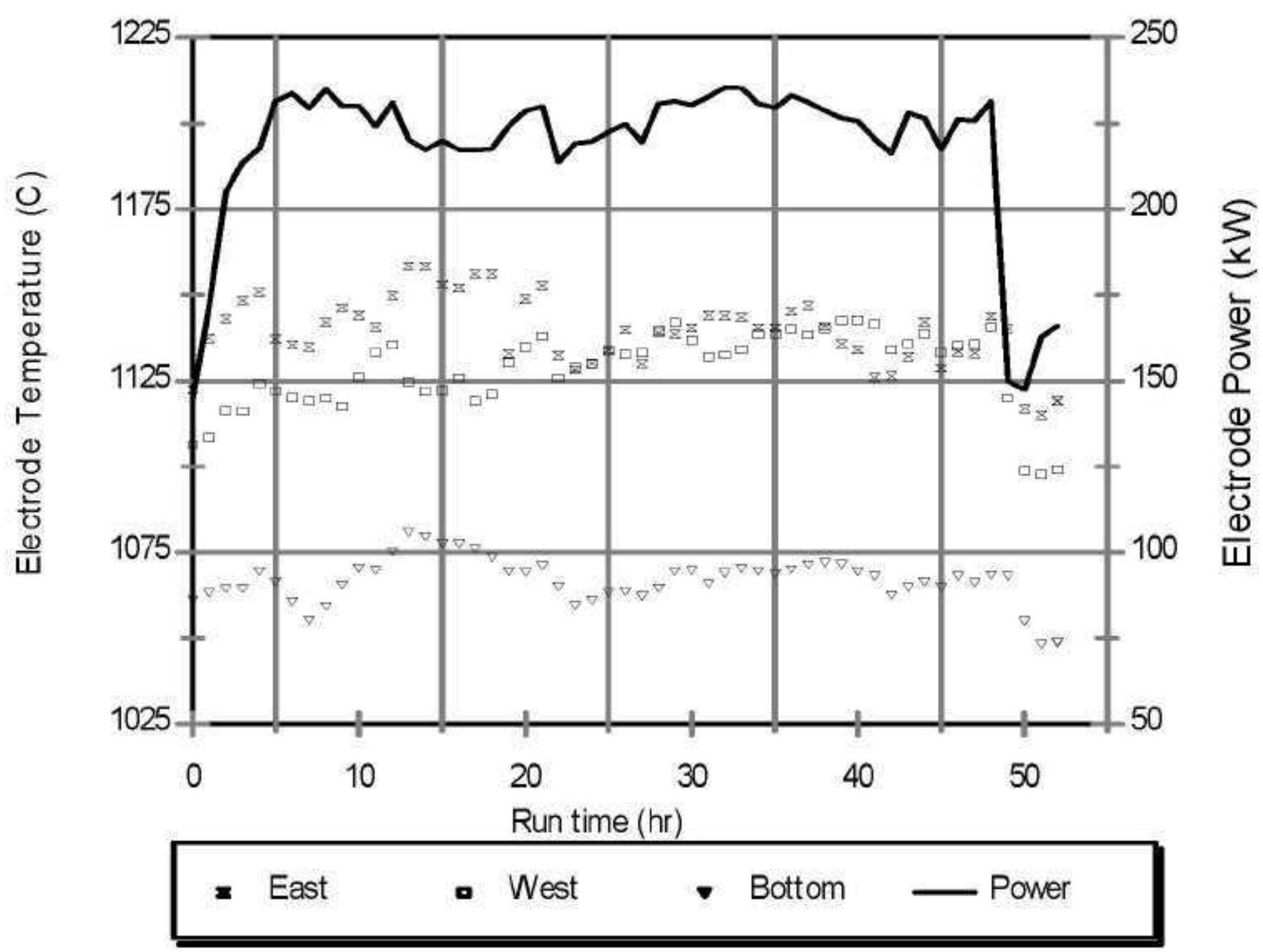

Figure 5.5.a. Electrode temperatures and power (hourly averages) for DM1200 Test 1. 


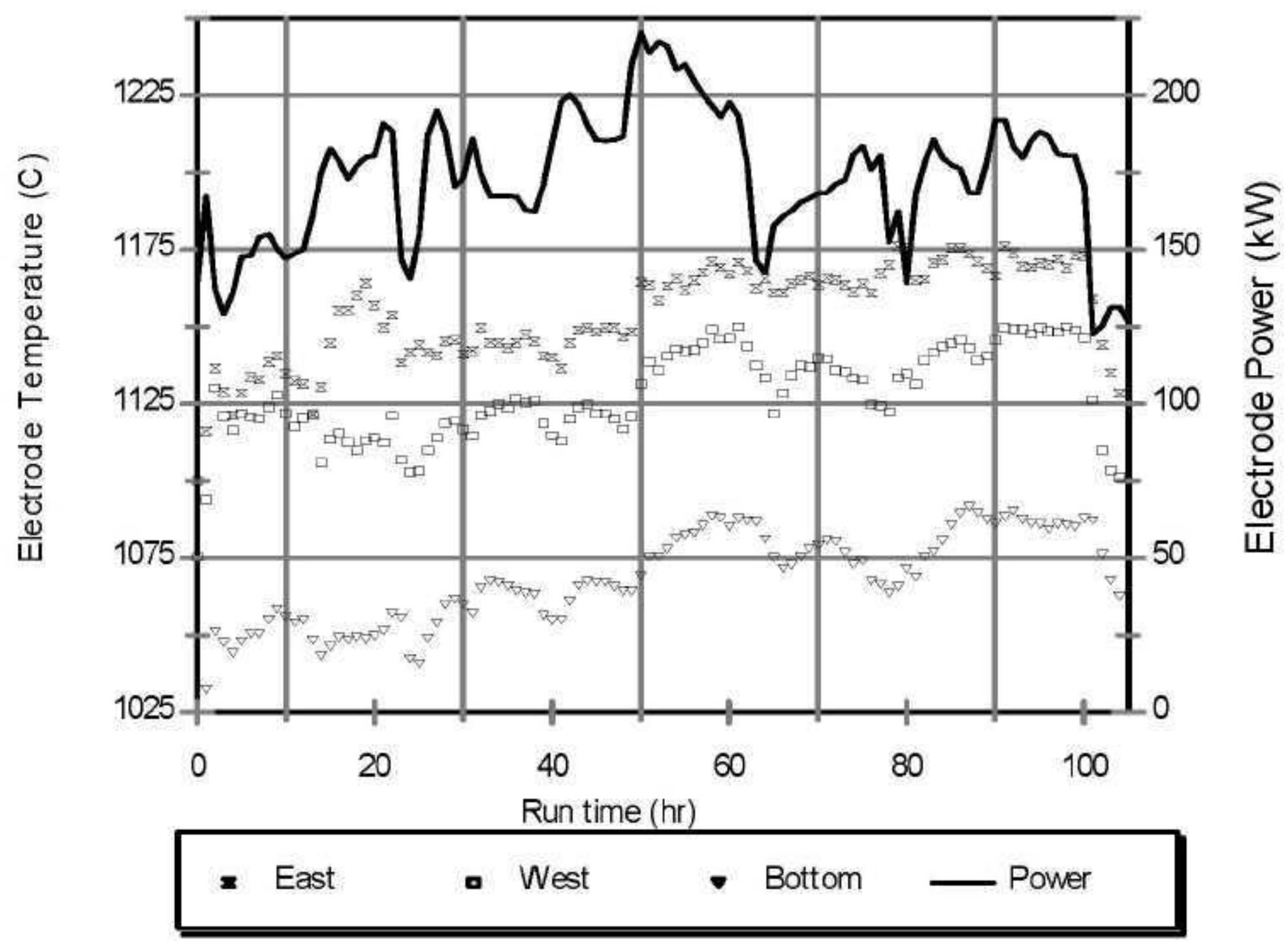

Figure 5.5.b. Electrode temperatures and power (hourly averages) for DM1200 Tests 2 and 3. 


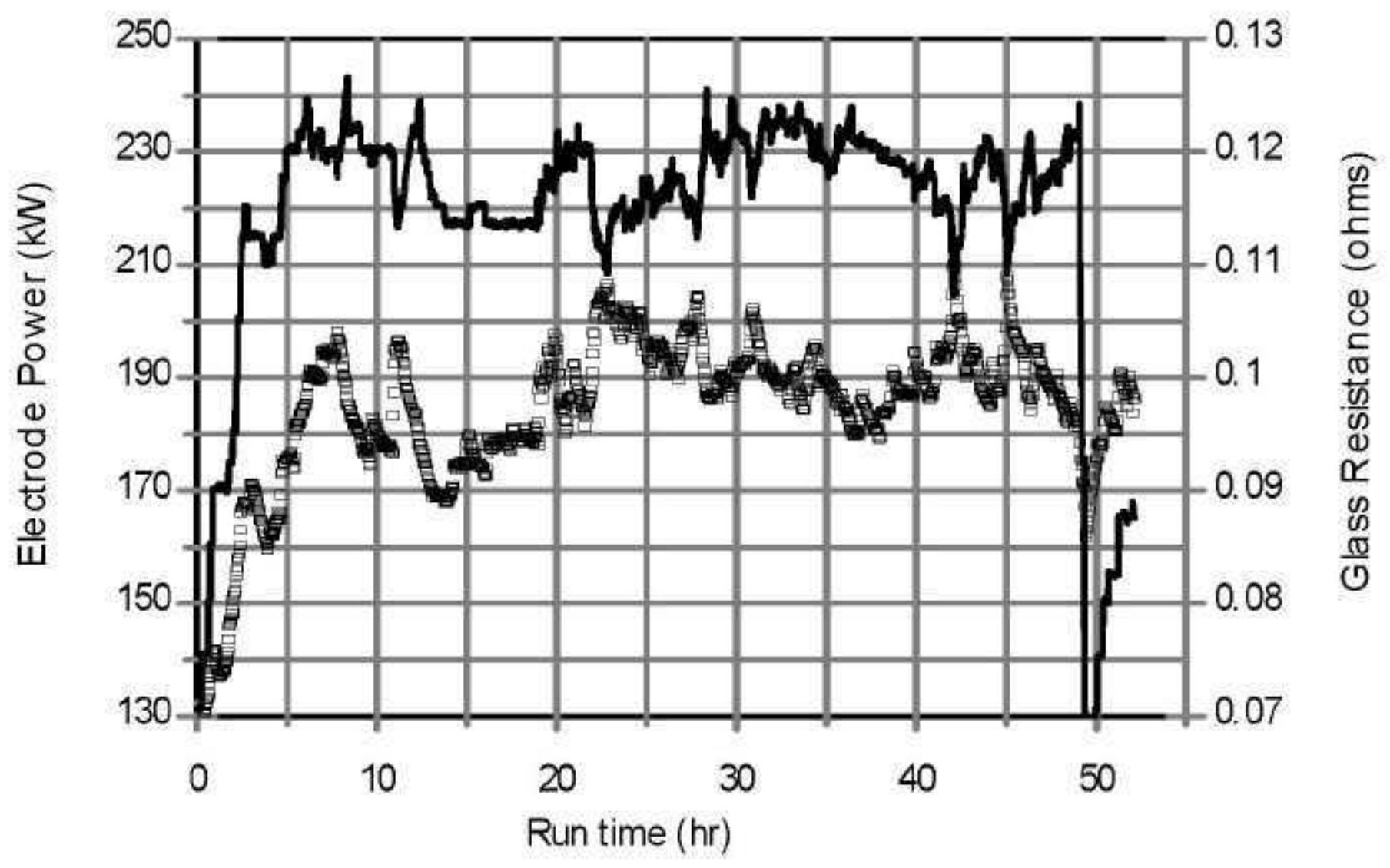

Power

- Resistance

Figure 5.6.a. Electrode power and glass resistance for DM1200 Test 1. 


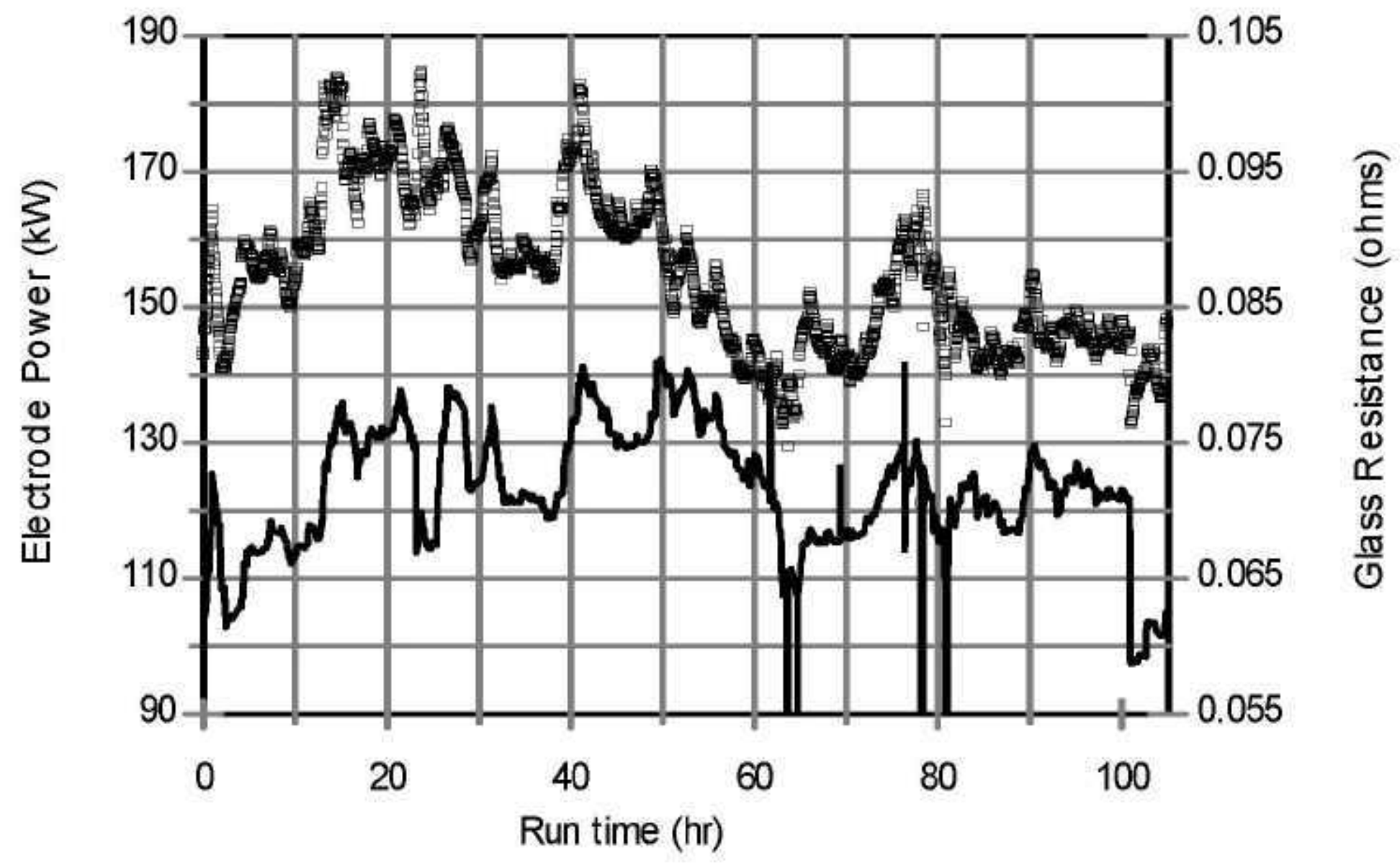

- Resistance

Figure 5.6.b. Electrode power and glass resistance for DM1200 Tests 2 and 3 . 


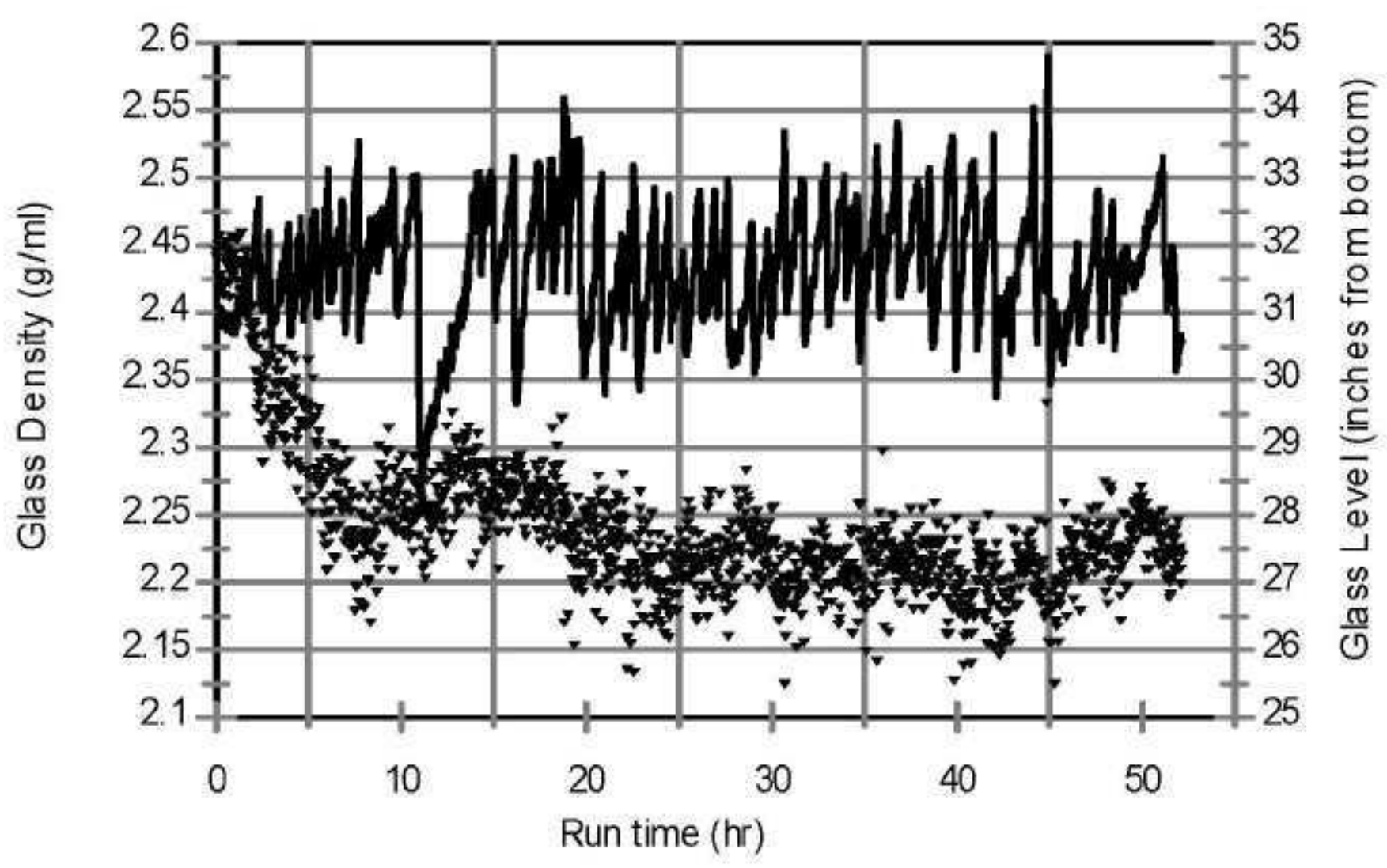

Figure 5.7.a. Glass density and level for DM1200 Test 1. 


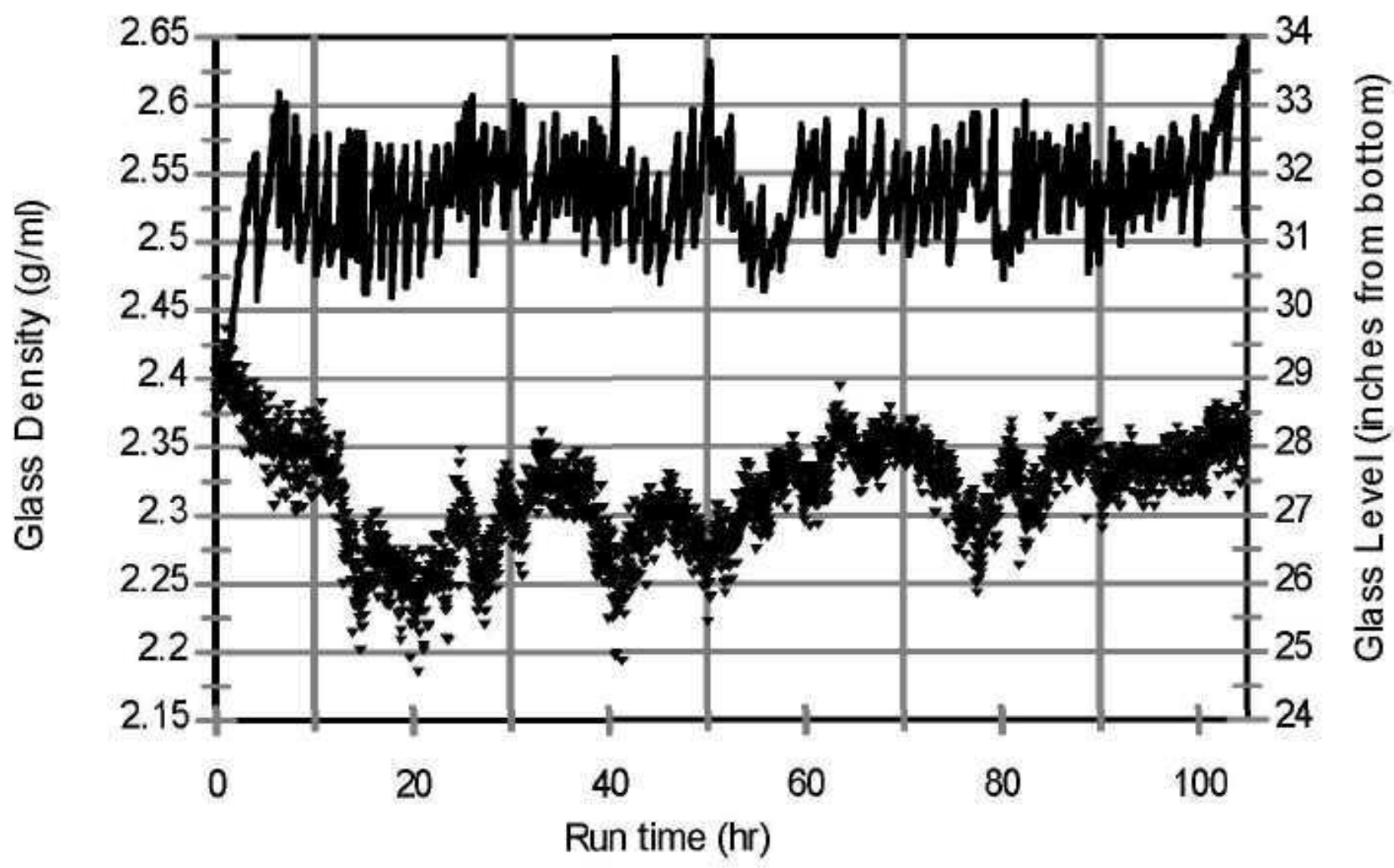

Figure 5.7.b. Glass density and level for DM1200 Tests 2 and 3. 


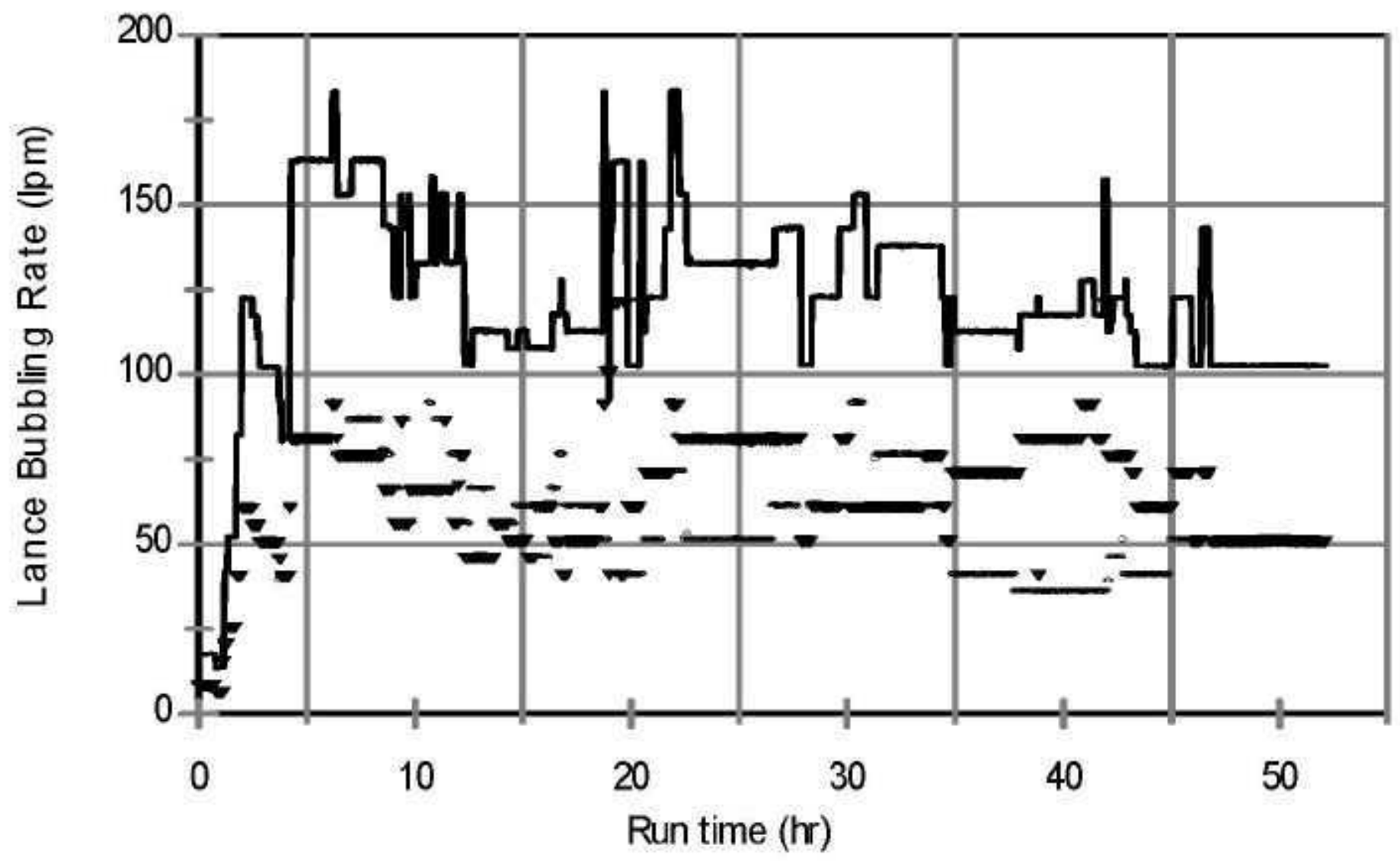

Figure 5.8.a. Glass pool bubbling for DM1200 Test 1. 


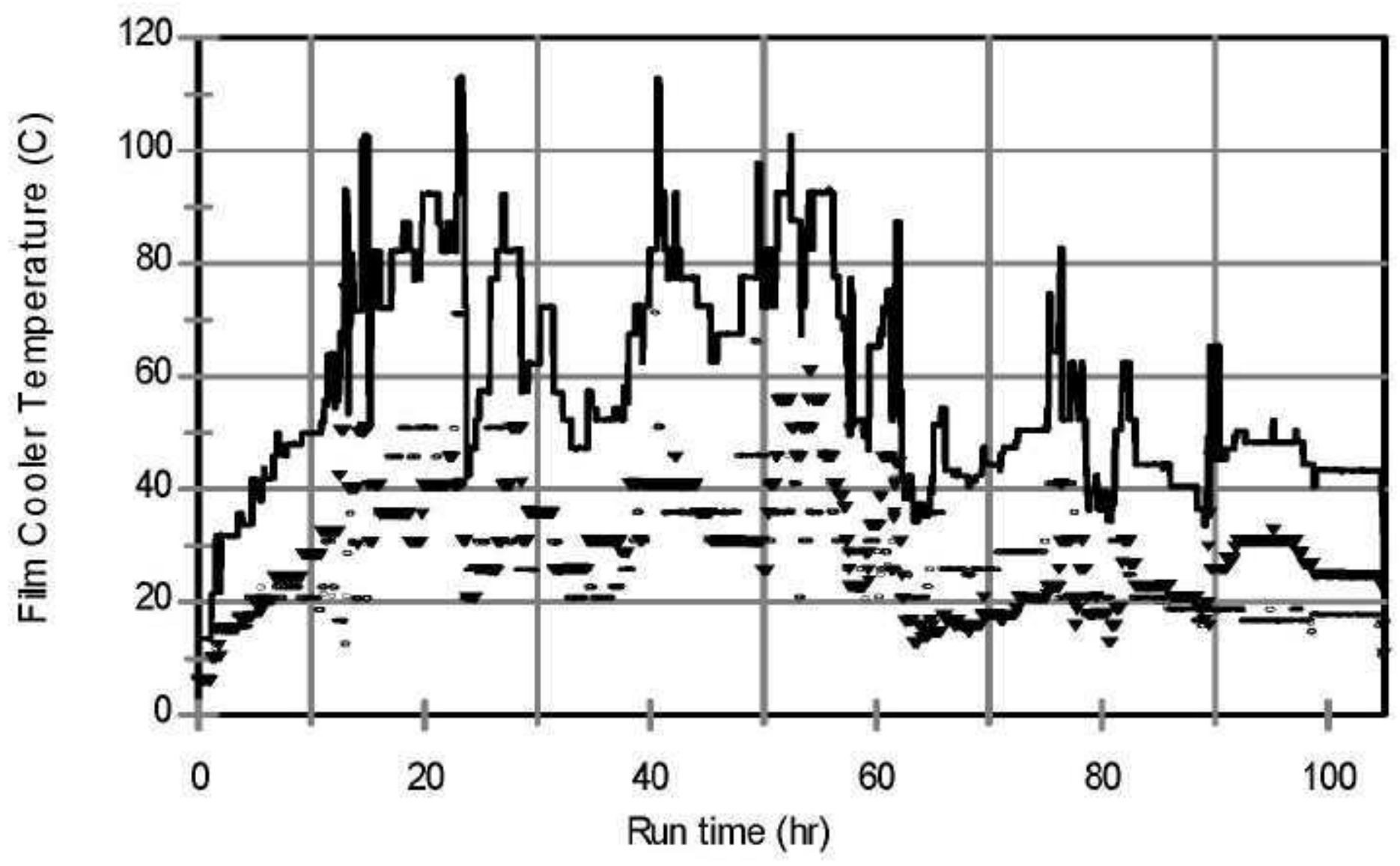

- Lance1 - Lance2 Total

Figure 5.8.b. Glass pool bubbling for DM1200 Tests 2 and 3 . 


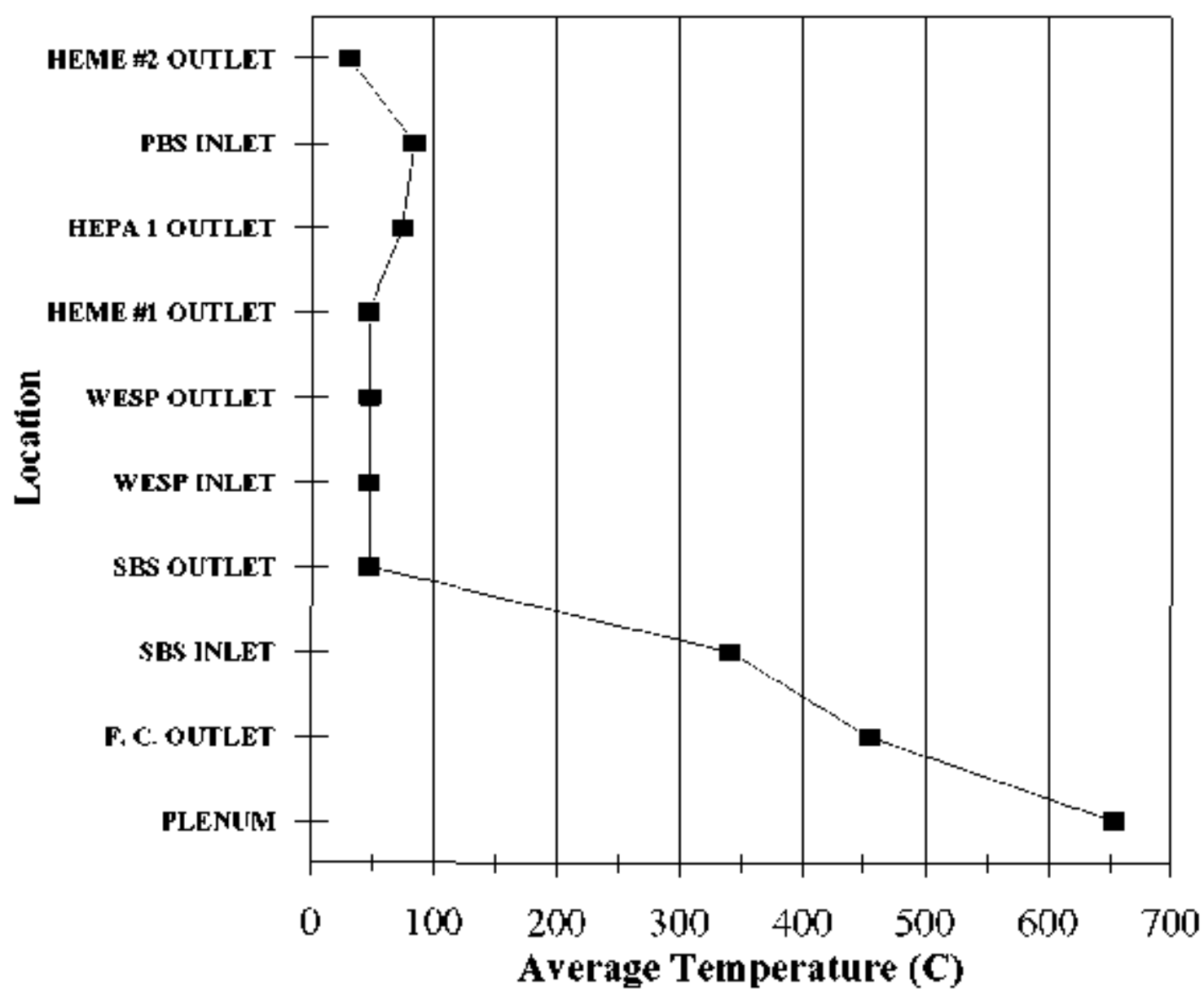

Figure 5.9.a. Average gas temperatures along the DM1200 off-gas train during Test 1 . 


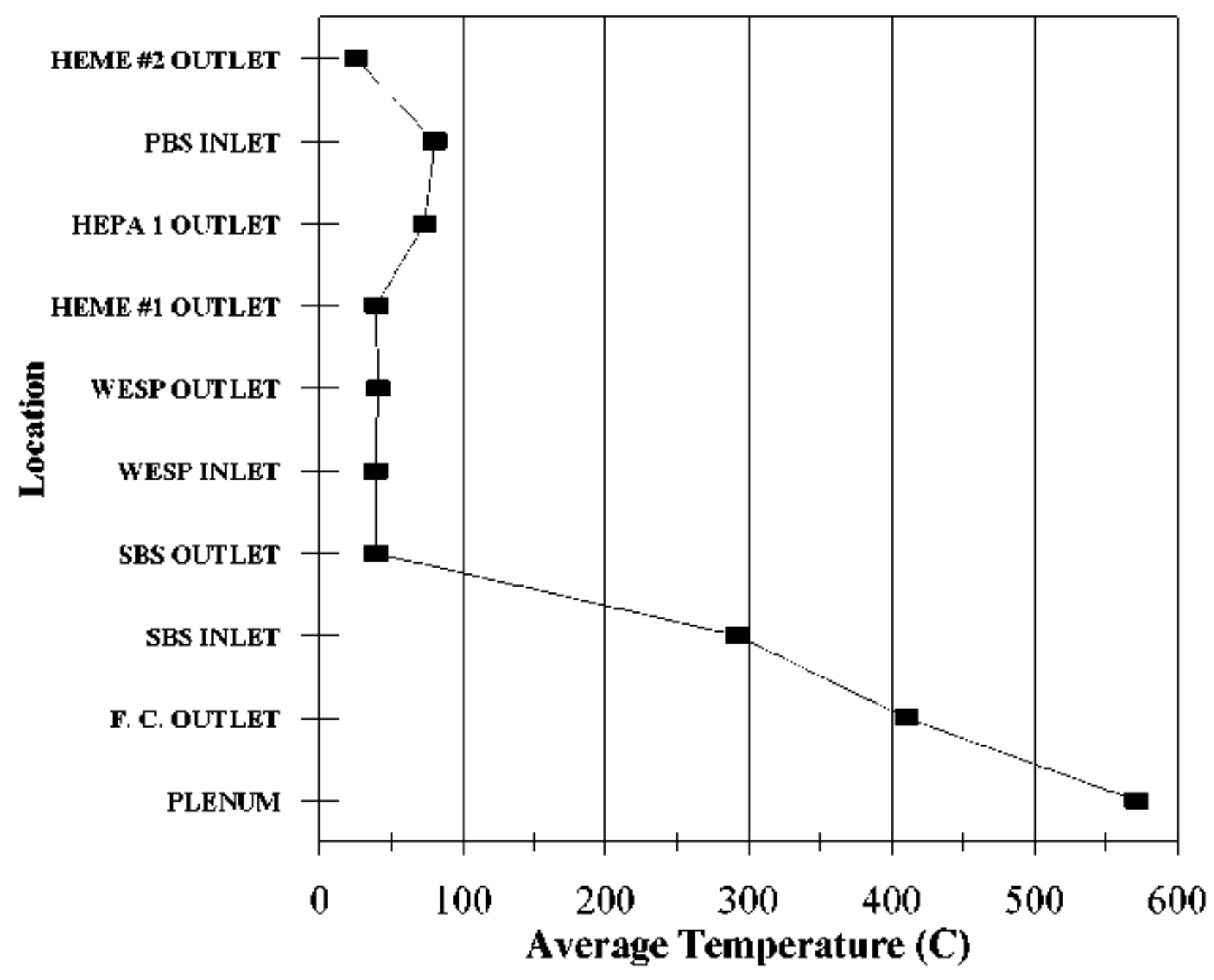

Figure 5.9.b. Average gas temperatures along the DM120il off-gas train during Test 2. 


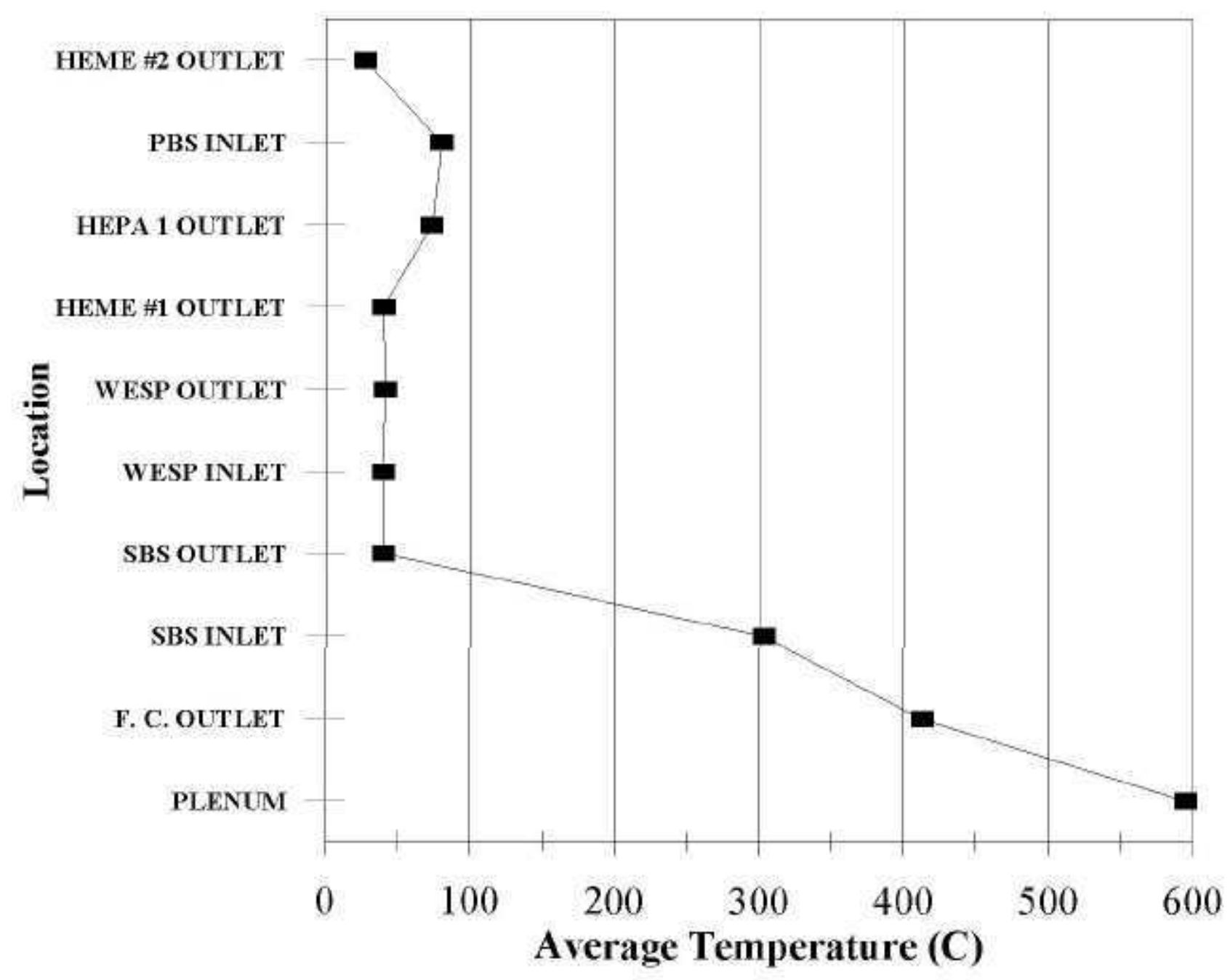

Figure 5.9.c. Average gas temperatures along the DM1200 off-gas train during Test 3. 


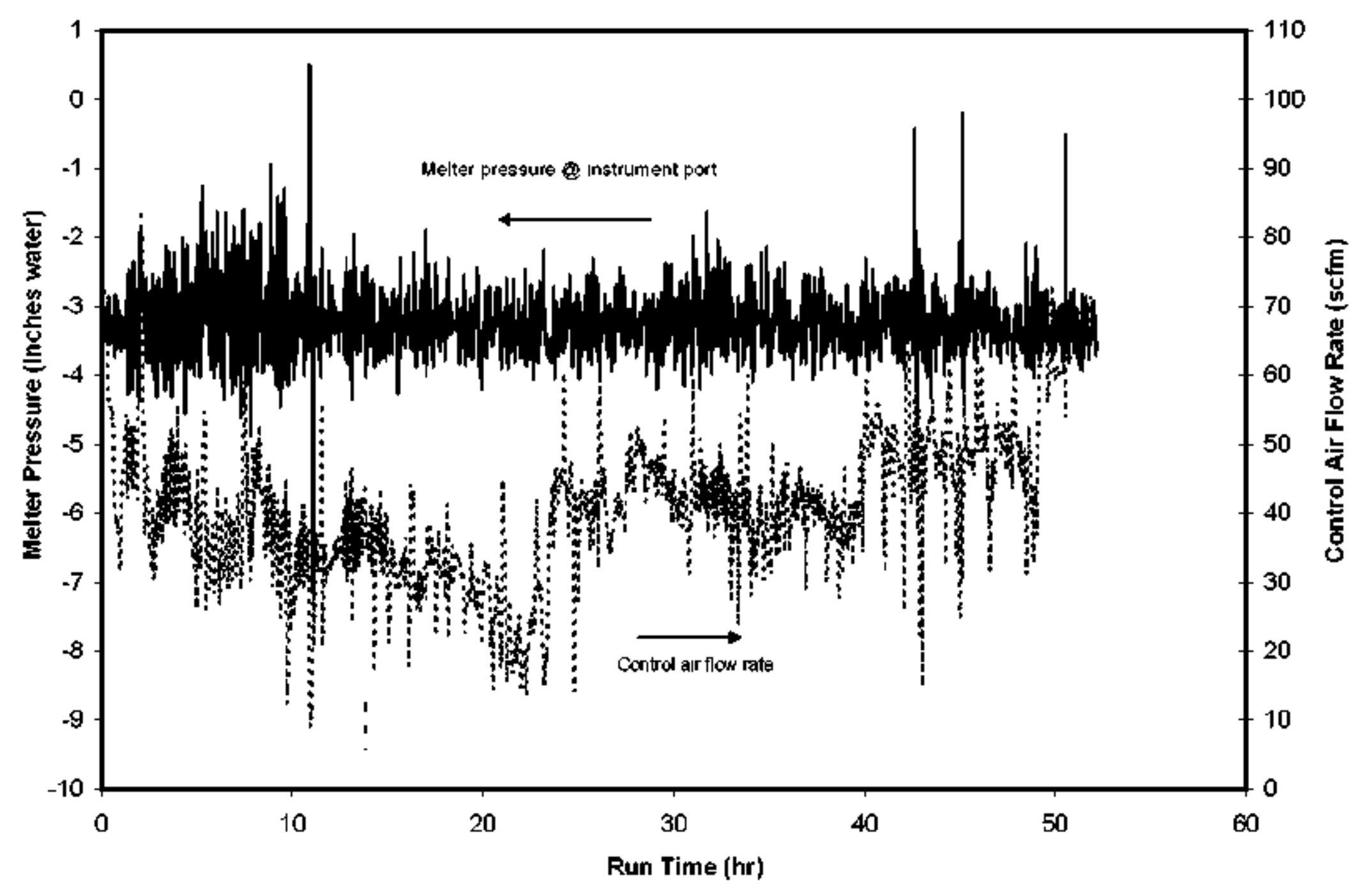

Figure 5.10.a. Melter pressure at instrument port and control air flow rate during Test 1. 


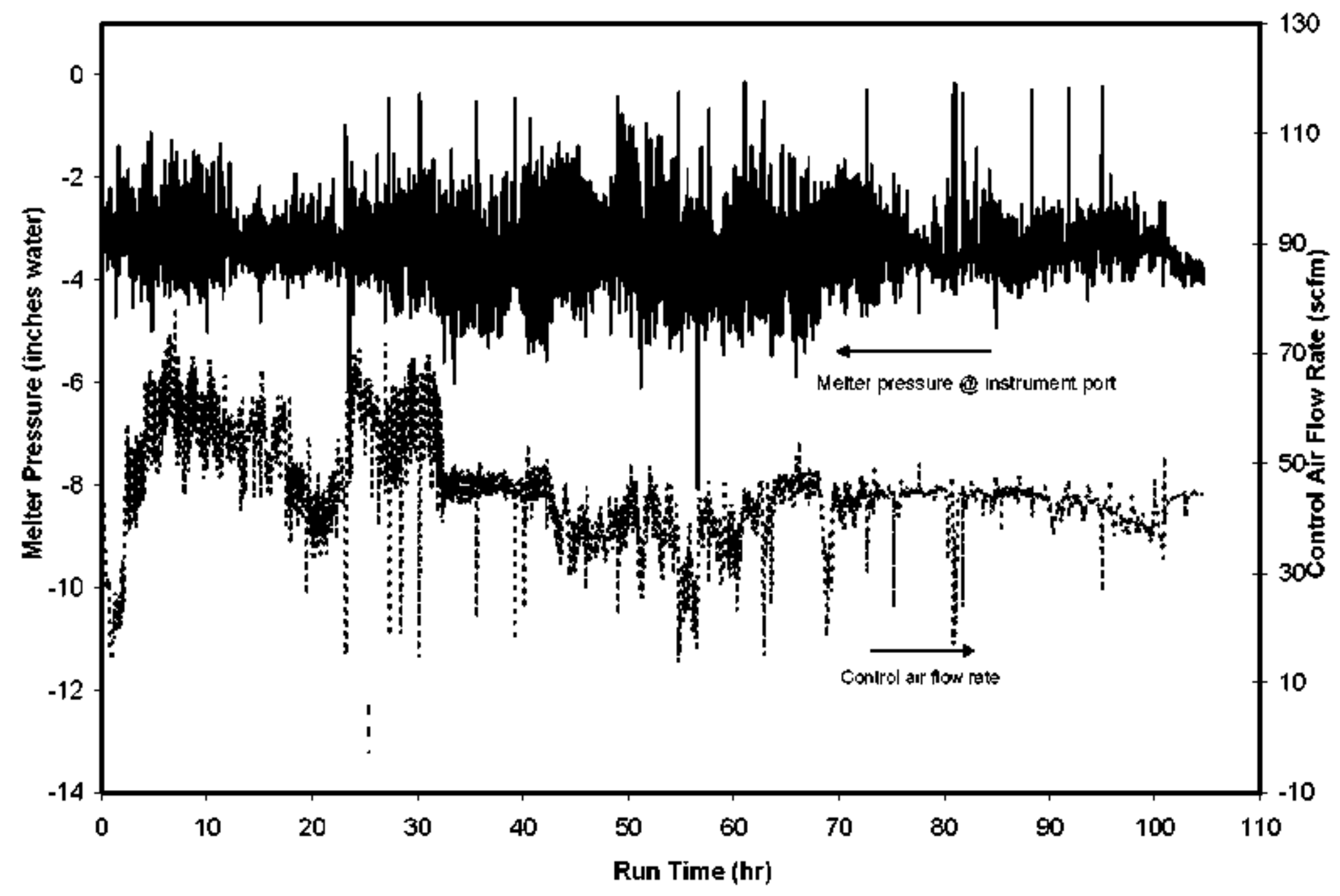

Figure 5.10.b. Melter pressure at instrument port and control air flow rate during Tests 2 and 3. 


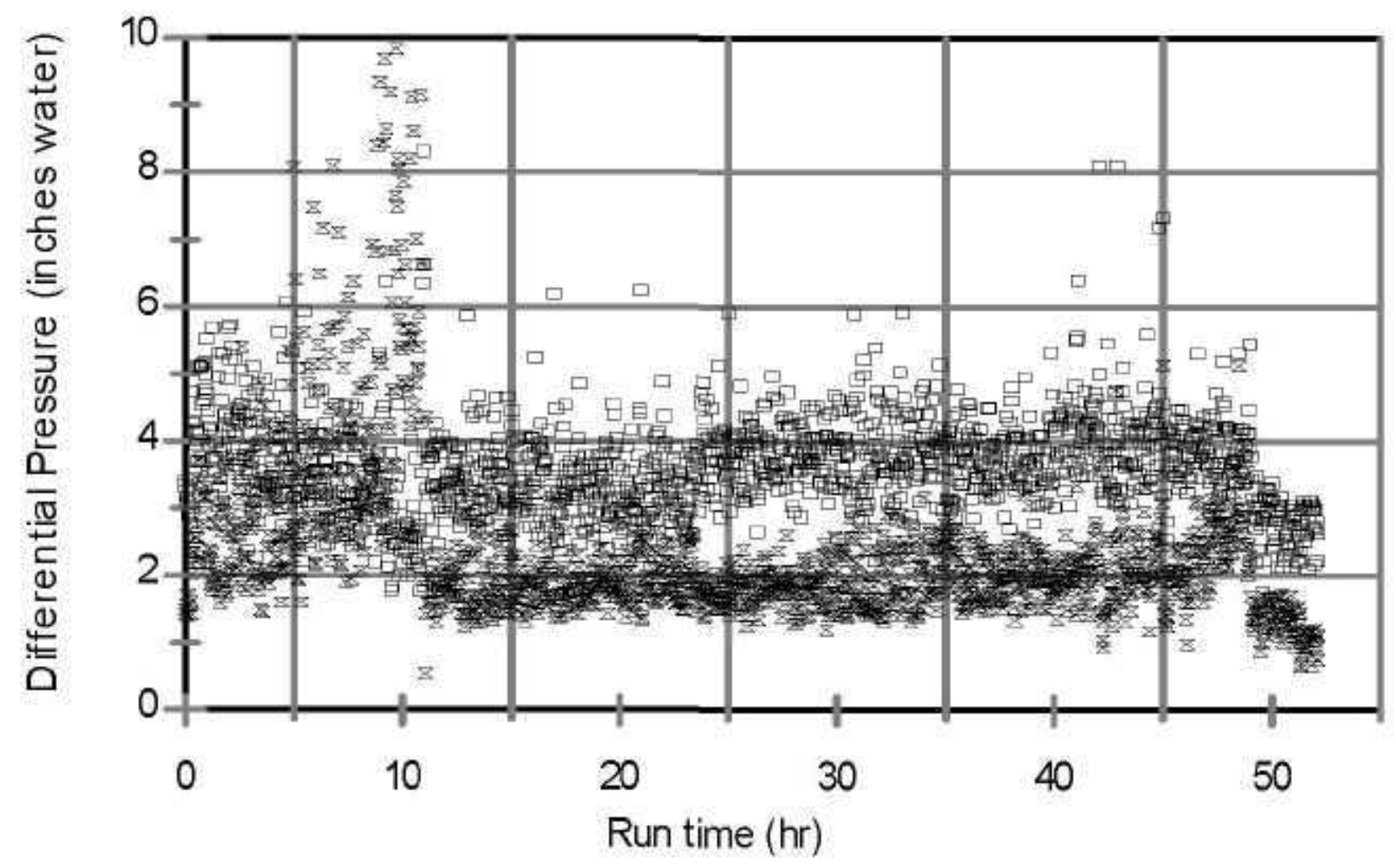

- Transition line $\quad$ a Film Cooler

Figure 5.11.a. Differential pressure across the transition line and film cooler during DM1200 Test 1. 


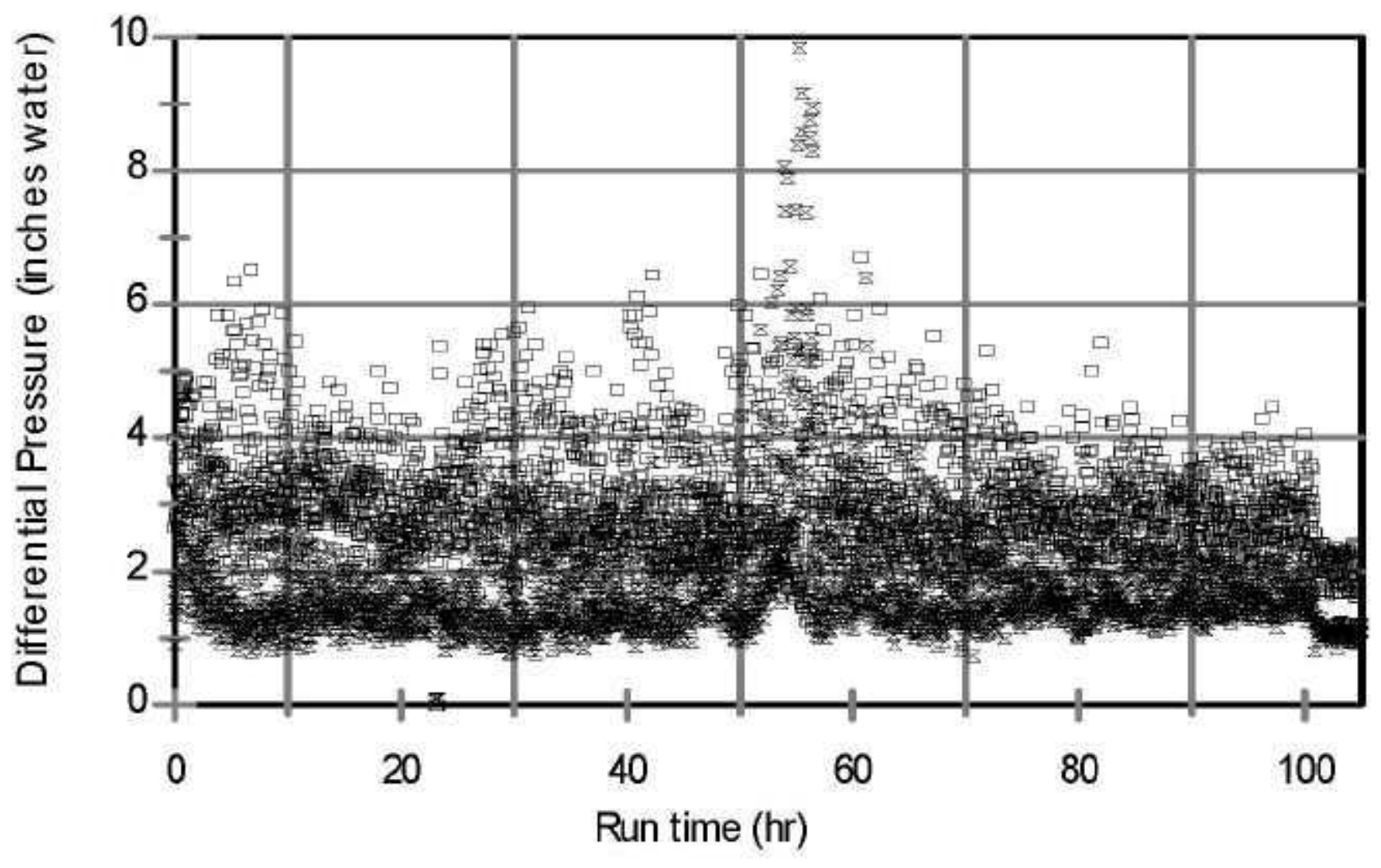

- Transition line

= Film Cooler

Figure 5.11.b. Differential pressure across the transition line and film cooler during DM1200 Tests 2 and 3. 


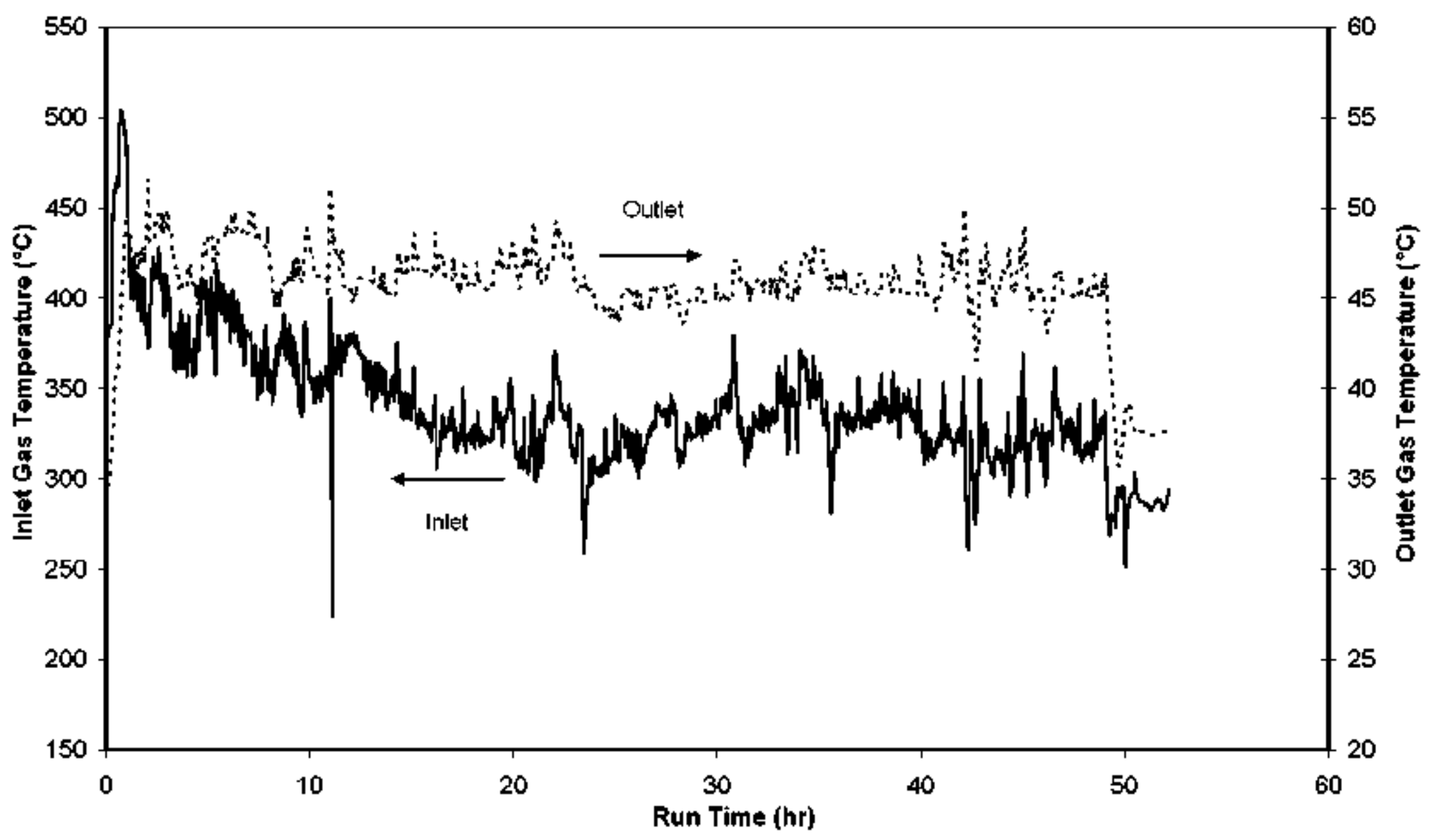

Figure 5.12.a. SBS inlet and outlet gas temperatures during Test 1. 


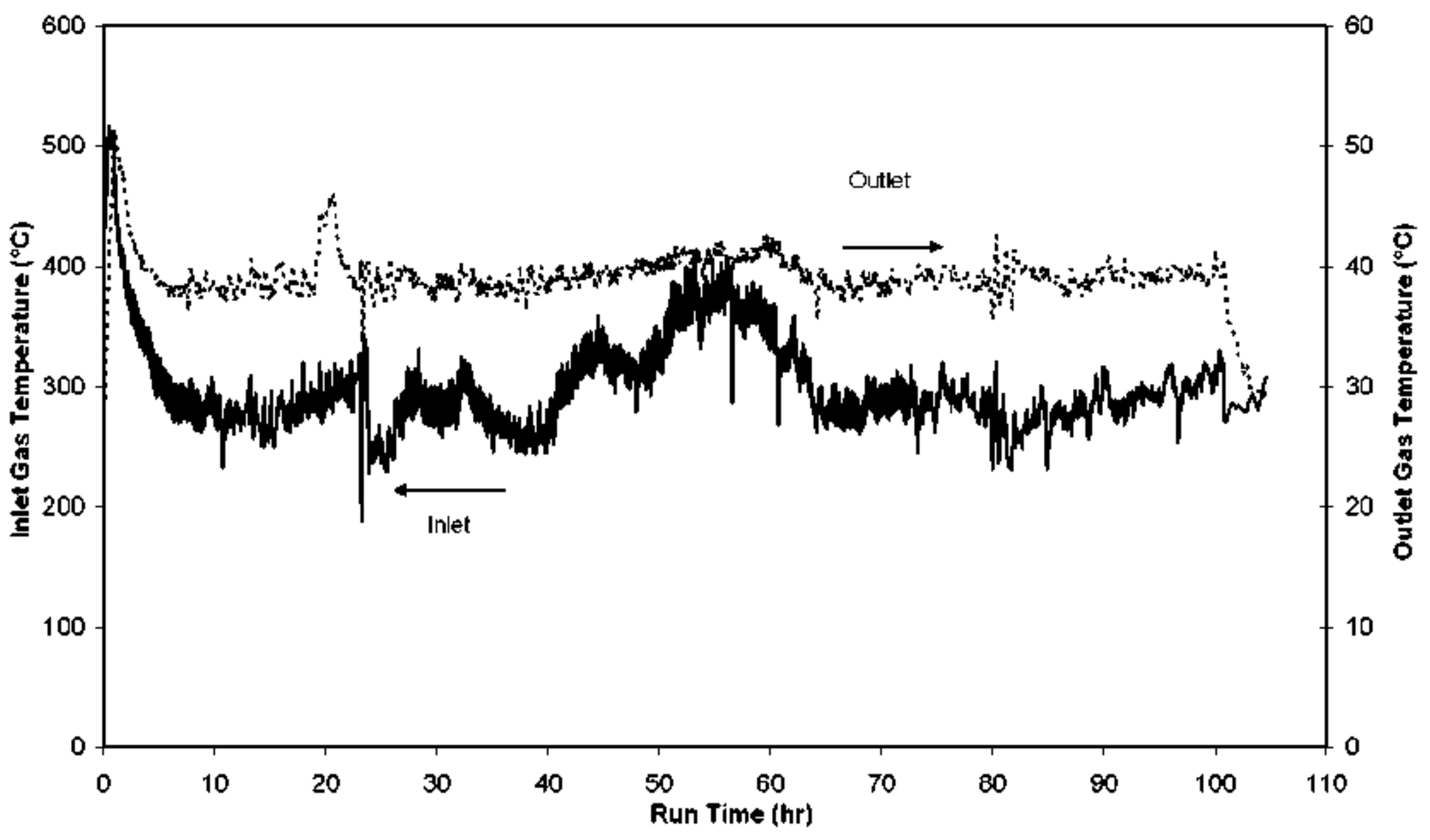

Figure 5.12.h. SBS inlet and outlet gas temperatures during Tests 2 and 3 . 


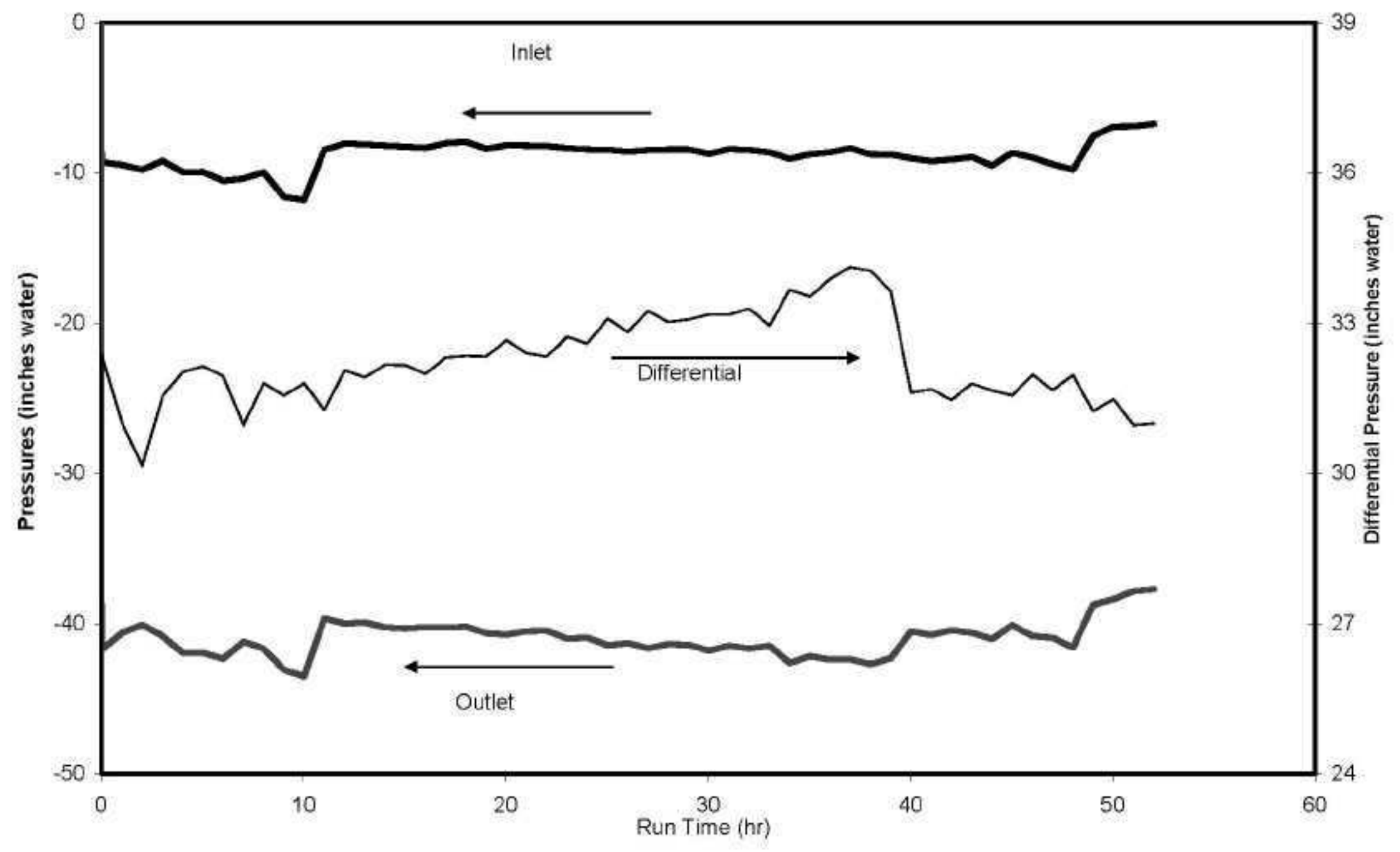

Figure 5.13.a. SBS inlet, outlet, and differential pressures (hourly average values) during Test 1. 


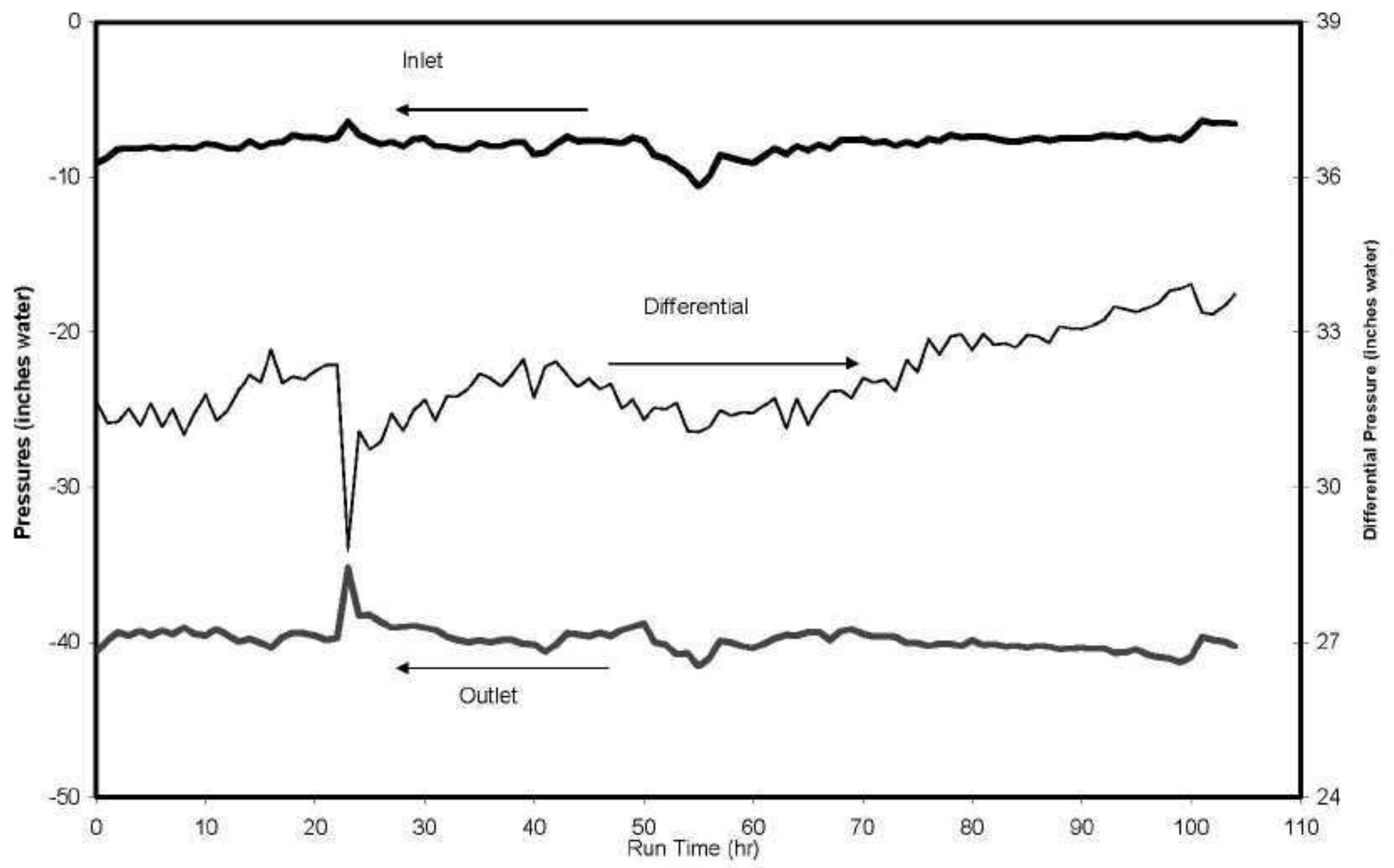

Figure 5.13.b. SBS inlet, outlet, and differential pressures (hourly average values) during Tests 2 and 3. 


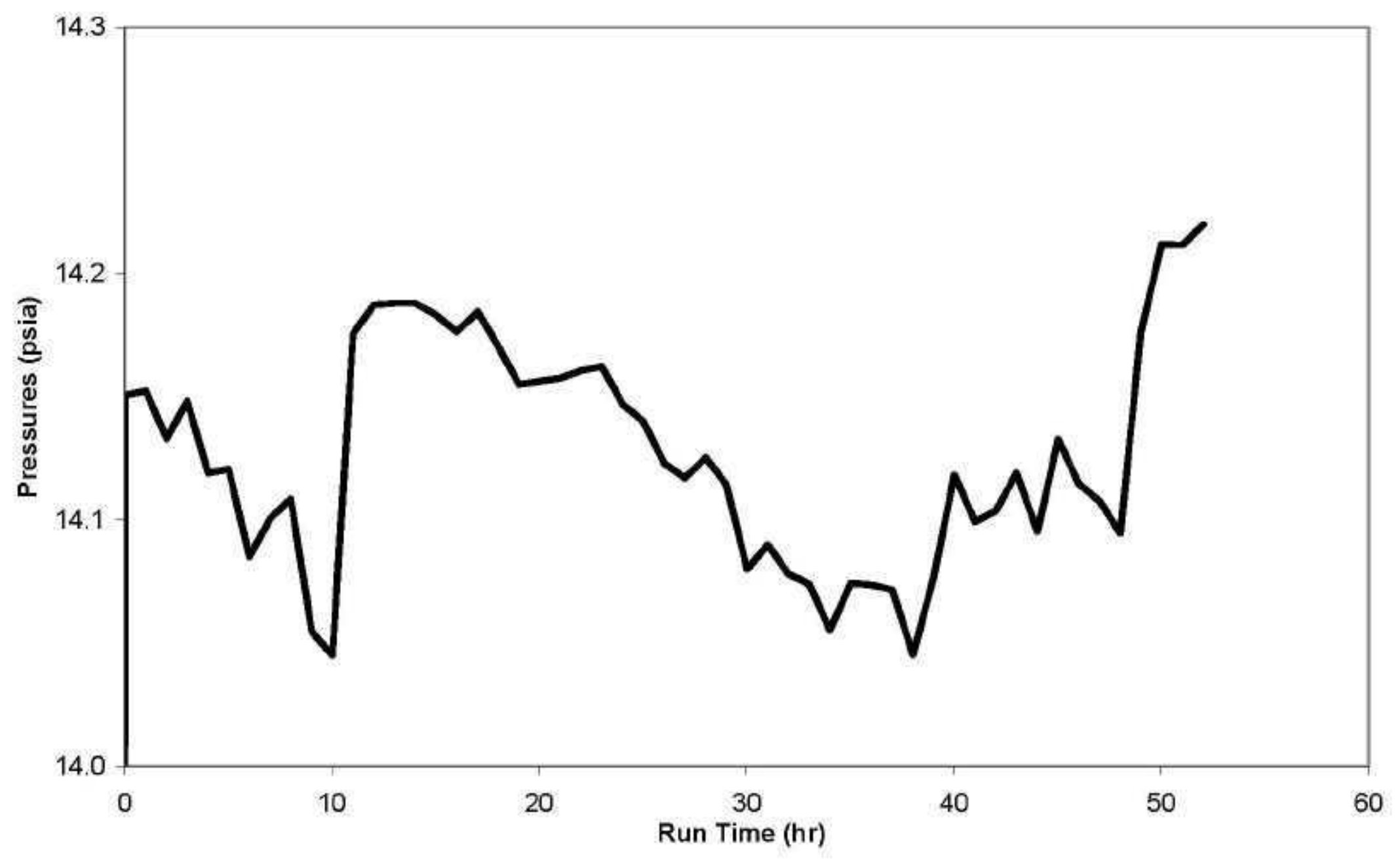

Figure 5.14.a. SBS downcomer annulus pressure (hourly average values) during Test 1. 


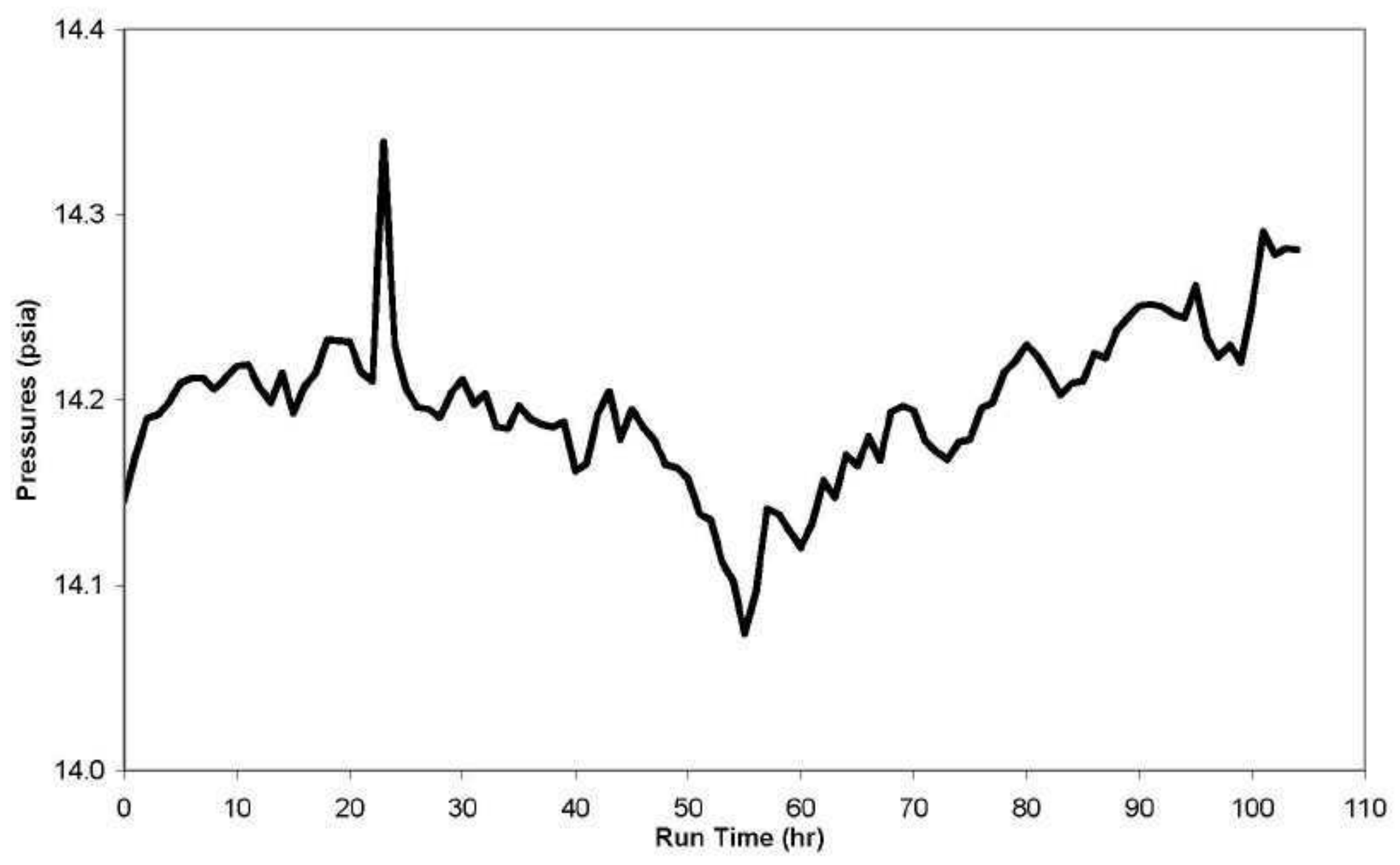

Figure 5.14.b. SBS downcomer annulus pressure (hourly average values) during Tests 2 and 3 . 

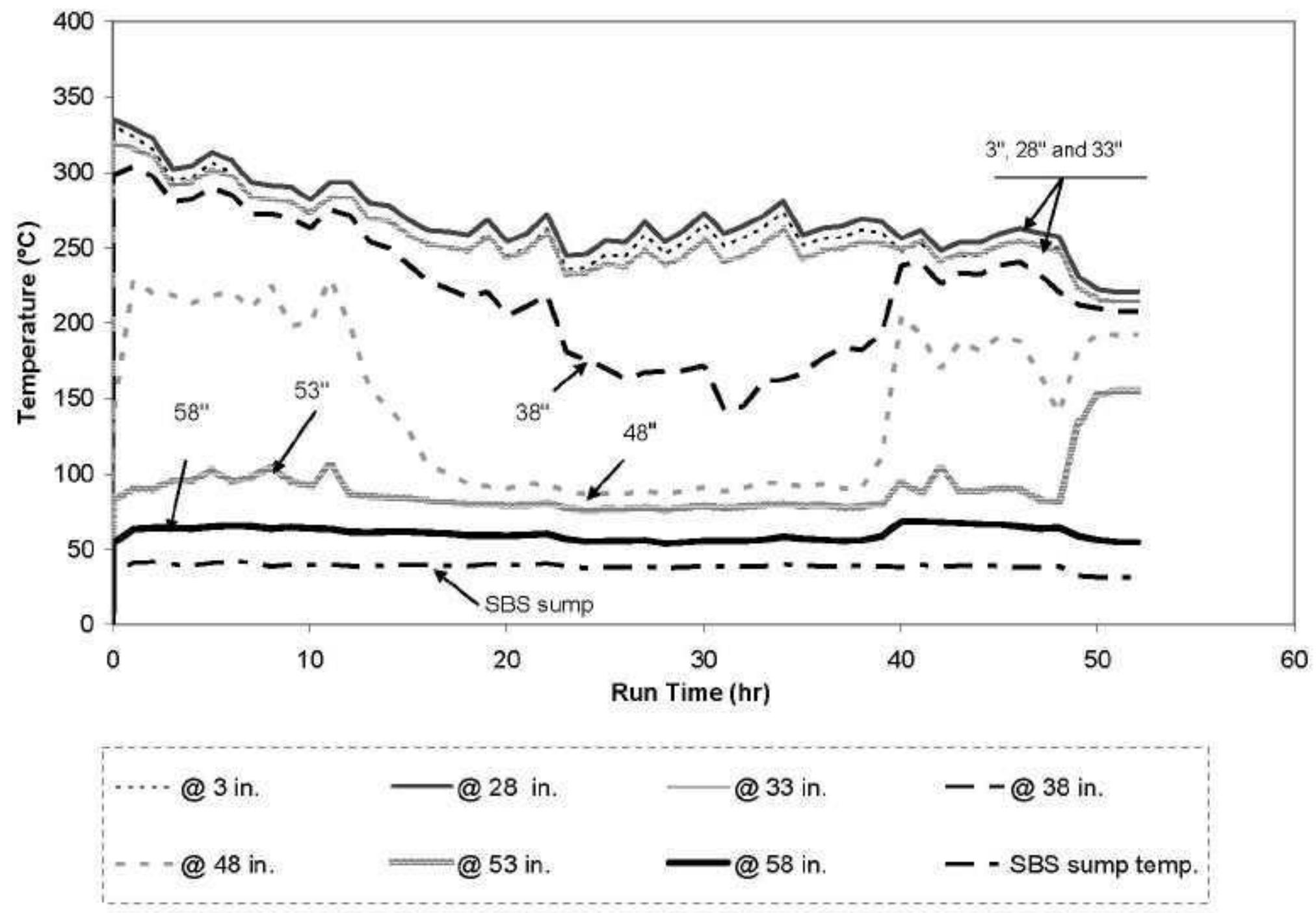

Figure 5.15.a. Off-gas temperatures in the SBS downcomer and sump water temperatures (hourly average values) during Test 1. 

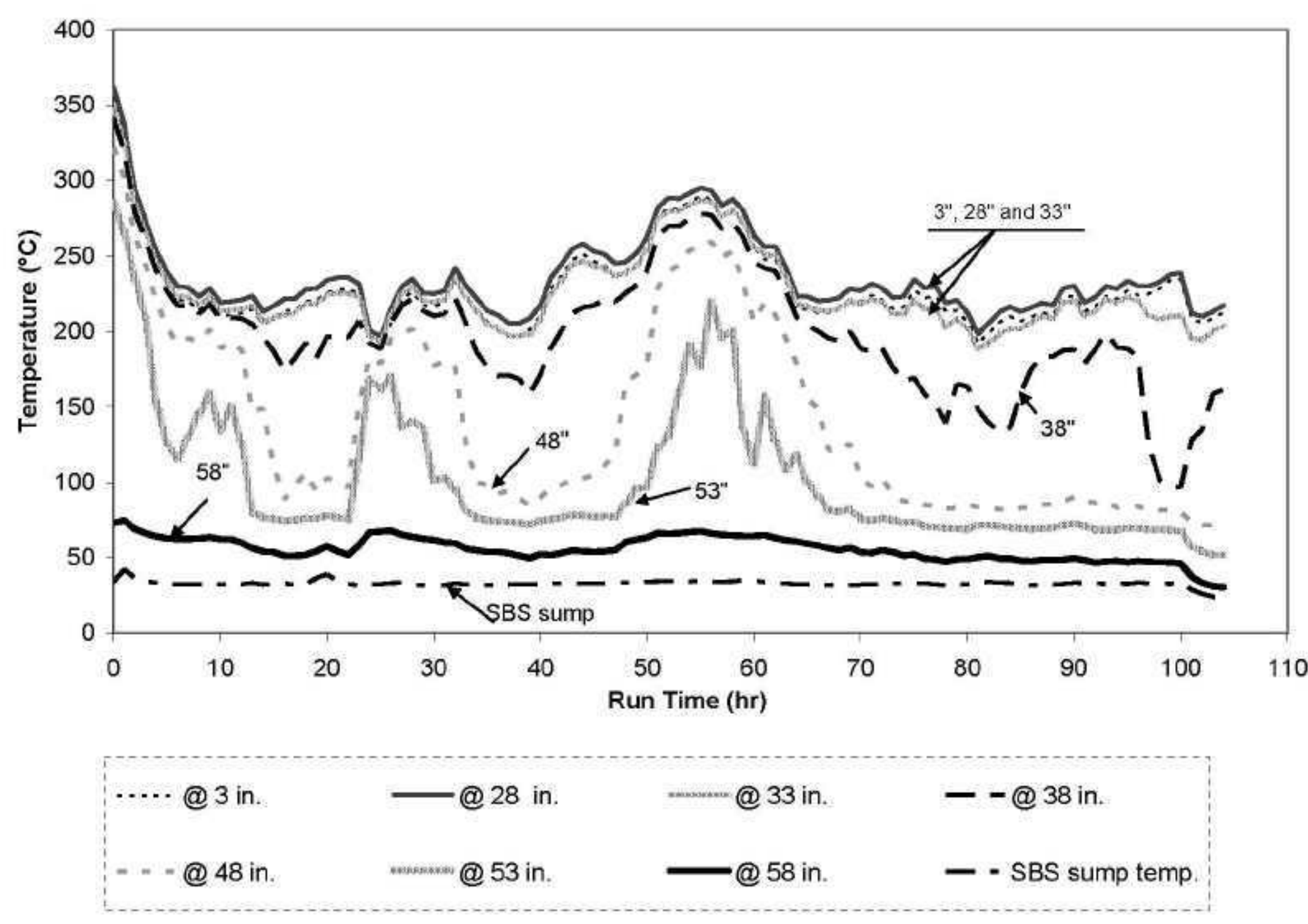

Figure 5.15.b. Off-gas temperatures in the SBS downcomer and sump water temperatures (hourly average values) during Tests 2 and 3 . 


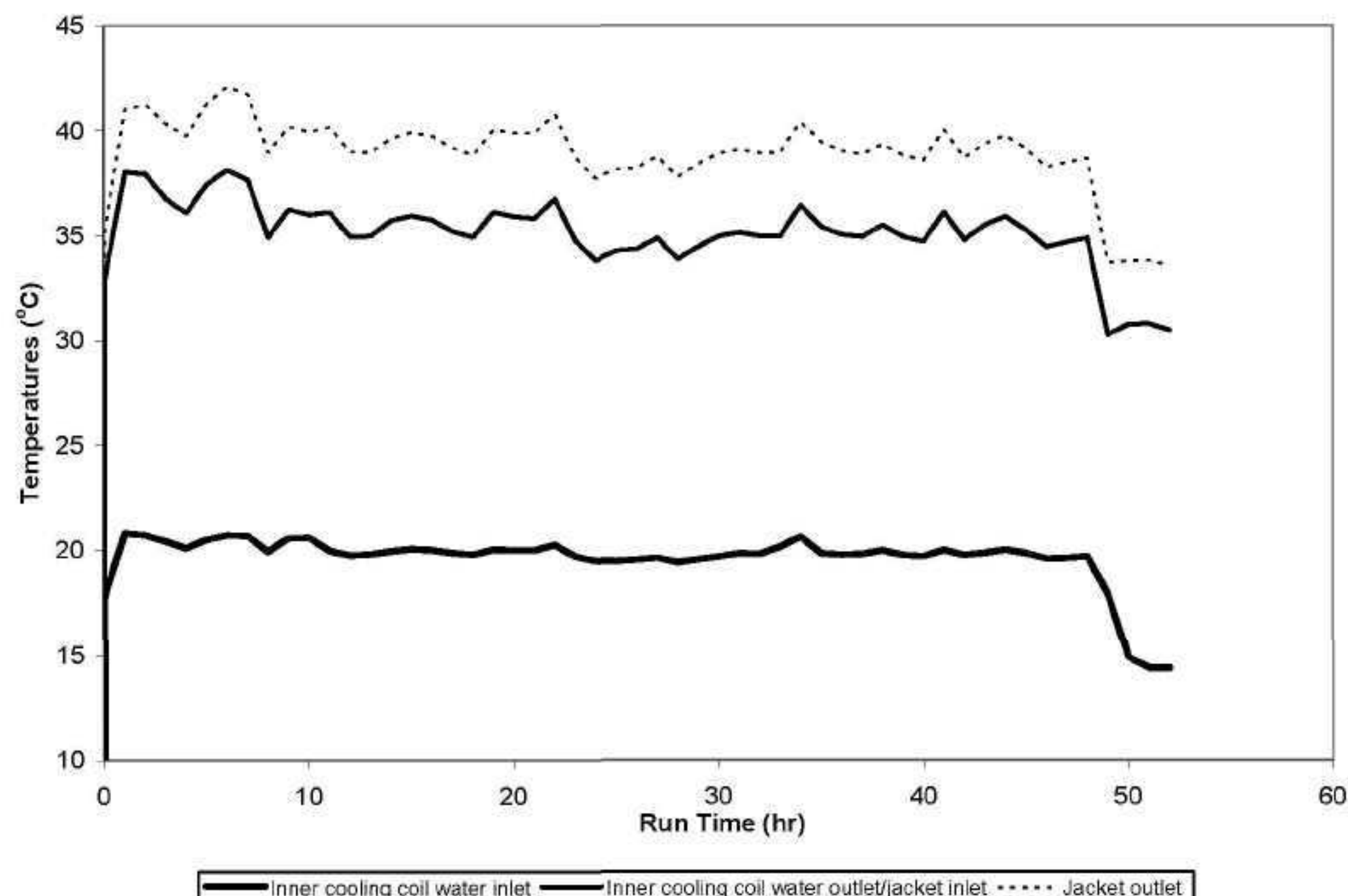

Figure 5.16.a. SBS cooling coil inlet, cooling coil outlet/jacket inlet and jacket outlet water temperatures (hourly average values) during Test 1 . 


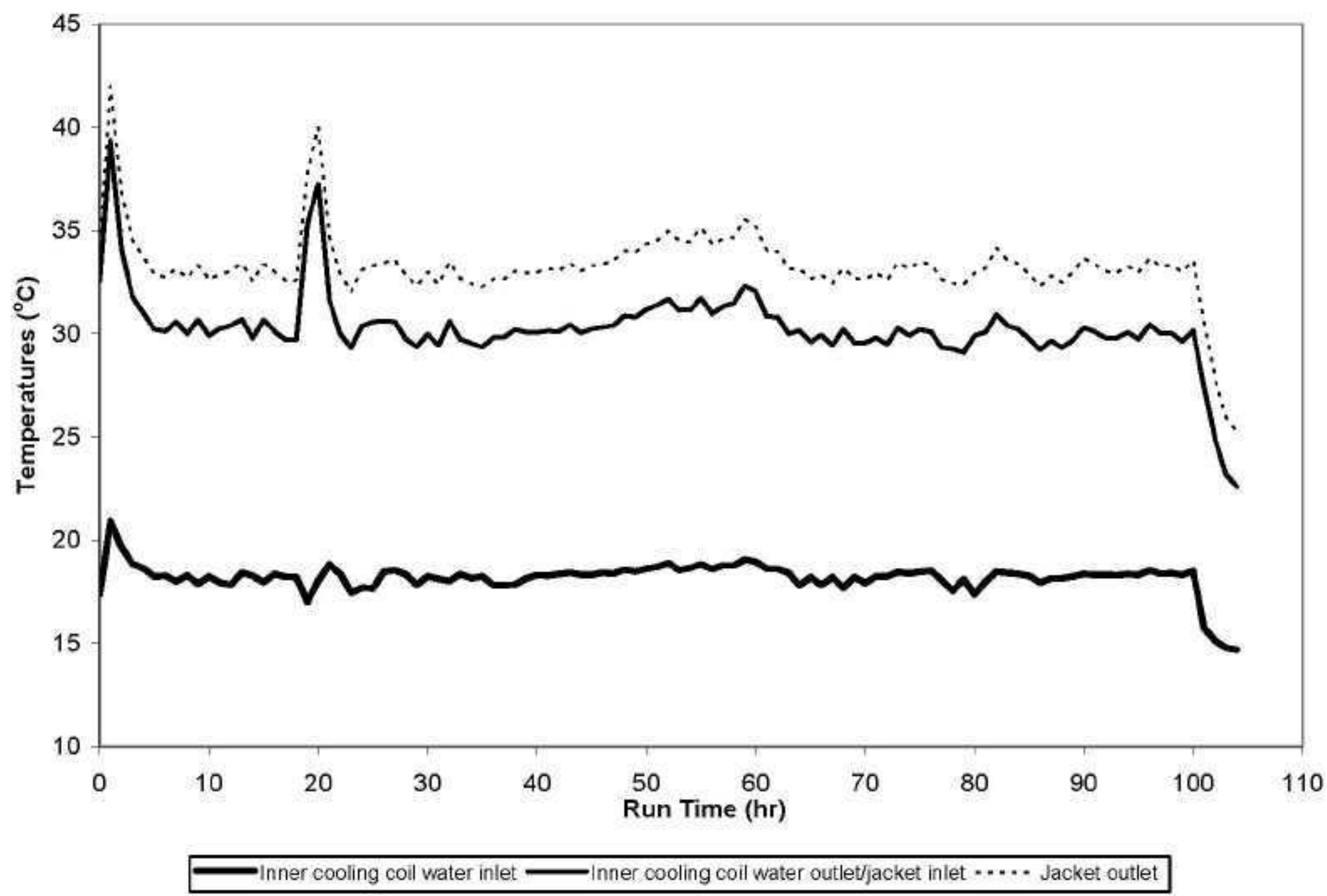

Figure 5,16.b. SBS cooling coil inlet, cooling coil outlet/jacket inlet and jacket outlet water temperatures (hourly average values) during Tests 2 and 3 . 


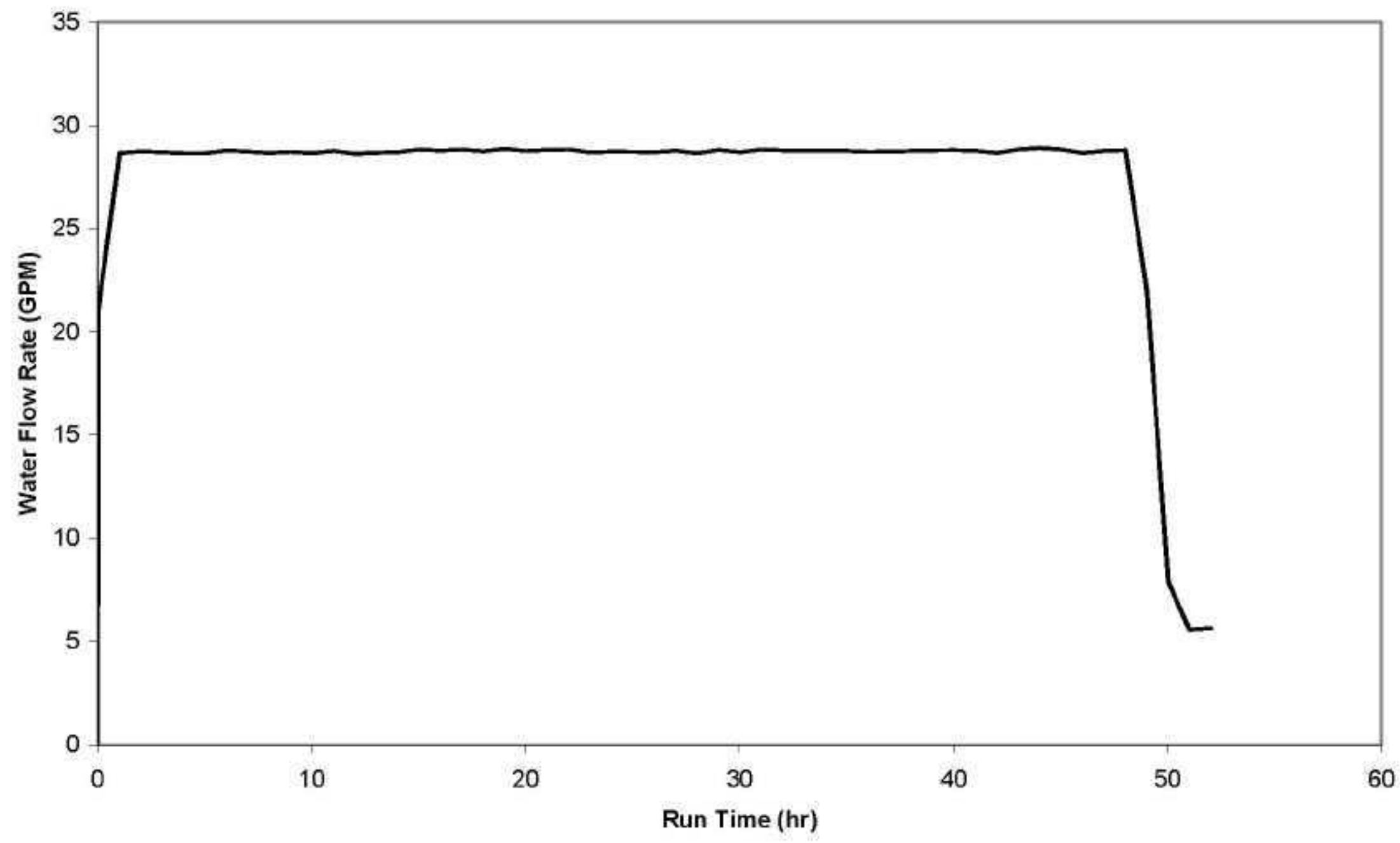

Figure 5.17.a. SBS cooling coil/jacket water flow rate (hourly average values) during Test 1 . 


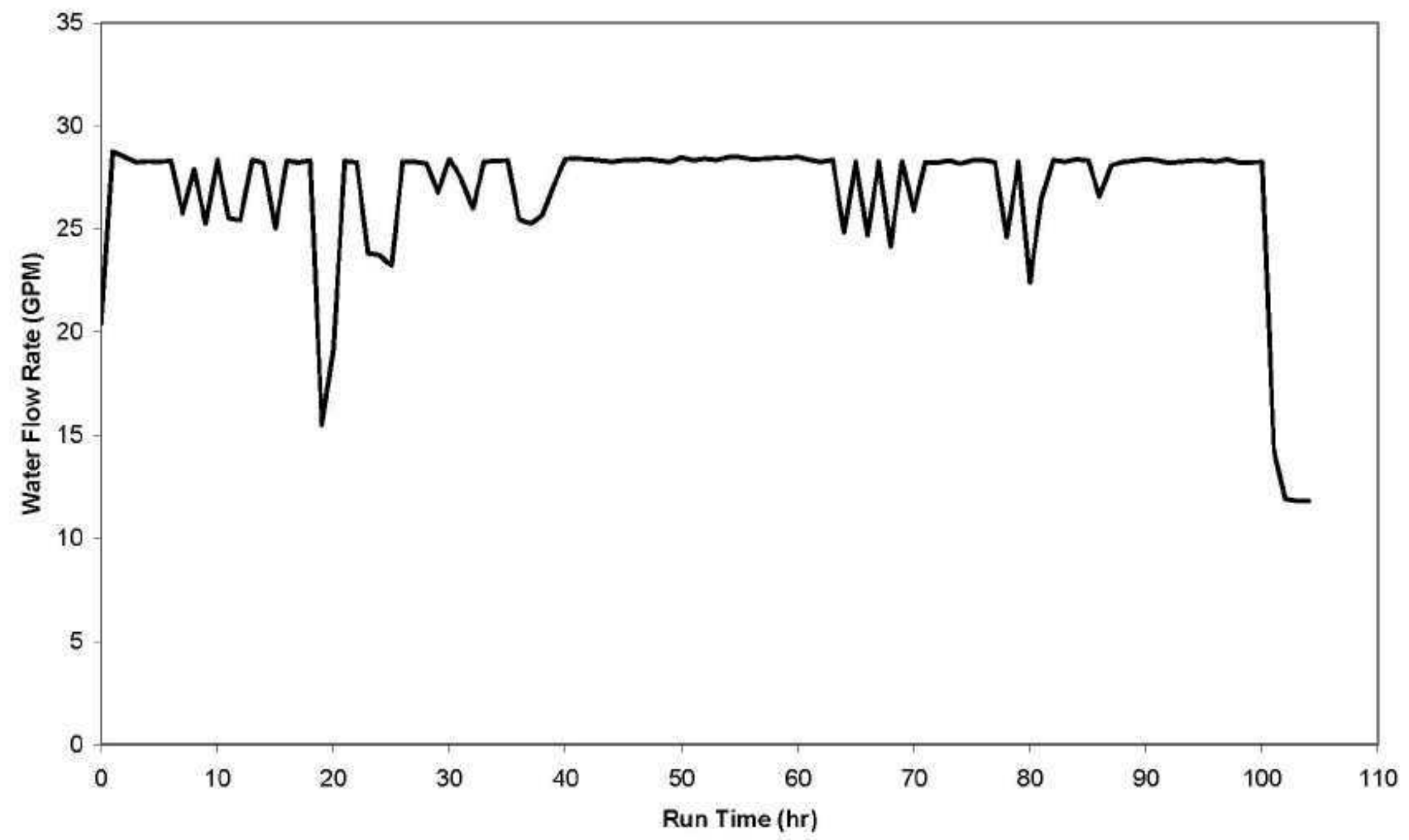

Figure 5.17.b. SBS cooling coil/jacket water flow rate (hourly average values) during Tests 2 and 3 . 


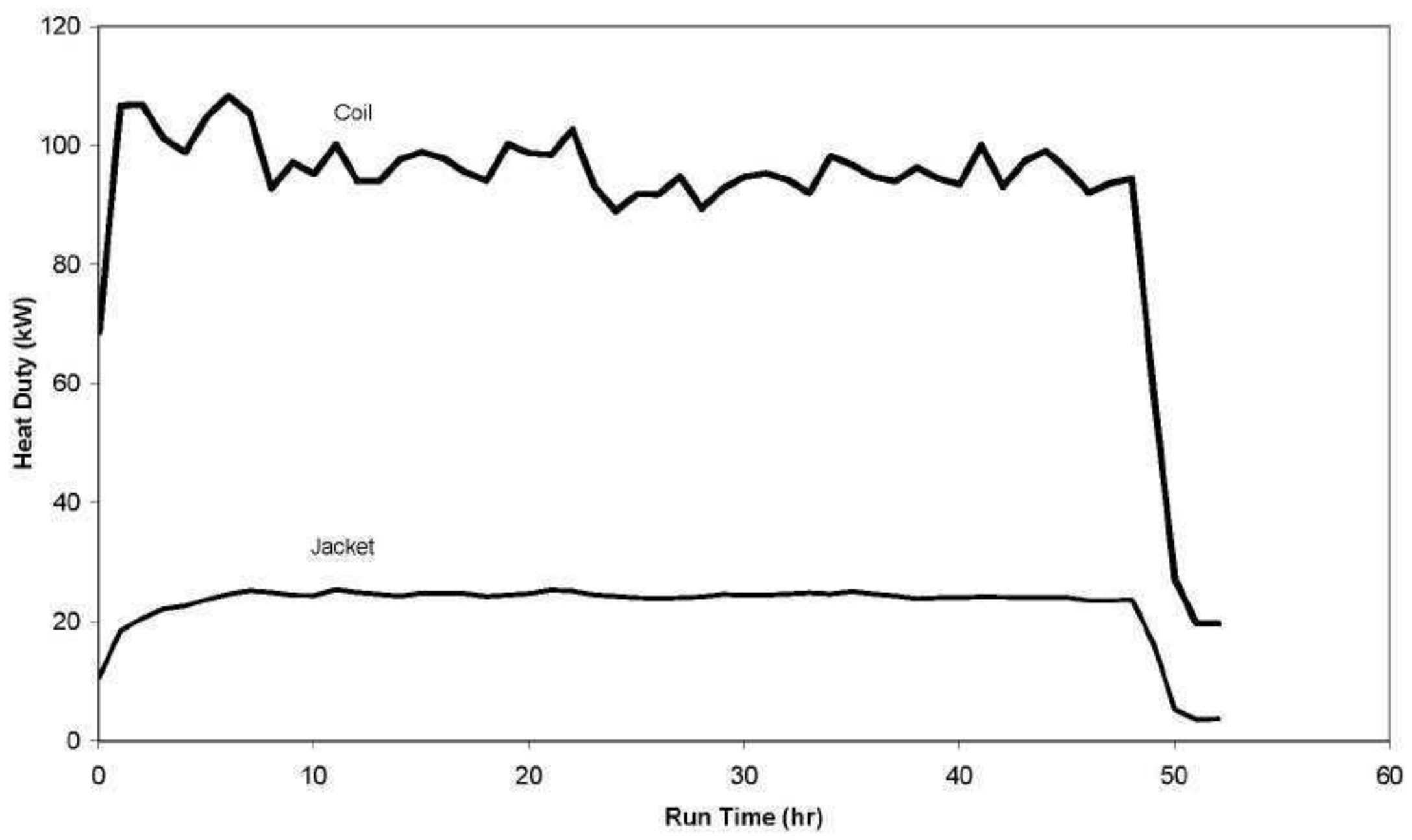

Figure 5.18.a. Calculated heat loads on the inner coil and jacket (hourly average values) during Test 1. 


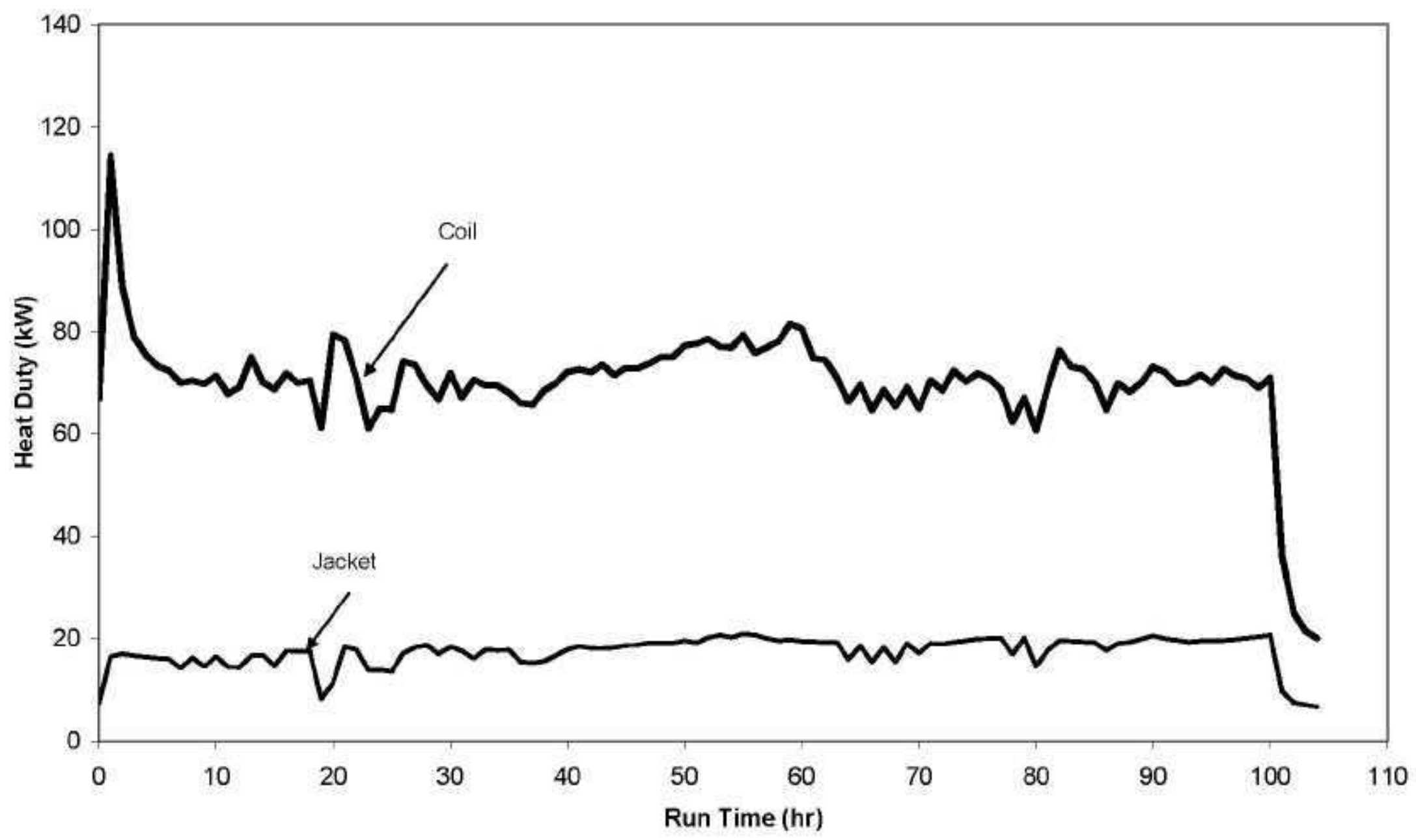

Figure 5.18.b. Calculated heat loads on the inner coil and jacket (hourly average values) during Tests 2 and 3 . 


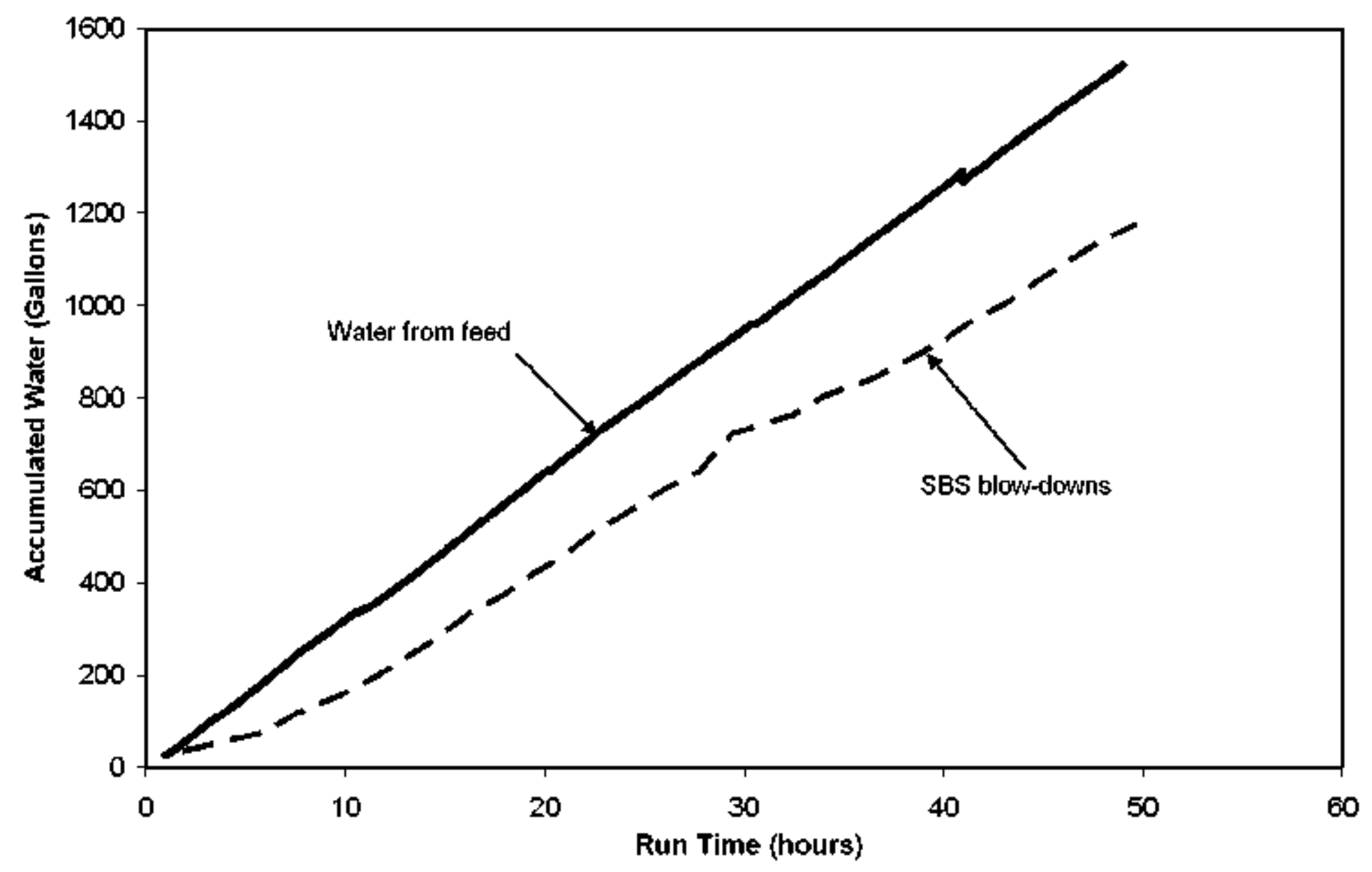

Figure 5.19.a. Accumulated SBS blowdown volune and accunulated feed water during Test 1. 


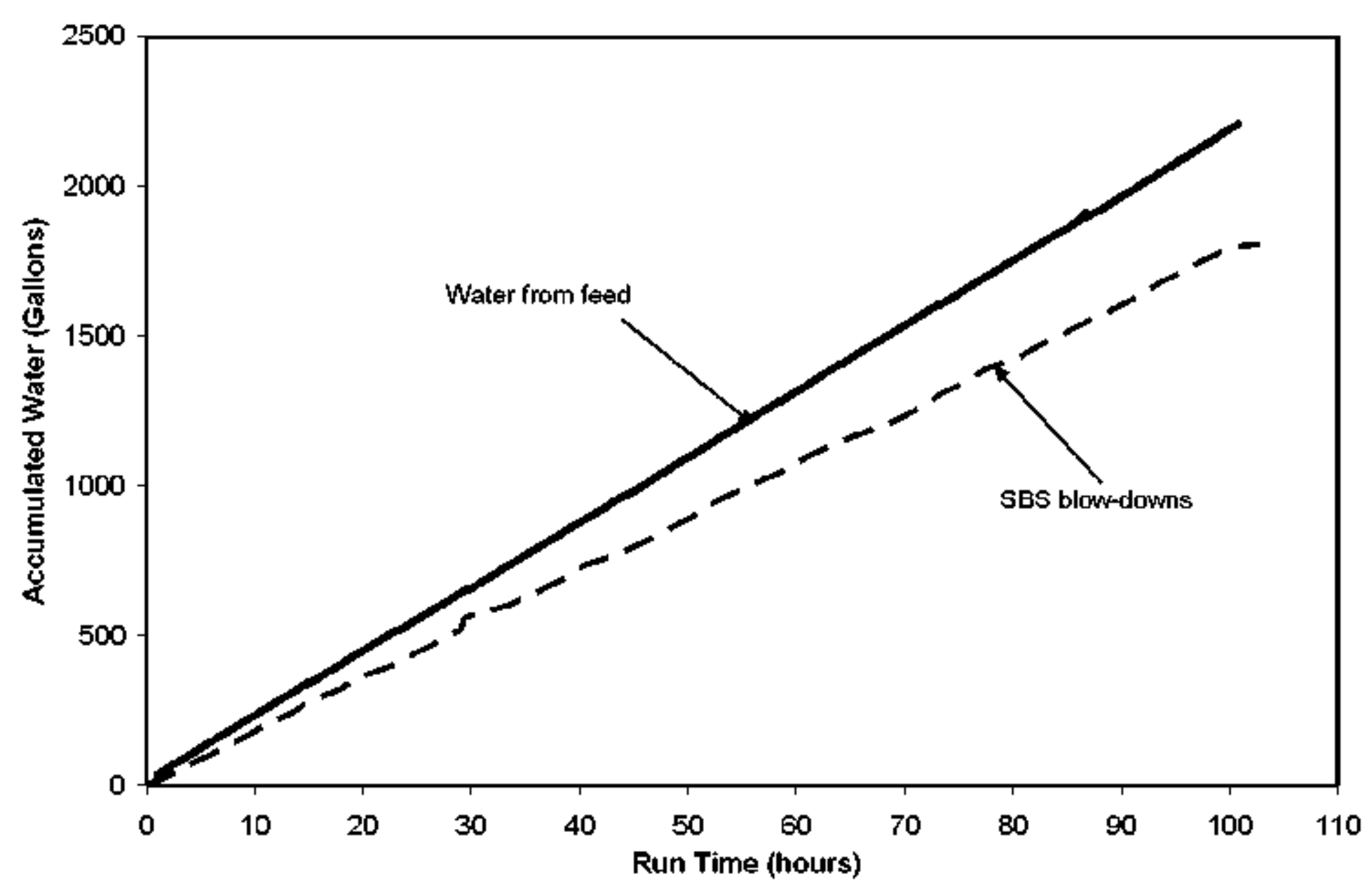

Figure 5.19.b. Accumulated SBS blow down volume and accumulated feed water during Tests 2 and 3 . 


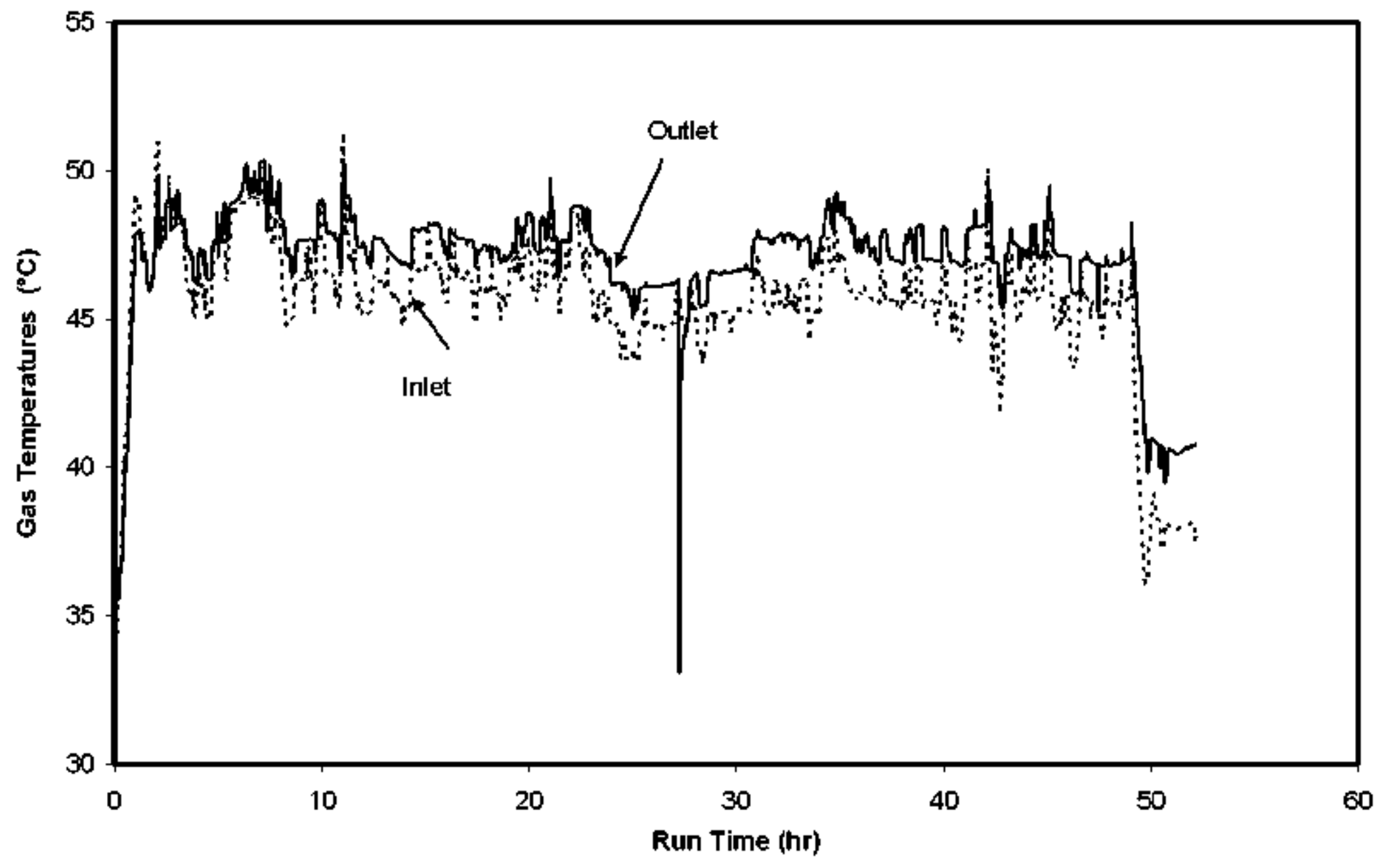

Figure 5.20.a. WESP inkt and outlet gas temperatures during Test 1. (Note: downward outlet temperature spikes are the result of WESP deluges,) 


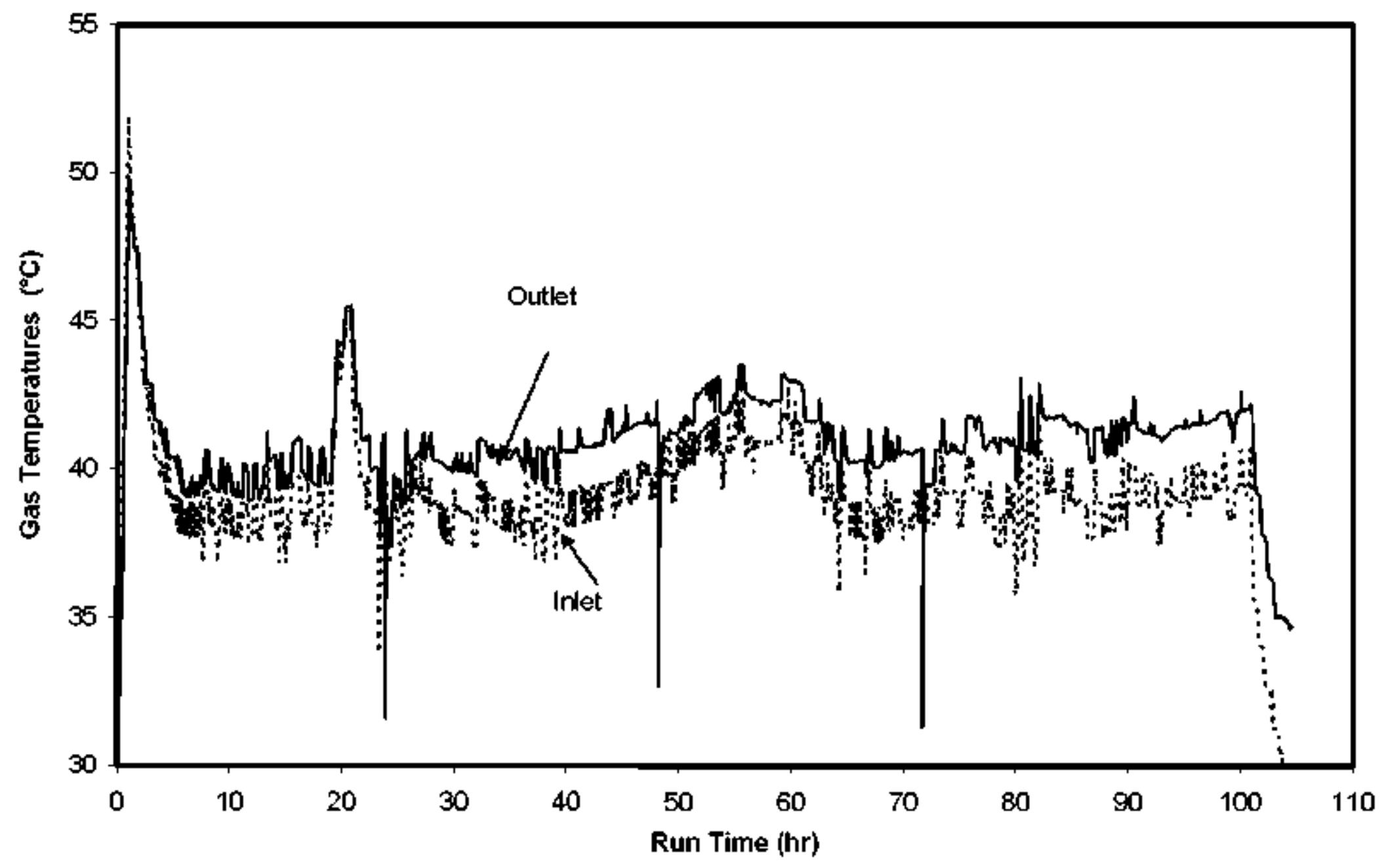

Figure 5.20,b. WESP inlet and outlet gas temperntures during Tests 2 and 3. (Note: downward outlet temperature spikes are the result of WESP deluges.) 


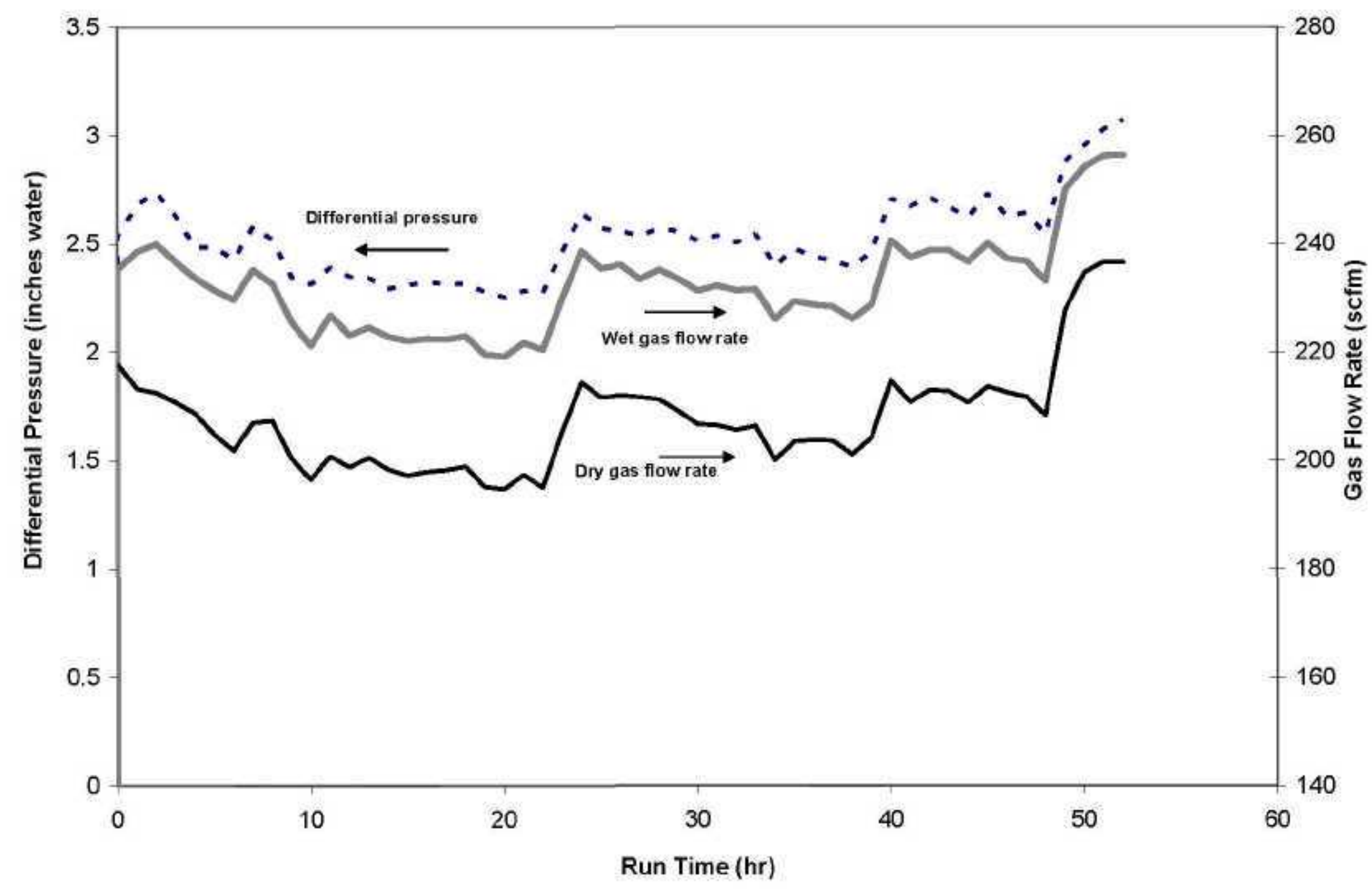

Figure 5.21.a. WESP differential pressure and outlet gas flow rate (hourly average values) during Test 1. 


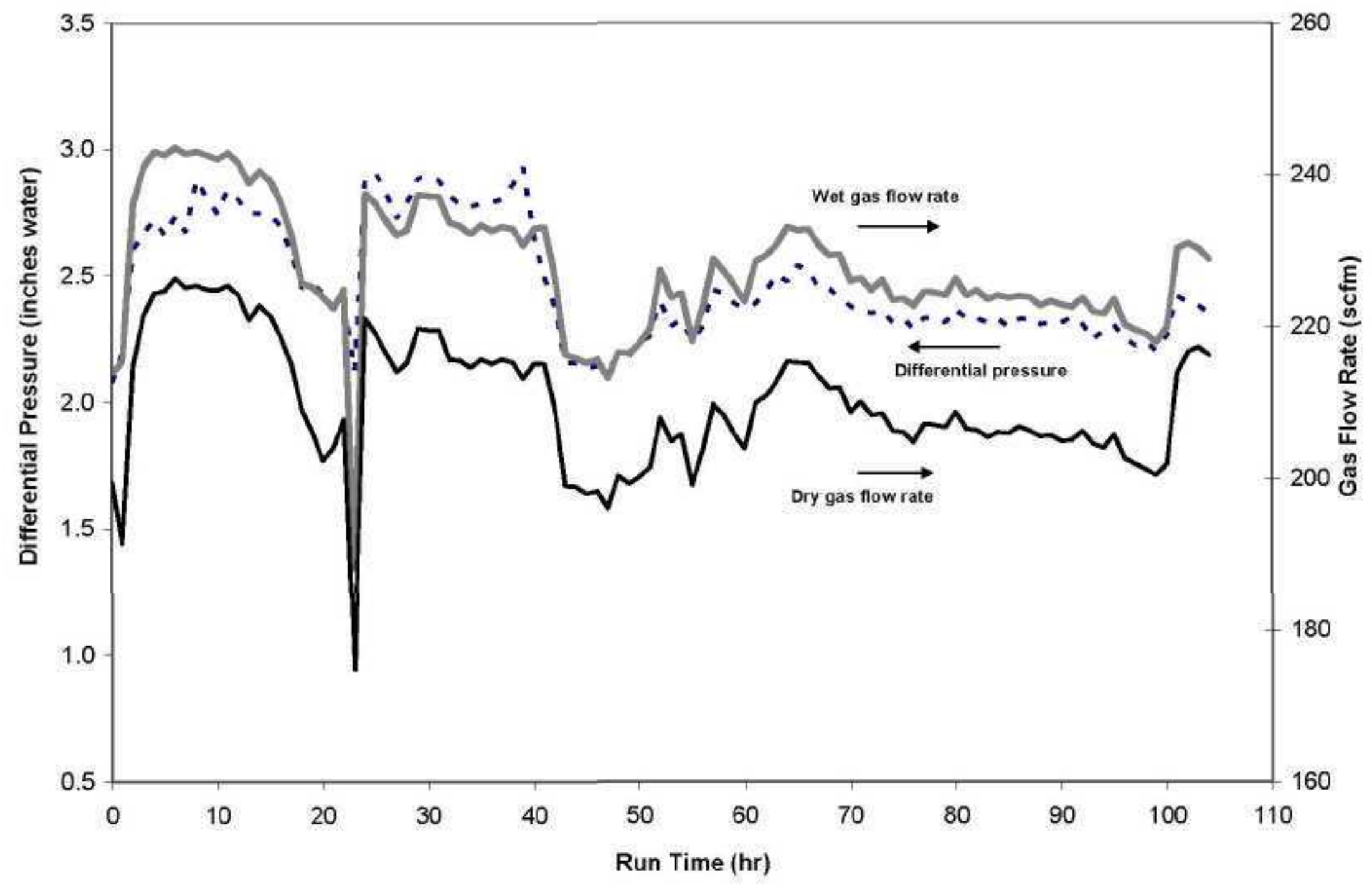

Figure 5.21.b. WESP differential pressure and outlet gas flow rate (hourly average values) during Tests 2 and 3. 


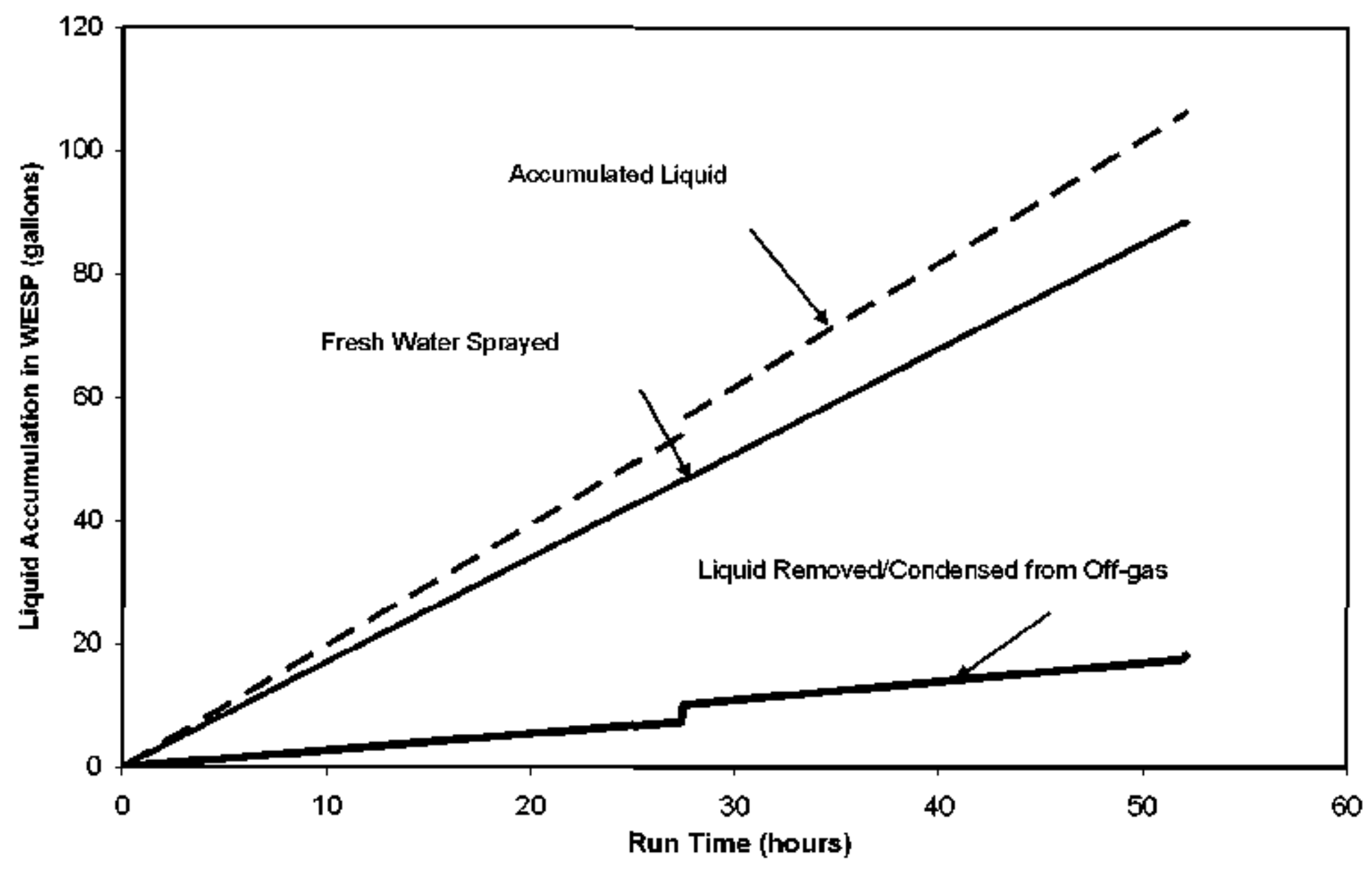

Figure 5.22,a. Accumulated WESP blowdown volume, accuniulated fresh spray water, and water removed from off-gas during Test 1 . 


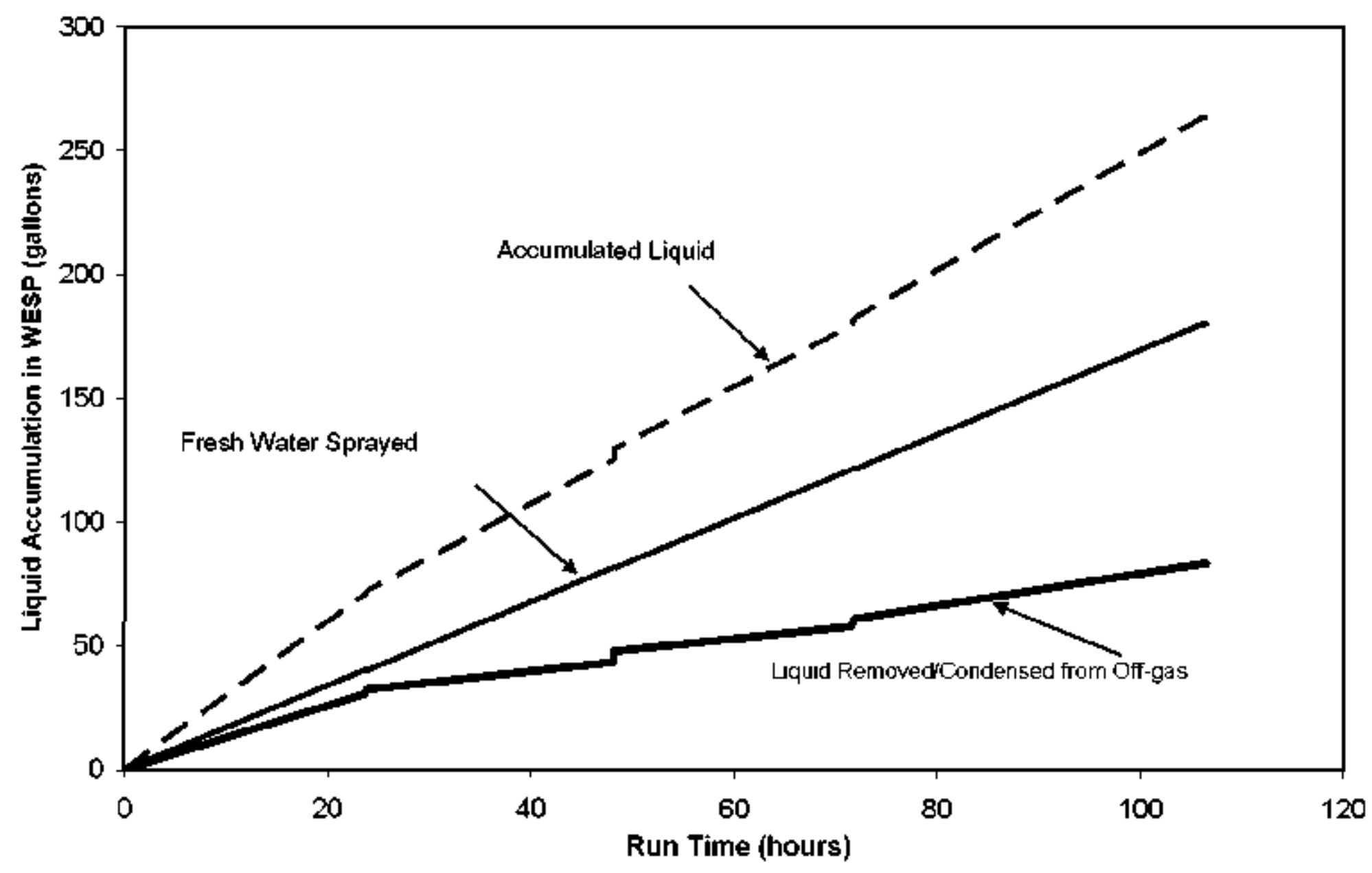

Figure 5.22,b. Accumulated WESP blowdown volume, accumulated fresh spray water, and water removed from off-gas during Tests 2 and 3 . 


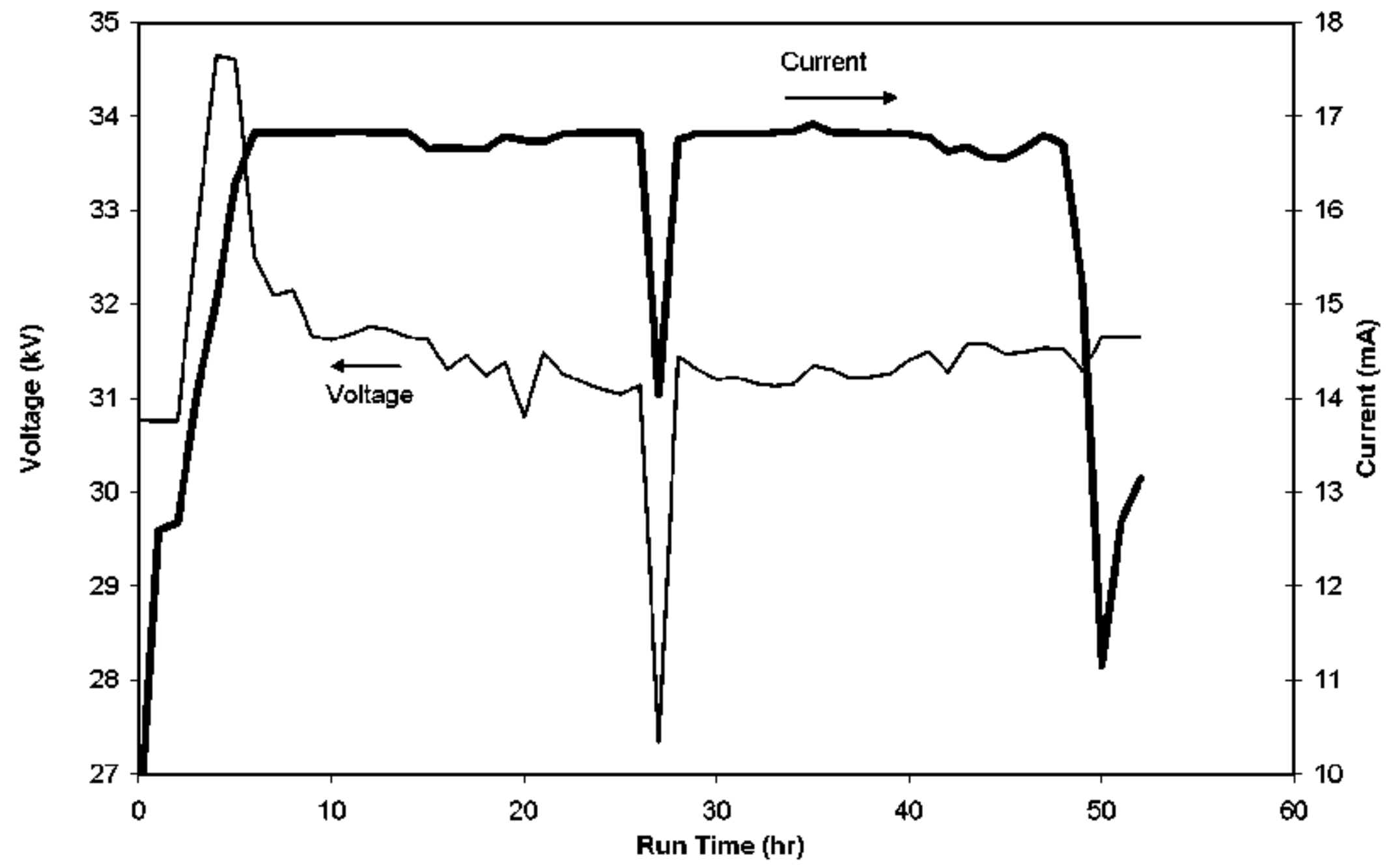

Figure 5.23.a. Voltage and current across the WESP during Test 1. 


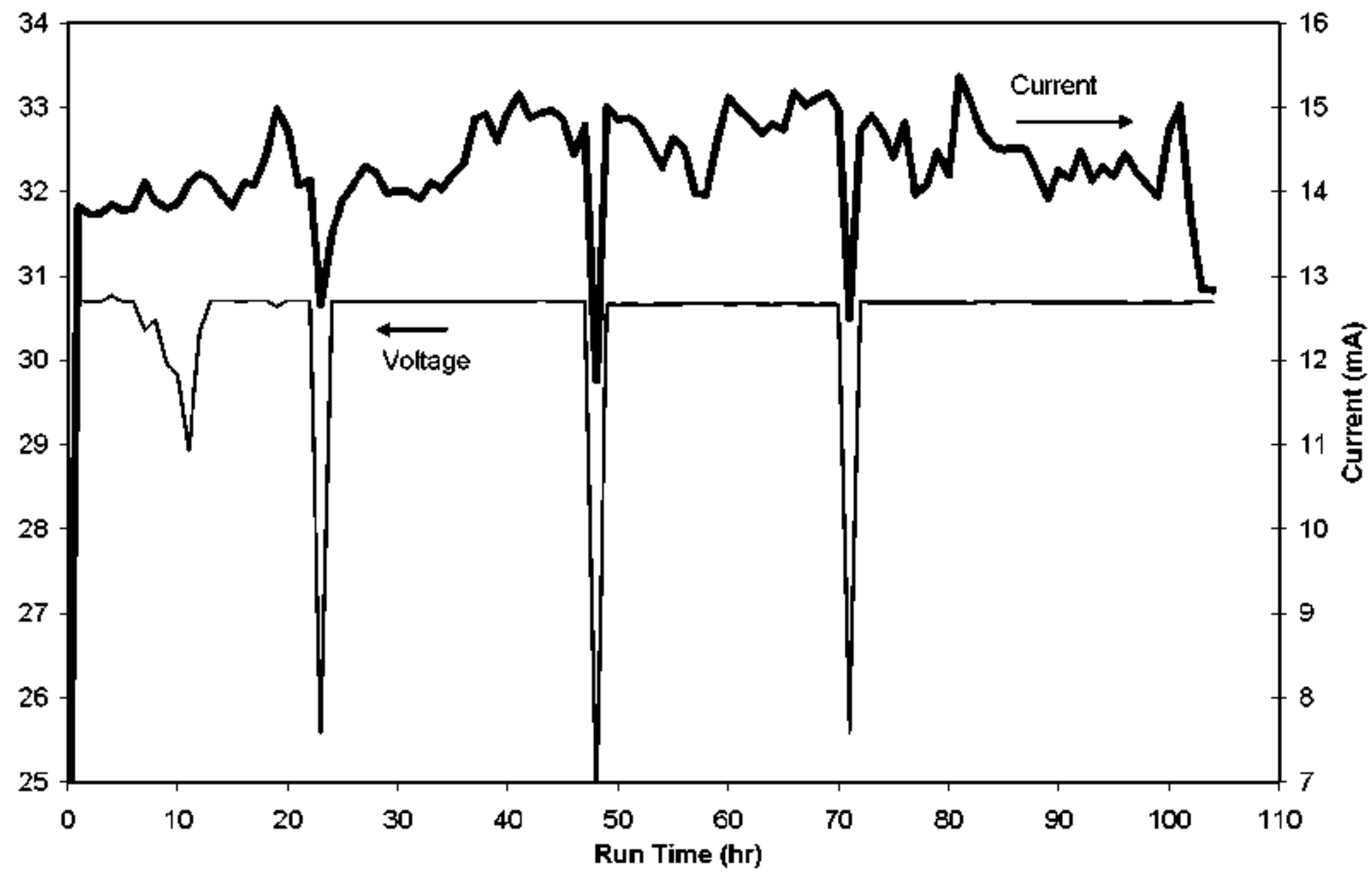

Figure 5.23.b. Voltage and current across the WESP during Tests 2 and 3. 


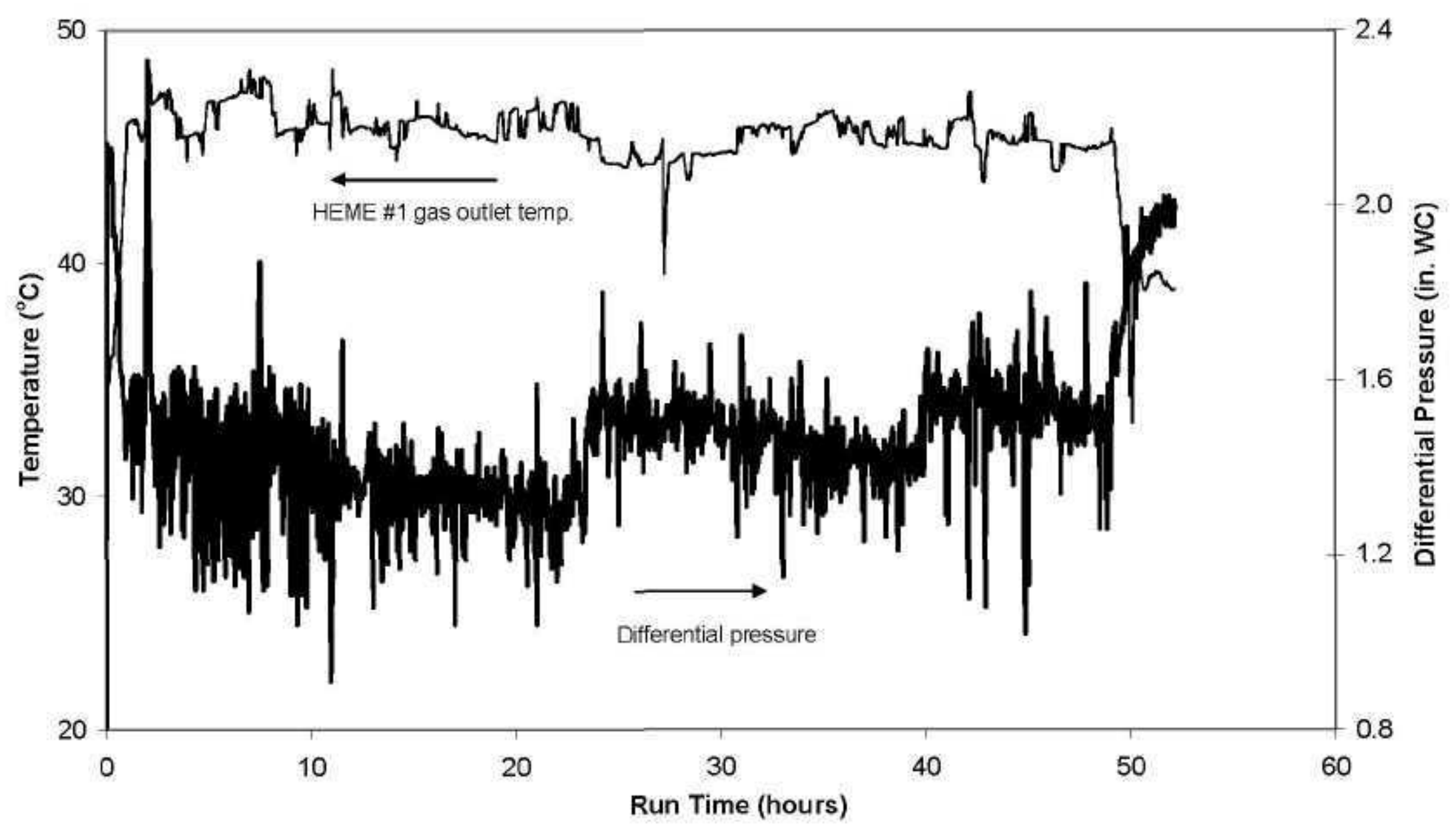

Figure 5.24.a. Outlet gas temperature and differential pressure for HEME \#1 during Test 1. 


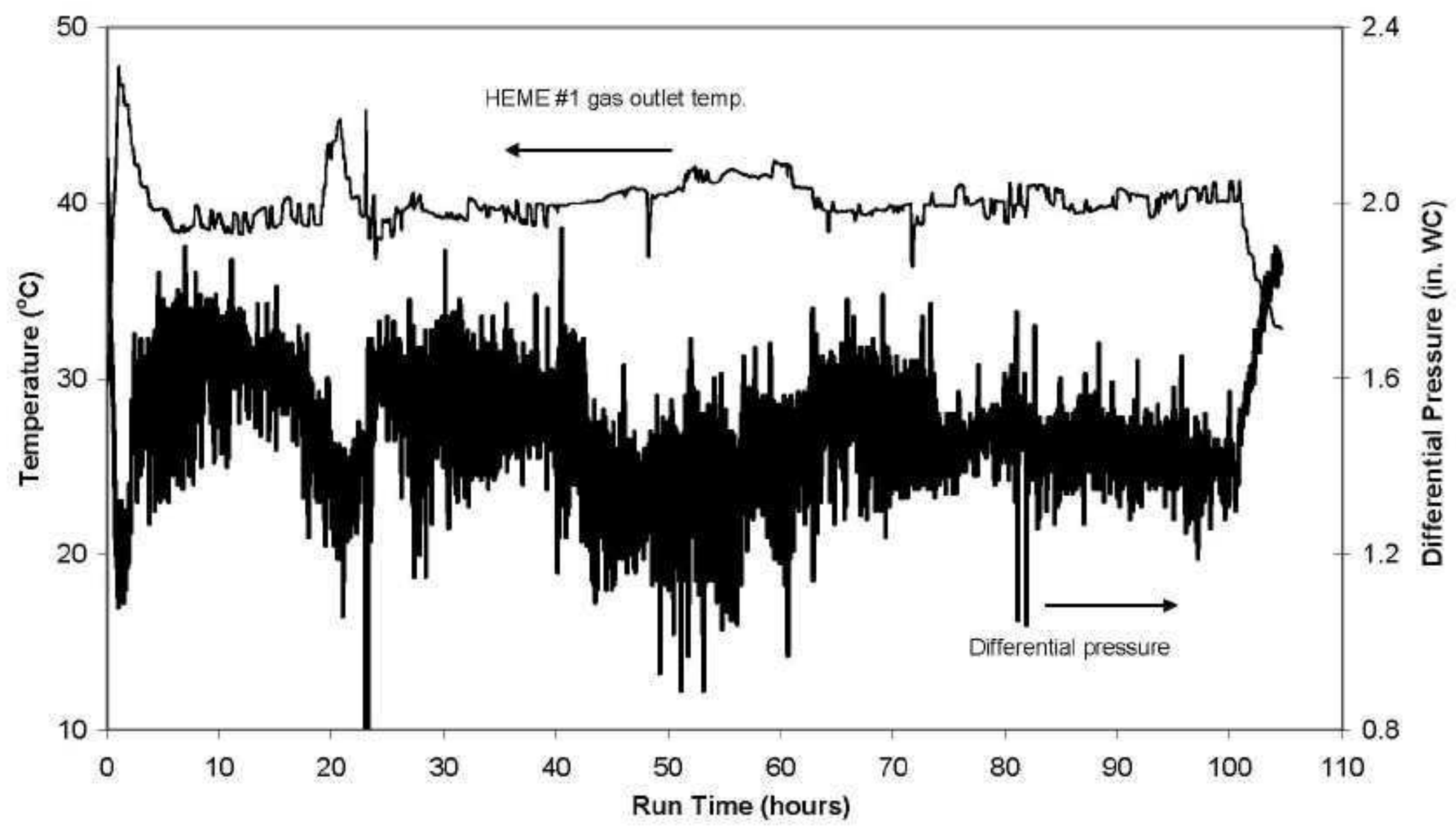

Figure 5.24.b. Outlet gas temperature and differential pressure for HEME \#1 during Tests 2 and 3. 


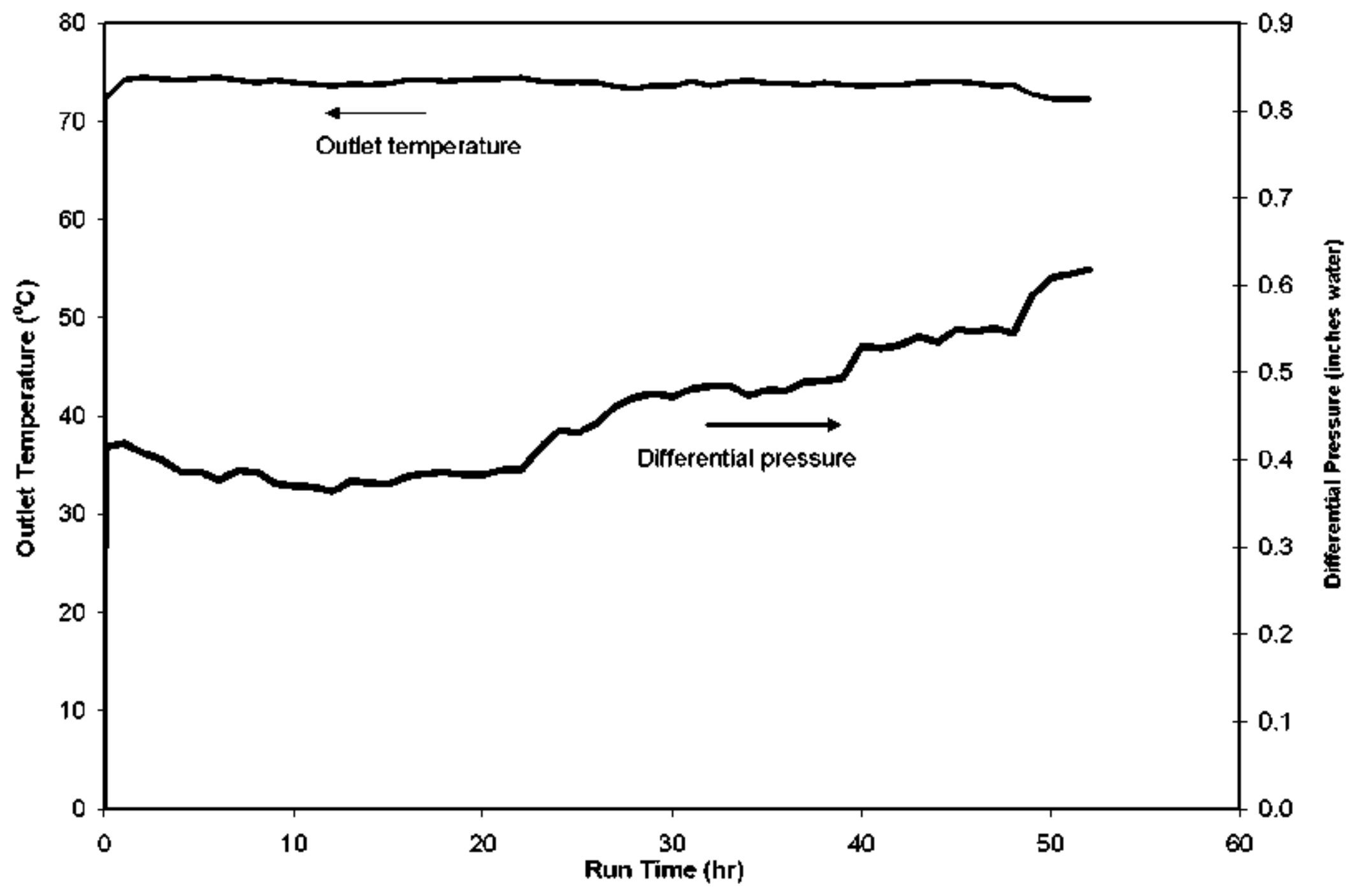

Figure 5.25.a. Outlet tempernture and differential pressure for HEPA \#1 (hourly averige values) during Test 1. 


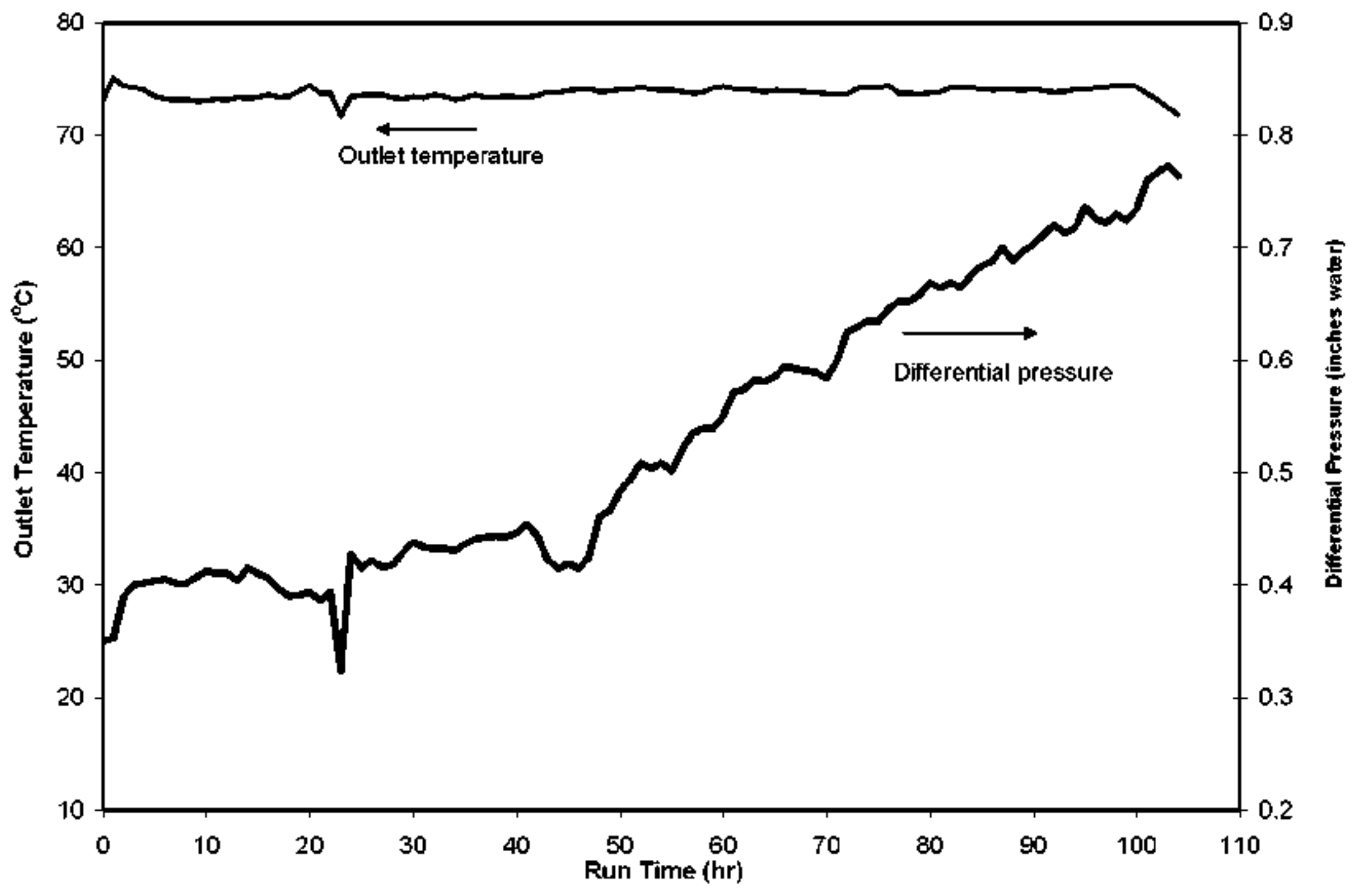

Figure 5.25. b. Outlet temperature and differential pressure for HEPA \#1 (hourly average values) during Tests 2 and 3. 


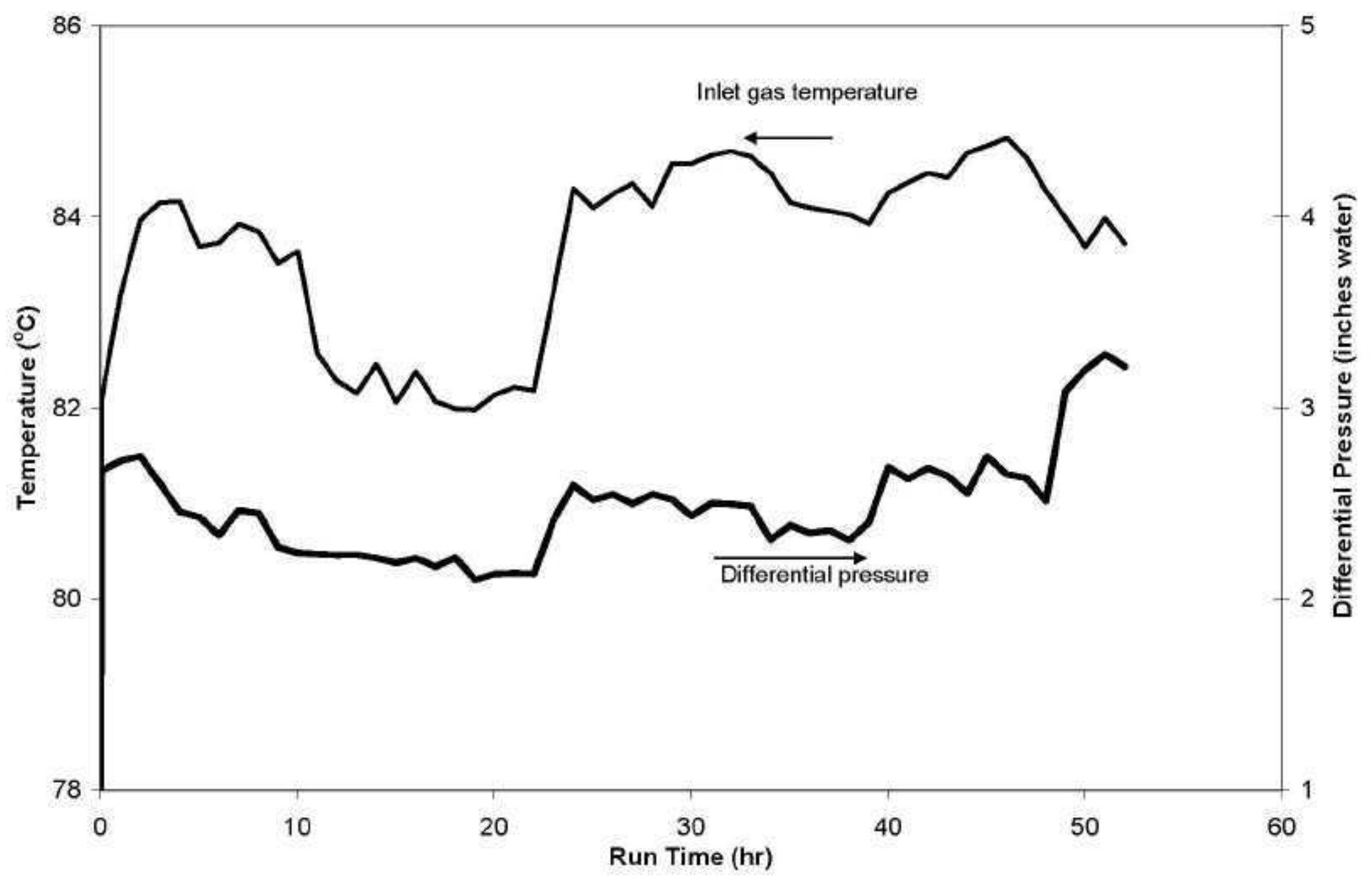

Figure 5.26.a. Inlet gas temperature and differential pressure for PBS (hourly average values) during Test 1. 


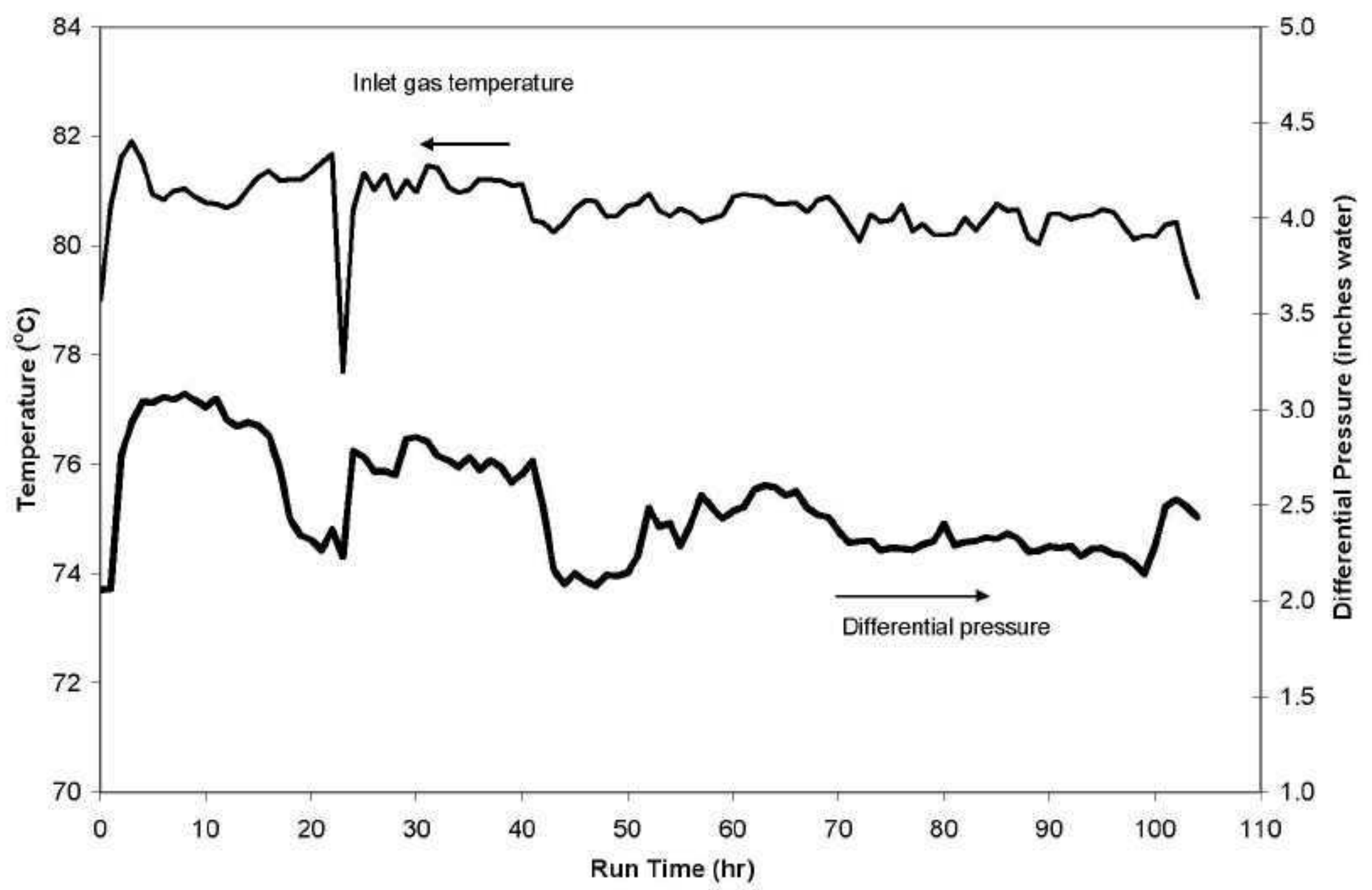

Figure 5.26.b. Inlet gas temperature and differential pressure for PBS (hourly average values) during Tests 2 and 3 . 


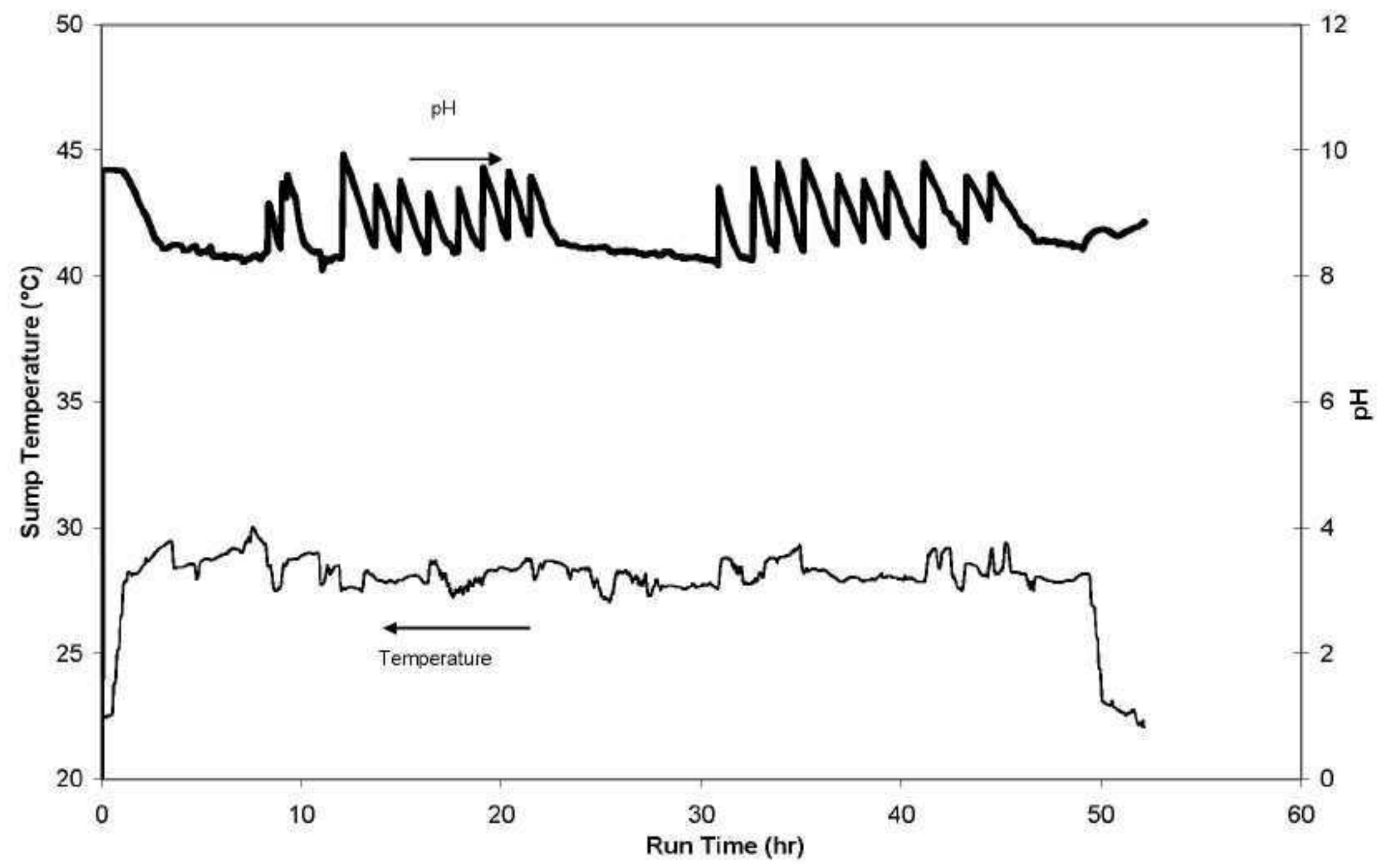

Figure 5.27.a. Sump temperature and $\mathrm{pH}$ for PBS (hourly average values) during Test 1 . 


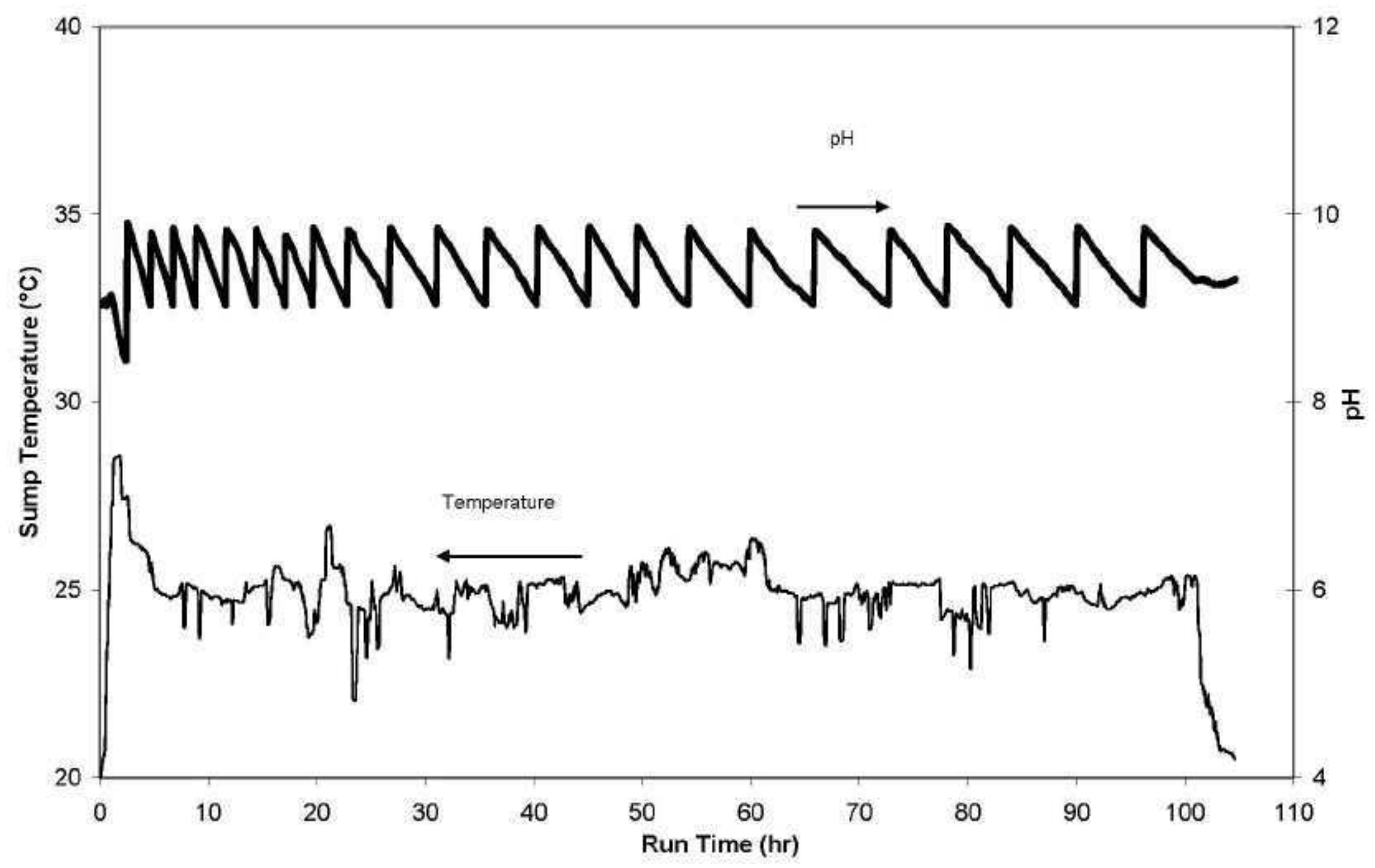

Figure 5.27.b. Sump Temperature and pH for PBS (hourly average values) during Tests 2 and 3. 

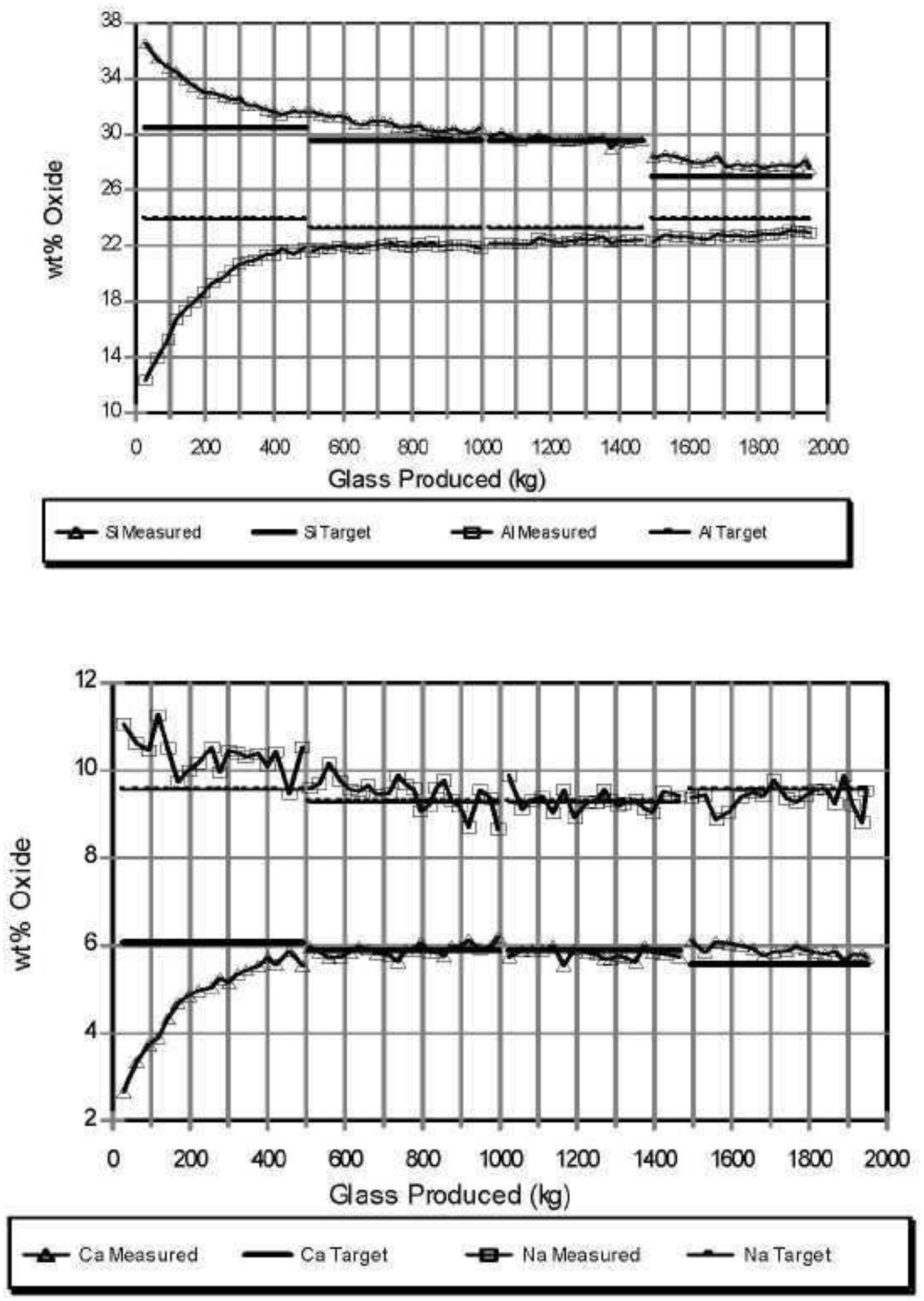

Figure 6.1.a. DM100 product and target glass compositions determined by XRF. 

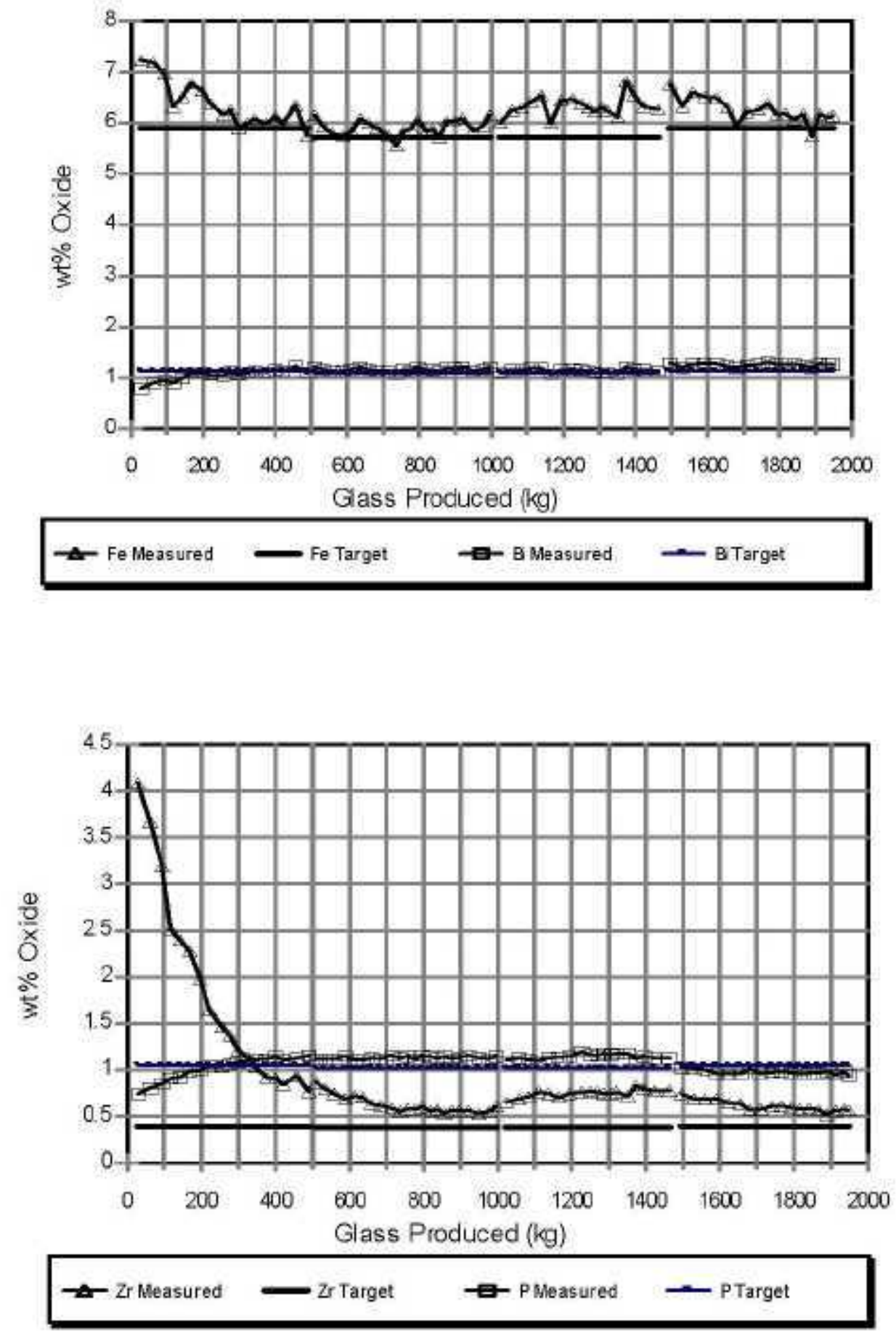

Figure 6.1.b. DM100 product and target glass compositions determined by XRF. 

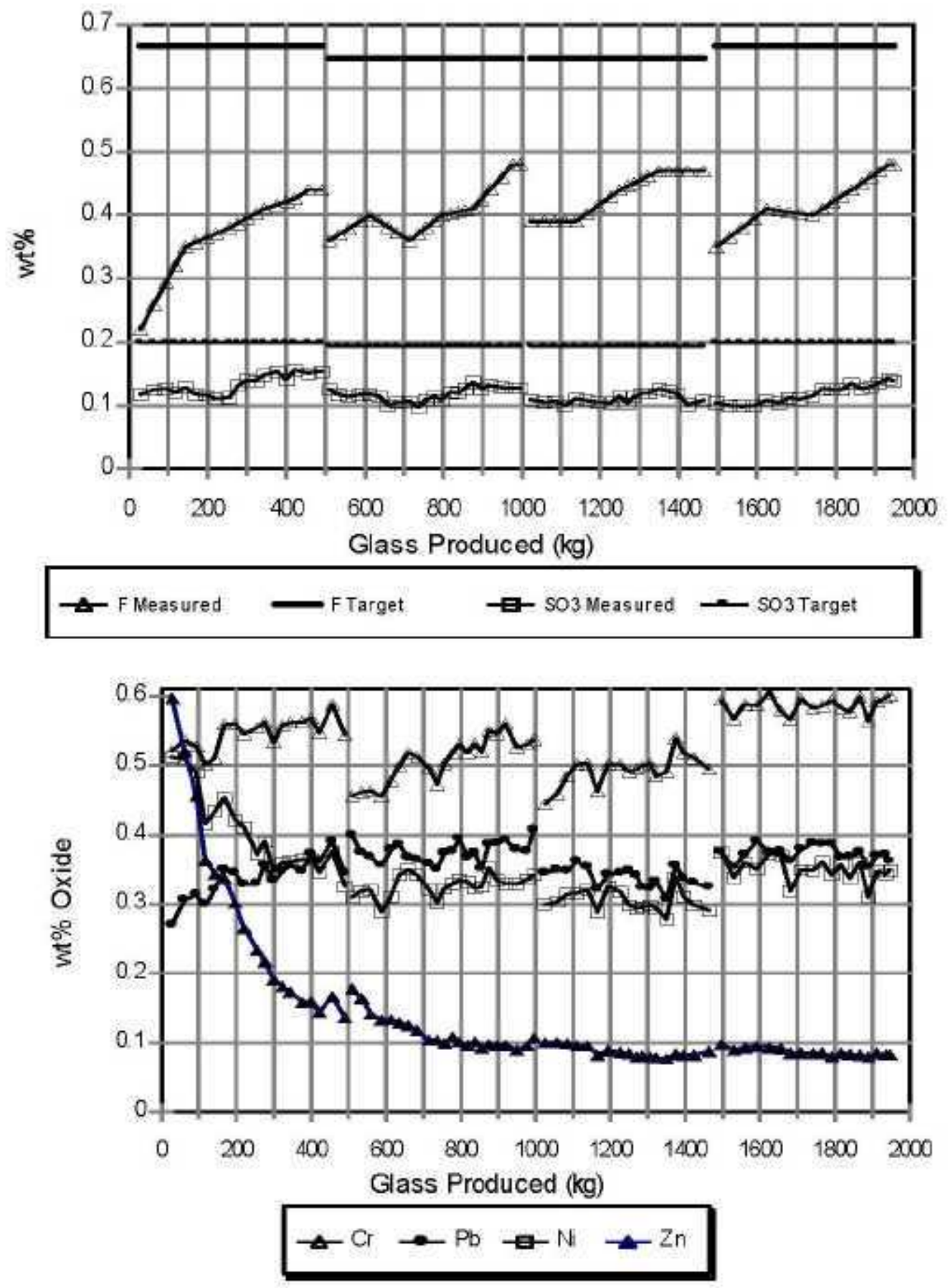

Figure 6.1.c. DM100 product and target glass compositions determined by XRF. 

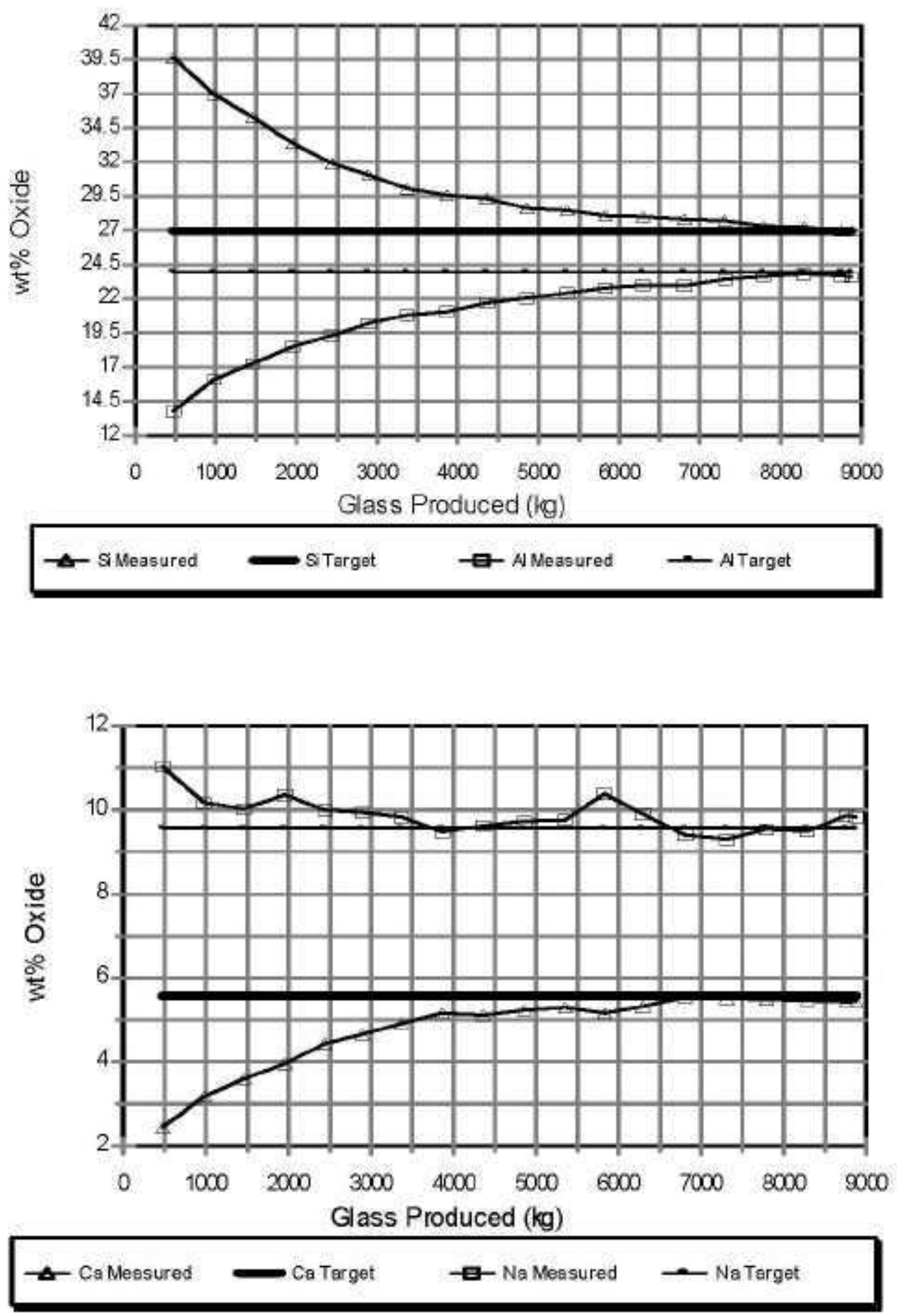

Figure 6.2.a. DM1200 product and target glass compositions determined by XRF. 

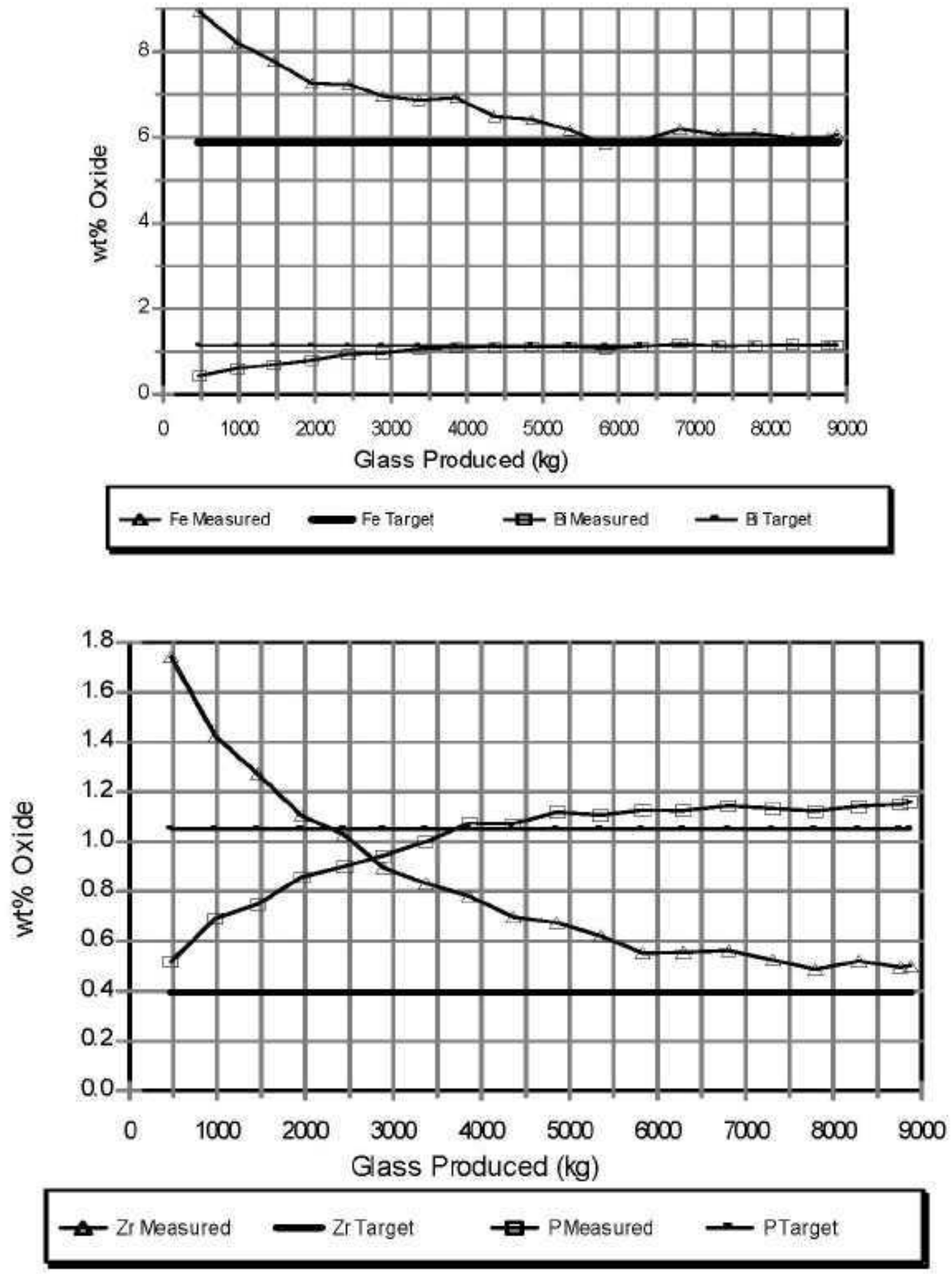

Figure 6.2.b. DM1200 product and target glass compositions determined by XRF. 

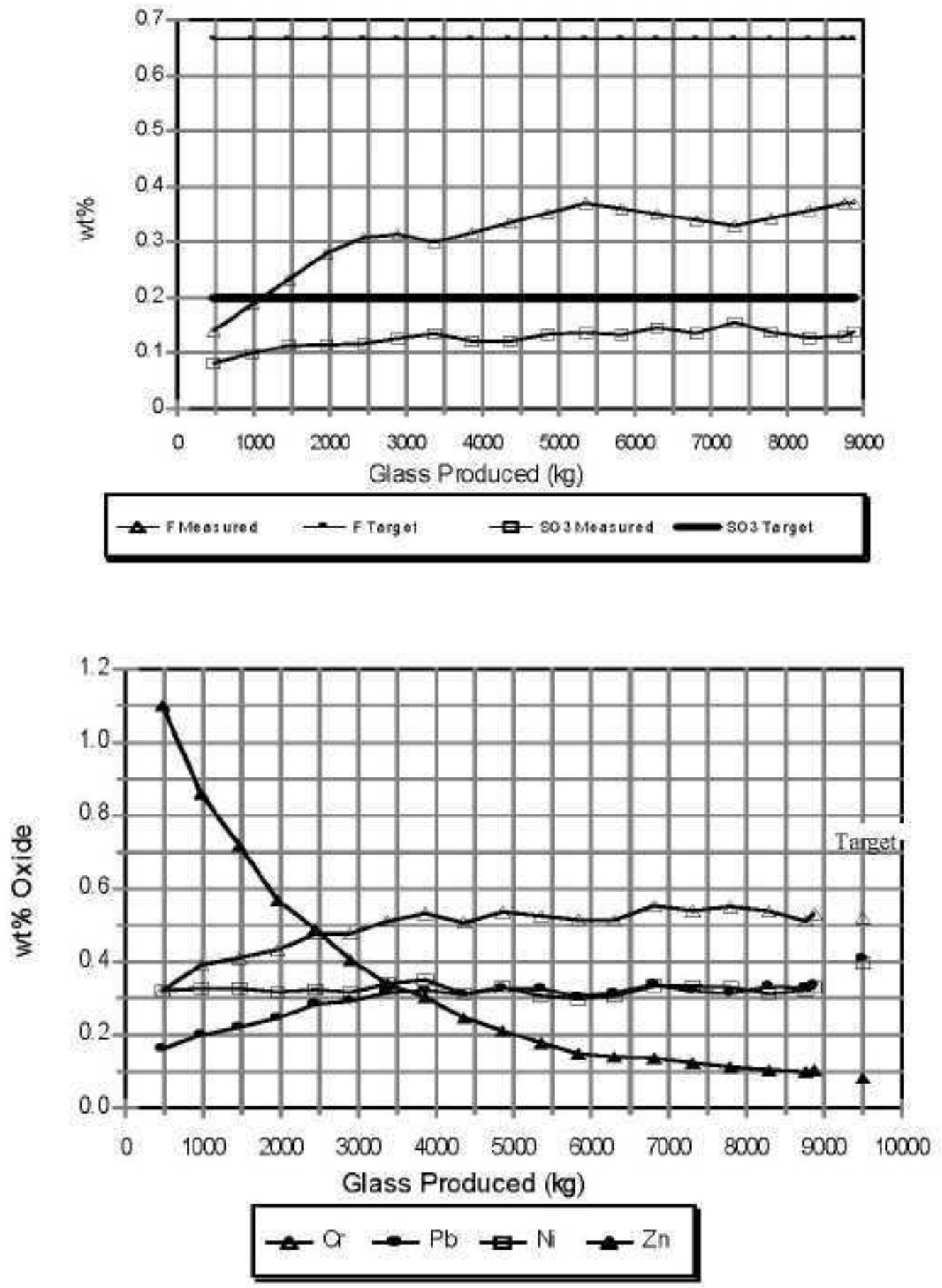

Figure 6.2.c. DM1200 product and target glass compositions determined by XRF. 
The Catholic University of Amenica Vitreous State Laboratory
ORP-44236, Rev. 0

Melt Rate Enhancement for High Aluminum HLW Glass Fomulations Final Report, VSL-08R1360-1, Rev. 0

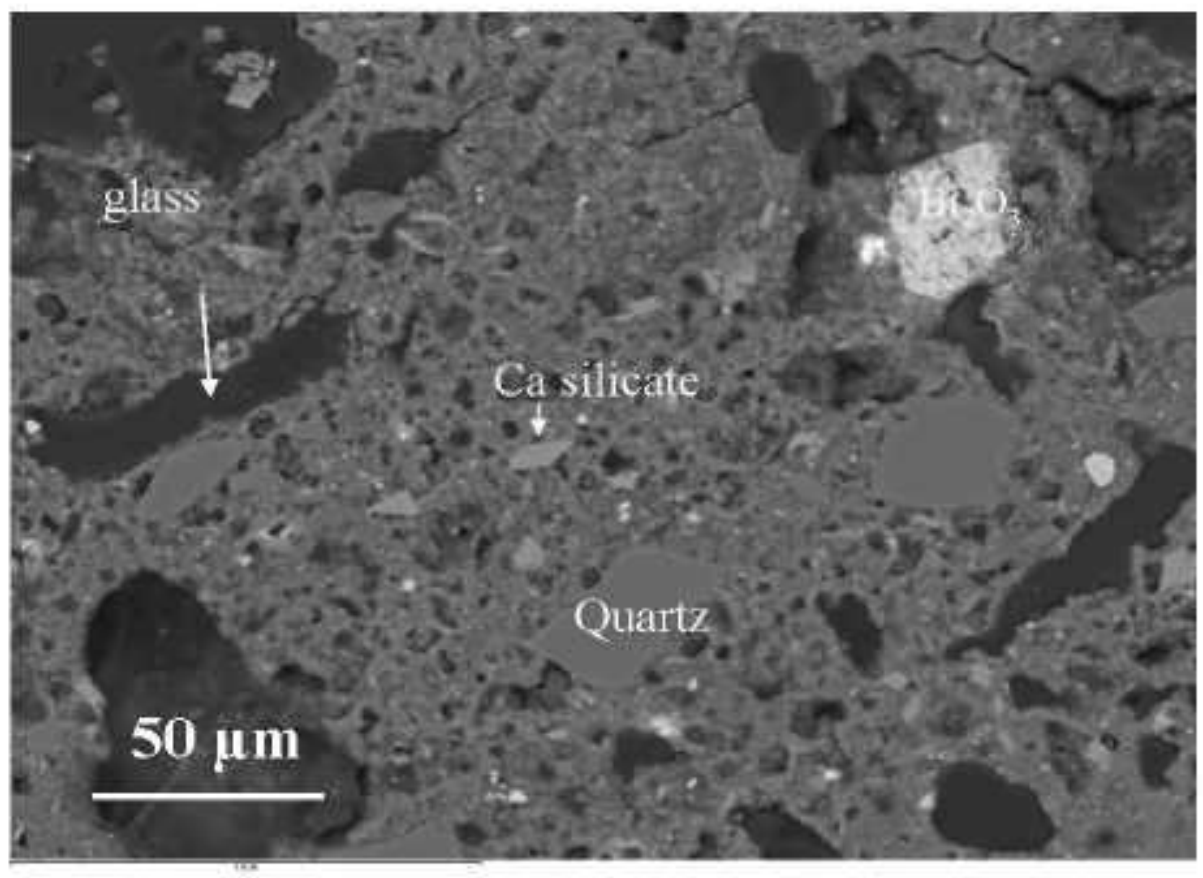

Backseattered electron image of a piece of cold cap sample (BLZ-O-37A)

Figure 6.3.a. SEM image of cold cap sample from DM100 Test 8. 


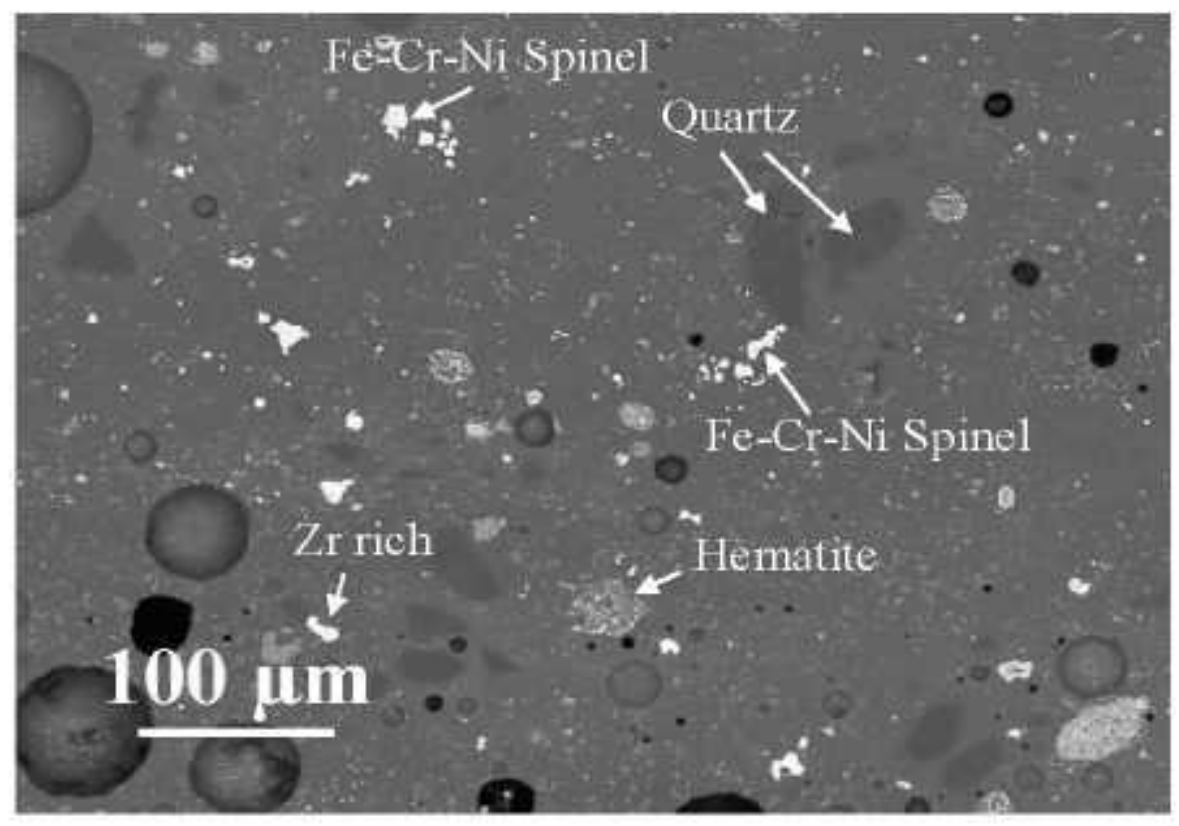

Backscattered electron image of cold cap sample (BLZ-O-35A)

Figure 6.3.b. SEM image of cold cap sample from DM100 Test 8. 
The Catholic University of America Vitreaus State Laboratory
ORP-44236, Rev, 0

Melt Rate Enhancement for High Aluminum HLW Glass Fonnulations Finat Report, TSL-0SR/360-1, Rev.0

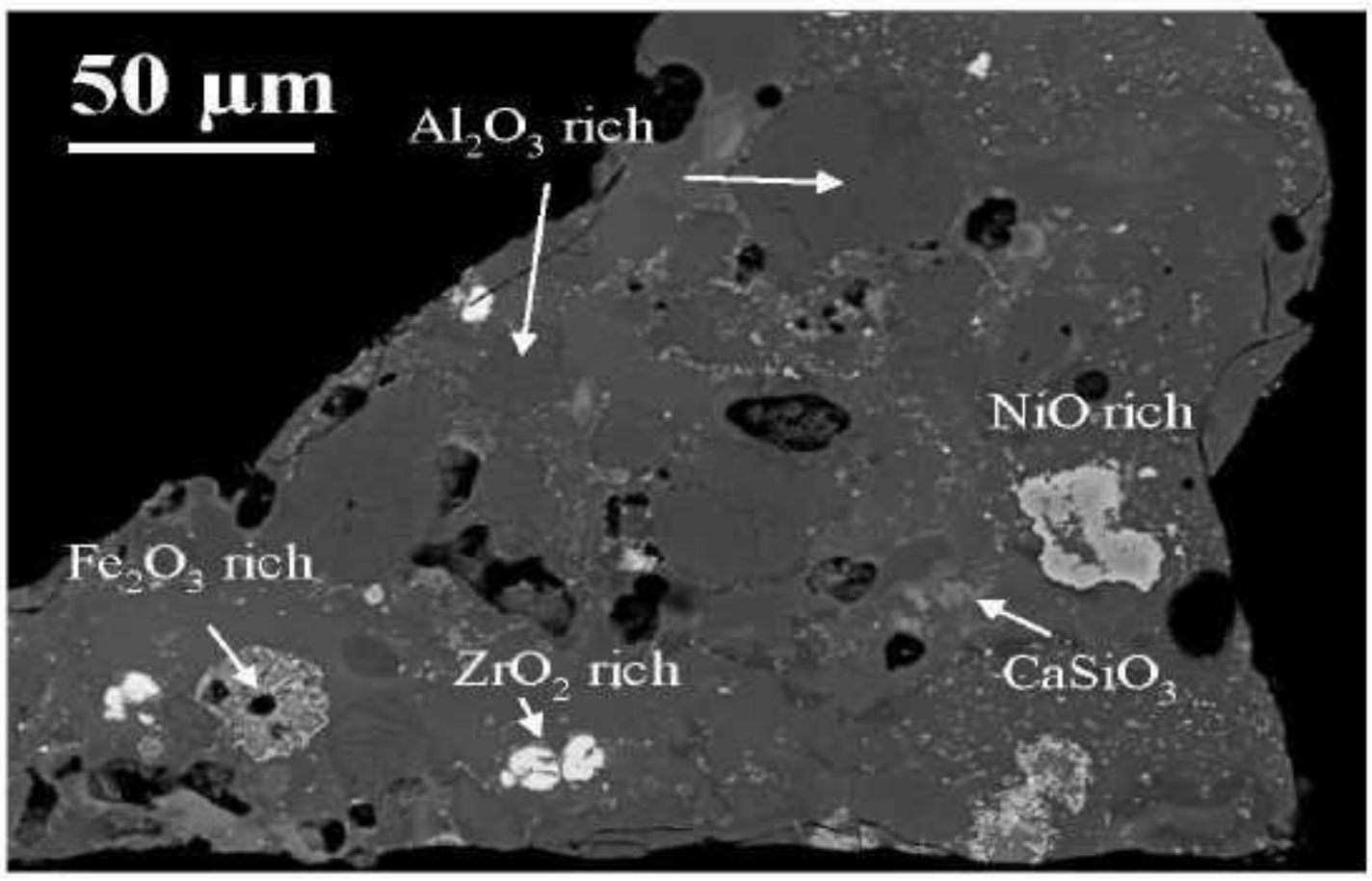

Backscattered electron image of the cold cap sample (O-12.J-106 A)

Figure 6.4. SEM image of cold cap sample from DM1200 Test 1. 

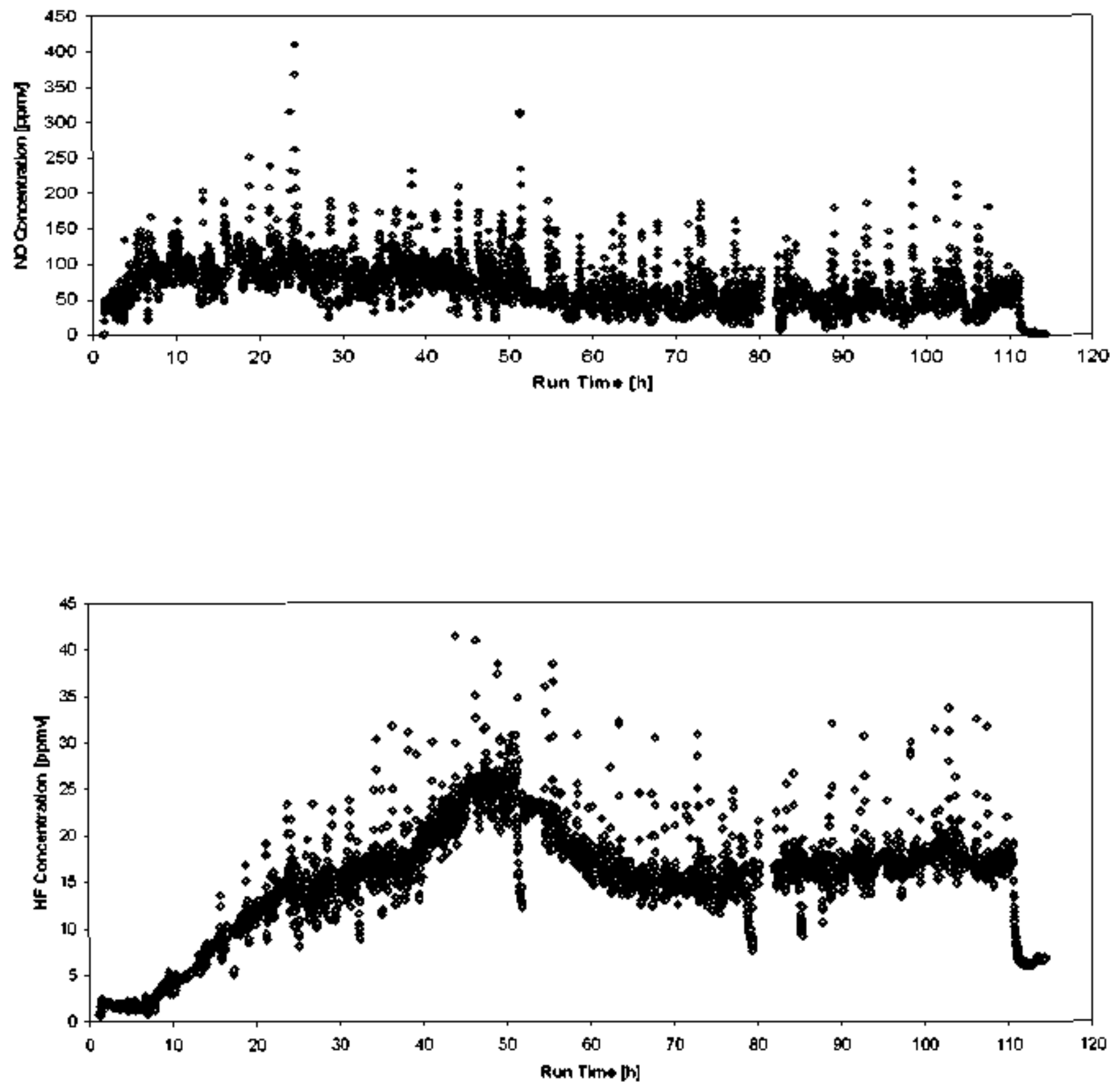

Fioure 7.1. FTIR monitored NO and HF emissions during DM 10n Tests 1 and 2. 

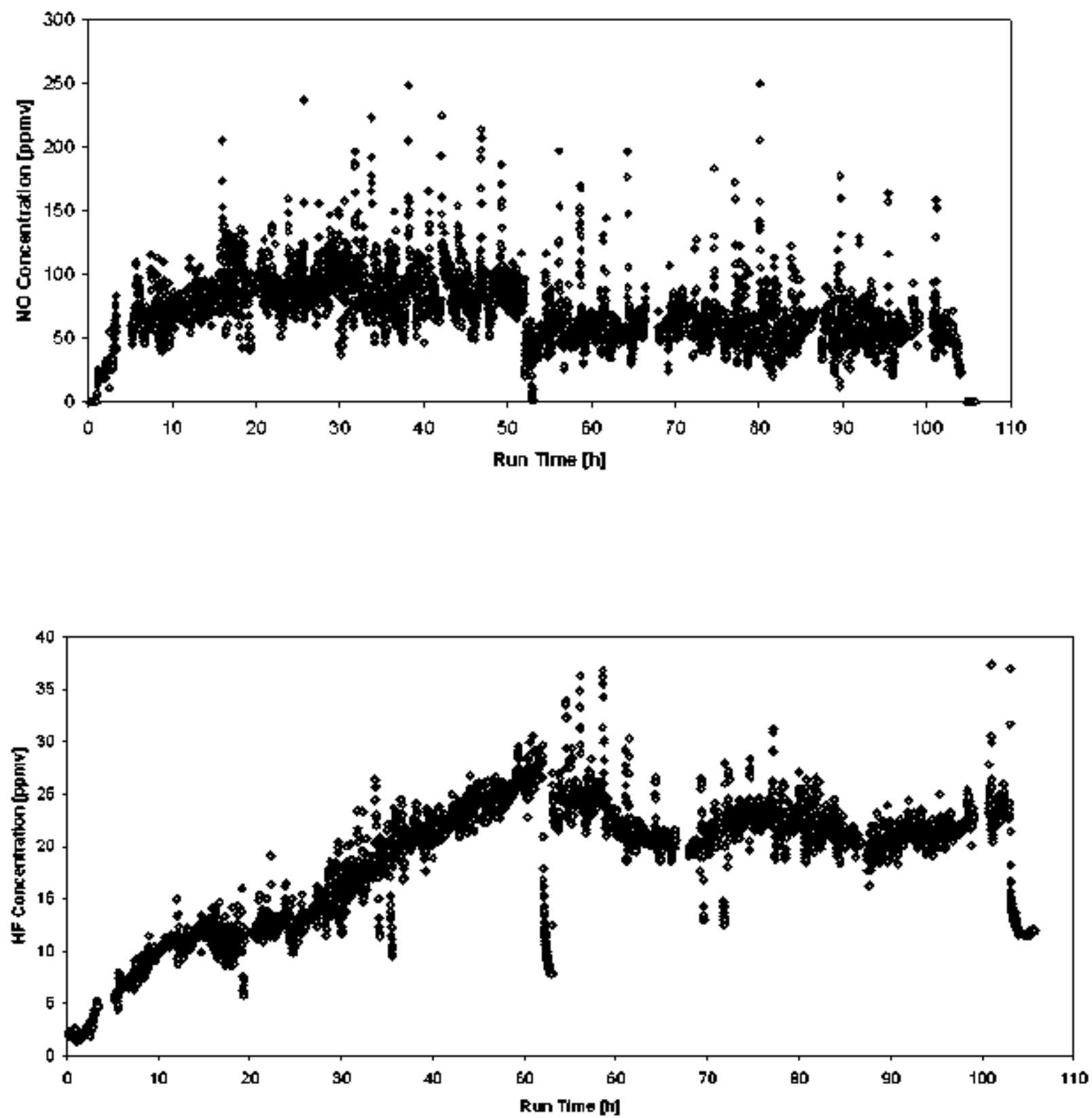

Figure 7.2. FTIR monitored NO and HF emissions during DM100 Tests 3 and 4. 

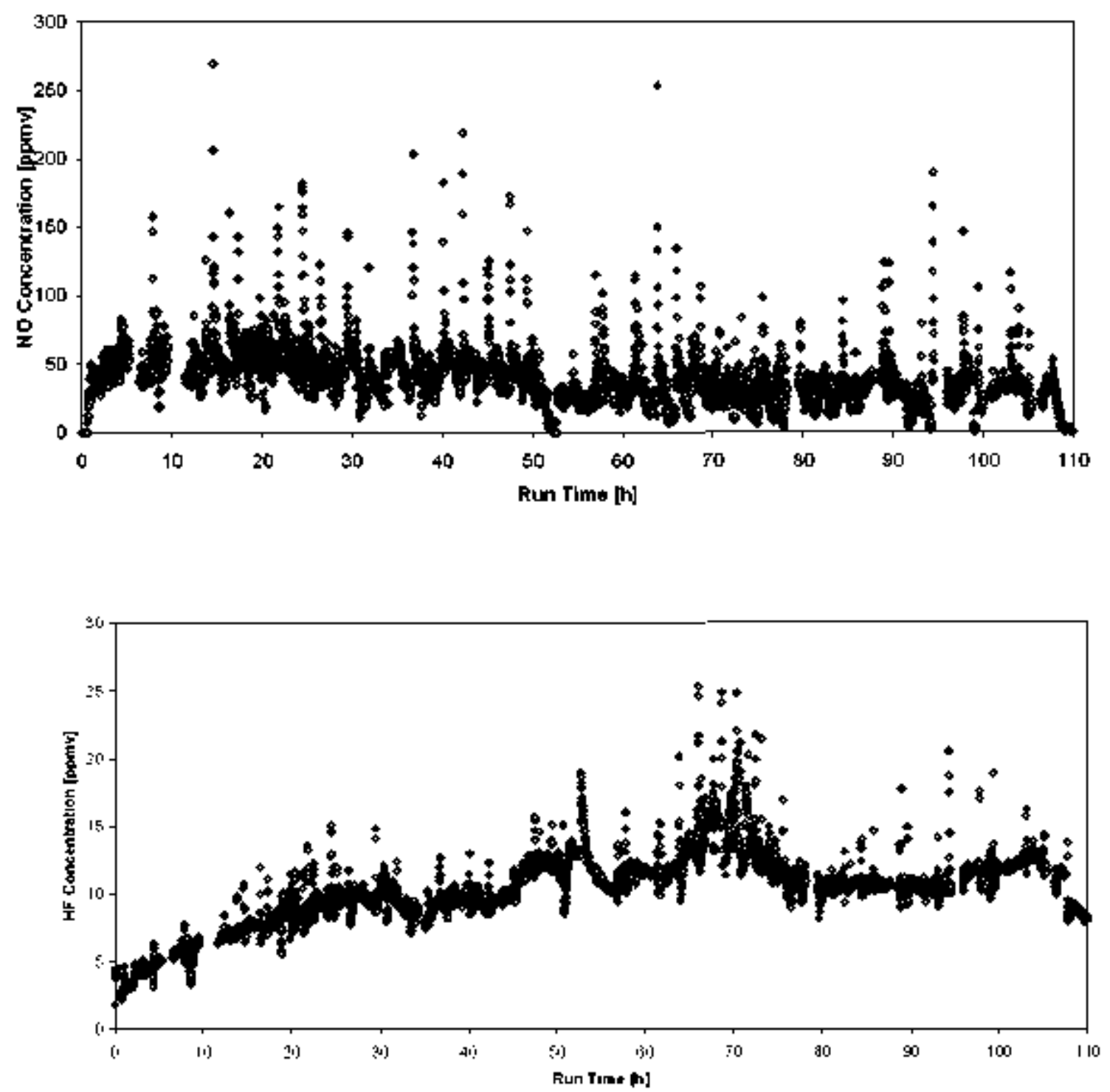

Figure 7.3. FTIR monitored NO and HF emissions during DM100 Tests 5 and 6. 

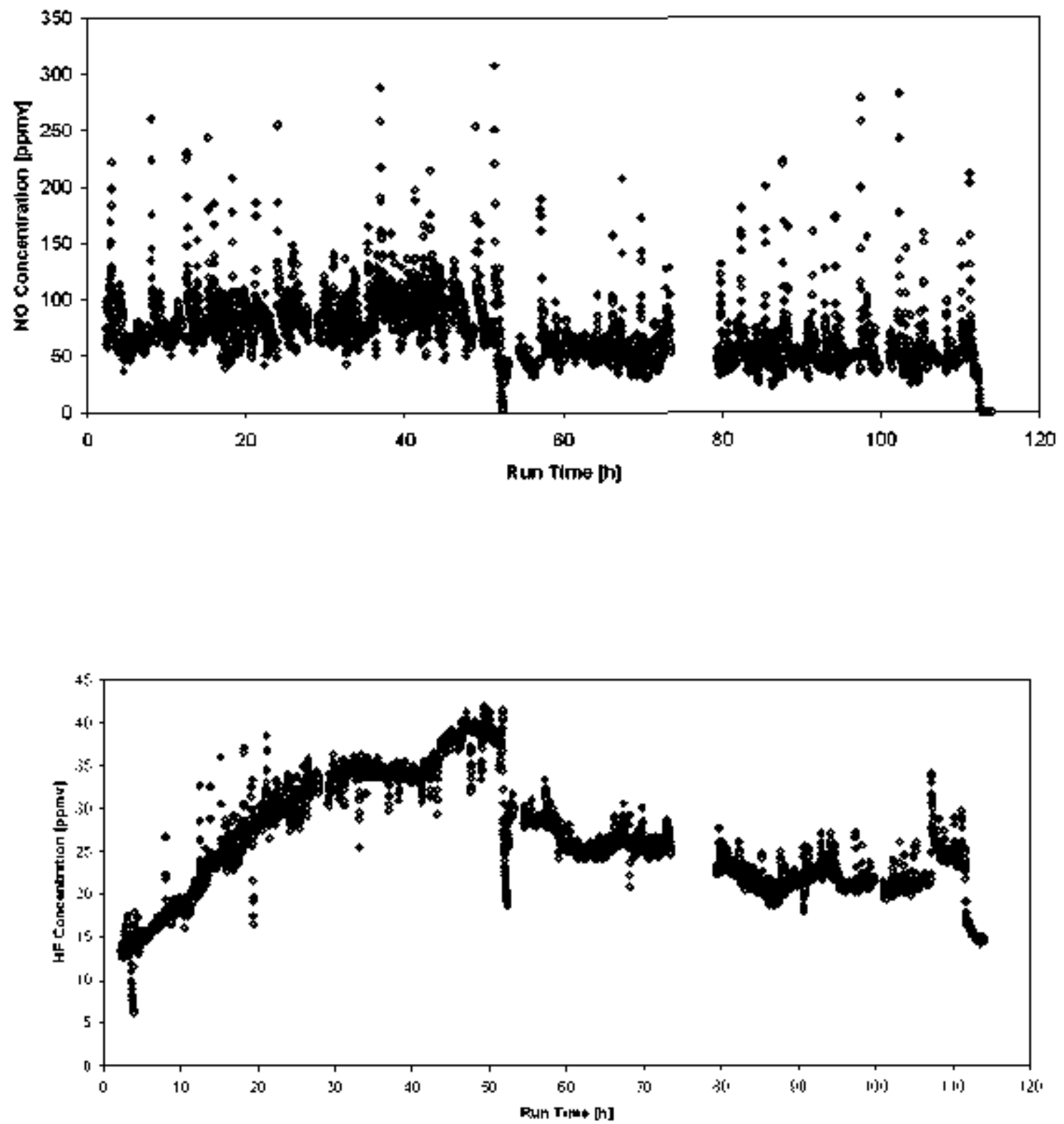

Figure 7.4. FTIR monitored NO and HF emissions during DM100 T ests 7 and 8 . 


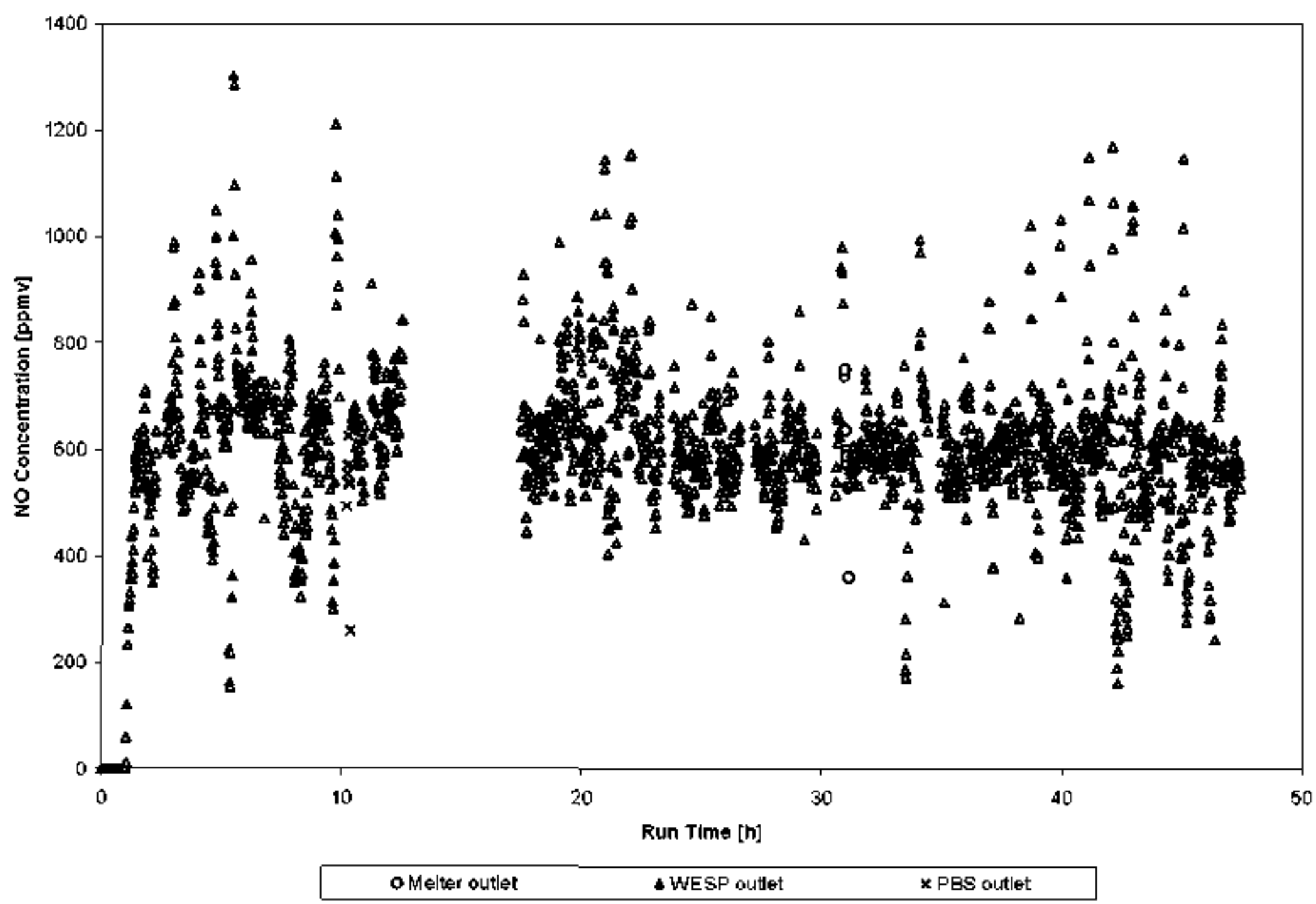

Figure 7.5. FTIR Monitored NO emissions during DM1200 Test 1. 


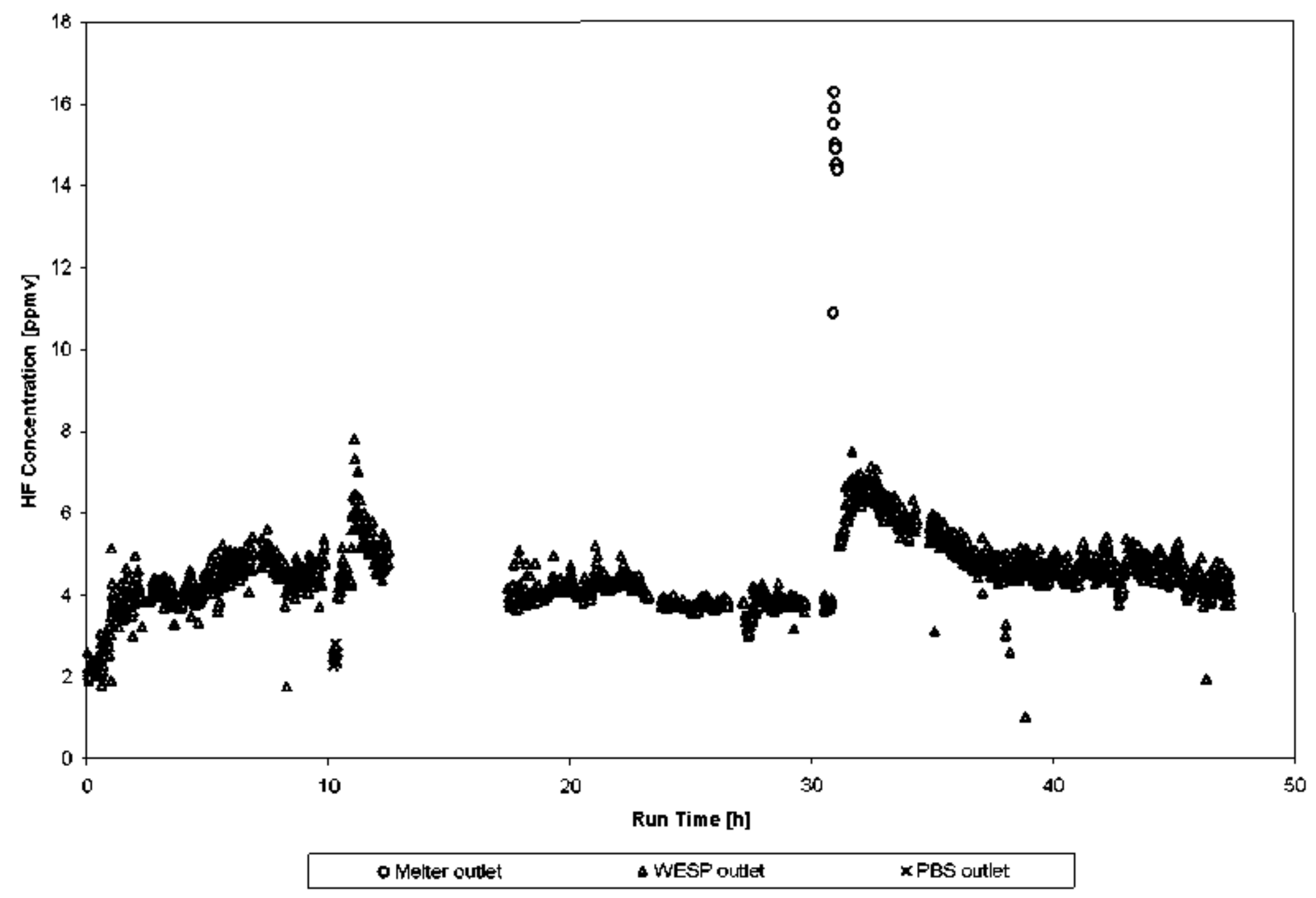

Fìgure 7.6. FTIR monitored HF emlssions during DM1200 Test 1. 


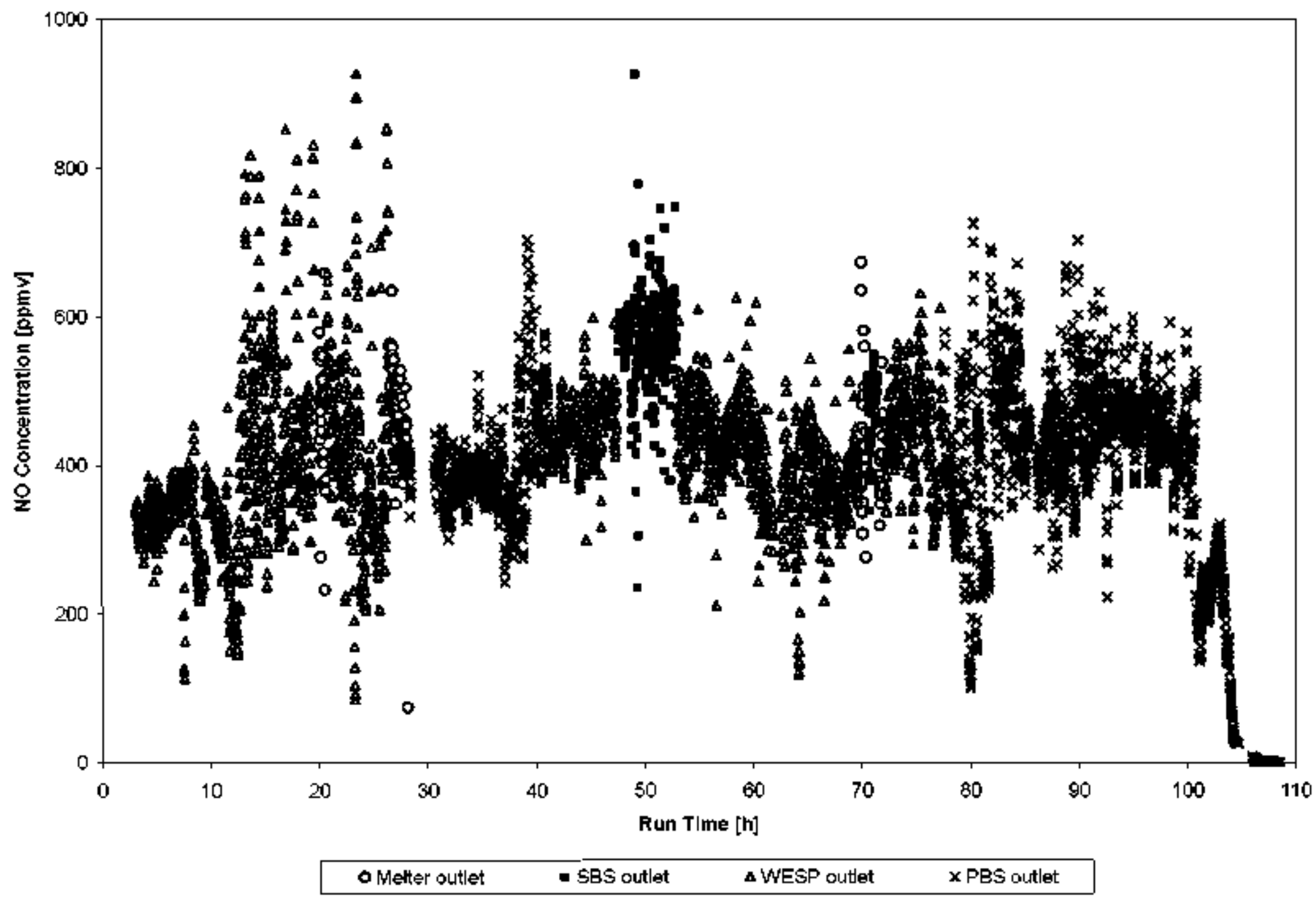

Figure 7.7. FTIR monitored NO enissions during DM1200 Tests 2 and 3. 


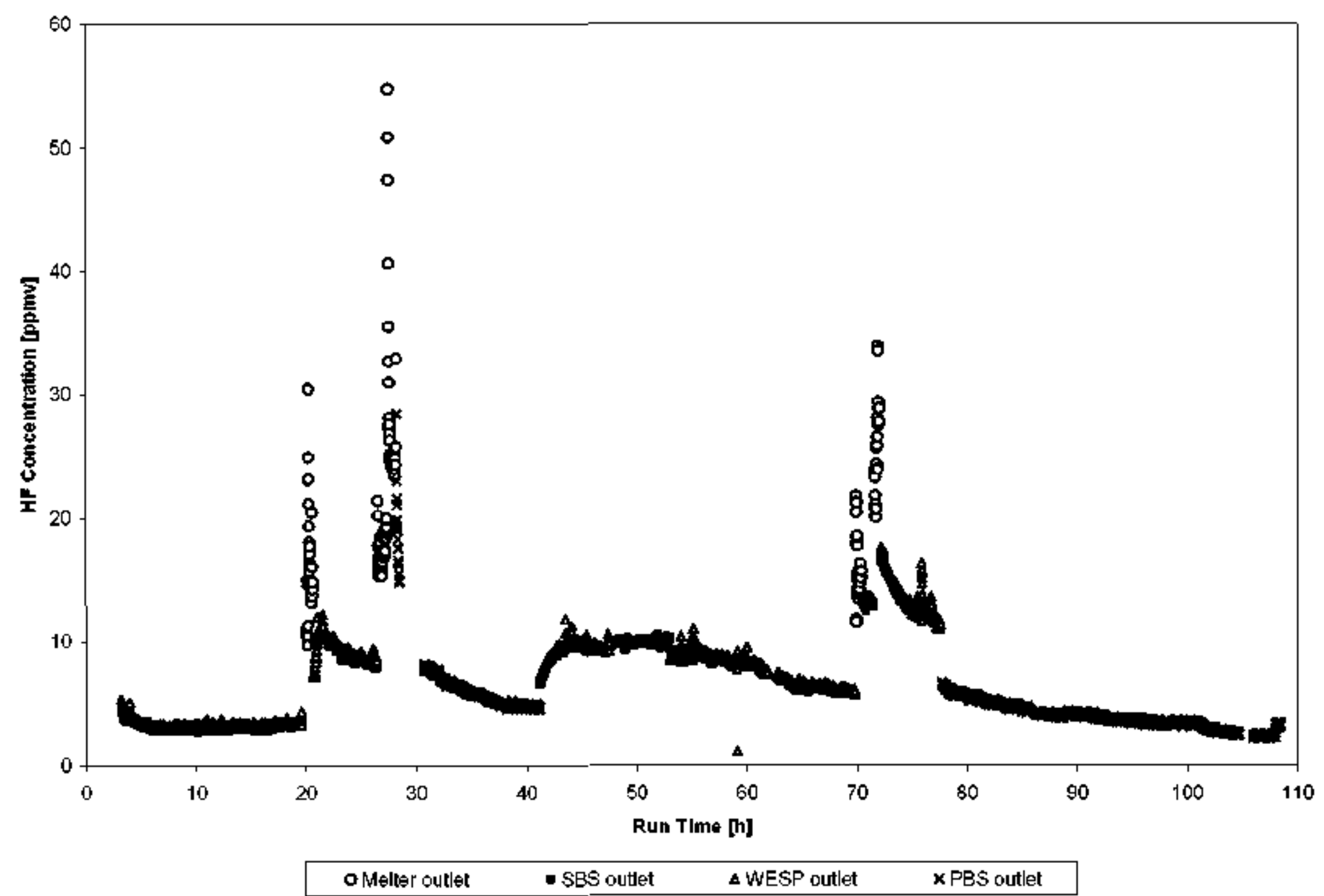

Figure 7.8. FTIR moni1ored HF emissions during DM1200 Tests 2 and 3. 